NIST NCSTAR 1-5B

Federal Building and Fire Safety Investigation of the World Trade Center Disaster

\title{
Experiments and Modeling of Structural Steel Elements Exposed to Fire
}

\author{
Anthony Hamins \\ Alexander Maranghides \\ Kevin B. McGrattan \\ Erik L. Johnsson \\ Thomas J. Ohlemiller \\ Michelle K. Donnelly \\ Jiann C. Yang \\ George W. Mulholland \\ Kuldeep R. Prasad \\ Scott R. Kukuck \\ Robert L. Anleitner \\ Therese P. McAllister
}





\title{
Federal Building and Fire Safety Investigation of the World Trade Center Disaster
}

\section{Experiments and Modeling of Structural Steel Elements Exposed to Fire}

\author{
Anthony Hamins \\ Alexander Maranghides \\ Kevin B. McGrattan \\ Erik L. Johnsson \\ Thomas J. Ohlemiller \\ Michelle K. Donnelly \\ Jiann C. Yang \\ George W. Mulholland \\ Kuldeep R. Prasad \\ Scott R. Kukuck* \\ Robert L. Anleitner \\ Therese P. McAllister \\ Building and Fire Research Laboratory \\ National Institute of Standards and Technology
}

*Scott R. Kukuck's current affiliation:

U.S. Army Research Laboratory

Aberdeen Proving Grounds, Maryland

September 2005

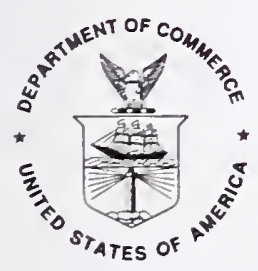

U.S. Department of Commerce

Carlos M. Gutierrez, Secretary

Technology Administration

Michelle O'Neill, Acting Under Secretary for Technology

National Institute of Standards and Technology

William Jeffrey, Director 


\section{Disclaimer No. 1}

Certain commercial entities, equipment, products, or materials are identified in this document in order to describe a procedure or concept adequately or to trace the history of the procedures and practices used. Such identification is not intended to imply recommendation, endorsement, or implication that the entities, products, materials, or equipment are necessarily the best available for the purpose. Nor does such identification imply a finding of fault or negligence by the National Institute of Standards and Technology.

\section{Disclaimer No. 2}

The policy of NIST is to use the International System of Units (metric units) in all publications. In this document, however, units are presented in metric units or the inch-pound system, whichever is prevalent in the discipline.

\section{Disclaimer No. 3}

Pursuant to section 7 of the National Construction Safety Team Act, the NIST Director has determined that certain evidence received by NIST in the course of this Investigation is "voluntarily provided safety-related information" that is "not directly related to the building failure being investigated" and that "disclosure of that information would inhibit the voluntary provision of that type of information" (15 USC 7306c).

In addition, a substantial portion of the evidence collected by NIST in the course of the Investigation has been provided to NIST under nondisclosure agreements.

\section{Disclaimer No. 4}

NIST takes no position as to whether the design or construction of a WTC building was compliant with any code since, due to the destruction of the WTC buildings, NIST could not verify the actual (or as-built) construction, the properties and condition of the materials used, or changes to the original construction made over the life of the buildings. In addition, NIST could not verify the interpretations of codes used by applicable authorities in determining compliance when implementing building codes. Where an Investigation report states whether a system was designed or installed as required by a code provision, NIST has documentary or anecdotal evidence indicating whether the requirement was met, or NIST has independently conducted tests or analyses indicating whether the requirement was met.

\section{Use in Legal Proceedings}

No part of any report resulting from a NIST investigation into a structural failure or from an investigation under the National Construction Safety Team Act may be used in any suit or action for damages arising out of any matter mentioned in such report (15 USC 281a; as amended by P.L. 107-231).

National Institute of Standards and Technology National Construction Safety Team Act Report 1-5B Natl. Inst. Stand. Technol. Natl. Constr. Sfty. Tm. Act Rpt. 1-5B, 352 pages (September 2005) CODEN: NSPUE2

\section{U.S. GOVERNMENT PRINTING OFFICE \\ WASHINGTON: 2005}

For sale by the Superintendent of Documents, U.S. Government Printing Office Internet: bookstore.gpo.gov - Phone: (202) 512-1800 - Fax: (202) 512-2250

Mail: Stop SSOP, Washington, DC 20402-0001 


\section{ABSTRACT}

Reconstructing the fires and their impact on structural components in the World Trade Center (WTC) buildings on September 11,2001, requires extensive use of computational models. For the use of such models to be a viable investigative tool, it is essential to know the accuracy with which they capture the physical phenomena of the fires and the concurrent heat transfer to the building structure. This report documents a series of large-scale experiments that was conducted in the National Institute of Standards and Technology (NIST) Large Fire Laboratory from March 10 to March 26, 2003. The experiments represent one phase of an effort to ascertain the validity of the models for the NIST WTC Investigation. The objective of the experiments was to assess the accuracy with which (1) the NIST Fire Dynamics Simulator (FDS) fire model predicts the thermal environment in a burning compartment and (2) the NIST Fire Structure Interface (FSI) model in combination with the ANSYS finite-element model predicts the temperature rise of structural steel components in a burning compartment. The experiments also had the potential to improve input parameters in the modeling, if appropriate, and, in general, help to increase understanding of the sequence of events that occurred in the WTC tower fires.

Within a steel-frame compartment ( $3 \mathrm{~m}$ by $7 \mathrm{~m}$ by $4 \mathrm{~m}$ ) lined with calcium silicate board were placed four steel components: two trusses, one thin-walled column, and a rod. The components either were uninsulated or had fibrous sprayed fire-resistive material (SFRM) applied; two thicknesses were tested. The $2 \mathrm{MW}$ and $3 \mathrm{MW}$ fires were generated using liquid hydrocarbon fuels introduced by a two-nozzle spray burner onto a $1 \mathrm{~m}$ by $2 \mathrm{~m}$ pan. The fuels were a commercial blend of heptane isomers and a mixture of the heptane blend with toluene. Six experiments were conducted.

Measurements were made of a large number of parameters, including the heat release rate; the radiative and total heat flux at various targets in the compartment, including locations near the floor and the ceiling; the temperatures of insulated and uninsulated steel components; the concentrations of soot, oxygen, carbon monoxide, and carbon dioxide; and the vertical profiles of gas-phase temperature. A video record was made from several orientations. Nearly 350 channels of data were acquired. Following the establishment of baseline signals from all of the measurement devices, the burner was ignited and burned at a steady rate. The test continued until the surface temperature of any one of several steel components present in the compartment reached approximately $600{ }^{\circ} \mathrm{C}$.

For each test, a prediction of the thermal environment in the compartment was determined using the NIST FDS fire model. A prediction of the rise of the steel temperature for the simulated thermal environment was made using the NIST FSI. A comparison of the FDS predictions and the experimental results showed that the predictions were within experimental and model uncertainty. The steel temperatures predicted by the FSI and the ANSYS finite-element models compared favorably with the measurements within experimental uncertainty and model sensitivity.

These experimental tests of the methodology using the FDS, the FSI, and the finite-element model to analyze the thermal environment in compartments experiencing fire and the associated temperature rise in steel components provide the level of confidence necessary to apply the modeling methodology to the investigation of the WTC disaster. 
Keywords: Finite-element model, fire measurements, fire model, thermal-structural model, World Trade Center. 


\section{TABLE OF CONTENTS}

Abstract .iii

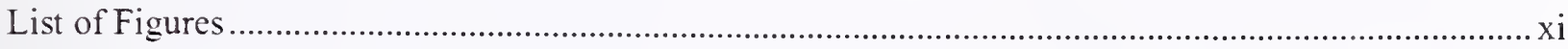

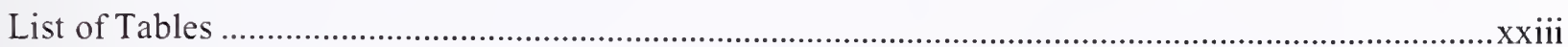

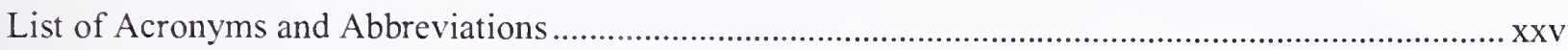

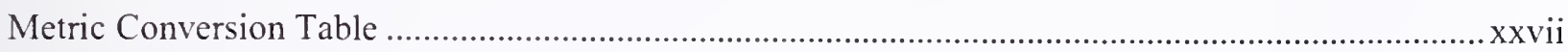

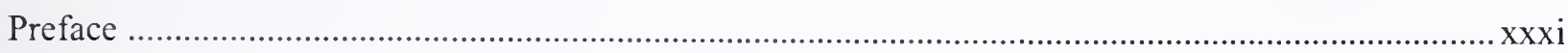

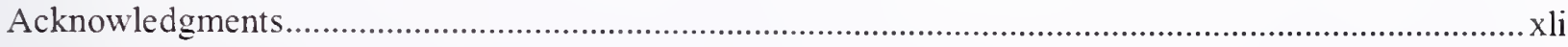

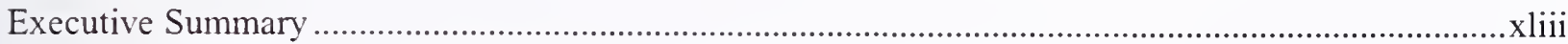

\section{Chapter 1}

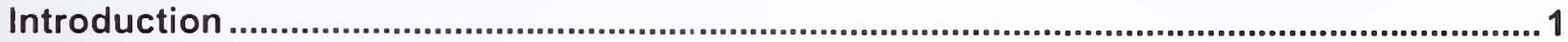

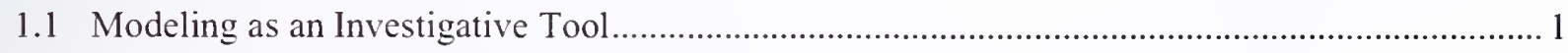

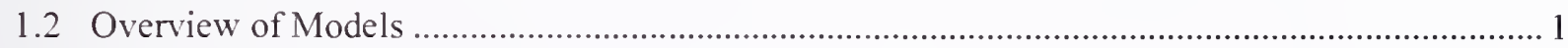

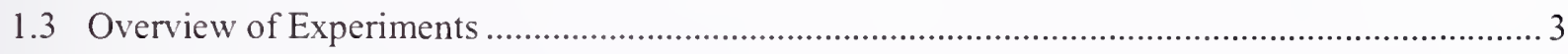

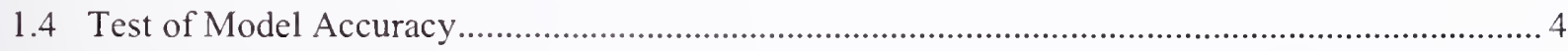

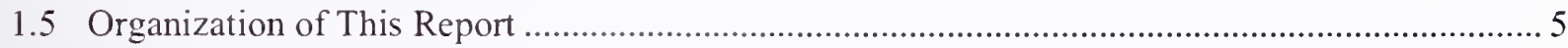

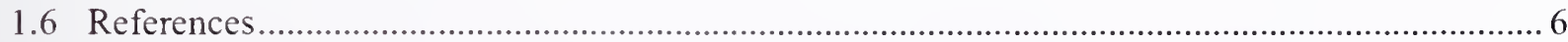

\section{Chapter 2}

Experimental Configuration and General Observations ........................................................

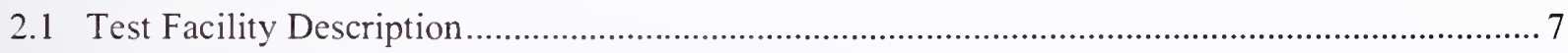

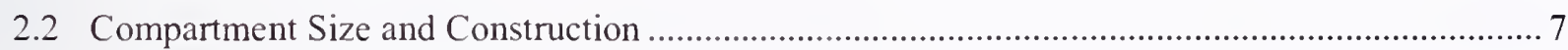

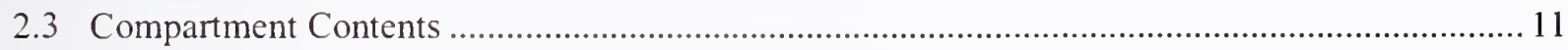

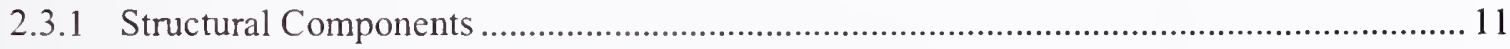

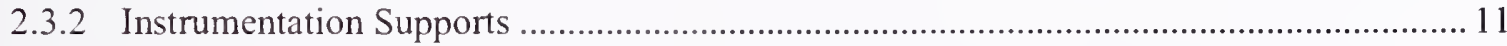

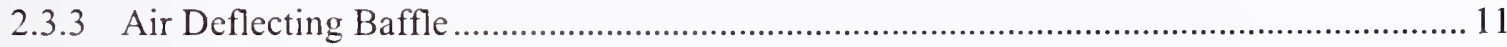

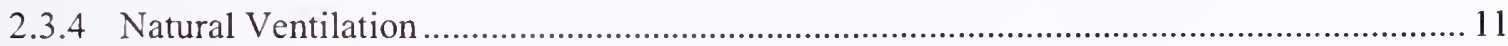

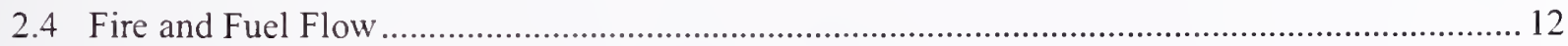

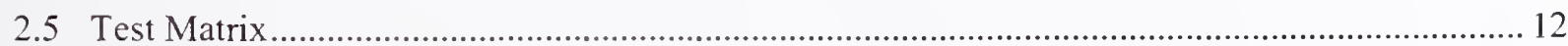

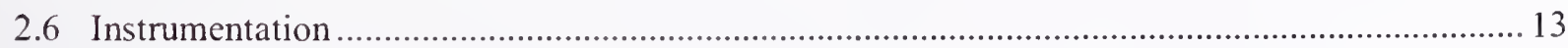

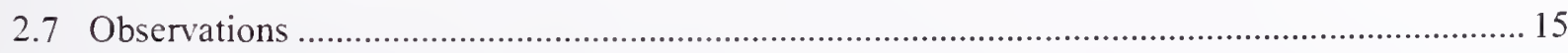

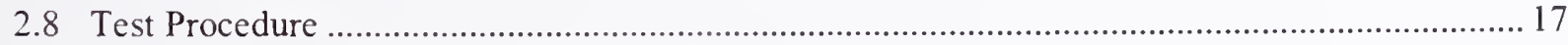

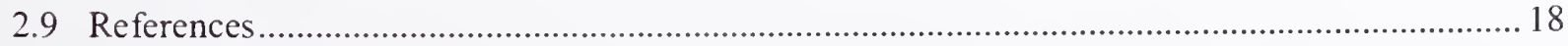




\section{Chapter 3}

Fuel Flow and Heat Release Rate ......................................................................................

3.1 Fuel Flow and Estimated Heat Release Rate ..................................................................... 19

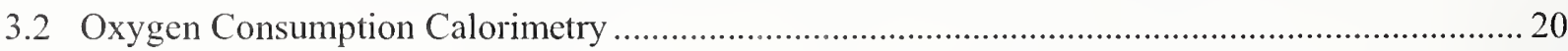

3.2.1 Description of the Heat Release Rate Measurement Facility ....................................... 20

3.2.2 Calibration and Measurement Uncertainty............................................................. 21

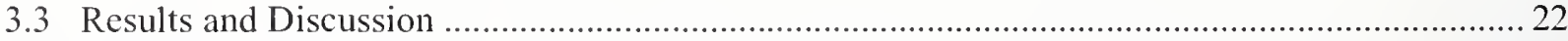

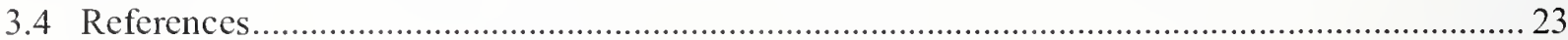

\section{Chapter 4}

Gas Temperature .............................................................................................. 25

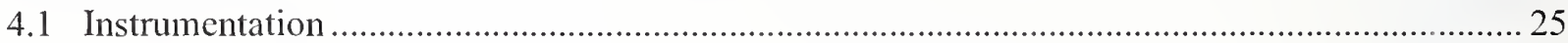

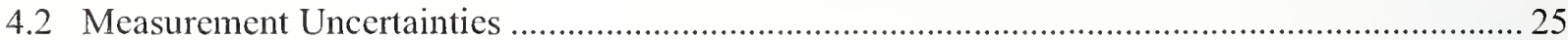

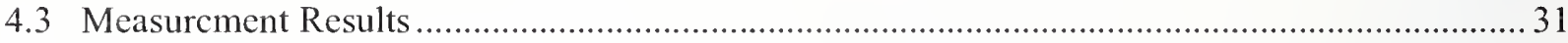

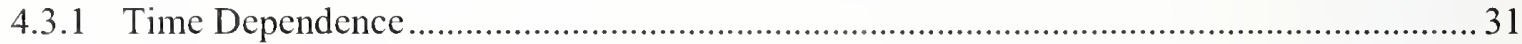

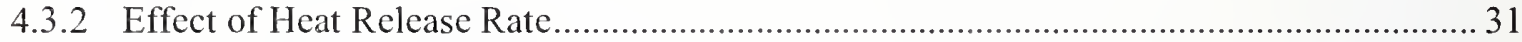

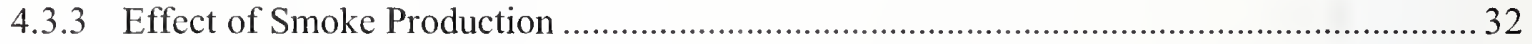

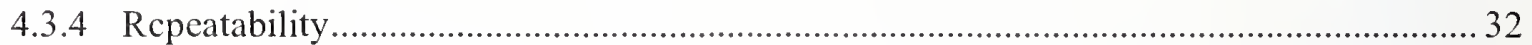

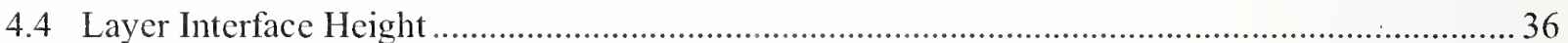

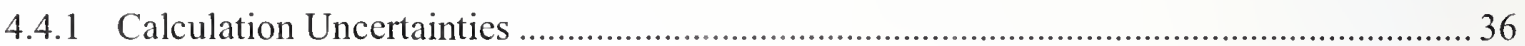

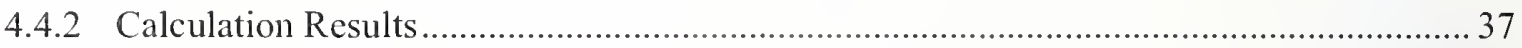

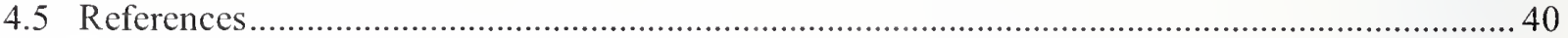

\section{Chapter 5}

Heat Flux Measurements........................................................................................ 41

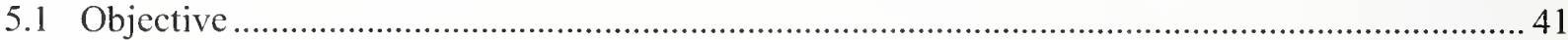

5.2 Description of the Heat Flux Measurement Devices ............................................................. 41

5.2.1 Location of Heat Flux Instrumentation .................................................................... 45

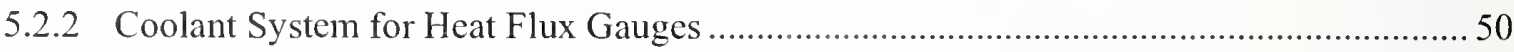

5.3 Data Reduction for the Slug Calorimeters .................................................................... 51

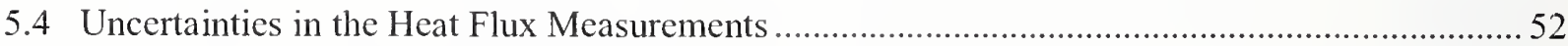

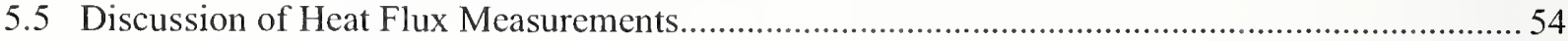

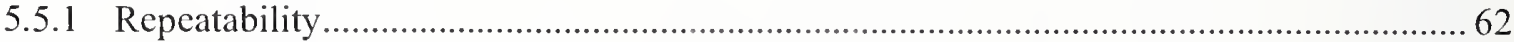

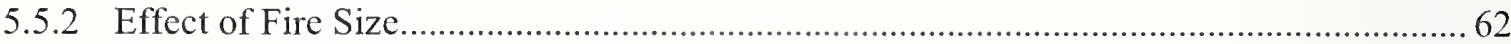

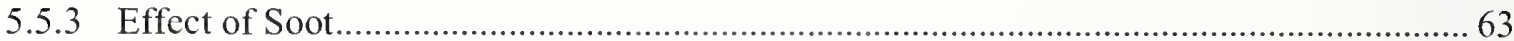

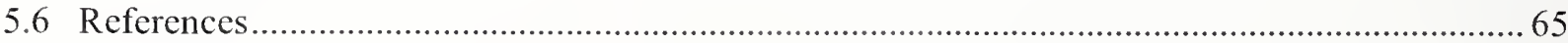




\section{Chapter 6}

Smoke, $\mathrm{CO}_{2}, \mathrm{CO}$, and $\mathrm{O}_{2}$ Concentrations 67

6.1 Instrumentation 67

6.2 Measurement Uncertainty for Gas Analyzer Results............................................................ 69

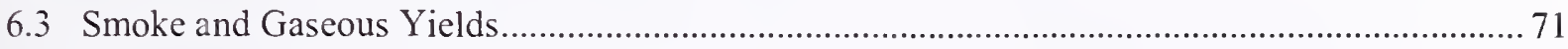

6.4 Measurement Uncertainty for Soot, $\mathrm{CO}_{2}$, and $\mathrm{CO}$ Yields ...................................................... 72

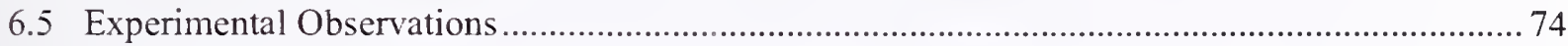

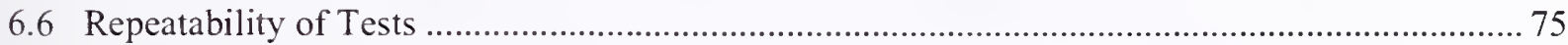

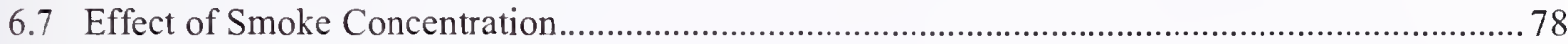

6.8 Effect of Heat Release Rate for a Low Sooting Fuel .......................................................... 79

6.9 Effect of the Fire Heat Release Rate on a High Sooting Fuel.................................................81

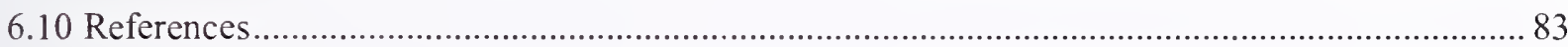

\section{Chapter 7}

Velocity Measurements ........................................................................................ 85

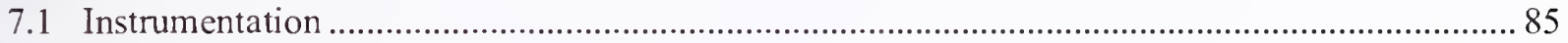

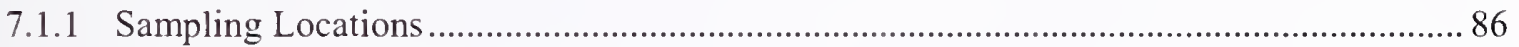

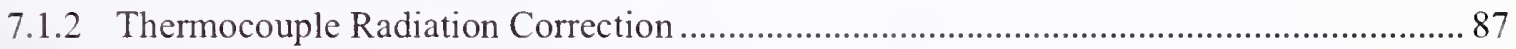

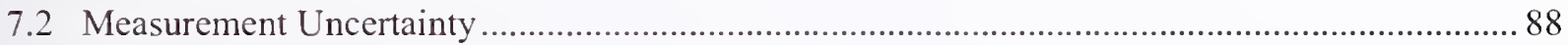

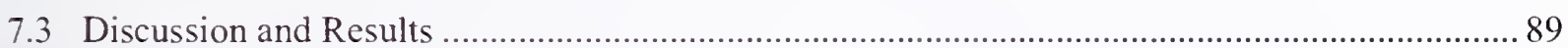

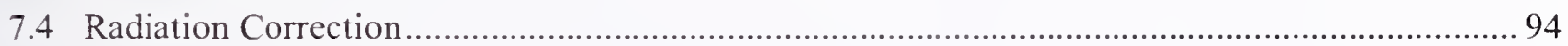

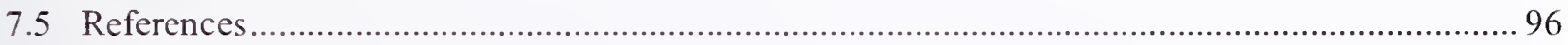

\section{Chapter 8}

Compartment Surface Temperature Measurements ..................................................... 97

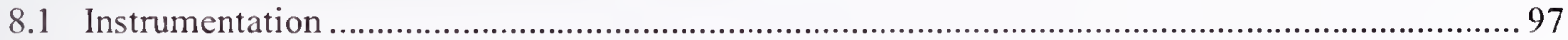

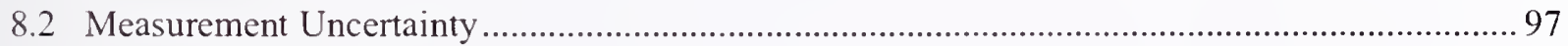

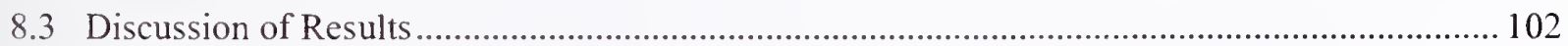

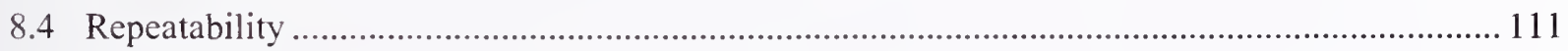

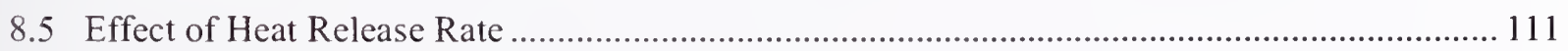

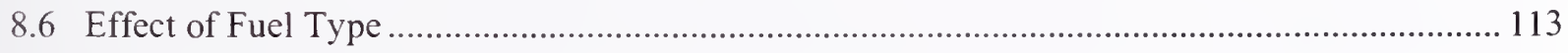

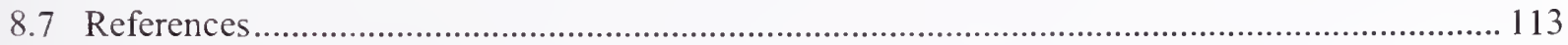

\section{Chapter 9}

Temperatures of Steel Components ......................................................................................115

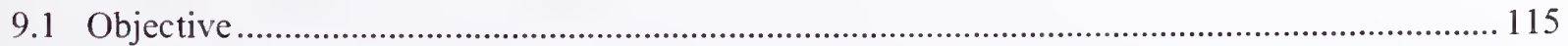

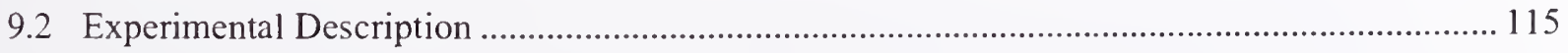




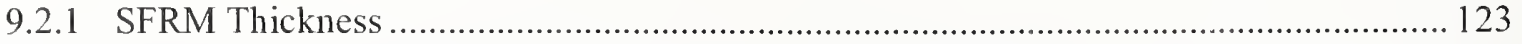

9.3 Description of the Temperature Measurements ............................................................... 131

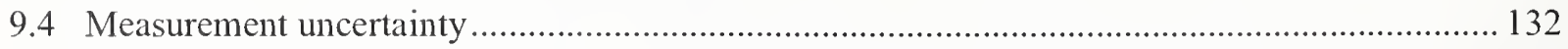

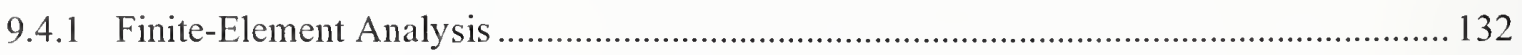

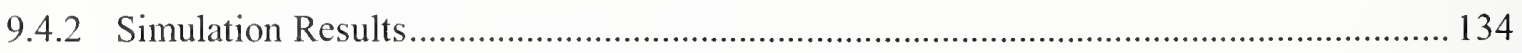

9.5 Measurement Uncertainty of the SFRM Surface Temperature............................................. 136

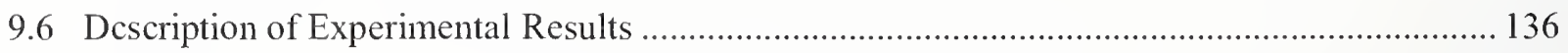

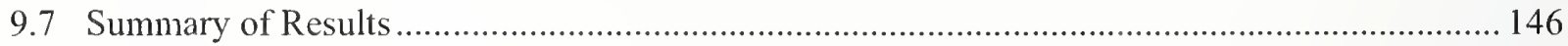

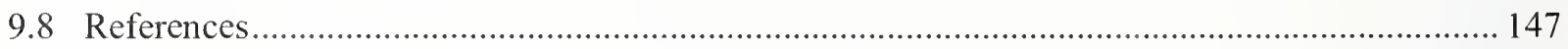

\section{Chapter 10}

Simulation of Compartment Fire Phenomena .....................................................................149

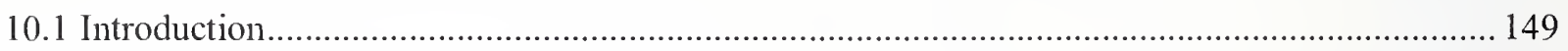

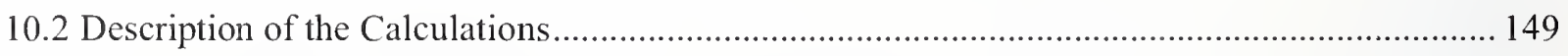

10.3 Discussion of Model Simulations and Measurements .................................................. 151

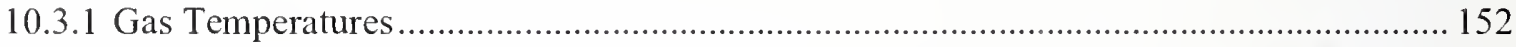

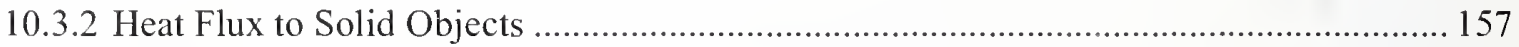

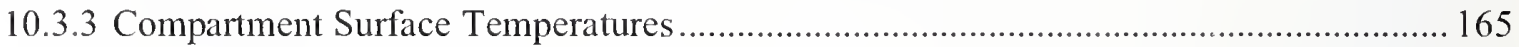

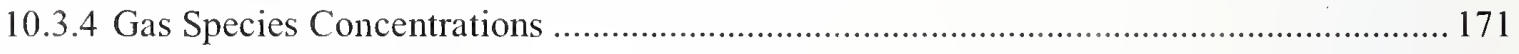

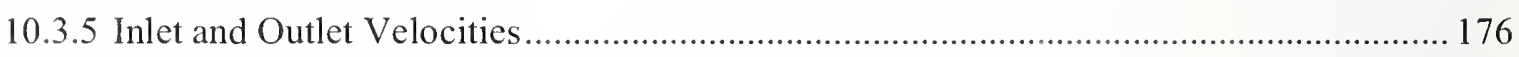

10.4 Sensitivity Analysis and Comparison to Mcasurements ..................................................... 178

10.4.1 Sensitivity of Gas Temperatures to Heat Release Rate .............................................. 178

10.4.2 Scnsitivity of Heat Flux to Solid Objects to Heat Rclease Rate .................................... 179

10.4.3 Sensitivity of Compartment Surface Temperature to Heat Release Rate....................... 179

10.4.4 Sensitivity of Gas Species Concentration to Heat Release Rate .................................. 180

10.4.5 Sensitivity of Inlet and Outlet Velocities to Heat Relcase Rate ................................... 180

10.4.6 Model Sensitivity to Parameters other than Heat Release Rate ................................... 180

10.5 Coupling with Thermal-Structural Models ................................................................ 184

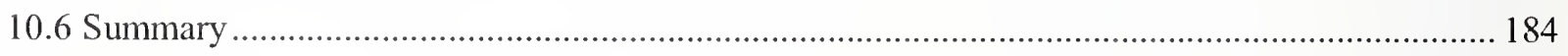

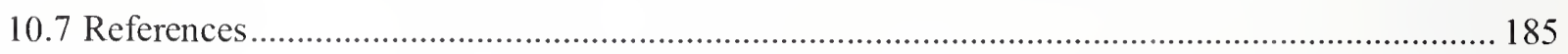

\section{Chapter 11}

Simulation of the Thermal Response of Structural Components ................................. 187

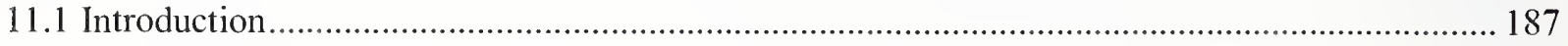

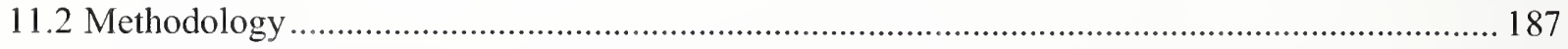

11.3 Comparison of Simulations with Measurements .......................................................... 194 


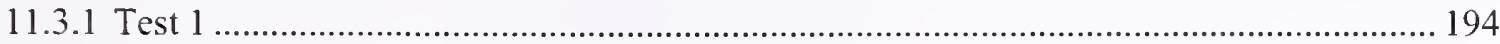

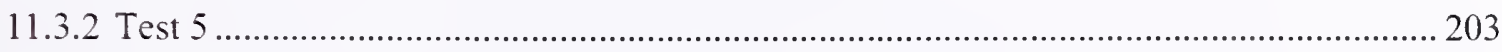

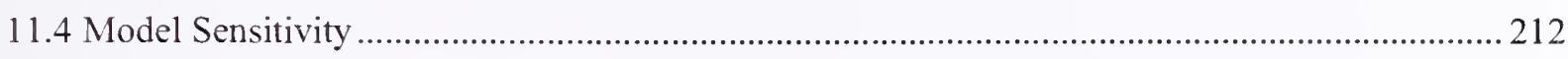

11.4.1 Sensitivity to Heat Release Rate.......................................................................... 217

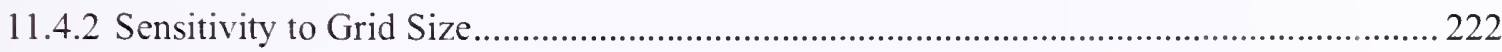

11.5 Sensitivity to the Thickness and Thermo-Physical Properties of the Sprayed Fire-Resistive Material

11.6 Summary

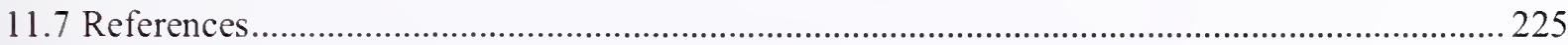

Chapter 12

Summary of Results

Appendix A Selection of Fuels ............................................................................. 231

Appendix B Instrument Locations ..................................................................... 233

Appendix C Gas-Phase Temperature Measurements .................................................. 243

Appendix D Velocity Measurements at the Compartment Inlet and Outlet......................... 251

Appendix E Heat Flux Measurements ..........................................................................2273

Appendix F Thermocouple Locations on Steel Components ........................................... 285

Appendix G Temperature Histories of Bare and Coated Steel Components.......................289 
This page intentionally left blank. 


\section{LIST OF FIGURES}

Figure P-1. The eight projects in the federal building and fire safety investigation of the WTC disaster.

Figure 2-1. Compartment contents as seen through the access panel on the south wall. 7

Figure 2-2. Experimental enclosure contents. 8

Figure 2-3. Experimental enclosure contents viewed with access panels removed. 9

Figure 2-4. Fuel pan, fuel nozzles, and instrumentation in the compartment.

Figure 2-5. Schematic drawing of compartment contents. 10

Figure 2-6. Instrumentation on the outside of the west wall of the compartment. ............................ 14

Figure 2-7. Fire impinging on the bare steel trusses $10 \mathrm{~s}$ after ignition in Test 1 ............................ 16

Figure 2-8. Smoke exiting the outlet vent into the exhaust hood during Test 2............................. 16

Figure 2-9. Radiating hot gases exiting the outlet vent into the exhaust hood during Test 5. 17

Figure 3-1. The measured heat release rate $(\dot{Q})$ as a function of time during Tests 1 through 6 . 23

Figure 4-1. $20 \mathrm{~s}$ average of the difference of bare-bead thermocouple temperatures minus aspirated thermocouple temperatures as a function of time for Test 1.

Figure 4-2. $20 \mathrm{~s}$ average of the difference of bare-bead thermocouple temperatures minus aspirated thermocouple temperatures as a function of time for Test 2.

Figure 4-3. $20 \mathrm{~s}$ average of the difference of bare-bead thermocouple temperatures minus aspirated thermocouple temperatures as a function of time for Test 3 .

Figure 4-4. $20 \mathrm{~s}$ average of the difference of bare-bead thermocouple temperatures minus aspirated thermocouple temperatures as a function of time for Test 4. 30

Figure 4-5. $20 \mathrm{~s}$ average of the difference of bare-bead thermocouple temperatures minus aspirated thermocouple temperatures as a function of time for Test 5.

Figure 4-6. $20 \mathrm{~s}$ average of the difference of bare-bead thermocouple temperatures minus aspirated thermocouple temperatures as a function of time for Test 6 .

Figure 4-7. Aspirated thermocouple temperatures as a function of time for Test 1......................... 33

Figure 4-8. Aspirated thermocouple temperatures as a function of time for Test 5......................... 33

Figure 4-9. Comparison of Test 1 and Test 4 aspirated thermocouple temperatures at the upper and middle locations as a function of time, showing the effect of heat release rate.

Figure 4-10. Comparison of Test 2 and Test 3 aspirated thermocouple temperatures at the upper and middle locations as a function of time, showing the effect of heat release rate for a sooty fuel. 
Figure 4-11. Comparison of Test 1 and Test 3 aspirated thermocouple tempcratures at the upper and middle locations as a function of timc, showing the effect of soot for nearly the same heat release rate.

Figure 4-12. Comparison of Test 5 and Test 6 aspirated thermocouple temperatures at the upper and middle locations as a function of time, showing the repeatability of the

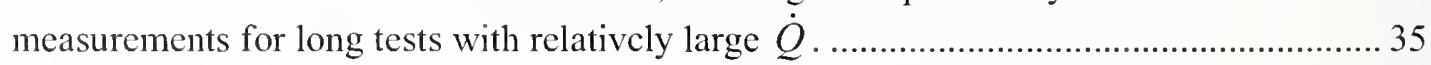

Figure 4-13. West thermocouple tree temperatures as a function of time in Test 1........................... 36

Figure 4-14. Calculated layer interface height as a function of time for Test 1 ............................... 38

Figure 4-15. Temperature profiles for West and East thermocouple trees for Test 1 at $t=850 \mathrm{~s} \ldots \ldots \ldots . . .39$

Figure 4-16. Temperature profiles for West and East thermocouple trees for Test 5 at $\mathrm{t}=3,020 \mathrm{~s}$

Figure 5-1. Flux gauge holder showing gauge sensor surface (black disc) and soot purge tube. Surface of gauge holder and gauge sensor surface were set flush with the surrounding Marinite cover on any monitored surface.

Figure 5-2. Schematic of slug calorimeter.

Figure 5-3. Front view of test compartment.

Figure 5-4. Top view of test compartment.

Figure 5-5. Expanded sisde view of circled area in Figure 5-4.

Figure 5-6. Locations of flux gauges and radiometers in the measurement station............................ 48

Figure 5-7. Schematic showing the locations of column heat flux gauges. ..................................... 48

Figure 5-8. Cooling water system for radiometers and flux gauges.............................................5 50

Figure 5-9. Total heat flux recorded by two flux gauges $15 \mathrm{~cm}$ above the floor, just downstream of the fire pan in Test 5 .

Figure 5-10. Total heat flux recorded by the four flux gauges in the compartment ceiling in Test 5. The periodic spikes are due to the soot purge operation.

Figure 5-11. Total heat flux recorded by the four flux gauges in structures adjacent to the vertical column in Test 5. The periodic spikes are due to the soot purge operation on the two higher gauges.

Figure 5-12. Average total heat flux to the cylindrical surface of the slug calorimeter 1 in Test 5........ 58

Figure 5-13. Average total heat flux to the cylindrical surface of slug calorimeter 2 in Test 5 .

Figure 5-14. Comparison of the average total heat flux to the cylindrical

surface of slug calorimeter 3 in Tests 5 and 6 .

Figure 5-15. Comparison of the average total heat flux to the cylindrical surface of slug calorimeter 4 in Tests 5 and 6 .

Figure 5-16. Comparison of the average total heat flux to the cylindrical surface of slug calorimeter 5 in Tests 5 and 6 .

Figure 5-17. Heat fluxes recorded by the radiometers and total flux gauges in the flux measurement station during Test 5. The periodic spikes are due to the soot purge operation. 
Figure 5-18. Effect of fire size in Tests 1 and 5 (2 MW and $3 \mathrm{MW}$, respectively) on total heat flux at ceiling gauge $\mathrm{HCe} 2$, directly above the fire pan.

Figure 5-19. Effect of fire size in Tests 1 and 5 (2 MW and $3 \mathrm{MW}$, respectively) on the recorded total heat flux at slug calorimeter 1 , upstream of the fire plume.

Figure 6-1. Schematic of apparatus for measuring the smoke yield and smoke concentration at location "Sm." The sampling tube extends from the inlet through the water jacket to the filter holder......

Figure 6-2. Oxygen volume fraction (on a dry basis) sampled at location E plotted as a function of time for Test 1 . 75

Figure 6-3. Comparison of the oxygen volume fraction (on a dry basis) for Tests 4 and 5 . 76

Figure 6-4. Comparison of $\mathrm{CO}_{2}$ volume fraction (on a dry basis) for Tests 4 and 5. Results are presented for the E sampling location and the Sm location, for which the gas is sampled twice for $120 \mathrm{~s}$ each.

Figure 6-5. Ratio of volume fraction of $\mathrm{CO}_{2}$ minus the background value to the decrease in the $\mathrm{O}_{2}$ volume fraction for Tests 4 and 5 at sample location $\mathrm{E}$ (on a dry basis).

Figure 6-6. Comparison of $\mathrm{CO}$ volume fraction (on a dry basis) for Tests 4 and 5. .77

Figure 6-7. $\mathrm{CO}_{2}$ and $\mathrm{O}_{2}$ volume fraction (on a dry basis for low (Test 1) and high sooting (Test 3).

Figure 6-8. Temperature as a function of time near the $\mathrm{Sm}$ probes

for low (Test 1) and high sooting (Test 3).

Figure 6-9. CO volume fraction (on a dry basis) as a function of time for low (Test 1)

and high sooting (Test 3 ).

Figure 6-10. The oxygen volume fraction (on a dry basis) for a lower (Test 1)

and a higher (Test 4 ) heat release rate.

Figure 6-11. The $\mathrm{CO}_{2}$ volume fraction (on a dry basis) for a lower (Test 1) and a higher (Test 4 ) heat release rate.

Figure 6-12. CO volume fraction (on a dry basis) for a lower (Test 1) and a higher (Test 4 ) heat release rate.

Figure 6-13. CO volume fraction (on a dry basis) for high sooting tests with a low (Test 3 ) and a high (Test 2) heat release rate.

Figure 7-1. Inlet velocity measurements for Test 1 , inlet velocity probe 1 .

Figure 7-2. Outlet velocity at location 1 for Test 1 and Test 4 ...... .90

Figure 7-3. Outlet velocity at location 10 for Test 3 and Test 5 . 90

Figure 7-4. Outlet velocities for Test 5 at probe locations 1, 2, and 3. 92

Figure 7-5. Outlet velocities for Test 5 at outlet locations 6,7 , and 8 . .92

Figure 7-6. Outlet velocities for probes located $15 \mathrm{~cm}$ above vent opening, Test 3 . Outlets 8 and 10 are the probes toward the sides of the compartment, while outlets 5 and 3 are closer to the center of the compartment. 
Figure 7-7. Outlet velocities for probes located $61 \mathrm{~cm}$ above vent opening in Tcst 3 . Outlets 6 and 9 are toward the side, while outlets 4 and 1 are closer to the compartment center.

Figure 7-8. Comparison of the measured temperature and corrected temperature in Test 6 at outlet 9

Figure 7-9. Comparison of the component of temperature correction due to incoming

flux and the component of temperature correction due to radiative loss.

Figure 7-10. Comparison of bare-bead temperature measurements with aspirated temperature measurements in Test 5 at outlet 5 .

Figure 7-11. Comparison of the mean velocity computed using bare-bead temperature measurements with the mean velocity computed using aspirated temperature measurements in Test 5 at outlet 5 .

Figure 8-1. A type K thermocouple attached to the Marinite surface.............................................. 97

Figure 8-2. Simplified configuration used for the numerical analysis. 98

Figure 8-3. Comparison of the measured and predieted ceiling surface thermocouple temperature in Test 2. The measured gas temperature is also shown.

Figure 8-4. The simulated thermocouple temperature minus the simulated Marinite surface temperature for two values of the upper layer emittance in Test 2.

Figure 8-5. Comparison of the measured and predicted ceiling surface thermocouple temperatures for Test 5 . The measured gas temperature is also shown.

Figure 8-6. The simulated thermocouple temperature minus the simulated Marinite surface tempcrature for two values of the upper layer emittance in Test 5.

Figure 8-7. The measured ceiling temperatures as a function of time at 15 locations along the compartment centerline ( $\mathrm{x}$ axis) during Test 1.

Figure 8-8. The measured temperatures between the two Marinite sheets in the ceiling along the compartment centerline ( $\mathrm{x}$ axis) as a function of time at several locations during Test 1

Figure 8-9. The peak temperatures on the ceiling surface and sandwiched between Marinite ceiling layers along the compartment centerline ( $\mathrm{x}$ axis) during Test 1.

Figure 8-10. The measured ceiling surface temperatures as a function of time at seven locations along the $y$ axis at $x=456 \mathrm{~cm}$ during Test 5 .

Figure 8-11. The measured peak ceiling surface temperatures as a function of location along the $y$ axis at two $\mathrm{x}$ locations $(\mathrm{x}=456 \mathrm{~cm}$ and $\mathrm{x}=612 \mathrm{~cm})$ during Test 5 .

Figure 8-12. The measured ceiling temperatures as a function of time at 15 locations along the compartment centerline ( $\mathrm{x}$ axis) during Test 2.

Figure 8-13. The measured temperatures between the two Marinite sheets in the ceiling along the compartment centerline ( $\mathrm{x}$ axis) as a function of time at several locations during Test 2

Figure 8-14. The measured ceiling temperatures as a function of time at 15 locations along the compartment centerline ( $\mathrm{x}$ axis) during Test 3. 
Figure 8-15. The measured temperatures between the two Marinite sheets in the ceiling along the compartment centerline ( $\mathrm{x}$ axis) as a function of time at sevcral locations during Test 3 .

Figure 8-16. The measured ceiling temperatures as a function of time at 15 locations along the compartment centerline ( $\mathrm{x}$ axis) during Test 4.

Figure 8-17. The measured temperatures between the two Marinite sheets in the ceiling along the compartment centerline ( $\mathrm{x}$ axis) as a function of time at scveral locations during Test 4

Figure 8-18. The measured ceiling temperatures as a function of time at 15 locations along the compartment centerline ( $\mathrm{x}$ axis) during Test 5.

Figure 8-19. The measured temperatures between the two Marinite sheets in the ceiling along the compartment centerline ( $\mathrm{x}$ axis) as a function of time at several locations during Test 5

Figure 8-20. The measured ceiling temperatures as a function of time at 15 locations along the compartment centerline ( $\mathrm{x}$ axis) during Test 6.

Figure 8-21. The measured temperatures between the two Marinite sheets in the ceiling along the compartment centerline ( $\mathrm{x}$ axis) as a function of time at several locations during Test 6 .

Figure 8-22. Comparison of the temperatures on the ceiling surface and sandwiched betwecn the two Marinite ceiling layers 3,000 s and 3,080 s after fire initiation, respectivcly, along the compartment centerline ( $\mathrm{x}$ axis) during Tests 5 and 6.

Figure 8-23. Comparison of the temperatures on the ceiling surface and sandwiched between thc two Marinite ceiling layers $830 \mathrm{~s}$ and $1,035 \mathrm{~s}$ after fire initiation, respectively, along the compartment centerline ( $\mathrm{x}$ axis) during Tests 1 and 5.

Figure 8-24. Comparison of the temperatures on the ceiling surface and sandwiched betwcen the two Marinite ceiling layers $350 \mathrm{~s}$ and $660 \mathrm{~s}$ after fire initiation, respectively, along the compartment centerline ( $\mathrm{x}$ axis) during Tests 2 and 3.

Figure 8-25. Comparison of the temperatures on the ceiling surface and sandwiched between the two Marinite ceiling layers $830 \mathrm{~s}$ and 1,040 s after fire initiation, rcspectively, along the compartment centerline ( $\mathrm{x}$ axis) during Tests 1 and 3 .

Figure 9-1. Bar dimensions

Figure 9-2. Tubular column dimcnsions.

Figure 9-3. Truss dimensions.

Figure 9-4a. Thermocouple locations for bars.

Figure 9-4b. SFRM measurement locations for bars.

Figure 9-5a. Thermocouple locations for columns.

Figure 9-5b. SFRM measurement locations for columns in Test 5 and 6.

Figure 9-6a. Thermocouple locations on trusses.

Figure 9-6b. Thermocouple bead spot welded onto the bottom chord of a steel truss with the wire running close to the steel surface. 
Figure 9-6c. Color photograph of a thermocouple wire supported on a wire tie, with the thermocouple bead placed just under the SFRM surface.

Figure 9-6d. Application of SFRM product to a truss.

Figure 9-6e. Steel components with SFRM product prior to testing.............................................. 122

Figure 9-6f. SFRM measurement locations for trusses................................................................ 122

Figure 9-7a. Steel component locations for Tests 1, 2, and 3................................................... 129

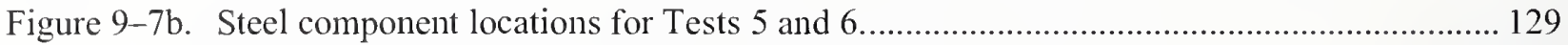

Figure 9-7c. Steel components in test compartment for Tests 1, 2, and 3................................... 130

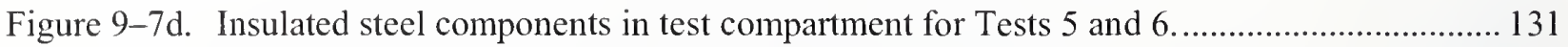

Figure 9-8. Simplified configuration used for the numerical analysis.......................................... 133

Figure 9-9. Calculated measurement error for thermocouples on uninsulated steel.......................... 135

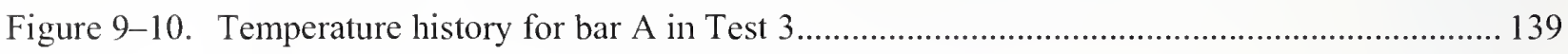

Figure 9-11. Temperature history for column in Test 3............................................................. 140

Figure 9-12. Temperature history for truss A in Test 3............................................................ 140

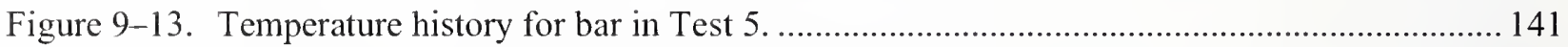

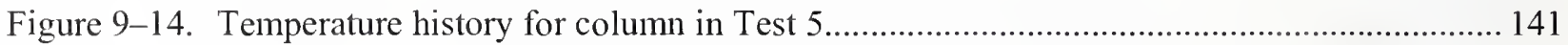

Figure 9-15. Temperature history for truss A in Test 5....................................................... 142

Figure 9-16. Temperature history for column in Test 5................................................................ 143

Figure 9-17. Temperature history for truss A in Test 5........................................................... 143

Figure 9-18. Temperature history for truss B in Test 5 ........................................................... 144

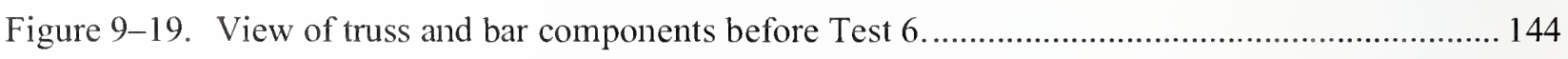

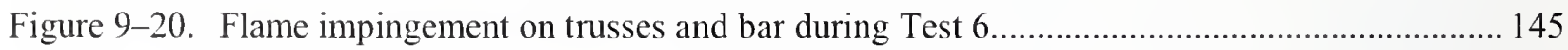

Figure 10-1. Snapshot of numerical simulation of Test 1 showing the fire as seen from a cutaway view looking towards the north wall.

Figure 10-2. Snapshot of the numerical simulation of Test 1 showing the fire and a contour plot of gas temperature along the centerline of the compartment as seen from a cutaway view looking towards the north wall.

Figure 10-3. Comparison of gas temperatures, Test 1, intake side of compartment. The pumps connected to the aspirated thermocouples began to operate at $180 \mathrm{~s}$.

Figure 10-4. Comparison of gas temperatures, Test 1, exhaust side of compartment. The pumps connected to the aspirated thermocouples began to operate at $180 \mathrm{~s}$.

Figure 10-5. Comparison of gas temperatures, Test 2, intake side of compartment.

Figure 10-6. Comparison of gas temperatures, Test 2, exhaust side of compartment.

Figure 10-7. Comparison of gas temperatures, Test 3, intake side of compartment. 
Figure 10-9. Comparison of gas temperatures, Test 4, intake side of compartment. ......................... 155

Figure 10-10. Comparison of gas temperatures, Test 4, exhaust side of compartment......................... 156

Figure 10-11. Comparison of gas temperatures, Test 5, intake side of compartment. .......................... 156

Figure 10-12. Comparison of gas temperatures, Test 5, exhaust side of compartment......................... 157

Figure 10-13. Comparison of heat fluxes to column, Test 1. The periodic spikes in the measurements were due to the influence of a nitrogen purge................................. 158

Figure 10-14. Comparison of heat fluxes to column, Test 1. The periodic spikes in the measurements were due to the influence of a nitrogen purge.

Figure 10-15. Comparison of heat fluxes to column, Test 2. The periodic spikes in the measurements were due to the influence of a nitrogen purge.

Figure 10-16. Comparison of heat fluxes to column, Test 2. The periodic spikes in the measurements were due to the influence of a nitrogen purge.

Figure 10-17. Comparison of heat fluxes to column, Test 3. The periodic spikes in the measurements were due to the influence of a nitrogen purge.

Figure 10-18. Comparison of heat fluxes to column, Test 3. The periodic spikes in the measurements were due to the influence of a nitrogen purge.

Figure 10-19. Comparison of heat fluxes to column, Test 4. The periodic spikes in the measurements were due to the influence of a nitrogen purge.

Figure 10-20. Comparison of heat fluxes to column, Test 4. The periodic spikcs in the measurements were due to the influence of a nitrogen purge.

Figure 10-21. Comparison of heat fluxes to column, Test 5. The periodic spikes

in the measurements were due to the influence of a nitrogen purge.

Figure 10-22. Comparison of heat fluxes to column, Test 5. The periodic spikes

in the measurements were due to the influence of a nitrogen purge.

Figure 10-23. Comparison of heat fluxes to floor targets, Test 1.

Figure 10-24. Comparison of heat fluxes to floor targets, Test 2.

Figure 10-25. Comparison of heat fluxes to floor targets, Test 3.

Figure 10-26. Comparison of heat fluxes to floor targets, Test 4.

Figure 10-27. Comparison of heat fluxes to floor targets, Test 5.

Figure 10-28. Comparison of ceiling tempcratures, Test 1. 166

Figure 10-29. Comparison of inner ceiling temperatures, Test 1 . ............................................. 166

Figure 10-30. Comparison of ceiling temperatures, Test 2 ................................................. 167

Figure 10-31. Comparison of inner ceiling temperatures, Test 2 ................................................ 167

Figure 10-32. Comparison of ceiling temperatures, Test 3 .......................................................... 168

Figure 10-33. Comparison of inner ceiling temperatures, Test 3 ................................................ 168

Figure 10-34. Comparison of ceiling temperatures, Test 4......................................................... 169

Figure 10-35. Comparison of inner ceiling temperatures, Test 4.................................................. 169

Figure 10-36. Comparison of ceiling temperatures, Test 5 ..................................................... 170 
Figure 10-37. Comparison of inner ceiling temperatures, Test 5.......................................... 170

Figure 10-38. Comparison of gas concentrations on a dry basis, Test 1 . ....................................... 171

Figure 10-39. Comparison of gas concentrations on a dry basis, Test 1 ......................................... 172

Figure 10-40. Comparison of gas concentrations on a dry basis, Test 2 .......................................... 172

Figure 10-41. Comparison of gas concentrations on a dry basis, Test 2 ........................................ 173

Figure 10-42. Comparison of gas concentrations on a dry basis, Test 3...................................... 173

Figure 10-43. Comparison of gas concentrations on a dry basis, Test 3 ........................................ 174

Figure 10-44. Comparison of gas concentrations on a dry basis, Test 4 .......................................... 174

Figure 10-45. Comparison of gas concentrations on a dry basis, Test 4 .......................................... 175

Figure 10-46. Comparison of gas concentrations on a dry basis, Test 5 ............................................ 175

Figure 10-47. Comparison of gas concentrations on a dry basis, Test 5 ........................................ 176

Figure 10-48. Comparison of velocity near top of vents, inlet and outlet in Test 1 ............................ 176

Figure 10-49. Comparison of velocity near center of vents, inlet and outlet in Test 1....................... 177

Figure 10-50. Comparison of velocity near bottom of vents, inlet and outlet in Test 1...................... 177

Figure 10-51. Coarse grid prediction of gas temperatures on the intake side of the compartment for Test 5

Figure 10-52. Coarse grid prediction of gas temperatures on the exhaust side of the compartment for Test 5 .

Figure 11-1. FDS simulation of the upper layer temperature on the plane $3.01 \mathrm{~m}$ above the floor (top figure) and the layer interface height (bottom figure) after $500 \mathrm{~s}$ in Test 1

Figure 11-2. FDS simulation of the predicted absorption coefficients on the plane $3.01 \mathrm{~m}$ above the floor (top figure) and the lower layer temperature (bottom figure) after $500 \mathrm{~s}$ in Test 1 .......

Figure 11-3. Temperature dependent thermophysical properties for A242 steel used in the thermal analysis.

Figure 11-4. Temperature dependent thermophysical properties of the SFRM used in the experiments and thermal analysis.

Figure 11-5. Temperature dependent thermophysical propertics for Marinite.

Figure 11-6. Finite-element model for the $3.05 \mathrm{~m}$ (10.0 ft) long steel bar, showing the elements distributed uniformly along the length of the bar.

Figure 11-7. Cross section of bar showing the elements used to model the steel (in blue) and the SFRM (in violet).

Figure 11-8. Typical temperature contours through the cross-section of the steel bar and the SFRM after $2,000 \mathrm{~s}$ in Test 5 .

Figure 11-9. Comparison of numerical simulations with measurements for the steel surface temperature at four locations on bar $\mathrm{A}$ in Test 1. 
Figure 11-10. Comparison of numerical simulations with measurements for the steel surface temperature at four locations on bar B in Test 1 .

Figure 11-11. Perspective and top view of the finite-element model of the steel column with SFRM... 196

Figure 11-12. Temperature contours plotted on the surface of the SFRM and the ceiling after $2,000 \mathrm{~s}$ in Test 5 .

Figure 11-13. Comparison of numerical simulations with measurements for the steel surface temperature at four locations $3.69 \mathrm{~m}$ above the floor on the column in Test 1.

Figure 11-14. Comparison of numerical simulations with measurements for the steel surface temperature at four locations $2.13 \mathrm{~m}$ above the floor on the column in Test 1 .......

Figure 11-15. Finite-element model of the insulated steel truss, the ceiling and the floor used in the thermal analysis of Test 5 .

Figure 11-16. Finite-element representation of the insulated steel truss (blue), the SFRM (violet), and the ceiling (red) used in the thermal analysis of Test 5.

Figure 1 1-17. Temperature contours (in $\mathrm{K}$ ) on the ceiling, floor, and the surface of the SFRM on truss $\mathrm{A}$ after $1,000 \mathrm{~s}$ in Test 5 .

Figure 11-18. Comparison of numerical simulations with measurements for the steel surface temperature at four locations $2.89 \mathrm{~m}$ above the floor on truss $\mathrm{A}$ in Test 1.

Figure 11-19. Comparison of numerical simulations with measurements for the steel surface temperature at four locations $3.29 \mathrm{~m}$ above the floor on truss $\mathrm{A}$ in Test 1 .

Figure 11-20. Comparison of numerical simulations with measurements for the steel surface temperature at four locations $3.70 \mathrm{~m}$ above the floor on truss $\mathrm{A}$ in Test 1 .

Figure 11-21. Comparison of numerical simulations with measurements for the steel surface temperature at four locations $2.89 \mathrm{~m}$ above the floor on truss B in Test 1.

Figure 11-22. Comparison of numerical simulations with measurements for the steel surface temperature at four locations $3.29 \mathrm{~m}$ above the floor on truss B in Test 1

Figure 11-23. Comparison of numerical simulations with measurements for the steel surface temperature at four locations $3.70 \mathrm{~m}$ above the floor on truss B in Test 1 .

Figure 11-24. Comparison of numerical simulations with measurements for the temperature of the SFRM surface at four locations on the insulated bar in Test 5 .

Figure 11-25. Comparison of numerical simulations with measurements for the temperature of the steel surface at four locations on the insulated bar in Test 5 .

Figure 11-26. Comparison of numerical simulations with measurements for the temperature of the SFRM surface at four locations $0.77 \mathrm{~m}$ above the floor on the insulated steel column in Test 5

Figure 11-27. Comparison of numerical simulations with measurements for the temperature of the SFRM surface at four locations $2.13 \mathrm{~m}$ above the floor on the insulated steel column in Test 5

Figure 11-28. Comparison of numerical simulations with measurements for the temperature of the SFRM surface at four locations $3.69 \mathrm{~m}$ above the floor on the insulated steel column in Test 5 
Figure 11-29. Comparison of numerical simulations with measurements for the temperature of the steel surface at four locations $0.77 \mathrm{~m}$ above the floor on the insulated column in Test 5 .

Figure 11-30. Comparison of numerical simulations with measurements for the temperature of the steel surface at four locations $2.13 \mathrm{~m}$ above the floor on the insulated column in Test 5 .

Figure 11-31. Comparison of numerical simulations with measurements for the temperature of the steel surface at four locations $3.69 \mathrm{~m}$ above the floor on the insulated steel column in Test 5

Figure 11-32. Comparison of numerical simulations with measurements for the temperature of the SFRM surface at four locations $3.70 \mathrm{~m}$ above the floor on truss A in Test 5.

Figure 11-33. Comparison of numerical simulations with measurements for the temperature of the SFRM surface at four locations $3.29 \mathrm{~m}$ above the floor on truss A in Test 5.

Figure 11-34. Comparison of numerical simulations with measurements for the temperature of the SFRM surface at four locations $2.89 \mathrm{~m}$ above the floor on truss $\mathrm{A}$ in Test 5.

Figure 11-35. Comparison of numerical simulations with measurements for the temperature of the steel surface at four locations $3.70 \mathrm{~m}$ above the floor on truss A in Test 5.

Figure 11-36. Comparison of numerical simulations with measurements for the temperature of the steel surface at four locations $3.29 \mathrm{~m}$ above the floor on truss A in Test 5 .

Figure 11-37. Comparison of numerical simulations with measurements for the temperature of the steel surface at four locations $2.89 \mathrm{~m}$ above the floor on truss A in Test 5.

Figure 11-38. FDS simulation of the upper layer temperature on a plane $3.01 \mathrm{~m}$ above the floor after $500 \mathrm{~s}$ in Test 1 using a heat release rate increased by 10 percent (top figure) and a crude mesh with $50 \mathrm{~cm}$ resolution (bottom figure).

Figure 11-39. FDS simulation of the layer interface height after $500 \mathrm{~s}$ in Test 1 using a heat release rate increased by 10 percent (top figure) and a crude mesh with $50 \mathrm{~cm}$ resolution (bottom figure).

Figure 11-40. FDS simulation of the absorption coefficient on a plane $3.01 \mathrm{~m}$ above the floor after $500 \mathrm{~s}$ in Test 1 using a heat release rate increased by 10 percent (top figure) and a crude mesh with $50 \mathrm{~cm}$ resolution (bottom figure).

Figure 11-41. FDS simulation of the lower layer temperature after $500 \mathrm{~s}$ in Test 1 using a heat release rate increased by 10 percent (top figure) and a crude mesh with

$50 \mathrm{~cm}$ resolution (bottom figure).

Figure 11-42. Numerical predictions of the steel surface temperature on bar A in Test 1 for an FDS calculation performed with a heat release rate 10 percent above baseline.

Figure 11-43. Numerical predictions of the steel surface temperature on bar B in Test 1 for an FDS calculation performed with a heat release rate 10 percent above baseline.

Figure 11-44. Numerical predictions of the steel surface temperature for the column in Test 1 at $3.69 \mathrm{~m}$ above the floor for an FDS calculation performed with a heat release rate 10 percent above baseline.

Figure 11-45. Numerical predictions of steel surface temperature for the column in Test 1 at $2.13 \mathrm{~m}$ above the floor for an FDS calculation performed with a heat release rate 10 percent above baseline. 
Figure 11-46. Numerical predictions of steel surface temperature at four locations $2.89 \mathrm{~m}$ above the floor on truss A in Test 1 for an FDS calculation performed with a heat release rate 10 percent above baseline.

Figure 11-47. Numerical predictions of steel surface temperature at four locations $3.29 \mathrm{~m}$ above the floor on truss $\mathrm{A}$ in Test 1 for an FDS calculation performed with a heat releasc ratc 10 percent above baseline.

Figure 11-48. Numerical simulations of the steel surface temperature at four locations $3.70 \mathrm{~m}$ above the floor on truss A in Test 1 for an FDS calculation performed with a heat release rate 10 percent above baseline.

Figure 11-49. Predicted numerical results for steel temperature for bar A in Test 1. These results correspond to an FDS calculation performed with a crude mesh $(50 \mathrm{~cm}$ resolution)

Figure 11-50. Predicted numerical results for steel temperature on bar B in Test 1. These results correspond to an FDS calculation performed with a crude mesh $(50 \mathrm{~cm}$ resolution)

Figure 11-51. Numerical predictions of steel surface temperature for bar A in Test 5 assuming a SFRM thickness 25 percent below baseline. 
This page intentionally left blank. 


\section{LIST OF TABLES}

Table P-1. Federal building and fire safety investigation of the WTC disaster..............................xxxii

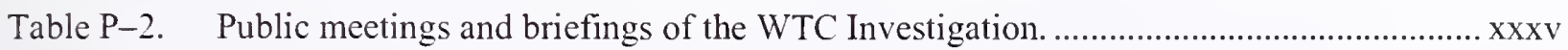

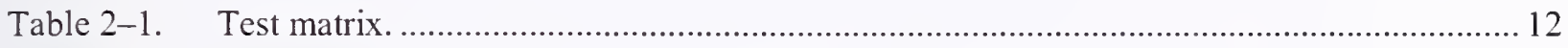

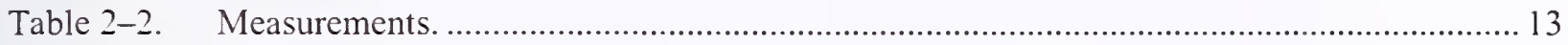

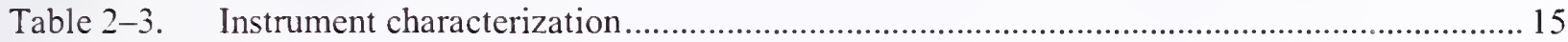

Table 3-1. Fuel flow and expected heat release rate........................................................... 20

Table 3-2. Combustion properties of the test fuels................................................................. 20

Table 3-3. Instruments used in the Calorimeter System.......................................................... 21

Table 3-4. Expanded relative uncertainty of the measured heat release rate...................................... 22

Table 3-5. The expected $\dot{Q}$, the measured mean $\dot{Q}$, and the experimental duration......................... 22

Table 4-1. Early (<60 s) mean difference: bare-bead minus aspirated at same location.....................26

Table 4-2. Late (>60 s) mean difference: bare-bead minus aspirated at same location. .....................26

Table 4-3. Early (<60 s) lower and upper expanded uncertainty limits. ......................................... 27

Table 4-4. Late $(>60 \mathrm{~s})$ lower and upper expanded uncertainty limits.......................................2 28

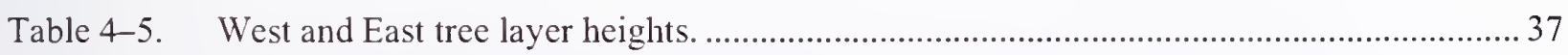

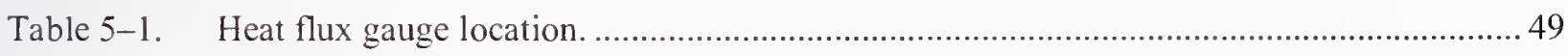

Table 5-2. Estimated certainties in heat flux measurements. .........................................................54

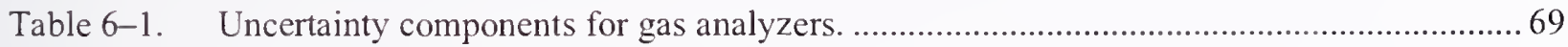

Table 6-2. Mean value and expanded uncertainty for gas and smoke volume fractions at the $\mathrm{S}_{\mathrm{m}}$

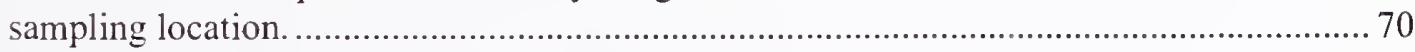

Table 6-3. Major contributors to the uncertainty in the smoke yield. ........................................... 73

Table 6-4. Mean value and expanded uncertainty for the smoke and gas yields (on a dry basis) at the $\mathrm{S}_{\mathrm{m}}$ sampling location.

Table 6-5. Mean value and expanded uncertainty for the smoke and gas yields (on a dry basis) for free burns.

Table 7-1. Bidirectional probe measurement locations. 
Table 7-2. Velocity measurement uncertainty..... 89

Table 8-1. Thermophysical properties of Marinite, Chromel, and Alumel.

Table 9-1. Statistical summary of SFRM thickness for steel components in Tests 5 and 6. 123

Table 9-2. SFRM thickness for bars in Tests 5 and 6 . 124

Table 9-3. SFRM thickness for columns in Tests 5 and 6. 125

Table 9-4. SFRM thickness for truss A in Test 5. 125

Table 9-5. SFRM thickness for truss B in Test 5. 126

Table 9-6. SFRM thickness for truss A in Test 6. 126

Table 9-7. SFRM thickness for truss B in Test 6. 127

Table 9-8. SFRM thickness measurements below allowable in Test 5. 127

Table 9-9. SFRM thickness measurements below allowable in Test 6. 128

Table 9-10. Thermophysical properties of steel, Chromel, and Alumel. 133

Table 9-11. Summary of peak temperatures recorded during Tests 1, 2, and 3 . 137

Table 9-12. Summary of peak temperatures recorded during Tests 5 and 6 . 138

Table 9-13. Thermal lag in insulated steel components during Tests 5 and 6 145

Table 11-1. Percentage difference between peak values of the measured and the simulated steel surface temperatures at the hottest and coolest locations on various uninsulated components in Test 1.

Table 11-2. Percentage difference between peak values of the measured and the simulated steel temperatures for the hottest and coolest locations on the steel surface of various components with SFRM in Test 5 .....

Table 11-3. Percentage difference in the peak value of temperatures between the baseline simulations and those with a 10 percent higher heat release rate at the hottest and coolest locations on the steel surface of various uninsulated components in Test 1 


\section{Acronyms}

\begin{tabular}{ll} 
ASTM & ASTM International \\
BFRL & Building and Fire Research Laboratory \\
BPS & Building Performance Study \\
CFD & computational fluid dynamics \\
COV & coefficient of variation \\
FDS & Fire Dynamics Simulator fire model \\
FEMA & Federal Emergency Management Agency \\
FSI & Fire Structure Interface model \\
LES & Large Eddy Simulation \\
NIST & National Institute of Standards and Technology \\
PANYNJ & Port Authority of New York and New Jersey \\
P.L. & Public Law \\
SEAoNY & Structural Engineers Association of New York \\
SFRM & sprayed fire-resistive material \\
USC & United States Code \\
WTC & World Trade Center \\
& \\
Abbreviations & \\
${ }^{\circ} \mathrm{C}$ & degrees Celsius \\
${ }^{\circ} \mathrm{F}$ & degrees Fahrenheit \\
$\mu \mathrm{m}$ & micrometer \\
$\mathrm{CO}{ }_{2}$ & carbon dioxide \\
$\mathrm{CO}$ & carbon monoxide \\
$\mathrm{cm}$ & centimeter \\
$\mathrm{ft}$ & foot \\
$\mathrm{ft}$ & cubic feet \\
$\mathrm{Hp}$ & horsepower \\
& hertz \\
\hline $\mathrm{H}$ &
\end{tabular}




$\begin{array}{ll}\text { in. } & \text { inch } \\ \mathrm{J} & \text { joule } \\ \mathrm{kW} & \text { kilowatt } \\ \mathrm{K} & \text { Kelvin } \\ \mathrm{kg} & \text { kilogram } \\ \mathrm{kPa} & \text { kilopascal } \\ \mathrm{lb} & \text { pound } \\ \mathrm{L} & \text { liter } \\ \mathrm{m} & \text { meter } \\ \mathrm{m}^{2} & \text { square meters } \\ \mathrm{mm} & \text { millimeter } \\ \mathrm{MW} & \text { megawatt } \\ \mathrm{min} & \text { minute } \\ \mathrm{O}_{2} & \text { oxygen } \\ \mathrm{Pa} & \text { pascal } \\ \mathrm{s} & \text { second } \\ \mathrm{TC} & \text { thermocouples }\end{array}$




\section{Metric Conversion TABLE}

To convert from

to

Multiply by

\section{AREA AND SECOND MOMENT OF AREA}

square foot $\left(\mathrm{ft}^{2}\right)$

square inch $\left(\right.$ in. $\left.^{2}\right)$

square inch $\left(\right.$ in. $\left.^{2}\right)$

square yard $\left(\mathrm{yd}^{2}\right)$

\section{ENERGY (includes WORK)}

kilowatt hour $(\mathrm{kW} \cdot \mathrm{h})$

quad (1015 BtuIT)

therm (U.S.)

ton of TNT (energy equivalent)

watt hour $(\mathrm{W} \cdot \mathrm{h})$

watt second $(\mathrm{W} \cdot \mathrm{s})$

\section{FORCE}

dyne (dyn)

kilogram-force (kgf)

kilopond (kilogram-force) (kp)

kip (1 kip $=1,000 \mathrm{lbf})$

kip (1 kip=1,000 lbf)

pound-force (lbf)

\section{FORCE DIVIDED BY LENGTH}

pound-force per foot (lbf/ft)

pound-force per inch (lbf/in.)

\section{HEAT FLOW RATE}

calorieth per minute (calth/min)

caloricth per second (calth/s)

kilocalorieth per minute (kcalth/min)

kilocalorieth per second (kcalth/s) square meter $\left(\mathrm{m}^{2}\right)$

square meter $\left(\mathrm{m}^{2}\right)$

square centimeter $\left(\mathrm{cm}^{2}\right)$

square meter $\left(\mathrm{m}^{2}\right)$

joule (J)

joule $(\mathrm{J})$

joule $(\mathrm{J})$

joule (J)

joule (J)

joule (J)

newton $(\mathrm{N})$

newton (N)

newton (N)

newton $(\mathrm{N})$

kilonewton $(\mathrm{kN})$

newton $(\mathrm{N})$

newton per meter $(\mathrm{N} / \mathrm{m})$

newton per meter $(\mathrm{N} / \mathrm{m})$

watt (W)

watt (W)

watt (W)

watt (W)
9.290304 E-02

$6.4516 \mathrm{E}-04$

$6.4516 \mathrm{E}+00$

8.361274 E-01

3.6 $\mathrm{E}+06$

$1.055056 \mathrm{E}+18$

$1.054804 \mathrm{E}+08$

$4.184 \mathrm{E}+09$

$3.6 \mathrm{E}+03$

$1.0 \mathrm{E}+00$
$1.0 \mathrm{E}-05$

$9.80665 \mathrm{E}+00$

$9.80665 \mathrm{E}+00$

$4.448222 \mathrm{E}+03$

$4.448222 \mathrm{E}+00$

$4.448222 \mathrm{E}+00$

$1.459390 \mathrm{E}+01$

$1.751268 \mathrm{E}+02$

$6.973333 \mathrm{E}-02$

$4.184 \mathrm{E}+00$

$6.973333 \mathrm{E}+01$

$4.184 \mathrm{E}+03$ 
To convert from

Multiply by

\section{LENGTH}

foot (ft)

inch (in)

inch (in.)

micron $(\mathrm{m})$

yard (yd)

\section{MASS and MOMENT OF INERTIA}

kilogram-force second squared per meter $\left(\mathrm{kgf} \cdot \mathrm{s}^{2} / \mathrm{m}\right)$

pound foot squared $\left(\mathrm{lb} \cdot \mathrm{ft}^{2}\right)$

pound inch squared $\left(\mathrm{lb} \cdot \mathrm{in}^{2}{ }^{2}\right)$

ton, metric $(\mathrm{t})$

ton, short $(2,000 \mathrm{lb})$

\section{MASS DIVIDED BY AREA}

pound per square foot $\left(\mathrm{lb} / \mathrm{ft}^{2}\right)$

pound per square inch

(not pound force) $\left(\mathrm{lb} / \mathrm{in} .{ }^{2}\right.$ )

\section{MASS DIVIDED BY LENGTH}

pound per foot $(\mathrm{lb} / \mathrm{ft})$

kilogram per meter $(\mathrm{kg} / \mathrm{m})$

pound per inch (lb/in.)

kilogram per meter $(\mathrm{kg} / \mathrm{m})$

pound per yard (lb/yd) meter $(\mathrm{m})$

$3.048 \mathrm{E}-01$

$2.54 \mathrm{E}-02$

$2.54 \mathrm{E}+00$

$1.0 \mathrm{E}-06$

$9.144 \mathrm{E}-01$ kilogram per square meter $\left(\mathrm{kg} / \mathrm{m}^{2}\right)$

$4.882428 \mathrm{E}+00$

kilogram $(\mathrm{kg})$

$9.80665 \mathrm{E}+00$

kilogram meter squared $\left(\mathrm{kg} \cdot \mathrm{m}^{2}\right)$

$4.214011 \mathrm{E}-02$

$2.926397 \mathrm{E}-04$

$1.0 \mathrm{E}+03$

$9.071847 \mathrm{E}+02$

kilogram per square meter $\left(\mathrm{kg} / \mathrm{m}^{2}\right) \quad 7.030696 \mathrm{E}+02$
$1.488164 \mathrm{E}+00$

$1.785797 \mathrm{E}+01$

$4.960546 \mathrm{E}-01$

\section{PRESSURE or STRESS (FORCE DIVIDED BY AREA)}

kilogram-force per square centimeter $\left(\mathrm{kgf} / \mathrm{cm}^{2}\right)$ pascal (Pa)

$9.80665 \mathrm{E}+04$

kilogram-force per square meter $\left(\mathrm{kgf} / \mathrm{m}^{2}\right)$

pascal $(\mathrm{Pa})$

$9.80665 \mathrm{E}+00$

kilogram-force per square millimeter $\left(\mathrm{kgf} / \mathrm{mm}^{2}\right)$ pascal $(\mathrm{Pa})$

$9.80665 \mathrm{E}+06$

kip per square inch (ksi) (kip/in. $\left.{ }^{2}\right)$

pascal $(\mathrm{Pa})$

$6.894757 \mathrm{E}+06$

kip per square inch (ksi) (kip/in. $\left.{ }^{2}\right)$

kilopascal $(\mathrm{kPa})$

$6.894757 \mathrm{E}+03$

pound-force per square foot $\left(\mathrm{lbf} / \mathrm{ft}^{2}\right)$

pascal $(\mathrm{Pa})$

$4.788026 \mathrm{E}+01$

pound-force per square inch (psi) (lbf/in. $\left.{ }^{2}\right)$

pascal $(\mathrm{Pa})$

$6.894757 \mathrm{E}+03$

pound-force per square inch (psi) (lbf/in. $\left.{ }^{2}\right)$

kilopascal (kPa)

psi (pound-force per square inch) (lbf/in. $\left.{ }^{2}\right)$

pascal (Pa)

$6.894757 \mathrm{E}+00$

psi (pound-force per square inch) $\left(\mathrm{lbf} / \mathrm{in}^{2}{ }^{2}\right)$

kilopascal $(\mathrm{kPa})$ 
To convert from

Multiply by

\section{TEMPERATURE}

degree Celsius $\left({ }^{\circ} \mathrm{C}\right)$

degree centigrade

degree Fahrenheit $\left({ }^{\circ} \mathrm{F}\right)$

degree Fahrenheit $\left({ }^{\circ} \mathrm{F}\right)$

kelvin $(\mathrm{K})$

\section{TEMPERATURE INTERVAL}

degree Celsius $\left({ }^{\circ} \mathrm{C}\right)$

degree centigrade

degree Fahrenheit $\left({ }^{\circ} \mathrm{F}\right)$

degree Fahrenheit $\left({ }^{\circ} \mathrm{F}\right)$

degree Rankine $\left({ }^{\circ} \mathrm{R}\right)$

\section{VELOCITY (includes SPEED)}

foot per second $(\mathrm{ft} / \mathrm{s}$ )

inch per second (in./s)

kilometer per hour $(\mathrm{km} / \mathrm{h})$

mile per hour $(\mathrm{mi} / \mathrm{h})$

mile per minute $(\mathrm{mi} / \mathrm{min})$

\section{VOLUME (includes CAPACITY)}

cubic foot $\left(\mathrm{ft}^{3}\right)$

cubic inch (in. ${ }^{3}$ )

cubic yard $\left(\mathrm{yd}^{3}\right)$

gallon (U.S.) (gal)

gallon (U.S.) (gal)

liter (L)

ounce (U.S. fluid) (floz)

ounce (U.S. fluid) ( $f$ oz) kelvin $(\mathrm{K})$

degree Celsius $\left({ }^{\circ} \mathrm{C}\right)$

degree Celsius $\left({ }^{\circ} \mathrm{C}\right)$

kelvin $(\mathrm{K})$

degree Celsius $\left({ }^{\circ} \mathrm{C}\right)$

kelvin $(\mathrm{K})$

degree Celsius $\left({ }^{\circ} \mathrm{C}\right.$ )

degree Celsius $\left({ }^{\circ} \mathrm{C}\right.$ )

kelvin $(\mathrm{K})$

kelvin (K)

meter per second $(\mathrm{m} / \mathrm{s})$

meter per second $(\mathrm{m} / \mathrm{s})$

meter per second $(\mathrm{m} / \mathrm{s})$

kilometer per hour $(\mathrm{km} / \mathrm{h})$

meter per second $(\mathrm{m} / \mathrm{s})$

cubic meter $\left(\mathrm{m}^{3}\right)$

cubic meter $\left(\mathrm{m}^{3}\right)$

cubic meter $\left(\mathrm{m}^{3}\right)$

cubic meter $\left(\mathrm{m}^{3}\right)$

liter (L)

cubic meter $\left(\mathrm{m}^{3}\right)$

cubic meter $\left(\mathrm{m}^{3}\right)$

milliliter $(\mathrm{mL})$
$2.54 \mathrm{E}-02$
$\mathrm{T} / \mathrm{K}=\mathrm{t} /{ }^{\circ} \mathrm{C}+273.15$

$\mathrm{t} /{ }^{\circ} \mathrm{C} \approx \mathrm{t} /$ deg. cent.

$\mathrm{t}^{\circ} \mathrm{C}=\left(\mathrm{t} /{ }^{\circ} \mathrm{F}-32\right) / 1.8$

$\mathrm{T} / \mathrm{K}=\left(\mathrm{t} /{ }^{\circ} \mathrm{F}+459.67\right) / 1.8$

$v^{\circ} \mathrm{C}=\mathrm{T} / \mathrm{K} 2273.15$

$1.0 \mathrm{E}+00$

$1.0 \mathrm{E}+00$

$5.555556 \mathrm{E}-01$

$5.555556 \mathrm{E}-01$

5.555556 E-01

3.048 E-01

2.777778 E-01

$1.609344 \mathrm{E}+00$

$2.68224 \mathrm{E}+01$

2.831685 E-02

$1.638706 \mathrm{E}-05$

$7.645549 \mathrm{E}-01$

3.785412 E-03

$3.785412 \mathrm{E}+00$

$1.0 \mathrm{E}-03$

2.957353 E-05

$2.957353 \mathrm{E}+01$ 
This page intentionally left blank. 


\section{PREFACE}

\section{Genesis of This Investigation}

Immediately following the terrorist attack on the World Trade Center (WTC) on September 11, 2001, the Federal Emergency Management Agency (FEMA) and the American Society of Civil Engineers began planning a building performance study of the disaster. The week of October 7, as soon as the rescue and search efforts ceased, the Building Performance Study Team went to the site and began its assessment. This was to be a brief effort, as the study team consisted of experts who largely volunteered their time away from their other professional commitments. The Building Performance Study Team issued its report in May 2002, fulfilling its goal "to determine probable failure mechanisms and to identify areas of future investigation that could lead to practical measures for improving the damage resistance of buildings against such unforeseen events."

On August 21. 2002, with funding from the U.S. Congress through FEMA, the National Institute of Standards and Technology (NIST) announced its building and fire safety investigation of the WTC disaster. On October 1, 2002, the National Construction Safety Team Act (Public Law 107-231), was signed into law. The NIST WTC Investigation was conducted under the authority of the National Construction Safety Team Act.

The goals of the investigation of the WTC disaster wcre:

- To investigate the building construction, the materials used, and the technical conditions that contributed to the outcome of the WTC disaster.

- To serve as the basis for:

- Improvements in the way buildings are designed, constructed, maintained, and used;

- Improved tools and guidance for industry and safety officials;

- Recommended revisions to current codes, standards, and practices; and

- Improved public safety.

The specific objectives were:

1. Determine why and how WTC 1 and WTC 2 collapsed following the initial impacts of the aircraft and why and how WTC 7 collapsed;

2. Determine why the injuries and fatalities were so high or low depending on location, including all technical aspects of fire protection, occupant behavior, evacuation, and emergency response;

3. Determine what procedures and practices were used in the design, construction, operation, and maintenance of WTC 1,2, and 7; and

4. Identify, as specifically as possible, areas in current building and fire codes, standards, and practices that warrant revision. 
NIST is a nonregulatory agency of the U.S. Department of Commerce's Technology Administration. The purpose of NIST investigations is to improve the safety and structural integrity of buildings in the United States, and the focus is on fact finding. NIST investigative teams are authorized to assess building performance and emergency response and evacuation procedures in the wake of any building failure that has resulted in substantial loss of life or that posed significant potential of substantial loss of life. NIST does not have the statutory authority to make findings of fault nor negligence by individuals or organizations. Further, no part of any report resulting from a NIST investigation into a building failure or from an investigation under the National Construction Safety Team Act may be used in any suit or action for damages arising out of any matter mentioned in such report (15 USC 281a, as amended by Public Law 107-231).

\section{Organization of the Investigation}

The National Construction Safety Team for this Investigation, appointed by the then NIST Director, Dr. Arden L. Bement, Jr., was led by Dr. S. Shyam Sunder. Dr. William L. Grosshandler served as Associate Lead Investigator, Mr. Stephen A. Cauffman served as Program Manager for Administration, and Mr. Harold E. Nelson served on the team as a private sector expert. The Investigation included eight interdependent projects whose leaders comprised the remainder of the team. A detailed description of each of these eight projects is available at http://wtc.nist.gov. The purpose of each project is summarized in Table $\mathrm{P}-1$, and the key interdependencies among the projects are illustrated in Fig. $\mathrm{P}-1$.

Table P-1. Federal building and fire safety investigation of the WTC disaster.

\begin{tabular}{|c|c|}
\hline Technical Area and Project Leader & Project Purpose \\
\hline $\begin{array}{l}\text { Analysis of Building and Fire Codes and } \\
\text { Practices; Project Leaders: Dr. H. S. Lew } \\
\text { and Mr. Richard W. Bukowski }\end{array}$ & $\begin{array}{l}\text { Document and analyze the code provisions, procedures, and } \\
\text { practices used in the design, construction, operation, and } \\
\text { maintenance of the structural, passive fire protection, and } \\
\text { emergency access and evacuation systems of WTC } 1,2 \text {, and } 7 .\end{array}$ \\
\hline $\begin{array}{l}\text { Baseline Structural Performance and } \\
\text { Aircraft Impact Damage Analysis; Project } \\
\text { Leader: Dr. Fahim H. Sadek }\end{array}$ & $\begin{array}{l}\text { Analyze the baseline performance of WTC } 1 \text { and WTC } 2 \text { under } \\
\text { design, service, and abnormal loads, and aircraft impact damage on } \\
\text { the structural, fire protection, and egress systems. }\end{array}$ \\
\hline $\begin{array}{l}\text { Mechanical and Metallurgical Analysis of } \\
\text { Structural Steel; Project Leader: Dr. Frank } \\
\text { W. Gayle }\end{array}$ & $\begin{array}{l}\text { Determine and analyze the mechanical and metallurgical properties } \\
\text { and quality of steel, weldments, and connections from steel } \\
\text { recovered from WTC } 1,2 \text {, and } 7 \text {. }\end{array}$ \\
\hline $\begin{array}{l}\text { Investigation of Active Fire Protection } \\
\text { Systems; Project Leader: Dr. David } \\
\text { D. Evans; Dr. William Grosshandler }\end{array}$ & $\begin{array}{l}\text { Investigate the performance of the active fire protection systems in } \\
\text { WTC } 1,2 \text {, and } 7 \text { and their role in fire control, emergency response, } \\
\text { and fate of occupants and responders. }\end{array}$ \\
\hline $\begin{array}{l}\text { Reconstruction of Thermal and Tenability } \\
\text { Environment; Project Leader: Dr. Richard } \\
\text { G. Gann }\end{array}$ & $\begin{array}{l}\text { Reconstruct the time-evolving temperature, thermal environment, } \\
\text { and smoke movement in WTC } 1,2 \text {, and } 7 \text { for use in evaluating the } \\
\text { structural performance of the buildings and behavior and fate of } \\
\text { occupants and responders. }\end{array}$ \\
\hline $\begin{array}{l}\text { Structural Fire Response and Collapse } \\
\text { Analysis; Project Leaders: Dr. John } \\
\text { L. Gross and Dr. Therese P. McAllister }\end{array}$ & $\begin{array}{l}\text { Analyze the response of the WTC towers to fires with and without } \\
\text { aircraft damage, the response of WTC } 7 \text { in fires, the performance } \\
\text { of composite steel-trussed floor systems, and determine the most } \\
\text { probable structural collapse sequence for WTC } 1,2 \text {, and } 7 \text {. }\end{array}$ \\
\hline $\begin{array}{l}\text { Occupant Behavior, Egress, and Emergency } \\
\text { Communications; Project Leader: Mr. Jason } \\
\text { D. Averill }\end{array}$ & $\begin{array}{l}\text { Analyze the behavior and fate of occupants and responders, both } \\
\text { those who survived and those who did not, and the performance of } \\
\text { the evacuation system. }\end{array}$ \\
\hline $\begin{array}{l}\text { Emergency Response Technologies and } \\
\text { Guidelines; Project Leader: Mr. J. Randall } \\
\text { Lawson }\end{array}$ & $\begin{array}{l}\text { Document the activities of the emergency responders from the time } \\
\text { of the terrorist attacks on WTC } 1 \text { and WTC } 2 \text { until the collapse of } \\
\text { WTC } 7 \text {, including practices followed and technologies used. }\end{array}$ \\
\hline
\end{tabular}




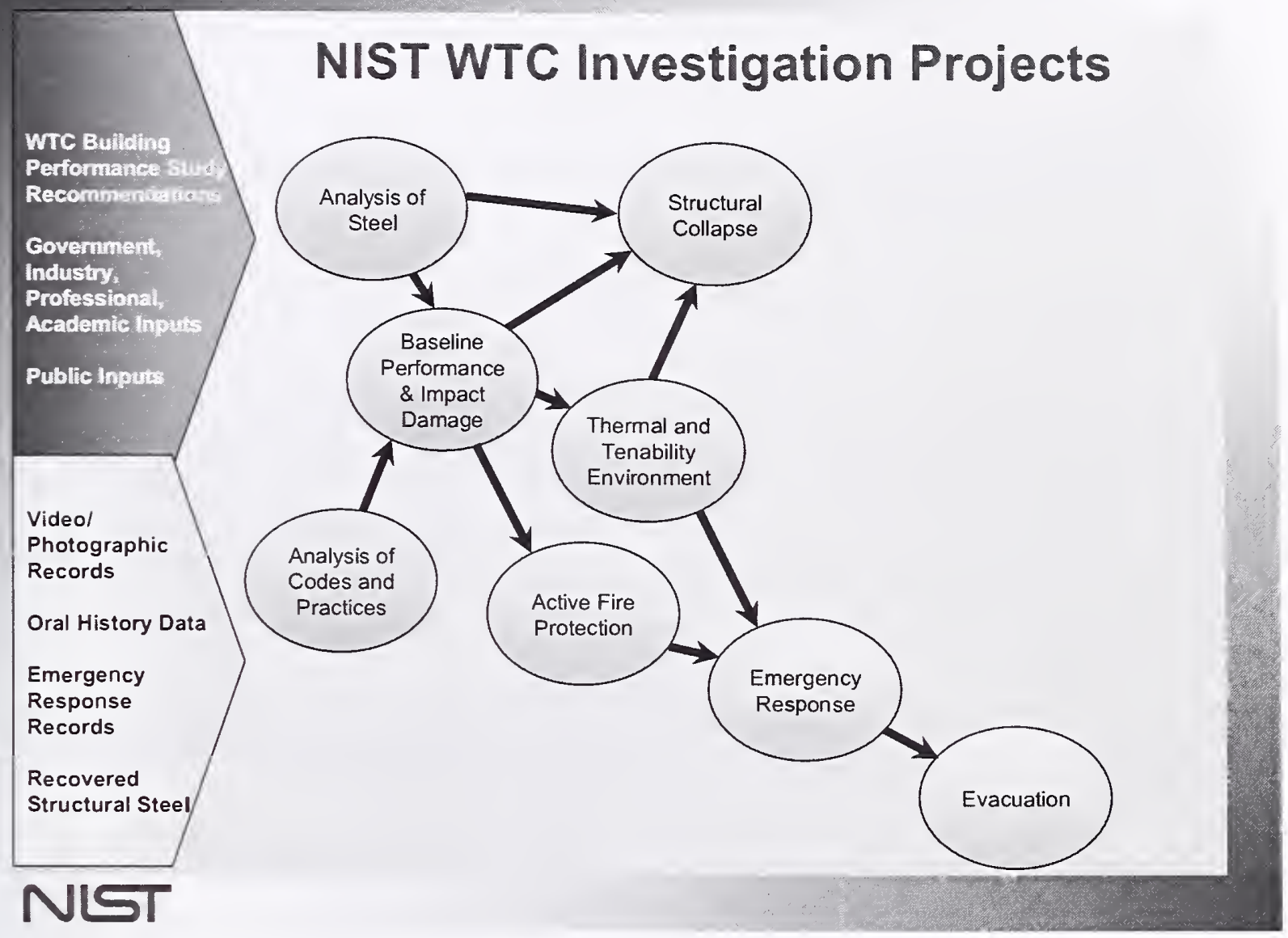

Figure $P-1$. The eight projects in the federal building and fire safety investigation of the WTC disaster.

\section{National Construction Safety Team Advisory Committee}

The NIST Director also established an advisory committee as mandated under the National Construction Safety Team Act. The initial members of the committee were appointed following a public solicitation. These were:

- Paul Fitzgerald, Executive Vice President (retired) FM Global, National Construction Safety Team Advisory Committee Chair

- John Barsom, President, Barsom Consulting, Ltd.

- John Bryan, Professor Emeritus, University of Maryland

- David Collins, President, The Preview Group, Inc.

- Glenn Corbett, Professor, John Jay College of Criminal Justice

- Philip DiNenno, President, Hughes Associates, Inc. 
- Robert Hanson, Professor Emeritus, University of Michigan

- Charles Thornton, Co-Chairman and Managing Principal, The Thornton-Tomasetti Group, Inc.

- Kathleen Tierney, Director, Natural Hazards Research and Applications Information Center, University of Colorado at Boulder

- Forman Williams, Director, Center for Energy Research, University of California at San Diego

This National Construction Safety Team Advisory Committee provided technical advice during the Investigation and commentary on drafts of the Investigation reports prior to their public release. NIST has benefited from the work of many people in the preparation of these reports, including the National Construction Safety Team Advisory Committee. The content of the reports and recommendations, however, are solely the responsibility of NIST.

\section{Public Outreach}

During the course of this Investigation, NIST held public briefings and meetings (listed in Table P-2) to solicit input from the public, present preliminary findings, and obtain comments on the direction and progress of the Investigation from the public and the Advisory Committee.

NIST maintained a publicly accessible Web site during this Investigation at http://wtc.nist.gov. The site contained extensive information on the background and progress of the Investigation.

\section{NIST's WTC Public-Private Response Plan}

The collapse of the WTC buildings has led to broad reexamination of how tall buildings are designed, constructed, maintained, and used, especially with regard to major events such as fires, natural disasters, and terrorist attacks. Reflecting the enhanced interest in effecting necessary change, NIST, with support from Congress and the Administration, has put in place a program, the goal of which is to develop and implement the standards, technology, and practices needed for cost-effective improvements to the safety and security of buildings and building occupants, including evacuation, emergency response procedures, and threat mitigation.

The strategy to meet this goal is a three-part NIST-led public-private response program that includes:

- A federal building and fire safety investigation to study the most probable factors that contributed to post-aircraft impact collapse of the WTC towers and the 47-story WTC 7 building, and the associated evacuation and emergency response experience.

- A research and development (R\&D) program to (a) facilitate the implementation of recommendations resulting from the WTC Investigation, and (b) provide the technical basis for cost-effective improvements to national building and fire codes, standards, and practices that enhance the safety of buildings, their occupants, and emergency responders. 
Table P-2. Public meetings and briefings of the WTC Investigation.

\begin{tabular}{|c|c|c|}
\hline Date & Location & Principal Agenda \\
\hline June 24,2002 & New York City, NY & $\begin{array}{l}\text { Public meeting: Public comments on the Draft Plan for the } \\
\text { pending WTC Investigation. }\end{array}$ \\
\hline August 21, 2002 & Gaithersburg, MD & Media briefing announcing the formal start of the Investigation. \\
\hline December 9,2002 & Washington, DC & $\begin{array}{l}\text { Media briefing on release of the Public Update and NIST request } \\
\text { for photographs and videos. }\end{array}$ \\
\hline April 8, 2003 & New York City, NY & $\begin{array}{l}\text { Joint public forum with Columbia University on first-person } \\
\text { interviews. }\end{array}$ \\
\hline April 29-30, 2003 & Gaithersburg, MD & $\begin{array}{l}\text { NCST Advisory Committee meeting on plan for and progress on } \\
\text { WTC Investigation with a public comment session. }\end{array}$ \\
\hline May 7,2003 & New York City, NY & Media briefing on release of May 2003 Progress Report. \\
\hline August $26-27,2003$ & Gaithersburg, MD & $\begin{array}{l}\text { NCST Advisory Committee meeting on status of the WTC } \\
\text { investigation with a public comment session. }\end{array}$ \\
\hline September 17,2003 & New York City, NY & $\begin{array}{l}\text { Media and public briefing on initiation of first-person data } \\
\text { collection projects. }\end{array}$ \\
\hline December 2-3, 2003 & Gaithersb & $\begin{array}{l}\text { NCST Advisory Committee meeting on status and initial results } \\
\text { and release of the Public Update with a public comment session. }\end{array}$ \\
\hline February 12,2004 & New York City, NY & $\begin{array}{l}\text { Public meeting on progress and preliminary findings with public } \\
\text { comments on issues to be considered in formulating final } \\
\text { recommendations. }\end{array}$ \\
\hline June 18,2004 & New York City, NY & Media/public briefing on release of June 2004 Progress Report. \\
\hline June $22-23,2004$ & Gaithersburg, MD & $\begin{array}{l}\text { NCST Advisory Committee meeting on the status of and } \\
\text { preliminary findings from the WTC Investigation with a public } \\
\text { comment session. }\end{array}$ \\
\hline August 24.2004 & Northbrook, IL & $\begin{array}{l}\text { Public viewing of standard fire resistance test of WTC floor } \\
\text { system at Underwriters Laboratories, Inc. }\end{array}$ \\
\hline October 19-20,2004 & Gaithersb & $\begin{array}{l}\text { NCST Advisory Committee meeting on status and near complete } \\
\text { set of preliminary findings with a public comment session. }\end{array}$ \\
\hline November 22,2004 & Gaithersburg, MD & $\begin{array}{l}\text { NCST Advisory Committee discussion on draft annual report to } \\
\text { Congress, a public comment session, and a closed session to } \\
\text { discuss pre-draft recommendations for WTC Investigation. }\end{array}$ \\
\hline April 5, 2005 & New York City, NY & $\begin{array}{l}\text { Media and public briefing on release of the probable collapse } \\
\text { sequence for the WTC towers and draft reports for the projects on } \\
\text { codes and practices, evacuation, and emergency response. }\end{array}$ \\
\hline June 23,2005 & New York City, NY & $\begin{array}{l}\text { Media and public briefing on release of all draft reports for the } \\
\text { WTC towers and draft recommendations for public comment. }\end{array}$ \\
\hline $\begin{array}{l}\text { September 12-13, } \\
2005\end{array}$ & Gaithersburg, MD & $\begin{array}{l}\text { NCST Advisory Committee meeting on disposition of public } \\
\text { comments and update to draft reports for the WTC towers. }\end{array}$ \\
\hline $\begin{array}{l}\text { September } 13-15 \text {, } \\
2005\end{array}$ & Gaithersburg, MD & $\begin{array}{l}\text { WTC Technical Conference for stakeholders and technical } \\
\text { community for dissemination of findings and recommendations } \\
\text { and opportunity for public to make technical comments. }\end{array}$ \\
\hline
\end{tabular}

- A dissemination and technical assistance program (DTAP) to (a) engage leaders of the construction and building community in ensuring timely adoption and widespread use of proposed changes to practices, standards, and codes resulting from the WTC Investigation and the R\&D program, and (b) provide practical guidance and tools to better prepare facility owners, contractors, architects, engineers, emergency responders, and regulatory authorities to respond to future disasters.

The desired outcomes are to make buildings, occupants, and first responders safer in future disaster events. 


\section{National Construction Safety Team Reports on the WTC Investigation}

A final report on the collapse of the WTC towers is being issued as NIST NCSTAR 1. A companion report on the collapse of WTC 7 is being issued as NIST NCSTAR 1A. The present report is one of a set that provides more detailed documentation of the Investigation findings and the means by which these technical results were achieved. As such, it is part of the archival record of this Investigation. The titles of the full set of Investigation publications are:

NIST (National Institute of Standards and Technology). 2005. Federal Building and Fire Safety Investigation of the World Trade Center Disaster: Final Report on the Collapse of the World Trade Center Towers. NIST NCSTAR 1. Gaithersburg, MD, September.

NIST (National Institute of Standards and Technology). 2006. Federal Building and Fire Safety Investigation of the World Trade Center Disaster: Final Report on the Collapse of World Trade Center 7. NIST NCSTAR 1A. Gaithersburg, MD.

Lew, H. S., R. W. Bukowski, and N. J. Carino. 2005. Federal Building and Fire Safety Investigation of the World Trade Center Disaster: Design, Construction, and Maintenance of Structural and Life Safety Systems. NIST NCSTAR 1-1. National Institute of Standards and Technology. Gaithersburg, MD, September.

Fanella, D. A., A. T. Derecho, and S. K. Ghosh. 2005. Federal Building and Fire Safety Investigation of the World Trade Center Disaster: Design and Construction of Structural Systems. NIST NCSTAR 1-1A. National Institute of Standards and Technology. Gaithersburg, MD, September.

Ghosh, S. K., and X. Liang. 2005. Federal Building and Fire Safety Investigation of the World Trade Center Disaster: Comparison of Building Code Structural Requirements. NIST NCSTAR 1-1B. National Institute of Standards and Technology. Gaithersburg, MD, September.

Fanella, D. A., A. T. Derecho, and S. K. Ghosh. 2005. Federal Building and Fire Safety Investigation of the World Trade Center Disaster: Maintenance and Modifications to Structural Systems. NIST NCSTAR 1-1C. National Institute of Standards and Technology. Gaithersburg, $\mathrm{MD}$, September.

Grill, R. A., and D. A. Johnson. 2005. Federal Building and Fire Safety Investigation of the World Trade Center Disaster: Fire Protection and Life Safety Provisions Applied to the Design and Constrnction of World Trade Center 1, 2, and 7 and Post-Construction Provisions Applied after Occupancy. NIST NCSTAR 1-1D. National Institute of Standards and Technology. Gaithersburg, MD, September.

Razza, J. C., and R. A. Grill. 2005. Federal Brilding and Fire Safety Investigation of the World Trade Center Disaster: Comparison of Codes, Standards, and Practices in Use at the Time of the Design and Construction of World Trade Center 1, 2, and 7. NIST NCSTAR 1-1E. National Institute of Standards and Technology. Gaithersburg, MD, September.

Grill, R. A., D. A. Johnson, and D. A. Fanella. 2005. Federal Building and Fire Safety Investigation of the World Trade Center Disaster: Comparison of the 1968 and Corrent (2003) New 
York City Blilding Code Provisions. NIST NCSTAR 1-1F. National Institute of Standards and Technology. Gaithersburg, MD, September.

Grill, R. A., and D. A. Johnson. 2005. Federal Bnilding and Fire Safety Investigation of the World Trade Center Disaster: Amendments to the Fire Protection and Life Safety Provisions of the New York City Building Code by Local Laws Adopted While World Trade Center 1, 2, and 7 Were in Use. NIST NCSTAR 1-1G. National Institute of Standards and Technology. Gaithersburg, MD, September.

Grill, R. A., and D. A. Johnson. 2005. Federal Building and Fire Safety Investigation of the World Trade Center Disaster: Post-Constriction Modifications to Fire Protection and Life Safety Systems of World Trade Center 1 ald 2. NIST NCSTAR 1-1H. National Institute of Standards and Technology. Gaithersburg, MD, September.

Grill, R. A., D. A. Johnson, and D. A. Fanella. 2005. Federal Building and Fire Safety Investigation of the World Trade Center Disaster: Post-Construction Modifications to Fire Protection, Life Safety, and Structural Systems of World Trade Center 7. NIST NCSTAR 1-1I. National Institute of Standards and Technology. Gaithersburg, MD, September.

Grill, R. A., and D. A. Johnson. 2005. Federal Burilding and Fire Safety Investigation of the World Trade Center Disaster: Design, Installation, and Operation of Fuel System for Emergency Power in World Trade Center 7. NIST NCSTAR 1-1J. National Institute of Standards and Technology. Gaithersburg, MD, September.

Sadek, F. 2005. Federal Building and Fire Safety Investigation of the World Trade Center Disaster: Baseline Structural Performance and Airctaft Impact Damage Analysis of the World Trade Center Towers. NIST NCSTAR 1-2. National Institute of Standards and Technology. Gaithersburg, MD, September.

Faschan, W. J., and R. B. Garlock. 2005. Federal Building and Fire Safety Investigation of the World Trade Center Disaster: Reference Stuctural Models and Baseline Performance Analysis of the World Trade Center Towers. NIST NCSTAR 1-2A. National Institute of Standards and Technology. Gaithersburg, MD, September.

Kirkpatrick, S. W., R. T. Bocchieri, F. Sadek, R. A. MacNeill, S. Holmes, B. D. Peterson, R. W. Cilke, C. Navarro. 2005. Federal Building and Fire Safety Investigation of the World Trade Center Disaster: Analysis of Aircraft Impacts into the World Trade Center Towers, NIST NCSTAR 1-2B. National Institute of Standards and Technology. Gaithersburg, MD, September.

Gayle, F. W., R. J. Fields, W. E. Luecke, S. W. Banovic, T. Foecke, C. N. McCowan, T. A. Siewert, and J. D. McColskey. 2005. Federal Building and Fire Safety Investigation of the World Trade Center Disaster: Mechanical and Metallurgical Analysis of Structural Steel. NIST NCSTAR 1-3. National Institute of Standards and Technology. Gaithersburg, MD, September.

Luecke, W. E., T. A. Siewert, and F. W. Gayle. 2005. Federal Building and Fire Safety Investigation of the World Trade Center Disaster: Contemporaneous Structural Steel Specifications. NIST Special Publication 1-3A. National Institute of Standards and Technology. Gaithersburg, MD, September. 
Banovic, S. W. 2005. Federal Butlding and Fire Safety Investigation of the World Trade Center Disaster: Steel Inventory and Identification. NIST NCSTAR 1-3B. National Institute of Standards and Technology. Gaithersburg, MD, September.

Banovic, S. W., and T. Foecke. 2005. Federal Building and Fire Safety Investigation of the World Trade Center Disaster: Danlage and Failure Modes of Structural Steel Conmonents. NIST NCSTAR 1-3C. National Institute of Standards and Technology. Gaithersburg, MD, September.

Luecke, W. E., J. D. McColskey, C. N. McCowan, S. W. Banovic, R. J. Fields, T. Foecke, T. A. Siewert, and F. W. Gayle. 2005. Federal Building and Fire Safety Investigation of the World Trade Center Disaster: Mechanical Properties of Structural Steels. NIST NCSTAR 1-3D. National Institute of Standards and Technology. Gaithersburg, MD, September.

Banovic, S. W., C. N. McCowan, and W. E. Luecke. 2005. Federal Building and Fire Safety Investigation of the World Trade Center Disaster: Physical Properties of Structural Steels. NIST NCSTAR 1-3E. National Institute of Standards and Technology. Gaithersburg, MD, September.

Evans, D. D., R. D. Peacock, E. D. Kuligowski, W. S. Dols, and W. L. Grosshandler. 2005. Federal Building and Fire Safety Imvestigation of the World Trade Center Disaster: Active Fire Protection Systems. NIST NCSTAR 1-4. National Institute of Standards and Technology. Gaithersburg, MD, September.

Kuligowski, E. D., D. D. Evans, and R. D. Peacock. 2005. Federal Building and Fire Safety Investigation of the World Trade Center Disaster: Post-Construction Fires Prior to September 11, 2001. NIST NCSTAR 1-4A. National Institute of Standards and Technology. Gaithersburg, MD, September.

Hopkins, M., J. Schoenrock, and E. Budnick. 2005. Federal Building and Fire Safety Investigation of the World Trade Center Disaster: Fire Snppression Systems. NIST NCSTAR 1-4B. National Institute of Standards and Technology. Gaithersburg, MD, September.

Keough, R. J., and R. A. Grill. 2005. Federal Bnilding and Fire Safety Investigation of the World Trade Center Disaster: Fire Alarn Systenis. NIST NCSTAR 1-4C. National Institute of Standards and Technology. Gaithersburg, MD, September.

Ferreira, M. J., and S. M. Strege. 2005. Federal Building and Fire Safety Investigation of the World Trade Center Disaster: Smoke Management Systems. NIST NCSTAR 1-4D. National Institute of Standards and Technology. Gaithersburg, MD, September.

Gann, R. G., A. Hamins, K. B. McGrattan, G. W. Mulholland, H. E. Nelson, T. J. Ohlemiller, W. M. Pitts, and K. R. Prasad. 2005. Federal Building and Fire Safety Investigation of the World Trade Center Disaster: Reconstruction of the Fires in the World Trade Center Towers. NIST NCSTAR 1-5. National Institute of Standards and Technology. Gaithersburg, MD, September.

Pitts, W. M., K. M. Butler, and V. Junker. 2005. Federal Building and Fire Safety Investigation of the World Trade Center Disaster: Vistral Evidence, Damage Estimates, and Timeline Analysis.

NIST NCSTAR 1-5A. National Institute of Standards and Technology. Gaithersburg, MD, September. 
Hamins, A., A. Maranghides, K. B. McGrattan, E. Johnsson, T. J. Ohlemiller, M. Donnelly, J. Yang, G. Mulholland, K. R. Prasad, S. Kukuck, R. Anleitner and T. McAllister. 2005. Federal Building and Fire Safety Investigation of the World Trade Center Disaster: Experiments and Modeling of Structural Steel Elements Exposed to Fire. NIST NCSTAR 1-5B. National Institute of Standards and Technology. Gaithersburg, MD, September.

Ohlemiller, T. J., G. W. Mulhoiland, A. Maranghides, J. J. Filliben, and R. G. Gann. 2005. Federal Building and Fire Safety Investigation of the World Trade Center Disaster: Fire Tests of Single Office Workstations. NIST NCSTAR 1-5C. National Institute of Standards and Technology. Gaithersburg, MD, September.

Gann, R. G., M. A. Riley, J. M. Repp, A. S. Whittaker, A. M. Reinhorn, and P. A. Hough. 2005. Federal Building and Fite Safety Investigation of the World Trade Center Disaster: Reaction of Ceiling Tile Systems to Shocks. NIST NCSTAR 1-5D. National Institute of Standards and Technology. Gaithersburg, MD, September.

Hamins, A., A. Maranghides, K. B. McGrattan, T. J. Ohlemiller, and R. Anleitner. 2005. Federal Building and Fire Safety Investigation of the World Trade Center Disaster: Experiments and Modeling of Multiple Workstations Buming in a Compartment. NIST NCSTAR 1-5E. National Institute of Standards and Technology. Gaithersburg, MD, September.

McGrattan, K. B., C. Bouldin, and G. Forney. 2005. Federal Building and Fire Safety Investigation of the World Trade Center Disaster: Computer Simulation of the Fires in the World Trade Center Towers. NIST NCSTAR 1-5F. National Institute of Standards and Technology. Gaithersburg, MD, September.

Prasad, K. R., and H. R. Baum. 2005. Federal Building and Fire Safety Investigation of the World Trade Center Disaster: Fire Stucture Interface and Thermal Response of the World Trade Center Towers. NIST NCSTAR 1-5G. National Institute of Standards and Technology. Gaithersburg, MD, September.

Gross, J. L., and T. McAllister. 2005. Federal Building and Fire Safety Investigation of the World Trade Center Disaster: Structural Fire Response and Probable Collapse Sequence of the World Trade Center Towers. NIST NCSTAR 1-6. National Institute of Standards and Technology. Gaithersburg, MD, September.

Carino, N. J., M. A. Starnes, J. L. Gross, J. C. Yang, S. Kukuck, K. R. Prasad, and R. W. Bukowski. 2005. Federal Building and Fire Safety Investigation of the World Trade Center Disaster: Passive Fire Protection. NIST NCSTAR 1-6A. National Institute of Standards and Technology. Gaithersburg, MD, September.

Gross, J., F. Hervey, M. Izydorek, J. Mammoser, and J. Treadway. 2005. Federal Building and Fire Safety Investigation of the World Trade Center Disaster: Fire Resistance Tests of Floor Truss Systems. NIST NCSTAR 1-6B. National Institute of Standards and Technology. Gaithersburg, MD, September.

Zarghamee, M. S., S. Bolourchi, D. W. Eggers, Ö. O. Erbay, F. W. Kan, Y. Kitane, A. A. Liepins, M. Mudlock, W. I. Naguib, R. P. Ojdrovic, A. T. Sarawit, P. R Barrett, J. L. Gross, and 
T. P. McAllister. 2005. Federal Building and Fire Safety Investigation of the World Trade Center Disaster: Component, Connection, and Subsystem Structural Analysis. NIST NCSTAR 1-6C. National Institute of Standards and Technology. Gaithersburg, MD, September.

Zarghamee, M. S., Y. Kitane, Ö. O. Erbay, T. P. McAllister, and J. L. Gross. 2005. Federal Building and Fire Safety Investigation of the World Trade Center Disaster: Global Structural Analysis of the Response of the World Trade Center Towers to Impact Damage and Fire. NIST NCSTAR 1-6D. National Institute of Standards and Technology. Gaithersburg, MD, September.

McAllister, T., R. W. Bukowski, R. G. Gann, J. L. Gross, K. B. McGrattan, H. E. Nelson, L. Phan, W. M. Pitts, K. R. Prasad, F. Sadek. 2006. Federal Building and Fire Safety Investigation of the World Trade Center Disaster: Structural Fire Response and Probable Collapse Sequence of World Trade Center 7. (Provisional). NIST NCSTAR 1-6E. National Institute of Standards and Technology. Gaithersburg, MD.

Gilsanz, R., V. Arbitrio, C. Anders, D. Chlebus, K. Ezzeldin, W. Guo, P. Moloney, A. Montalva, J. Oh, K. Rubenacker. 2006. Federal Building and Fire Safety Investigation of the World Trade Center Disaster: Structural Analysis of the Response of World Trade Center 7 to Debris Damage and Fire. (Provisional). NIST NCSTAR 1-6F. National Institute of Standards and Technology. Gaithersburg, MD.

Kim, W. 2006. Federal Building and Fire Safety Investigation of the World Trade Center Disaster: Analysis of September 11, 2001, Seismogram Data. (Provisional). NIST NCSTAR 1-6G. National Institute of Standards and Technology. Gaithersburg, MD.

Nelson, K. 2006. Federal Building and Fire Safety Investigation of the World Trade Center Disaster: The Con Ed Substation in World Trade Center 7. (Provisional). NIST NCSTAR 1-6H. National Institute of Standards and Technology. Gaithersburg, MD.

Averill, J. D., D. S. Mileti, R. D. Peacock, E. D. Kuligowski, N. Groner, G. Proulx, P. A. Reneke, and H. E. Nelson. 2005. Federal Building and Fire Safety Investigation of the World Trade Center Disaster: Occupant Behavior, Egress, and Entergency Communication. NIST NCSTAR 1-7. National Institute of Standards and Technology. Gaithersburg, MD, September.

Fahy, R., and G. Proulx. 2005. Federal Building and Fire Safety Investigation of the World Trade Center Disaster: Analysis of Published Accounts of the World Trade Center Evacnation. NIST NCSTAR 1-7A. National Institute of Standards and Technology. Gaithersburg, MD, September.

Zmud, J. 2005. Federal Building and Fire Safety Investigation of the World Trade Center Disaster: Technical Documentation for Strvey Administration. NIST NCSTAR 1-7B. National Institute of Standards and Technology. Gaithersburg, MD, September.

Lawson, J. R., and R. L. Vettori. 2005. Federal Building and Fire Safety Investigation of the World Trade Center Disaster: The Emergency Response Operations. NIST NCSTAR 1-8. National Institute of Standards and Technology. Gaithersburg, MD, September. 


\section{ACKNOWLEDGMENTS}

The authors are grateful to National Institute of Standards and Technology staff including Lauren DeLauter, Edward Hnetkovsky, Jack Lee, Roy McLane, Jay McElroy, and Mike Selepak for their assistance conducting the experiments, to Tyler Smith for assistance with data analysis, and to Dr. Rodney Bryant for helpful discussions. 
This page intentionally left blank. 


\section{EXECUTIVE SUMMARY}

This report represents part of the reconstruction of the thermal and tenability environment of the World Trade Center (WTC) Investigation, the goal of which was to evaluate the structural performance of the buildings. As part of this endeavor, three computational models were used to reconstruct the timeevolving temperature, thermal environment, and smoke movement in WTC 1,2, and 7 and to assess the effect of the fire on the temperature rise of the insulated structural steel components.

The models applied to the analysis of the WTC fires were (1) the National Institute of Standards and Technology (NIST) Fire Dynamic Simulator (FDS), which is a computational model of fire behavior and its effects; (2) the NIST Fire-Structure Interface (FSI), which applies the fire model (FDS) results to determine boundary conditions for computational finite-element models of the temperature behavior of the insulated structural components; and (3) the commercially available ANSYS finite-element thermal model. The FDS is the first large-domain computational fluid dynamics (CFD) fire model that predicts and visualizes the spread, growth and suppression of a fire based on the underlying scientific principles governing fluid motion. The FDS code numerically solves the modeled conservation equations of mass, momentum and energy that govern low-speed, thermally driven flows with an emphasis on smoke and heat transport from fires. The companion software package, called Smokeview, graphically presents the results of the FDS three-dimensional time-dependent simulation. Smokeview animates in three dimensions the smoke particulates, heat fluxes, temperatures and fluid velocities within a building. Users of the FDS/Smokeview software package can view the simulated results from any angle and from inside or outside the computational boundaries. The FSI calculates the transfer of radiant and convective heat from a CFD fire model such as FDS to a coupled, transient, three-dimensional finite-element model for the thermal response of structural components such as ANSYS. The structural components may be simple (e.g., uninsulated steel) or complex (e.g., steel insulated with a fire protective coating).

For application to the WTC Investigation. each of these models needs experimental data (a) to guide adaptation/development of the models for this specific purpose and (b) with which to ascertain the accuracy of the model predictions. Ideally, the uncertainty in the agreement with experiments would be much smaller than the effect of varying the unknowns in the actual conditions on September 11, 2001.

To gain confidence in the accuracy of these models as applied to the WTC investigation, two large-scale test series were conducted to assess the accuracy of the numerical model. A number of small-scale experiments were conducted to provide input data on the different materials used in the experiment. The two large-scale test series involved fires in compartments with approximately the same height as a floor in the WTC towers. The results of the first series of tests are described in this report. In these experiments, a liquid fuel spray burner was used to generate a fixed amount of energy in a compartment that was fitted with various targets and obstructions including steel objects such as columns, trusses and rods, and the fire conditions were over-ventilated, that is, the rate of burning was not limited by the availability of oxygen. In the experiments described in this report, the fuels used were well-characterized hydrocarbons or mixture of hydrocarbons. This facilitated experimental control of the fire heat release. The heat release rate drives fire effects including radiative and convective heat transfer within the compartment and the temperature rise of the gases and the contents of the compartment and its surfaces. 
A second series of fire tests (NIST NCSTAR 1-5E ) was conducted in a larger compartment in which multiple office workstations similar to those present in the WTC were burned under conditions similar to those experienced on September 11,2001. The second series of experiments investigated the accuracy of the fire model for under-ventilated conditions. In those experiments, actual furniture was used as the fuel. The experiments were designed to recreate very different aspects of the fire model for application to the WTC fires including issues associated with limited ventilation, fire spread and growth on real furnishings, and the effects of debris and jet fuel on the heat release rate of the fires.

Both series of experiments were conducted at the NIST Large Fire Laboratory. An objective of the first series of experiments, which is reported here, was to assess the accuracy with which the NIST FDS predicted the thermal environment in a burning compartment and to establish a data set to validate the prediction of the temperature rise of structural steel components. Within a steel-frame compartment (nominally $3 \mathrm{~m}$ by $7 \mathrm{~m}$ by $4 \mathrm{~m}$ high) lined with calcium silicate boards were placed several steel components including two trusses, one thin-walled hollow column, and simple rods. The components were tested in both an uninsulated (unprotected bare) state and with an insulating coating of fireproofing or fibrous sprayed fire-resistive material (SFRM), which was applied by the manufacturer. Two thicknesses of SFRM were tested. A significant variation in the thickness of the SFRM applied to the steel components was measured, with the $1.91 \mathrm{~cm}$ specified thickness averaging $2.2 \mathrm{~cm}$ to $2.7 \mathrm{~cm}$ with a coefficient of variation (COV; equal to the ratio of the standard deviation to the mean value of the thickness) from 0.17 to 0.27 and the $3.81 \mathrm{~cm}$ specified thickness averaging $4.05 \mathrm{~cm}$ to $4.10 \mathrm{~cm}$ with a COV of 0.07 to 0.20 . The lower COV values were measured for the columns; the higher COV values occurred for the bars and angles, which are morc difficult shapes for uniform application of the SFRM product. The SFRM measurements may be considered as a lower bound estimate of the variance that would be expected for field applications.

The fires wcre gcnerated using liquid hydrocarbon fuels introduced by a two-nozzle spray burner onto a $1 \mathrm{~m}$ by $2 \mathrm{~m}$ pan. The fire size tested was between $1.9 \mathrm{MW}$ and 3.4 MW to assure that the structural components were immersed in flames and hot gases. The fuels used were a commercial blend of heptane isomers and a mixture of the hcptane blend with toluene. These fuels were selected to cover the expected range of soot loading in fires generated by typical office furnishings. Six fire experiments were conducted.

Nearly 350 instruments were used to measure a number of important variables, including the heat release rate of the fire, the radiative and total heat flux at various targets in the compartment at locations near the floor and the ceiling, the tempcratures of insulated and uninsulated steel components, the concentrations of oxygen, carbon monoxide and carbon dioxide, and the vertical profiles of gas-phase temperature. The overall fire behavior was documented using four video cameras viewing fire behavior inside the compartment from different orientations.

Following the establishment of baseline signals from all the measurement devices, the burner was ignited and continued burning at a steady rate. The fire was allowed to burn until the temperature at any steel surface approached approximately $600{ }^{\circ} \mathrm{C}$, which is a temperature at which steel mechanical properties begin to degrade significantly. Data were acquired for several minutes after the fuel flow was stopped to observe cooling of the compartment and its contents.

1 This reference is to one of the companion documents from this Investigation. A list of these documents appears in the Preface to this report. 
The measurements led to findings regarding the thermal behavior of the compartment and its contents. including the steel components, as they were exposed to fires of various size, fuel sootiness, and proximity to the fire plume. The effect of the SFRM on the rate of temperature rise of the steel components was also measured. Noteworthy results included the following:

- Ceiling surface temperatures obtained values as high as $700{ }^{\circ} \mathrm{C}$ to $800{ }^{\circ} \mathrm{C}$ and $800{ }^{\circ} \mathrm{C}$ to $900{ }^{\circ} \mathrm{C}$ after $15 \mathrm{~min}$ and $50 \mathrm{~min}$, respectively, of exposure to a $3 \mathrm{MW}$ heat release rate fire with peak temperatures observed to occur above the fuel pan.

- The value of the heat flux about the compartment was dependent on location and test conditions. For example, at the floor in front of the fire pan, the heat flux varied from $20 \mathrm{~kW} / \mathrm{m}^{2}$ to $90 \mathrm{~kW} / \mathrm{m}^{2}$. In the upper layer near the ceiling, the heat flux was measured to be as high as $90 \mathrm{~kW} / \mathrm{m}^{2}$.

- The experimental results showed that the SFRM significantly delayed the rise in the steel temperature. The highest temperatures obtained at the steel surface were significantly lower than the temperature at the outside face of the insulation material.

- The surface temperature of uninsulated steel trusses that were subject to impingement or proximity of flames from fires with a nominal $3 \mathrm{MW}$ heat release rate reached $600{ }^{\circ} \mathrm{C}$ within $15 \mathrm{~min}$. In comparison, the insulated steel trusses with $1.91 \mathrm{~cm}$ thick SFRM protection reached $100^{\circ} \mathrm{C}$ to $200{ }^{\circ} \mathrm{C}$ and the truss with $3.81 \mathrm{~cm}$ SFRM reached $50^{\circ} \mathrm{C}$ to $100{ }^{\circ} \mathrm{C}$ after 15 min of exposure to a $3 \mathrm{MW}$ heat release rate fire. The steel surface of an insulated steel truss with $1.91 \mathrm{~cm}$ (nominal) and $3.81 \mathrm{~cm}$ (nominal) SFRM obtained a maximum temperature of $680^{\circ} \mathrm{C}$ and $415^{\circ} \mathrm{C}$, respectively, after $50 \mathrm{~min}$ of exposure to a $3 \mathrm{MW}$ fire.

- For the insulated steel components, the steel surface temperatures obtained a maximum sometime after the fire was stopped due to lag of the thermal wave through the SFRM. A thermal lag of between $100 \mathrm{~s}$ and $800 \mathrm{~s}$ for the nominal $1.91 \mathrm{~cm}$ SFRM thickness and 1,000 s to over $1,900 \mathrm{~s}$ for the nominal $3.81 \mathrm{~cm}$ SFRM thickness was observed, depending on the values of the temperature and the temperature gradients within the SFRM and the steel.

FDS, FSI, and ANSYS were used to simulate the thermal environment in the compartment and the time varying steel temperature distribution. The numerical accuracy of the fire dynamic predictions was determined through quantitative comparison with the data. Similar analysis was performed to validate the finite-element modeling of the thermal behavior of the bare and insulated steel components. A comparison of predictions with measurements showed that:

- FDS predictions of the upper layer gas temperature increase agreed with measurements to within 10 percent, which was fairly accurate considering model sensitivity to input parameters such as the heat release rate. Since the heat flux to the walls and objects within the upper layer is highly dependent on the upper layer temperature, these predictions were also equally accurate.

- The sootier-burning fuel led to similar temperature rise in the ceiling and the steel above the fire plume, while the measured and predicted flux to the lower layer was smaller. 
- FDS predicted asymmetry of the fire plume caused by obstructions to uniform flow through the compartment, but did not accurately predict the extent of the asymmetry, which adversely impacted the FSI prediction of structural components very close to the fire. Away from the fire, small differences in the exact flame position were not as important.

- The prcdictions of the steel surface temperature increases for the uninsulated and the SFRM insulated steel components using FSI in combination with ANSYS agreed with measurements to within 8 percent and 20 percent on average, respectively. Quantitative disagreements between the models and the measurements were attributed to model sensitivity to specific input parameters that had experimental uncertainty. For the bare steel, a series of calculations showed that the differences between the predictions and the measurements could be attributed primarily to sensitivity of the fire model to the fire heat release rate. For the insulated steel, the differences between the predictions and the measurements depcnded mainly on the uncertainty of the SFRM coating thickness.

In summary, measurcments in a series of specially designed large-scale fire experiments were compared with predictions from the FDS/FSI/ANSYS methodology to quantify the accuracy of the calculation results and to determine which parameters the models were most sensitive. The models provided a reasonable characterization of the thermal environment for compartments experiencing a fire as well as the associated temperature rise in steel components, providing the level of confidence necessary to apply the methodology to the investigation of the WTC disaster. 


\section{Chapter 1 \\ INTRODUCTION}

\section{$1.1 \quad$ MODELING AS AN INVESTIGATIVE TOOL}

Reconstructing the fires and their impact on structural components in the World Trade Center (WTC) buildings on September 11, 2001, required extensive use of computational models. WTC buildings 1, 2, and 7 each survived for a different amount of time from the start of the disaster. Each time to failure resulted from complex interactions among the features of the building construction, the initial damage to the buildings, and the ensuing fires. Accurate computational modeling was critical to the Investigation because of this complexity and because so little direct evidence was available. While the Investigation team, led by the National Institute of Standards and Technology, compiled and catalogued an extensive array of photographic and videographic records, these were limited to perspectives external to the building. They provided little information on the physical damage and the progress of the fires inside the buildings, other than near the immediate vicinity of the windows and other openings. Analysis of the recovered WTC steel provides some indication of the maximum temperatures experienced. However, this analysis cannot identify the times at which peak temperatures were reached or the time-varying history of the thermal environment throughout the buildings. Information on the timeline of the thermal environment in the buildings, combined with characterization of the building damage from the incident aircraft (WTC 1 and WTC 2) or from debris from the collapsing towers (WTC 7), was ccntral to assessing the plausibility of various possible explanations for the collapse of the three buildings.

Computer simulation of the fires included consideration of such factors as:

- The initial building damage (exterior and interior);

- The nature, quantity and distribution of the combustibles and debris; and

- Changes in the ventilation as the fires progressed.

Additional modeling of the transfer of heat from the fire to the structural components complemented these modeling considerations. Combined, the simulations then produced a complete thermal history, filling in the gaps left by the paucity of information. Simulations that captured the essence of the photographic evidence and the occupant accounts were then presumed to be the more probable replications of the actual events.

For models to be a viable investigative tool, it is essential to know the accuracy with which thcy captured the physical phenomena of the fires and the concurrent heat transfer to the building structure. This report documents one phase of the effort to ascertain the validity of the models for this Investigation.

\subsection{OVERVIEW OF MODELS}

Simulating the effects of a fire on the structural integrity of a building requires a coupling between the gas-phase enthalpy released by the fire and the transfer of that enthalpy to the solid-phase load bearing 
structure, which is vulnerable to thermal effects. The methodology involves the implementation of the two pieces of software that are described below. The connection between the two is established primarily through the interaction of radiative and convective heat transfer between the solid-and gas-phases, with the conduction of heat through the structural components. This process is made difficult in large, geometrically complex buildings by the wide disparity in length and time scales that must be accounted for in the simulations. A methodology for achieving this coupling was developed and applied to the investigation of the WTC collapse (Prasad and Baum 2005).

The building fires are modeled using the National Institute of Standards and Technology (NIST) Fire Dynamics Simulator/Smokeview (McGrattan 2004) software package. The Fire Dynamics Simulator (FDS) is one of the first large-domain computational fluid dynamics (CFD) fire codes that predicts and visualizes the spread, growth and suppression of a fire based on the underlying scientific principles governing fluid motion. Smokeview is an OpenGL graphics-based software application for visualizing information from large calculations. Since the purpose of computing is insight, not numbers, Smokeview facilitates an understanding of calculation output through visualization of the results. Smokeview animates FDS results in a varicty of user selected modes, including the trajectory of smoke and slices of the temperature and velocity fields within the three-dimensional domain.

The code numerically solves the modeled conservation equations of mass, momentum, and energy that govern low-speed, thermally driven flows, with an emphasis on smoke and heat transport from fires. The formulation of the equations and the numerical algorithm are contained in a companion document, called Fire Dynamics Simmlator (Version 4) - Technical Reference Guide (McGrattan 2004). The models and their documentation are available to the public free of charge on the World Wide Web (http://www.fire.nist.gov/fds/). This site gives links to a setup program for PC installation. It also contains documentation for Smokeview and FDS, sample calculations, software updates, and links for requesting feedback about the software.

The core algorithm is an explicit predictor-corrector scheme, second order accurate in space and time. Turbulence is treated by means of the Smagorinsky form of Large Eddy Simulation (LES). For most applications, FDS uses a mixture fraction combustion model. Radiative heat transfer is included in the model via the solution of the radiation transport equation for a non-scattering gray gas, and in some limited cases using a wide band model. The equation is solved using a technique similar to finite volume methods for convective transport and uses approximately 100 discrete angles. All solid surfaces are assigned thermal boundary conditions, plus information about the burning behavior of the material. More detailed information regarding the FDS model is discussed in Chapter 10 of this report and in the technical reference guide (McGrattan 2004) and references therein.

The companion software package, called Smokeview, graphically presents the results of the FDS threedimensional time-dependent simulation. Smokeview is a software tool designed to visualize numerical predictions generated by FDS. FDS and Smokeview are used in concert to respectively model and visualize fire phenomena. Smokeview visualizes both dynamic and static data. Dynamic data are visualized by animating particle flow (showing location and "values" of tracer particles), 2D contour slices (both within the domain and on solid surfaces), and 3D level surfaces. 2D contour slices can also be drawn with colored vectors that use velocity data to show flow direction, speed, and value. Static data are visualized similarly by drawing $2 \mathrm{D}$ contours, vector plots, and $3 \mathrm{D}$ level surfaces anywhere within a simulation scene at a fixed time. 
Normally, Smokeview is used in a post-processing step to visualize FDS data after a calculation has been completed. Smokeview may also be used during a calculation to monitor a simulation's progress and before a calculation to visualize the calculation set-up, which may include walls, vents, sprinklers, smoke detectors, etc. In order to set up correct FDS input files more quickly, Smokeview is typically used to edit or create blockages by specifying the size, location, and/or material properties. More detailed information regarding Smokeview can be found in the Smokeview User's Guide (Forney and McGrattan 2004).

The Fire Structure Interface (FSI) (NIST NCSTAR 1-5G $\mathrm{G}^{\mathrm{l}}$ ) involves calculating heat transfer to sub-grid scale structural components through consideration of both convection and radiation. Radiative heat transfer, which dominate the heat transfer process, is calculated using a simple radiative transport model that assumes that the compartment is locally divided into a hot, soot laden upper layer and a cool relatively clear lower layer. The properties of the two layers are extracted from temporal averages of the results obtained from the FDS (NIST NCSTAR 1-5F). Explicit formulae for the heat flux are obtained as a function of temperature, hot layer depth, soot concentration and orientation of each structural element. These formulae are used to generate realistic thermal boundary conditions for a coupled transient threedimensional finite-element code. Convective heat transfer is calculated based on simplifying assumptions and heat transfer correlations available in the literature. The code is used to generate solutions for the heating of complex structural assemblies.

The thermal response of the steel structure and any associated fire protective coating is modeled using the ANSYS (2003) finite-element software. ANSYS uses iterative, direct, and eigenvalue matrix solvers to analyze the thermal field in complex structural geometries. The output of the FDS calculation is used by the FSI to develop thermal boundary conditions for the ANSYS calculation. The FSI calculates the transfer of radiant and convective heat from the FDS fire model, which acts as the input to ANSYS for calculation of the thermal response of structural components. The structural components may be bare steel or insulation-coated steel. The FSI results are applied in a time dependent fashion at each location on a structural component.

In summary, the objectives of this study are to (1) assess the accuracy of FDS predictions of the thermal environment in a burning compartment through comparison with a series of measurements, and (2) assess the accuracy of the numerically predicted temperature profiles for the structural steel components and the fire-proofing through comparison with experimental data. In this manner, the efficacy of the proposed coupled methodology is tested through a series of calculations and thcir comparison with experimcntal measurements.

\subsection{OVERVIEW OF EXPERIMENTS}

A series of large-scale experiments was conducted in the NIST Large Fire Laboratory from March 13 to March 26, 2003. Within a steel-frame compartment ( $3 \mathrm{~m}$ by $7 \mathrm{~m}$ by $4 \mathrm{~m}$ ) lined with calcium silicate board (referred to as Marinite) were placed several steel components: two trusses, one thin-walled tubular column, and a simple rod. The components were either left bare or had a fibrous sprayed fire-resistive material (SFRM) applied in two nominal thicknesses (17 $\mathrm{mm}$ and $34 \mathrm{~mm}$ ). The fire was generated using liquid hydrocarbon fuels introduced by a two-nozzle spray burner onto a $1 \mathrm{~m}$ by $2 \mathrm{~m}$ pan. Two fuels were

1 This reference is to one of the companion documents from this Investigation. A list of these documents appears in the Preface to this report. 
used: either a commercial blcnd of heptane isomers or a mixture of the commcrcial heptane with toluene in the proportions of 60 percent heptane and 40 percent toluene (by mass). The latter produced a significantly sootier fire. The openings in the room through which fresh air entered were located $1 \mathrm{~m}$ above the floor. The openings through which heat and combustion products wcre emitted were located 2 $m$ above the floor on the other end of the enclosure.

The experimental configuration and fire scenarios were selected to examine the effects of (1) fire size or heat release rate, (2) distance between fire and a structural element, (3) smokiness of the fire, (4) the impact of various thicknesses of the SFRM, and (5) fire immcrsion on the thermal response of vertical and horizontally mounted structural steel components.

The cross sectional thicknesses of the steel and the fibrous SFRM were selected based on representative values used in the WTC. The fire heat release rates were selected such that steel temperatures of $600{ }^{\circ} \mathrm{C}$ would bc obtained in approximately $60 \mathrm{~min}$ of steady burning. The temperature $600{ }^{\circ} \mathrm{C}$ was regarded as significant because steel mechanical properties significantly degrade at $600{ }^{\circ} \mathrm{C}$. For steel temperatures between $600{ }^{\circ} \mathrm{C}$ and $700{ }^{\circ} \mathrm{C}$, the yield strength is reduced by approximately 40 percent and 10 percent, respectively, of the room temperature value, and the modulus of elasticity (stiffness) is reduced to approximately 75 percent and 60 percent, respectively, of the room temperature value (refer to NIST NCSTAR 1-3D). The structural elements were unloaded in these tests. The 60 min duration was regarded as important because collapse of the WTC buildings occurred on this time frame.

The experimental configuration included natural ventilation flowing from one side of the compartment to the other. Such a situation may have occurred in WTC 1 with ventilation through open windows on one side of the building leading to an inner area in the building where chimney-like flow may have occurred. The video record suggests the plausibility of this flow pattern as smoke was observed to flow out from near the top of WTC 1 as it burned (NIST NCSTAR 1-5A). Regardless of the actual WTC ventilation, the over-ventilated fire scenario selected for testing here is a worst-case condition in terms of the heat release rate and in this sense is a good test of the model. The efficacy of the model under conditions of under-ventilated burning had been investigated with real fuels in a separate series of experiments (Hamins et al. 2003).

\subsection{TEST OF MODEL ACCURACY}

The experiments reported here were designed to provide the data necessary to test the accuracy of the fire and thermal-structural simulations that were applied to model the WTC disaster. The experiments allowed comparison of measurements and predictions of a number of critical parameters, which facilitated a check of the accuracy of the predictions and ensured that the models were capturing properly the physics of fire dynamics and thermal-structural behavior.

For these reasons, the compartment was instrumented to measure key transient fire dynamic effects such as total and radiative heat flux to targets within the compartment and the upper layer compartment temperatures and species concentrations, as well as the temperatures of bare and insulated steel elements situated in the upper layer of the compartment. Additional qualitative comparisons of the extent and shape of the flames within the compartment were considered. The large number of measurements was intendcd to provide information beyond single location comparisons with the models. The instrumentation for the tests measured nearly 350 channels of data, including over 100 thermocouples that 
measured the temperature at various locations in the test chamber. Approximately 40 measurements were made to determine the global heat release rate of the fire. Thermocouples were placed on the surfaces of the walls and ceiling, within the walls, on the surface of the steel components, and at the surface of the SFRM. Heat flux gauges were placed strategically around the compartment to measure the transport of radiant energy at various targets in the compartment including locations near the floor and the ceiling. The values of heat flux and temperature are useful for testing how well the fire model is tracking the pathways of enthalpy transport associated with the fire, which is one of the most important operations of the fire model. It is particularly important in the case of the WTC investigation because the fire model is being applied to simulate the time varying boundary conditions on the structural components in the building.

Inaccuracy in the fire model calculations propagate as inaccuracies in the calculation of temperatures of the building structure. The fire model can then be thought of as providing boundary conditions for modeling the thermal behavior of the structure. After the experiments were simulated using the FDS, the time varying computed upper and lower layer temperatures, local absorption coefficients, and depth of the hot layer were used to compute the heat flux incident on the structural components. The ANSYS finiteelement program computed the local temperatures of the structural components for comparison with values of the temperature measured on the steel and fire resistive coating.

Other important measurements were made during the experiments. The concentrations of smoke, oxygen, carbon monoxide $(\mathrm{CO})$, and carbon dioxide $\left(\mathrm{CO}_{2}\right)$ were measured in the upper layer of the compartment. Since the calculation of heat release rate is dependent on the reaction of oxygen to form $\mathrm{CO}_{2}$, measurements of this gas specie in the upper layer provided a consistency check on the efficacy of the model calculation. The velocity at the inlets and outlets of the compartment was coupled with burning of the fuel and the rise of temperature in the compartment. Velocity measurements made at a limited number of locations documented the flows through the inlets and exits of the compartment. Finally, a video record of the experiments was completed to qualitatively compare the model simulations with observed fire behavior.

\section{$1.5 \quad$ ORGANIZATION OF THIS REPORT}

A description of the instrumentation, procedure, uncertainties, and results are given in detail in the following chapters of this report. Chapter 2 presents the overall experimental set up. Chapters 3 through 9 describe the measurements of the fuel flow and the heat release rates (Chapter 3 ), the gas temperatures (Chapter 4), heat fluxes (Chapter 5), the smoke and gas species concentrations (Chapter 6), velocity measurements at the compartment openings (Chapter 7), compartment surface temperatures (Chapter 8), and the steel component temperatures (Chapter 9). Chapter 10 provides a description of the fire simulations, which were conducted using the NIST FDS, and compares the simulation results to the experimental measurements. Chapter 11 provides a description of the simulations used to predict the temperature rise in the structural steel, and the simulations of the time varying temperature fields in the structural components are compared to the experimental measurements. Chapter 13 summarizes the results of this study.

To increase readability, a significant portion of the experimental results are presented in a series of appendixes. Appendix A discusses the rationale for the selection of the fuel mixture. Appendix B is a detailed list of the instrumentation, including the location of each measurement device. Appendix $\mathrm{C}$ 
documents the temperatures measured at the east and west thermocouple trees in each of the experiments, analogous to the measurements presented in Chapter 4. Appendix D documents the bidirectional probe velocity data obtained at the compartment inlets and outlets in each of the experiments, analogous to the measurements presented in Chapter 7. Appendix E contains heat flux measurement data supplementary to that presented in Chapter 5. Appendix F contains information on the location of some of the thermocouples mounted on the surfaces of the SFRM and the steel components. Appendix G documents the thermocouple temperature data measured on the surface of the SFRM and the steel components in each of the experiments, analogous to the measurements presented in Chapter 9.

\subsection{REFERENCES}

ANSYS, Inc. 2003. ANSYS Release 8.0 Documentation.

Forney, G.P., and K. McGrattan. 2004. User's Guide for Snlokeview Version 4 - A Tool for Visualizing Fire Dynanuics Silnulation Data. NIST Special Publication 1017, National Institute of Standards and Technology, August.

Hamins, A., A. Maranghides, and G. Mulholland. 2003. The Global Contbustion Behavior of $1 \mathrm{MW}$ to 3 MW Hydrocarbon Spray Fires Burning in an Open Environment, NISTIR 7013, National Institute of Standards and Technology, Gaithersburg, MD, June.

McGrattan, K.B., ed. 2004. Fire Dynanics Simulator (Version 4), Technical Reference Guide. NIST Special Publication 1018. National Institute of Standards and Technology, Gaithersburg, MD, July.

Prasad, K., and H.R. Baum. 2005. "Coupled Fire Dynamics and Thermal Response of Complex Building Structures," Proc. Conbustion Institute 30, 2255-2262. 


\section{$2.1 \quad$ TEST FACILITY DESCRIPTION}

Experiments were conducted in the National Institute of Standards and Technology (NIST) Large Fire Laboratory, which is $27 \mathrm{~m}$ ( $90 \mathrm{ft}$ ) by $37 \mathrm{~m}$ (120 ft) in size. Fire products flow into a large exhaust hood for measurement of the heat release rate and are then exhausted from the building. The hood for these

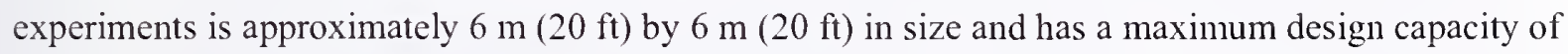
approximately $10 \mathrm{MW}$. A computerized data acquisition system was used to record the instrumentation signals.

\subsection{COMPARTMENT SIZE AND CONSTRUCTION}

The compartment dimensions were $7.04 \mathrm{~m}(23.1 \mathrm{ft})$ long by $3.60 \mathrm{~m}(11.8 \mathrm{ft})$ wide and $3.82 \mathrm{~m}(12.5 \mathrm{ft})$ high. The total compartment volume was $99 \mathrm{~m}^{3}\left(3,420 \mathrm{ft}^{3}\right)$. The compartment was built inside an exoskeleton of steel tubing and "I" beams. Two removable panels provided access to load materials from the compartment. The walls and ceiling were covered with $25 \mathrm{~mm}$ of calcium silicate board, Marinite I, manufactured by BNZ Materials, Inc. The floor was covered with $25 \mathrm{~mm}$ of gypsum, with Marinite I placed under the fire pan (described in Sec. 2.4). The short west wall of the compartment had the supply air vents and was defined as the front. The compartment was located so that the exhaust vents were under the $6 \mathrm{~m}$ by $6 \mathrm{~m}$ exhaust hood. Figures $2-1$ through $2-5$ illustrate the compartment layout and its contents.
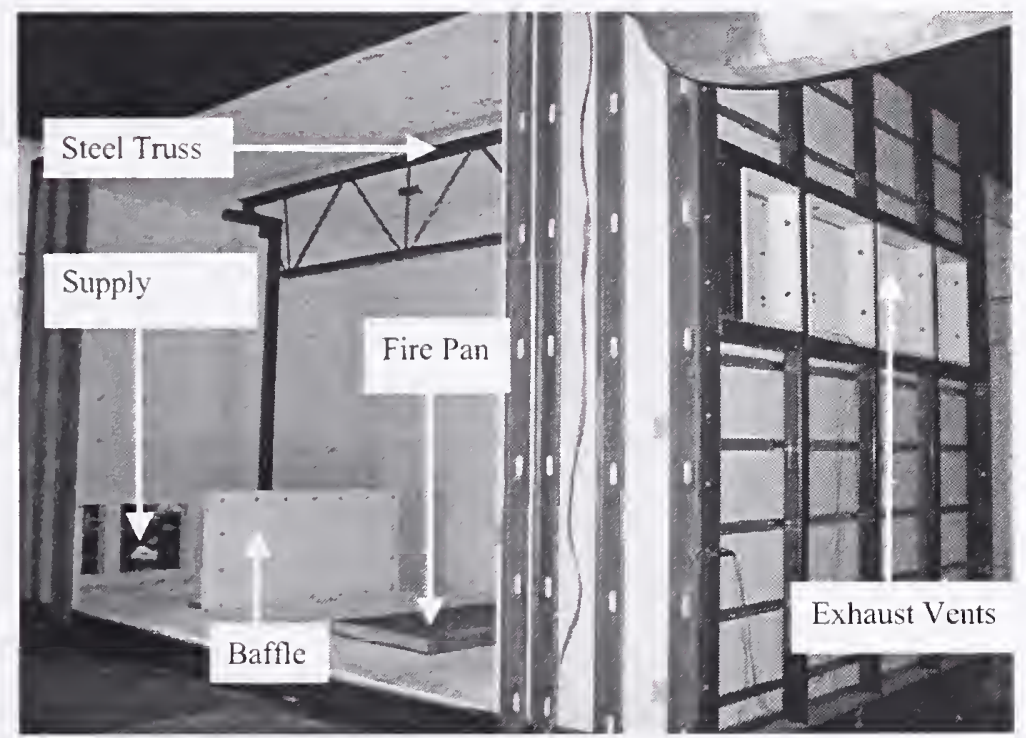

Source: NIST.

Figure 2-1. Compartment contents as seen through the access panel on the south wall. 


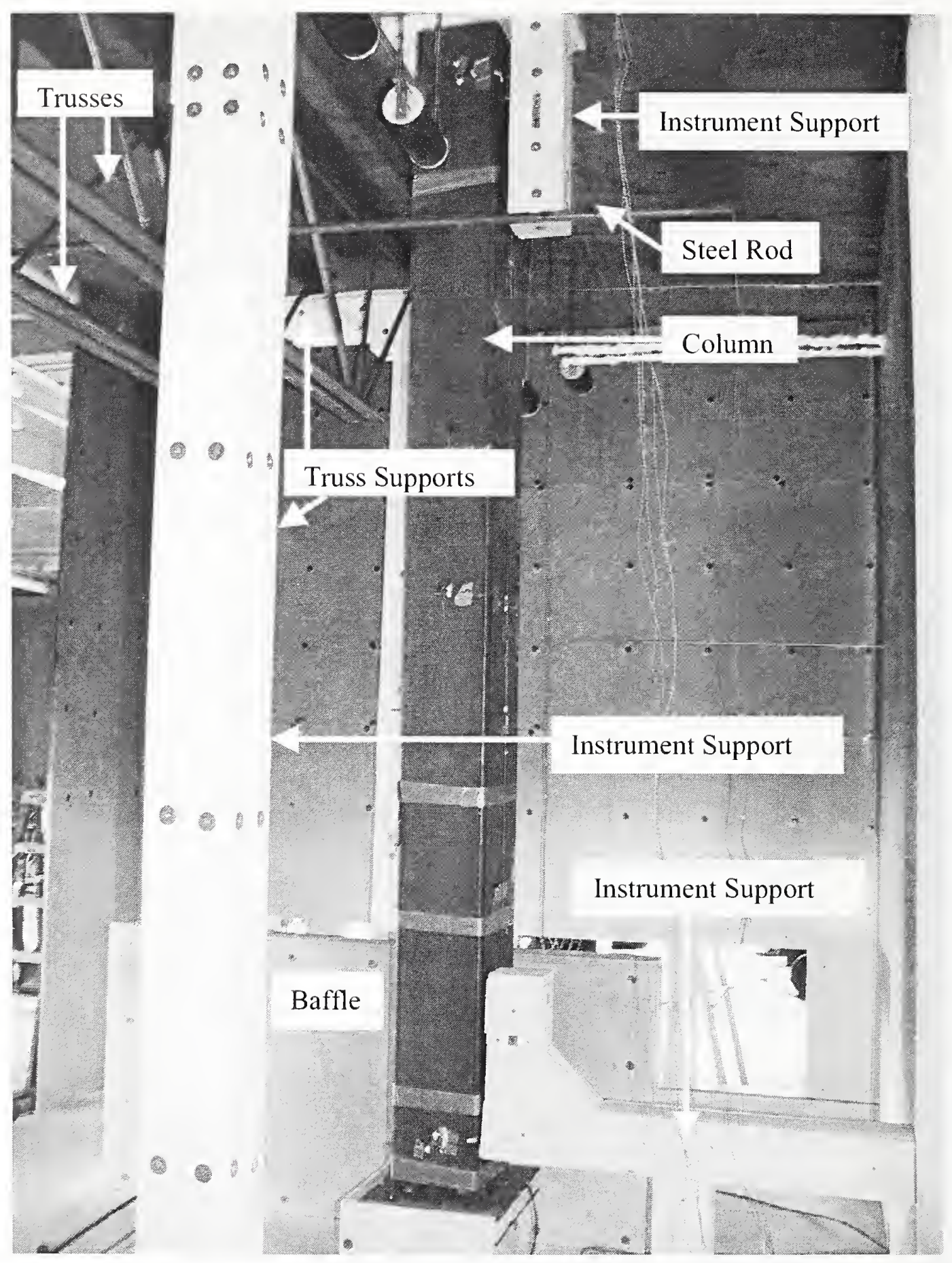

Source: NIST.

Figure 2-2. Experimental enclosure contents. 


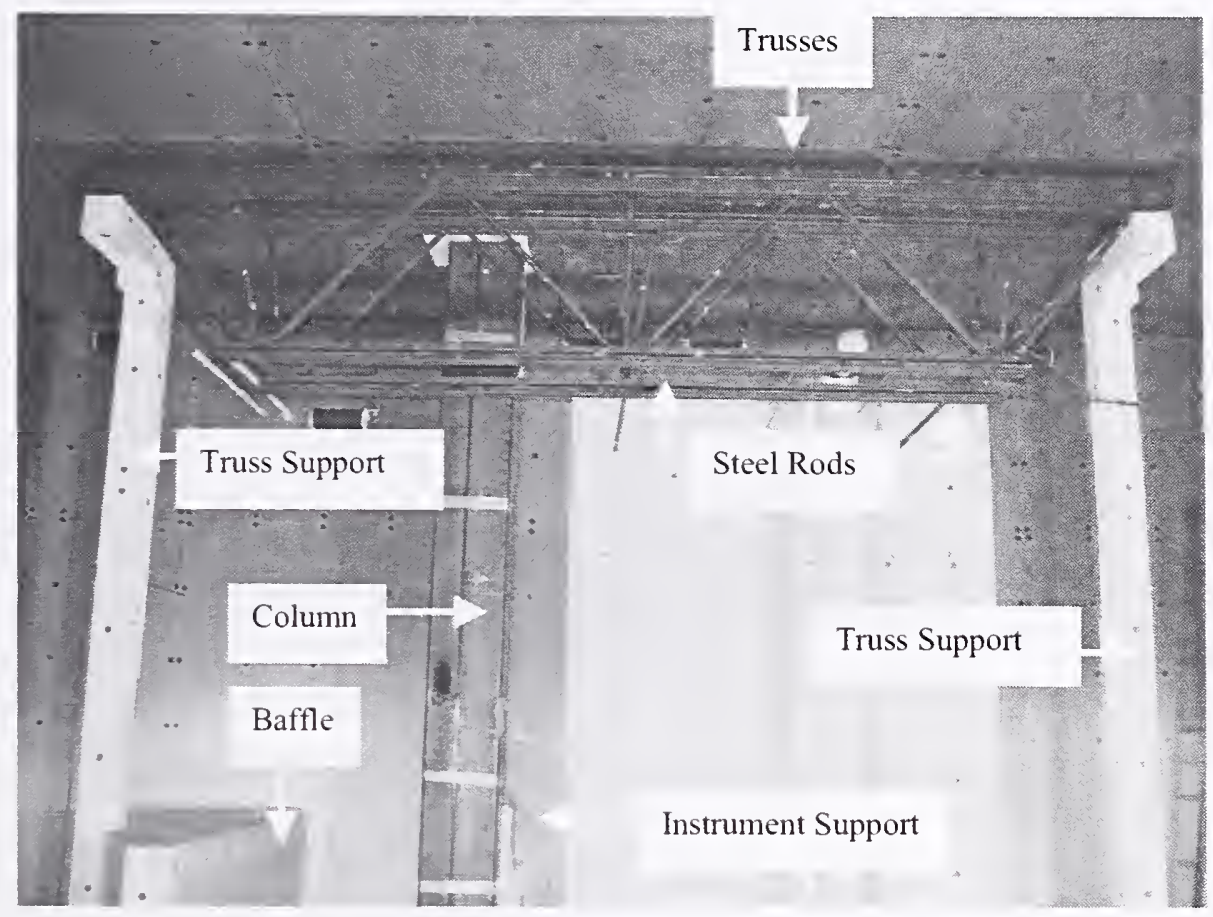

Source: NIST.

Figure 2-3. Experimental enclosure contents viewed with access panels removed.

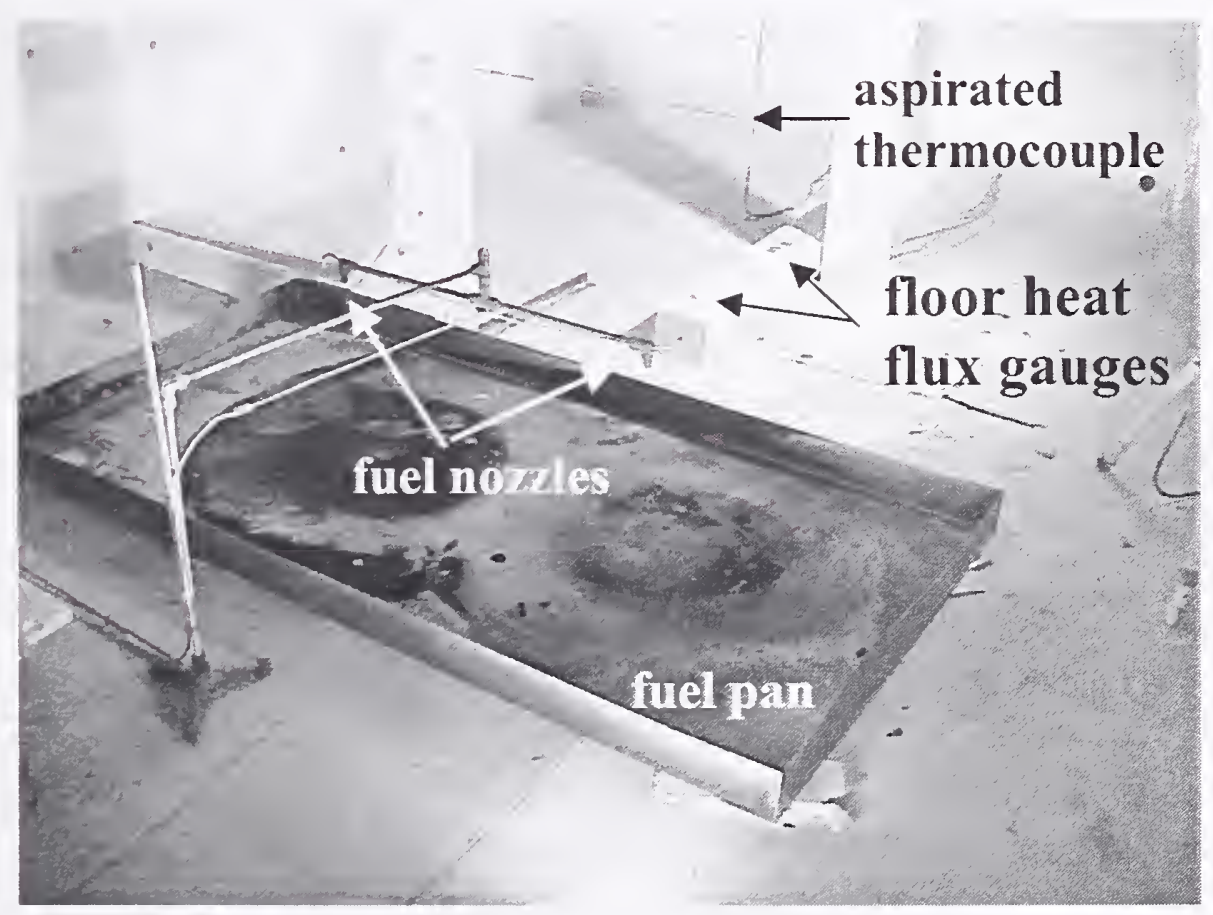

Source: NIST.

Figure 2-4. Fuel pan, fuel nozzles, and instrumentation in the compartment. 


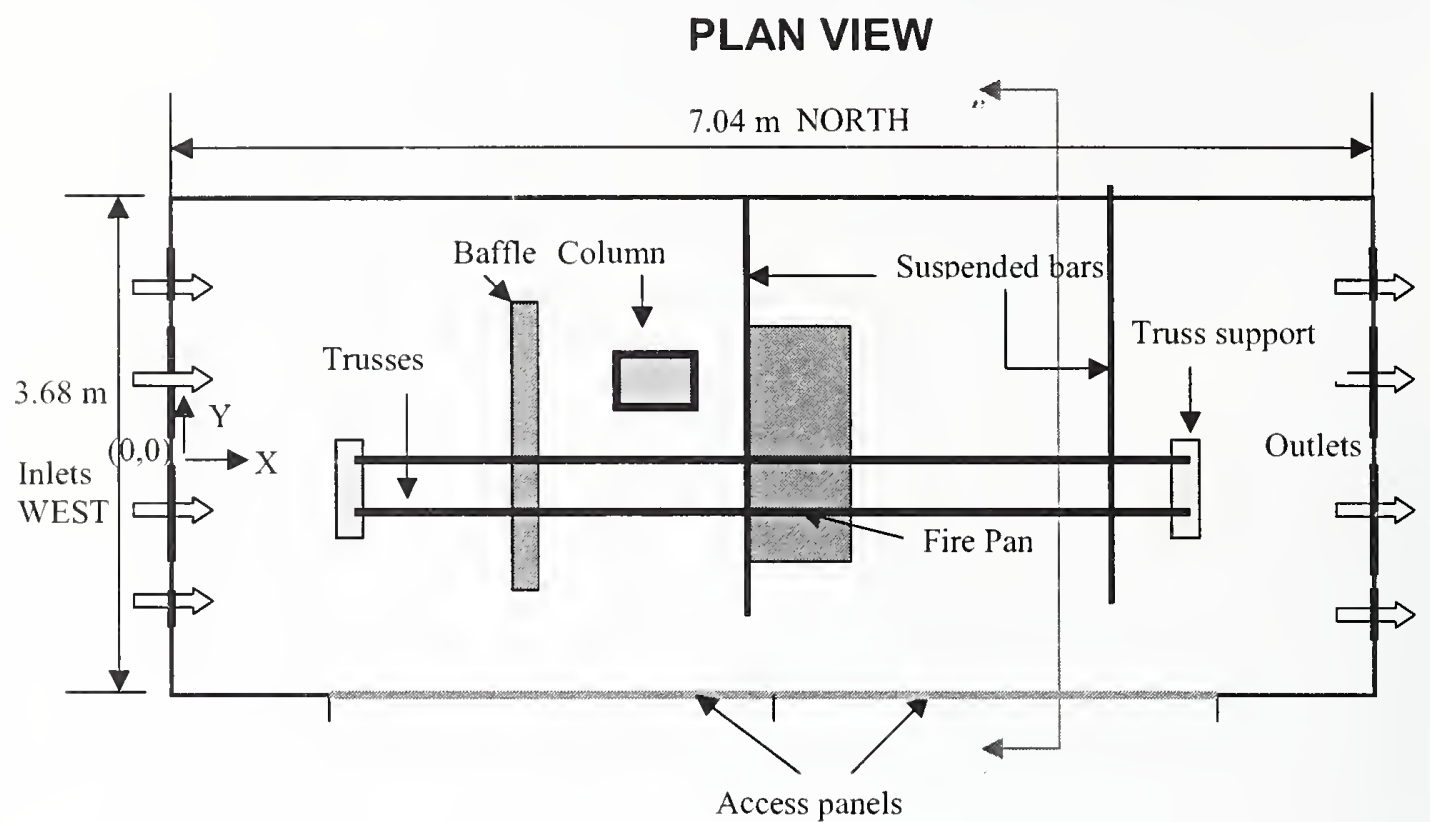

1.2 SECTION A-A

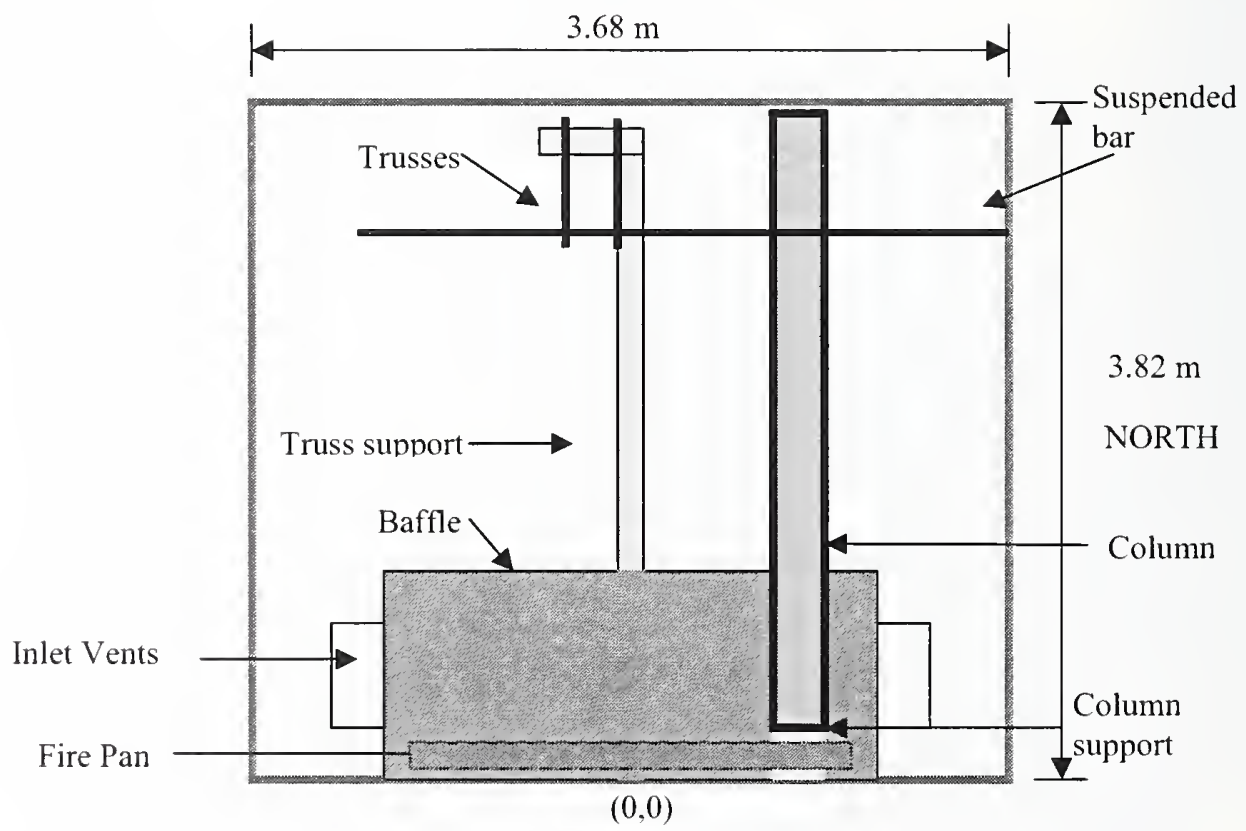

Figure 2-5. Schematic drawing of compartment contents. 


\subsection{COMPARTMENT CONTENTS}

The compartment contained structural components (targets), instrumentation, and their supports. Additionally, the compartment contained a fire pan and an air deflecting baffle. Figures 2-1 through 2-4 illustrate the compartment contents relative to the layout. The location of the compartment contents, including the instrumentation, are referred to a $(x, y, z)$ coordinate system with reference origin on the inner wall of the air inlet $(\mathrm{y}=0)$, along the centerline of the compartment $(\mathrm{x}=0)$, and at floor level $(z=0)$ as shown in Fig. 2-5. The following describes the particulars of the compartment contents.

\subsubsection{Structural Components}

The structural components used in these tests were two steel trusses, two rods, and one column. The particulars of the steel components along with the specifics of their instrumentation are listed in Chapter 9. Two truss supports were fabricated to support the trusses. The steel rods rested on the lower chord of the steel trusses. The steel truss supports were made out of $0.1 \mathrm{~m}$ steel tubes covered with $25 \mathrm{~mm}$ to $37 \mathrm{~mm}$ of Marinite.

\subsubsection{Instrumentation Supports}

The supports housed total heat flux gauges and radiometers. Chapter 5 describes these gauges and their location in detail. Two total flux gauges and two radiometers were placed within a $0.15 \mathrm{~m}$ diameter insulated stainless steel cylinder (see Fig. 5-4). The cylinder rested on a $0.1 \mathrm{~m}$ steel tube. All instrumentation wire leads and cooling lines were run through the steel tube station support to the outside of the compartment. The station support was covered with $25 \mathrm{~mm}$ to $37 \mathrm{~mm}$ of Marinite. Two other flux gauges were placed in a $0.1 \mathrm{~m}$ steel tube to measure total fluxes in two orientations near the upper portions of the column. The instrumentation support adjacent to the upper part of the column was inserted through the ceiling and covered with $25 \mathrm{~mm}$ of Marinite. An additional instrumentation support, fabricated of $0.1 \mathrm{~m}$ steel tube and covered with $25 \mathrm{~mm}$ of Marinite, housed two other flux gauges. This instrumentation support was located near the base of the column.

\subsubsection{Air Deflecting Baffle}

A vertical baffle $1.00 \mathrm{~m}$ high, $2.05 \mathrm{~m}$ wide, and $0.15 \mathrm{~m}$ deep was placed $2 \mathrm{~m}$ from the west wall of the compartment. Baffle placement and dimensions were selected to limit flame tilt and prevent flames from extending through the outlet vents beyond the compartment. The baffle design was based on FDS simulations of the compartment, its obstructions, and the fire induced flowfield.

\subsubsection{Natural Ventilation}

Ventilation in the compartment was induced by the fire. There was no forced ventilation. The compartment was equipped with eight openings, four low for supply and four high for exhaust air. The vents were located on the front and back walls. The bottom of the supply vents was $0.3 \mathrm{~m}$ above the floor and $0.7 \mathrm{~m}$ tall. The two outer vents were $0.5 \mathrm{~m}$ wide and the two inner vents were $0.7 \mathrm{~m}$ wide. The top of the four exhaust vents were $1 \mathrm{~m}$ below the ceiling and had similar dimensions to the supply vents. 


\section{$2.4 \quad$ FIRE AND FUEL FLOW}

The fire was designed to generate a constant heat release rate up until the steel elements approached $600{ }^{\circ} \mathrm{C}$. This was accomplished by using a hydrocarbon spray fire. A blend of heptane isomers (designated here as "heptane") was selected as the baseline fuel. A mixture composed of 60 percent heptane and 40 percent toluene by mass was selected as the second fuel because it is representative of fires that yield elevated amounts of soot. Appendix A describes the rationale for selection of the proportions in the fuel blend and shows that the two fuels span the range of sooting expected during the burning of office furniture. The density, the heat of combustion, and the carbon to hydrogen ratio for the fucls were measured for the commercial heptane and n-heptane (Hamins et al. 2003). The heat of combustion and the carbon to hydrogen ratio for the commercial heptane was within 1 percent (by mass) of the value for n-heptane (Galbraith Labs 2003). This was within experimental uncertainty for the measurements. The properties of the fuel mixture were calculated from its components. The fuel mixture was prepared before use in Tests 3 and 4 by measuring heptane and toluene into a large storage container using a calibrated scale.

The liquid fuel was sprayed through two Bete WL1 $1 / 2$ atomizing nozzles onto the fire pan. The fire pan was located on the floor of the enclosure, $3.5 \mathrm{~m}$ from the front of the compartment (air inlet side) as seen in Figs. 2-1 and 2-4. The fire pan was constructed out of $3 \mathrm{~mm}$ stainless steel. The pan measured $2 \mathrm{~m}$ by $1 \mathrm{~m}$ by $0.1 \mathrm{~m}$ deep. The flow through the nozzles was calibrated before each test with a stopwatch and a graduated cylinder.

\section{$2.5 \quad$ TEST MATRIX}

The test matrix and experimental conditions are presented in Table $2-1$. The table lists the test number, the date the test was conducted, the nominal fire heat release rate $(\dot{Q})$, the fuel type, the nominal thickness of the SFRM on the steel, and the approximate test duration. The experimental series consisted of six tests. The nominal heat release rate was $2 \mathrm{MW}$ in Tests 1 through 3 and $3 \mathrm{MW}$ in Tests 4 through 6 . In Chapter 3, Table 3-5 lists the actual heat release rate, which was measured. The fuel mixture was used in Tests 3 and 4; otherwise heptane was used as the fuel. The duration of the fuel flow was nominally 15 min for Tests 1,3 , and 4 , and 50 min for Tests 5 and 6 . Test 2 was stopped after 6 min because a number of the thermocouples on the steel mistakenly read over $600{ }^{\circ} \mathrm{C}$ (the preset limit for the test). The components were tested in an unprotected (bare) state in Tests 1, 2, and 3 and with fibrous SFRM in Tests 4, 5, and 6. The SFRM was typically applied in two nominal thicknesses (17 mm or $34 \mathrm{~mm})$ on different steel elements to test the effectiveness of various insulation thicknesses.

Table 2-1. Test matrix.

\begin{tabular}{|c|c|c|c|c|c|}
\hline Test & Date & $\begin{array}{c}\text { Nominal } \dot{Q} \\
(\mathbf{M W})\end{array}$ & Fuel & $\begin{array}{c}\text { SFRM } \\
\text { Thickness (mm) }\end{array}$ & $\begin{array}{c}\text { Nominal } \\
\text { Duration (min) }\end{array}$ \\
\hline 1 & $3 / 13 / 03$ & 2.0 & Heptane & None & 14.3 \\
\hline 2 & $3 / 17 / 03$ & 2.4 & Heptane/toluene $^{\mathrm{a}}$ & None & 6.2 \\
\hline 3 & $3 / 18 / 03$ & 2.0 & Heptane/toluene $^{\mathrm{a}}$ & None & 16.3 \\
\hline 4 & $3 / 20 / 03$ & 3.2 & Heptane & 17 and 34 & 14.0 \\
\hline 5 & $3 / 24 / 03$ & 3.0 & Heptane & 17 and 34 & 51.2 \\
\hline 6 & $3 / 26 / 03$ & 3.0 & Heptane & 17 & 50.3 \\
\hline
\end{tabular}

a. The fuel mixture was composed of 60 percent heptane and 40 percent toluene by mass. 


\section{$2.6 \quad$ INSTRUMENTATION}

More than 350 channels of data were acquired for each of the six experiments. Table 2-2 summarizes the instrumentation, measurement technique, measurement locations, and the chapters of this report where they are discussed. Appendix B is a detailed list of the instrumentation, including the location of each measurement. Data were acquired with a sampling rate of $1 \mathrm{~Hz}$. The test duration was approximately $15 \mathrm{~min}$ for Tests 1, 3, and 4; $6 \mathrm{~min}$ for Test 2; and $50 \mathrm{~min}$ for the last two tests, yielding approximately 1 million discrete pieces of data.

Table 2-2. Measurements.

\begin{tabular}{|c|c|c|}
\hline (Chapter) Measurement & Method & Location \\
\hline (3) Heat release rate & Oxygen consumption calorimetry & Exhaust duct \\
\hline (3) Fuel flow & Calibration before test & Fuel pan \\
\hline $\begin{array}{l}\text { (4) Gas temperature and location } \\
\text { of upper/lower layer }\end{array}$ & $\begin{array}{l}\text { 1. Bare-bead thermocouples } \\
\text { 2. Aspirated thermocouples }\end{array}$ & $\begin{array}{l}\text { Thermocouple tree at two } \\
\text { locations }\end{array}$ \\
\hline (5) Heat flux to steel and SFRM & $\begin{array}{l}\text { 1. Total and radiative flux gauges } \\
\text { 2. Slug calorimeters with } \\
\text { thermocouples }\end{array}$ & $\begin{array}{l}\text { Attached and embedded on } \\
\text { surfaces }\end{array}$ \\
\hline (6) Upper layer soot & $\begin{array}{l}\text { Gravimetric extractive sampling with } \\
\text { heated sample line }\end{array}$ & Upper layer \\
\hline $\begin{array}{l}\text { (6) Upper layer } \mathrm{O}_{2}, \mathrm{CO}_{2} \text {, and } \mathrm{CO} \\
\text { volume fractions (on a dry basis) }\end{array}$ & $\begin{array}{l}\text { Nondispersive } 1 \mathrm{R}\left(\mathrm{CO}, \mathrm{CO}_{2}\right) \\
\text { Paramagnetic }\left(\mathrm{O}_{2}\right)\end{array}$ & Upper layer \\
\hline (7) Velocity/temperature & $\begin{array}{l}\text { 1. Thermocouples/aspirated } \\
\text { thermocouples } \\
\text { 2. Bidirectional probes }\end{array}$ & $\begin{array}{l}\text { At inlets and near structural } \\
\text { components }\end{array}$ \\
\hline $\begin{array}{l}\text { (8) Temperature of compartment } \\
\text { surfaces }\end{array}$ & Bare bead thermocouples & $\begin{array}{l}\text { Compartment ceiling; } \\
\text { between Marinite layers. }\end{array}$ \\
\hline $\begin{array}{l}\text { (9) Surface temperature of steel } \\
\text { and the SFRM }\end{array}$ & Bare bead thermocouples & Steel surface and SFRM \\
\hline Video record & Digital and Hi-8 video cameras & Inside and outside views \\
\hline
\end{tabular}

Many of the measurements involved thermocouples measuring temperature on the surfaces of the walls and ceiling, within the walls, and on the surface of steel components and its SFRM coating. Approximately 40 independent measurements were involved with oxygen consumption calorimetry, which was used to determine the heat release rate. Heat flux gauges were placed strategically around the compartment to measure the transport of radiant energy. Twelve Schmidt-Bolter total heat flux gauges, two ellipsoidal radiometers, and five slug calorimeters were used to measure the total and radiative heat flux onto and near the steel components. A comparison of the fluxes betwcen the ellipsoidal and Schmidt-Bolter measurements allowed differentiation of radiative and convective heat flux. Slug calorimeters, which are a large piece of brass with embedded thermocouples, were used to determine the net heat flux onto their surface. The slug calorimeter design was based on calculations of its heat-up time, the experimental duration, and geometric considerations in terms of the fire experiments. Thermocouples were used throughout the fire enclosure to characterize the temperature of the walls, ceiling, and the gas phase. Temperature measurements in the ceiling above the flux meters using bare-bead thermocouples gave information on the location of the fire plume. Two thermocouple trees, each composed of 15 Type 
$\mathrm{K}$ thermocouples aligned vertically, were positioned within the enclosure. Surface temperature measurements were made in the ceiling and walls by embedding the bead of type $\mathrm{K}$ thermocouples into the Marinite. Bidirectional probes and thermocouples were used to measure flow velocities near the inlets and outlets. A number of aspirated thermocouples were used to check the validity of the bare bead thermocouple measurements.

Thermocouple and flux gauge signal wires, and tubes for the flux gauge water cooling lines, the fuel flow, aspirated thermocouples, and gas sampling were passed into the compartment through small holes drilled through the floor and walls near the instrumentation. Small gaps around the wires and tubing in the holes were filled with SFRM. Since the large access panel to the compartment comprised most of the south wall of the compartment, signal wire and necessary hardware were passed mainly through the north wall. Signal wire for the bidirectional probes and thcrmocouples positioned at the middle of the inlet and outlet vents was insulated with a combination of Kaowool and an outer sheet of aluminum foil. Figure 2-6 shows the outside of the west wall with the signal wires and tubing running on the outer wall of the compartment.

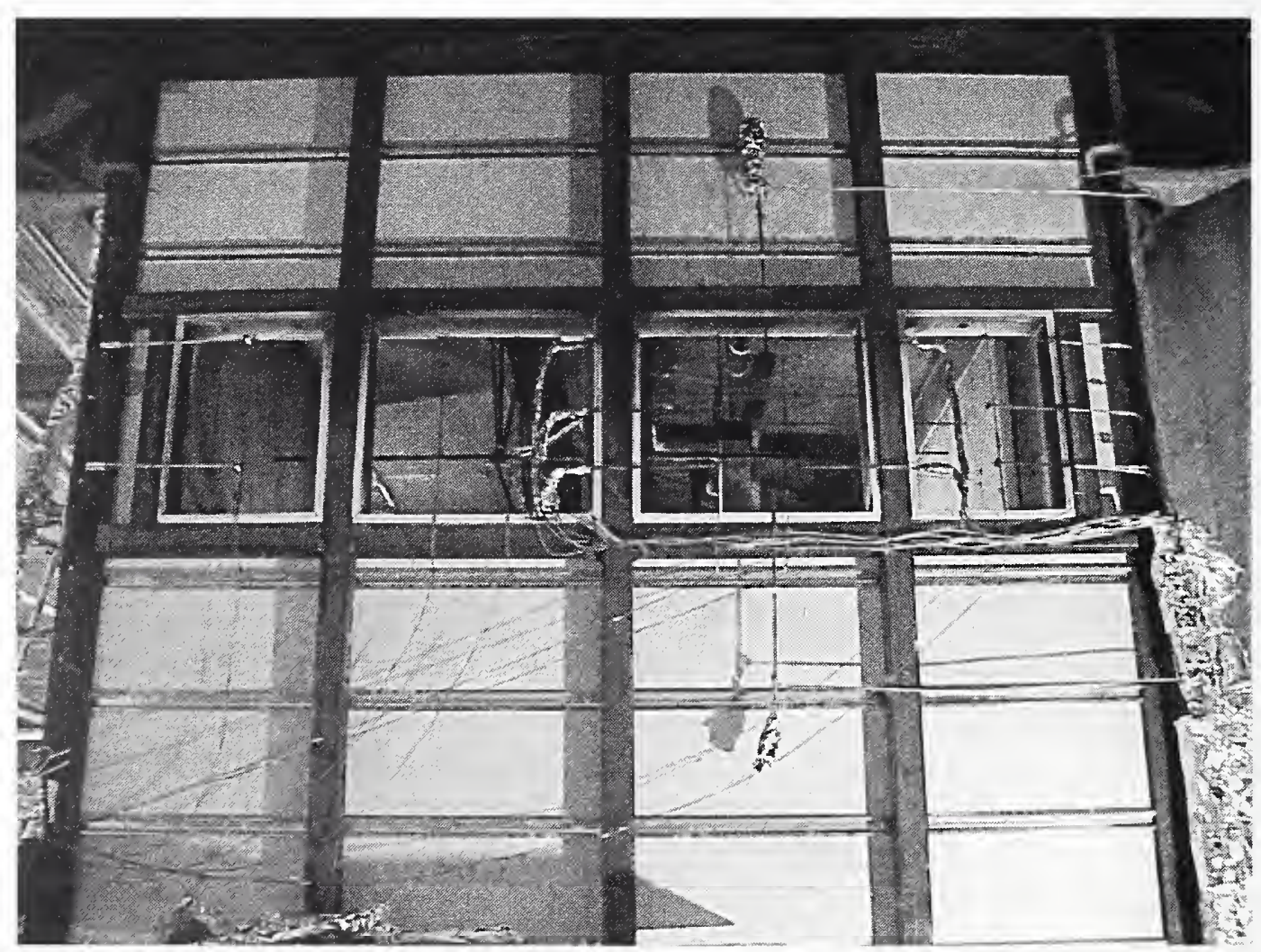

Source: NIST

Figure 2-6. Instrumentation on the outside of the west wall of the compartment.

Chapters 3 to 9 of this report describe each of the measurements in detail, including the instrumentation that was used, an estimate of uncertainty, and the experimental results. Table 2-3 summarizes some of this information and lists the character of the instrumentation, including typical values of the expanded measurement uncertainty (with an expansion factor of 2), the measurement time response, and estimates of the spatial resolution of the measurement. The time response varied from $0.2 \mathrm{~s}$ for the flux gauges to $100 \mathrm{~s}$ for the soot gravimetric measurement. The spatial resolution of the measurements varied from 
sub-centimeter to $25 \mathrm{~cm}$ for the slug calorimeter. These properties characterize and limit the utility of a measurement and are important considerations in terms of comparison of models with measurements.

Table 2-3. Instrument characterization

\begin{tabular}{|c|c|c|c|}
\hline Instrumentation & $\begin{array}{l}\text { Typical Uncertainty } \\
\text { (Expanded; } k=2 \text { ) }\end{array}$ & $\begin{array}{l}\text { Nominal } \\
\text { Time } \\
\text { Response (s) }\end{array}$ & $\begin{array}{l}\text { Spatial } \\
\text { Resolution } \\
\text { (cm) }\end{array}$ \\
\hline $\begin{array}{l}\text { Heat release rate via oxygen } \\
\text { consumption calorimetry }\end{array}$ & $\begin{array}{c}11 \% \\
(\text { for } \dot{Q}>0.8 \mathrm{MW})\end{array}$ & 15 & Global measure \\
\hline $\begin{array}{l}\text { Radiative heat flux: } \\
\text { ellipsoidal radiometer }\end{array}$ & $10 \%$ & $\approx 0.2$ & 0.3 \\
\hline $\begin{array}{l}\text { Total heat flux: Schmidt- } \\
\text { Boelter gauge }\end{array}$ & $6 \%$ & $\approx 0.2$ & 0.6 to 2 \\
\hline $\begin{array}{l}\text { Total heat flux: slug } \\
\text { calorimeter }\end{array}$ & $\begin{array}{l}8 \% \text { to } \mathrm{I} 0 \% \text { for } \dot{Q}=2 \mathrm{MW} \\
16 \% \text { to } 20 \% \text { for } \dot{Q}=3 \mathrm{MW}\end{array}$ & 10 & 25 \\
\hline Velocity: bidirectional probe & $\begin{array}{l}15 \% \text { inlet } \\
10 \% \text { outlet }\end{array}$ & 1 & 2 \\
\hline $\begin{array}{l}\text { Gas temperature: bare bead } \\
\text { thermocouple }\end{array}$ & $\begin{array}{c}<76{ }^{\circ} \mathrm{C} \text { (dependent on upper layer } \\
\text { temperature, which varied with time, } \\
\text { location and test) }\end{array}$ & 1 & 0.5 \\
\hline $\begin{array}{l}\text { Gas temperature: aspirated } \\
\text { thermocouple }\end{array}$ & $7^{\circ} \mathrm{C}$ & 1 & 5 \\
\hline Temperature of steel surface & $-9^{\circ} \mathrm{C}$ to $+1{ }^{\circ} \mathrm{C}$ & 1 & 0.3 \\
\hline $\begin{array}{l}\text { Temperature of SFRM } \\
\text { surface }\end{array}$ & $-7 \%$ to $+5{ }^{\circ} \mathrm{C}$ at steady state & 1 & 0.1 \\
\hline $\begin{array}{l}\text { Temperature of Marinite } \\
\text { surface }\end{array}$ & $\approx 50^{\circ} \mathrm{C}$ at steady state & 1 & 0.3 \\
\hline Soot gravimetric & $15 \%$ & $\begin{array}{l}100 ; \text { time- } \\
\text { averaged }\end{array}$ & $\approx 5$ \\
\hline $\mathrm{CO}$ via nondispersive $\mathrm{IR}^{\mathrm{a}}$ & $7 \%$ & $\approx 10$ & $\approx 5$ \\
\hline $\mathrm{CO}_{2}$ via nondispersive $\mathrm{IR}^{\mathrm{a}}$ & $2 \%$ & $\approx 10$ & $\approx 5$ \\
\hline $\mathrm{O}_{2}$ via paramagnetic ${ }^{a}$ & $5 \%$ & $\approx 10$ & $\approx 5$ \\
\hline
\end{tabular}

a. Gas volume percentages are reported on a dry basis.

\section{$2.7 \quad$ OBSERVATIONS}

Figure 2-7 is a frame extracted from the digital video record of the fire impinging on the bare steel trusses $10 \mathrm{~s}$ after ignition in Test 1 . The camera viewed the compartment through a window located $20 \mathrm{~cm}$ above the floor on the north side of the west wall of the compartment. The baffle, instrument support, column, and exit vents were visible. Figures 2-8 and 2-9 are photographs of the smoke and hot gases exiting the outlet vent on the east wall of the compartment during Tests 2 and 5 , respectively. The combustion products contained copious amounts of soot in Test 2 as seen in Fig. 2-8 when the fuel was composed of the heptane/toluene fuel mixture. This was also the case in Test 3, but did not occur in Test 5 as seen in Fig. 2-9, which shows the glowing hot gas products exiting the outlet vent. Tests 1 and 4 through 6 used 
heptane as the fuel, and heptane is known to produce less soot than toluene (see discussion in Appendix A). The measurement of the soot concentration in the upper layer of the compartment is consistent with these observations (see Chapter 6).

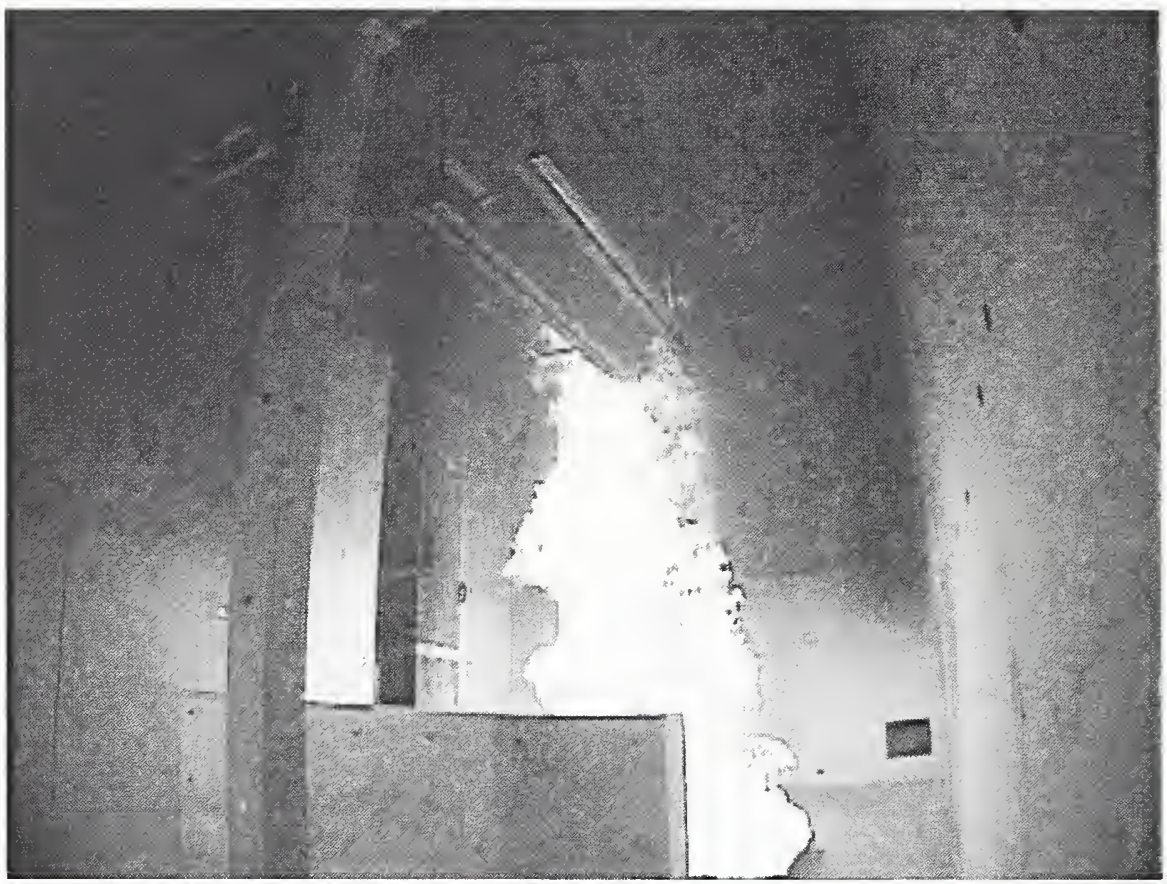

Source: NIST.

Figure 2-7. Fire impinging on the bare steel trusses $10 \mathrm{~s}$ after ignition in Test 1.

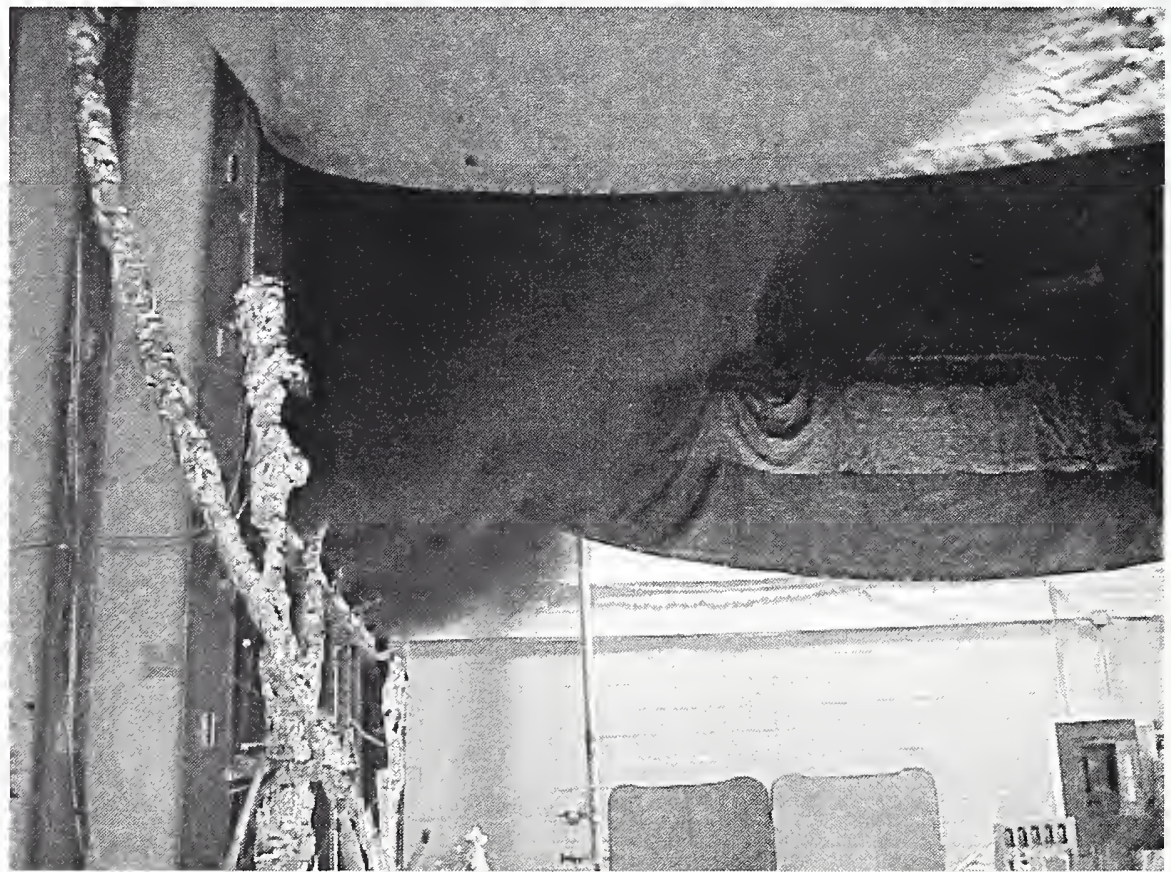

Source: NIST.

Figure 2-8. Smoke exiting the outlet vent into the exhaust hood during Test 2. 


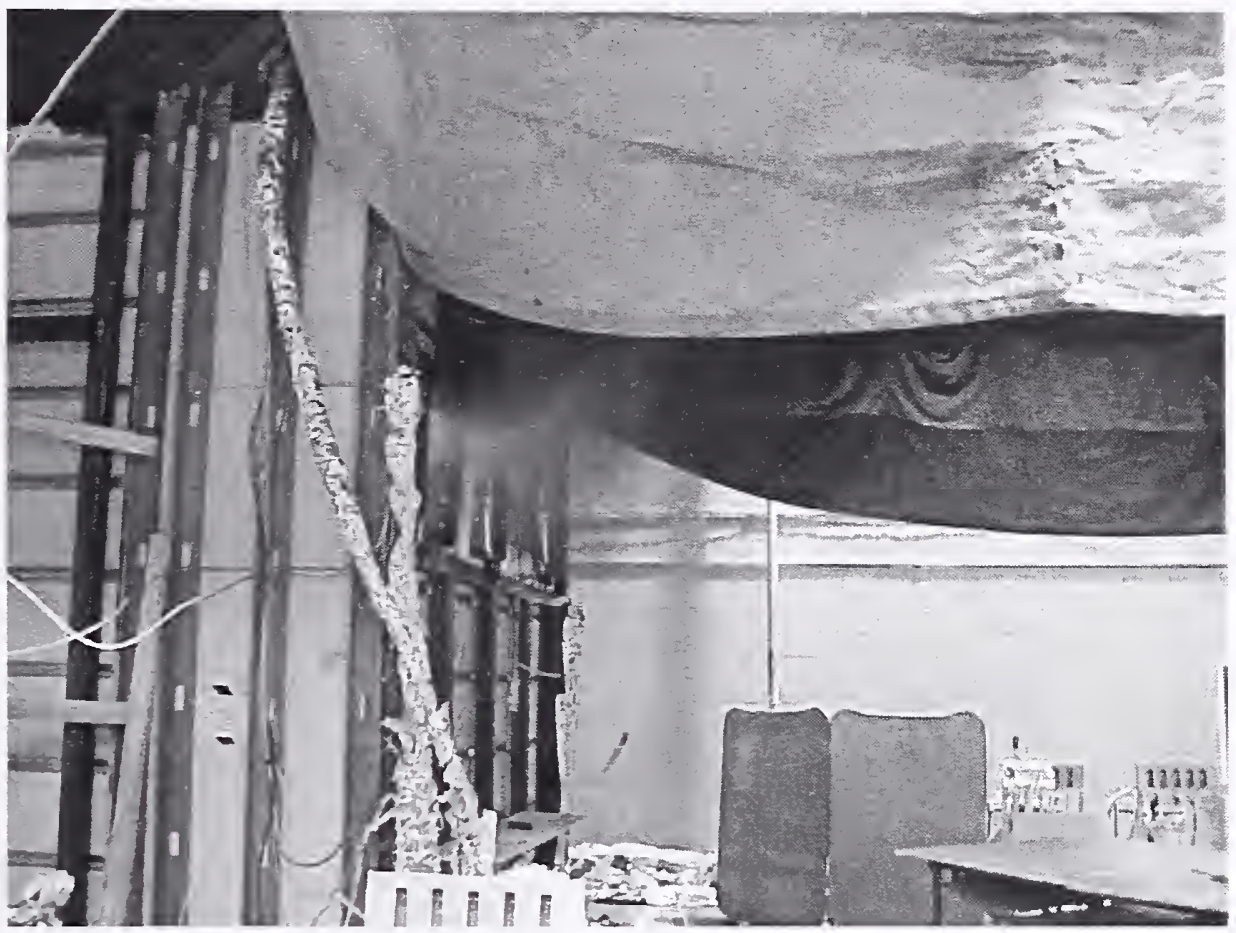

Source: NIST.

Figure 2-9. Radiating hot gases exiting the outlet vent into the exhaust hood during Test 5.

During Test 4, the Type K Omega GG Glass Braid wire thermocouple extension cables failed, leading to erroneous thermocouple readings. This was likely due to the opening-up of the Kaowool thermal insulation protective blanket around the thermocouple wires and subsequent shorting. To prevent reoccurrence of this problem during Tests 5 and 6, the extensions were water cooled and double wrapped with Kaowool insulation. Each layer of Kaowool insulation was secured to the thermocouples using steel wire. Additionally, the thermocouple extensions were rerouted through the cooler west side of the compartment. After Tests 5 and 6, the thermocouple extensions were visually inspected and were observed to be undamaged.

\section{8}

\section{TEST PROCEDURE}

The list below identifies the procedure sequence performed to prepare and conduct the experiments:

- Checked that all fixed instrumentation was functioning

- Installed steel components (column, trusses, and rods)

- Photographically documented steel components

- Connected and checked steel member instrumentation

- Calibrated liquid spray burner fuel flow 
- Conducted final check of compartment instrumentation

- Installed experimental enclosure access panels

- Initiated radiometer and calorimeter cooling

- Calibrated heat release rate oxygen calorimeter using natural gas burner

- Conducted safety brief

- Collected background/baseline data

- Ignited spray burner

- Monitored steel temperatures

- Secured spray burner when steel temperatures exceeded $600^{\circ} \mathrm{C}$

- Allowed compartment to cool to ambient

- Photographically documented steel components

- Removed experimental enclosure access panels

- Disconnected steel member instrumentation and removed steel components

After each expcriment, at lcast one day was required to remove the steel components, inspect the compartment, patch cracks in the Marinite, check instrumentation, and install new steel components.

\section{$2.9 \quad$ REFERENCES}

Galbraith Labs. 2003. Knoxville, TN, Report of Test Results, March.

Hamins, A., A. Maranghides, and G. Mulholland. 2003. The Global Counbustion Behavior of $1 \mathrm{MW}$ to 3 MW Hydrocarbon Spray Fires Burning in an Open Environment, NISTIR 7013, National Institute of Standards and Technology, Gaithersburg, MD, June. 


\section{Chapter 3 \\ Fuel Flow and Heat Release Rate}

The heat release rate of a fire is a critical experimental parameter as it represents the amount of energy per unit time that is generated by the fire. The value of the heat release rate drives the thermal environment, including the radiative and convective heat transfer, the fluid flow, the thermal insult onto secondary items such as structural components, the rate of fire spread and growth, the volume of smoke and toxic products, and ultimately, the hazard associated with a fire. This chapter is broken into several parts that address the heat release rate determined from the fuel flow and oxygen consumption calorimetry and measurement uncertainty. This chapter also contains a discussion of the measurement results.

\subsection{FUEL FLOW AND ESTIMATED HEAT RELEASE RATE}

The fuel system was designed to deliver a controlled amount of liquid fuel in the form of a spray. The fuels were heptane and a mixture of heptane and toluene. The nominal heat release rate was $2 \mathrm{MW}$ in Tests 1 through 3 and $3 \mathrm{MW}$ in Tests 4 through 6 . The fuel flow was rapidly ramped up from zero to the steady value in less than $5 \mathrm{~s}$. The mean flow during the steady period is listed in Table $3-1$. At the end of the burn, the fuel flow was rapidly shut, but data collection continued for at least 1,000 s.

The heat release rate $(\dot{Q})$ was estimated as the product of the mass flow rate of fuel ( $\dot{m})$, the heat of combustion of the fuel $\left(\mathrm{H}_{c}\right)$, and the fuel combustion efficiency $\left(\chi_{\mathrm{a}}\right)$ :

$$
\dot{Q}=\chi_{\mathrm{a}} \cdot \dot{m} \cdot \mathrm{H}_{\mathrm{c}}
$$

A companion series of experiments was conducted to measure the global combustion properties of the hydrocarbon fuels used here (a commercial blend of heptane isomers, and a mixture of the heptane isomer blend and toluene) (Hamins et al. 2003). The measurements included the combustion efficiency, radiative fraction, and the yields of soot, $\mathrm{CO}$, and $\mathrm{CO}_{2}$ from a downward-oriented spray fire burning in a configuration similar to that used here, with the spray fire burning in the open (Hamins et al. 2003). This information is often needed as input for fire models. FDS, for example, uses information on the yields of soot and $\mathrm{CO}$ as input. For convenience those results are summarized in Table 3-2, which lists the measured combustion properties of the test fuels, including the combustion efficiency, and the yields of soot, $\mathrm{CO}$, and $\mathrm{CO}_{2}$. Measurements of the fuel density and the heat of combustion per mass of oxygen consumed, which was used in the calorimetry measurements, are described in Hamins et al. (2003).

The mass flow rate of fuel is equal to the product of the measured volumetric flow rate of fuel $(\dot{V})$ and the fuel density $(\rho)$ :

$$
\dot{m}=\rho \cdot \dot{V}
$$

The estimated heat release rate assumes that the combustion efficiency in the compartment was the same as that measured during the free burn experiments, which were in the open. The uncertainty in $\dot{Q}$ (see Table 3-2) is dominated by the uncertainty in $\chi_{\mathrm{a}}$, and to a lesser extent by uncertainties associated with $\dot{m}$ and $\mathrm{H}_{\mathrm{c}}$. The uncertainty in $\chi_{\mathrm{a}}$ was described in detail in Hamins et al. (2003). The uncertainties 
in Table 3-2, are expressed as the expanded relative uncertainty with an expansion factor equal to two (i.e., $2 \cdot \sigma$ ), which represents a 95 percent confidence interval.

Table 3-1. Fuel flow and expected heat release rate.

\begin{tabular}{|c|l|c|c|c|c|}
\hline Test & \multicolumn{1}{|c|}{ Fuel } & $\begin{array}{c}\text { Fuel Flow } \\
(\mathbf{L} / \mathbf{m i n})\end{array}$ & $\begin{array}{c}\text { Idealized } \dot{Q} \\
(\mathbf{M W})\end{array}$ & $\begin{array}{c}\text { Combustion } \\
\text { Efficiency }\end{array}$ & $\begin{array}{c}\text { Expected } \dot{Q} \\
(\mathbf{M W})\end{array}$ \\
\hline 1 & Heptane & $3.80 \pm 0.04$ & $1.96 \pm 0.02$ & $1.0 \pm 0.05$ & $1.96 \pm 0.10$ \\
\hline 2 & Heptane/toluene ${ }^{\mathrm{a}}$ & $4.80 \pm 0.12$ & $2.61 \pm 0.06$ & $0.89 \pm 0.05$ & $2.33 \pm 0.14$ \\
\hline 3 & Heptane/toluene ${ }^{\mathrm{a}}$ & $3.97 \pm 0.07$ & $2.16 \pm 0.04$ & $0.89 \pm 0.05$ & $1.93 \pm 0.10$ \\
\hline 4 & Heptane & $5.65 \pm 0.14$ & $2.91 \pm 0.07$ & $1.0 \pm 0.05$ & $2.91 \pm 0.16$ \\
\hline 5 & Heptane & $5.58 \pm 0.15$ & $2.88 \pm 0.08$ & $1.0 \pm 0.05$ & $2.88 \pm 0.16$ \\
\hline 6 & Heptane & $5.54 \pm 0.23$ & $2.86 \pm 0.12$ & $1.0 \pm 0.05$ & $2.86 \pm 0.19$ \\
\hline
\end{tabular}

a. The fuel mixture was composed of 60 percent heptane and 40 percent toluene by mass.

Table 3-2. Combustion properties of the test fuels.

\begin{tabular}{|l|c|c|c|c|c|}
\hline \multicolumn{1}{|c|}{ Fuel $^{\mathrm{a}}$} & $\begin{array}{c}\text { Combustion } \\
\text { Efficiency }\end{array}$ & $\begin{array}{c}\text { Radiative } \\
\text { Fraction }\end{array}$ & Soot Yield & CO Yield & CO $_{2}$ Yield \\
\hline Heptane $^{\mathrm{b}}$ & $1.01 \pm 0.14^{\mathrm{c}}$ & $0.44 \pm 0.06$ & $0.0149 \pm .0033$ & $<0.008$ & $3.03 \pm 0.12$ \\
\hline Heptane/toluene $^{\mathrm{d}}$ & $0.90 \pm 0.13$ & $0.39 \pm 0.08$ & $0.114 \pm 0.022$ & $0.042 \pm 0.016$ & $2.70 \pm 0.15$ \\
\hline
\end{tabular}

a. Data from Hamins et al. 2003.

b. A commercial blend of heptane isomers; not n-heptane.

c. By definition $\chi_{a} \leq 1$. The uncertainty in the determination of $\chi_{a}$ is dominated by uncertainty in the measurement of the heat release rate.

d. The fuel mixture was composed of 60 percent heptane and 40 percent toluene by mass.

\subsection{OXYGEN CONSUMPTION CALORIMETRY}

\subsubsection{Description of the Heat Release Rate Measurement Facility}

Much of this section of the report is based on Bryant et al. (2003). The fire heat release rate $(\dot{Q})$ was measured using oxygen consumption calorimetry in the standard manner through measurement of exhaust products in the $6 \mathrm{~m}$ by $6 \mathrm{~m}$ hood. This form of fire calorimetry was used by Huggett (1980), who showed that the oxygen deficit in the duct flow (relative to ambient air), is a measure of the heat release rate of a fire. Parker (1982) and Janssens and Parker (1995) discuss the details of the heat release rate calculation.

The combustion products from the compartment flowed into the exhaust duct where the gas flow was characterized. Bryant et al. (2003) give a detailed description of the experimental methodology, hardware, instrumentation, calibration, experimental procedures, and uncertainty. The facility was designed to provide quantitative results with minimum uncertainty. A large number of instruments were employed in the heat release rate measurement (see Table 3-3), including the measurement of temperature and pressure in the exhaust duct. Gas was sampled in the exhaust duct and transported to the instruments in a control room for measurements of the oxygen, carbon dioxide, and carbon monoxide concentrations. Relative humidity was measured in the test bay area, and a correction was made for ambient humidity. The computation of heat release rate $(\dot{Q})$ was made following Bryant et al. (2003) shown in Eq. 3-3. 


$$
\dot{Q}=\left[E_{H C} \phi-\left(E_{C O}-E_{H C}\right) \frac{1-\phi}{2} \frac{X_{C O}}{X_{O_{2}}}\right] \frac{\dot{m}_{e}}{1+\phi(\alpha-1)}\left[\frac{\left(1-X_{H_{2} O}^{o}\right) M_{O_{2}}}{M_{\text {air }}}\right] X_{O_{2}}^{o}
$$

with

$$
\phi=\frac{X_{O_{2}}^{o}\left(1-X_{\mathrm{CO}_{2}}-X_{\mathrm{CO}}\right)-X_{\mathrm{O}_{2}}\left(1-X_{\mathrm{CO}_{2}}^{o}\right)}{\left(1-X_{\mathrm{O}_{2}}-X_{\mathrm{CO}_{2}}-X_{\mathrm{CO}}\right) X_{O_{2}}^{o}}
$$

where:

$E_{H C}=$ heat of combustion of hydrocarbon fuel

$E_{C O}=$ heat of combustion of carbon monoxide

$\phi=$ oxygen depletion factor

$\dot{m}_{e}=$ mass flow rate in exhaust duct

$\dot{m}_{\text {air }}=$ mass flow rate of air

$\alpha=$ combustion products expansion factor

$M_{i}=$ molecular weight of species i

$X_{i}=$ exhaust-gas concentration measurement of species $\mathrm{i}$

$X_{i}^{o}=$ ambient-gas concentration measurement of species $\mathrm{i}$

Table 3-3. Instruments used in the Calorimeter System.

\begin{tabular}{|l|c|c|c|}
\hline \multicolumn{1}{|c|}{$\begin{array}{c}\text { Parameter } \\
\text { Measured }\end{array}$} & $\begin{array}{c}\text { Instrument } \\
\text { Type }\end{array}$ & $\begin{array}{c}\text { Make and } \\
\text { Model }\end{array}$ & Ranges \\
\hline Oxygen & Paramagnetic & Servomex 540 & $0 \%-21 \% \mathrm{v} / \mathrm{v}$ \\
\hline Carbon dioxide & Infrared extinction & Siemens Ultramat $5 \mathrm{E}$ & $0 \%-5 \% \mathrm{v} / \mathrm{v}$ \\
\hline Carbon monoxide & Infrared extinction & Siemens Ultramat $5 \mathrm{E}$ & $0 \%-3 \% \mathrm{v} / \mathrm{v}$ \\
\hline Relative humidity & Thin film capacitance & Dickson THDx & $0 \%-95 \%$ \\
\hline Temperature & Thermocouple & Omega K-type & $0{ }^{\circ} \mathrm{C}-1,250^{\circ} \mathrm{C}$ \\
\hline Exhaust velocity & Bidirectional probe & $\begin{array}{c}\text { MKS model 220 differential } \\
\text { pressure transducer }\end{array}$ & $0 \mathrm{~Pa}-10 \mathrm{~Pa}$ \\
\hline
\end{tabular}

Key: v/v=volume percent.

\subsubsection{Calibration and Measurement Uncertainty}

A calibration burner was used to establish that the Heat Release Rate Facility provided repeatable results within 2 percent for fire sizes of $1 \mathrm{MW}$ and larger (Bryant et al. 2003). Table 3-4, which is reproduced from Bryant et al. (2003), summarizes a comprehensive study to determine the expanded relative uncertainty for the measured peak heat release rate in the $6 \mathrm{~m}$ exhaust hood that was used in the experiments. A propagation of uncertainty analysis showed that the uncertainty was dominated by 
uncertainty in the measurement of the oxygen concentration, the exhaust mass flux, and the heat of combustion of the fuel (Bryant et al. 2003). The expanded uncertainty (with a coverage factor k equal 2) corresponds to a level of confidence of 94.5 percent. The term "relative" means that the uncertainty is expressed as a ratio of the uncertainty to the measured value and represents two times the standard deviation of the uncertainty.

Table 3-4. Expanded relative uncertainty of the measured heat release rate.

\begin{tabular}{|c|c|}
\hline Heat Release Rate (MW) & Expanded Relative Uncertainty $^{\mathbf{2}}$ \\
\hline $0.10-0.20$ & \pm 0.235 \\
\hline $0.20-0.40$ & \pm 0.187 \\
\hline $0.40-0.80$ & \pm 0.110 \\
\hline $0.80-3.00$ & \pm 0.107 \\
\hline
\end{tabular}

a. From Bryant et al. (2003).

Calibration burns using natural gas were conducted several times during the tcst series to assure accurate measurement of the heat release rate $(\dot{Q})$. The calibration burner uscd natural gas flowing at a measured and controlled rate. This provided an independent measurement of the heat release rate to compare to the measurement by oxygen consumption calorimetry. The heat output of the burner was held constant for $3 \mathrm{~min}$ to $5 \mathrm{~min}$ at each setting. The measured $\dot{Q}$ was typically within 10 percent of the expected heat release rate based on the natural gas mass flow rate.

The calorimetry measurement response time was on the order of $15 \mathrm{~s}$ (Bryant et al. 2003). The volume of the test compartment also affected the time response of the measurement as filling and mixing caused a time-averaging and a lag in the calorimetry results.

\subsection{RESULTS AND DISCUSSION}

Table 3-5 summarizes the heat release rate measurement results and includes the mean measured heat release rate $(\dot{Q})$, its expanded uncertainty, and the experimental duration. For comparison to the measured $\dot{Q}$, the expected $\dot{Q}$ (taken from Table 3-1) is also listed. The mean heat release rate was computed from data acquired over the period encompassing $100 \mathrm{~s}$ after burner ignition to $50 \mathrm{~s}$ prior to the burner being extinguished. The relative expanded uncertainty of the mean heat release measurement was 11 percent (see Table 3-4).

Table 3-5. The expected $\dot{Q}$, the measured mean $\dot{Q}$, and the experimental duration.

\begin{tabular}{|c|c|c|c|c|}
\hline Test & Fuel & Expected $^{\mathbf{a}} \dot{Q}(\mathbf{k w})$ & Measured $\dot{Q}(\mathbf{k W})$ & $\begin{array}{c}\text { Experimental } \\
\text { Duration (s) }\end{array}$ \\
\hline 1 & Heptane & $1,960 \pm 100$ & $1,970 \pm 220$ & $860 \pm 4$ \\
\hline 2 & Heptane/toluene $^{\mathrm{b}}$ & $2,330 \pm 140$ & $2,410 \pm 260$ & $370 \pm 4$ \\
\hline 3 & Heptane/toluene & $1,930 \pm 100$ & $1,990 \pm 220$ & $980 \pm 4$ \\
\hline 4 & Heptane & $2,910 \pm 160$ & $3,240 \pm 360$ & $840 \pm 4$ \\
\hline 5 & Heptane & $2,880 \pm 160$ & $3,000 \pm 330$ & $3,070 \pm 4$ \\
\hline 6 & Heptane & $2 ; 860 \pm 190$ & $2,980 \pm 330$ & $3,020 \pm 4$ \\
\hline
\end{tabular}

a. The expected $\dot{Q}$ is taken from Table $3-1$.

b. The fuel mixture was composed of 60 percent heptane and 40 percent toluene by mass. 
Figure 3-1 shows the heat release rate as a function of time for Tests 1 through 6 . The noise or range of scatter in the data is on the order of $200 \mathrm{~kW}$ for all of the tests, which is on the same order of magnitude as the uncertainty (see Table 3-5). The results show that $\dot{Q}$ was relatively steady for Tests 2 and 3 , while $\dot{Q}$ continuously increased by approximately 7 percent and 6 percent, during Tests 1 and 4, respectively. In Test $6, \dot{Q}$ increased by approximately 5 percent over the first $600 \mathrm{~s}$ and then became nearly steady. In Test 5, $\dot{Q}$ increased by approximately 1 percent over the first $600 \mathrm{~s}$, became steady, and then decreased by approximately 2 percent over the last $1.200 \mathrm{~s}$. The experimental duration is listed in Table $3-5$. At the completion of the test, the fuel flow valve was secured. The fuel flow continued for approximately $10 \mathrm{~s}$ to $20 \mathrm{~s}$, as the line pressure equilibrated. Even after this time, a finite value of $\dot{Q}$ was measured in the exhaust hood due to continued flow of hot combustion products exiting the compartment into the exhaust hood.

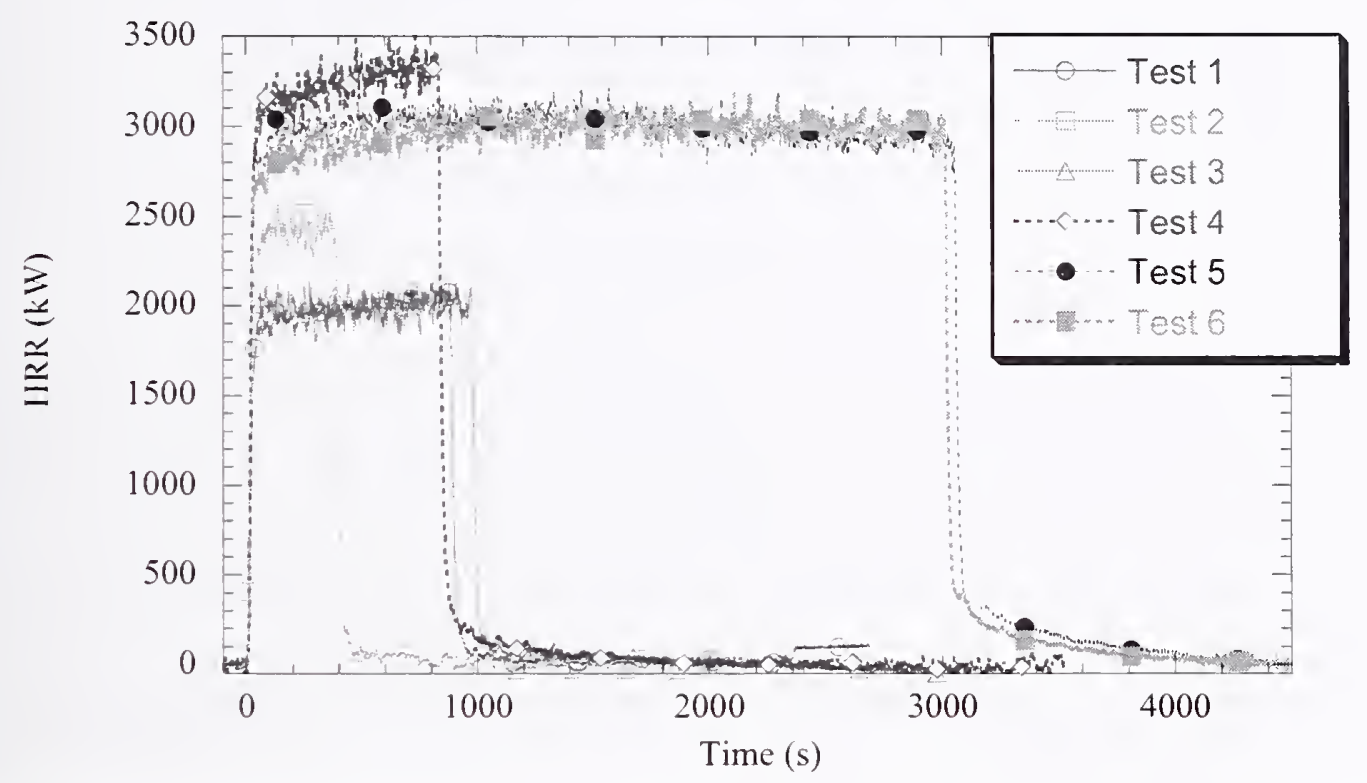

Figure $3-1$. The measured heat release rate $(\dot{Q})$ as a function of time during Tests 1 through 6.

A comparison of the expected and measured heat release rates in Table 3-5 shows agreement within experimental uncertainty. This suggests that the free burn combustion efficiency measurements for the fuel mixture are an adequate representation of the fires burning in the compartment. The value of $\dot{Q}$ is a very important parameter as it impacts the dynamics of the fire within the compartment and influences the temperature and other parameters in the upper layer. As FDS uses $\dot{Q}$ as input, the uncertainty in $\dot{Q}$ can be linked to uncertainty in various important parameters in the FDS output (see Chapter 10).

\section{4} REFERENCES

Bryant, R., T. Ohlemiller, E. Johnsson, A. Hamins, B. Grove, W.F. Guthrie, A. Maringhides, and G. Mulholland. 2003. The NIST 3 Megawatt Quantitative Heat Release Rate Facility-Procedures 
and Guidance, NIST Special Report 1007. National Institute of Standards and Technology, Gaithersburg, MD, September.

Galbraith Labs. 2003. Knoxville, TN, Report of Test Results, March.

Hamins, A., A. Maranghides, and G. Mulholland. 2003. The Global Conbustion Behavior of 1 MW to 3 MW Hydrocarbon Spray Fires Burning in an Open Environment, NISTIR 7013. National Institute of Standards and Technology, Gaithersburg, MD, June.

Huggett, C. 1980. "Estimation of the rate of heat release by means of oxygen consumption," Journal of Fire and Materials, 12, 61-65.

Janssens, M., and W. J. Parker. 1995. "Oxygen consumption calorimetry," Heat Release in Fires, (Babrauskas, V., Grayson, S. J., Eds., E \& FN Spon), pp. 31-59, London, UK.

Parker, W. J. 1982. Calculations of the Heat Release Rate by Oxygen Consumption for Various Applications, NBSIR 81-2427. National Bureau of Standards, Gaithersburg, MD 


\section{Chapter 4 \\ GAS TEMPERATURE}

\subsection{INSTRUMENTATION}

Most gas temperatures were measured on two vertical thermocouple "trees" referred to as the "East" and "West" trees with $(\mathrm{x}, \mathrm{y})$ coordinates $(6.04 \mathrm{~m}, 0.52 \mathrm{~m})$ and $(0.95 \mathrm{~m}, 0.51 \mathrm{~m})$, respectively (in Chapter 5 , see Figs. 5-3 and 5-4). Appendix B lists the $(x, y, z)$ coordinates of each of the thermocouples. Type $\mathrm{K}$ thermocouples were used and were constructed from 24 gauge wires with glass braid insulation. The beads were located on individual horizontal "branches" approximately $6 \mathrm{~cm}$ from the vertical tree support. Each tree was suspended from the ceiling and attached to the floor with a screw to provide tension for maintaining vertical alignment.

Three additional gas temperature measurements were made near each tree using aspirated thermocouples. These were located at nearly the same $(x, y)$ locations as the trees and within a few centimcters of the bare-bead thermocouples at heights (z) approximately $0.34 \mathrm{~m}$ (low), $2.15 \mathrm{~m}$ (mid), and $3.65 \mathrm{~m}$ (high) above the compartment floor. The purpose of the aspirated thermocouple measurements was to gcnerate measurements more accurate than the bare-bead thermocouples in the highly radiating environment. The aspirated thermocouples provided a basis for uncertainty estimates for the bare-bead thermocouple temperature measurements. The aspirated probes used a double-shielded design, which overcomes radiation effects on the bead much more effectively than a single-shield model (Pitts et al. 1998). The materials were either 304 SS or Inconel. The outer diameter of the outer shield was $0.95 \mathrm{~cm}$. The probes extended $1.27 \mathrm{~m}$ into the enclosure from the north wall $(53 \mathrm{~cm}$ from the compartment centerline, i.e., $\mathrm{x}=$ $0.53 \mathrm{~m}$ ). To generate sufficient velocity (greater than $4 \mathrm{~m} / \mathrm{s}$ ) and convective heat transfer over the bead, gases were pulled through the probes at a fixed flow of $24 \mathrm{~L} / \mathrm{min}$. This flow pulled room tcmperature gas over the bead at approximately $5 \mathrm{~m} / \mathrm{s}$. The gas velocity at the bead was at least $5 \mathrm{~m} / \mathrm{s}$ and increased in proportion to the ratio of the gas temperature at the end of the probe to the gas temperature at the flowmeter (near ambient).

\subsection{MEASUREMENT UNCERTAINTIES}

A discussion of uncertainties is nccessary before describing the results of the gas tempcrature measurements and the layer height calculations dcrived from the temperatures. The uncertainties in the temperatures measured by the bare bead thermocouples in the East and West trees werc highly dependent on the radiative and convective environment in which they were locatcd. Whereas a radiative environment tends to cause a bead to have a temperature different from the local gas temperature, convection from the local gas velocity tends to drive a bead's temperature closer to that of the gas. Radiation heat transfer has a $\mathrm{T}^{4}$ dependence $\left(\mathrm{T}_{\text {high }}{ }^{4}-\mathrm{T}_{\text {low }}{ }^{4}\right)$ calculated from the high and low temperatures (in Kelvin). Upper layer thermocouples tend to underestimate gas temperatures because any view of relatively cool surfaces acts as a radiative heat sink, lowering a bead's temperature. Lower layer thermocouples tend to overestimate gas temperatures because they can view very hot surfaces and gases that radiatively heat a bead. Since the thermal environment surrounding a given thermocouple was very difficult to characterize, aspirated thermocouples, which do not suffer radiative exchange problems 
(McCaffrey and Heskestad 1976), were used to check the magnitude of the needed temperature correction at a limited number of locations and to estimate the uncertainties of all of the thermocouples.

Three aspirated thermocouples were located next to the West and East thermocouple trees at the same heights as the low, middle, and high bare-bead thermocouple locations. The temperature differences measured by the bare bead and aspirated thermocouples varied during each test and from test to test. Tables 4-1 and 4-2 list the heights associated with the thermocouple pairs on each tree and summarize these tcmperature variations as represented by the mean and standard deviation of the differences that occurred during each of the tests. Because of the large differences at the beginning of the tests relative to later in the tests, a demarcation was made between the transient and quasi-steady periods for each test. Table 4-1 lists the statistics during the first $60 \mathrm{~s}$ after ignition for each test. Table 4-2 summarizes the statistics from $60 \mathrm{~s}$ to extinguishment. An exception was the East tree middle pair of thermocouples in Tests 4,5, and 6. At this location and for these tests, the division between transient and quasi-steady was set at $240 \mathrm{~s}$ because the rise to quasi-steady temperatures was relatively slow. Also, transient statistics were not available for Test 1 as the aspirated thermocouple pumps were not activated until $\mathrm{t}=177 \mathrm{~s}$. To correct a bare-bead thermocouple temperature at or near an aspirated thermocouple, the mean difference value from the bare-bead temperature should be subtracted.

Table 4-1. Early $(<60 \mathrm{~s})^{\mathrm{a}}$ mean difference: bare-bead minus aspirated at same location.

\begin{tabular}{|c|c|c|c|c|c|c|c|c|c|c|c|c|}
\hline \multirow{3}{*}{$\begin{array}{c}\text { Height } \\
\text { Test No. }\end{array}$} & \multicolumn{6}{|c|}{ West Tree } & \multicolumn{6}{|c|}{ East Tree } \\
\hline & \multicolumn{2}{|c|}{$3.65 \mathrm{~m}$} & \multicolumn{2}{|c|}{$2.16 \mathrm{~m}$} & \multicolumn{2}{|c|}{$0.33 \mathrm{~m}$} & \multicolumn{2}{|c|}{$3.65 \mathrm{~m}$} & \multicolumn{2}{|c|}{$2.16 \mathrm{~m}$} & \multicolumn{2}{|c|}{$0.34 \mathrm{~m}$} \\
\hline & $\begin{array}{c}\text { mean } \\
\left({ }^{\circ} \mathrm{C}\right)\end{array}$ & $\begin{array}{l}\text { s.d. } \\
\left({ }^{\circ} \mathrm{C}\right)\end{array}$ & $\begin{array}{c}\text { mean } \\
\left({ }^{\circ} \mathrm{C}\right)\end{array}$ & $\begin{array}{l}\text { s.d. } \\
\left({ }^{\circ} \mathrm{C}\right)\end{array}$ & $\begin{array}{c}\text { Mean } \\
\left({ }^{\circ} \mathrm{C}\right)\end{array}$ & $\begin{array}{l}\text { s.d. } \\
\left({ }^{\circ} \mathrm{C}\right)\end{array}$ & $\begin{array}{c}\text { mean } \\
\left({ }^{\circ} \mathrm{C}\right)\end{array}$ & $\begin{array}{l}\text { s.d. } \\
\left({ }^{\circ} \mathrm{C}\right)\end{array}$ & $\begin{array}{c}\text { mean } \\
\left({ }^{\circ} \mathrm{C}\right)\end{array}$ & $\begin{array}{l}\text { s.d. } \\
\left({ }^{\circ} \mathrm{C}\right)\end{array}$ & $\begin{array}{c}\text { mean } \\
\left({ }^{\circ} \mathrm{C}\right)\end{array}$ & $\begin{array}{l}\text { s.d. } \\
\left({ }^{\circ} \mathrm{C}\right)\end{array}$ \\
\hline 1 & NA & $\mathrm{NA}$ & NA & NA & NA & $\mathrm{NA}$ & NA & $\mathrm{NA}$ & NA & NA & $\mathrm{NA}$ & $\mathrm{NA}$ \\
\hline 2 & 52 & 46 & 46 & 31 & 1 & 1 & 48 & 56 & 56 & 38 & 16 & 6 \\
\hline 3 & 44 & 36 & 46 & 27 & 1 & 1 & 34 & 43 & 52 & 33 & 17 & 6 \\
\hline 4 & 30 & 59 & 67 & 50 & 5 & 2 & 132 & 68 & 183 & 105 & 30 & 10 \\
\hline 5 & 74 & 57 & 48 & 39 & 4 & 2 & 166 & 89 & 199 & 110 & 33 & 10 \\
\hline 6 & 75 & 56 & 54 & 38 & 6 & 2 & 181 & 80 & 190 & 115 & 38 & 10 \\
\hline
\end{tabular}

a. For Tests 4,5 , and 6 , the East Tree difference at $Z=2.16 \mathrm{~m}$ was calculated for $\mathrm{t}<240 \mathrm{~s}$ (early times) and $\mathrm{t}>240 \mathrm{~s}$ (late times). Key: NA, not available.

Table 4-2. Late $(>60 \mathrm{~s})^{\mathrm{a}}$ mean difference: bare-bead minus aspirated at same location.

\begin{tabular}{|c|c|c|c|c|c|c|c|c|c|c|c|c|}
\hline \multirow{3}{*}{$\begin{array}{c}\text { Height (Z) } \\
\text { Test No. }\end{array}$} & \multicolumn{6}{|c|}{ West Tree } & \multicolumn{6}{|c|}{ East Tree } \\
\hline & \multicolumn{2}{|c|}{$3.65 \mathrm{~m}$} & \multicolumn{2}{|c|}{$2.16 \mathrm{~m}$} & \multicolumn{2}{|c|}{$0.33 \mathrm{~m}$} & \multicolumn{2}{|c|}{$3.65 \mathrm{~m}$} & \multicolumn{2}{|c|}{$2.16 \mathrm{~m}$} & \multicolumn{2}{|c|}{$0.34 \mathrm{~m}$} \\
\hline & $\begin{array}{c}\text { mean } \\
\left({ }^{\circ} \mathrm{C}\right)\end{array}$ & $\begin{array}{l}\text { s.d. } \\
\left({ }^{\circ} \mathrm{C}\right)\end{array}$ & $\begin{array}{c}\text { mean } \\
\left({ }^{\circ} \mathrm{C}\right)\end{array}$ & $\begin{array}{l}\text { s.d. } \\
\left({ }^{\circ} \mathrm{C}\right)\end{array}$ & $\begin{array}{c}\text { mean } \\
\left({ }^{\circ} \mathrm{C}\right)\end{array}$ & $\begin{array}{l}\text { s.d. } \\
\left({ }^{\circ} \mathrm{C}\right)\end{array}$ & $\begin{array}{c}\text { mean } \\
\left({ }^{\circ} \mathrm{C}\right)\end{array}$ & $\begin{array}{l}\text { s.d. } \\
\left({ }^{\circ} \mathrm{C}\right)\end{array}$ & $\begin{array}{c}\text { mean } \\
\left({ }^{\circ} \mathrm{C}\right)\end{array}$ & $\begin{array}{l}\text { s.d. } \\
\left({ }^{\circ} \mathrm{C}\right)\end{array}$ & $\begin{array}{c}\text { mean } \\
\left({ }^{\circ} \mathrm{C}\right)\end{array}$ & $\begin{array}{l}\text { s.d. } \\
\left({ }^{\circ} \mathrm{C}\right)\end{array}$ \\
\hline 1 & -16 & 8 & -10 & 4 & 2 & 1 & -13 & 7 & 2 & 5 & 6 & 3 \\
\hline 2 & -13 & 5 & -5 & 4 & 2 & 1 & -15 & 5 & 1 & 5 & 11 & 3 \\
\hline 3 & -12 & 5 & -4 & 4 & 5 & 2 & -17 & 5 & -1 & 3 & 16 & 4 \\
\hline 4 & -41 & 17 & -5 & 4 & 26 & 12 & 4 & 11 & 5 & 17 & 35 & 6 \\
\hline 5 & -7 & 6 & -1 & 4 & 40 & 15 & 9 & 12 & -43 & 32 & 53 & 13 \\
\hline 6 & -3 & 6 & 5 & 3 & 38 & 13 & 8 & 15 & -53 & 26 & 36 & 9 \\
\hline
\end{tabular}

a. For Tests 4,5 , and 6 , the East Tree difference at $Z=2.16 \mathrm{~m}$ was calculated for $\mathrm{t}<240 \mathrm{~s}$ (early times) and $\mathrm{t}>240 \mathrm{~s}$ (late times). 
One consistent pattern in the differences is that during the early periods, the mean difference was always positive which means that the bare-bead temperature was always higher than the corresponding aspirated temperature because of early radiative heating with slowly increasing real gas temperatures. Also, during the transient periods, the East tree experienced much greater mean differences and fluctuations (seen in the standard deviations) than did the West tree. During the quasi-steady periods, all of the high and middle height differences on the West tree were negative, which means that the real gas temperatures were higher than the measured bare-bead temperatures. On the East tree, these locations were not generally consistent. During the quasi-steady periods at low positions on both trees, all differences were positive, which indicates consistent radiative heating of the lower-layer thermocouples above the real gas temperatures.

Tables 4-3 and 4-4 detail the resulting expanded temperature uncertainty limits (relative to the nominal temperatures) for regions surrounding the six locations. The uncertainties were calculated using the means and standard deviations from Tables $4-1$ and $4-2$ as well as the inherent uncertainties $(\mathrm{k}=2 \sigma)$ in each thermocouple of about $5{ }^{\circ} \mathrm{C}$ and the approximately $5{ }^{\circ} \mathrm{C}$ uncertainty in the extent to which aspiration causes the aspirated thermocouple to approach the real gas temperature (Blevins and Pitts 1999). The expanded measurement uncertainty based on these two effects is equal to $7^{\circ} \mathrm{C}$. The uncertainty limits are asymmetric and consider radiation effects as well as the inherent uncertainty associated with thermocouple calibration. To generate the absolute expanded $(\mathrm{k}=2 \sigma)$ uncertainty limits for a nominal, or uncorrected. temperature, add the lower and upper relative uncertainty limits to the nominal temperature. Figures 4-1 through 4-6 are plots showing the differences (with a 20 s running average) between the bare-bead and aspirated thermocouples on the West and East thermocouple trees for the six experiments.

Table 4-3. Early $(<60 \mathrm{~s})^{\mathrm{a}}$ lower and upper expanded uncertainty limits.

\begin{tabular}{|c|c|c|c|c|c|c|c|c|c|c|c|c|}
\hline \multirow{3}{*}{$\begin{array}{c}\text { Regions } \\
\begin{array}{c}\text { Unc } \\
\text { Limits }\end{array} \\
\text { Test }\end{array}$} & \multicolumn{6}{|c|}{ West Tree } & \multicolumn{6}{|c|}{ East Tree } \\
\hline & \multicolumn{2}{|c|}{$\begin{array}{c}\text { Upper } \\
2.90 \text { to } 3.82 \mathrm{~m}\end{array}$} & \multicolumn{2}{|c|}{$\begin{array}{c}\text { Middle } \\
1.25 \text { to } 2.90 \mathrm{~m}\end{array}$} & \multicolumn{2}{|c|}{$\begin{array}{l}\text { Lower } \\
0 \text { to } 1.25 \mathrm{~m}\end{array}$} & \multicolumn{2}{|c|}{$\begin{array}{c}\text { Upper } \\
2.90 \text { to } 3.82 \mathrm{~m}\end{array}$} & \multicolumn{2}{|c|}{$\begin{array}{c}\text { Middle } \\
1.25 \text { to } 2.90 \mathrm{~m}\end{array}$} & \multicolumn{2}{|c|}{$\begin{array}{l}\text { Lower } \\
0 \text { to } 1.25 \mathrm{~m}\end{array}$} \\
\hline & $\begin{array}{c}\text { Lower } \\
\left({ }^{\circ} \mathrm{C}\right)\end{array}$ & $\begin{array}{l}\text { Upper } \\
\left({ }^{\circ} \mathrm{C}\right)\end{array}$ & $\begin{array}{c}\text { Lower } \\
\left({ }^{\circ} \mathrm{C}\right)\end{array}$ & $\begin{array}{c}\text { Upper } \\
\left({ }^{\circ} \mathrm{C}\right)\end{array}$ & $\begin{array}{c}\text { Lower } \\
\left({ }^{\circ} \mathrm{C}\right)\end{array}$ & $\begin{array}{c}\text { Upper } \\
\left({ }^{\circ} \mathrm{C}\right)\end{array}$ & $\begin{array}{c}\text { Lower } \\
\left({ }^{\circ} \mathrm{C}\right)\end{array}$ & $\begin{array}{c}\text { Upper } \\
\left({ }^{\circ} \mathrm{C}\right)\end{array}$ & $\begin{array}{c}\text { Lower } \\
\left({ }^{\circ} \mathrm{C}\right)\end{array}$ & $\begin{array}{c}\text { Upper } \\
\left({ }^{\circ} \mathrm{C}\right)\end{array}$ & $\begin{array}{c}\text { Lower } \\
\left({ }^{\circ} \mathrm{C}\right)\end{array}$ & $\begin{array}{c}\text { Upper } \\
\left({ }^{\circ} \mathrm{C}\right)\end{array}$ \\
\hline 1 & NA & $\mathrm{NA}$ & $\mathrm{NA}$ & $\mathrm{NA}$ & $\mathrm{NA}$ & $\mathrm{NA}$ & $\mathrm{NA}$ & $\mathrm{NA}$ & $\mathrm{NA}$ & $\mathrm{NA}$ & $\mathrm{NA}$ & $\mathrm{NA}$ \\
\hline 2 & -144 & 41 & -108 & 17 & -10 & 8 & -161 & 64 & -132 & 20 & -30 & -1 \\
\hline 3 & -116 & 28 & -100 & 8 & -10 & 8 & -120 & 53 & -117 & 14 & -32 & -1 \\
\hline 4 & -148 & 89 & -166 & 33 & -15 & 4 & -268 & 4 & -393 & 28 & -51 & -9 \\
\hline 5 & -189 & 41 & -125 & 30 & -14 & 5 & -344 & 13 & -419 & 21 & -55 & -11 \\
\hline 6 & -186 & 37 & -131 & 23 & -16 & 3 & -342 & -21 & -420 & 40 & -59 & -16 \\
\hline
\end{tabular}

a. For Tests 4,5 , and 6 , the East Tree difference at $Z=2.16 \mathrm{~m}$ was calculated for $t<240 \mathrm{~s}$ (early times) and $\mathrm{t}>240 \mathrm{~s}$ (late times).

Key: NA, not available. 
Table 4-4. Late (>60 s) ${ }^{a}$ lower and upper expanded uncertainty limits.

\begin{tabular}{|c|c|c|c|c|c|c|c|c|c|c|c|c|}
\hline \multirow{3}{*}{$\begin{array}{c}\text { Regions } \\
\begin{array}{c}\text { Unc } \\
\text { Limits }\end{array} \\
\text { Test }\end{array}$} & \multicolumn{6}{|c|}{ West Tree } & \multicolumn{6}{|c|}{ East Tree } \\
\hline & \multicolumn{2}{|c|}{$\begin{array}{c}\text { Upper } \\
2.90 \text { to } 3.82 \mathrm{~m} \\
\end{array}$} & \multicolumn{2}{|c|}{$\begin{array}{c}\text { Middle } \\
1.25 \text { to } 2.90 \mathrm{~m}\end{array}$} & \multicolumn{2}{|c|}{$\begin{array}{c}\text { Lower } \\
0 \text { to } 1.25 \mathrm{~m} \\
\end{array}$} & \multicolumn{2}{|c|}{$\begin{array}{c}\text { Upper } \\
2.90 \text { to } 3.82 \mathrm{~m}\end{array}$} & \multicolumn{2}{|c|}{$\begin{array}{c}\text { Middle } \\
1.25 \text { to } 2.90 \mathrm{~m}\end{array}$} & \multicolumn{2}{|c|}{$\begin{array}{c}\text { Lower } \\
0 \text { to } 1.25 \mathrm{~m} \\
\end{array}$} \\
\hline & $\begin{array}{c}\text { Lower } \\
\left({ }^{\circ} \mathrm{C}\right)\end{array}$ & $\begin{array}{l}\text { Upper } \\
\left({ }^{\circ} \mathrm{C}\right)\end{array}$ & $\begin{array}{c}\text { Lower } \\
\left({ }^{\circ} \mathrm{C}\right)\end{array}$ & $\begin{array}{l}\text { Upper } \\
\left({ }^{\circ} \mathrm{C}\right)\end{array}$ & $\begin{array}{c}\text { Lower } \\
\left({ }^{\circ} \mathrm{C}\right)\end{array}$ & $\begin{array}{l}\text { Upper } \\
\left({ }^{\circ} \mathrm{C}\right)\end{array}$ & $\begin{array}{c}\text { Lower } \\
\left({ }^{\circ} \mathrm{C}\right)\end{array}$ & $\begin{array}{l}\text { Upper } \\
\left({ }^{\circ} \mathrm{C}\right)\end{array}$ & $\begin{array}{c}\text { Lower } \\
\left({ }^{\circ} \mathrm{C}\right) \\
\end{array}$ & $\begin{array}{c}\text { Upper } \\
\left({ }^{\circ} \mathrm{C}\right)\end{array}$ & $\begin{array}{c}\text { Lower } \\
\left({ }^{\circ} \mathrm{C}\right)\end{array}$ & $\begin{array}{c}\text { Upper } \\
\left({ }^{\circ} \mathrm{C}\right)\end{array}$ \\
\hline 1 & -2 & 34 & -2 & 23 & -11 & 7 & -4 & 29 & -16 & 12 & -17 & 5 \\
\hline 2 & 0 & 27 & -8 & 17 & -11 & 7 & 1 & 29 & -14 & 12 & -21 & 0 \\
\hline 3 & -1 & 25 & -8 & 16 & -15 & 5 & 4 & 30 & -10 & 12 & -28 & -3 \\
\hline 4 & 7 & 76 & -7 & 17 & -52 & 0 & -28 & 20 & -41 & 30 & -50 & -20 \\
\hline 5 & -8 & 21 & -10 & 12 & -72 & -8 & -33 & 16 & -22 & 107 & -80 & -26 \\
\hline 6 & -12 & 18 & -16 & 7 & -65 & -10 & -40 & 24 & 0 & 106 & -56 & -15 \\
\hline
\end{tabular}

a. For Tests 4,5 , and 6 , the East Tree difference at $Z=2.16 \mathrm{~m}$ was calculated for $\mathrm{t}<240 \mathrm{~s}$ (early times) and $\mathrm{t}>240 \mathrm{~s}$ (late times).

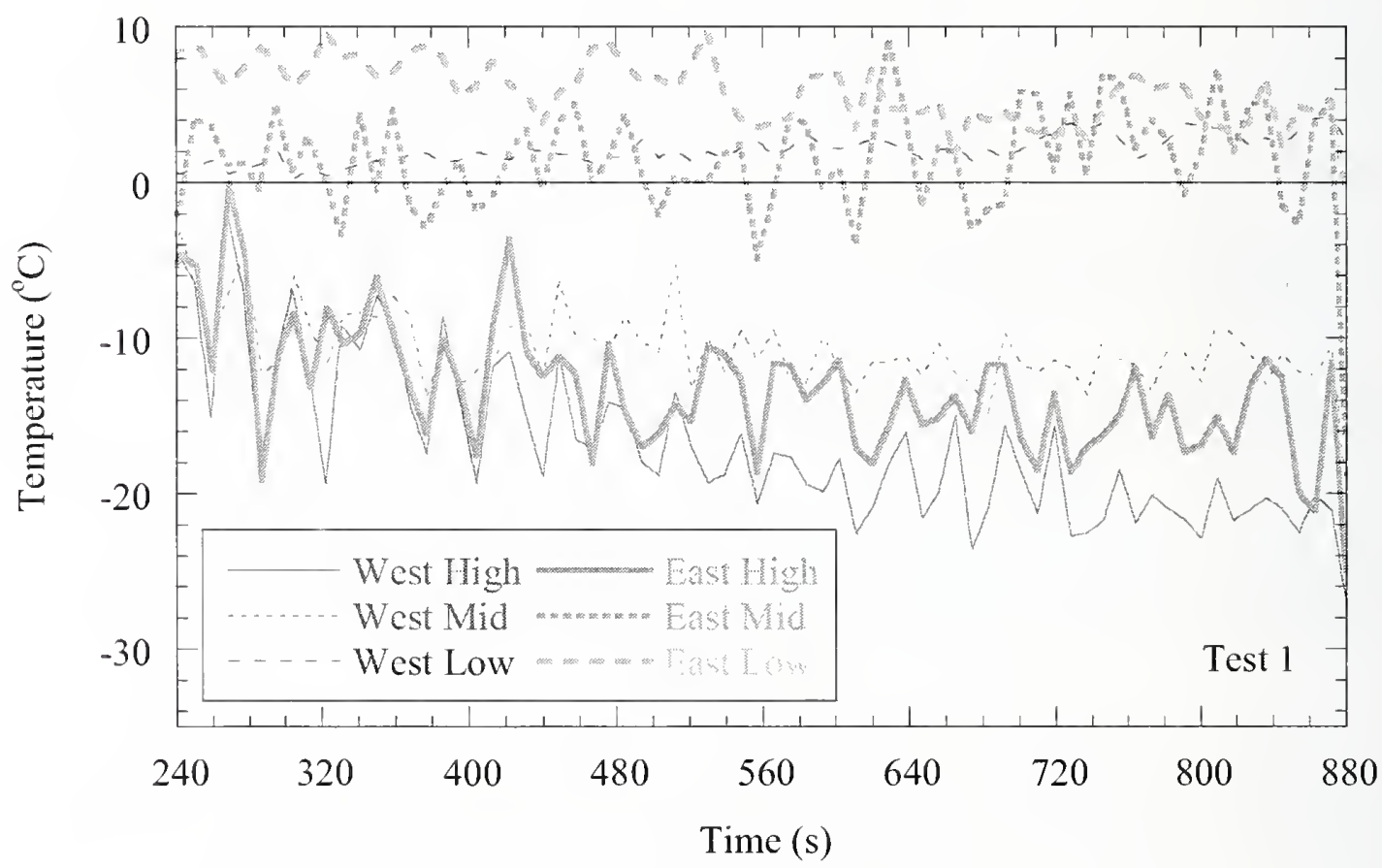

Figure 4-1. $20 \mathrm{~s}$ average of the difference of bare-bead thermocouple temperatures minus aspirated thermocouple temperatures as a function of time for Test 1. 


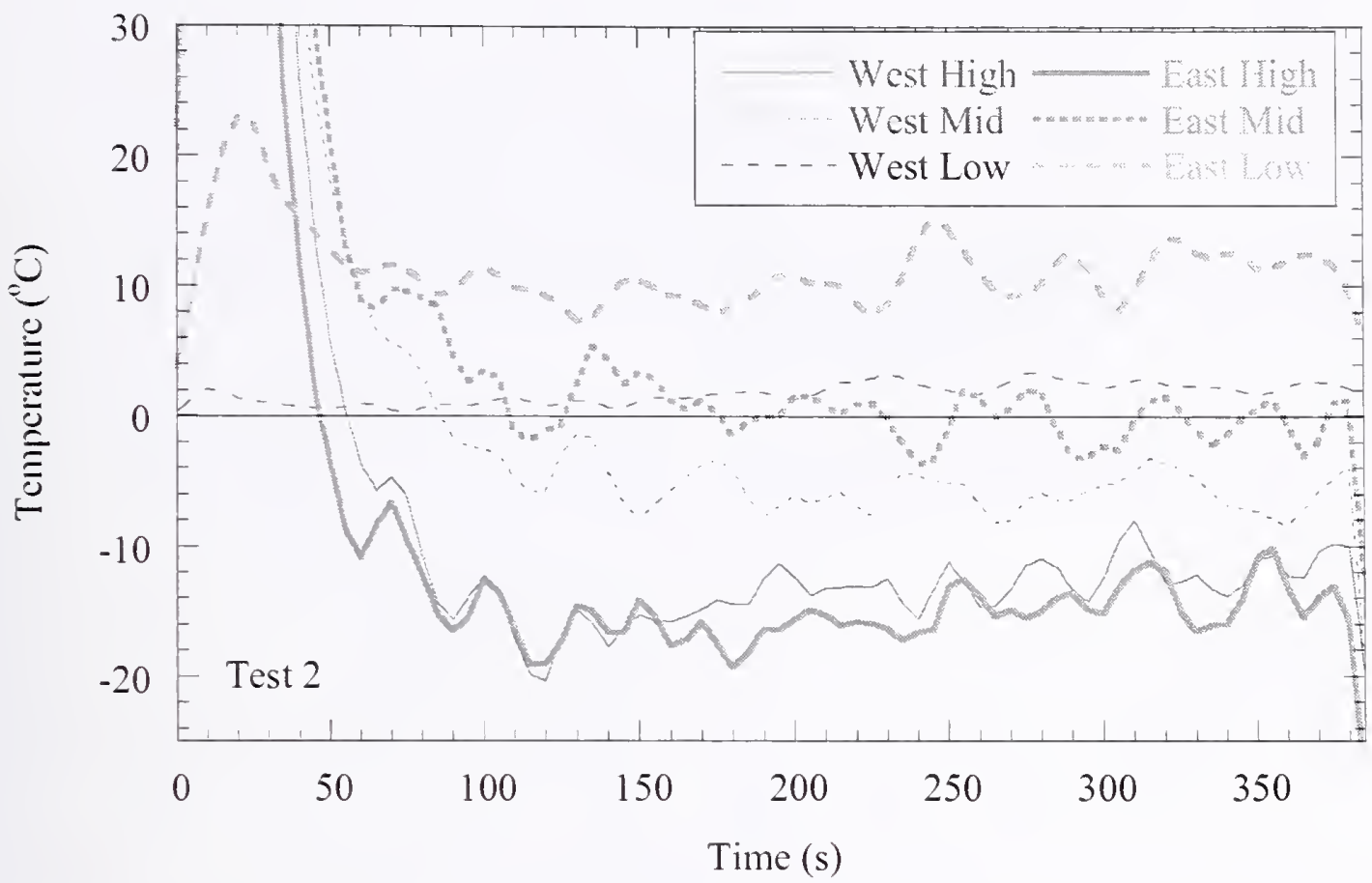

Figure 4-2. $20 \mathrm{~s}$ average of the difference of bare-bead thermocouple temperatures minus aspirated thermocouple temperatures as a function of time for Test 2.

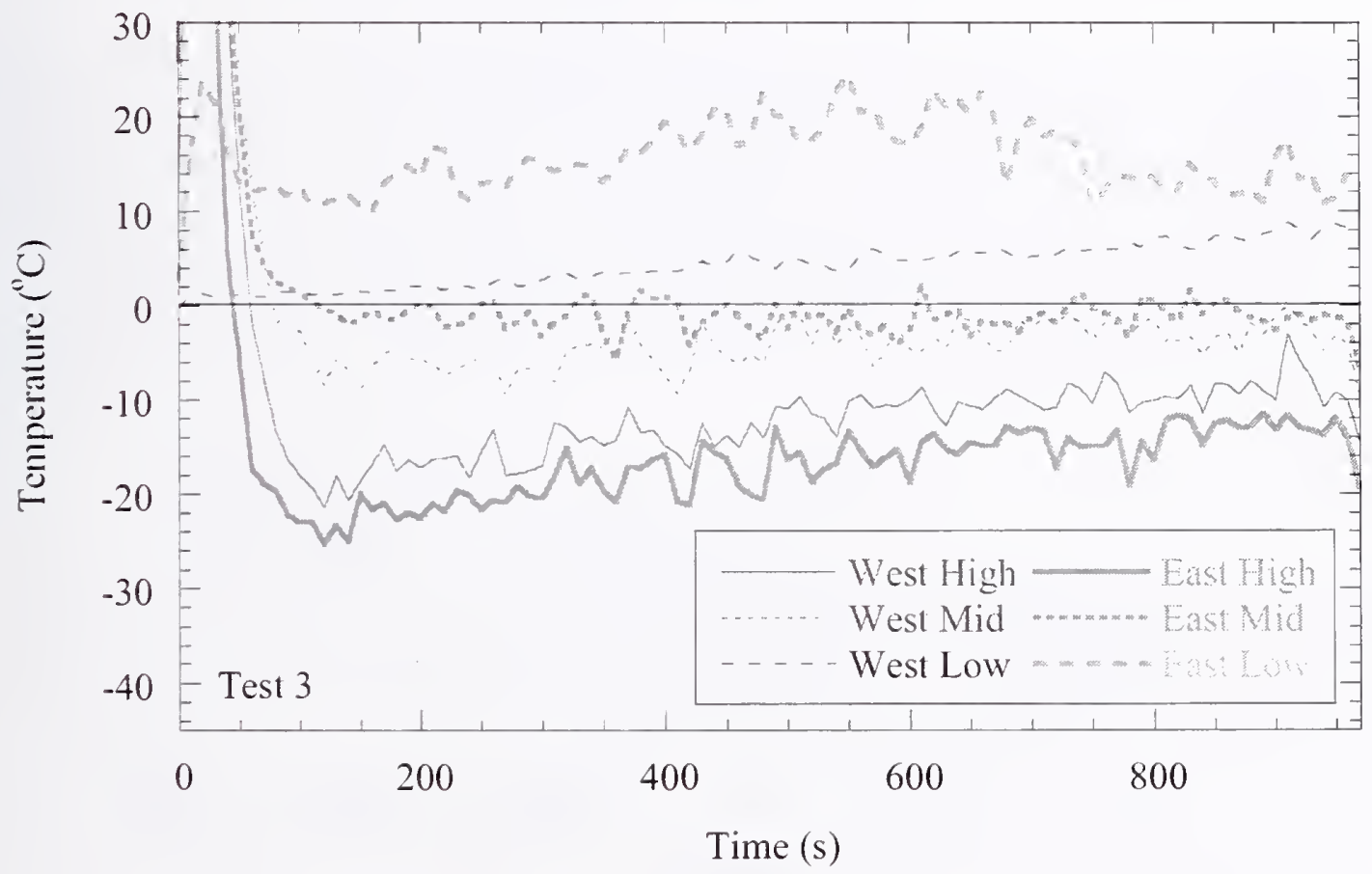

Figure 4-3. $20 \mathrm{~s}$ average of the difference of bare-bead thermocouple temperatures minus aspirated thermocouple temperatures as a function of time for Test 3. 


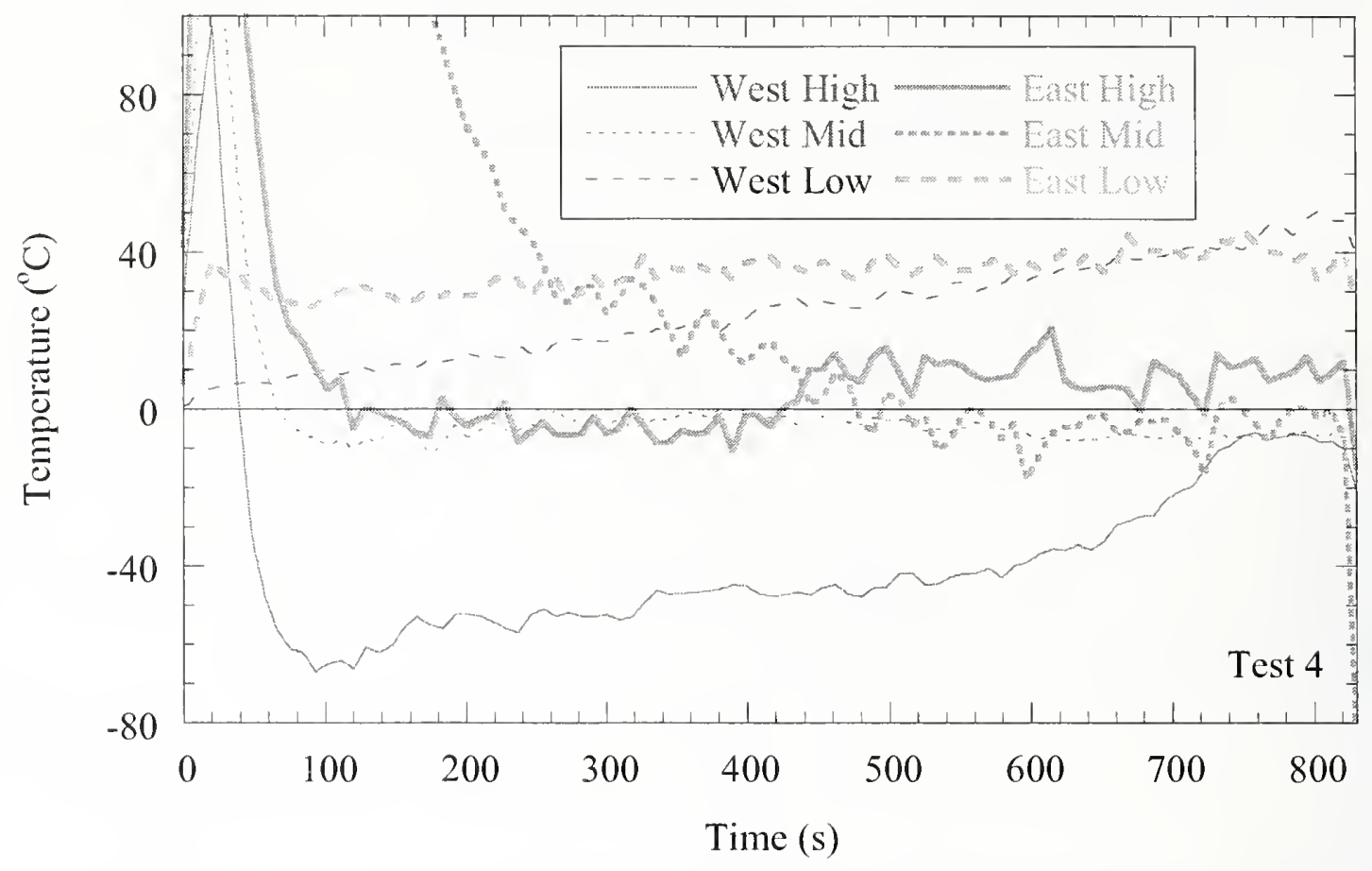

Figure 4-4. $20 \mathrm{~s}$ average of the difference of bare-bead thermocouple temperatures minus aspirated thermocouple temperatures as a function of time for Test 4.

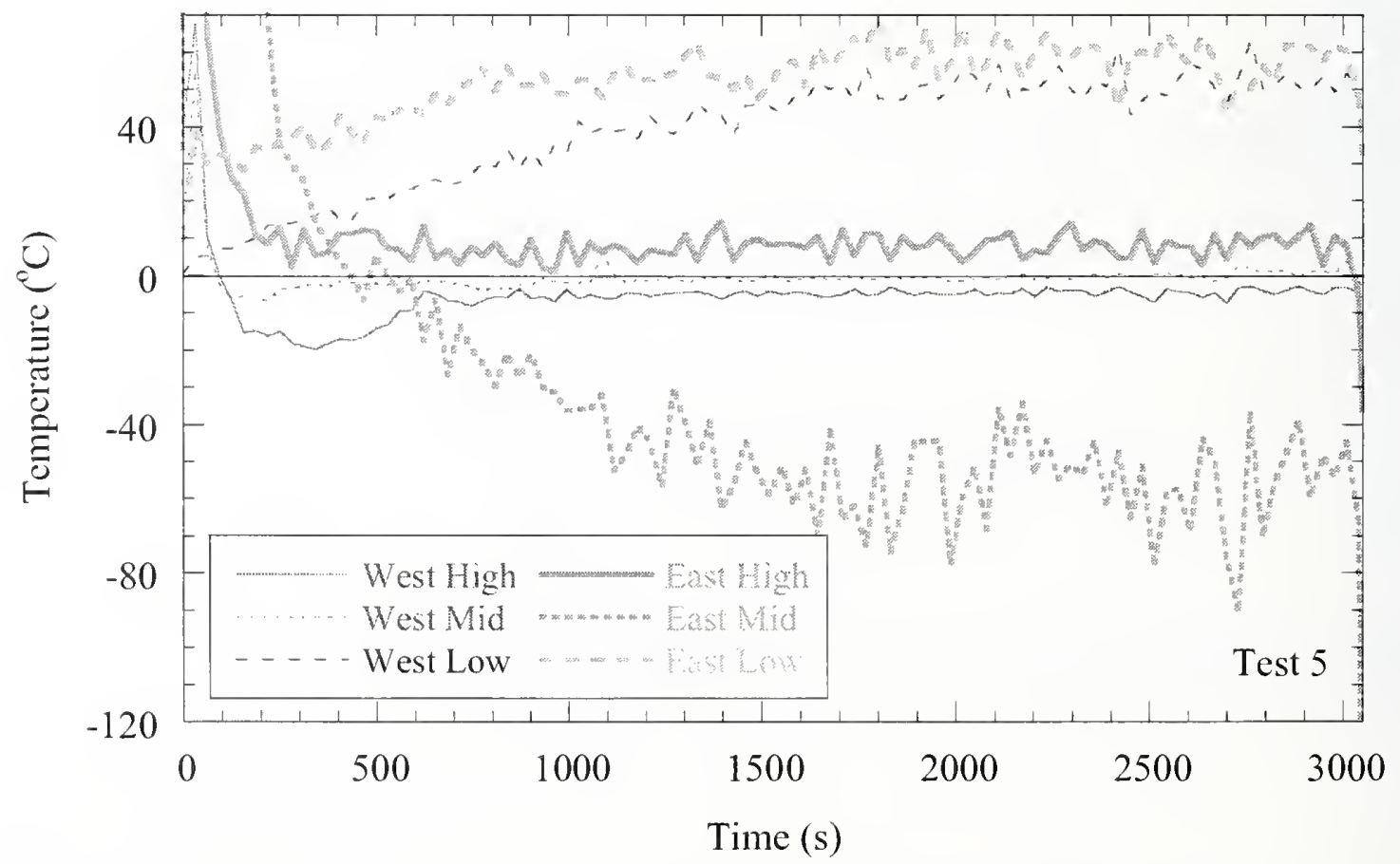

Figure 4-5. $20 \mathrm{~s}$ average of the difference of bare-bead thermocouple temperatures minus aspirated thermocouple temperatures as a function of time for Test 5. 


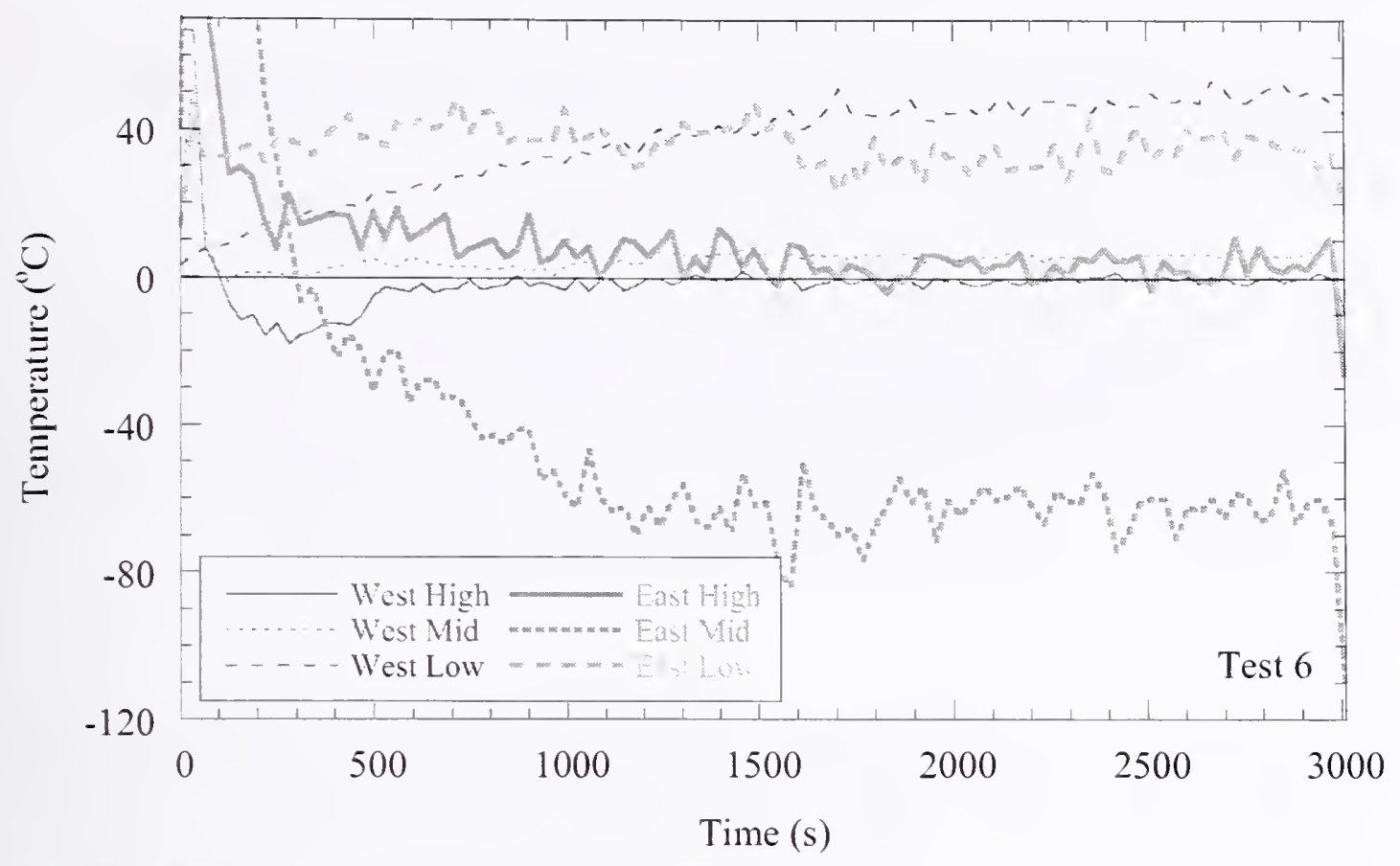

Figure 4-6. $20 \mathrm{~s}$ average of the difference of bare-bead thermocouple temperatures minus aspirated thermocouple temperatures as a function of time for Test 6.

\subsection{MEASUREMENT RESULTS}

Figures 4-7 and 4-8 are plots of all of the aspirated thermocouple temperatures versus time for Tests 1 and 5, respectively. The upper and middle height temperatures are shown for the other tests in subsequent comparison plots. Note that at the West location, low position temperatures remain less than $30{ }^{\circ} \mathrm{C}$ for Test 1 and less than $60^{\circ} \mathrm{C}$ for Test 5 . The low position temperatures at the East location remain near $100{ }^{\circ} \mathrm{C}$ for Test 1 and $200{ }^{\circ} \mathrm{C}$ for Test 5 . Since the temperatures at the low positions on each tree are consistently not of the magnitude of interest for this study, further plots focus on the middle and high position results. Figures $\mathrm{C}-1$ through $\mathrm{C}-4$ in Appendix $\mathrm{C}$ document analogous measurements from Tests 2, 3, 4, and 6, respectively.

\subsubsection{Time Dependence}

The plots in Figs. $4-7$ and $4-8$ show time dependence in that the temperatures continued to rise throughout each experiment. The temperatures during Test 5, which was allowed to proceed much longer than Test 1 because of the insulated steel, approached steady values by the end of the experiment. High and middle position Test 1 temperatures were still rising at about $10^{\circ} \mathrm{C} / \mathrm{min}$ at the end of the experiment.

\subsubsection{Effect of Heat Release Rate}

Figure 4-9 is a plot of the upper and middle position aspirated thermocouple temperatures versus time for Tests 1 and 4. The experiments were identical except that the Test 1 heat release rate $(\dot{Q})$ was $2 \mathrm{MW}$ whereas in Test 2, $\dot{Q}$ was $3 \mathrm{MW}$. The West tree high position temperature was $205^{\circ} \mathrm{C}$ greater for Test 4 than for Test 1. The differences for West middle, East high, and East middle positions were $185^{\circ} \mathrm{C}$, 
$245^{\circ} \mathrm{C}$, and $230{ }^{\circ} \mathrm{C}$, respectively, over the minute prior to $800 \mathrm{~s}$ after ignition (an interval in common late in the fires over which the temperatures were averaged). The magnitude order of the temperatures was different between Tests 1 and 4 with the West middle position hotter than the East middle position for Test 1 , but cooler for Test 4 .

Figure 4-10 is a plot of the upper and middle aspirated thermocouple temperatures versus time for Tests 2 and 3. Again, the experiments were identical except that the $\dot{Q}$ in Test 2 was $2.4 \mathrm{MW}$, whereas the $\dot{Q}$ in Test 3 was $2 \mathrm{MW}$. The West tree high position temperature was $80^{\circ} \mathrm{C}$ greater for Test 2 than for Test 3 . The differences for West middle, East high, and East middle positions were $75^{\circ} \mathrm{C}, 95{ }^{\circ} \mathrm{C}$, and $65^{\circ} \mathrm{C}$, respectively, over the minute prior to $380 \mathrm{~s}$ after ignition. The relative order of the temperatures was the same for both experiments. Temperatures at the East tree were generally higher than those at the West tree at the highest position, but at the middle position, the West temperatures were higher.

\subsubsection{Effect of Smoke Production}

Figure $4-11$ is a plot of the upper and middle aspirated thermocouple temperatures as a function of time for Tests 1 and 3. The experiments were identical except that the Test 1 fuel was heptane whereas the Test 3 fuel was a mixture of heptane and toluene. The high and middle position temperatures in Test 1 were consistently $15^{\circ} \mathrm{C}$ to $25^{\circ} \mathrm{C}$ higher than for the same locations in Test 3 over the minute prior to $880 \mathrm{~s}$ after ignition. This is consistent with the expectation that the smokier, and therefore, less efficient fuel would release less heat energy, and that the higher flame emissivity due to the soil would lose more heat via radiation (as opposed to the soot trapping the radiation, which could lead to higher temperatures).

\subsubsection{Repeatability}

The aspirated thermocouple temperatures for Tests 5 and 6 were compared to determine the repeatability of the tests and whether the results wcre within the expected uncertainty. Figure 4-12 shows the middle and high position temperatures versus time for the two trees. The average difference between temperatures at the same time from ignition ranged from $1{ }^{\circ} \mathrm{C}$ to $5^{\circ} \mathrm{C}$ for these positions with Test 5 generally hotter than Test 6 . It is not shown on the figure, but one position was not as repeatable as the rest. The average difference for the lowest height on the East tree was $21{ }^{\circ} \mathrm{C}$ over the whole test. The divergence occurred after $800 \mathrm{~s}$. Prior to $800 \mathrm{~s}$, the agreement was within $4^{\circ} \mathrm{C}$, but after $800 \mathrm{~s}$, the difference averaged $27^{\circ} \mathrm{C}$. There is no obvious explanation for this since the other five positions agreed well within the expanded measurement uncertainty of about $\pm 7{ }^{\circ} \mathrm{C}$ for each aspirated thermocouple. Thermocouple failure is not a likely explanation for this result. Unexpected leaning of the fire is a possible reason, although this is not clearly demonstrated by the video record. 


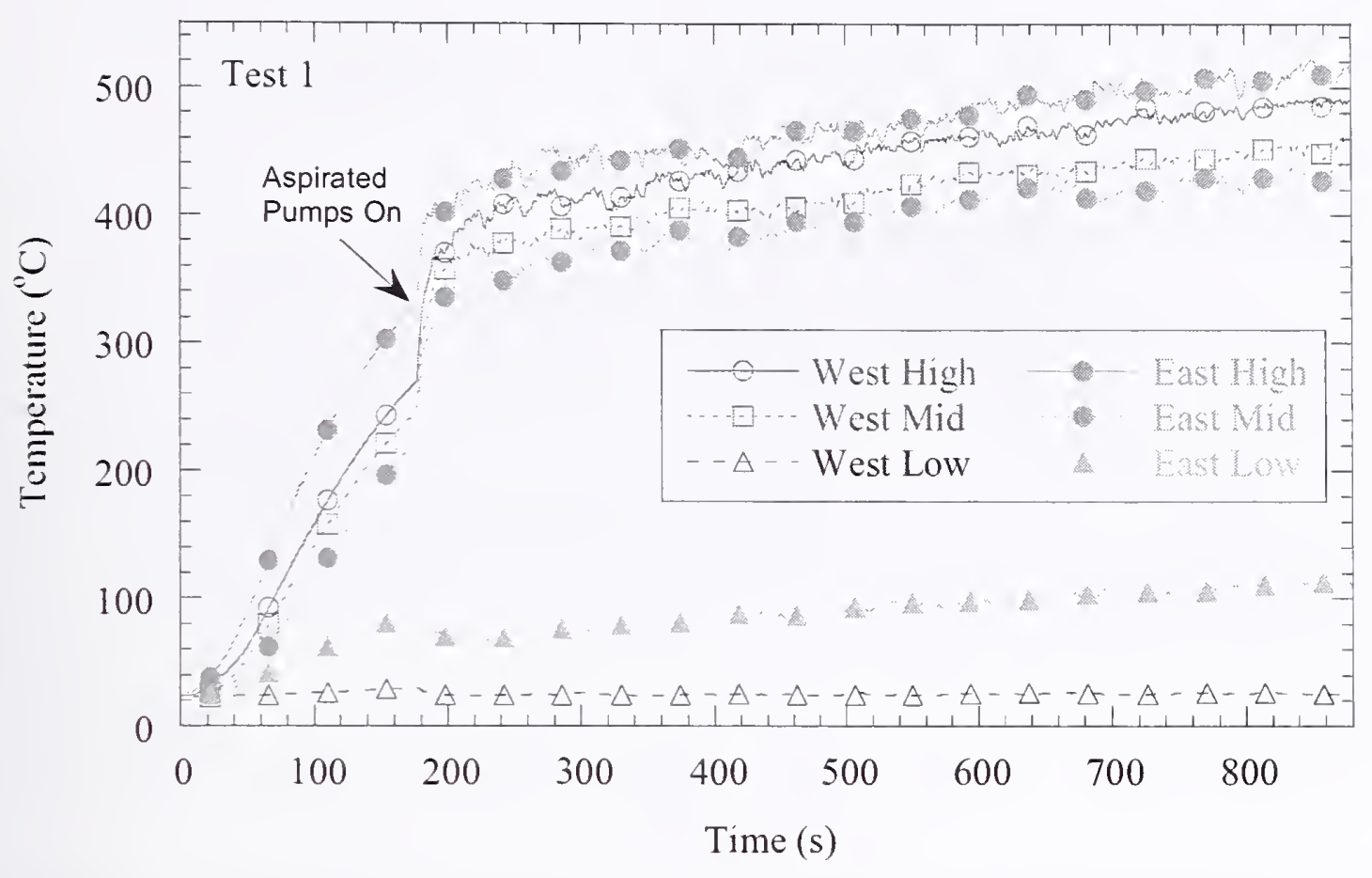

Figure 4-7. Aspirated thermocouple temperatures as a function of time for Test 1.

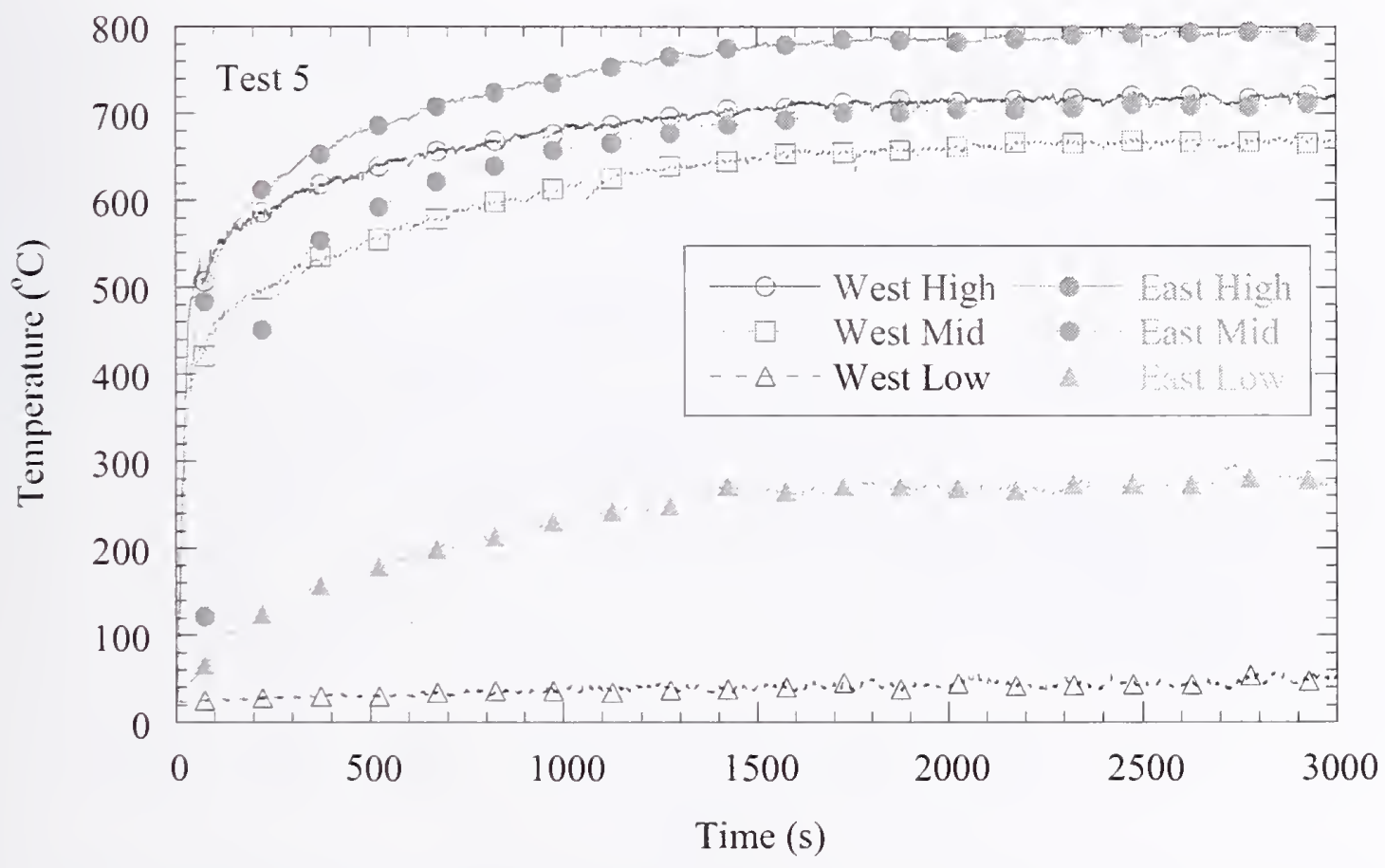

Figure 4-8. Aspirated thermocouple temperatures as a function of time for Test 5. 


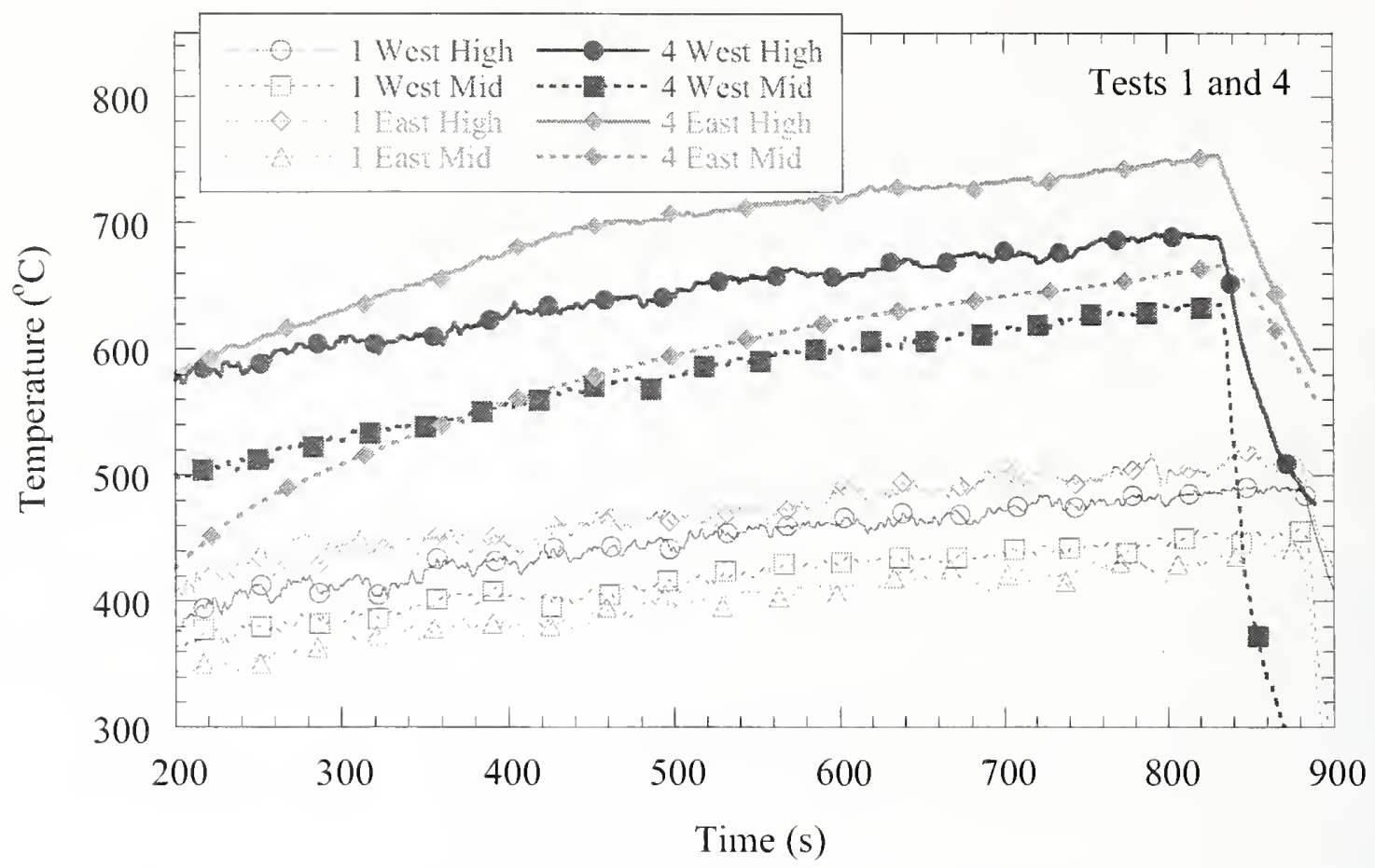

Figure 4-9. Comparison of Test 1 and Test 4 aspirated thermocouple temperatures at the upper and middle locations as a function of time, showing the effect of heat release rate.

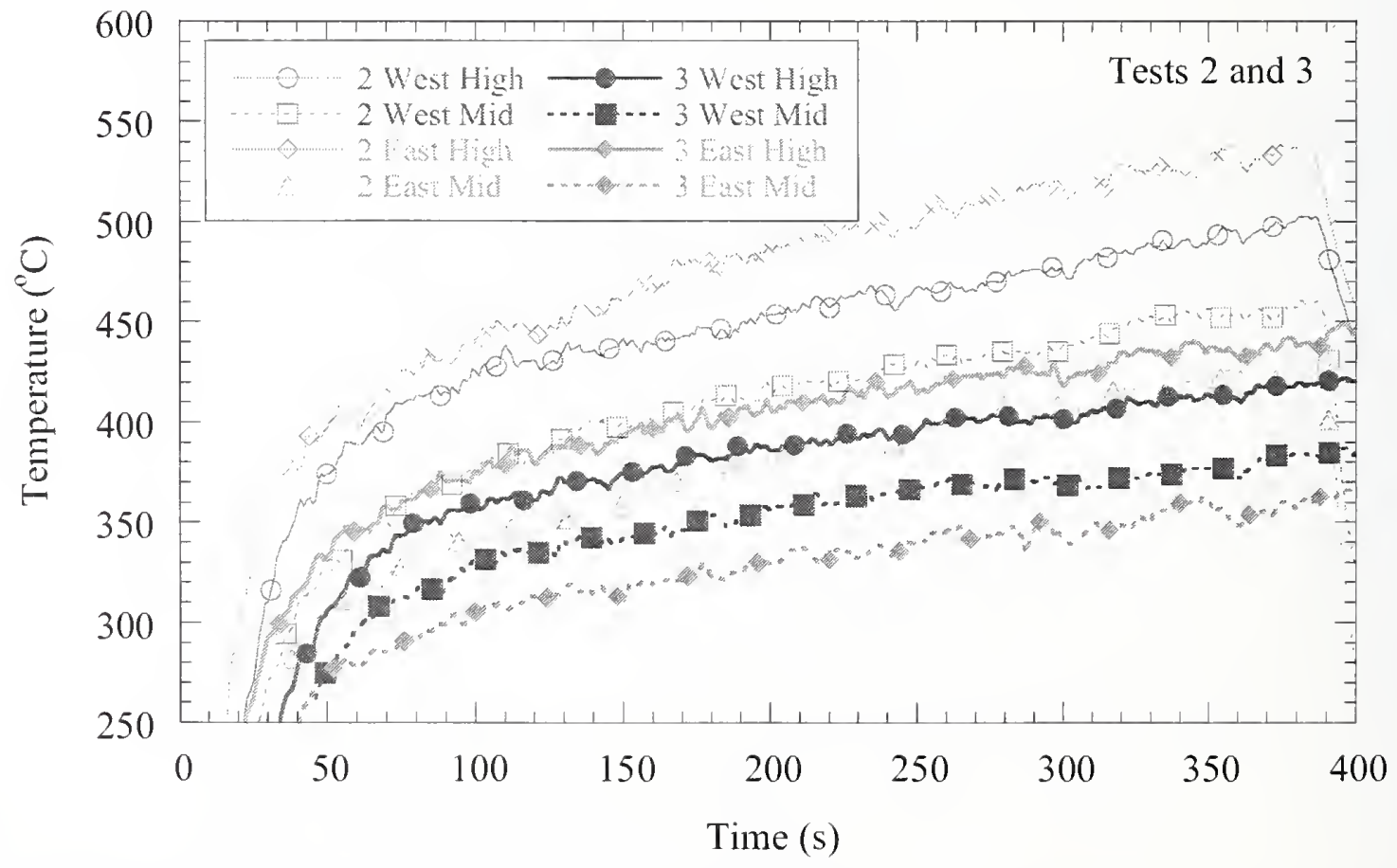

Figure 4-10. Comparison of Test 2 and Test 3 aspirated thermocouple temperatures at the upper and middle locations as a function of time, showing the effect of heat release rate for a sooty fuel. 


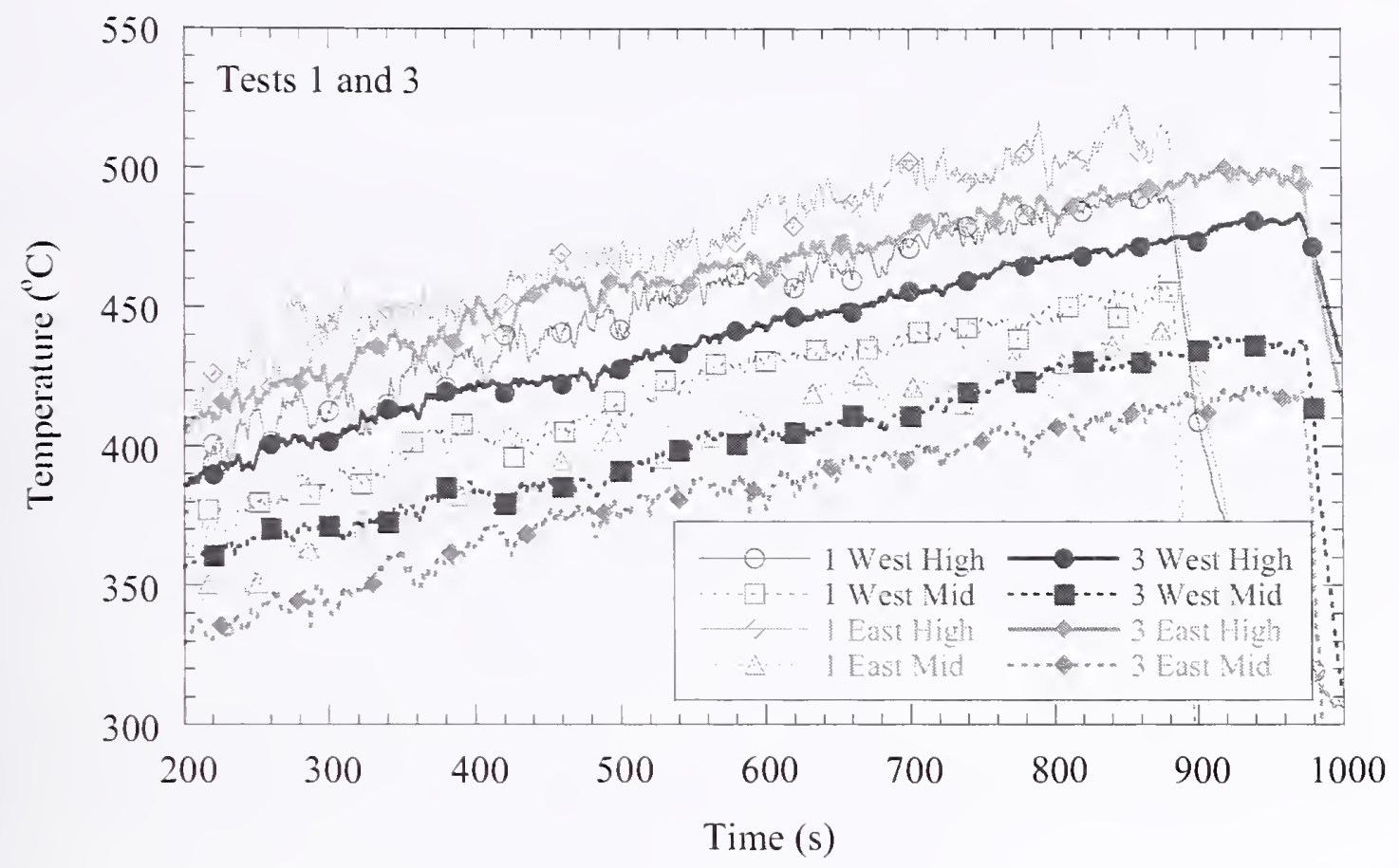

Figure 4-11. Comparison of Test 1 and Test 3 aspirated thermocouple temperatures at the upper and middle locations as a function of time, showing the effect of soot for nearly the same heat release rate.

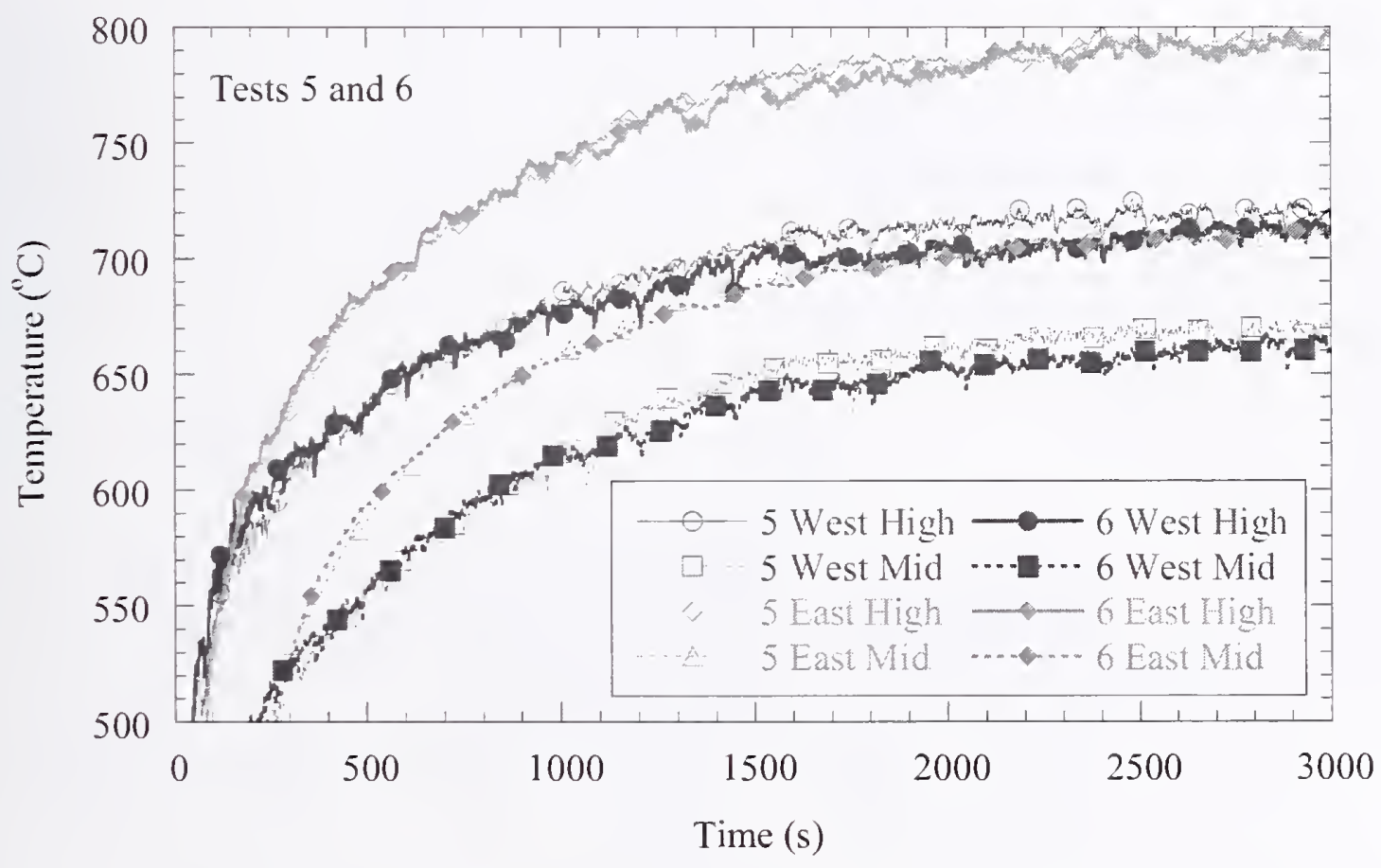

Figure 4-12. Comparison of Test 5 and Test 6 aspirated thermocouple temperatures at the upper and middle locations as a function of time, showing the repeatability of the measurements for long tests with relatively large $\dot{Q}$. 


\subsection{LAYER INTERFACE HEIGHT}

\subsubsection{Calculation Uncertainties}

The results reported for the hot gas layer interface height are from an analysis of each thermocouple tree's temperature profile using the two-layer reduction method. Figure 4-13 shows the temperatures from the West thermocouple tree in Test 1 as an example of such a profile. Figures $\mathrm{C}-5$ through $\mathrm{C}-15$ in Appendix $\mathrm{C}$ document analogous measurements from the East and West thermocouple trees for Tests $1-6$. The two-layer reduction model is a one-dimensional analytical method based on the zone model concept. It uses conservation of mass and energy and temperature profiles to define the height at which the upper and lower masses are equal. It can only be applied when the temperatures can be broken into two distinct regions. The equations used in this method are the following:

$$
\begin{gathered}
I 1 \equiv \int_{0}^{H} T(z) d z=(H-z \mathrm{int}) T_{u p}+z \mathrm{int} \text { Tlow } \\
I 2 \equiv \int_{0}^{H} \frac{1}{T(z)} d z=(H-z \mathrm{int}) \frac{1}{T_{u p}}+z \mathrm{int} \frac{1}{T_{\text {low }}} \\
z \text { int }=\frac{T_{\text {low }}\left(I_{1} I_{2}-H^{2}\right)}{I_{1}+I_{2} T_{\text {low }}{ }^{2}-2 T_{\text {low }} H}
\end{gathered}
$$

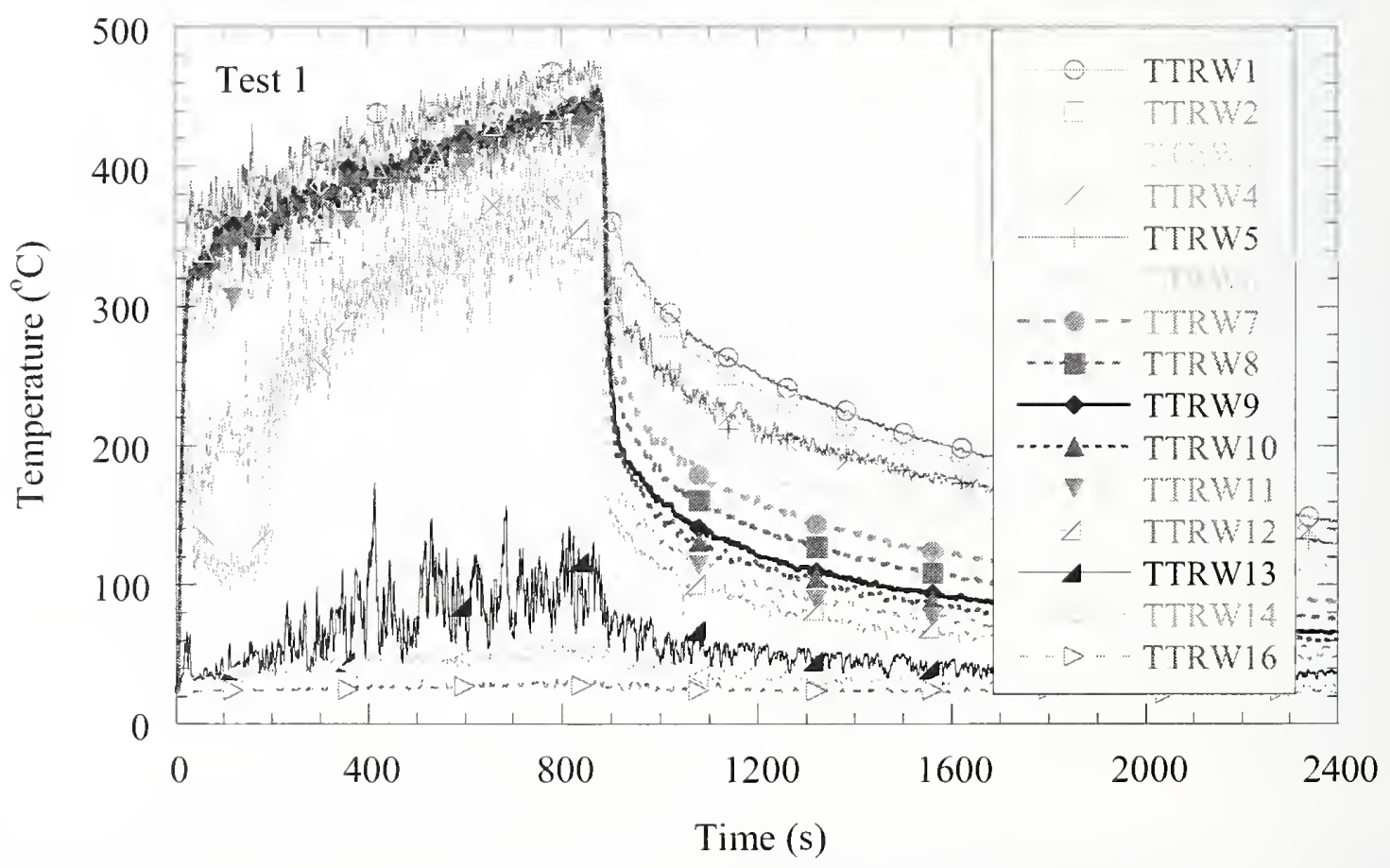

Figure 4-13. West thermocouple tree temperatures as a function of time in Test 1. 
where $H$ is the ceiling height $(\mathrm{m}), Z_{\text {int }}$ is the layer interface height $(\mathrm{m}), T_{\text {up }}$ is the hot layer average temperature $(\mathrm{K}) . T_{\text {low }}$ is the lower layer average temperature $(\mathrm{K}), T(z)$ is the temperature as a function of height $(\mathrm{K})$, and $z$ is the height $(\mathrm{m})$.

The layer interface height uncertainties were calculated by the following procedure. Typical temperature profiles were chosen for each test within 2 min of extinguishment. Those times were $850 \mathrm{~s}, 380 \mathrm{~s}, 950 \mathrm{~s}$, $800 \mathrm{~s}, 3,020 \mathrm{~s}$, and 3,000 s for Tests 1 to 6, respectively. At those times, the appropriate expanded temperature uncertainties listed in Table 4-4 were added to the tree temperatures to obtain the two standard deviation limits around the nominal measurements. Since each tree had three regions of uncertainty based on the three aspirated thermocouple temperatures, eight possible combinations of highest and lowest temperature were generated. These eight temperature profiles and the corrected profile (each temperature in the center of its range of uncertainty) were applied using the two-layer reduction equations (Eqs. 4-1 through 4-3). This generated a set of 9 layer heights for each tree. Two times the standard deviation of these nine values was considered the uncertainty for this calculation.

The estimated expanded uncertainties for the layer interface height are contained in Table 4-5. The West tree uncertainties for all of the tests are clustered around 1 percent of the values calculated using the nominal temperature profiles. For the East tree, the uncertainties are significantly higher than for the West, but are still quite low. They range between 2 percent and 6 percent.

Table 4-5. West and East tree layer heights.

\begin{tabular}{|c|c|c|c|c|c|c|}
\hline \multirow[b]{2}{*}{ Test } & \multicolumn{3}{|c|}{ West Tree Layer Interface Height } & \multicolumn{3}{|c|}{ East Tree Layer Interface Height } \\
\hline & $\begin{array}{c}\text { End of Test } \\
\text { Uncorrected } \\
(\mathrm{m})\end{array}$ & $\begin{array}{c}\text { Expanded } \\
\text { Uncertainty } \\
(m)\end{array}$ & $\begin{array}{c}\text { Expanded } \\
\% \\
\text { Uncertainty }\end{array}$ & $\begin{array}{c}\text { End of Test } \\
\text { Uncorrected } \\
\text { (m) }\end{array}$ & $\begin{array}{c}\text { Expanded } \\
\text { Uncertainty } \\
(\mathrm{m})\end{array}$ & $\begin{array}{c}\text { Expanded } \\
\% \\
\text { Uncertainty }\end{array}$ \\
\hline 1 & 1.16 & 0.009 & 0.8 & 1.48 & 0.058 & 3.9 \\
\hline 2 & 1.02 & 0.010 & 1.0 & 1.20 & 0.030 & 2.5 \\
\hline 3 & 1.04 & 0.009 & 0.8 & 1.23 & 0.030 & 2.4 \\
\hline 4 & 0.99 & 0.011 & 1.1 & 1.17 & 0.052 & 4.5 \\
\hline 5 & 1.17 & 0.009 & 0.8 & 1.15 & 0.069 & 6.0 \\
\hline 6 & 1.11 & 0.009 & 0.8 & 0.97 & 0.053 & 5.4 \\
\hline
\end{tabular}

\subsubsection{Calculation Results}

Figure 4-14 shows the results of the two-layer reduction method on the thermocouple tree data from Test 1. For this figure and the following two, the height is plotted on the $y$-axis since it allows the reader to better visualize the temperature profile. The independent parameter is time, not height or temperature. There is very little trend with time and the fluctuations are not very large. The implication of the plot is that the layer interface is over $1 \mathrm{~m}$ below the top of the exit vent. This seems counterintuitive since the smoke layer should not be easily maintained far below the soffit. 
Figure 4-15 shows the temperature profiles with height for Test 1 at $t=850 \mathrm{~s}$. It suggests that a strong thermal transition begins between $1 \mathrm{~m}$ and $1.5 \mathrm{~m}$ and ends between $2.1 \mathrm{~m}$ and $2.4 \mathrm{~m}$. This indicates that a mixed transitional layer begins near the bottom of the exit vent and ends near the top with lesser temperature gradients above and below. Figure 4-16 shows results for Test 5 , which has a temperature profile similar in structure to Test 1 , but with higher temperatures.

The two-layer reduction method apparently generates the lowest height at which the thermal gradients increase dramatically from the relatively cool lower layer. The Table 4-5 list of layer heights can still be used to compare the relative positions of this onset of the uppcr layer between East and West locations and different tests. The visible upper smoke layer interface was most likely higher than the tabulated values.

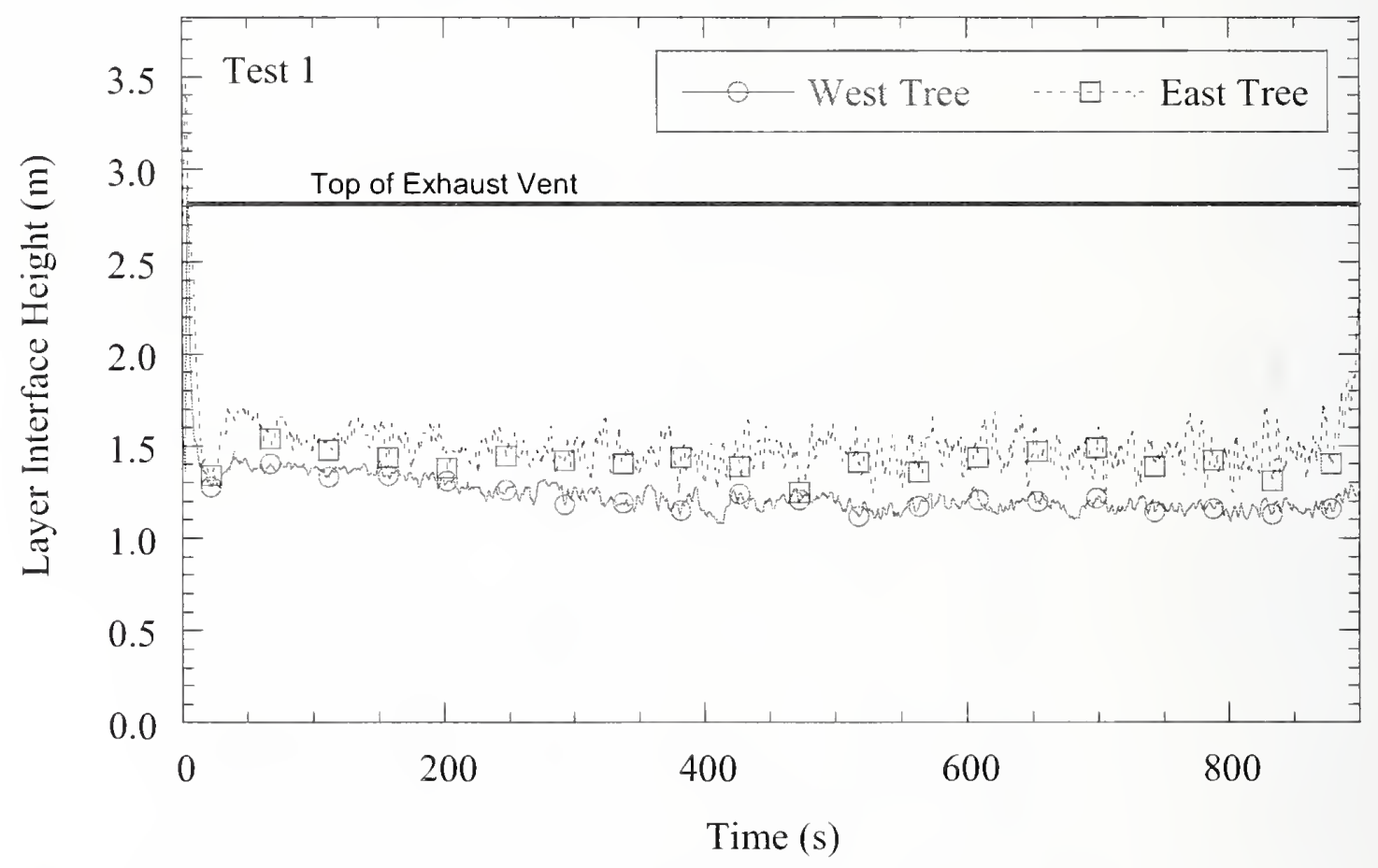

Figure 4-14. Calculated layer interface height as a function of time for Test 1. 


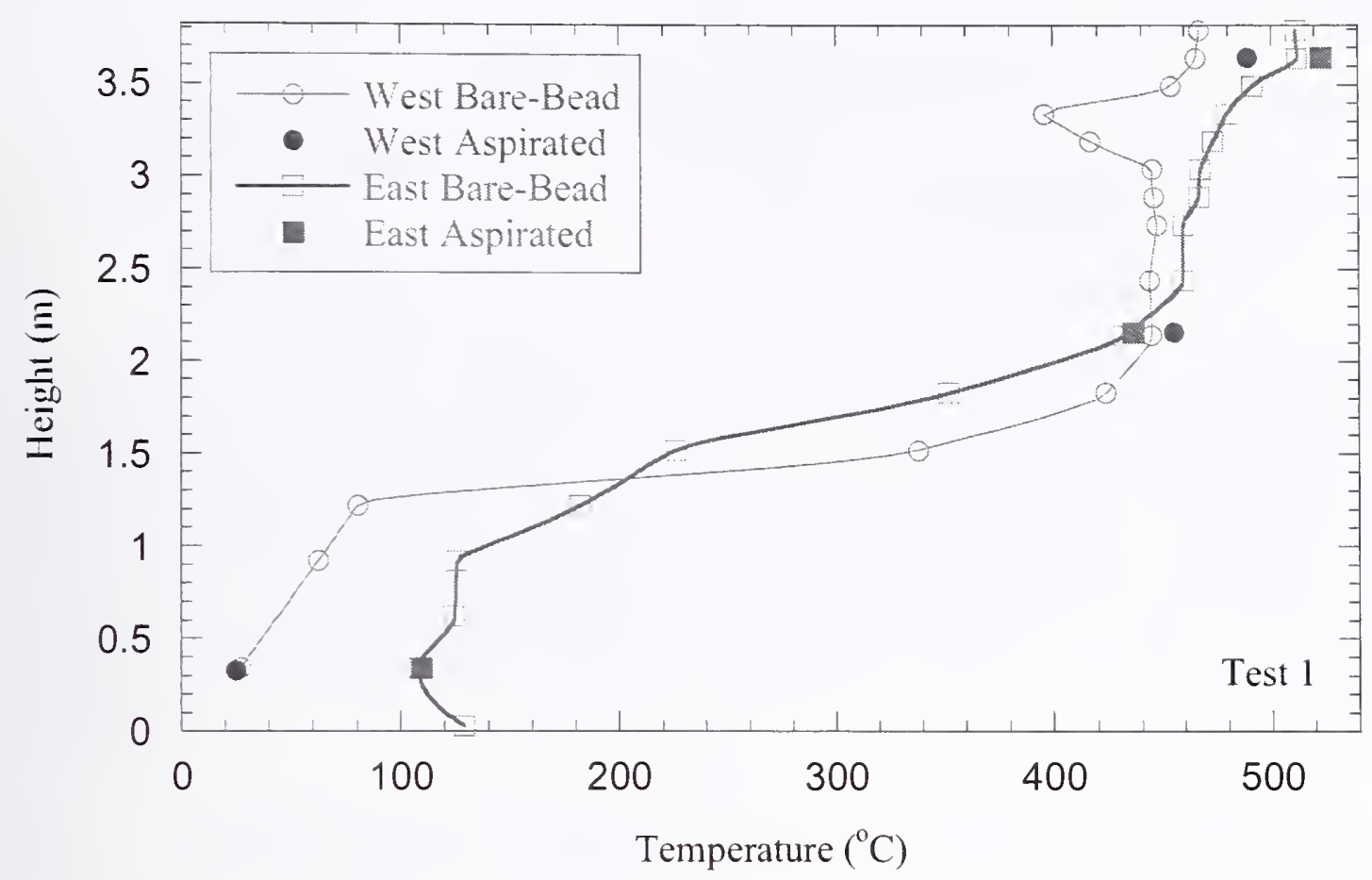

Figure 4-15. Temperature profiles for West and East thermocouple trees for Test 1 at $\mathrm{t}=850 \mathrm{~s}$.

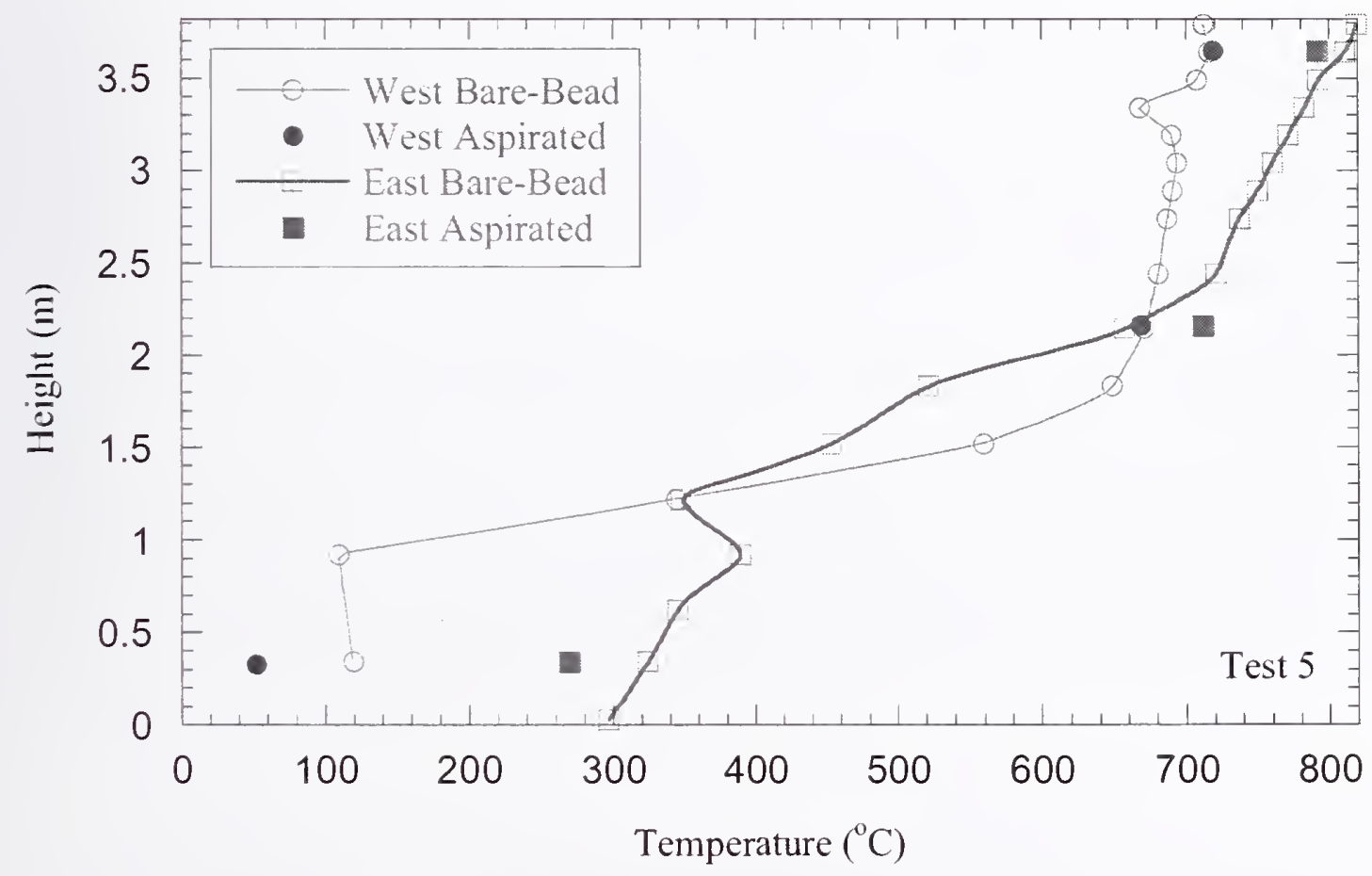

Figure 4-16. Temperature profiles for West and East thermocouple trees for Test 5 at $t=3,020 \mathrm{~s}$. 


\subsection{REFERENCES}

Blevins, L. G., and W. M. Pitts. 1999. Fire Safety Jomrnal, 33, 239-259, and National Institute of Standards and Technology, Gaithersburg, MD, NISTIR 6310, April. Available at http://fire.nist.gov/bfrlpubs/fire99/PDF/f99022.pdf.

He, Y. P., A. Fernando, and M. C. Luo. 1998. Fire Safety Jomnal, 31, 19-38.

McCaffrey, B.J., and G. Heskestad. 1976. Combnst. Flame, 26, 125-127.

Pitts, W. M., E. Braun, R. D. Peacock, H. E. Mitler, E. L. Johnsson, P. A. Reneke, and L. G. Blevins. 1998. Temperatmre Uncertainties for Bare-Bead and Aspirated Thermoconple Measurements in Fire Enviromments, National Institute of Standards and Technology, Gaithersburg, MD, NISTIR 6242; October. Available at http://fire.nist.gov/bfrlpubs/fire03/PDF/f03052.pdf. 


\section{Chapter 5 \\ Heat FluX MEASUREMENTS}

\section{$5.1 \quad$ OBJECTIVE}

The heat flux measurements were used to assess the accuracy of the National Institute of Standards and Technology (NIST) Fire Dynamic Simulator (FDS) model. The heat flux incident on the surfaces of the structural components is key to their temperature behavior. However, it was not deemed practical to place flux measuring devices on or in the structural components as the instruments themselves are inherently disruptive. ${ }^{l}$ Instead, the flux devices were distributed throughout the compartment, in separate enclosures for mounting and lead protection, to characterize the heat flux field in which the structural components were immersed and to provide an extensive basis for model comparison. The model, with its accuracy determined, can then be used to predict the heat flux that falls on the surface of structural components.

\subsection{DESCRIPTION OF THE HEAT FLUX MEASUREMENT DEVICES}

Twelve Schmidt-Boelter total heat flux gauges, two ellipsoidal radiometers, and five slug calorimeters were used to measure the total and radiative heat fluxes at various locations throughout the test compartment.

A Schmidt-Boelter flux gauge is a calibrated, water-cooled thermopile whose sensor surface facc temperature is uniform and close to that of the cooling water used. These qualities make it preferable to flux gauges of the Gardon design (metal foil sensor with a single central thermocouple) in handling mixed convective and radiative heat fluxes. Schmidt-Boelter gauges have a field of view of 180 degrees and record the sum of the radiant and convective fluxes (total heat flux) to the scnsor surfacc. The gauges were rated at $150 \mathrm{~kW} / \mathrm{m}^{2}$. Schmidt-Boelter sensors have a time response of approximately $0.1 \mathrm{~s}$ to $0.2 \mathrm{~s}$.

The convective component of the total heat flux is enhanced by the fact that the scnsor face of the gauge remains near the water coolant temperature (whereas the surface temperaturc of the objects in the enclosure is rising considerably). Such a gauge thus provides a "cold wall" hcat flux. The FDS model can predict the convective component on this basis, so this is not a drawback to the goal of model-versusexperiment comparisons (see caveat noted below). Here, the cooling water was elevated in temperature to preclude water vapor condensation on the gauge face. Typically, the gauge temperature was in the $70{ }^{\circ} \mathrm{C}$ to $80^{\circ} \mathrm{C}$ range though it exceeded this upper limit in the longer experiments. This was one source of uncertainty in the flux gauge readings, as discussed bclow.

1 The typical heat flux gauge is a $1.6 \mathrm{~cm}$ diameter by $2.5 \mathrm{~cm}$ long water-cooled metal cylinder with a pair of water leads, electrical leads and, in some cases, a gas purge lead, as well. Inserting the gauge into a structural element alters the local temperature. The bundle of leads, with its necessary insulation, cannot run along the structural element without blocking heat transfer to the element's surface. Even if the leads run normal to the element surface, they still present significant shadows, blocking radiative transfer. 
The relatively cold sensor surface of a Schmidt-Boelter gauge is potcntially a drawback in another way - it is a natural deposition site for fire-generated soot, pushed toward it by thermophoresis. Preliminary experiments were done with this type of gauge suspended above a $0.4 \mathrm{~m}$ diametcr pool fire. Two such gauges were mounted side-by-side in a plate that provided both a means of covering one of the gauges and of blowing any soot deposition off of the surface of the other gauge (by means of a nearly tangential blast of high pressure nitrogen). Experiments were done as a function of height above the pool surface and of fuel type (see Chapter 3). The heptane/toluene fuel mixturc provided a particularly challenging soot deposition environment, especially one diameter above the pool surface; the indicated flux level from a clean gauge would immediately decay downward as soot deposited at a rapid rate. A nitrogen purge was found to be capable of restoring this flux reading to the same level as the adjacent gauge read the moment its cover (which kcpt its face clcan) was removed. The same purge flow and physical configuration were used for all of the total flux gauges in the hot upper layer for the tests reported here. (see Fig. 5-1 and also below for gauge locations.) The purge duty cycle was varied during the experiments. For most tests it was $3 \mathrm{~s}$ of purging cvery $120 \mathrm{~s}$; in the early experiments it was as frequent as every $30 \mathrm{~s}$. The gauges showed no sign of signal decay due to soot accumulation in any test. Post-test inspection showed a very light soot layer on the sensor face that was wiped clean before being used in any subsequent tcst.

Radiometers measure only the radiation portion of the incident heat flux on a surface in which they are imbedded. Each consists of a Schmidt-Boelter sensor at the base of a shallow cavity that is ellipsoidal in shapc. An opening at one end accepts radiation incident over a 160 degree wide field of view. All radiation incident on the approximately $3 \mathrm{~mm}$ diameter hole at the open end of the cavity is absorbed by the sensor at the other end. Soot deposition on the reflective cavity walls could modify this behavior, so the cavity was purged with a wcak nitrogen flow to keep soot from entcring. The temperature of this gas purge proved to be difficult to fully control in some of the experiments, and this was a source of uncertainty in the radiometer readings (see below). The radiometers were also cooled with heated water in the same temperature range as above, though given the nitrogen purge, hcating was unnecessary to prevent water vapor condensation in this case. The gauges were rated at $150 \mathrm{~kW} / \mathrm{m}^{2}$.

Medtherm Inc. supplied all of the flux gauges and radiometers. The total flux gauges were re-calibrated at NIST using $75^{\circ} \mathrm{C}$ cooling water. The radiometers could not be calibrated with the NIST radiant source due to its partially focused nature, so the factory calibration was used with the uncertainty estimated as 5 percent.

The slug calorimeters used here were an adaptation of a technique that has long been used to infer heat fluxes (e.g., in ASTM E 457 [2002]). Here, the slugs were $18 \mathrm{~kg}$ (40 lb) cylinders of nickel 200 ( $\geq 99$ percent nickel), $10.2 \mathrm{~cm}$ (4.00 in.) in diameter by $25.4 \mathrm{~cm}$ (10.0 in.) long (see Fig. 5-2). The large mass was chosen to extend the useful measurement time since the slugs must lag the local temperature in the technique used here. Nickel was chosen for its high tcmperature inertncss and relatively high thermal conductivity. The cylinders were insulated on the ends $(1.3 \mathrm{~cm}$ of ceramic wool insulation). The cylinder surface can be thought of as the sensor. It was coated with a black paint designed for high temperature applications (Medtherm flat black) with a known absorptivity of 0.92 . The cylinders were suspended from the compartment ceiling by means of $1.3 \mathrm{~cm}$ diameter threaded rods to minimize shadowing of the cylindrical surface. These rods attached to brackets on each cylinder end; each bracket was in turn attached to the end of the cylinder only via a pair of $1 / 4-20$ stainless steel screws to minimize thermal conduction to/from the bracket to the cylinder. The cylinders were oriented with their axes parallel to the 
long axes of the trusses. In this sense, they averaged their incident flux distribution in much the same manner as does a unit length of the longitudinal element of a truss in the compartment. ${ }^{2}$ Note, however, that they do not necessarily see the same fluxes as the trusses because the radiation field in the compartment is not uniform.

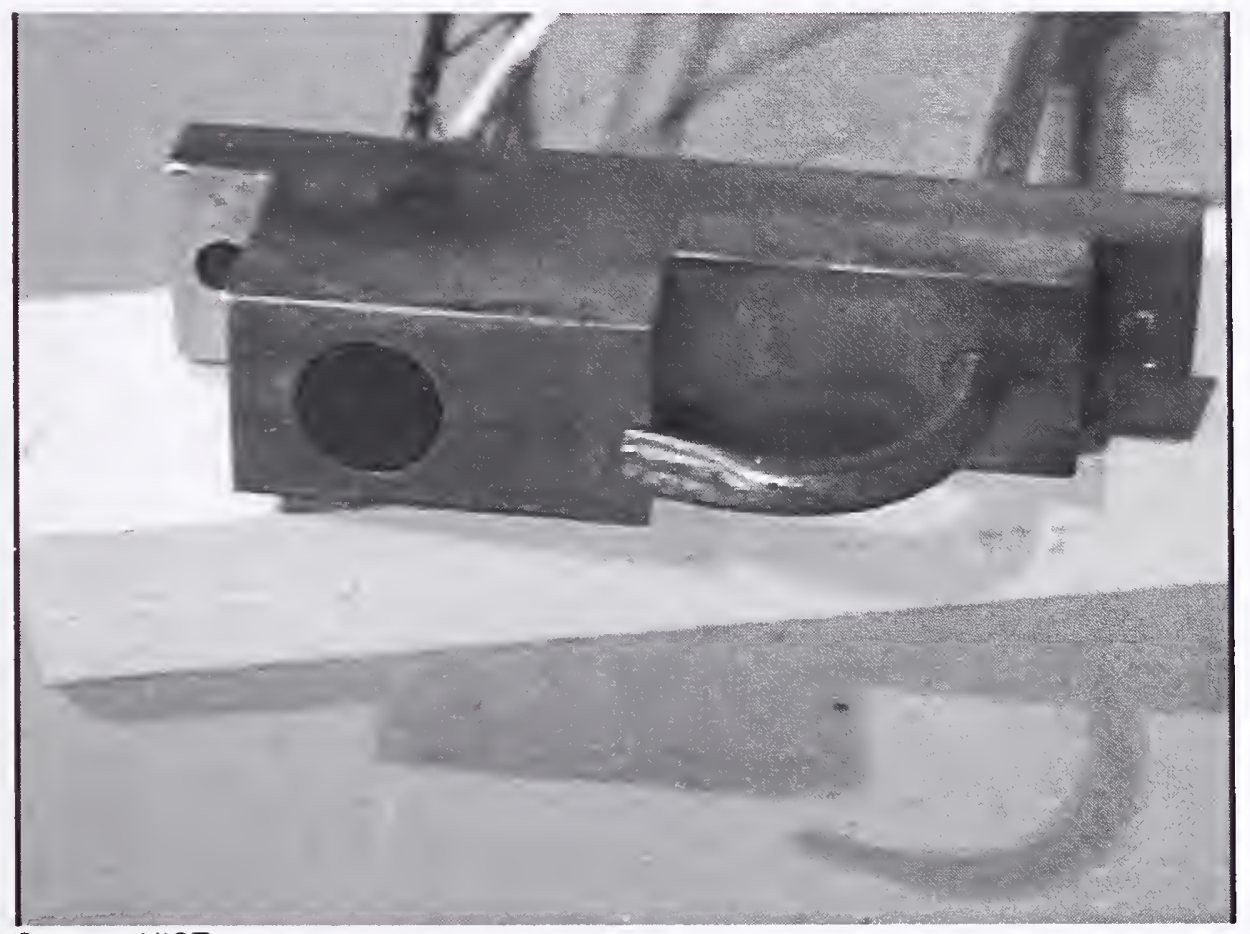

Source: NIST.

Figure 5-1. Flux gauge holder showing gauge sensor surface (black disc) and soot purge tube. Surface of gauge holder and gauge sensor surface were set flush with the surrounding Marinite cover on any monitored surface.

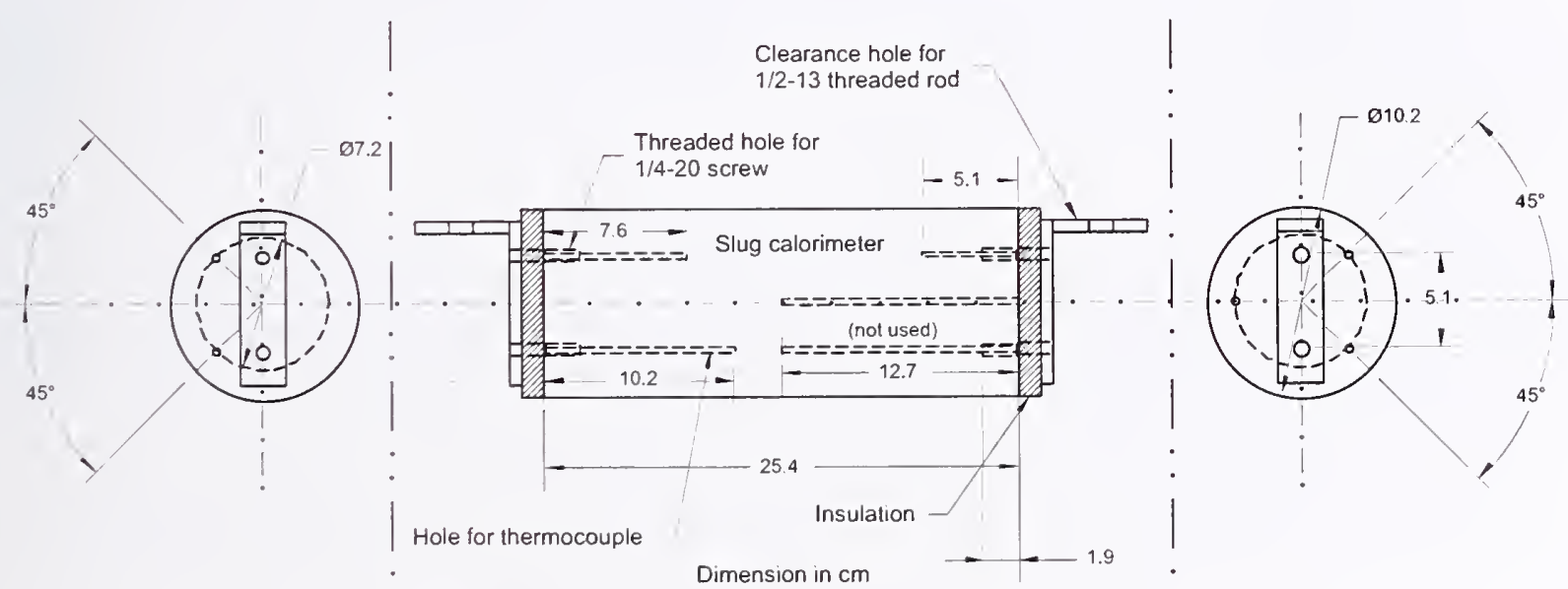

Figure 5-2. Schematic of slug calorimeter.

\footnotetext{
2 Being more massive and having a lesser surface area per unit length than an element of the truss, they heat up more slowly.
} 
A metal cylinder exposed to a constant heat flux on its cylindrical surface necessarily has a temperature gradient between the outcr surface and the cylinder center, even as its average temperature goes up at a steady rate in response to the flux (Carslaw and Jaeger 1959). However, the average temperature of the cylinder is very near the mass mean radius of 0.707 (radius). Thus, all cylinder temperature measurements were done at this radius. Since the slugs used here were placed into a complex, threedimensional heat flux environment and nickel has a finite thermal conductivity, temperature variations were anticipated. ANSYS solutions for the internal temperature field resulting from a heat flux field with a 2:1 asymmetry in the flux on opposite sides of the cylinder indicated an approximately $20^{\circ} \mathrm{C}$ difference in temperature around the mass mean radius. Thus, four thermocouples ( $3 \mathrm{~mm}$ diameter stainless steel sheathed, type K) were embedded in each cylinder (two from each end, through the ends) as shown in Fig. 5-2. The time-varying average heat flux over the cylindrical surface of each slug was calculated from the instantaneous average of the four thermocouple signals using a heat balance as discussed below.

Since a slug remains below the local gas temperature, it too is a thermophoretic target for soot deposition, at least until the slug surface is hot enough to oxidize soot (see below). The same can be said of the uninsulated steel trusses in the fire compartment-since they have a greater surface area per unit volume, they heat faster, gathering somewhat less soot. The point is that soot deposition is, in fact, a natural part of exposure of structural components to a fire and it potentially affects the heat flux reaching the surface of the element on which it deposits. Soot has an absorptivity of 0.95 or greater, enhancing radiation absorption. The slugs started the first test at 0.92 absorptivity due to their black paint, and though it was wiped off after each test, they probably retained enough to stay very near 0.95 even at the start of the next three tests (the last two tests are discussed below). Thus, their radiation absorption was little affected by soot deposition. It can probably be safely assumed that the bare steel trusses acquired enough soot on their surfaces to quickly become highly absorbent early in any of the tests. There is a second potential effect of soot absorption that could be more of a problem to heat transfer analysis: a sufficient layer of soot becomes a significant thermal insulator on its own (this is how it affects heat flux sensor readings). All of thc slugs were inspected at the end of each test for soot deposition. When present, it was estimated to be $0.1 \mathrm{~mm}$ to $0.2 \mathrm{~mm}$ thick, which was not expected to have an apprcciable effect on the heat transfer rate to the slug (or to the uninsulated trusses, which could have had comparable build-ups). ${ }^{3}$ The two tests using toluene/heptane mixtures yielded much sootier fires, however. At the end of those experiments the slugs had a layer estimated at $0.5 \mathrm{~mm}$, which possibly had some retarding effect on heat transfer to these units and to the bare steel trusses used in these tests for late timcs in the experiments.

In the last two experiments, which were extended in duration, the slugs reached a sufficient temperature to burn off the soot (estimated at $\geq 600{ }^{\circ} \mathrm{C}$ in the oxidizing environment of the upper layer) and the organic part of the black paint (they were not recoated). As a result, after each of these experiments, the slug surfaces were dark gray, not black. At the beginning of each test, soot deposition would have rapidly blackcned them, as discussed above.

It is not possible to be more quantitative about this issue since the thermal properties of these very thin soot layers are not known. The layers appeared to have a complex structure, making quantification even more difficult. There appeared to be a denser inner layer covered by an outer layer that included a large proportion of agglomerated soot particles, which lowered the density of this outer layer. 


\subsubsection{Location of Heat Flux Instrumentation}

Heat flux measurement devices were placed in the ceiling, in the floor, in locations next to a test column and in a special "flux measurement station" approximately above the fire. The exact locations are indicated below.

The heat flux measurement station, which incorporated two total heat flux gauges $(1.6 \mathrm{~cm}$ diameter, with nitrogen purge to prevent soot deposition, rated to $150 \mathrm{~kW} / \mathrm{m}^{2}$ ) and two ellipsoidal radiometers discussed above, was placed at the mid-height of the trusses and just downstream of the downstream end of the fire pan (see Figs. 5-3 and 5-4 for the location). The station was made of a 310 stainless steel cylindrical shell with an outer diameter of $15.2 \mathrm{~cm}$, a length of $50.8 \mathrm{~cm}$, and a thickness of $1.3 \mathrm{~cm}$. One flux gauge and one radiometer were mounted flush on the top of the tube facing the ceiling of the compartment, while the pair on the bottom faced straight down. A schematic cross section of the station is shown in Fig. 5-5; not shown is the ceramic wool insulation that filled the interstices inside the shell. The station was anchored on an L-shaped steel box beam support, $10.2 \mathrm{~cm}$ by $10.2 \mathrm{~cm}$ square, and $0.3 \mathrm{~cm}$ thick (see Fig. 5-6) insulated with Marinite up to $3.8 \mathrm{~cm}$ in thickness. Output signal and thermocouple wires from the gauges, cooling water to the gauges, return water lines, and nitrogen purge lines were bundled together (with all the electrical lead wires placed in the core of the bundle), wrapped with ceramic wool, and run from the station through the L-shaped insulated steel support to the outside of the test compartment. This arrangement proved adequate to protect the lead wires until the last two extended duration tests. Thermocouple lead wires, which carried information on the water temperature in the flux gauge interiors, began to short during these tests as the shell of the flux measurement station reached $750^{\circ} \mathrm{C}$. Flux gauge signal wires also failed later in the test.

Total heat flux gauges $\left(6 \mathrm{~mm}\right.$ diameter, rated at $\left.100 \mathrm{~kW} / \mathrm{m}^{2}\right)$ were mounted $15 \mathrm{~cm}$ off the floor flush within stainless steel blocks on top of a $10.2 \mathrm{~cm}$ by $10.2 \mathrm{~cm}$ square, $0.3 \mathrm{~cm}$ thick steel box beam insulated with $2.54 \mathrm{~cm}$ thick Marinite (flush with the top of the gauge-holding blocks and the Marinite). Signal wires from the gauges and the cooling water lines were placed inside the insulated steel box beam in a manner similar to the station support described above. Since soot deposition was negligible at these two locations, the floor flux gauges were not purged with nitrogen. The locations of the two gauges, designated as HF1 and HF2, are shown in Figs. 5-3 and 5-4. Note that they have a large view factor with respect to the fire plume.

Two larger total heat flux gauges $\left(1.6 \mathrm{~cm}\right.$ diameter, rated at $\left.150 \mathrm{~kW} / \mathrm{m}^{2}\right)$, one facing the north-side wall and one facing the fire pan, were also mounted within stainless steel blocks on a similar insulated steel support box beam adjacent to the upper part of the structural column element under test. Two other total flux gauges $\left(0.6 \mathrm{~cm}\right.$ diameter, rated at $\left.100 \mathrm{~kW} / \mathrm{m}^{2}\right)$ with the same orientation as the upper ones, were mounted on an L-shaped insulated steel support adjacent to the lower part of the column. Only the upper two of these four gauges were purged with nitrogen to prevent soot accumulation. The locations of these four gauges are shown in Figure 5-7 (designated as $\mathrm{HCoHW}, \mathrm{HCoHF}, \mathrm{HCoLW}$, and HcoLF. Table 5-1 lists the location and the orientation of the active surface of the heat flux gauges used in the experiment. 


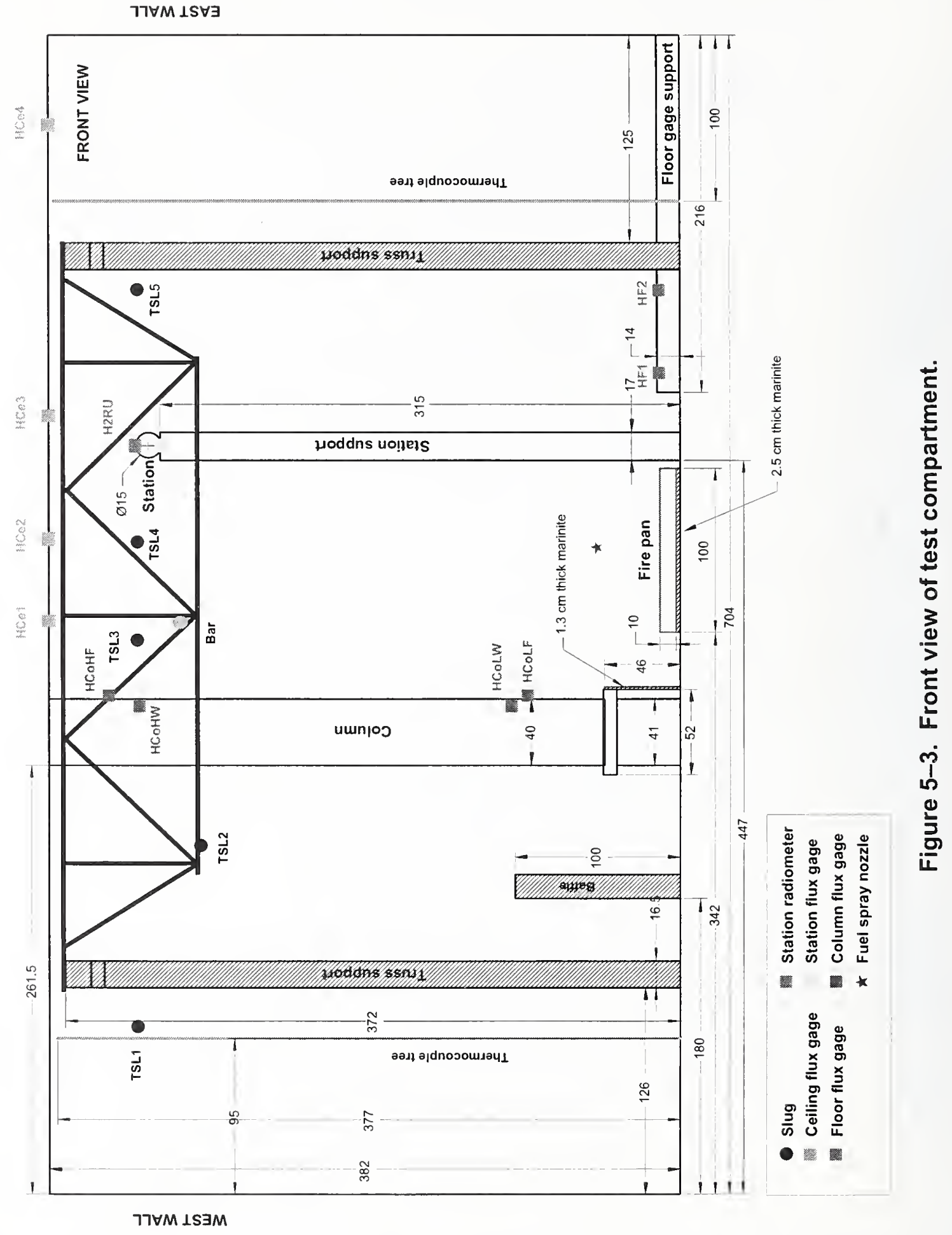




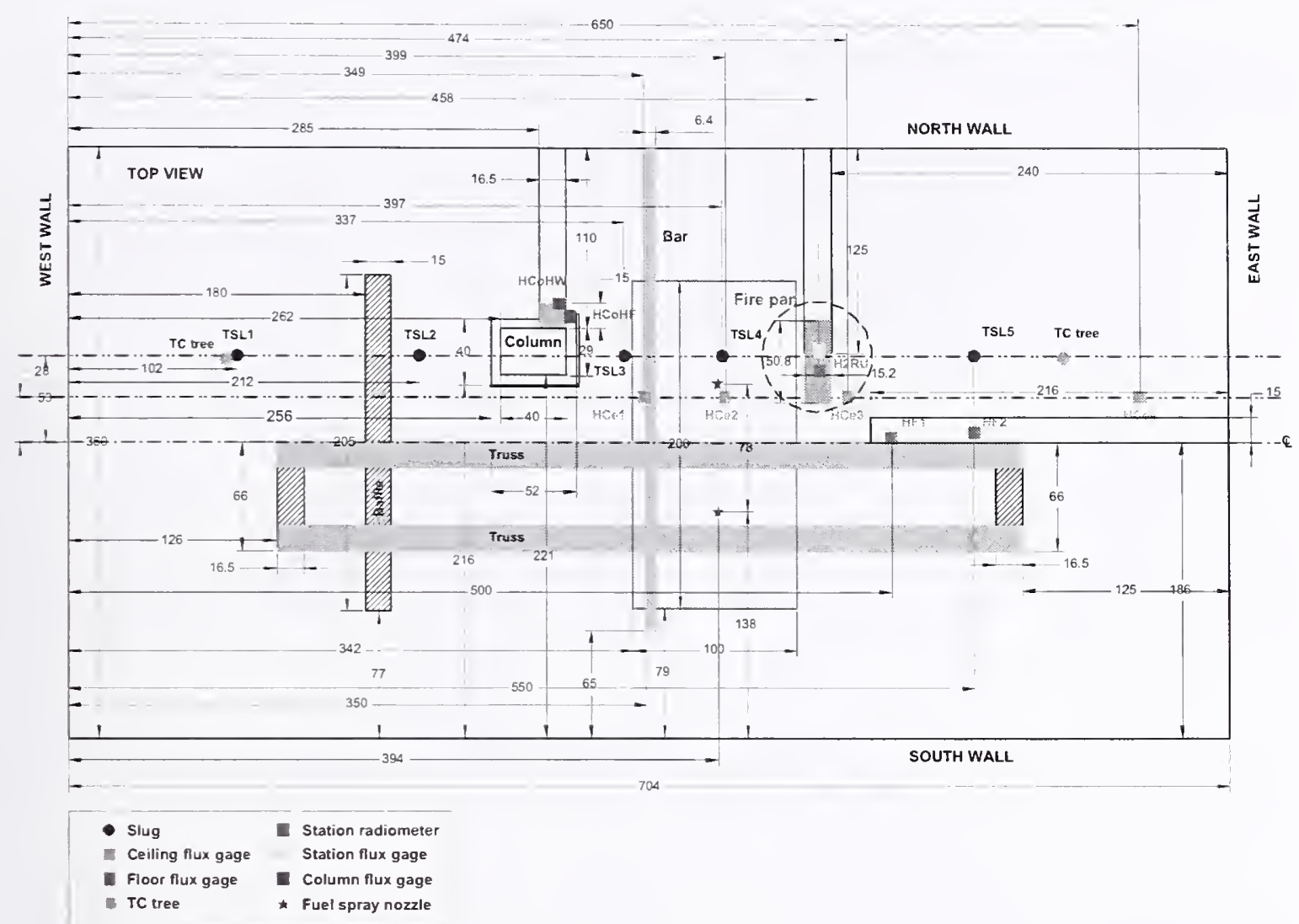

Note: All units in centimeters. An expanded view of circled area is given in Figure 5-5.

Figure 5-4. Top view of test compartment.

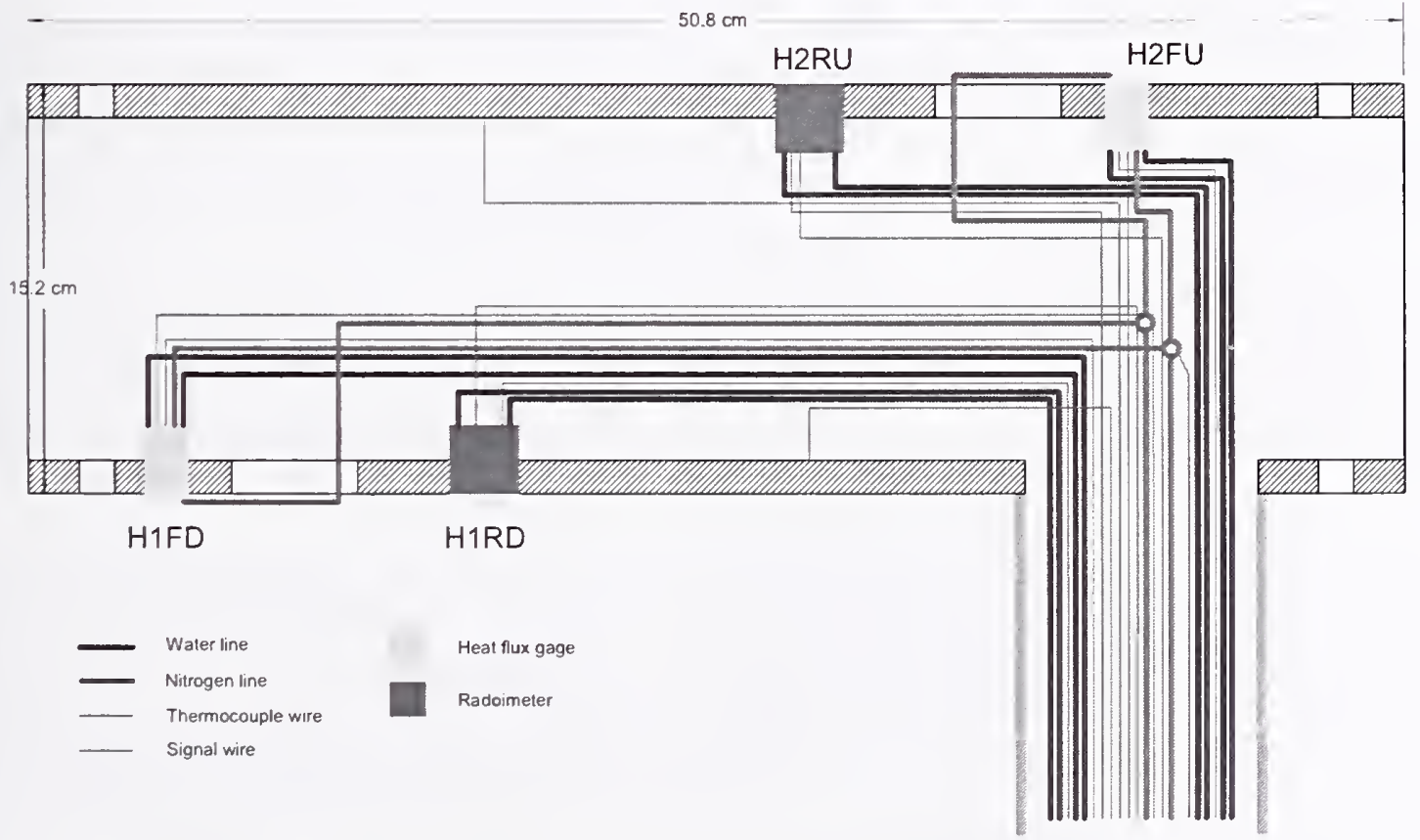

Figure 5-5. Expanded sisde view of circled area in Figure 5-4. 


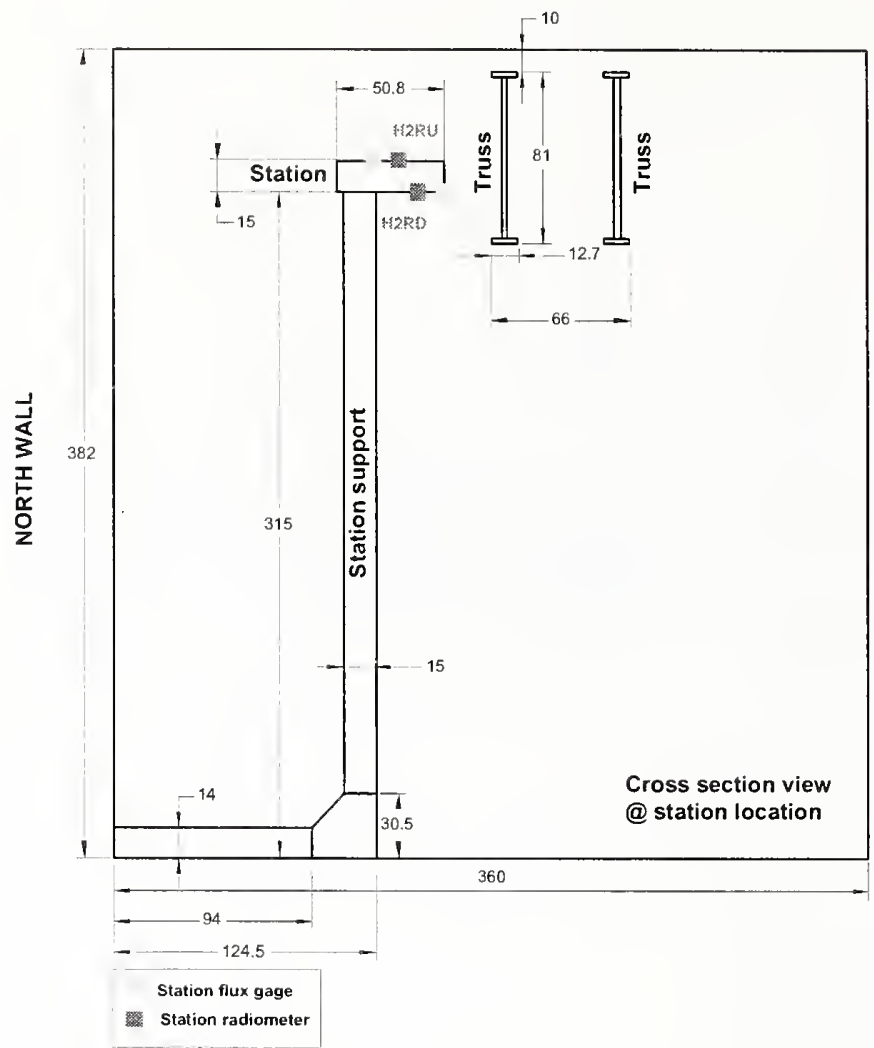

1
$\frac{1}{3}$
3
1
5
0
0

Figure 5-6. Locations of flux gauges and radiometers in the measurement station.

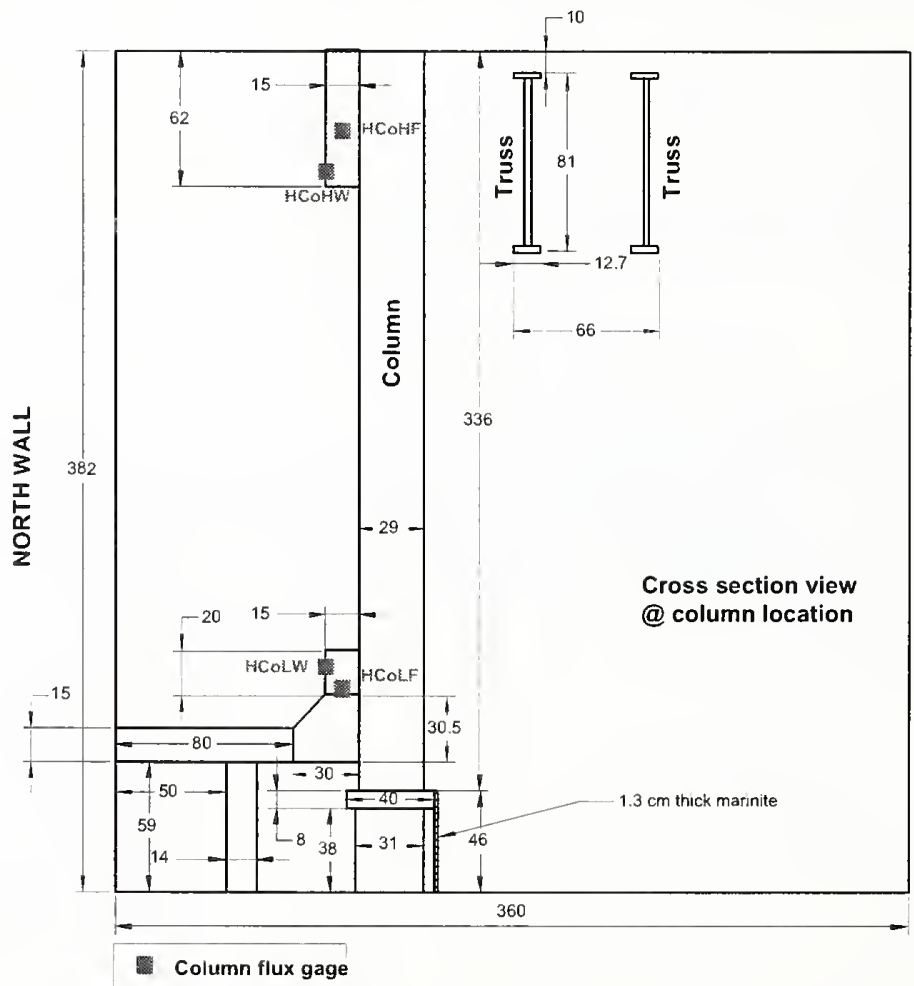

$\frac{1}{4}$
3
$\frac{1}{5}$
음

Figure 5-7. Schematic showing the locations of column heat flux gauges. 
Table 5-1. Heat flux gauge location.

\begin{tabular}{|c|c|l|l|l|}
\hline Designation & Channel & Type & \multicolumn{1}{|c|}{ Location } & Orientation \\
\hline HF1 & 346 & Total & Near Floor: $(500 \mathrm{~cm}, 6 \mathrm{~cm}, 13 \mathrm{~cm})$ & Upward \\
\hline HF2 & 347 & Total & Near Floor: $(550 \mathrm{~cm}, 3 \mathrm{~cm}, 13 \mathrm{~cm})$ & Upward \\
\hline HCoHW & 343 & Total & Column: $(297 \mathrm{~cm}, 85 \mathrm{~cm}, 327 \mathrm{~cm})$ & Northward \\
\hline HCoHF & 342 & Total & Column: $(304 \mathrm{~cm}, 77 \mathrm{~cm}, 346 \mathrm{~cm})$ & Eastward \\
\hline HCoLW & 345 & Total & Column: $(297 \mathrm{~cm}, 85 \mathrm{~cm}, 102 \mathrm{~cm})$ & Northward \\
\hline HCoLF & 344 & Total & Column: $(304 \mathrm{~cm}, 77 \mathrm{~cm}, 92 \mathrm{~cm})$ & Eastward \\
\hline H1FU & 338 & Total & Station: $(458 \mathrm{~cm}, 56 \mathrm{~cm}, 330 \mathrm{~cm})$ & Upward \\
\hline H1RU & 339 & Radiometer & Station: $(458 \mathrm{~cm}, 44 \mathrm{~cm}, 330 \mathrm{~cm})$ & Upward \\
\hline H2FD & 340 & Total & Station: $(458 \mathrm{~cm}, 23 \mathrm{~cm}, 315 \mathrm{~cm})$ & Downward \\
\hline H2RD & 341 & Radiometer & Station: $(458 \mathrm{~cm}, 35 \mathrm{~cm}, 315 \mathrm{~cm})$ & Downward \\
\hline HCe1 & 60 & Total & Ceiling $(349 \mathrm{~cm}, 28 \mathrm{~cm}, 382 \mathrm{~cm})$ & Downward \\
\hline HCe2 & 61 & Total & Ceiling $(399 \mathrm{~cm}, 28 \mathrm{~cm}, 382 \mathrm{~cm})$ & Downward \\
\hline HCe3 & 62 & Total & Ceiling $(474 \mathrm{~cm}, 28 \mathrm{~cm}, 382 \mathrm{~cm})$ & Downward \\
\hline HCe4 & 63 & Total & Ceiling $(650 \mathrm{~cm}, 28 \mathrm{~cm}, 382 \mathrm{~cm})$ & Downward \\
\hline TSL1 & $299-302$ & Slug & Upper Layer: $(102 \mathrm{~cm}, 53 \mathrm{~cm}, 329 \mathrm{~cm})$ & Not directional \\
\hline TSL2 & $303-306$ & Slug & Upper Layer: $(212 \mathrm{~cm}, 53 \mathrm{~cm}, 291 \mathrm{~cm})$ & Not directional \\
\hline TSL3 & $307-310$ & Slug & Upper Layer: $(337 \mathrm{~cm}, 53 \mathrm{~cm}, 329 \mathrm{~cm})$ & Not directional \\
\hline TSL4 & $311-314$ & Slug & Upper Layer: $(397 \mathrm{~cm}, 53 \mathrm{~cm}, 329 \mathrm{~cm})$ & Not directional \\
\hline TSL5 & $315-318$ & Slug & Upper Layer: $(550 \mathrm{~cm}, 53 \mathrm{~cm}, 329 \mathrm{~cm})$ & Not directional \\
\hline
\end{tabular}

a. Also listed in Appendix C.

Four flux gauges ( $1.6 \mathrm{~cm}$ diameter; total flux; rated at $150 \mathrm{~kW} / \mathrm{m}^{2}$ ) were mounted flush with the ceiling surface near the compartment centerline. They were positioned at locations in the east half of the compartment, beginning approximately above the upstream edge of the fire pan and continuing toward the east wall (see HCel through HCe4 in Fig. 5-4). These gauges were mounted within stainless steel block holders that also provided soot purge nozzles.

The positions of the slug calorimeters in the test compartment, designated as TSL1, TSL2, TSL3, TSL4, and TSL5 are shown in Figs. 5-3 and 5-4. They were arrayed in a line $53 \mathrm{~cm}$ to the north of the compartment centerline but covering much of the east-west length of the compartment. Note that four of the slugs were at the mid-height of the trusses and one, denoted TSL2, was at the height of the lowest element of the trusses.

All of the flux measuring devices have diverse objects in their fields of view. The actual field of view depends, of course, on the radiation path length in the fire atmosphere and that, in turn, depends on the soot concentration, mainly in the hot upper layer (which varied with fuel type). The FDS model attempts to take all of this "clutter" into account in characterizing the radiation field, though it cannot do so with sufficient spatial resolution to precisely describe the shapes of some of the smaller objects. 


\subsubsection{Coolant System for Heat Flux Gauges}

Figure 5-8 shows a schematic of the closed flow system used to circulate hot water through the gauges and radiometers. Three of these systems were used to serve all of the heat flux gauges. The water was heated inside a $114 \mathrm{~L}$ electric water heater tank. The tank contained two $4.5 \mathrm{~kW}$ heating components controlled by thermostats to heat the water to an operating temperature between $70{ }^{\circ} \mathrm{C}$ and $80{ }^{\circ} \mathrm{C}$. The tank had a maximum operating pressure of $1,031 \mathrm{kPa}$, which was also the pressure limit of the gauges and radiometers. Water was pumped from the tank using a self-priming, bronze gear pump coupled to a $373 \mathrm{~W}(1 / 2 \mathrm{hp})$ motor. The pump was rated for fluids at temperatures up to $99{ }^{\circ} \mathrm{C}$, and had an adjustable pressure relief valve set to approximately $687 \mathrm{kPa}$. The water was pumped through a $50 \mu \mathrm{m}$ polyester string wound filter to remove any contaminants that could clog the lines. The filter was contained in a stainless steel housing with a temperature rating of $135^{\circ} \mathrm{C}$ and a pressure rating of $1,718 \mathrm{kPa}$. An aluminum manifold distributed the main flow into five separate flows, which were regulated using five flow meters with a pressure rating of $1,718 \mathrm{kPa}$ and a temperature rating of $121{ }^{\circ} \mathrm{C}$. The flows were kept above $0.9 \mathrm{~L} / \mathrm{min}$, the gauge manufacturer's recommended minimum flow. Copper lines were used to transport the heated water to individual flux gauges and radiometers and back to the tank where it was reheated to the operating temperature. The copper lines were insulated using foam plastic and fiberglass insulation to prevent heat loss from the lines to the surroundings.

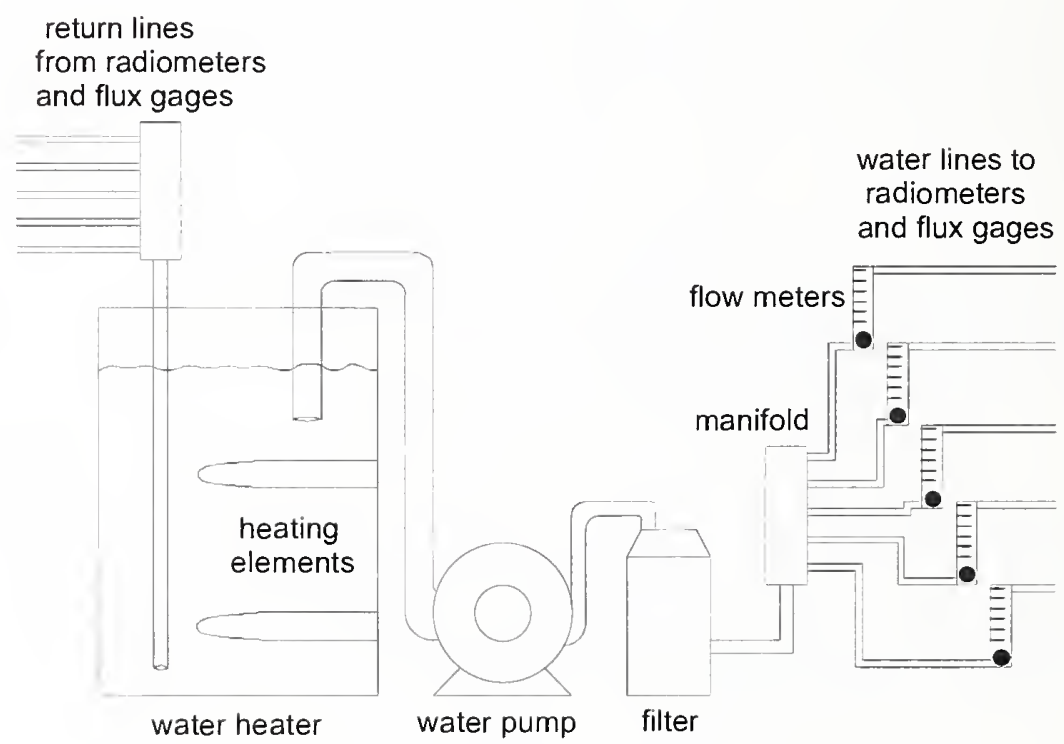

Figure 5-8. Cooling water system for radiometers and flux gauges. 


\subsection{DATA REDUCTION FOR THE SLUG CALORIMETERS}

As discussed above, the output data from the slug calorimeters consisted of four individual measures of the temperature within each slug, in all cases on the mass mean radius. ${ }^{5}$ For simplicity and tractability, the data analysis discussed below assumes that the temperature within a slug is uniform, and thus, the analysis uses the average of these measurements. As was noted above, there is necessarily a radial temperature gradient within a cylinder subjected to a constant (and spatially uniform) heat flux on its surface but that can be factored out, to a first approximation, by focusing on the temperature at the mass mean radius within the cylinder. In general, there can be asymmetrical gradients, as well, due to the nonuniform heat flux field impinging on the cylinder surface. Higher thermal conductivity minimizes all internal temperature differences; thus, nickel, which can withstand exposure to high temperatures, was chosen as the slug material. Its thermal conductivity is about one fourth that of copper. Temperature differences among the four readings did always exist since the flux on the slug surface was not spatially uniform. In general, the differences increased with increases in the average flux to the calorimeter surface, but they were always less than $5{ }^{\circ} \mathrm{C}$. The implications of these differences are discussed below in the section on measurement uncertainties.

Given the assumption of a uniform temperature within a cylindrical slug subjected to a spatially uniform heat flux on its cylindrical surface (adiabatic end surfaces), a heat balance leads to the following:

$$
\rho_{c} V_{c} C_{c}(T) \frac{d T}{d t}=q_{t o t} A_{c}-A_{c} \varepsilon_{c} \sigma T^{4}
$$

where $\rho_{c}$ is the density of the cylinder material, $V_{c}$ is the cylinder volume, $C_{c}(T)$ is the temperature dependent specific heat of the cylinder material, $\mathrm{T}$ is the temperature, $\mathrm{q}_{\mathrm{tot}}$ is the total heat flux (radiation plus convection) absorbed by unit area of the cylinder surface, $\mathrm{A}_{\mathrm{c}}$ is the area of the cylinder (exclusive of the ends), $\varepsilon_{c}$ is the emissivity of the cylinder surface and $\sigma$ is the Stefan-Boltzmann radiation constant.

The temperature dependent heat capacity of nickel 200 is describable by a polynomial, and all the other parameters in the above equation are known. The equation can be solved for the item of interest, $\mathrm{q}_{\text {tot }}$ :

$$
q_{t o t}=\left(\rho_{c} D_{c} / 4\right) C_{c}(T) \frac{d T}{d t}+\varepsilon_{c} \sigma T^{4}
$$

Here $\left(D_{c} / 4\right)$, where $D_{c}$ is the cylinder diameter, has been substituted for $\left(V_{c} / A_{c}\right)$. This is the form used in the data reduction. Since the average temperature (as a function of time) is used, the $\mathrm{q}_{\text {tot }}$ inferred is the average heat flux over the cylinder surface.

5 In a few cases, one of the thermocouples in a slug failed to give useable data due to poor contact in the ceramic connectors on top of the compartment. The analyzed information was then based on the average of the remaining three thermocouples in that slug. 
The actual application of this equation to a data file was done with SigmaPlot software, using its transform capability. Thus, at each time step the four temperatures from within the slug were first averaged, then the average temperature history was fitted with a running cubic spline transform which also calculated the time-derivative of this spline fit. The derivative had high frequency noise, which was removed with a low pass filter transform with the bandpass set so that it just began to visibly affect the starting transient at the beginning of a test. ${ }^{6}$ The heat capacity term was then calculated and all terms were combined in accord with the above equation to yield $\mathrm{q}_{\text {tot }}$ at a given time.

Nickel is a magnetic material with a Curie point of $358^{\circ} \mathrm{C}$ at which it becomes non-magnetic (Toulakian and Buyco 1970). This is an order-disorder transition that causes an abrupt step downward in the heat capacity. In principle, the data reduction process above can handle this transition. Its ability to do so was tested successfully using temperature data generated from a numerical solution of Eq. 5-1; the data reduction procedure recovered the imposed incident heat flux history right through the Curie point and beyond to within \pm 1 percent except within a few degrees of the Curie point. Localized noise in the computed flux near the Curie point occurred upon processing the data, but this disappeared above the Curie point.

\subsection{UNCERTAINTIES IN THE HEAT FLUX MEASUREMENTS}

For the total heat flux gauges, the output voltage was measured with the data acquisition system and converted via a calibration to a heat flux reading. In the absence of soot accumulation effects (due to the use of a nitrogen purge to remove soot), ${ }^{7}$ the sources of uncertainty are in the voltage reading process and in the calibration. The latter, in turn, has contributions from uncertainties in the calibration process itself and in the applicability of the calibration done at $75^{\circ} \mathrm{C}$ to a gauge temperature that is somewhat different from this value. The uncertainty due to the coolant water temperature variation (estimated as lcss than \pm $0.5 \mathrm{~kW} / \mathrm{m}^{2}$, indepcndent of incident heat flux, for the worst case) easily dominates over that due to voltage measurement uncertainty. However, the dominant uncertainty with this type of gauge is in the calibration process itself. A recent round robin test (Pitts 2003) of one such gauge at five fire facilities internationally (using a variety of calibration methods) indicated a standard deviation of about \pm 3 percent, or $\pm 3 \mathrm{~kW} / \mathrm{m}^{2}$ at a flux of $100 \mathrm{~kW} / \mathrm{m}^{2}$.

This type of heat flux gauge is calibrated with a purely radiant source, and the round robin mentioned above used a variety of such sources. In the measurements reported here, a mix of convective and radiative heating is expected. At present, there is no widely used technique for calibrating this type of heat flux gauge with a purely convective heat input so as to ascertain how differently it may respond to pure convection. The complexities attendant with convective heating imply a larger uncertainty. For all of the measurements, the dominant portion of the total flux to the gauges is radiation. However, in mixed radiation plus convection situations, the expanded uncertainty in the total heat flux is expected to be higher than for pure radiation; it is estimated to be at least \pm 10 percent (with an expansion factor of two).

6 Carslaw and Jaeger (1959) show that the time response for a nickel slug of this size to reach a steady state rate of increase to a constant surface flux is $20 \mathrm{~s}$ to $30 \mathrm{~s}$. Thus, any variations appreciably faster than this are not of interest and are filtered out.

7 The nitrogen soot purge greatly altered the flux gauge reading while it was on, but the gauge recovered from this in less than I s. The purge also briefly disrupted temperature readings in its neighborhood, but the total volume of purge gas emitted per purge cycle from all the purge tubes was less than 0.3 percent of the gas volume of the upper layer. 
The soot purge nozzle on each of the total flux gauges in the upper layer blocks a portion of its field of view by superimposing an end-on view of a piece of tubing. The fraction of the field of view that is blocked (altered) by this is quite small, however, estimated at 0.6 percent.

The radiometer measurements have two other sources of uncertainty: a less than hemispherical field of view and a purge gas whose temperature could not be kept fully under control since the lead tubing was heated by the fire impinging on the flux measurement station. Both of these were systematic, rather than random, sources of error. As was noted previously, the radiometers had a 160 degree, not a 180 degree, field of view, presumably due to limitations in machining the ellipsoidal cavity. This translates to about 97 percent of the available radiation (assuming a uniform radiation field). Countering this was a convective input to the sensor due to an increasingly hot nitrogen purge caused mainly by the heating of the flux station shell containing the gauges. Ideally, the nitrogen purge would have stayed at the same temperature as the sensor itself (approximately $75^{\circ} \mathrm{C}$ ) so that it would have transferred no heat to it. However. in Test 5 . where the flux station shell became very hot, the nitrogen purge reached about $250{ }^{\circ} \mathrm{C}$ to $300{ }^{\circ} \mathrm{C}$ by the time the gauge signal leads shorted (approximately $2,000 \mathrm{~s}$ into the test). The heat transfer coefficient between the purge gas and the sensor within the ellipsoidal cavity was estimated to be that for flow over a sphere of the same radius as the cavity. With this, the convective input to the radiometer sensor was estimated as less than $4 \mathrm{~kW} / \mathrm{m}^{2}$ for Test 5 . The two radiometers gave no useful data in Test 6 . This convective effect was minimal $\left(\leq 0.2 \mathrm{~kW} / \mathrm{m}^{2}\right)$ in the first four tests that were much shorter in duration.

The radiometers could not be calibrated at NIST, so the manufacturer's calibration was used. In the roundrobin study of a single total flux gauge mentioned above, the manufacturer's calibration fell well within the range of variation of the other lab-to-lab variations. It is probable that the same calibration expanded uncertainty $( \pm 6$ percent $)$ applies here as well.

The total heat flux levels derived from the temperature measurements in the slug calorimeters used other implicitly or explicitly measured quantities: slug diameter, slug density and slug heat capacity as a function of temperature. A formal analysis (Holman 1970) of the propagation of uncertainties from each of these sources shows temperature uncertainty to contribute 90 percent of the total, while heat capacity contributes most of the remainder. This is for a case where the standard deviation among the four thermocouple measurements was $\pm 4.5^{\circ} \mathrm{C}$, among the largest seen. In the first three tests, the temperature variation was less than half of this value. The corresponding flux uncertainty for the $4.5^{\circ} \mathrm{C}$ standard deviation was $\pm 6 \mathrm{~kW} / \mathrm{m}^{2}$ at a time when the calculated total flux was above $80 \mathrm{~kW} / \mathrm{m}^{2}$.

There is a systematic error in the slug calorimeter analysis due to the implicit assumption that the surface temperature of the slug equals the average temperature of the slug. The calculated re-radiation term (last term in Eq. 5-2) is thus less than in reality, since the surface must be hotter than the average bulk temperature. If the average surface temperature was in reality $25^{\circ} \mathrm{C}$ above the average slug temperature (a value suggested by ANSYS software solutions for the transient heat conduction problem) when the latter is at $350{ }^{\circ} \mathrm{C}$, then the radiation term was underestimated by $1.5 \mathrm{~kW} / \mathrm{m}^{2}$, and the total flux to the slug was also underestimated by this amount. This error was appreciably less in the first three tests in which the average slug temperature by the end of the test was much less. Another systematic error is the neglect of heat transfer through the ends of the cylinder (conduction through the insulation and through the support bolts). These two leakage paths (inward) are estimated to be comparable in size and to result in an overestimate by about 4 percent when the calculated average heat flux is $25 \mathrm{~kW} / \mathrm{m}^{2}$. This source of error helped to counter the error induced by underestimating the cylinder surface temperature. Overall, 
the slug data have an expanded uncertainty for the $3 \mathrm{MW}$ tests (Tests 4, 5, and 6) estimated to be approximately 16 percent to 20 percent; the uncertainty for the 2 MW Tests ( 1 through 3 ) is approximately half this value.

The uncertainty estimates for the three types of heat flux measuring devices are summarized in Table 5-2.

Table 5-2. Estimated certainties in heat flux measurements.

\begin{tabular}{|l|c|}
\hline \multicolumn{1}{|c|}{ Measurement Device } & Estimate of Expanded Uncertainty \\
\hline Total heat flux gauge & $\pm 10 \%$ \\
\hline Radiometer & $\pm 6 \%$ \\
\hline Slug calorimeter & $\pm 16 \%$ to $20 \%$ \\
\hline
\end{tabular}

\subsection{DISCUSSION OF HEAT FLUX MEASUREMENTS}

Initially, all wall and other solid object temperatures are cold (at room temperature) as is the gas in the room. The fire plume mixes in, fills and heats the space above the soffit level of the exhaust openings in a time on the order of the volume of this space divided by the plume volumetric flow ( $5 \mathrm{~s}$ to $10 \mathrm{~s}$ ). As the gas temperature there rises, the ceiling (and upper wall) surface temperatures in this volume follow fairly closely due to the insulating character of the Marinite lining. The subsequent rise in ceiling and wall temperatures occurs on a time scale on the order of $1,000 \mathrm{~s}$, representative of the thermal relaxation time of the $2.54 \mathrm{~cm}$ thick Marinite. Even though the ceiling temperatures in Test 5, for example, rose only about $100{ }^{\circ} \mathrm{C}$ in the last $2,000 \mathrm{~s}$ of the test, this results in nearly 50 percent increase in radiative flux from the Marinite ceiling. In this enclosure, all of the surfaces are coupled by these rising radiative fluxes though the rates of rise will not be equal. An additional complication is the optical thickness of the smoke layer. Different flux gauges see different surfaces and smoke volumes and have differing view factors with respect to the fire plume. They also have differing contributions from convective heating.

With this temperature history in mind, consider first a typical set of measurements from one test. For this we chose Test 5 , which was a 3 MW heptane fire with a 50 min duration.

The two floor gauges (total flux) in Fig. 5-9 have a relatively simple behavior to interpret since convective effects should be minimal (though not zero) in the cool lower gas layer. Time zero was the start of the fire; the rapid decay at about 3,050 s (here and in the other figures below) was due to the abrupt termination of the fire. As soon as the fire was ignited, these two gauges, with their wide views of the fire plume, jumped to substantial readings as a result of direct plume radiation. Subsequently, both climbed monotonically and substantially, leveling only after about $2,500 \mathrm{~s}$; the difference between the two gauge readings, due principally to their differing distances from the fire plume, grew only slightly. Both had appreciable fluctuation levels, reflecting the highly transient nature of the radiative processes from the turbulent fire plume. Nearly the entire subsequent climb in flux above the initial level was attributable to radiation, from the room surfaces and from the soot in the hot upper gas layer. Some fraction was due, however, to convection as the lower layer became warmer. 


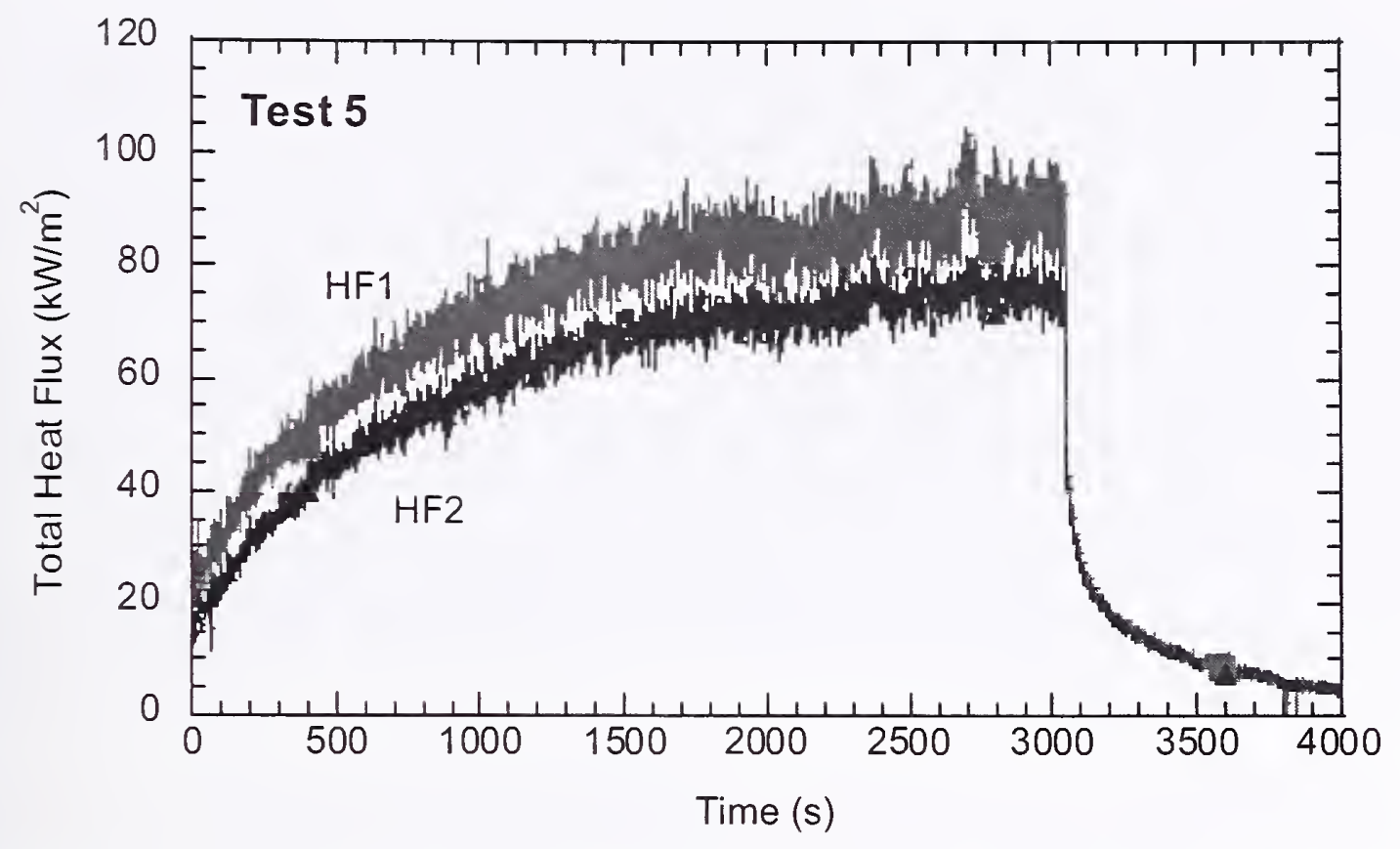

Figure 5-9. Total heat flux recorded by two flux gauges $15 \mathrm{~cm}$ above the floor, just downstream of the fire pan in Test 5.

The convective component is difficult to estimate accurately for all of the total flux gauges. All of these gauges respond to a combination of incident radiation and convection:

$$
q_{\text {tot }}=q_{\text {rad }}+h\left(T_{\text {gas }}-T_{\text {gauge }}\right)
$$

where $\mathrm{q}_{\text {tot }}$ is the total heat flux to which the flux gauge responds, $\mathrm{q}_{\mathrm{rad}}$ is the radiative component of the flux and the second term on the right in Eq. 5-3 is the convective flux seen by the gauge. Note that, as mentioned previously, it is dependent on the gauge surface temperature, $\mathrm{T}_{\text {gauge, }}$, which is typically lower than that of the surface in which the gauge is embedded. Thus the convective component of the gauge signal is somewhat exaggerated, but this effect is accounted for in the FDS model comparison (see Chapter 10). The difficultly in estimating the convective contribution, both here and in the FDS model, is the proper choice of the value of the heat transfer coefficient, $h$, since the flows are not simple. It is necessary to select a situation that resembles that in which the gauge is placed and for which a heat transfer correlation is available.

For the floor flux gauges above, one can estimatc ${ }^{8}$ the convective flux component of the total flux to these gauges using the local gas temperature and the assumption of buoyant convection locally as $\leq 2 \mathrm{~kW} / \mathrm{m}^{2}$. Here, the buoyant convection to the cooled gauge surface (Williams and Smith 1978) exceeds the estimated forced convection for turbulent flow over a flat plate (Roshenow and Choi 1961). Since these estimates are based on the gas temperatures achieved after an extended test period (approximately $300^{\circ} \mathrm{C}$ ), the estimates for the shorter experiments (Tests 1 through 4 ) will be less.

8 Convective fluxes are estimated here and below from one or more of the heat transfer correlations that appear to most closely fit the specific configuration under consideration. Any velocity estimates that go into these calculations are in the range suggested by the FDS calculations. Gas temperatures come from the nearest aspirated thermocouple. 
Figure 5-10 shows the total heat fluxes seen by the four gauges set flush into the ceiling in Test 5 . The strong spikes (in this case every $120 \mathrm{~s}$ ) were due to the soot purge flow blowing across the gauge faces. The fluctuations in the data were again due to the turbulence in the fire plume whose eddies had an influence even at a substantial distance from the plume. ${ }^{9}$ The fluctuations were greatest for heat flux gauge $\mathrm{HCe} 3$, which was just downstream of the fire pan and most sensitive to plume position variations. The ceiling heat fluxes started at moderately low levels (especially HCe4), but all immediately started climbing monotonically. Only by the end of the more than 3,000 s test did the flux seen by these gauges appear to be leveling off fully. The overall upward trend was again due to the heating of the upper layer and the compartment surfaces. Here, the convective heat transfer component to the "cold" flux gauges was secondary to radiation; it was estimated, on the assumption that the plume produces a stagnation point flow (Kays 1966) at some distance from these gauges to have been in the $5 \mathrm{~kW} / \mathrm{m}^{2}$ to $10 \mathrm{~kW} / \mathrm{m}^{2}$ range by the end of the test when the upper layer gases were at their hottest. The assumption of a turbulent flow over a flat plate (Roshenow and Choi 1961) gives comparable numbers. In the shorter tests (or early in the long tests), where the gas temperature was somewhat lower, Eq. 5-3 indicates that the convective component would be less.

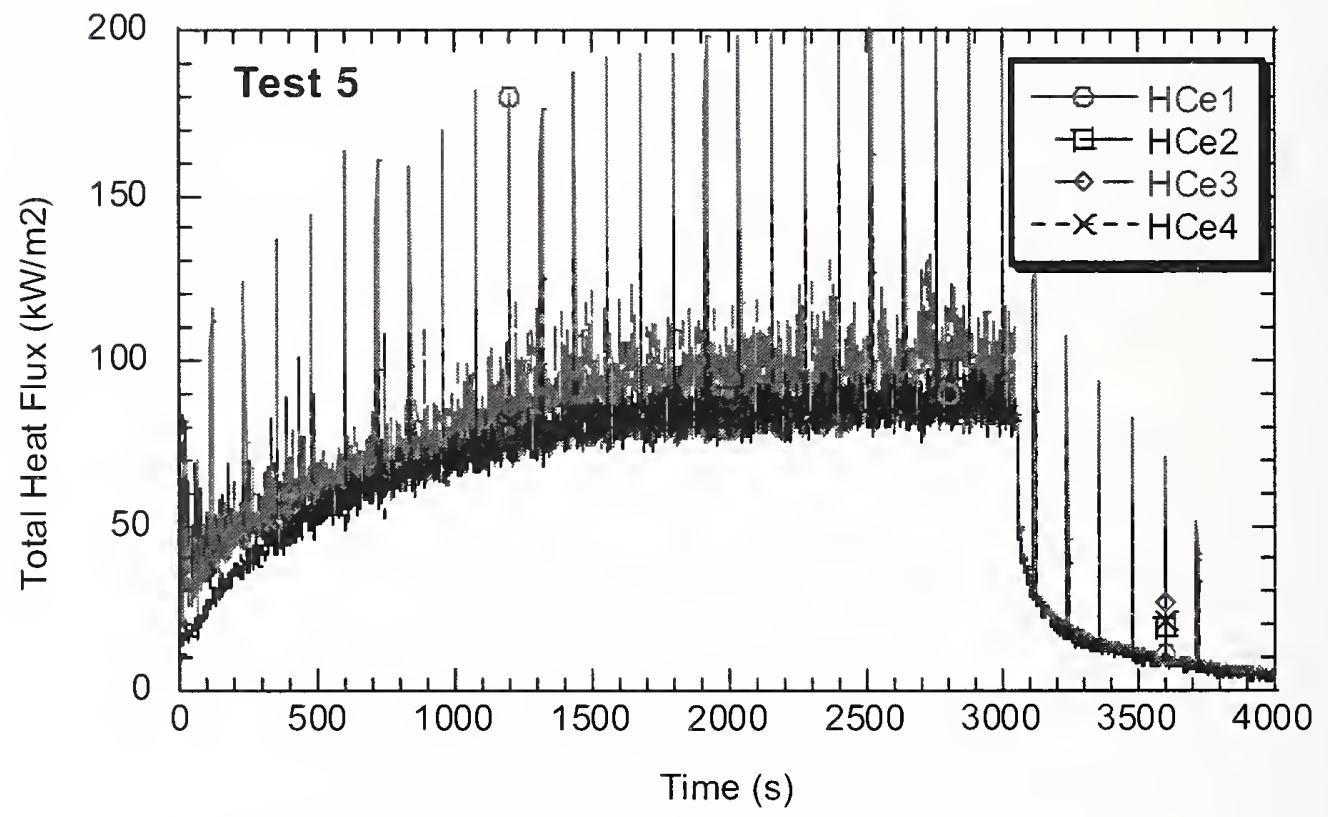

Figure 5-10. Total heat flux recorded by the four flux gauges in the compartment ceiling in Test 5 . The periodic spikes are due to the soot purge operation.

\footnotetext{
9 The eddies cause not only convective heat flux variations but also radiative flux variations.
} 
Figure 5-11 shows the total heat fluxes recorded by the four flux gauges in structures adjacent to the vertical column in Test 5 . The periodic spikes were due to the soot purge operation on the two higher gauges. As with the preceding results, the trend was monotonically upward with time, approaching an asymptotic value by the end of the test. The underlying cause of this behavior was the same progressive heating of the compartment surfaces. The two gauges facing the north compartment wall (HCoHW and $\mathrm{HCoLW}$ ) rather than the fire plume received the lowest fluxes, as one would expect. ${ }^{10}$ The higher of these two gauges had a good view of the wall (and, to some extent, the ceiling) in the upper laycr region where its surface would have radiated more strongly. In addition, this "cold" gauge received an estimated $10 \mathrm{~kW} / \mathrm{m}^{2}$ to $15 \mathrm{~kW} / \mathrm{m}^{2}$ as a convective input in the latter half of the test (assuming natural convection to a vertical plate as the dominant flow mode [Williams and Smith 1978]). A comparable convective input applies to the other high gauge (HCoHF); this, plus its enhanced radiative input, explains the fact that it had the highest total flux readings of the column gauges. The convective inputs to the lower column flux gauges are estimated, using the same assumptions, to have been in the $3 \mathrm{~kW} / \mathrm{m}^{2}$ to $5 \mathrm{~kW} / \mathrm{m}^{2}$ range. Again, these fluxes would have been lower earlier in this test or in the shorter tests since the gas temperature was lower.

The total heat flux inferred from the average temperatures (vs. time) in the five slug calorimeters are shown in Figs. 5-12 through 5-16. Only Figs. 5-12 and 5-13 show the full test duration. The others show just under $1,000 \mathrm{~s}$ of inferred flux results; this is close enough to the long term flux levels that one can discern the variations among the five slugs. This, in turn, indicatcs how the fluxes would vary along the length of the horizontal steel trusses in the compartment. Slugs 1 and 2 yielded nearly identical flux histories (slug 2 was 5 percent to 10 percent higher for the last 2,000 s of the test) and had the lowest flux values of all the slugs, though for somewhat differing reasons. Slug 1 was the farthest from the fire plume and had the smallest radiative view factor with respect to it. ${ }^{11}$ Slug 2 was closcr to the fire, thereby receiving more plume radiation, but it was also lower, being at the height of the bottom element of the trusses; it thus was in a lower temperature gas region and also would be expected to receive less soot radiation on its lower surface.

\footnotetext{
${ }^{10}$ The immediate readings on the order of $10 \mathrm{~kW} / \mathrm{m}^{2}$ do not see the fire plume directly, so they are responding to fire plume radiation reflected from the Marinite.

${ }^{11}$ The slugs receive heat (radiation plus convection) only on their cylindrical surfaces, and the axis of each cylinder was parallel to the trusses.
} 


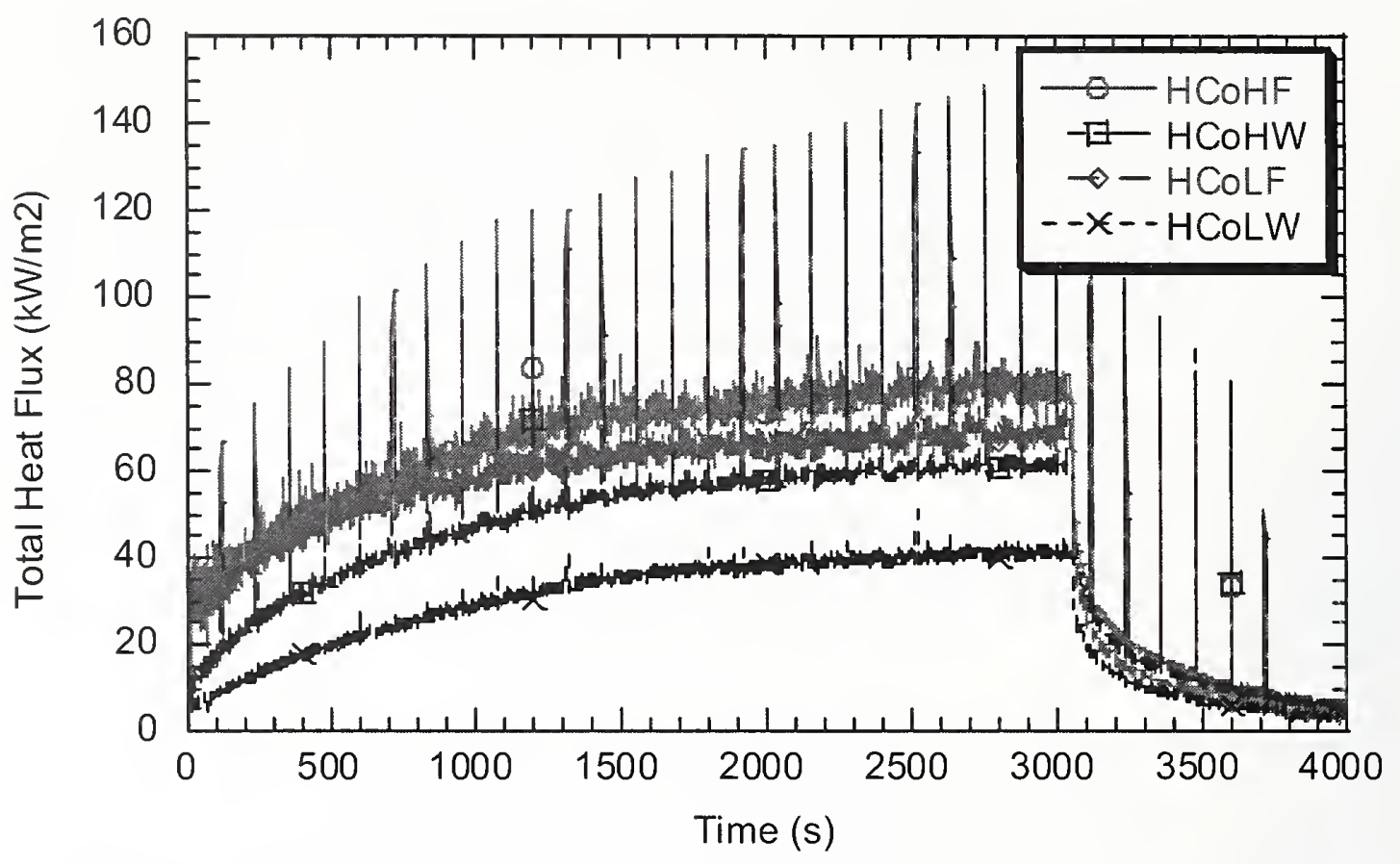

Figure 5-11. Total heat flux recorded by the four flux gauges in structures adjacent to the vertical column in Test 5 . The periodic spikes are due to the soot purge operation on the two higher gauges.

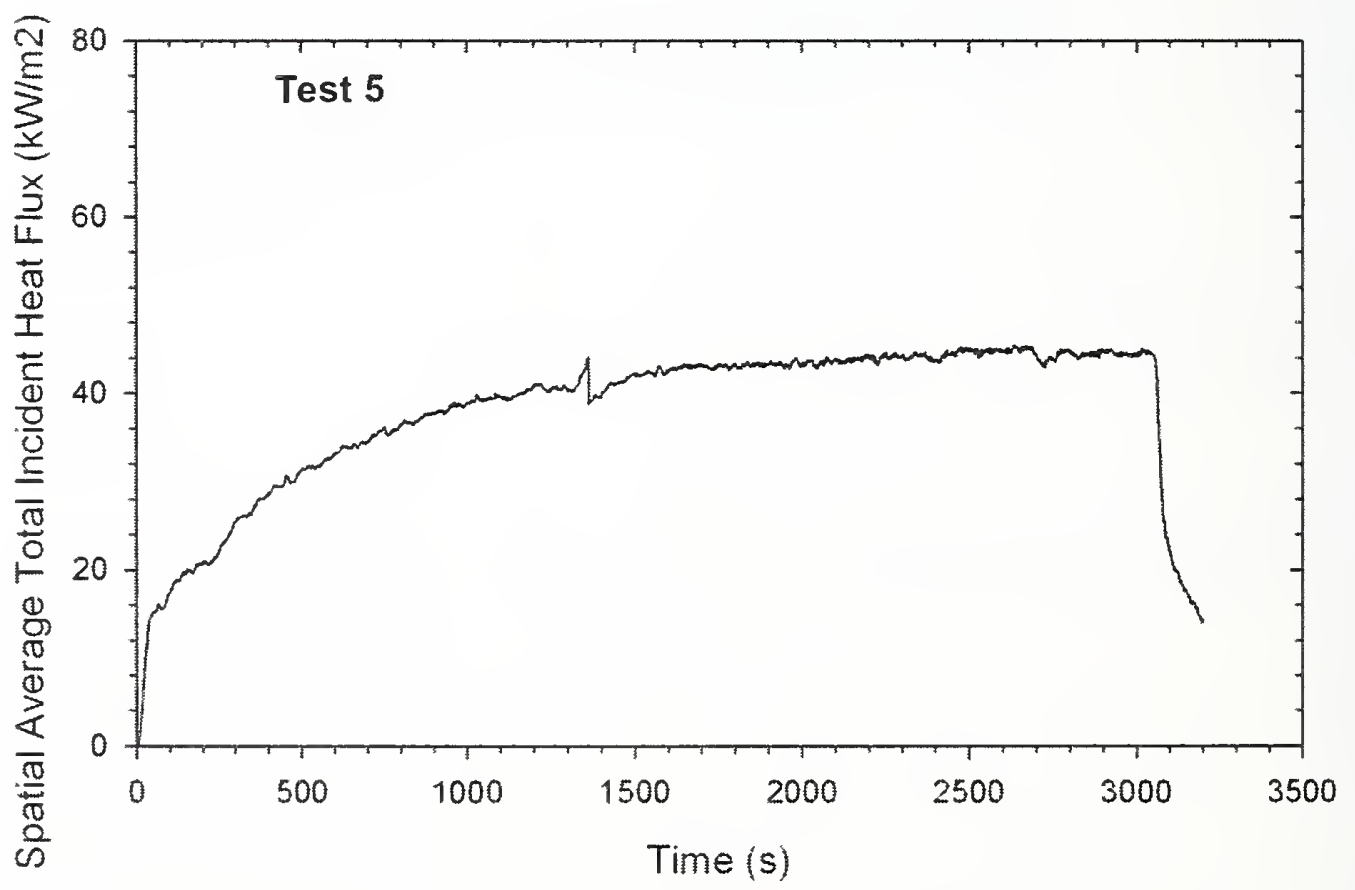

Figure 5-12. Average total heat flux to the cylindrical surface of the slug calorimeter 1 in Test 5 . 


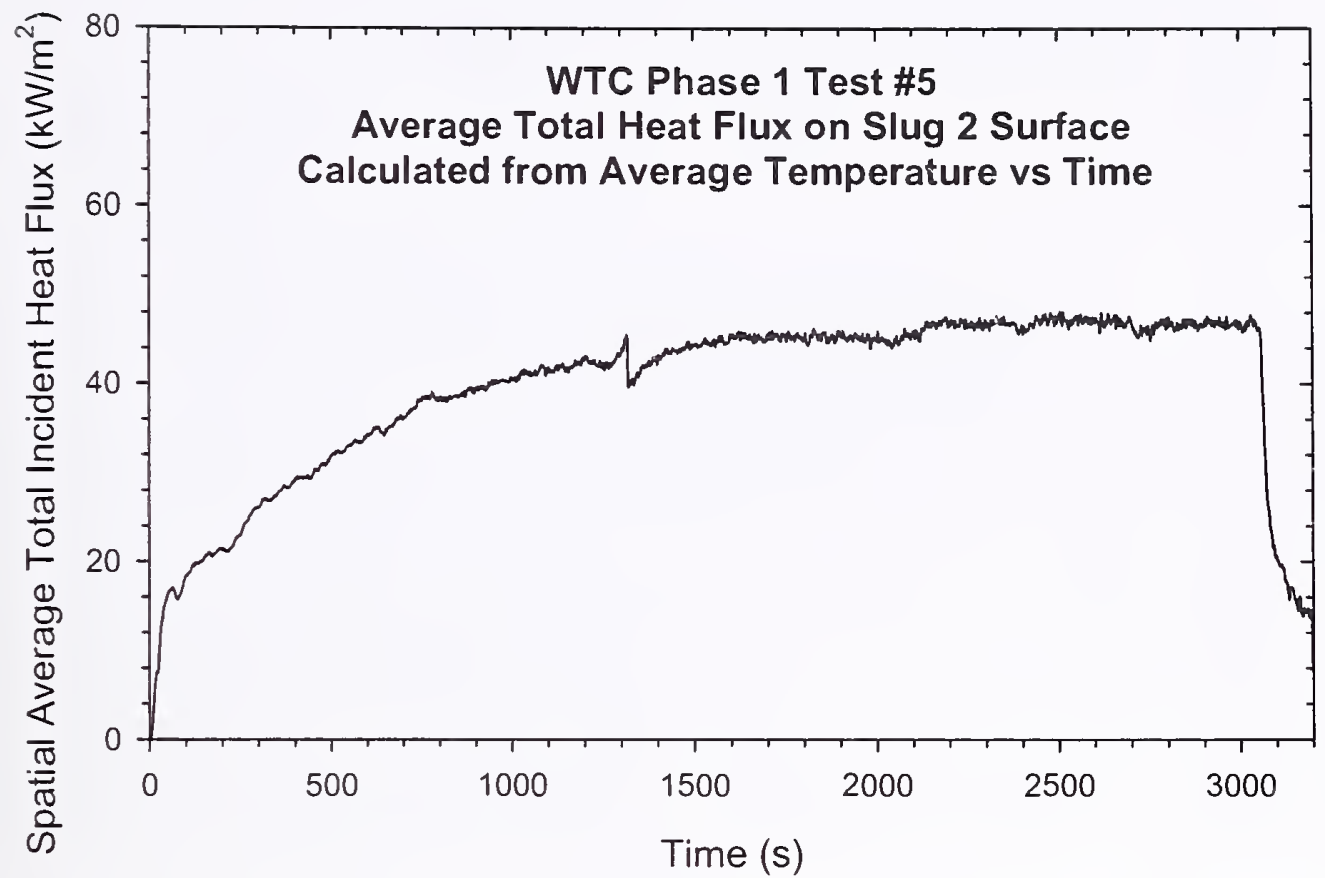

Figure 5-13. Average total heat flux to the cylindrical surface of slug calorimeter 2 in Test 5.

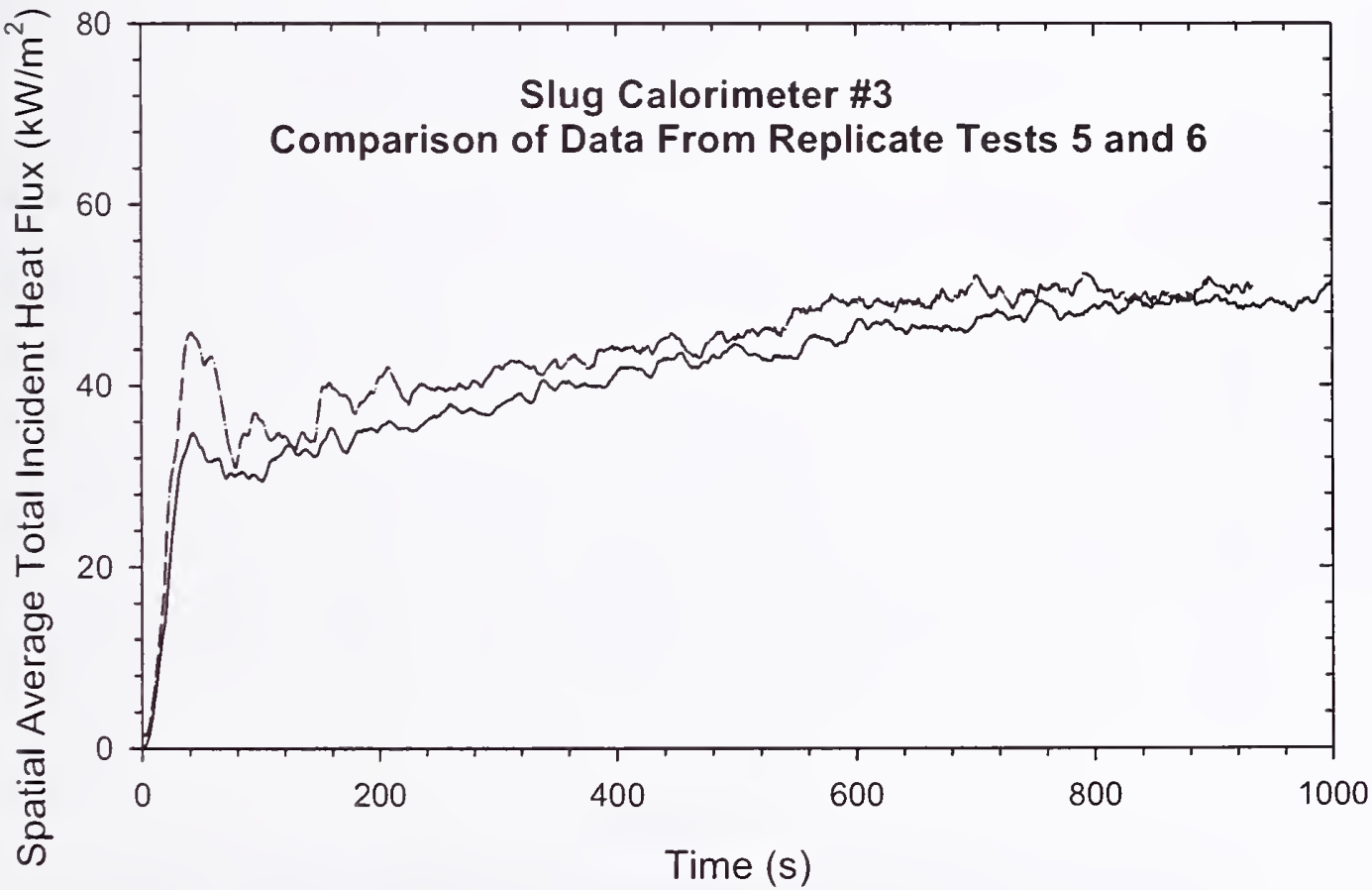

Figure 5-14. Comparison of the average total heat flux to the cylindrical surface of slug calorimeter 3 in Tests 5 and 6. 


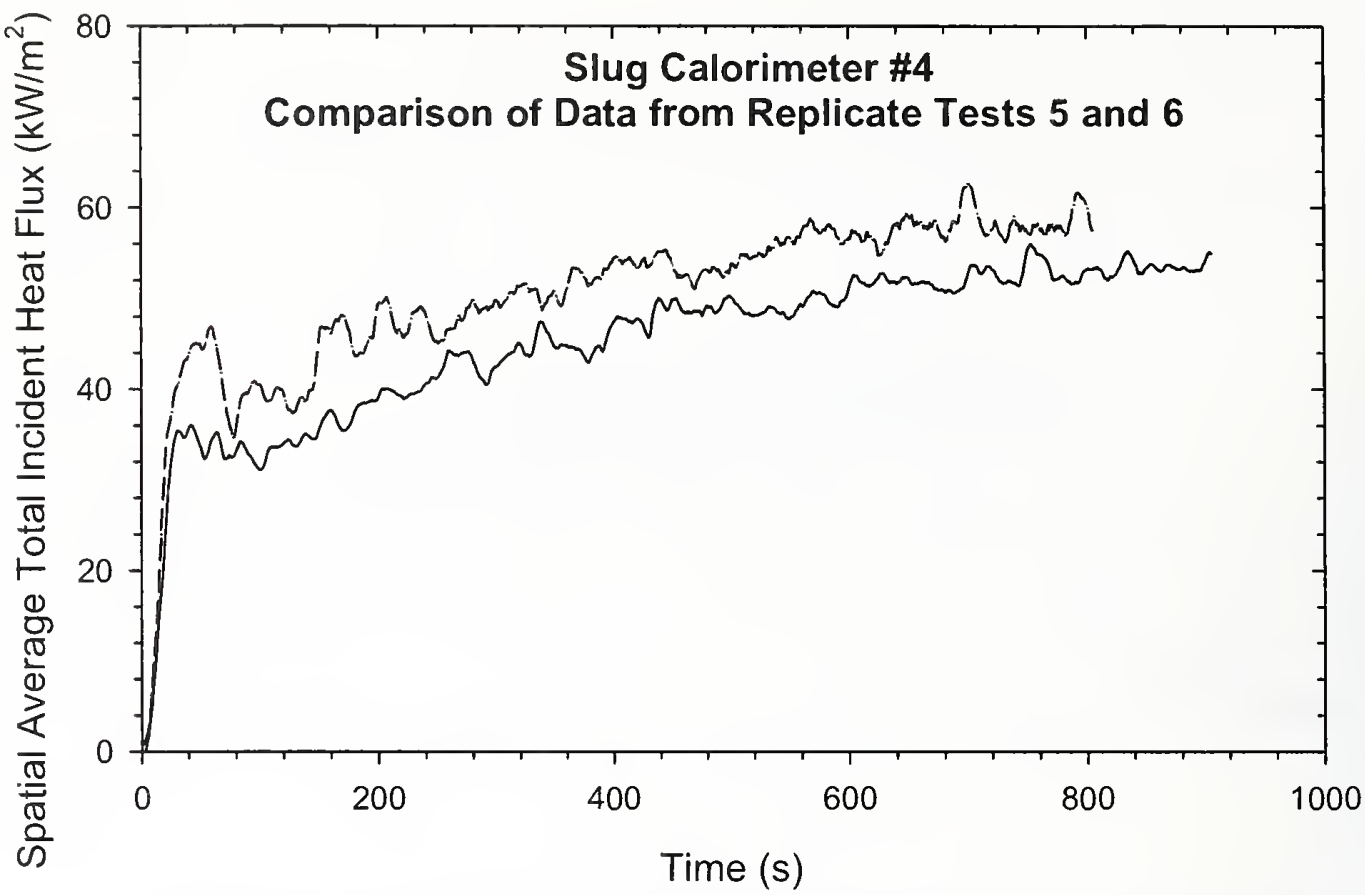

Figure 5-15. Comparison of the average total heat flux to the cylindrical surface of slug calorimeter 4 in Tests 5 and 6 .

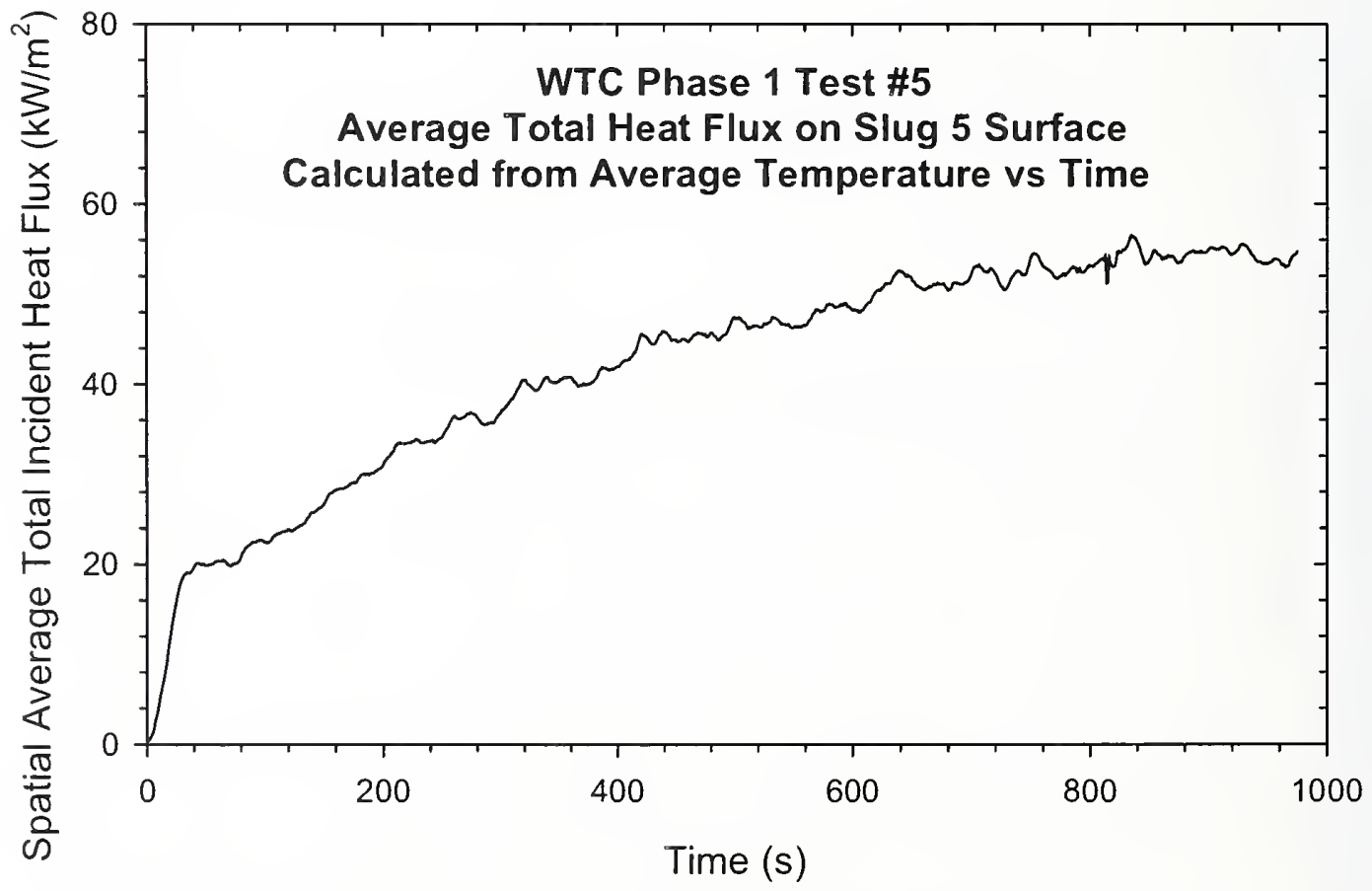

Figure 5-16. Comparison of the average total heat flux to the cylindrical surface of slug calorimeter 5 in Tests 5 and 6 . 
The early transient in the slug fluxes was due to their time response and, to a lesser extent, the filtering of the temperature gradient calculated during the data reduction. The residual noise in the data was partly a real heat flux variation and partly a result of heat conduction processes in the slugs interacting with the calculated average slug temperature. Figures 5-12 and 5-13 also show a weak spike at about 1,300 s that is due to the abrupt change in the heat capacity of nickel at its Curie point. The spike is a result of the data treatment and is not real.

Slugs 3 and 4 were both relatively close to the fire plume and, thus, received significantly (approximately 20 percent to 30 percent) higher heat fluxes than slugs 1 and 2 . The fire plume tended to bend toward the outlet side of the compartment, putting it somewhat closer to slug 4, which showed a slightly higher flux (e.g., at $800 \mathrm{~s}$, approximately $60 \mathrm{~kW} / \mathrm{m}^{2}$ vs. about $50 \mathrm{~kW} / \mathrm{m}^{2}$ for slug 3). The results from the slug calorimeter measurements were consistent with the measurement of total heat flux in the upper layer. In this sense, the slug data were useful in confirming the accuracy of the total heat flux gauge measurements. Inspection of Fig. 5-16 shows that slug 5 began with a low flux reading (comparable to slug 2 but lower than slug 3 ), then ended with a reading comparable to slug 4 . This suggests the increasing importance with time of radiation from the hot ceiling and walls, especially on the exit end of the compartment towards which the bulk of the hot gas flow was moving. The maximum contribution of convection to these total heat fluxes is estimated to have been in the $4 \mathrm{~kW} / \mathrm{m}^{2}$ to $6 \mathrm{~kW} / \mathrm{m}^{2}$ range (Williams and Smith 1978; Roshenow and Choi 1961).

Finally, consider the results from the flux measurement station, shown in Fig. 5-17. There were two pairs of flux gauges, each pair consisting of a radiometer and a total heat flux gauge, approximately side by side, one pair looking directly up at the ceiling, and the other pair looking directly downward to one side of the fire plume. Assuming that the components of each pair were exposed to the same radiative input, the difference in their readings is attributable to convective heating of the total flux gauge. The total flux looking downward was, as expected, the largest of the four readings, with an asymptotic value of about $90 \mathrm{~kW} / \mathrm{m}^{2}$. The downward-looking radiometer failed at about $1,700 \mathrm{~s}$. Prior to failure, the flux was approximately $30 \mathrm{~kW} / \mathrm{m}^{2}$ below the total flux reading in the same direction. This implies a convective component of $30 \mathrm{~kW} / \mathrm{m}^{2}$. which is difficult to rationalize. Using an available correlation for turbulent convection to a cylinder (Eckert and Drake 1972), taking into account the difference in local heat transfer between the upstream and downstream convection coefficients, one can calculate an expected convective flux of $8 \mathrm{~kW} / \mathrm{m}^{2}$ to $12 \mathrm{~kW} / \mathrm{m}^{2}$. The real flow is, of course, more complex than is assumed by the available correlation but it is difficult to see how the convection was evidently so enhanced. The problem is quite comparable for the other pair of flux gauges (facing the ceiling). One can calculate an expected convective contribution of $4 \mathrm{~kW} / \mathrm{m}^{2}$ to $6 \mathrm{~kW} / \mathrm{m}^{2}$, but the data indicate a convective contribution of about $20 \mathrm{~kW} / \mathrm{m}^{2}$. There are no checks on this issue elsewhere in the enclosure; it is possible that the convective fluxes elsewhere are also greater than the calculated values reported above. On the other hand, it is also possible that the radiometers do not read this complex radiation field accurately. 


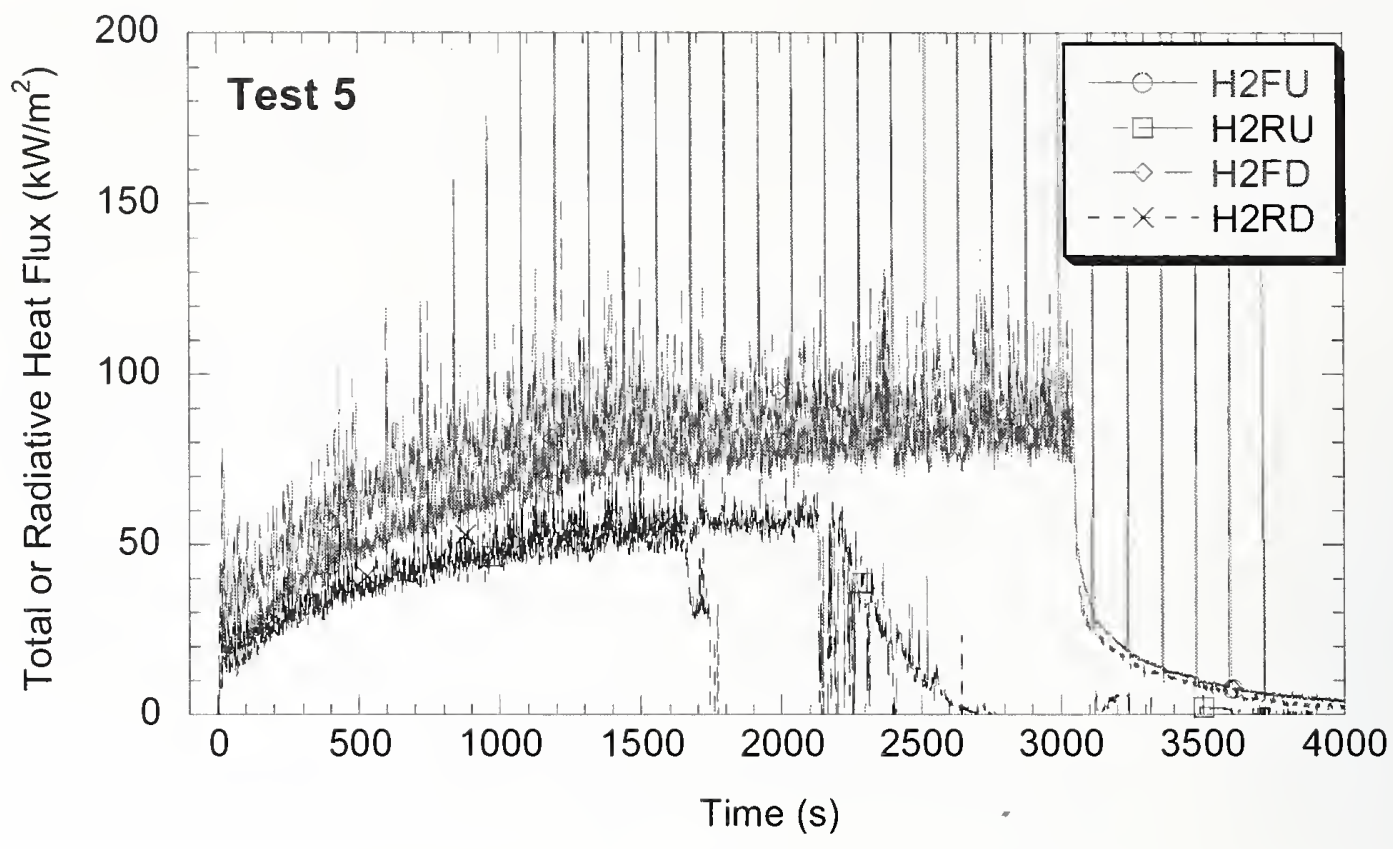

Figure 5-17. Heat fluxes recorded by the radiometers and total flux gauges in the flux measurement station during Test 5 . The periodic spikes are due to the soot purge operation.

\subsubsection{Repeatability}

Repeatability was examined in Tests 5 and 6, which both used $3 \mathrm{MW}$ heptane fires within nominally identical compartment set-ups. In general, the heat flux measurements tracked very close to each other (differences approximately 5 percent or less) with the greatest departure being at slugs 3 and 4; see Figs. 5-14 and 5-15. The source of these larger differences is not clear, but may have been related to average plume position.

It was intended that the average plume impingement position on the ceiling would be determined by an array of thermocouples on the ceiling surface. These formed a cross, centered above the downstream edge of the fire pan. The data proved to be insufficient to pin down the plume position in a definite manner. In Test 5 , the mean impingement position was approximately $0.5 \mathrm{~m}$ downstream (toward flow exit) of the downstream edge of the fire pan and more than $0.5 \mathrm{~m}$ south of the compartment centerline. In Test 6 , the mean impingement was $0.5 \mathrm{~m}$ to $1.0 \mathrm{~m}$ downstream of the downstream edge of the fire pan and approximately $0.5 \mathrm{~m}$ south of the compartment centerline. Thus, the plume did move appreciably in the replicate tests, possibly because of differing thermal warp patterns in the fire pan itself.

\subsubsection{Effect of Fire Size}

All of the above results were for a $3 \mathrm{MW}$ heptane fire. In Test 1, the fire size for the same fuel was $2 \mathrm{MW}$. The effect of this 50 percent fire size reduction was considerable. At an equivalent time (approximately $800 \mathrm{~s}$, since Test 1 was much shorter than Test 5), upper gas layer and ceiling 
temperatures were $200{ }^{\circ} \mathrm{C}$ to $300{ }^{\circ} \mathrm{C}$ less with the smaller fire (e.g., $500{ }^{\circ} \mathrm{C}$ vs. $700{ }^{\circ} \mathrm{C}$ ). ${ }^{12}$ This, in turn, strongly decreased the total heat fluxes seen by the various measuring devices. For example, Fig. 5-18 shows the ceiling heat fluxes for gauge HCe2 (directly over the fire pan) for Tests 1 (2 MW) and 5 ( $3 \mathrm{MW}$ ). The $2 \mathrm{MW}$ fire yielded a ceiling flux of less than half than that of the $3 \mathrm{MW}$ fire. Similarly, Fig. 5-19 shows a comparison of the results from slug 1 for the two fire sizes. Slug 1 was well away from the fire in the upstream end of the compartment; as explained above, it responded mainly to the gas and solid surface temperatures around it. All of the other flux measuring devices showed comparable changes in their results (including those in the lower layer). The temperature difference easily explains the greater than a factor of two heat flux differences in a situation like this where radiation dominated the total heat fluxes. Even the relatively small difference in fire size between Tests 2 and 3 (2.4 MW vs. $2 \mathrm{MW}$ ) led to substantial heat flux differences: e.g., $40 \mathrm{~kW} / \mathrm{m}^{2}$ vs. $25 \mathrm{~kW} / \mathrm{m}^{2}$ at $400 \mathrm{~s}$ for $\mathrm{HCe} 2$ and $20 \mathrm{~kW} / \mathrm{m}^{2}$ vs. $13 \mathrm{~kW} / \mathrm{m}^{2}$ at $380 \mathrm{~s}$ for slug 1 . Thus, fire size has a potent influence on the heat flux field impinging on structural components in the hot upper layer of a compartment and on surfaces elsewhere in the compartment. This is consistent with previous results from other laboratories (Wakamatsu et al. 2003).

\subsubsection{Effect of Soot}

The effect of fuel soot yield was explored in switching from heptane to a mixture of heptane plus toluene. The effect on measured heat fluxes can be seen by comparing results from Test 1 (heptane) and Test 3 (60 percent heptane $/ 40$ percent toluene), where the fire size was $2.0 \mathrm{MW}$ for both (see Table $2-1$ ). Soot yield increased both the emissivity and the absorptivity in this layer. The former should increase heat fluxes to the surfaces while the latter could trap heat in the gas and prevent ceiling and floor, for example, from seeing each other radiatively. Inspection of the aspirated thermocouple records from the two tests showed minimal differences, which appear to be within the test repeatability. Comparison of the flux readings from the various devices gives mixed results. For the slug calorimeters, only slug 4 differed significantly with the heptane fire giving approximately 20 percent higher readings at this location close to the fire plume. (This comparison is in the last half of the tests; the difference was greater than 30 percent at some earlier times.) The ceiling gauges all gave quite comparable results, in spite of some being in the same area as slugs 3 and 4. The column gauges tended to read slightly higher (approximately 10 percent) for the heptane fire. The floor gauges read 10 percent to 15 percent higher for the heptane fire. The largest difference was for the downward looking radiometer in the flux mcasurement station above the fire: the flux from the heptane fire was 60 percent higher. Other station readings were higher for the heptane fire, but appreciably less so. The overall trend for the flux gauges suggests that soot from the toluene fire makes the fire plume opaque.

\footnotetext{
${ }^{12}$ Equation 5-3 implies that the convective portion of the heat fluxes would have been reduced only about 30 percent, but the convective portion was, as discussed above, typically much less than radiation.
} 


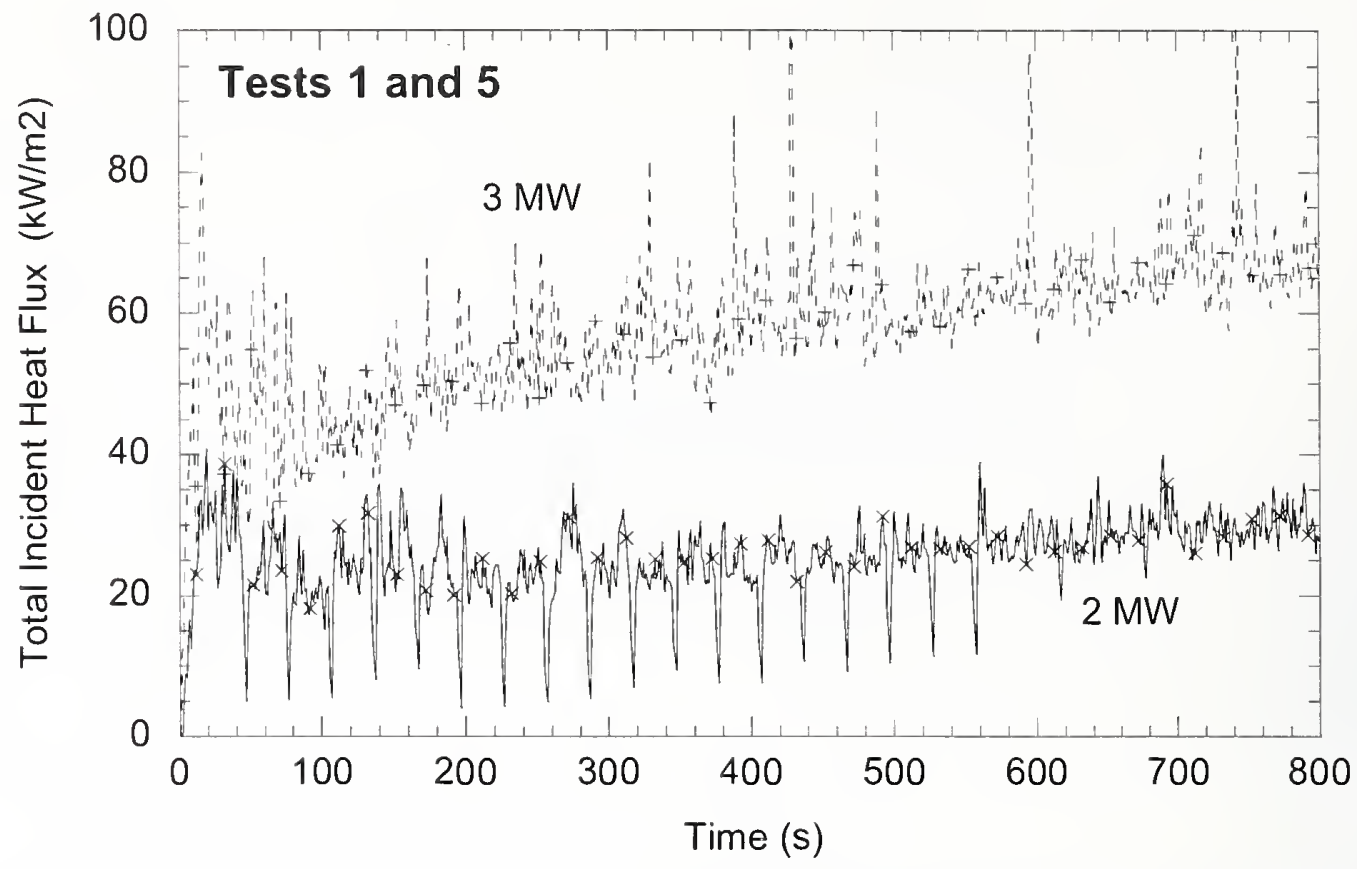

Figure 5-18. Effect of fire size in Tests 1 and 5 ( $2 \mathrm{MW}$ and $3 \mathrm{MW}$, respectively) on total heat flux at ceiling gauge $\mathrm{HCe} 2$, directly above the fire pan.

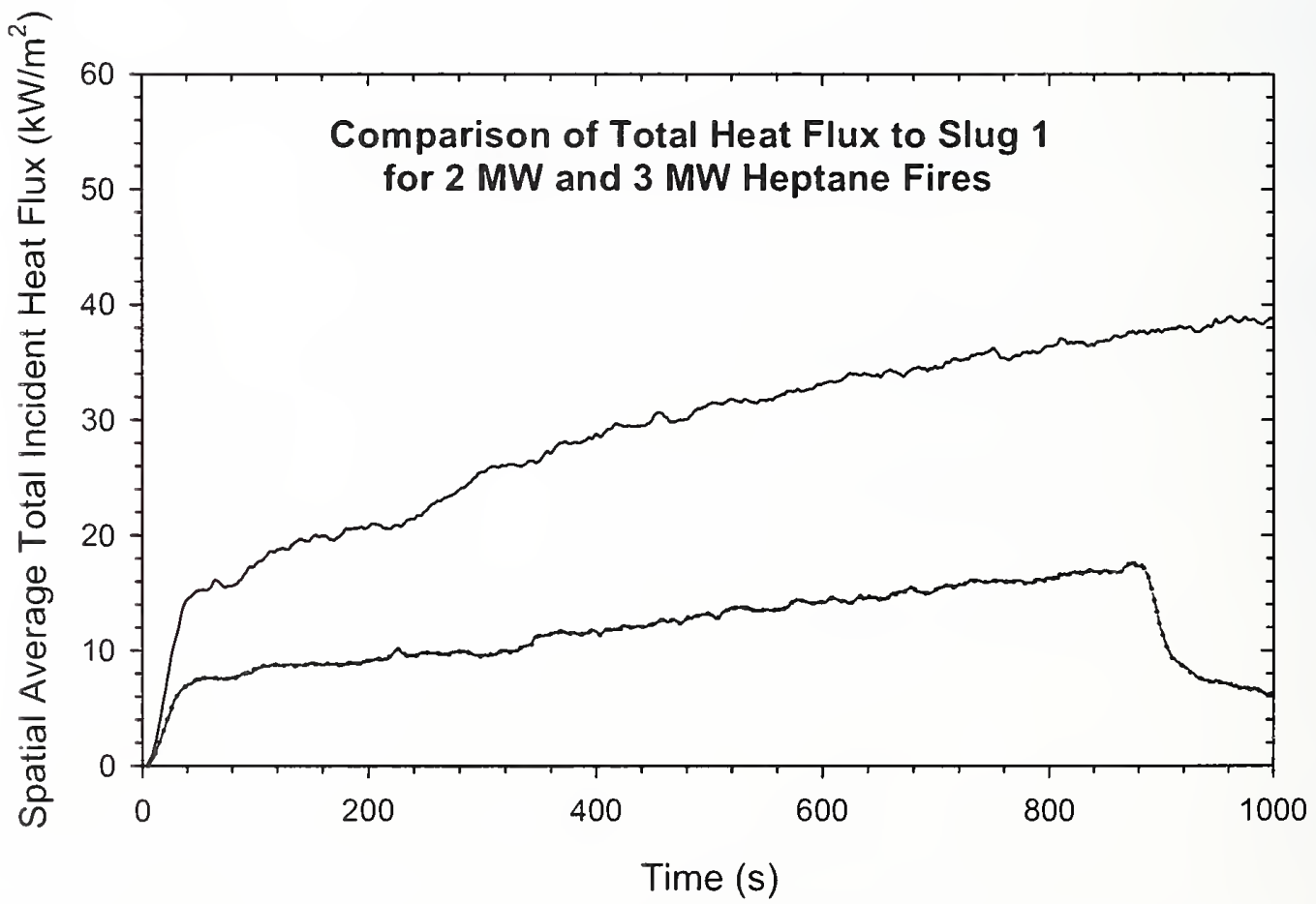

Figure 5-19. Effect of fire size in Tests 1 and 5 (2 MW and $3 \mathrm{MW}$, respectively) on the recorded total heat flux at slug calorimeter 1 , upstream of the fire plume. 


\subsection{REFERENCES}

ASTM International. 2002. ASTM E 457-96 (2002), Standard Test Method for Measuring HeatTransfer Rate Using a Thernal Capacitance (Slug) Calorimeter. West Conshohocken, PA.

Carslaw, H., and J. Jaeger. 1959. Conduction of Heat in Solids, 2nd edition, p. 203, Oxford University Press, London.

Eckert, E.. and R. Drake. 1972. Analysis of Heat and Mass Transfer, p. 406, McGraw-Hill, NY.

Holman, J. 1970. Experintental Methods for Engineers, 3rd edition, p. 44, McGraw-Hill, NY.

Kays, W. 1966. Comective Heat and Mass Transfer, pp. 209ff, McGraw-Hill, NY.

Pitts, W. 2003. NIST Building and Fire Research Laboratory, personal communication, April.

Roshenow, W., and H. Choi. 1961. Heat, Mass and Momentum Transfer, p. 198, Prentice-Hall, Engelwood Clifffs. NJ.

Toulakian, Y., and E. Buyco. 1970. Specific Heat, Metallic Elements and Alloys, Volume 4 of Thermophysical Properties of Matter, Plenum Press, NY.

Wakamatsu. T., Y. Hasemi, K. Kagiya, and K. Kamikawa. 2003. Proceedings of the Seventh International Symposinm on Fire Safety Science, pp. 1099-1110.

Williams, G., and K. Smith. 1978. Marks Mechanical Engineer's Handbook, Eighth Edition, p. 4-68, McGraw-Hill, NY. 
This page intentionally left blank. 


\section{Chapter 6 \\ SMOKE, $\mathrm{CO}_{2}, \mathrm{CO}$, AND $\mathrm{O}_{2}$ CONCENTRATIONS}

\section{$6.1 \quad$ INSTRUMENTATION}

Smoke/gas samples were extracted from the compartment at two locations for subsequent analysis of the volume (or mass) fraction of the smoke aerosol and three gas species $\mathrm{CO}_{2}, \mathrm{CO}$, and $\mathrm{O}_{2}$. The first location labeled with the prefix "Sm" (see Fig. 6-1) was in the northwestern quadrant of the enclosure near the ceiling at $(\mathrm{x}, 0.59 \mathrm{~m}, 3.24 \mathrm{~m})$ with two closely spaced probes: probe 1 at $\mathrm{x}=1.63 \mathrm{~m}$ and probe 2 at $\mathrm{x}=1.38 \mathrm{~m}$. Each probe contained a filter. The flow system allowed bypass flow of air, flow through probe 1 , or flow through probe 2. Downstream of the filter, the volume fractions of $\mathrm{CO}$ and $\mathrm{CO}_{2}$ were monitored. This arrangement allowed the collection of two sequential filter samples. The second location labeled "E" was at the east central location near the ceiling at $(6.04 \mathrm{~m}, 1.56 \mathrm{~m}, 3.65 \mathrm{~m})$. At this location the volume fractions of $\mathrm{CO}, \mathrm{CO}_{2}$, and $\mathrm{O}_{2}$ were monitored, but there was no smoke aerosol collection.

Figure 6-1 is a schematic diagram of the sampling system at the Sm location. The smoke was sampled at $3 \mathrm{~L} / \mathrm{min}$ through $2 \mathrm{~m}$ of unheated section of $0.95 \mathrm{~cm}$ diameter stainless steel tubing and then a $60 \mathrm{~cm}$ long section heated to $60^{\circ} \mathrm{C}$ by a water jacket. This length of tubing allowed the incoming flow, which was as hot as $500^{\circ} \mathrm{C}$, to equilibrate to about $60{ }^{\circ} \mathrm{C}$ before being collected on a particulate filter located just downstream of the water jacket. After the filter, the gas flowed through wet ice and dry ice traps to remove moisture, an absolute filter (99.9 percent efficient), a diaphragm pump, and another absolute filter to protect the mass flow controller. The flow was split after the flow controller with $1 \mathrm{~L} / \mathrm{min}$ at a pressure of about $100 \mathrm{kPa}$ gauge to both $\mathrm{CO}$ and $\mathrm{CO}_{2}$ nondispersive infrared gas analyzers. The remaining flow was transported to the exhaust system. The total time from the start of sampling to a ncarly constant output (within 10 percent of steady value) was about $45 \mathrm{~s}$. This included about a $9 \mathrm{~s}$ response time of the gas analyzers.

The sampling system at $\mathrm{E}$ was simplified relative to $\mathrm{Sm}$ because there was no smoke aerosol collection. Thus there was no heated water jacket, heated filter holder, flow controller, or HEPA filter just before the flow controller. Instead of a wet ice trap and dry ice trap in series, two dry ice traps were uscd in parallel to remove moisture from the $50 \mathrm{~L} /$ min sampling flow. The high flow was used to minimize the delay time from the $8 \mathrm{~m}$ long copper sampling tube $(0.95 \mathrm{~cm}$ OD tubing). The lower flow for the filter collection was required to allow thermal equilibration of the high temperature smoke with the water jacket $\left(60^{\circ} \mathrm{C}\right)$ before reaching the filter. The total delay/response time at location $\mathrm{E}$ was about $15 \mathrm{~s}$ compared to $45 \mathrm{~s}$ at the $\mathrm{Sm}$ location. From the exhaust of the pump, a flow of $1 \mathrm{~L} / \mathrm{min}$ each was directed to the same type of $\mathrm{CO}$ and $\mathrm{CO}_{2}$ analyzer as above plus a paramagnetic type oxygen analyzer.

The effluent was continuously sampled at the E location throughout a test and the concentrations were determined as volume fractions of $\mathrm{CO}_{2}, \mathrm{CO}$, and $\mathrm{O}_{2}$ on a dry basis. Two hundred data points were averaged over a $1 \mathrm{~s}$ period, and this average was recorded by the data acquisition system. 


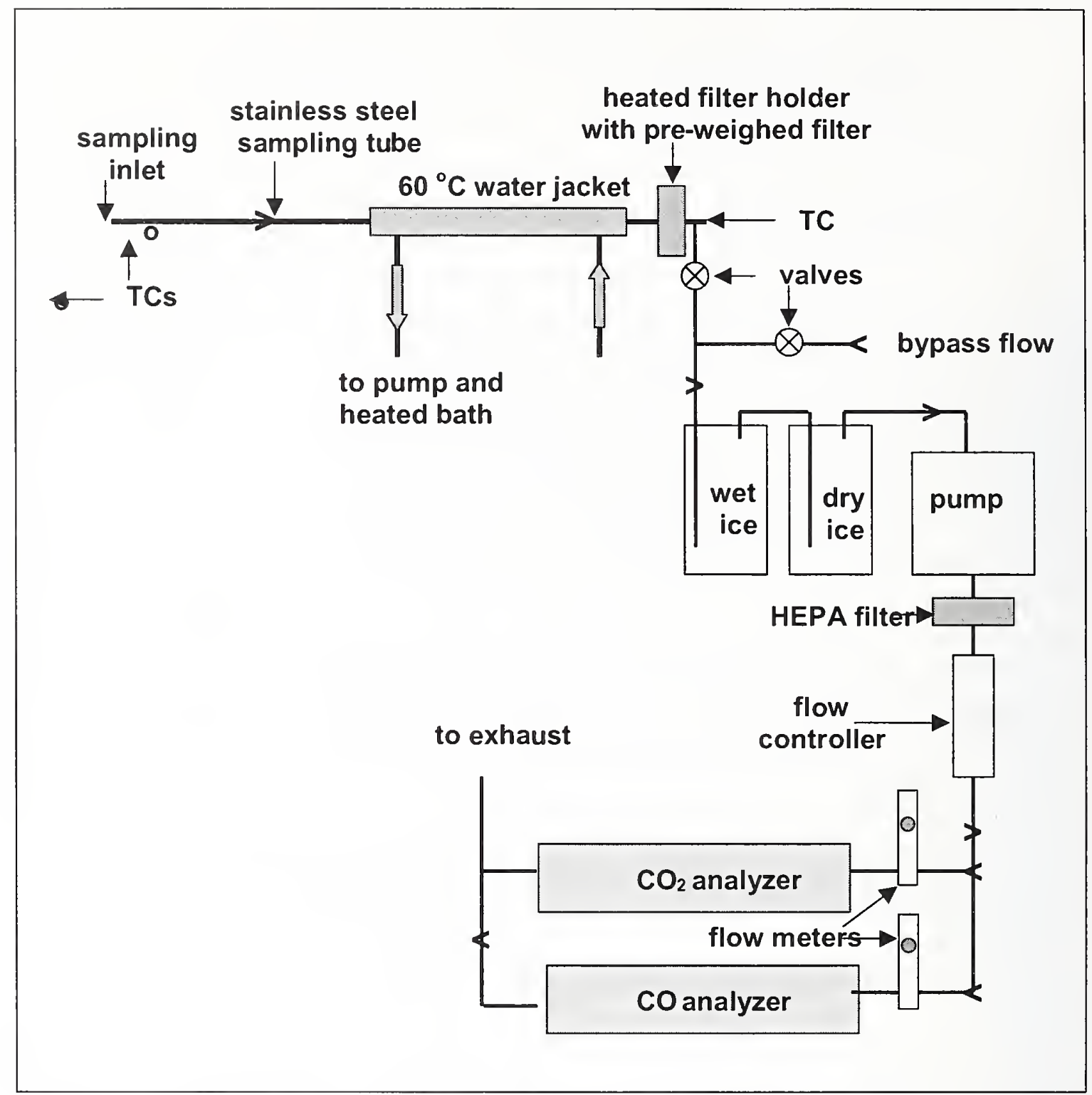

Figure 6-1. Schematic of apparatus for measuring the smoke yield and smoke concentration at location "Sm." The sampling tube extends from the inlet through the water jacket to the filter holder.

For the Sm location, the smoke was sampled for an interval of $60 \mathrm{~s}$ or $120 \mathrm{~s}$, assuring adequate collection of particulate on the filter/tubing wall to make a quantitative smoke mass measurement. Two such samples were collected during each test. As the gases flowed through the system, the $\mathrm{CO}_{2}$ and $\mathrm{CO}$ analyzers increased to peak values about $45 \mathrm{~s}$ after the filter collection was started. After the filter sample was collected, the valve position was changed so that clean air purged the remaining gases through the analyzers. This way essentially all of the $\mathrm{CO}$ and $\mathrm{CO}_{2}$ passing through the filter also passed through the gas analyzers. This was crucial for determining the species yield based on the carbon balance method as discussed below. 


\section{2} MEASUREMENT UNCERTAINTY FOR GAS ANALYZER RESULTS

All three gas analyzers have the same major sources of uncertainty: the uncertainty in the span gas, instrument noise, and instrument drift. The values of these uncertainties are summarized in Table 6-1. The noise in the gas analyzer output, $u_{n}$, was computed as a standard deviation in the instrument response to the calibration gas after correcting for long term drift. The value of $u_{n}$ was $1 \times 10^{-5}$ for the oxygen analyzer and a factor of 2 greater for the $\mathrm{CO}$ and $\mathrm{CO}_{2}$ analyzers.

Table 6-1. Uncertainty components for gas analyzers.

\begin{tabular}{|c|c|c|c|c|c|c|c|}
\hline $\begin{array}{c}\text { Gas } \\
\text { Analyzer }\end{array}$ & $\begin{array}{c}\text { Nominal } \\
\text { Volume } \\
\text { Fraction }\end{array}$ & $\begin{array}{c}\text { Calibration } \\
\text { Gas Volume } \\
\text { Fraction }\end{array}$ & $\begin{array}{c}\text { Noise, } \\
\mathbf{u}_{\mathbf{n}}\end{array}$ & $\begin{array}{c}\text { Calibration } \\
\text { Gas Uncert., } \\
\mathbf{u}_{\mathbf{s}}\end{array}$ & $\begin{array}{c}\text { Total } \\
\text { Uncert., } \\
\mathbf{u}_{\mathbf{f}}\end{array}$ & $\begin{array}{c}\text { Drift/ } \\
\mathbf{3 0} \text { min, } \\
\mathbf{u}_{\mathbf{d}}\end{array}$ & $\begin{array}{c}\text { Expanded } \\
\text { Uncert., } \\
\mathbf{U}_{\mathbf{c}}\end{array}$ \\
\hline $\mathrm{O}_{2}$ & 0.15 & 0.2095 & $1.0 \times 10^{-5}$ & $5.0 \times 10^{-4}$ & $3.6 \times 10^{-4}$ & $10.0 \times 10^{-5}$ & $7.0 \times 10^{-4}$ \\
\hline $\mathrm{CO}_{2}$ & 0.04 & 0.1800 & $2.0 \times 10^{-5}$ & $1.8 \times 10^{-3}$ & $4.0 \times 10^{-5}$ & $4.0 \times 10^{-5}$ & $8.0 \times 10^{-4}$ \\
\hline $\mathrm{CO}$ & 0.0015 & 0.0700 & $2.0 \times 10^{-5}$ & $7.0 \times 10^{-4}$ & $2.5 \times 10^{-5}$ & $5.0 \times 10^{-5}$ & $11.0 \times 10^{-5}$ \\
\hline
\end{tabular}

Ambient air was used as the span gas for the oxygen analyzer. The volume fraction of oxygen in dried ambient air was 0.20950 . Based on scientific judgment, the estimated standard uncertainty for the span gas. $u_{s}$, was $5.0 \times 10^{-4}$. For the $\mathrm{CO}_{2}$ and $\mathrm{CO}$ span gases, the estimated standard uncertainties were 1 percent of the volume fraction of the calibration gas.

The volume fraction of the gas, $x$, is proportional to the instrument voltage output.

$$
x=\frac{x_{s}}{V_{S}} V
$$

where $x_{\mathrm{s}}$ was the volume fraction, and $V_{s}$ and $V$ are the voltage outputs for the calibration gas and the measured gas, respectively. The total uncertainty in $x, u_{t}$, was computed using the law of propagation of uncertainties. The result is conveniently expressed in terms of the relative uncertainty in the volume fraction, $u_{1}(x) / x$ :

$$
\frac{u_{f}(x)}{x}=\left[\left(\frac{u_{s}}{x_{s}}\right)^{2}+\left(\frac{u_{V}}{V}\right)^{2}+\left(\frac{u_{V s}}{V s}\right)^{2}\right]^{1 / 2}
$$

It is assumed that the voltage noise is the same for both the calibration and the measurements during the test. For this case the ratios $u_{V} / V$ and $u_{V_{S}} / V_{s}$ are equal to $u_{n} / x$ and $u_{n} / x_{S}$. The computed values for $u_{t}$ for typical concentrations are given in Table 6-1.

There is one additional uncertainty component: the drift in the analyzer output. The drift in the output of the gas analyzers was computed from repeat measurements over a $30 \mathrm{~min}$ period based on a linear regression of the data. The drift uncertainty, $u_{d}$, was $10 \times 10^{-5}$ for the oxygen analyzer and about a factor of two smaller for the other gas analyzers (see Table 6-1). 
A conservative estimate of the combined uncertainty, $u_{c}$, was obtained by computing the root-sum-of squares of $u_{t}$ and $u_{d}$

$$
u_{c}=\left[u_{t}^{2}+u_{d}^{2}\right]^{1 / 2}
$$

The expanded uncertainty, $\mathrm{U}$, corresponding to the 95 percent confidence interval, is obtained as twice $u_{c}$. Table 6-1 shows the computed $U$ for an oxygen volume fraction of $0.15, \mathrm{a} \mathrm{CO}_{2}$ volume fraction of 0.04 , and a $\mathrm{CO}$ volume fraction of 0.0015 . The first two values are representative of the values observed for the smaller tests, and the value for $\mathrm{CO}$ was about the largest observed for the heptane-toluene burns. For the relatively high $\mathrm{O}_{2}$ and $\mathrm{CO}_{2}$ concentrations, the dominant source of the uncertainty is the calibration gas, while for the low $\mathrm{CO}$ concentration, the drift term is the dominant uncertainty. In Table 6-2, the quantities $\Delta \Phi_{\mathrm{CO}_{2}}$ and $\Delta \Phi_{\mathrm{CO}}$, which are the volume fractions of $\mathrm{CO}_{2}$ and $\mathrm{CO}$ of the gas minus the ambient background volume fractions of these gases, are tabulated along with their uncertainties for the samples collected at the Sm port for five tests. The reported values are the averages for the steady portion of the two smoke sampling periods for each test. The expanded uncertainty for each quantity is also included.

Table 6-2. Mean value and expanded uncertainty for gas and smoke volume fractions at the $S_{m}$ sampling location.

\begin{tabular}{|c|c|c|c|c|c|c|}
\hline $\begin{array}{l}\text { Test\#- } \\
\text { Probe\# }\end{array}$ & Fuel & $\begin{array}{l}\text { Sample } \\
\text { Period, s }\end{array}$ & $\Delta \Phi_{C_{2}} \pm \mathbf{U}$ & $\Delta \Phi_{C O} \pm \mathbf{U}$ & $\left(M_{s} \pm U\right), g / m^{3}$ & $\Phi_{\mathrm{s}} \pm \mathbf{U}$ \\
\hline $1-1$ & Heptane & $60-180$ & $\begin{array}{c}0.039 \\
\pm 0.001\end{array}$ & $\begin{array}{c}1.1 \times 10^{-4} \\
\pm 1.1 \times 10^{-4}\end{array}$ & $\begin{array}{c}0.141 \\
\pm 0.010\end{array}$ & $\begin{array}{c}0.78 \times 10^{-7} \\
\pm 0.07 \times 10^{-7}\end{array}$ \\
\hline $1-2$ & Heptane & $270-390$ & $\begin{array}{c}0.039 \\
\pm 0.001\end{array}$ & $\begin{array}{c}2.7 \times 10^{-4} \\
\pm 1.1 \times 10^{-4}\end{array}$ & $\begin{array}{c}0.283 \\
\pm 0.018\end{array}$ & $\begin{aligned} & 1.57 \times 10^{-7} \\
\pm & 0.13 \times 10^{-7}\end{aligned}$ \\
\hline $2-1$ & $\begin{array}{l}60 \% \text { heptane } \\
40 \% \text { toluene }\end{array}$ & $90-150$ & $\begin{array}{c}0.050 \\
\pm 0.001\end{array}$ & $\begin{array}{l}12.5 \times 10^{-4} \\
\pm 1.3 \times 10^{-4}\end{array}$ & $\begin{array}{c}1.58 \\
\pm 0.15\end{array}$ & $\begin{array}{c}8.8 \times 10^{-7} \\
\pm 0.9 \times 10^{-7}\end{array}$ \\
\hline $2-2$ & $\begin{array}{l}60 \% \text { heptane } \\
40 \% \text { toluene }\end{array}$ & $300-360$ & $\begin{array}{c}0.051 \\
\pm 0.001\end{array}$ & $\begin{array}{l}14.5 \times 10^{-4} \\
\pm 1.4 \times 10^{-4}\end{array}$ & $\begin{array}{c}1.85 \\
\pm 0.17\end{array}$ & $\begin{array}{l}10.3 \times 10^{-7} \\
1.1 \times 10^{-7}\end{array}$ \\
\hline $3-1$ & $\begin{array}{l}60 \% \text { heptane } \\
40 \% \text { toluene }\end{array}$ & $90-150$ & $\begin{array}{c}0.038 \\
\pm 0.001\end{array}$ & $\begin{array}{c}8.1 \times 10^{-4} \\
\pm 1.2 \times 10^{-4}\end{array}$ & $\begin{array}{c}1.01 \\
\pm 0.08\end{array}$ & $\begin{array}{c}5.6 \times 10^{-7} \\
\pm 0.5 \times 10^{-7}\end{array}$ \\
\hline $3-2$ & $\begin{array}{l}60 \% \text { heptane } \\
40 \% \text { toluene }\end{array}$ & $300-360$ & $\begin{array}{c}0.038 \\
\pm 0.001\end{array}$ & $\begin{array}{c}9.6 \times 10^{-4} \\
\pm 1.2 \times 10^{-4}\end{array}$ & $\begin{array}{c}1.44 \\
\pm 0.12\end{array}$ & $\begin{array}{c}8.0 \times 10^{-7} \\
\pm 0.8 \times 10^{-7}\end{array}$ \\
\hline $4-1$ & Heptane & $90-210$ & $\begin{array}{c}0.069 \\
\pm 0.001\end{array}$ & $\begin{array}{l}18.0 \times 10^{-4} \\
\pm 1.5 \times 10^{-4}\end{array}$ & $\begin{array}{c}0.176 \\
\pm 0.011\end{array}$ & $\begin{array}{c}0.98 \times 10^{-7} \\
\pm 0.08 \times 10^{-7}\end{array}$ \\
\hline $4-2$ & Heptane & $510-630$ & $\begin{array}{c}0.089 \\
\pm 0.002\end{array}$ & $\begin{array}{c}5.9 \times 10^{-4} \\
\pm 1.1 \times 10^{-4}\end{array}$ & $\begin{array}{c}0.134 \\
\pm 0.010\end{array}$ & $\begin{array}{c}0.74 \times 10^{-7} \\
\pm 0.07 \times 10^{-7}\end{array}$ \\
\hline $5-1$ & Heptane & $90-210$ & $\begin{array}{c}0.068 \\
\pm 0.001\end{array}$ & $\begin{array}{l}16.0 \times 10^{-4} \\
\pm 1.4 \times 10^{-4}\end{array}$ & $\begin{array}{c}0.214 \\
\pm 0.014\end{array}$ & $\begin{array}{c}1.19 \times 10^{-7} \\
\pm 0.10 \times 10^{-7}\end{array}$ \\
\hline $5-2$ & Heptane & $510-630$ & $\begin{array}{c}0.077 \\
\pm 0.002\end{array}$ & $\begin{array}{c}6.8 \times 10^{-4} \\
\pm 1.2 \times 10^{-4}\end{array}$ & $\begin{array}{c}0.213 \\
\pm 0.016\end{array}$ & $\begin{aligned} & 1.18 \times 10^{-7} \\
\pm & 0.11 \times 10^{-7}\end{aligned}$ \\
\hline
\end{tabular}




\subsection{SMOKE AND GASEOUS YIELDS}

The smoke yield was determined by the carbon balance method. This method required determination of the ratio of the smoke mass in a given volume to the total mass of carbon in the form of gas or particulate in the same volume. This was accomplished by dividing the smoke mass collected by the sum of the smoke mass and the mass of carbon contained in the forms of $\mathrm{CO}$ and $\mathrm{CO}_{2}$. Laboratory scale studies with ethene indicate that for free burning conditions the contributions of unburned vapor phase hydrocarbons account for about 2 percent or less of the carbon (Leonard et al. 1994). The unburned hydrocarbons were neglected in this analysis. The equation for calculating the smoke yield $\left(y_{s}\right)$ in terms of the $\mathrm{CO}_{2}$ and $\mathrm{CO}$ concentrations is given by:

$$
y_{s}=\frac{f m_{s}}{\left[m_{s}+12 \dot{n} \sum_{i}\left(\Delta \Phi_{C O_{2}}\left(t_{i}\right)+\Delta \Phi_{C O}\left(t_{i}\right)\right) \Delta t\right]}
$$

The quantity $f$ is the carbon mass fraction of the fuel. $m_{\mathrm{s}}$ is the mass of the smoke sample per second collected on a filter and on the wall of the sampling probe, $\dot{n}$ is the number of moles of gas sampled, the constant 12 represents the molar mass of carbon in grams, and $\Delta t$ is the 1 second sampling interval. The quantities $\Delta \Phi_{\mathrm{CO}_{2}}\left(t_{i}\right)$ and $\Delta \Phi_{\mathrm{CO}}\left(t_{i}\right)$ are the $\mathrm{i}^{\text {it }}$ samples of the $\mathrm{CO}_{2}$ and $\mathrm{CO}$ gas volume fraction taken during the test minus the ambient background volume fractions of these gases.

The yield for $\mathrm{CO}$ is given by a similar formula:

$$
y_{C O}=\frac{\mathrm{f} \dot{n} 28 \sum_{i} \Delta \Phi_{C O}\left(t_{i}\right) \Delta t}{\left[m_{s}+12 \dot{n} \sum_{i}\left(\Delta \Phi_{C O_{2}}\left(t_{i}\right)+\Delta \Phi_{C O}\left(t_{i}\right) \Delta t\right)\right]}
$$

where 28 is the molecular weight of CO. The expression for $y_{\mathrm{CO}_{2}}$ is identical to $y_{\mathrm{CO}}$, except the 28 is replaced with 44 (molecular weight of $\mathrm{CO}_{2}$ ), and the $\mathrm{CO}$ volume fraction term in the numerator is replaced with the $\mathrm{CO}_{2}$ volume fraction. The results for the yields of smoke, $\mathrm{CO}$, and $\mathrm{CO}_{2}$ are given in Table $6-4$.

The measured mass concentrations of soot correspond to the values at the sample location at the gas temperature measured by a thermocouple near the inlet. The value was computed using the following formula:

$$
M_{s}=\frac{m_{s}}{V\left(T_{\text {smoke }}\right)}
$$

where $V$ is the volume of smoke sampled at temperature $T_{\text {smoke. }}$. The volume is corrected for the moisture removed by the ice bath by estimating the amount of water vapor at the inlet as a stoichiometric factor times the volume fraction of $\mathrm{CO}_{2}$. The stoichiometric factor, $\mathrm{SF}$, is the ratio of the moles of $\mathrm{H}_{2} \mathrm{O}$ produced to the number of moles of $\mathrm{CO}_{2}$ produced based on complete combustion. This factor is 1.143 for heptane and 0.868 for the heptane-toluene mixture. The equation for the corrected volume is given by:

$$
V_{c}=V /\left(1-S F \times \Phi_{\mathrm{CO}_{2}}\right)
$$


The volume fraction of soot, $\Phi_{\mathrm{s}}$, was obtained by dividing the mass concentration by the density of soot, which was taken to be $1.8 \mathrm{~g} / \mathrm{cm}^{3}$. This represents the volume of the condensed phase soot per volume of gas at the sampling point. The results for the smoke concentration and volume fraction of smoke are given in Table 6-2.

\subsection{MEASUREMENT UNCERTAINTY FOR SOOT, $\mathrm{CO}_{2}$, AND CO YIELDS}

The law of propagation of uncertainty was used to compute the total uncertainty in the smoke yield arising from the quantities appearing in Eq. 6-4. The contributions from smoke and $\mathrm{CO}$ in the denominator were neglected since they represent a small percent of the total carbon (less than 15 percent). The resulting expression for the total standard relative uncertainty in the smoke yield is given by:

$$
u_{r r}\left(y_{s}\right)=\left[\left(\frac{u_{f}}{f}\right)^{2}+\left(\frac{u_{m_{s}}}{m_{s}}\right)^{2}+\left(\frac{u_{n}}{\dot{n}}\right)^{2}+\left(\frac{u_{\mathrm{CO}_{2}}}{\Delta \bar{\Phi}_{\mathrm{CO}_{2}}}\right)^{2}\right]^{1 / 2}
$$

In this equation, the relative uncertainty in the sum of $\mathrm{CO}_{2}$ volume fractions was estimated as the uncertainty in the avcrage $\mathrm{CO}_{2}$ concentration, $u_{\mathrm{CO}_{2}}$, divided by the average value.

The uncertainty in the smoke mass, $u_{m_{s}}$, includes contributions from the measurement of the mass of smoke collected on the filter and on the walls of the tubing before the filter. The filter mass ranged from about $2 \mathrm{mg}$ to $10 \mathrm{mg}$, and the wall mass was in the range of 10 percent to 30 percent of the filter mass. For the filter, the estimated standard uncertainty for weighing was $\pm 0.007 \mathrm{mg}$ and for particle penetration through the filter was $\pm 0.02 m_{f}$. These contributions were combined in quadrature to obtain the uncertainty associated the mass on the filter. The tubing walls are cleaned three times to remove the deposited soot, $m_{\mathfrak{w}}$. The standard uncertainty in $m_{w}$. was estimated as $\pm 0.10 m_{\mathrm{w}}$ based on weighing uncertainty of the cleaning cloth and on the residual smoke mass not removed from the tubing surface. The total uncertainty for the smoke mass, $u_{m_{s}}$, was computed by combining in quadrature the uncertainties in $m_{f}$ and $m_{\psi}$.

There was uncertainty in $f$ for the heptane blend and the heptane/tolucne mixture because the compositions of the mixtures are not exactly known. In these cases, the uncertainty in $f$ was taken to be 1 percent of the estimated value $(f=0.84$, heptane blend; $f=0.87,40$ percent toluene. 60 percent heptane blend by volume).

The molar flow, $\dot{n}$, was obtained from the measured pressure, temperature, and volumetric flow using the ideal equation of state:

$$
\dot{n}=\frac{P \dot{V}}{R T}
$$

The uncertainties in $P, T$, and $\dot{V}$ were $\pm 0.3 \mathrm{kPa}, \pm 1{ }^{\circ} \mathrm{C}$, and $1.1 \times 10^{-3} \mathrm{~L} / \mathrm{s}$, respectively. The volumetric flow uncertainty includes an uncertainty in the flow calibration and an estimated leakage rate. Using the law of propagation of uncertainty, the combined uncertainty for the molar flow, $u_{\dot{n}}$, was $\pm 4.9 \times 10^{-5}$ moles/s for a nominal flow of $2.18 \times 10^{-3} \mathrm{moles} / \mathrm{s}$. 
The last pieces of information for computing values of $u_{n}\left(y_{s}\right)$ is $\Delta \Phi_{\mathrm{CO}_{2}}$ and its associated uncertainty, which was given in Table 6-2. The values of the uncertainties listed above are given in Table 6-3 for one specific test, and the results for the smoke yields together with the expanded uncertainty (with a coverage factor of two) are given in Table 6-4.

Table 6-3. Major contributors to the uncertainty in the smoke yield.

\begin{tabular}{|l|c|c|}
\hline \multicolumn{1}{|c|}{ Variable } & Typical Value & $\begin{array}{c}\text { Relative Standard } \\
\text { Uncertainty }\end{array}$ \\
\hline Mass on the filter & $1.594 \mathrm{mg}$ & 0.020 \\
\hline Mass on cloth & $0.366 \mathrm{mg}$ & 0.10 \\
\hline Total mass of smoke & $1.960 \mathrm{mg}$ & 0.025 \\
\hline Carbon fraction of fuel & 0.84 & 0.01 \\
\hline Molar flow rate & $2.19 \times 10^{-3} \mathrm{~mole} / \mathrm{s}$ & 0.022 \\
\hline Volume fraction of $\mathrm{CO}_{2}-$ bgd. value & 0.0393 & 0.010 \\
\hline Smoke yield & 0.0135 & $0.036^{\mathrm{a}}$ \\
\hline
\end{tabular}

a. This value, the relative total standard uncertainty, was computed as the root-sum-squares of the uncertainties in the mass of smoke, carbon fraction, molar flow, and $\mathrm{CO}_{2}$ volume fraction.

Table 6-4. Mean value and expanded uncertainty for the smoke and gas yields (on a dry basis) at the $S_{m}$ sampling location.

\begin{tabular}{|c|l|l|l|l|l|}
\hline $\begin{array}{c}\text { Test\#- } \\
\text { Probe\# }\end{array}$ & \multicolumn{1}{|c|}{ Fuel } & $\begin{array}{c}\text { Sample } \\
\text { Period (s) }\end{array}$ & \multicolumn{1}{c|}{$y_{s} \pm \mathbf{U}$} & \multicolumn{1}{c|}{$y_{\mathrm{CO}} \pm \mathbf{U}$} & \multicolumn{1}{c|}{$y_{\mathrm{CO}_{2}} \pm \mathbf{U}$} \\
\hline $1-1$ & Heptane & $60-180$ & $0.014 \pm 0.001$ & $0.006 \pm 0.006$ & $3.02 \pm 0.06$ \\
\hline $1-2$ & Heptane & $270-390$ & $0.028 \pm 0.002$ & $0.013 \pm 0.005$ & $2.96 \pm 0.06$ \\
\hline $2-1$ & $\begin{array}{l}60 \% \text { heptane } \\
40 \% \text { toluene }\end{array}$ & $90-150$ & $0.12 \pm 0.01$ & $0.045 \pm 0.005$ & $2.70 \pm 0.07$ \\
\hline $2-2$ & $\begin{array}{l}60 \% \text { heptane } \\
40 \% \text { toluene }\end{array}$ & $300-360$ & $0.14 \pm 0.01$ & $0.048 \pm 0.005$ & $2.60 \pm 0.08$ \\
\hline $3-1$ & $\begin{array}{l}60 \% \text { heptane } \\
40 \% \text { toluene }\end{array}$ & $90-150$ & $0.089 \pm 0.006$ & $0.038 \pm 0.06$ & $2.80 \pm 0.07$ \\
\hline $3-2$ & $\begin{array}{l}60 \% \text { heptane } \\
40 \% \text { toluene }\end{array}$ & $300-360$ & $0.13 \pm 0.01$ & $0.042 \pm 0.005$ & $2.64 \pm 0.07$ \\
\hline $4-1$ & Heptane & $90-210$ & $0.012 \pm 0.001$ & $0.049 \pm 0.004$ & $2.96 \pm 0.06$ \\
\hline $4-2$ & Heptane & $510-630$ & $0.0088 \pm 0.0007$ & $0.013 \pm 0.003$ & $3.03 \pm 0.06$ \\
\hline $5-1$ & Heptane & $90-210$ & $0.015 \pm 0.001$ & $0.045 \pm 0.004$ & $2.96 \pm 0.06$ \\
\hline $5-2$ & Heptane & $510-630$ & $0.015 \pm 0.001$ & $0.018 \pm 0.003$ & $3.00 \pm 0.06$ \\
\hline
\end{tabular}

The major terms contributing to the uncertainty in the $\mathrm{CO}$ yield are the uncertainty in the $\mathrm{CO}$ volume fraction, which affects the numerator of Eq. 6-5, and the volume fraction of $\mathrm{CO}_{2}$, which was the dominant term in the denominator. The relative total standard uncertainty in the $\mathrm{CO}$ yield, $\mathrm{u}_{\mathrm{tr}}\left(\mathrm{y}_{\mathrm{CO}}\right)$, was equal to the root-sum-square of the relative standard uncertainties for $\mathrm{CO}$ and $\mathrm{CO}_{2}$ measurements.

$$
u_{r r}\left(y_{C O}\right)=\left(u_{1 r}^{2}(C O)+u_{1 r}^{2}\left(C O_{2}\right)\right)^{1 / 2}
$$


The relative uncertainty for the $\mathrm{CO}$ and $\mathrm{CO}_{2}$ measurements are obtained from Table 6-2. The expanded uncertainty was computed based on Eq. 6-8, using the same general approach as above. The results are given in Table 6-4.

The uncertainty in the yield of $\mathrm{CO}_{2}$ was small, because the numerator and denominator of the yield equation were dominated by the volume fraction of $\mathrm{CO}_{2}$. Making use of the dominance of the $\mathrm{CO}_{2}$ term in the denominator, the following approximate expression for $y_{\mathrm{CO}_{2}}$ was obtained:

$$
y_{\mathrm{CO}_{2}}=\frac{44}{12} f-\frac{44}{12} y_{s}-\frac{44}{28} y_{\mathrm{CO}}
$$

Applying the law of the propagation of uncertainties and a coverage factor of two, the expanded uncertainty was computed for each test based on the uncertainties in $f, y_{s}$, and $y_{c o}$. The results are given in Table 6-4.

As seen from Eq. 6-6, the uncertainty in the mass concentration of smoke results from the uncertainty in the mass of smoke collected, in the uncertainty in the temperature, which was estimated as \pm 1.5 percent of the absolute temperature of the smoke, and the uncertainty in the corrected volume, which was estimated to be \pm 2.7 percent for the $60 \mathrm{~s}$ smoke sample and \pm 1.8 percent for the $120 \mathrm{~s}$ sample. The large uncertainty in the smoke temperature results from the effect of radiant transport on the thermocouple. The dominant factors affecting the volume of smoke sampled are the timing uncertainty $( \pm 1.4 \mathrm{~s})$, the flow calibration ( \pm 1 percent), and uncertainty in the water vapor corrcction ( \pm 1 percent). The expanded uncertainty in the mass concentration of smoke was computed via the law of propagation of uncertainty for Eq. 6-6. The results are given in Table 6-2.

The uncertainty in the soot volume fraction measurements are a quadrature sum of the uncertainty in the mass concentration and the uncertainty in the soot density, which was estimated to be \pm 2.5 percent of the nominal value. These results are also presented in Table 6-2.

\subsection{EXPERIMENTAL OBSERVATIONS}

Figure 6-2 shows the oxygen reading at the E location as a function of time for Test 1 . The oxygen volume fraction decreased rapidly from a value of about 0.21 to 0.16 and then fluctuated about this value for the remainder of the test. The standard deviation of the oxygen volume fraction computed over a small time interval (about $10 \mathrm{~s}$ ) during the nominally steady period was about 0.001 . This value was more than two orders of magnitude larger than the standard uncertainty associated with the noise of the oxygen analyzer responding to ambient air. This was a result of the fluctuations in the oxygen concentration in the enclosure. The actual fluctuations in the oxygen concentration were greater than those recorded by the oxygen analyzer because the analyzer signal was smoothed by the $9 \mathrm{~s}$ response time of the instruments.

Representative plots are presented, and key features of the tests are described, regarding the following topics: repeatability, effect of smoke concentration, and the effect of heat release rate on the low and high sooting fuel. 


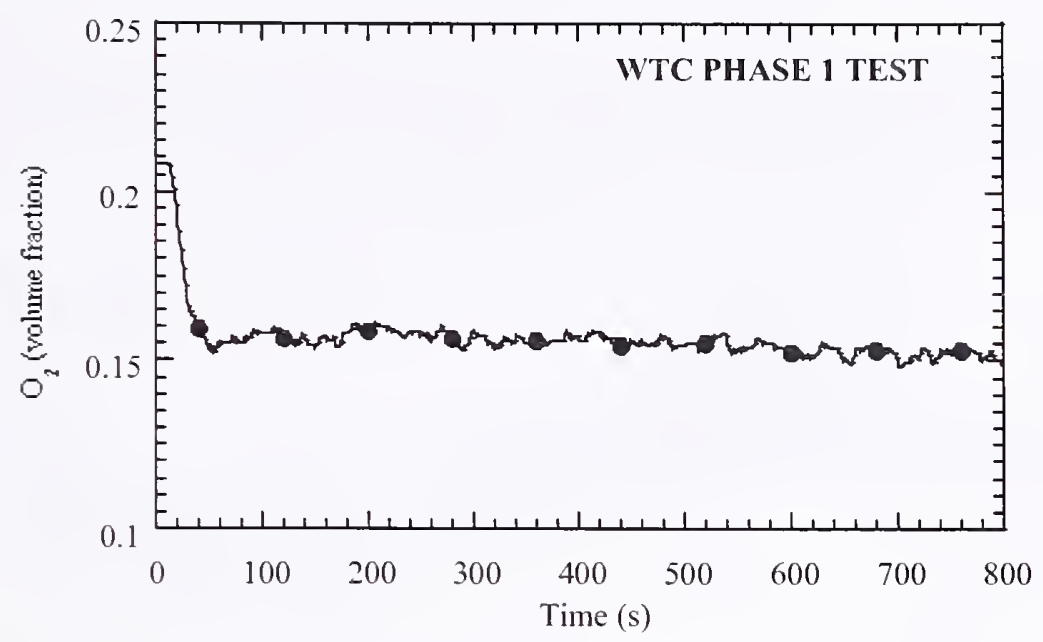

Figure 6-2. Oxygen volume fraction (on a dry basis) sampled at location $E$ plotted as a function of time for Test 1.

\subsection{REPEATABILITY OF TESTS}

Tests 4 and 5 were basically repeat tests with heptane as the fuel at a heat release rate near $3 \mathrm{MW}$. As mentioned above, the gases were sampled continuously at the E location but only for 2 min intervals at the $\mathrm{Sm}$ location. The results for $\mathrm{O}_{2}$ and $\mathrm{CO}_{2}$ (Figs. 6-3 and 6-4) were typically within 10 percent for all the data. Over a period of $800 \mathrm{~s}$, the $\mathrm{CO}_{2}$ volume fraction increased by 10 percent to 20 percent, and the $\mathrm{O}_{2}$ volume fraction decreased by a similar amount. The $\mathrm{CO}_{2}$ and temperaturc were slightly higher for Test 4 and the $\mathrm{O}_{2}$ slightly lower. These results are consistent with the slightly higher heat release rate measured in Test 4.

A consistency test was made for the $\mathrm{O}_{2}$ and $\mathrm{CO}_{2}$ measurements by computing the ratio of the volume fraction of $\mathrm{CO}_{2}$ to the decrease in the volume fraction of the $\mathrm{O}_{2}$. For the $\mathrm{CO}_{2}$ volume fraction, the ambient $\mathrm{CO}_{2}$ volume fraction was subtracted. For complete combustion of heptane, this $\mathrm{CO}_{2} / \mathrm{O}_{2}$ ratio (on a dry basis) was 0.64 . The measured values ranged from about 0.67 to 0.69 (Fig. 6-5). The relatively close agreement and the absence of large drifts provide validation of the gas analyzer output.

Some of the difference between experiment and theory could also be due to incomplcte products of combustion. The ratio for Test 5 was nearly constant at a value of about 0.67 over an $800 \mathrm{~s}$ period with significantly less fluctuation than either the $\mathrm{O}_{2}$ or $\mathrm{CO}_{2}$ measurement. Increases in $\mathrm{O}_{2}$ concentration were accompanied by decreases in the $\mathrm{CO}_{2}$ concentration. A clear example of this effect is seen in Figs. 6-3 and $6-4$ at a time of about $360 \mathrm{~s}$.

The CO results (Fig. 6-6) were similar for Tests 4 and 5, considering the low concentration and higher measurement uncertainty. The CO concentration was a factor of 1.5 to 2.5 larger at the smoke sampling port $(\mathrm{Sm})$ compared to the ceiling port $(\mathrm{E})$ to the east of the fire. This was compared to a factor of 1.1 to 1.2 for the case of $\mathrm{CO}_{2}$. This same qualitative effect of a higher $\mathrm{CO}$ concentration at the Sm sampling port was observed for all the other tests except for the $2 \mathrm{MW}$ heptane fire without insulation on the steel. In this case, the $\mathrm{CO}$ was near the noise level of the instrument. The higher $\mathrm{CO}$ concentration at the $\mathrm{Sm}$ port may result from a difference in the combustion environment on one side of the enclosure versus the other. Another possibility is a performance issue with the $\mathrm{CO}$ analyzers. The measured $\mathrm{CO}$ volume 
fraction varied from about $2 \times 10^{-4}$ to $2 \times 10^{-3}$ compared to an estimated expanded uncertainty of $1.1 \times 10^{-4}$. The linearity of the $\mathrm{CO}$ analyzer output was verified at a concentration as low as $1.6 \times 10^{-3}$, which was comparable to the observed concentration at $200 \mathrm{~s}$. It is unlikely that this difference was a gas analyzer issue, but such an effect cannot be ruled out without additional study.

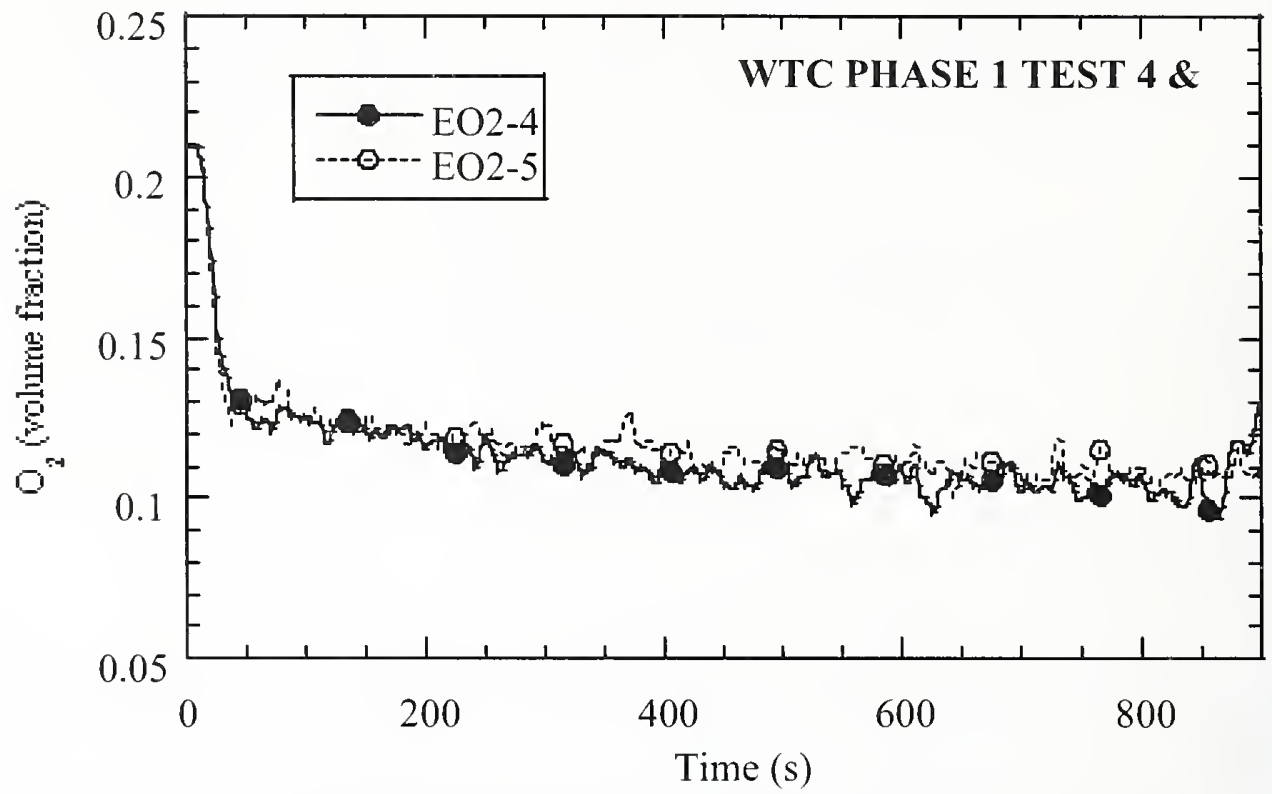

Figure 6-3. Comparison of the oxygen volume fraction (on a dry basis) for Tests 4 and 5.

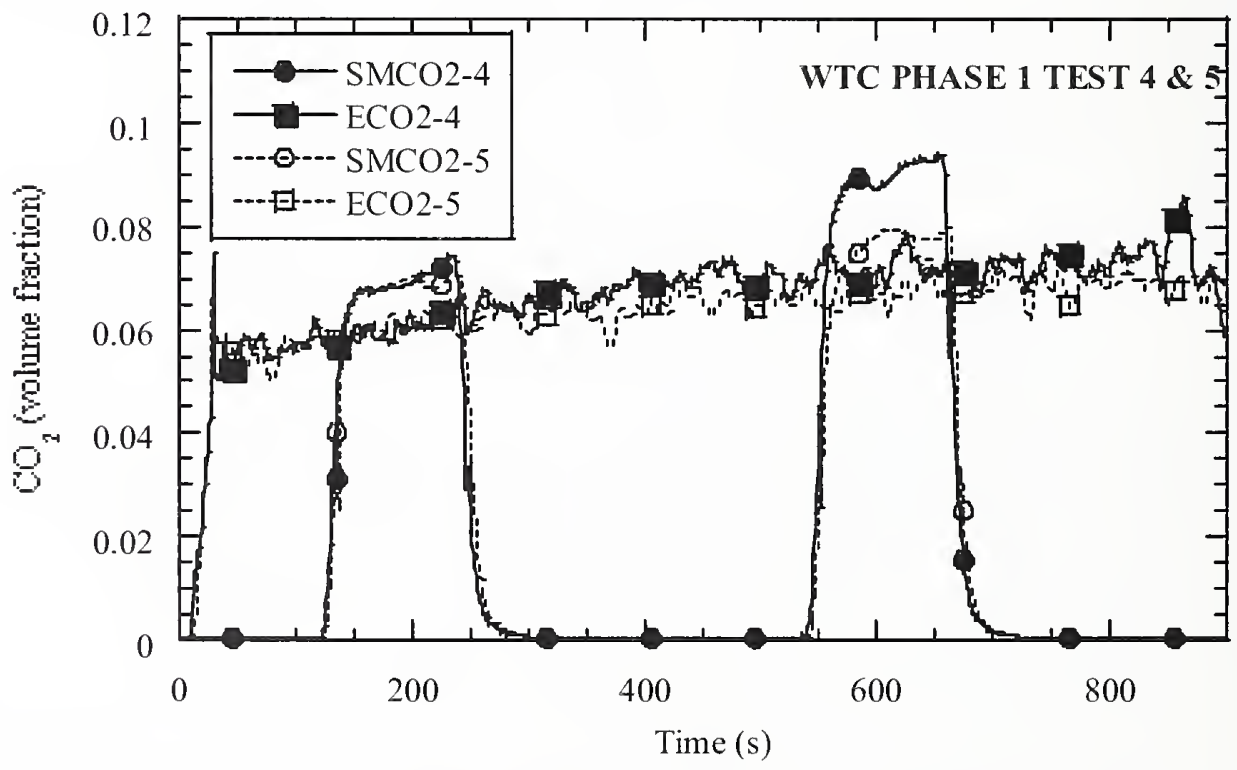

Figure 6-4. Comparison of $\mathrm{CO}_{2}$ volume fraction (on a dry basis) for Tests 4 and 5. Results are presented for the E sampling location and the Sm location, for which the gas is sampled twice for $120 \mathrm{~s}$ each. 


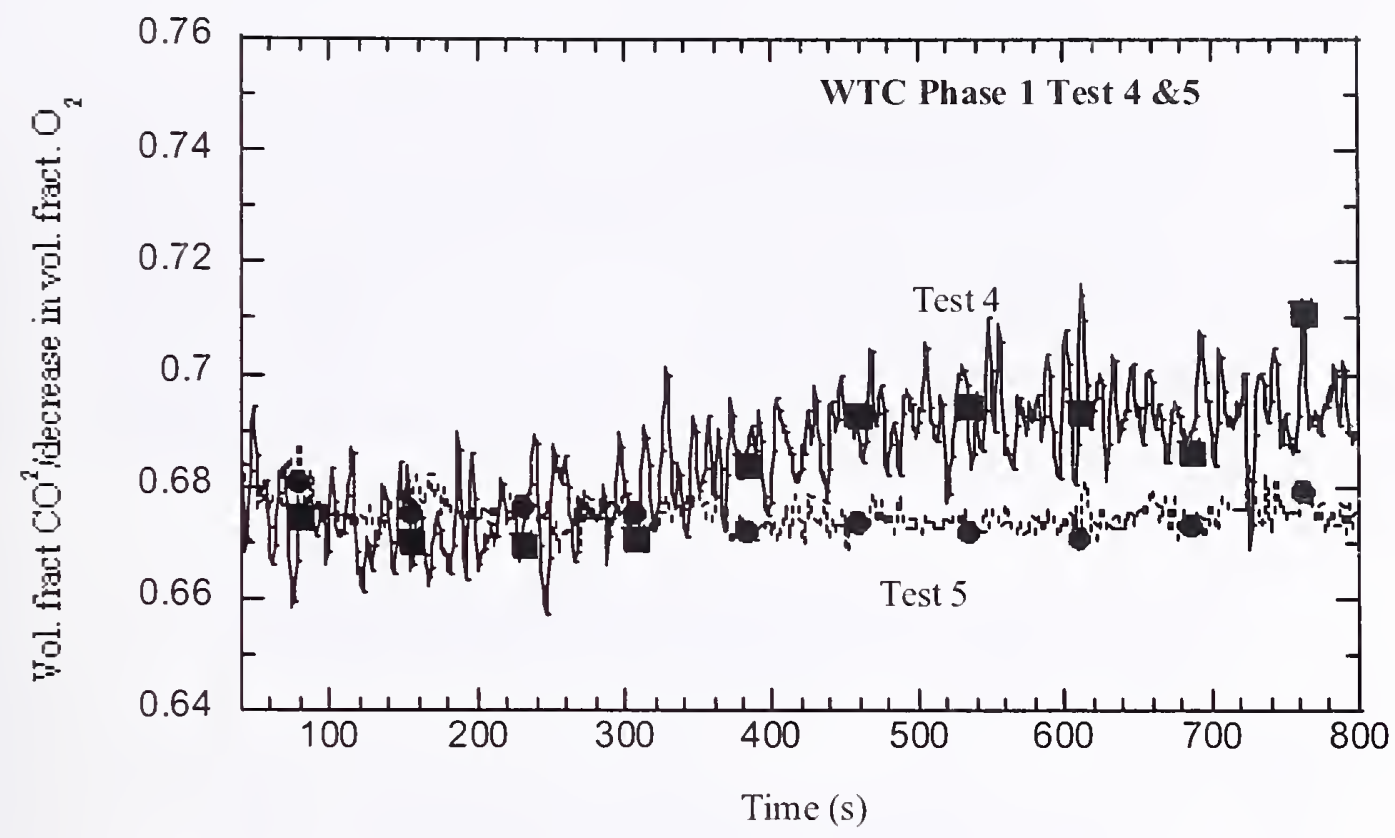

Figure 6-5. Ratio of volume fraction of $\mathrm{CO}_{2}$ minus the background value to the decrease in the $\mathrm{O}_{2}$ volume fraction for Tests 4 and 5 at sample location $\mathrm{E}$ (on a dry basis).

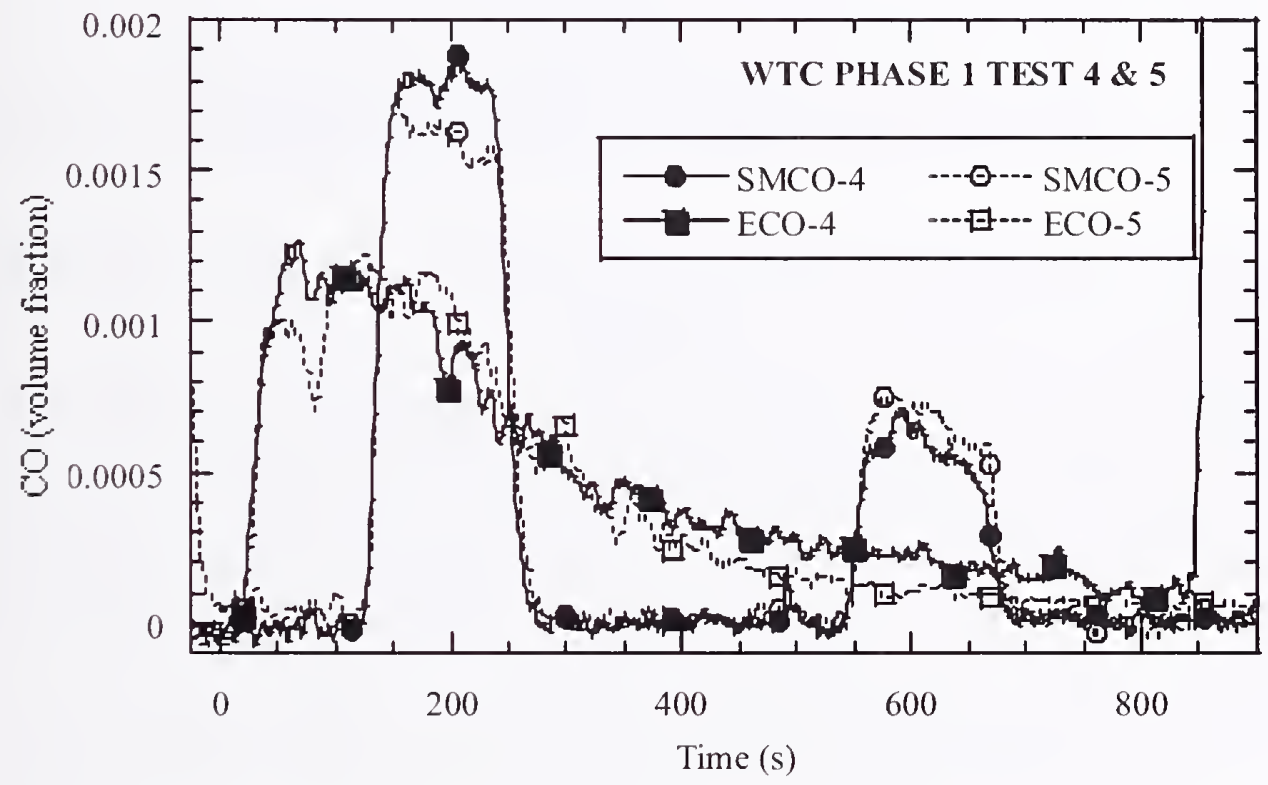

Figure 6-6. Comparison of CO volume fraction (on a dry basis) for Tests 4 and 5.

The soot yields for Test 4 were 0.013 and 0.0092 and for Test 5 were 0.015 and 0.015 . These results are similar to the free burn results (refer to NIST NCSTAR 1-5C), although one of the Test 4 results was unexpectedly low in value. The soot yield does not exhibit the large sensitivity to the sampling time that was observed by $\mathrm{CO}$, so it appears that a constant soot yield equal to the free burn value was not a bad approximation for this case. 


\subsection{EFFECT OF SMOKE CONCENTRATION}

Tests 1 and 3, both with a heat release rate of about $2 \mathrm{MW}$, involved a relatively clean burning heptane blend (Test 1) and the sootier heptane/toluene mixture (Test 3). The results for the concentrations of $\mathrm{CO}_{2}$ and $\mathrm{O}_{2}$ for the two tests typically agreed within 5 percent of their values. The $\mathrm{CO}_{2}$ concentration reached a constant value shortly after ignition as illustrated in Fig. 6-7. The $\mathrm{O}_{2}$ concentration behaved in a similar fashion. This steady behavior differed from the time dependent behavior for these species for the $3 \mathrm{MW}$ fires. The $\mathrm{CO}_{2}$ concentration was about 15 percent larger at the $\mathrm{Sm}$ port compared to the concentration at the E port. A similar difference was found in Tests 4 and 5. The temperature near the Sm port increased from about $300{ }^{\circ} \mathrm{C}$ to $450{ }^{\circ} \mathrm{C}$ during the test as shown in Fig. $6-8$.

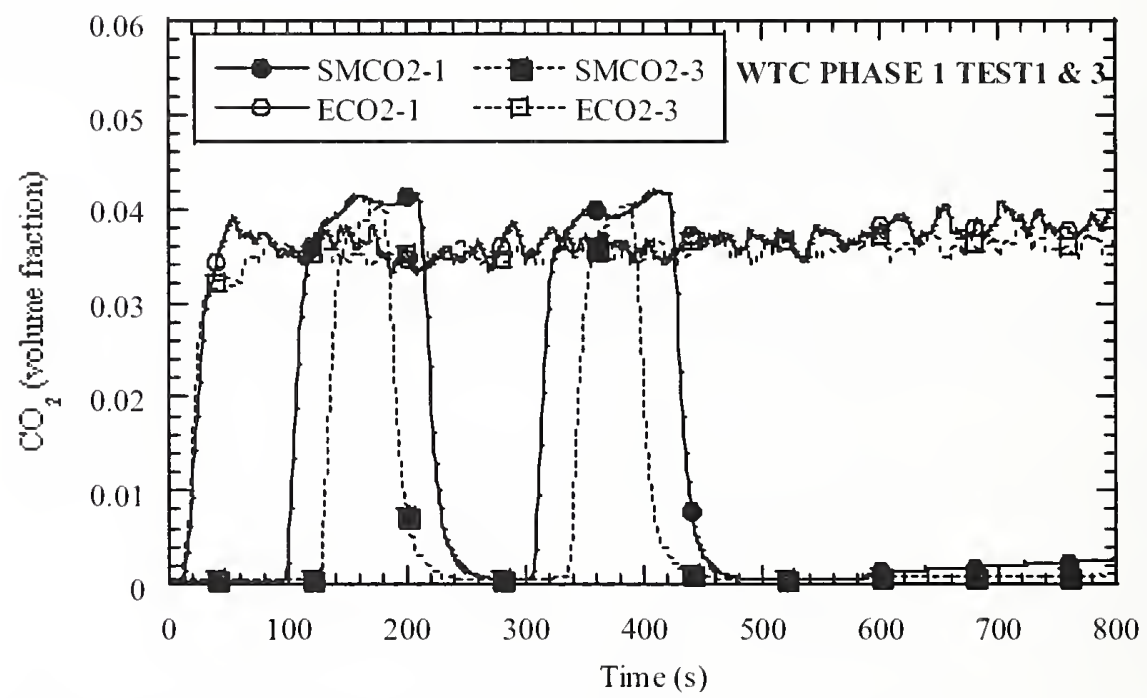

Figure 6-7. $\mathrm{CO}_{2}$ and $\mathrm{O}_{2}$ volume fraction (on a dry basis for low (Test 1 ) and high sooting (Test 3).

For the Test 3 burn of the heptane/toluene mixture, the yields of both $\mathrm{CO}$ and soot were about five times larger than for Test 1. The CO volume fraction at both sampling locations (Fig. 6-9) increased slightly (10 percent to 20 percent) during Test 3 , while the $\mathrm{CO}$ volume fraction increased by more than a factor of two for heptane. The soot yield for the second sample collected for the heptane burn was also found to approximately double the first value, while for the heptane/toluene mixture, the second value increased by about 40 percent. 


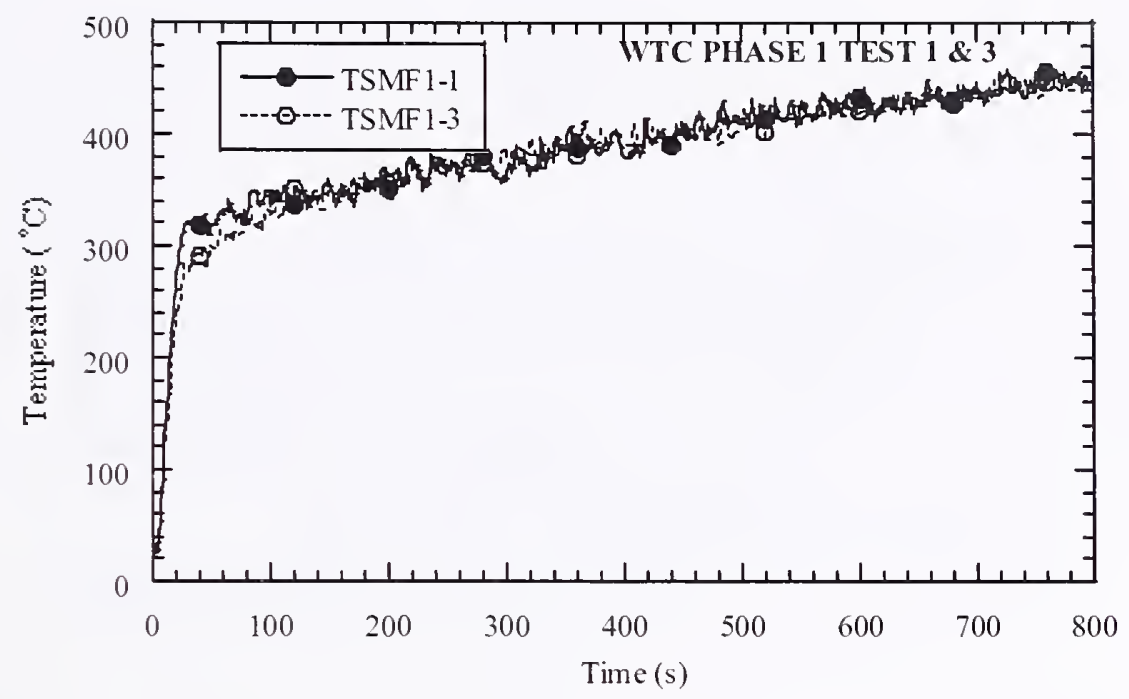

Figure 6-8. Temperature as a function of time near the $\mathrm{Sm}$ probes for low (Test 1) and high sooting (Test 3).

\subsection{EFFECT OF HEAT RELEASE RATE FOR A LOW SOOTING FUEL}

The effect of the heat release rate on species concentrations can be examined by comparing Test 1 and Test 4. As seen in Figs. 6-9 and 6-10, the $\mathrm{O}_{2}$ and $\mathrm{CO}_{2}$ volume fraction in Test 1 approached a constant value, whereas in Test 4 , the concentrations continued to change as discussed in Sec. 6.6. The larger fire resulted in nearly a $200{ }^{\circ} \mathrm{C}$ higher temperature. At $800 \mathrm{~s}$, the temperature near the Sm port was $660{ }^{\circ} \mathrm{C}$ for Test 4 , as compared to $460{ }^{\circ} \mathrm{C}$ for Test 1 .

The trends in the $\mathrm{CO}$ concentration were the most complex as illustrated in Fig. 6-11. First, consider the $\mathrm{CO}$ data at location E. The larger fire (Test 4) initially had more than 10 times the CO conccntration of the smaller fire (Test 1); however, by $800 \mathrm{~s}$, the situation reversed and the CO concentration was larger for the smaller fire. For the smaller fire, the smoke yield also increased with time and approximately doubled from $200 \mathrm{~s}$ to $400 \mathrm{~s}$. Such an increase was not surprising, since the fire plume entrained an increasing amount of combustion products as the smoke layer developed. The surprising result was the very large $\mathrm{CO}$ volume fraction at the test start in the larger fire. One would cxpect the $\mathrm{CO}$ yield to be similar to the free burn results, but the value was about 5 times greater for Test 4 as compared to the free burn (Table 6-5) (Hamins et al. 2003). This suggests a drastic difference in the fire conditions. The one difference from the free burn fires was the inclusion of sprayed fire-resistive material (SFRM) around the steel. It is possible that the SFRM may have been responsible for the increased amount of CO observed. The high initial amount of CO was seen in both tests (see Fig. 6-6) involving the insulated steel, and it was observed at both sampling points. 


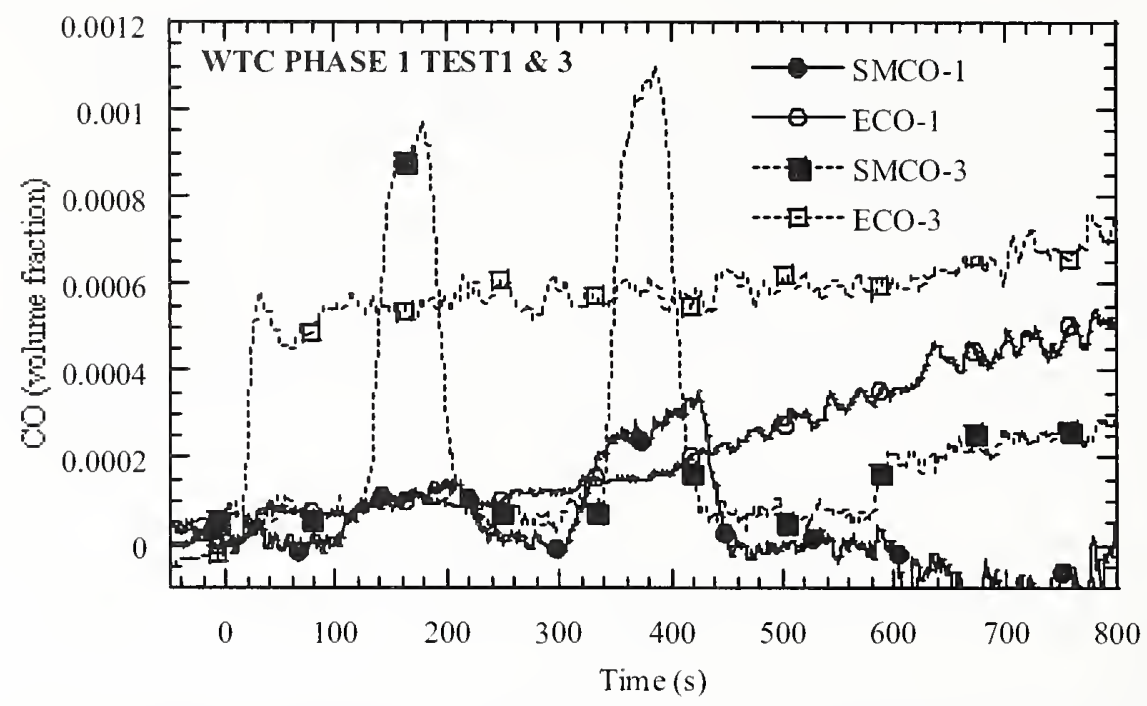

Figure 6-9. Co volume fraction (on a dry basis) as a function of time for low (Test 1 ) and high sooting (Test 3 ).

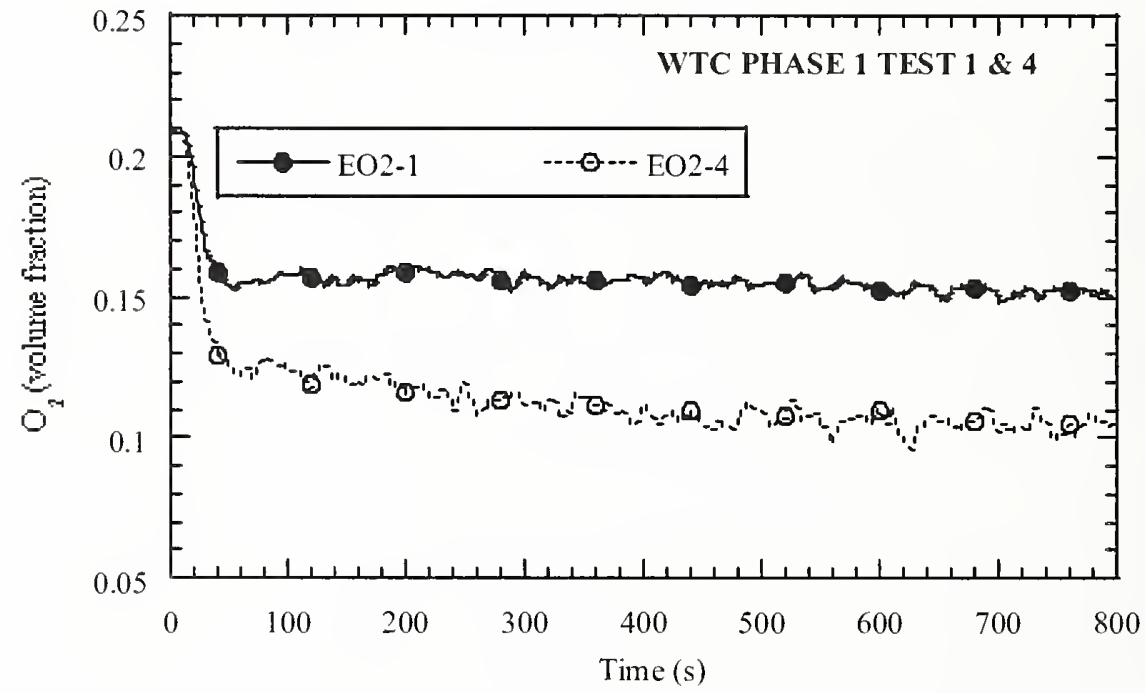

Figure 6-10. The oxygen volume fraction (on a dry basis) for a lower (Test 1) and a higher (Test 4) heat release rate. 


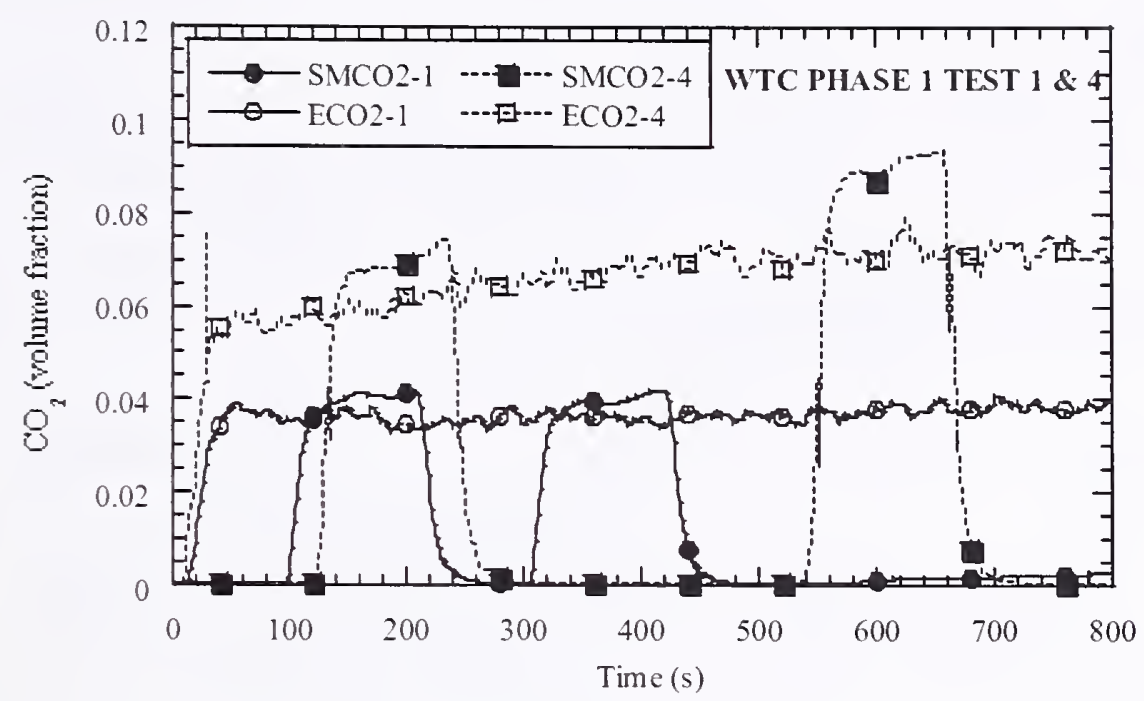

Figure 6-11. The $\mathrm{CO}_{2}$ volume fraction (on a dry basis) for a lower (Test 1) and a higher (Test 4) heat release rate.

Table 6-5. Mean value and expanded uncertainty for the smoke and gas yields (on a dry basis) for free burns.

\begin{tabular}{|l|l|l|l|}
\hline \multicolumn{1}{|c|}{ Fuel } & \multicolumn{1}{c|}{$y_{\mathrm{s}} \pm \mathbf{U}$} & \multicolumn{1}{c|}{$y_{\mathrm{CO}} \pm \mathbf{U}$} & \multicolumn{1}{c|}{$y_{\mathrm{CO}_{2}} \pm \mathbf{U}$} \\
\hline Heptane & $0.015 \pm 0.002$ & $<0.008$ & $3.0 \pm 0.1$ \\
\hline $\begin{array}{l}60 \% \text { heptane } \\
40 \% \text { toluene }\end{array}$ & $0.11 \pm 0.02$ & $0.042 \pm 0.016$ & $2.7 \pm 0.02$ \\
\hline
\end{tabular}

Source: Hamins et al. 2003.

6.9

\section{EFFECT OF THE FIRE HEAT RELEASE RATE ON A HIGH SOOTING FUEL}

Tests 2 and 3 also provided information on the effect of the heat release rate, but in these cases the heptane/toluene mixture produced a high smoke concentration (Fig. 6-12). The heat release rate was varied by about 20 percent from $2.4 \mathrm{MW}$ for Test 2 to $2.0 \mathrm{MW}$ for Test 3 . The insulated steel was not present during the heptane/toluene fires. The trends in terms of the magnitude and time dependence for the $\mathrm{CO}_{2}, \mathrm{O}_{2}$, and temperature are qualitatively similar to that for Tests 1 and 4 . The one major difference was the trend regarding the $\mathrm{CO}$ concentration. As seen in Fig. 6-13, the $\mathrm{CO}$ concentration increased slightly with time for both tests with, possibly, a greater increase for the larger fire. The CO results after $400 \mathrm{~s}$ for the E port were not valid because the fuel flow was stopped at this time and the pump turned off. The time dependence of the CO was not similar to either Test 1 or Test 4. Perhaps the higher CO production from this sooty flame made it less sensitive to small changes in the combustion conditions. 


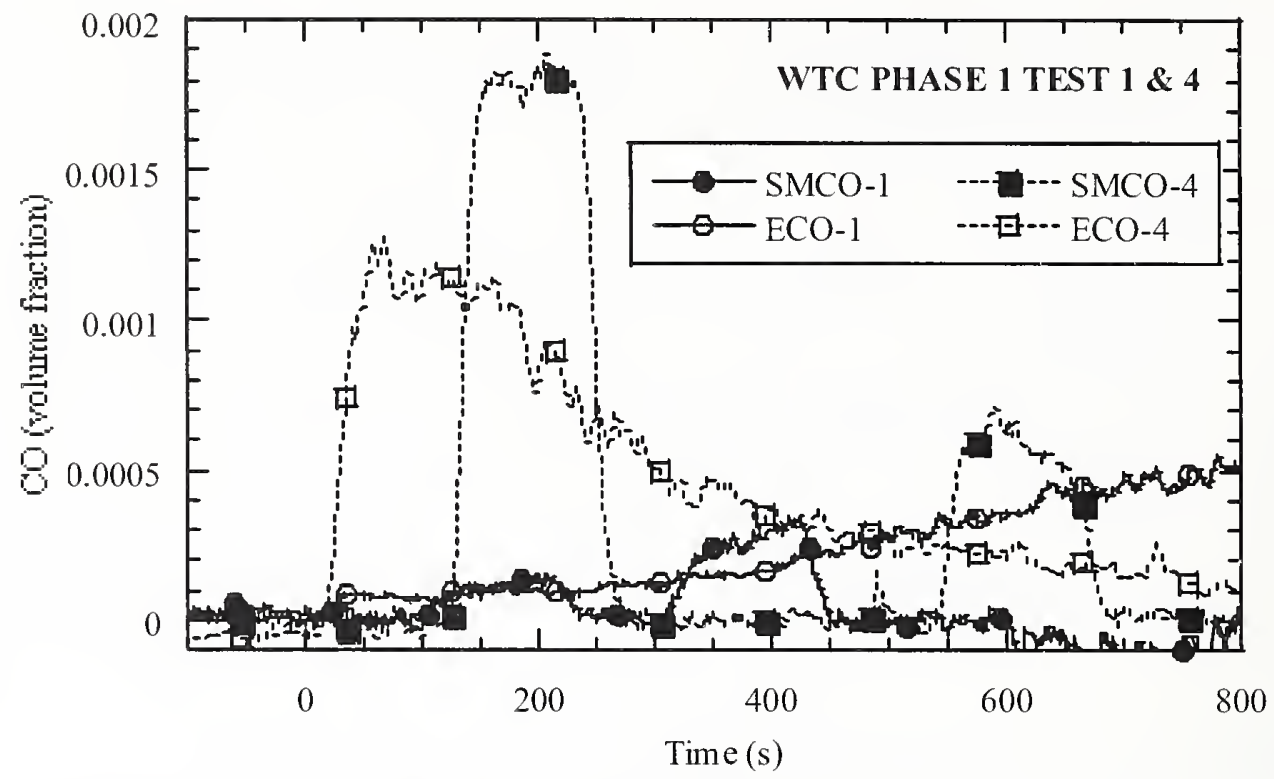

Figure 6-12. Co volume fraction (on a dry basis) for a lower (Test 1) and a higher (Test 4) heat release rate.

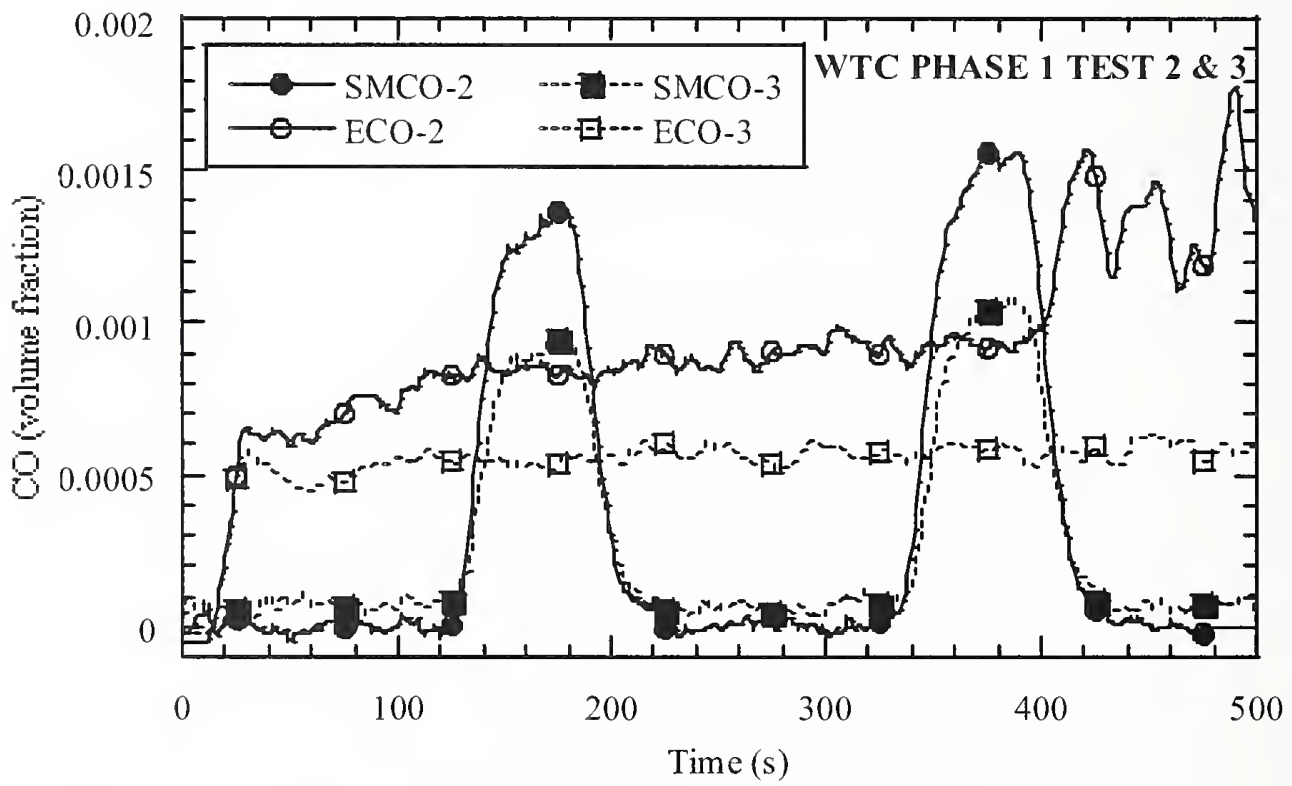

Figure 6-13. Co volume fraction (on a dry basis) for high sooting tests with a low (Test 3) and a high (Test 2) heat release rate. 


\subsection{REFERENCES}

Blevins, L. G., and W. M. Pitts. 1999. Fire Safety Journal, 33, 239-259, and National Institute of Standards and Technology, Gaithersburg, MD, NISTIR 6310, April. Available at http://ire.nist.gov/bfrlpubs/fire99/PDF/199022.pdf.

Hamins, A., A. Maranghides, and G. Mulholland. 2003. The Global Combustion Behavior of $1 \mathrm{MW}$ to 3 MW Hydrocarbon Spray Fires Burning in an Open Environment, NISTIR 7013, National Institute of Standards and Technology, Gaithersburg, MD, June.

He, Y. P., A. Fernando, and M. C. Luo. 1998. Fire Safety Journal, 31, 19-38.

McCaffrey, B.J., and G. Heskestad. 1976. Combust. Flame, 26, 125-127.

Pitts, W. M., E. Braun, R. D. Peacock. H. E. Mitler, E. L. Johnsson, P. A. Reneke, and L. G. Blevins. 1998. Temperature Uncertainties for Bare-Bead and Aspirated Thermoconple Measurements in Fire Environments and National Institute of Standards and Technology, Gaithersburg, MD, NISTIR 6242, October. Available at http://fire.nist.gov/bfrlpubs/fire03/PDF/f03052.pdf. 
This page intentionally left blank. 


\section{Chapter 7 \\ VELOCITY MEASUREMENTS}

\section{$7.1 \quad$ INSTRUMENTATION}

Bidirectional probes were used to measure gas velocities at the inlets and outlets of the compartment as a check on the computational model. These instruments were selected because thcy arc durable and have the necessary measurement characteristics. McCaffrey and Heskestad (1976) showed that bidirectional probes are capable of measuring low velocities and are relatively insensitive to the direction of flow. They found the velocity (mean speed) measurement to be accurate to within 10 percent, provided that the velocity probe was aligned to within \pm 50 degrees of the mean velocity direction.

The bidirectional probe measurement involves relating the differential pressure across the probe to the local Reynolds number, $R e$, of the gas. The calibration for the probe is typically presented in terms of the amplification factor $K$ :

$$
K=\sqrt{\Delta p / p_{d}}=\sqrt{(2 \Delta p) /\left(\rho V^{2}\right)}
$$

where, $D, \mu, \Delta p$ and $p_{d}$ are the probe diameter, gas viscosity, differential pressure across the probe, and dynamic pressure of the gas, respectively, and $K$ is a function of Reynolds number $(R e)$ :

$$
R e=\rho D V / \mu
$$

The velocity of the gas, $V$, and gas density, $\rho$, both appear in the amplification factor and the Reynolds number. Thus, determination of the gas velocity from the measured data can be an iterative procedure. For the measurements reported here, the probe dimensions were chosen to ensure that the Reynolds numbers obtained would be in the asymptotic regime $(R e>600)$ to minimize the mcasurement uncertainty and eliminate the need for an iterative procedure.

Calibrations relating the amplification factor, $K$, to the Reynolds number have been reported by several researchers. The original calibration by McCaffrey and Heskestad (1976) found that $K$ decreases from approximately $K \approx 1.5$ at $R e \approx 0$ to $K \approx 1.1$ at $R e \approx 2000$. An asymptotic value of $K=1.08$ was reported for large values of $R e$. In contrast, Kent and Schneider (1987) reported that $K$ decreascs with decrcasing $R e$ for $R e<600$. These rcsearchers reported an asymptotic value of $K=1.07$, which thcy claim is valid for all values of $R e>600$. The data of Liu et al. (1990), which correspond to bidircctional probcs of four different sizes, indicate that the amplification factor neither increases nor decreases for low values of $R e$. However, the data indicate that the uncertainty in the calibration increases significantly for small $R e$.

They reported a mean value of 1.18 for $K$ for $R e>600$ and noted that this corresponds to a differcnce of about 7 percent from the data of McCaffrcy and Heskestad (1976). For these calculations, the asymptotic value of $K$ (equal to 1.08 as reported by McCaffrey and Heskestad [1976]) was used, and the uncertainty in this value was taken as 10 percent. 
The three investigations discussed above also included measurements of the effect of yaw angle, $\theta$, on the velocity measurement. McCaffrey and Heskestad (1976) reported that the mean velocity was within \pm 10 percent provided that the approaching flow direction was known to be within approximately 50 degrees of the axis of the probe. This conclusion was based upon data obtained at a Reynolds number of 3400. Kent and Schneider (1987) explored the effect of yaw angle at $R e=900$ and concluded that their data were consistent with those of McCaffrey and Heskestad (1976). Liu et al. (1990) observed a variation of approximately 15 percent in the value of the amplification factor over the range of yaw angles $0 \leq \theta \leq 60$ degrees. Their data correspond to Reynolds numbers ranging from 300 to 550 .

Two conclusions can be drawn from the published data. First, valid measurements of the mean gas speed can be obtained provided the probe is aligned to within 50 degrees of the mean flow direction. The bidirectional probe measurement corresponds to a total velocity and cannot be decomposed into individual components. The probes were aligned perpendicular to the plane defined by the compartment openings. The flow predicted by the simulations confirmed that this was within 50 degrees of the mean flow direction. Second, the uncertainty is very large for low values of $R e$, and the measurement should be limited to regions of the velocity field where $R e>600$. For the probes used here, that corresponds to mean velocities of $V_{\min } \approx 0.5 \mathrm{~m} \mathrm{~s}^{-1}$ for $T=20^{\circ} \mathrm{C}$ and $V_{\min } \approx 3 \mathrm{~m} \mathrm{~s}^{-1}$ for $T=500{ }^{\circ} \mathrm{C}$. The probe dimensions were chosen to ensure the measurements would be in the high Reynolds number regime and thereby provide reliable data.

Bare-bead thermocouples (Type-K) were used to measure the temperature of the gas. Data obtained from bare-bead thermocouples requires a correction for radiative heating effects on the thermocouple. Aspirated thermocouples (Type-K) were used in conjunction with the bare-bead thermocouples to measure the temperature of the gas. The aspirated thermocouple data provide a check for the radiation correction and was useful in the estimate of measurement uncertainties.

\subsubsection{Sampling Locations}

The bidirectional probes and their corresponding thermocouples were placed in the inlet and outlet openings of the compartment. During Test 1, there were six probes located in the compartment inlet and eight probes at the outlet. For Tests 2 through 6, an additional two probes were added to the outlet so there were six probes at inlet locations and ten at outlet locations. A larger number of measurement locations were used at the outlet because the gradient of velocity was expected to be larger there. Table 7-1 lists the horizontal and vertical positions of the bidirectional probes. 
Table 7-1. Bidirectional probe measurement locations.

\begin{tabular}{|l|c|c|}
\hline \multicolumn{1}{|c|}{ Probe } & Inlet Measurements \\
\hline Inlet 1 & Y location & z location (from floor) \\
\hline Inlet 2 & $0.33 \mathrm{~m}$ & $0.71 \mathrm{~m}$ \\
\hline Inlet 3 & $0.33 \mathrm{~m}$ & $0.46 \mathrm{~m}$ \\
\hline Inlet 4 & $0.33 \mathrm{~m}$ & $0.25 \mathrm{~m}$ \\
\hline Inlet 5 & $1.27 \mathrm{~m}$ & $0.71 \mathrm{~m}$ \\
\hline Inlet 6 & $1.27 \mathrm{~m}$ & $0.46 \mathrm{~m}$ \\
\hline & $1.27 \mathrm{~m}$ & $0.25 \mathrm{~m}$ \\
\hline \multicolumn{1}{|c|}{ Probe } & Outlet Measurements & \\
\hline Outlet 1 & y location & z location (from floor) \\
\hline Outlet 2 & $0.33 \mathrm{~m}$ & $2.61 \mathrm{~m}$ \\
\hline Outlet 3 & $0.33 \mathrm{~m}$ & $2.36 \mathrm{~m}$ \\
\hline Outlet 4 & $0.33 \mathrm{~m}$ & $2.15 \mathrm{~m}$ \\
\hline Outlet 5 & $0.60 \mathrm{~m}$ & $2.61 \mathrm{~m}$ \\
\hline Outlet 6 & $0.60 \mathrm{~m}$ & $2.15 \mathrm{~m}$ \\
\hline Outlet 7 & $1.26 \mathrm{~m}$ & $2.61 \mathrm{~m}$ \\
\hline Outlet 8 & $1.26 \mathrm{~m}$ & $2.36 \mathrm{~m}$ \\
\hline $\begin{array}{l}\text { Outlet 9 } \\
\text { (excluding Test 1) }\end{array}$ & $1.26 \mathrm{~m}$ & $2.15 \mathrm{~m}$ \\
\hline $\begin{array}{l}\text { Outlet 10 } \\
\text { (excluding Test 1) }\end{array}$ & $-1.26 \mathrm{~m}$ & $2.61 \mathrm{~m}$ \\
\hline
\end{tabular}

\subsubsection{Thermocouple Radiation Correction}

Radiative exchange affects the bare-bead thermocouple signal because there is a differcnce between the local gas temperature and the temperature of the thermocouple bead as discussed in Section 4.2. Thus, a correction was applied to the temperature measurements. It was necessary to consider the flux of encrgy to and from the thermocouple due to radiation and convection. The thermocouple can exchange encrgy with the surrounding gas by radiation and convection. An energy balance on the thermocouple bead sets the net flux on the bead equal to the radiative and convective exchange:

$$
Q_{b} A_{b}=A_{b} \sigma \varepsilon T_{b}^{4}+A_{b} h\left(T_{b}-T_{\text {gas }}\right)
$$


Here, $Q_{b}$ is the incident radiation flux on the thermocouple bead, estimated based on FDS model predictions. $A_{b}$ is the surface area of the thermocouple bead, $T_{b}$ is the temperature of the thermocouple bead, and $T_{g a s}$ is the free stream temperature of the gas. The emissivity, $\varepsilon$, is assumed to be equal to 1.0 , and $\sigma$ is the Stefan-Boltzmann constant. The convective heat transfer coefficient, $h$, is obtained from a semi-empirical correlation for the Nusselt number, which relates the convective heat transport from the thermocouple, assumed to be spherical, to the local Reynolds number, Re, and Prandtl number, $\operatorname{Pr}$, of the fluid:

$$
N u=\frac{2 r h}{k_{g}}=2+0.6 \operatorname{Re}^{1 / 2} \operatorname{Pr}^{1 / 3}
$$

Here, $N u$ is the Nusselt number, $r$ is the bead radius, and $k_{g}$ is the thermal conductivity of the gas. To solve for the free stream gas temperature, Eq. $7-3$ is rewritten as:

$$
T_{\text {gas }}=T_{b}+\frac{\sigma \varepsilon T_{b}^{4}}{h}-\frac{Q_{b}}{h}
$$

From Eq. 7-4, the convective heat transfer coefficient, $h$ is a function of $\operatorname{Re}, \operatorname{Pr}$, and $k_{g}$, which all depend on $T_{g a s}$. An initial value for $T_{g a s}$ is assumed and an iterative process is used to solve for the correct gas temperature. These equations were developed using the study by Blevins and Pitts (1999), which contains additional information on radiation corrections for bare-bead thermocouples.

\subsection{MEASUREMENT UNCERTAINTY}

Estimation of the uncertainty in the velocity measurements involves estimation of the uncertainty of the various components of the measurement and the effect that each component has on the overall uncertainty. Computation of the overall uncertainty involved uncertainties for the pressure transducer calibrations, temperature measurements and the gas density calculation. To account for the various components that contribute to the overall uncertainty, the equations used to analyze the data are considered and a propagation-of-error analysis is performed using the following equation:

$$
u_{c}(v)=\left[\left(\frac{\partial v}{\partial \Delta P}\right)^{2} u_{c}^{2}(\Delta P)+\left(\frac{\partial v}{\partial \rho}\right)^{2} u_{c}^{2}(\rho)+\left(\frac{\partial v}{\partial K}\right)^{2} u_{c}^{2}(K)\right]^{1 / 2}
$$

Table 7-2 summarizes the estimates of the uncertainty of the various components and of the overall uncertainty of the velocity. 
Table 7-2. Velocity measurement uncertainty.

\begin{tabular}{|l|c|c|c|c|}
\hline \multirow{2}{*}{ Parameter } & \multicolumn{2}{|c|}{ Inlet } & \multicolumn{2}{c|}{ Outlet } \\
\cline { 2 - 5 } & Mean Value & Uncertainty, $\boldsymbol{u}_{c}$ & Mean Value & Uncertainty, $\boldsymbol{u}_{c}$ \\
\hline Molec. $\mathrm{Wt}^{\mathrm{a}}$ & $0.029 \mathrm{~kg} / \mathrm{mol}$ & Negligible & $0.029 \mathrm{~kg} / \mathrm{mol}$ & $0.002 \mathrm{~kg} / \mathrm{mol}$ \\
\hline$K$ (Eq. $7-1)$ & 1.08 & 0.108 & 1.08 & 0.108 \\
\hline $\mathrm{T}$ & $21{ }^{\circ} \mathrm{C}$ & $3{ }^{\circ} \mathrm{C}$ & $400{ }^{\circ} \mathrm{C}$ & $50{ }^{\circ} \mathrm{C}$ \\
\hline$\Delta \mathrm{P}$ & $1.5 \mathrm{~Pa}$ & $0.51 \mathrm{~Pa}$ & $7 \mathrm{~Pa}$ & $0.59 \mathrm{~Pa}$ \\
\hline$\rho$ & $1.20 \mathrm{~kg} / \mathrm{m}^{3}$ & $0.012 \mathrm{~kg} / \mathrm{m}^{3}$ & $0.52 \mathrm{~kg} / \mathrm{m}^{3}$ & $0.053 \mathrm{~kg} / \mathrm{m}^{3}$ \\
\hline$V$ & $1.7 \mathrm{~m} / \mathrm{s}$ & $0.29 \mathrm{~m} / \mathrm{s}$ & $5.6 \mathrm{~m} / \mathrm{s}$ & $0.57 \mathrm{~m} / \mathrm{s}$ \\
\hline
\end{tabular}

a. Molec. Wt. is an estimate of the average molecular weight of the gases near the probe.

\subsection{DISCUSSION AND RESULTS}

Velocity measurements were taken at both the inlet and the outlet of the enclosure as identified in Table 7-1. Plots of the velocities and temperatures measured at each of the inlet and outlet locations are included in Appendix D of this report, while representative data are discussed in this section. The velocities measured at the inlet increased in the seconds immediately following ignition and then remained fairly steady. Figure 7-1 shows the velocity measurement of inlet probe 1 during Test 1 . Its behavior is typical of the results measured at all inlet locations for all six tests. All of the inlet velocities measured had mean steady values between $1.5 \mathrm{~m} / \mathrm{s}$ and $2.1 \mathrm{~m} / \mathrm{s}$ with a standard deviation of approximately $\pm 0.3 \mathrm{~m} / \mathrm{s}$. To eliminate radiation effects on the measurements, the inlet gas temperature was assumed to remain at its initial ambient temperature throughout the test duration. This temperature approximation was found to have a minimal effect on the velocity mcasurement, as the velocity calculated using the assumed inlet temperature varied by less than 5.0 percent from the velocity calculated using the bare-bead thermocouple temperature.

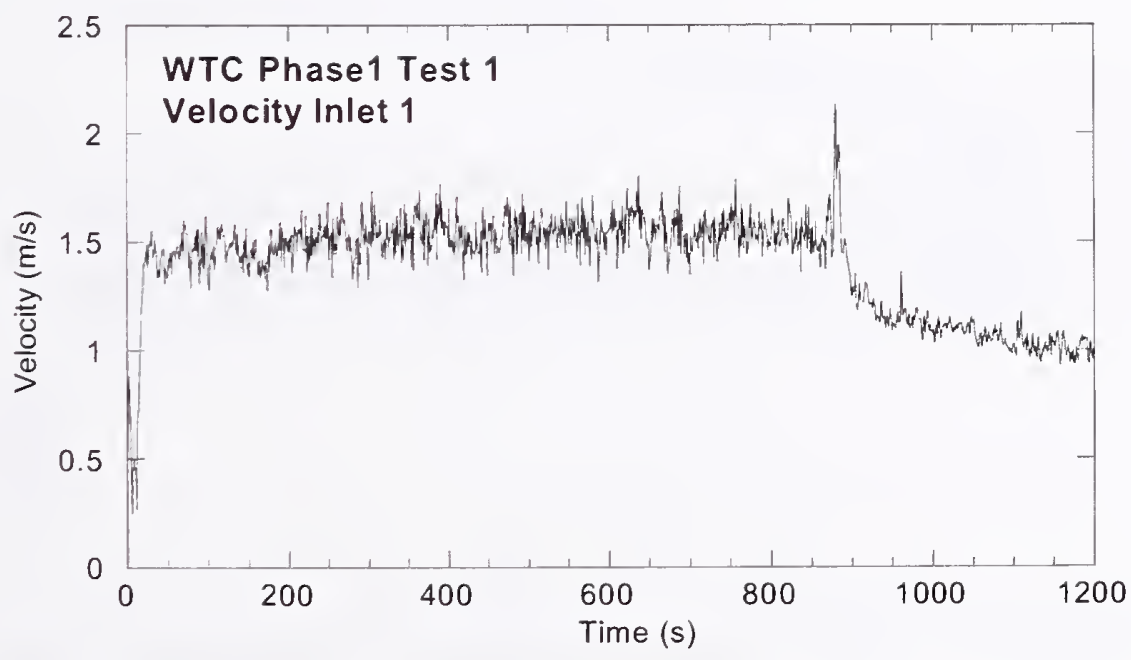

Figure 7-1. Inlet velocity measurements for Test 1 , inlet velocity probe 1. 
As expected, most of the outlet velocities rose from the beginning of the test to several minutes into the test, and many continued to increase throughout the test. The velocities varied with both the heat release rate $(\dot{Q})$ and the location. For measurements at the same location, the velocity was greater when the heat release rate was higher. This is demonstrated in Fig. 7-2, in which the velocity at location 1 in Test 1 ( $\dot{Q}=2 \mathrm{MW}$ ) was significantly smaller than in Test $4(\dot{Q}=3.2 \mathrm{MW})$. The mean velocity for Test 1 increased from approximately $6.0 \mathrm{~m} / \mathrm{s}$ to approximately $6.5 \mathrm{~m} / \mathrm{s}$ during the test. The increase in mean velocity during Test 4 was much steeper, again starting near $6.0 \mathrm{~m} / \mathrm{s}$, but reaching nearly $10 \mathrm{~m} / \mathrm{s}$ over the same time period as Test 1 . The increased velocity for higher heat release rate $(\dot{Q})$ tests was consistent for all locations. Another example is shown in Fig. 7-3, where the velocity at location 10 for Test 3 ( $\dot{Q}=2 \mathrm{MW}$ ) was lower than for Test $5(\dot{Q}=3 \mathrm{MW})$.

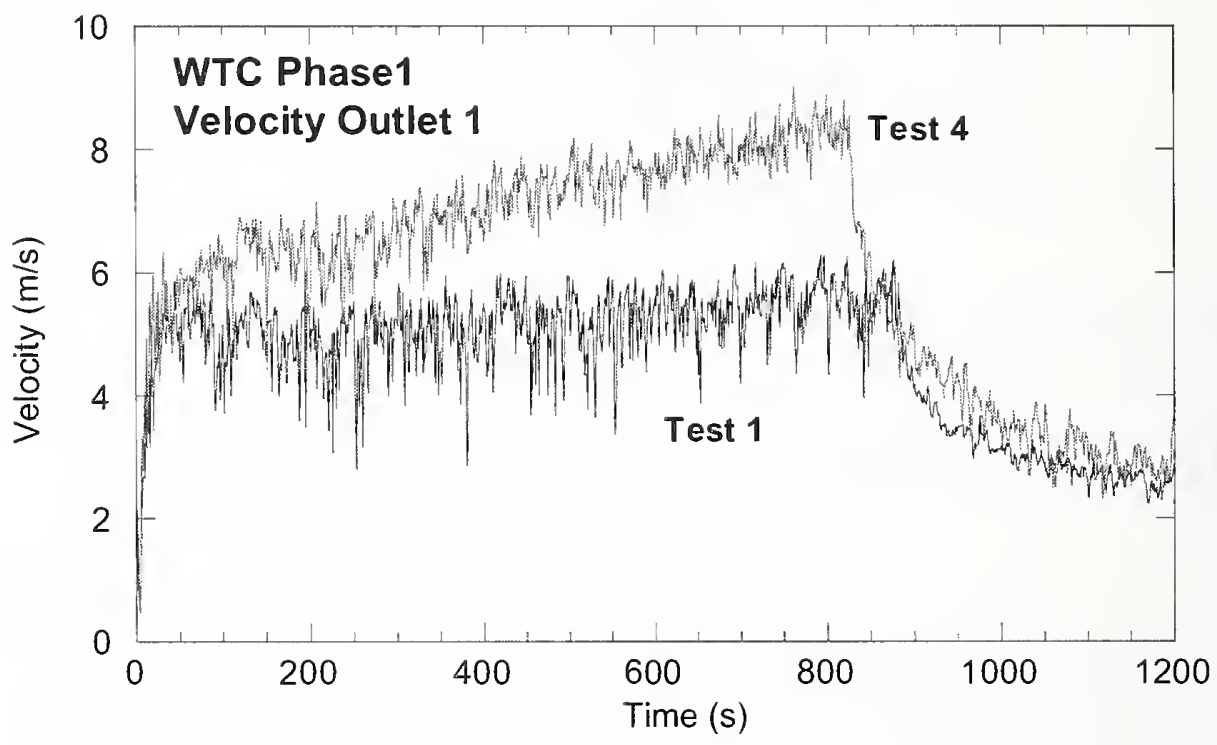

Figure 7-2. Outlet velocity at location 1 for Test 1 and Test 4.

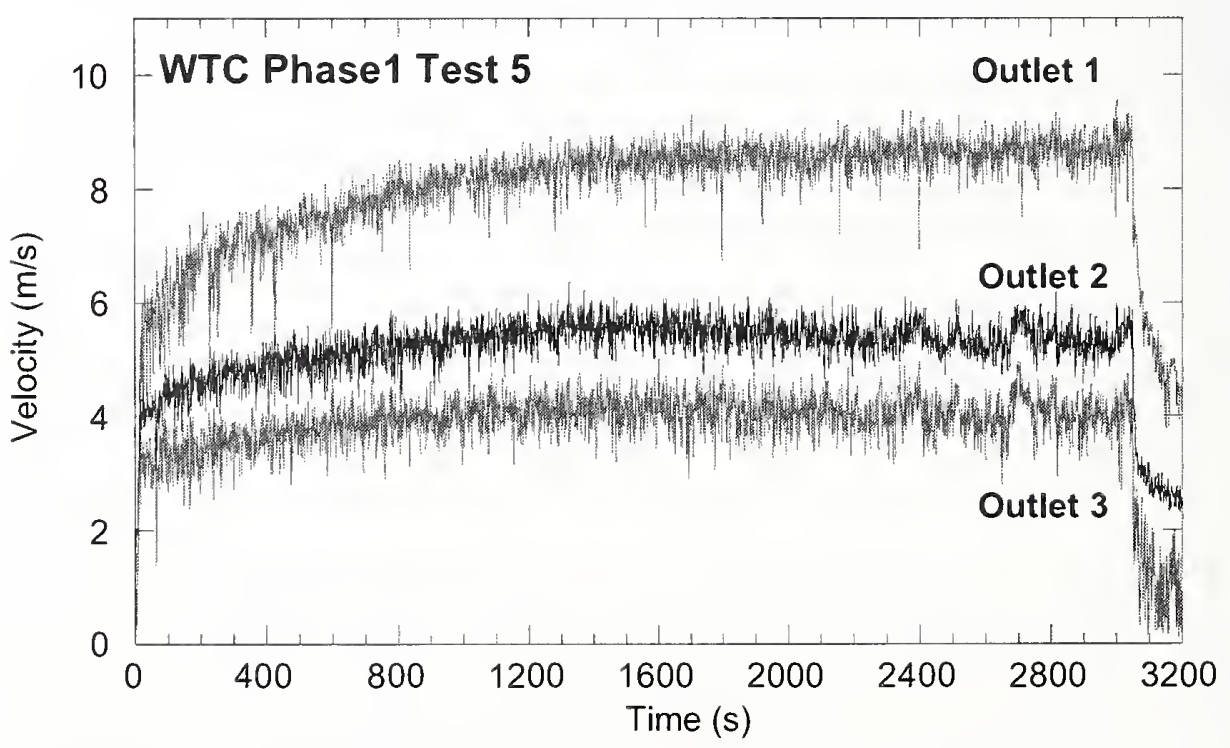

Figure 7-3. Outlet velocity at location 10 for Test 3 and Test 5. 
The measurements indicate that the gas velocity was greatest at the top of the vent and decreased with height. Figure 7-4 shows an example of the measured outlet velocities for probes at locations 1,2 , and 3 during Test 5 . These three probes were aligned vertically. Location 1 was at the uppermost location, $61 \mathrm{~cm}$ above the vent opening. location 2 was in the middle, $35.5 \mathrm{~cm}$ above the vent opening, and location 3 was the lowest location, $15 \mathrm{~cm}$ above the vent opening. The velocity at location 1 was greatest, and decreased for lower locations in the vent. This trend for probes at 1,2, and 3 was consistent for all of the tests. In general, the upper probes recorded higher velocities than the lower ones for the other sets of probes aligned vertically. Some of the locations, however, saw more fluctuations and there was some amount of overlapping. Figure 7-5 illustrates another example of probes aligned vertically during Test 5, this time with location 6 as the uppermost location, location 7 in the middle, and location 8 as the lowest. The velocity at location 7 was consistently higher than the velocity at location 8 . The velocity at 6 (shown with dotted line), however, overlapped the other velocities during the early part of the test, before finally surpassing the other velocities about $25 \mathrm{~min}$ into the test. The velocity at location 6 deviated from the mean much more than the other measurement locations, fluctuating by about $\pm 1 \mathrm{~m} / \mathrm{s}$ or more compared to about $\pm 0.5 \mathrm{~m} / \mathrm{s}$ for the other locations. The velocity at location 6 behaved in this manner for all of the tests.

A comparison of Figs. 7-4 and 7-5 shows that the outlet velocities were not symmetric about the enclosure, which was consistent with the non-symmetric appearance of the fire. The probes at locations 6,7 and 8 were positioned at the same heights as probes 1,2 and 3, respectively. But, as seen in Fig. 7-5 for Test 5, the velocities at location 7, approximately $7 \mathrm{~m} / \mathrm{s}$, were greater than the velocities at location 2, approximately $5.5 \mathrm{~m} / \mathrm{s}$, and the velocities measured at location 8 , approximately $5 \mathrm{~m} / \mathrm{s}$, were greater than those at location 3 , less than $4 \mathrm{~m} / \mathrm{s}$, even though these probes were at the same heights in the outlet. The velocity at location 6 was consistently lower than location 1 during the first half of the test, and the velocity at location 6 fluctuated much more than at location 1.

Figure 7-6 is an example of non-symmetry in measurements across the enclosure outlet. The figure shows the velocities for Test 3 at the lowest location, $15 \mathrm{~cm}$ above the vent opening. Location 8 was closest to the south wall, followed by location 5 , location 3 , and location 10 , which was closest to the north wall. As shown in Fig. 7-6, the velocities were higher at the outermost locations, 8 and 10, than at inner locations 5 and 3. This trend of lower velocities at the inner locations for the lower row of probes was evident during all of the tests. although the magnitudes of the velocities varied.

The opposite was seen for the probes at the uppermost location in the outlet, $61 \mathrm{~cm}$ above the opening. The probes near the center of the compartment, locations 4 and 1, measured higher velocities than the probes at the outermost locations of the compartment, at locations 6 and 9. This is shown in Fig. 7-7, which plots the mean velocities for probes at outlet locations $6,4,1$, and 9 for Test 3. Mean velocities are plotted because the measurements were all within $2 \mathrm{~m} / \mathrm{s}$ of each other and often overlapped. Similar results were obtained in all six tests. With the exception of Test 2 , the velocity at location 9 was lower than the other velocities at this height in the outlet. 


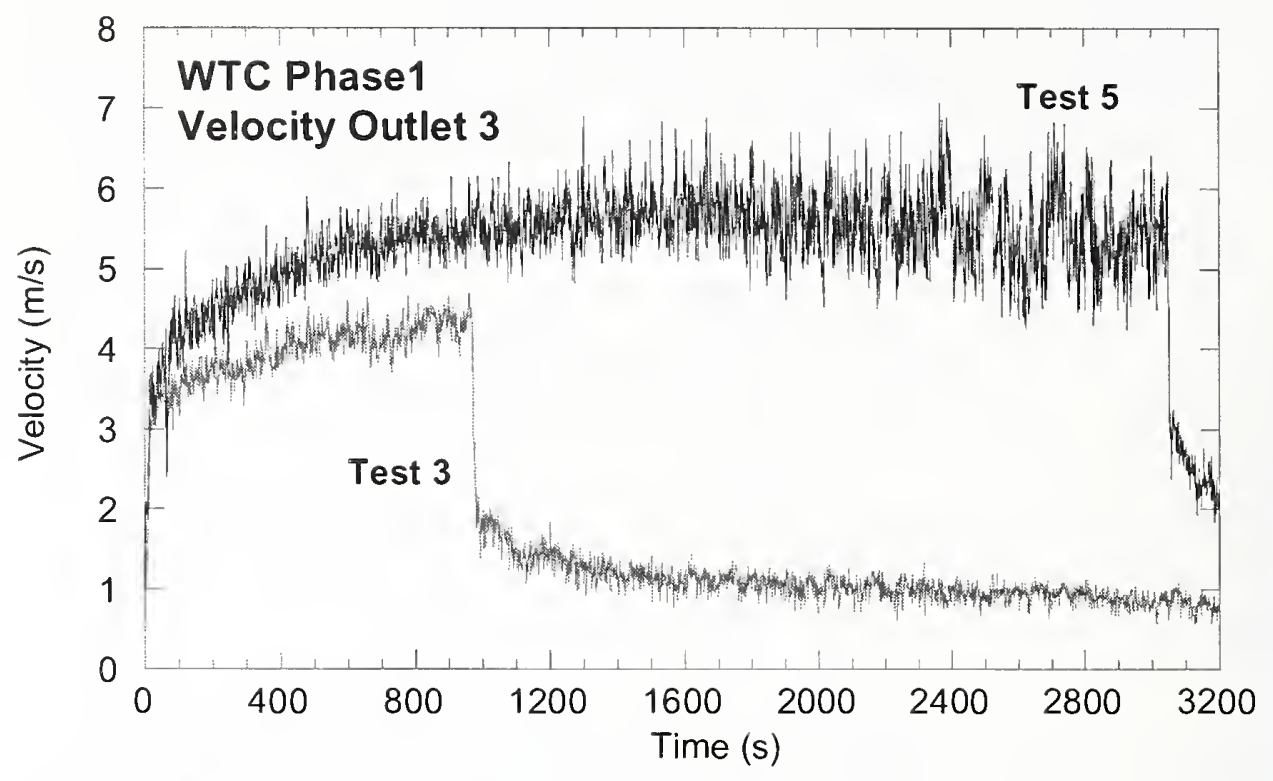

Figure 7-4. Outlet velocities for Test 5 at probe locations 1, 2, and 3.

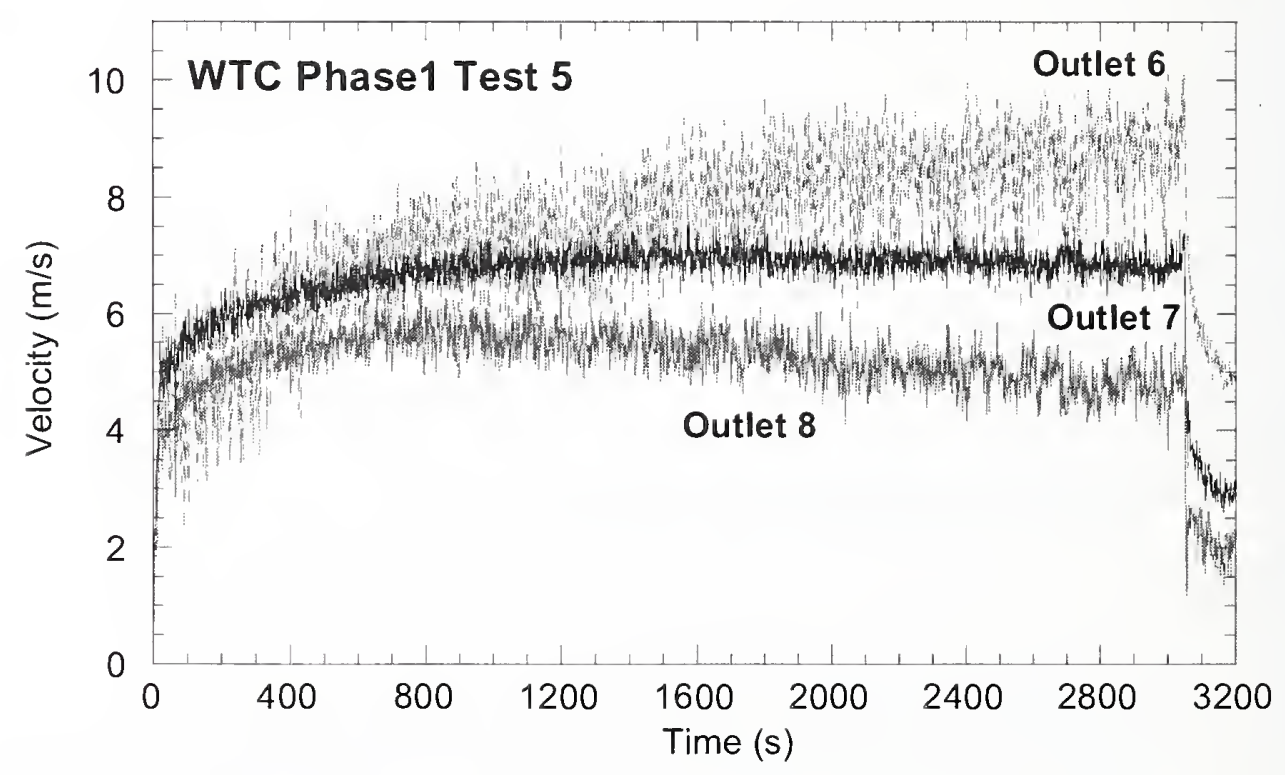

Figure 7-5. Outlet velocities for Test 5 at outlet locations 6, 7, and 8. 


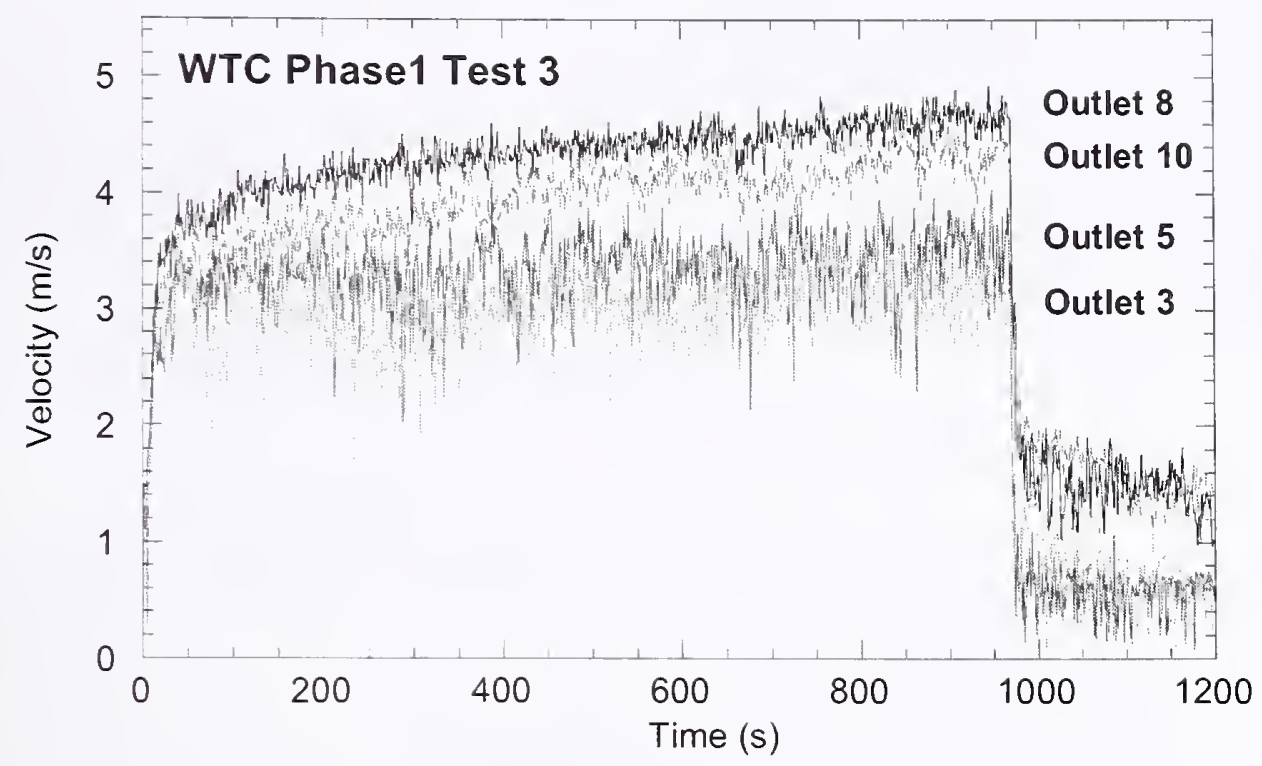

Figure 7-6. Outlet velocities for probes located $15 \mathrm{~cm}$ above vent opening, Test 3. Outlets 8 and 10 are the probes toward the sides of the compartment, while outlets 5 and 3 are closer to the center of the compartment.

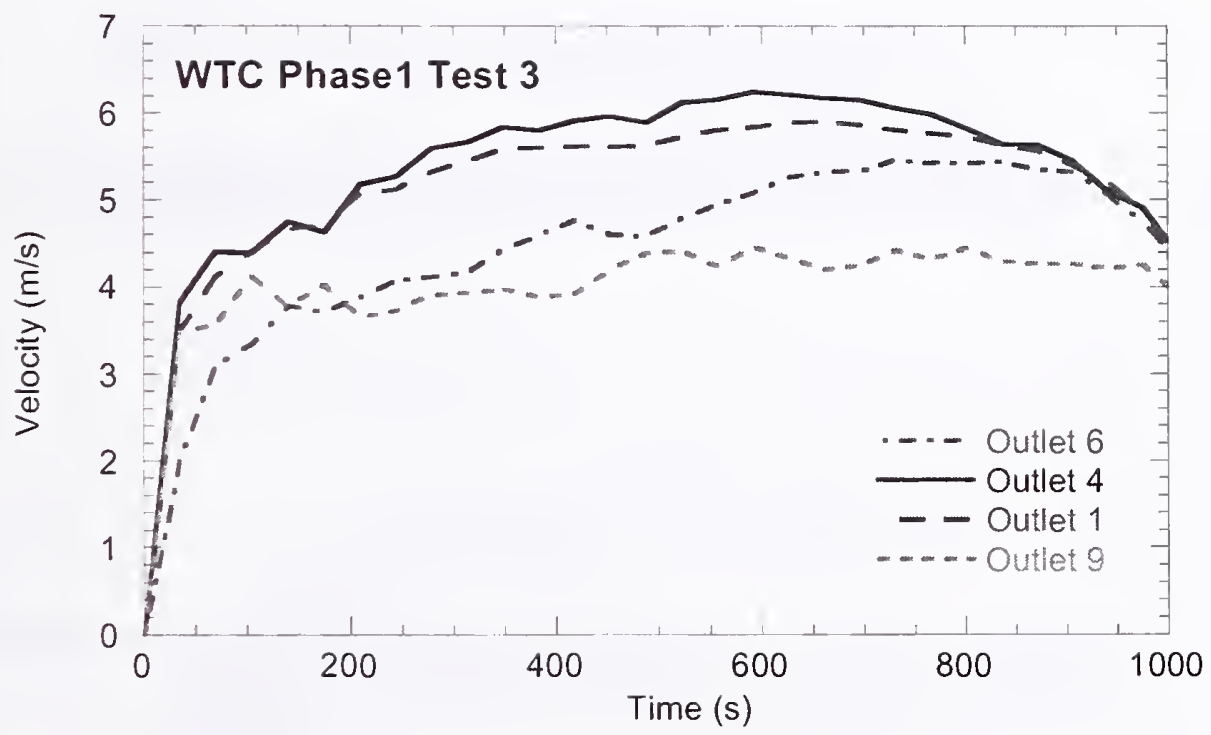

Figure 7-7. Outlet velocities for probes located $61 \mathrm{~cm}$ above vent opening in Test 3 . Outlets 6 and 9 are toward the side, while outlets 4 and 1 are closer to the compartment center. 


\subsection{RADIATION CORRECTION}

The outlet velocities were computed using a gas temperature value that was corrected for radiation effects using values of $Q_{b}$ taken from the FDS simulations. The corrected gas temperature $T_{\text {gas }}$ was found by reducing the measured bare-bead temperature $T_{b}$ by a correction $\Delta T$ according to $T_{b}-\Delta T=T_{\text {gas }}$. The term $\Delta T$ is from Eq. 7-3, which can be rewritten as:

$$
\Delta T=\frac{Q_{b}}{h}-\frac{\sigma \varepsilon T_{b}^{4}}{h}
$$

Equation 7-7 illustrates the separation of the temperature correction into a flux term $\left(Q_{b} / h\right)$ and a radiative loss term $\left(\sigma \varepsilon T_{b} / h\right)$. The temperature correction is an approximation since it uses the predicted flux from the model simulations. Figure 7-8 shows the difference between the measured thermocouple bead temperature, $T_{b}$, and the corrected gas temperature, $T_{\text {gas }}$, at outlet location 9 for Test 6 . Here, the corrected gas temperature differs from the measured bead temperature by up to $140^{\circ} \mathrm{C}$. This particular example represents one of the largest temperature corrections for all of the data. Most temperature corrections were $50^{\circ} \mathrm{C}$ or less.

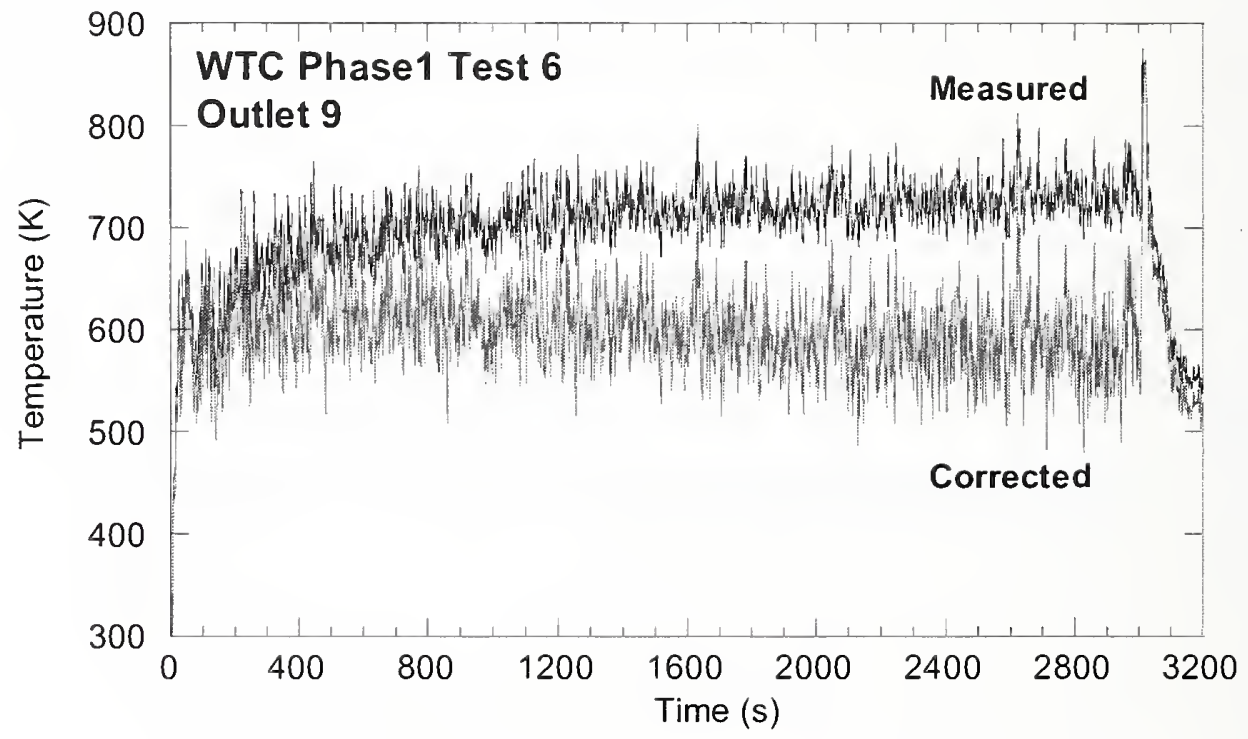

Figure 7-8. Comparison of the measured temperature and corrected temperature in Test 6 at outlet 9.

Figure 7-9 is a plot of the magnitudes of the two components of the temperature correction from Eq. 7-5. The flux component is larger than the radiative component and increases significantly as the test progresses, causing a greater temperature correction for the latter part of the test. Aspirated thermocouples were used in addition to the many bare-bead thermocouples because aspirated thermocouples have lower measurement uncertainty. The expanded uncertainty in the aspirated thermocouple measurements was approximately $7{ }^{\circ} \mathrm{C}$ (Blevins and Pitts 1999). Aspirated thermocouple measurements were taken at outlet location 5. Additional aspirated thermocouple measurements were attempted at outlet location 4 , but due to equipment failure measurements were not successful. Figure 7-10 compares the temperatures measured with the aspirated thermocouple to the corrected and uncorrected temperature measurements 
using the bare-bead thermocouple at outlet location 5 during Test 5 . As expected, the temperatures measured by the aspirated thermocouple were lower than those measured directly by the bare-bead thermocouples. As shown in Fig. 7-10, the aspirated thermocouple temperature measurements were within $50^{\circ} \mathrm{C}$ of the bare-bead temperatures corrected for radiation. Data for the other five tests included in Appendix D show that the temperatures recorded by the aspirated thermocouples were within approximately $50{ }^{\circ} \mathrm{C}$ of the corrected temperatures for all of the tests. The value of these differences was taken as the uncertainty in the bare-bead temperature measurements and is consistent with uncertainties estimated for the thermocouple trees reported in Chapter 4.

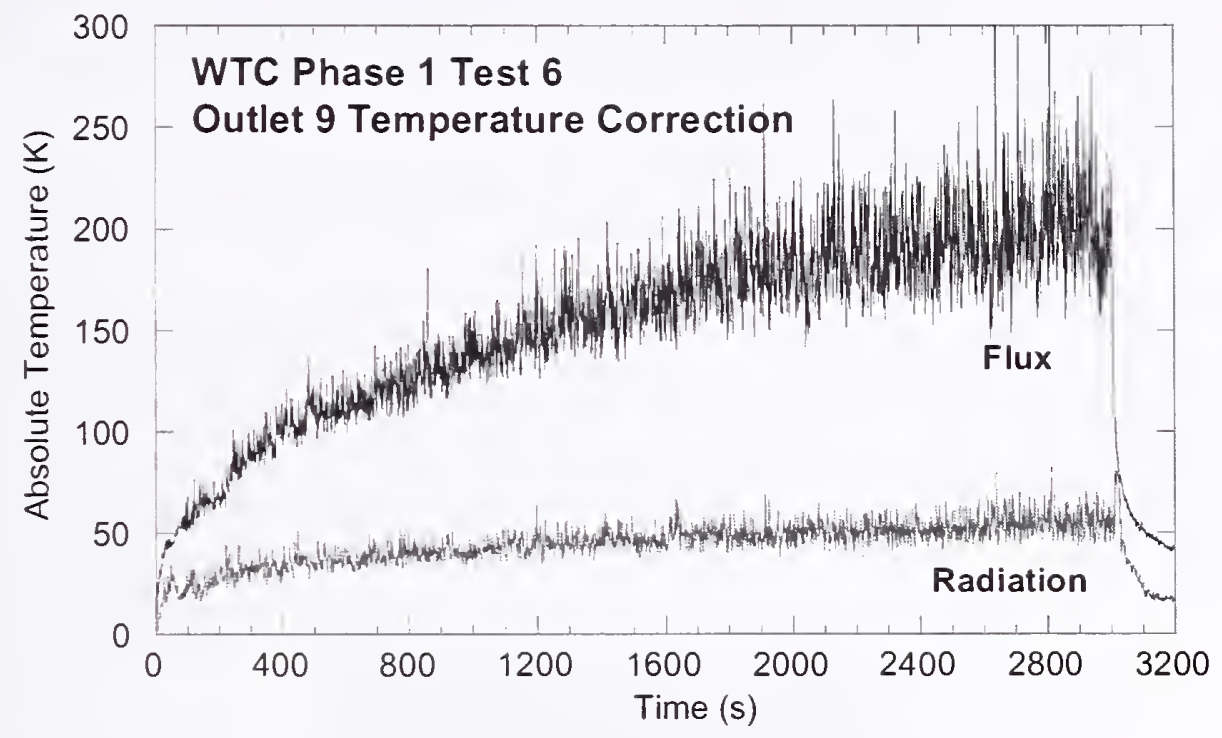

Figure 7-9. Comparison of the component of temperature correction due to incoming flux and the component of temperature correction due to radiative loss.

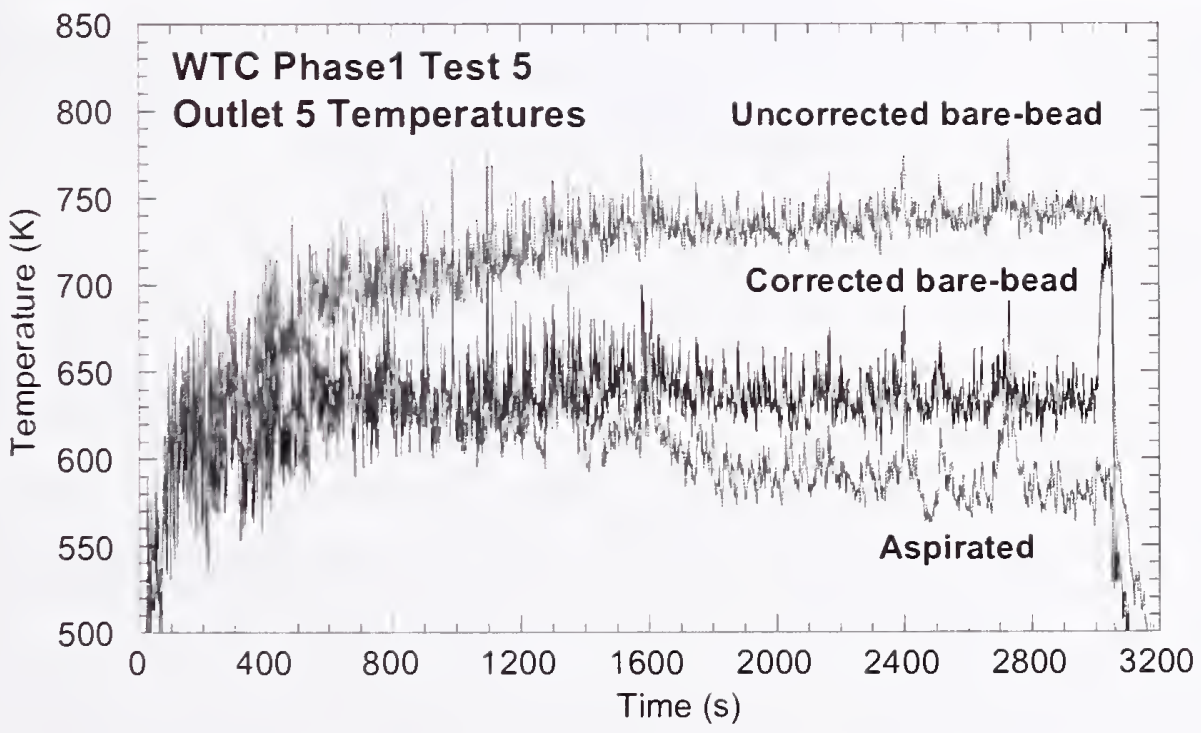

Figure 7-10. Comparison of bare-bead temperature measurements with aspirated temperature measurements in Test 5 at outlet 5. 
The diffcrence between the aspirated thcrmocouple reading and the corrected temperature is due to using an estimated value for the radiant flux when computing the corrected temperatures. As described in Section 7.1.2, model predictions of the radiant flux on the thermocouple bead were used in the corrections because actual flux measurements at these locations were not available. The corrected bare-bead temperature measurements were used to compute the velocity because aspirated thermocouple data was available at only one location. The $50^{\circ} \mathrm{C}$ uncertainty in the temperature had only a small effect on the velocity computations, as shown in Fig. 7-11. Here, the mean velocity computed using the corrected bare-bead thermocouple temperature is compared with the mean velocity calculated using the aspirated temperatures. The resulting difference in the mean velocity was less than 6 pcrcent. The temperature uncertainty contributed to the uncertainty of the velocity measurement as described in Sec. 7.2 and listed in Table $7-2$.

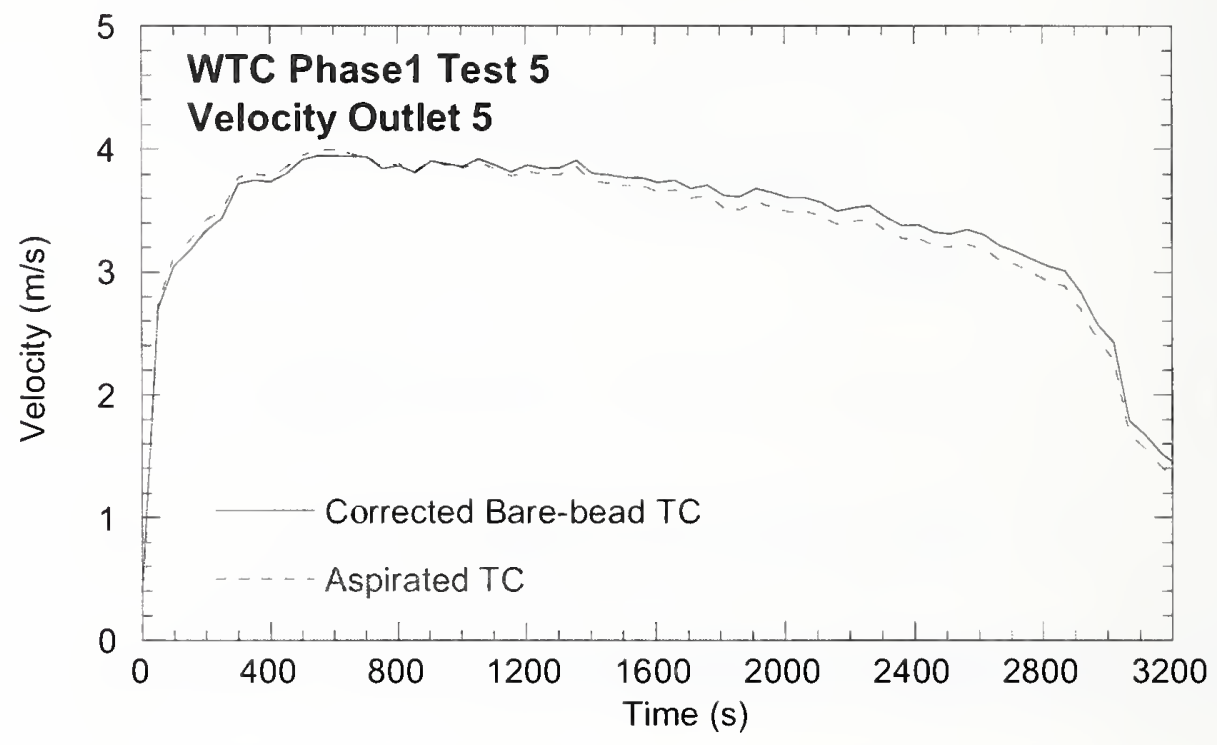

Figure 7-11. Comparison of the mean velocity computed using bare-bead temperature measurements with the mean velocity computed using aspirated temperature measurements in Test 5 at outlet 5.

\subsection{REFERENCES}

Blevins, L.G., and W.M. Pitts. 1999. Fire Safety Jonnnal, 33, 239-259, 1999; or see NISTIR 6310, April. Available at: http://ire.nist.gov/bfrlpubs/fire99/PDF/f99022.pdf.

Kent, L.A., and M.E. Schneider. 1987. ISA Transactions, 26, 25-32.

Liu, C.Y., Y.W. Wong, W.K. Chan, and T.C. Gan. 1990. Experiments in Fluids, 9, 354-356.

McCaffrey, B.J., and G. Heskestad. 1976. Combust. Flame, 26, 125-127. 


\section{Chapter 8 \\ COMPARTMENT SURFACE TEMPERATURE MEASUREMENTS}

\subsection{INSTRUMENTATION}

The compartment surfaces were composed of two $1.27 \mathrm{~cm}$ sheets of calcium silicate board (referred to as Marinite) that were tightly held together by screws. The temperature of the inner compartment surface was measured at select locations on the ceiling and walls using thermocouples. The exact position of the thermocouples is given in the list of instrumentation (see Appendix B). Approximately 25 gauges were located on the surface of the ceiling, while 6 gauges were located between the two $1.27 \mathrm{~cm}$ Marinite layers in the ceiling.

The thermocouples were type $\mathrm{K} 30$ gauge $(0.25 \mathrm{~mm}$ wire diameter). The thermocouple beads were created by removing approximately $1 \mathrm{~cm}$ of insulation from the Chromel and Alumel lead wires and spot welding them together. The mean bead diameter was approximately two times the wire diameter. Each thermocouple bead was attached to the Marinite surface by spring-loading it (bending it near the end so the bead pushed against the surface) and lightly peening the bead into the surface. The insulated thermocouple leads were attached to the Marinite by a staple approximately $2 \mathrm{~cm}$ from the bead. Figure $8-1$ is a photograph of a thermocouple mounted on the Marinite surface.

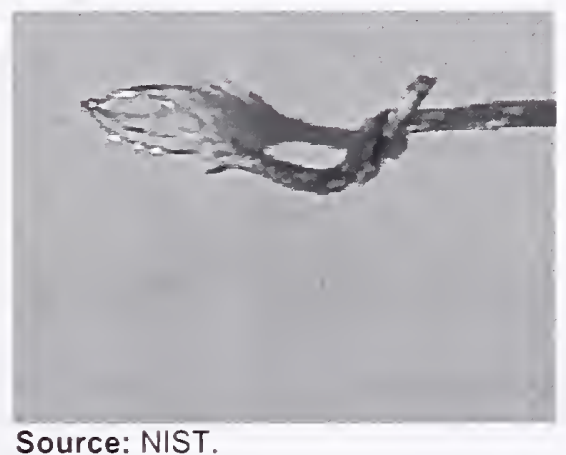

Figure 8-1. A type $\mathrm{K}$ thermocouple attached to the Marinite surface.

\subsection{MEASUREMENT UNCERTAINTY}

An uncertainty analysis associated with the thermocouple measurement of the Marinite surface temperature is presented. The analysis is similar to that presented in Chapter 9 of this report on the uncertainty in the measurement of the steel surface temperature using thermocouples. Two contributors to the uncertainty were considered. The first is the inherent expanded uncertainty associated with a type $\mathrm{K}$ thermocouple, which is approximately $5{ }^{\circ} \mathrm{C}$ (Omega 2000). The second contributor is related to the systematic difference in the measurement affected by the presence of the thermocouple itself.

Although it may be possible to develop an analytic expression for the systematic measurement error as a function of time, this would necessarily entail the solution of a non-linear, unsteady problem, which is not straight forward, or require the inclusion of possibly overly restrictive simplifying assumptions. Although 
an analytic steady-state solution may be simple, the transient analysis presented here is not so. In addition, the transient problem is the most important as it leads to a much larger systematic measurement error than the steady-state solution.

The error in the measurement arises from the fact that the actual measurement location is at the thermocouple bead and not at the Marinite surface. Of course, the surface temperature of the Marinite influences the thermocouple bead temperature, but there is a difference between the temperature of the bead and the surface due to the various heat transfer processes that occur. Several mechanisms contribute to the temperature measured at the thermocouple bead, including radiative and convective heat transfer from the hot gas layer to the bead and lead wires of the thermocouple, as well as conductive transfer from the bead to the Marinite, from the lead wires to the bead, and along the lead wires.

The systematic measurement error was considered using a finite-element code (ANSYS 2003) for the simplified geometry presented in Fig. 8-2. An idealized spherical thermocouple bead was peened to the surface of a flat Marinite slab taken to be $2.5 \mathrm{~cm}$ thick. Thermocouple lcad wires were attached to the bcad and extend away from the Marinite surface. The lead wire diameter was $0.25 \mathrm{~mm}$ ( 30 gauge), and the bead diameter was taken to be twice the diameter of the wire leads, consistent with measurements of the thcrmocouple used in the experiment. One-half of the bead was embedded in the Marinite. Although composed of two different metals, the thermocouple was assumed to consist of only one material to simplify the computation through application of symmetry conditions. Multiple calculations, using each of the component materials, were performed to assess the validity of this assumption.

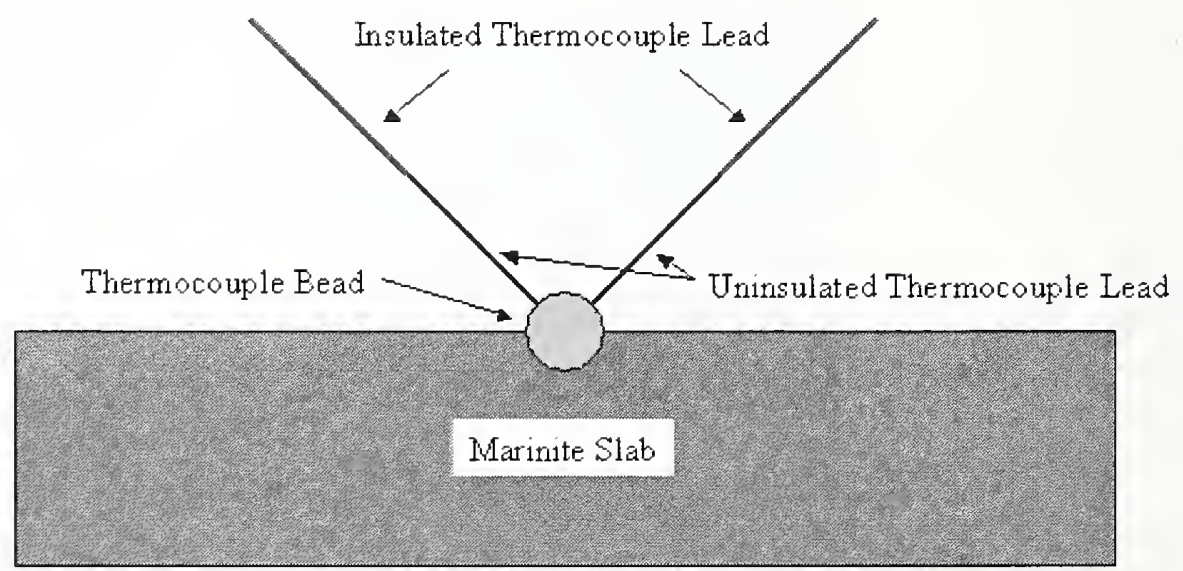

Figure 8-2. Simplified configuration used for the numerical analysis.

Representative thermophysical properties of the materials comprising a Type $\mathrm{K}$ thermocouple were based on literature values (Omega 2000). Representative thermophysical properties for the Marinite were taken from a testing report (Taylor 2003). The properties of interest at ambient temperature are listed in Table 8-1. The temperature dependence of the Marinite properties was incorporated into the analysis, but was neglected for the thermocouple materials. Replicate calculations were performed using a different set of thermophysical properties for the Marinite as suggested by the manufacturer, with negligible effect on the results. The emissivities of the Marinite and thermocouple surfaces were taken to equal one, assuming that the surfaces were rapidly covered with soot during the experiment. 
Table 8-1. Thermophysical properties of Marinite, Chromel, and Alumel.

\begin{tabular}{|l|c|c|c|}
\hline \multicolumn{1}{|c|}{ Material } & $\begin{array}{c}\text { Density } \\
\left(\mathbf{k g} / \mathbf{m}^{\mathbf{3}}\right)\end{array}$ & $\begin{array}{c}\text { Heat Capacity } \\
(\mathbf{J} / \mathbf{k g ~ K})\end{array}$ & $\begin{array}{c}\text { Conductivity } \\
(\mathbf{W} / \mathbf{m ~ K} \mathbf{~})\end{array}$ \\
\hline Marinite $^{\mathrm{a}}$ & 669 & $778-1,223$ & $0.111-0.198$ \\
\hline Alumel $^{\mathrm{b}}$ & 8,600 & 523 & 29.7 \\
\hline Chromel $^{\mathrm{b}}$ & 8,730 & 448 & 19.2 \\
\hline
\end{tabular}

a. Taylor 2003.

b. Omega 2000.

The temperature of the thermocouple bead was taken as an average across the entire bead. The lead wires were taken sufficiently long so that the end condition could be assumed to be at ambient conditions outside of the test compartment. The first $1 \mathrm{~cm}$ of lead wire from the thermocouple bead was left uninsulated as in the experiment, while the remaining length was covered with a perfect insulator. In the calculations, heat conduction through the leads was balanced by conduction into the Marinite, and the leads were heated by radiation.

To test the efficacy of the model developed here for the systematic measurement error, the calculation results were compared to experimental measurements. Tests 2 and 5 were selected as representative of the fires observed during the experimental sequence. Test 2 was a $2.4 \mathrm{MW}$ heptane/toluene fire, whereas Test 5 was a 3.0 MW heptane fire. Aspirated thermocouple measurements (see Chapter 4) were used to estimate the incident heat flux to the ceiling by assuming that heat transfer was dominated by radiation from a sooty upper gas layer. Convection was neglected because heat transfer occurs predominantly by radiation for gas temperatures of this magnitude. Reradiation from the exposed Marinite surface and the thermocouple was considered. To obtain appropriate boundary conditions for the unexposed back surface of the Marinite, a Biot number $(B i)$ was computed:

$$
B i=\frac{h l}{k}
$$

Because of the low thermal conductivity of the Marinite, $\mathrm{Bi}>>1$, implying that convection of heat away from the unexposed back surface provided a thermal resistance small compared with the heat conduction through the Marinite. It was reasonable to assume a constant temperature on this surface, equal to the ambient temperature.

The results of the simulation for Test 2 are presented in Figs. 8-3 and 8-4. Figure 8-3 plots the measured aspirated gas temperature at location $(604 \mathrm{~cm}, 53 \mathrm{~cm}, 365 \mathrm{~cm})$, the measured ceiling surface thermocouple temperature at $(612 \mathrm{~cm}, 60 \mathrm{~cm}, 382 \mathrm{~cm})$, and predicted thermocouple temperatures for two values of the gas emittance (Siegel and Howell 2002). For an emittance of 0.6, the predicted thermocouple temperature resembles that observed during the experiment at early times. As the test proceeded, the thermocouple temperature was underpredicted. For a gas emittance of 0.8 , the predicted thermocouple temperature was high for early times, but the data late in the tcst were more closely predicted. These two values provide upper and lower bounds for the upper gas layer emittance during Test 2. 


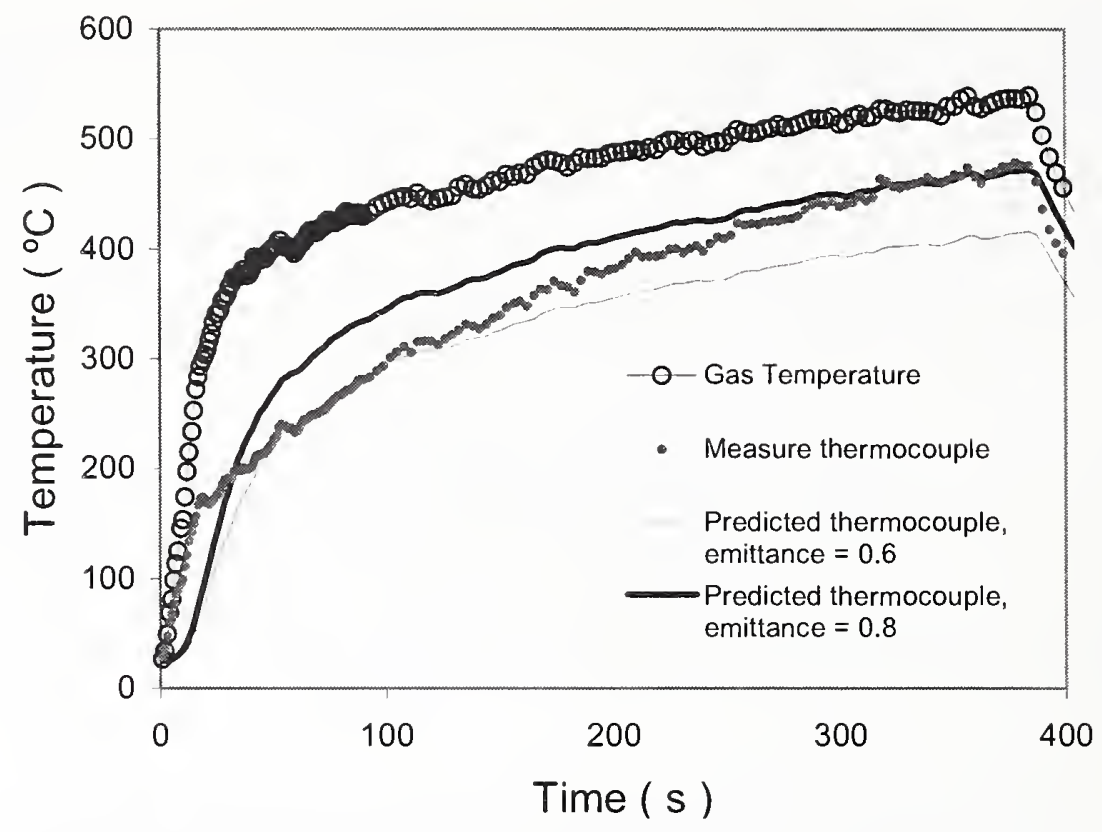

Figure 8-3. Comparison of the measured and predicted ceiling surface thermocouple temperature in Test 2. The measured gas temperature is also shown.

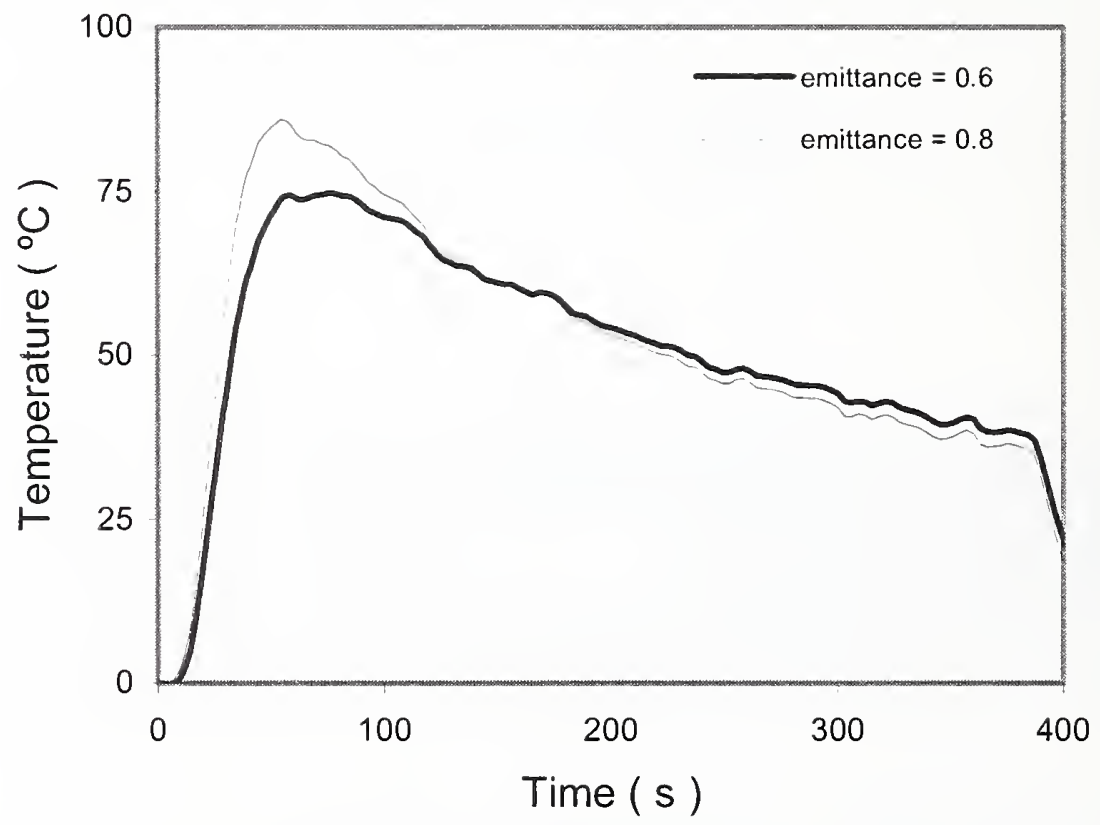

Figure 8-4. The simulated thermocouple temperature minus the simulated Marinite surface temperature for two values of the upper layer emittance in Test 2.

Figure 8-4 presents the uncertainty in the measurements by plotting the difference between the predicted thermocouple temperature and the predicted Marinite surface temperature for bounding values of the upper layer emittance. At early times, there is a significant difference between the two temperatures, on the order of $75^{\circ} \mathrm{C}$ to $85^{\circ} \mathrm{C}$. This difference decayed as the test proceeded until it obtained a value of nearly $35^{\circ} \mathrm{C}$ when the fuel flow was stopped. The reason for the temperature difference was due to the heat that was rapidly transferred to the bead early in the test, which was unable to rapidly diffuse into the 
Marinite because of its highly insulating properties. The relatively large thermal mass of the Marinite (as compared to the thermocouple) exhibited a slower heating and, thus, there was a lag in the Marinite surface temperature as compared to the thermocouple.

Figures 8-5 and 8-6 present the results for simulation of Test 5. In Fig. 8-5, the measured gas temperatures, the measured thermocouple temperatures, and the predicted thermocouple temperatures are plotted. Predicted thermocouple temperatures for a gas layer emittance of 0.8 and 1.0 provide upper and lower bounds for the upper gas layer emittance. The 0.8 and 1.0 emittance values adequately match the measurements for early and later times in the experiment, respectively.

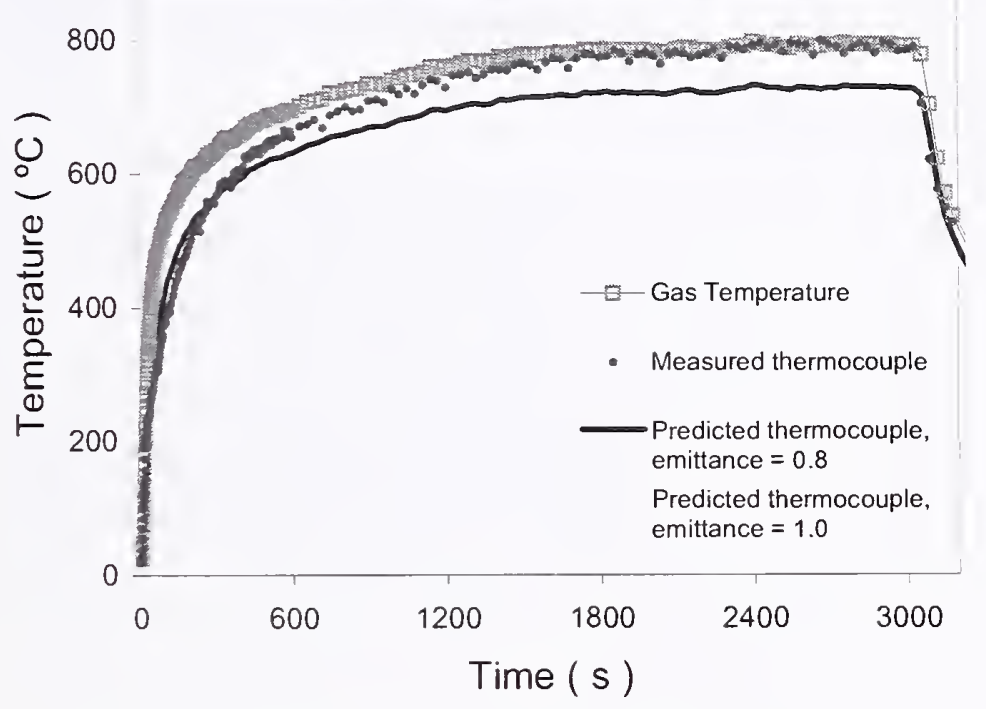

Figure 8-5. Comparison of the measured and predicted ceiling surface thermocouple temperatures for Test 5 . The measured gas temperature is also shown.

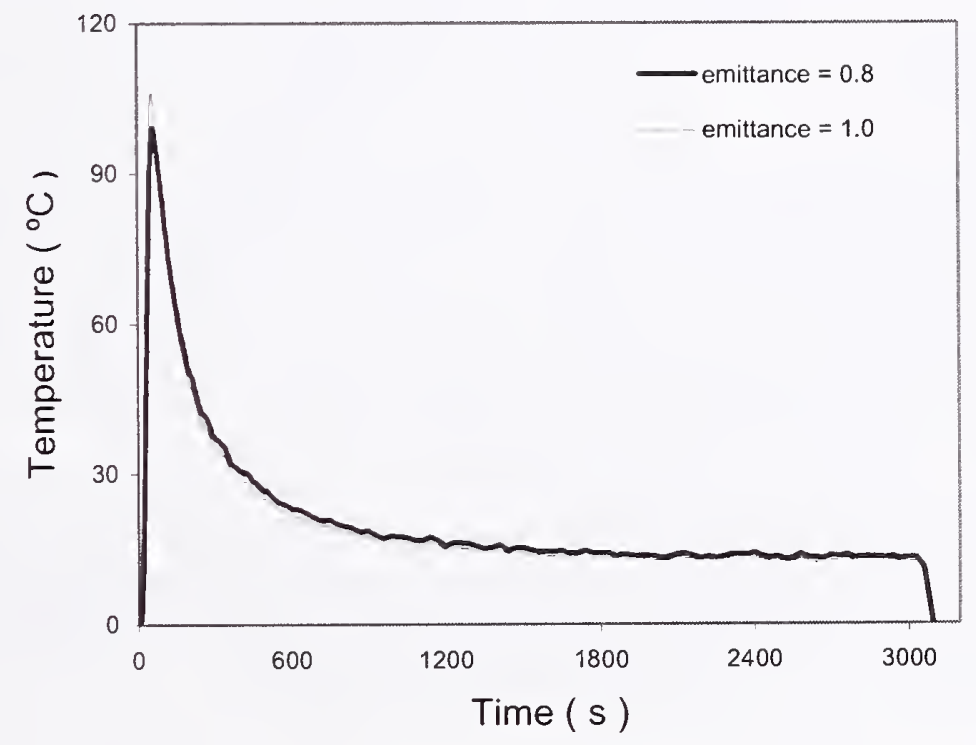

Figure 8-6. The simulated thermocouple temperature minus the simulated Marinite surface temperature for two values of the upper layer emittance in Test 5. 
Figure 8-6 plots the difference between the thermocouple and Marinite surface obtained from the simulations. As in Test 2, significant differences are observed early in the experiment, with values on the order of $100^{\circ} \mathrm{C}$. The differences are greater for Test 5, as the fire was more intense and the upper layer temperatures were larger. Again, there is a gradual decay in the difference as time progresses, obtaining a value of $13{ }^{\circ} \mathrm{C}$ after long times. This difference is due to the competition between the various heat transfer mechanisms that are present. Because the Marinite has one surface exposed to the ambient, there will be some conductive heat transfer across its thickness. Conservation of energy dictates that the radiative loss from the Marinite surface must be less than the net incident heat flux to account for this conduction, lowering the exposed surface temperature of the Marinite. A similar mechanism is present for the thermocouple, but because it is in contact with the hot surface of the Marinite and because of its small mass, the effect will be significantly less. This disparity results in the steady state temperature difference.

In summary, Marinite surface thermocouple measurements were found to possess a high degree of systematic error during initial phases of the fire exposure due to the relatively large insulating properties of the Marinite and the low thermal mass of the thermocouple. The error diminished as steady state conditions were approached. After long times, the error was as little as $13{ }^{\circ} \mathrm{C}$. If the systematic error is treated like a measurement uncertainty, then the total expanded uncertainty is bounded by $-8{ }^{\circ} \mathrm{C}$ and $-18^{\circ} \mathrm{C}$. For times at which there are large temporal changes in the incident flux, it is difficult to quantify the systematic error due to uncertainty in the boundary conditions. This is exemplified by the significant differences between the model and measurements seen for early times in the experiment in Fig. 8-3. Therefore, tests of model predictions for the Marinite are most meaningful at later times in the experiments, when systematic measurement error was small. This will be considered in Chapter 11, when measurement results are compared to simulations.

\subsection{DISCUSSION OF RESULTS}

Figure 8-7 shows the measured ceiling temperature as a function of time at 15 locations along the centerline ( $\mathrm{x}$ axis) of the compartment during Test 1 . The temperatures rapidly rose from ambient to greater than $100^{\circ} \mathrm{C}$ within $15 \mathrm{~s}$. The temperatures varied as a function of location on the ceiling. After the rapid initial rise, the temperatures increased in a near-linear fashion until the fuel flow was closed, and the measured temperatures dropped precipitously. Data were acquired for a significant period after the fuel flow was stopped. This information may also be useful for validation of heat transfer sub-models without the complications of the presence of a fire plume. The scatter in the data varied from $3{ }^{\circ} \mathrm{C}$ to $30{ }^{\circ} \mathrm{C}$ and was largest for positions above the fire and smallest for locations away from the fire. Regular fluctuations were observed for a few locations that were affected by the $\mathrm{N}_{2}$ purging of nearby total heat flux gauges (see Chapter 5). This was particularly noticeable after the fire was stopped.

Figure 8-8 shows the temperatures between the Marinite layers as a function of time during Test 1 . The temperatures measured bctween the Marinite layers obtained a maximum about $160 \mathrm{~s}$ after the fuel flow was stopped (at $860 \mathrm{~s}$ ), driven by conduction from the relatively high, but falling surface temperatures even after the fire was stopped. The temperatures varied as a function of location, but were much lower than the surface temperatures. 


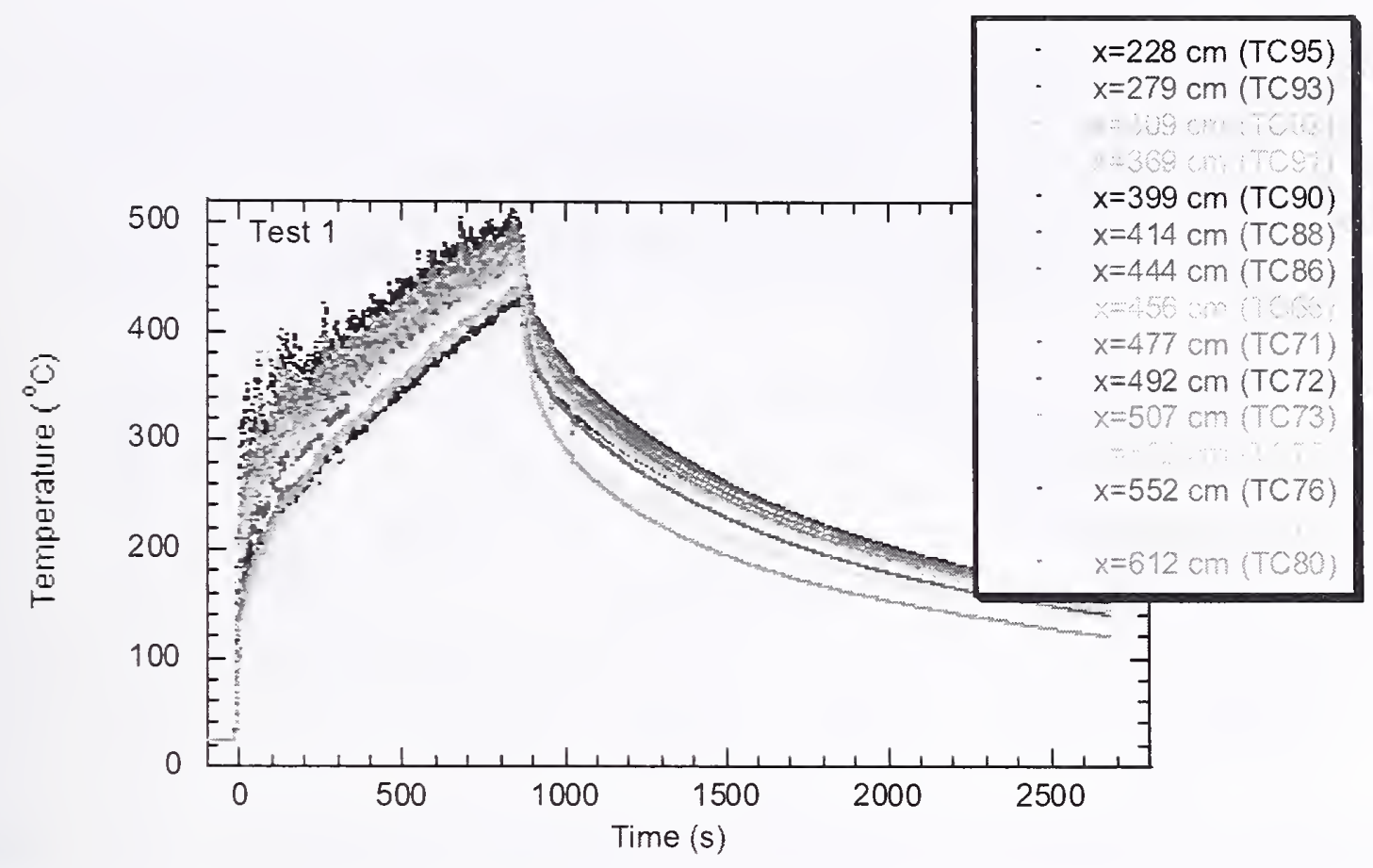

Figure 8-7. The measured ceiling temperatures as a function of time at 15 locations along the compartment centerline ( $x$ axis) during Test 1.

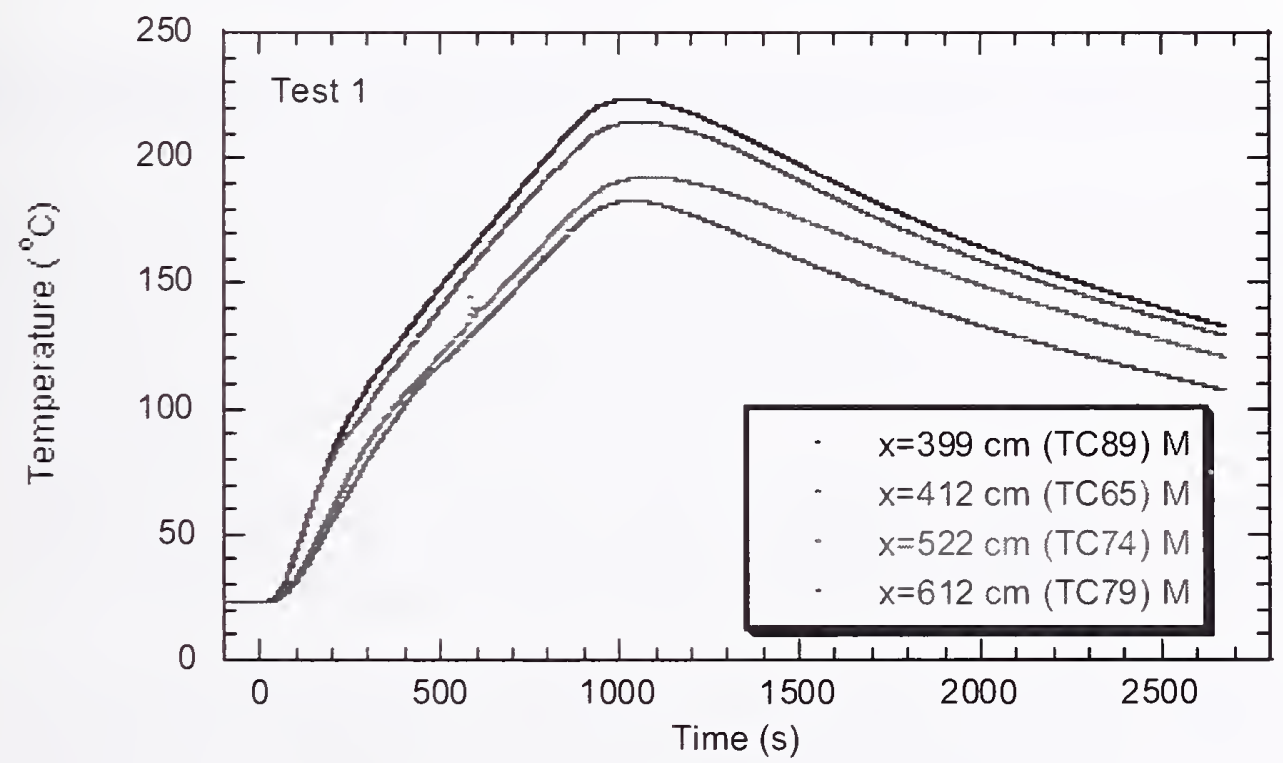

Figure 8-8. The measured temperatures between the two Marinite sheets in the ceiling along the compartment centerline ( $x$ axis) as a function of time at several locations during Test 1. 
Figure 8-9 uses a portion of the temperature data shown in Figs. 8-7 and 8-8. Figure 8-9 shows the peak ceiling temperatures as a function of location on the centerline (x axis) $860 \mathrm{~s}$ after fire initiation, when the temperatures were at their peak values and the fuel flow was stopped. The highest temperatures were measured almost above the fuel pan, extending from $x=342 \mathrm{~cm}$ to $442 \mathrm{~cm}$ (see Fig. 2-5). Figure 8-9 also shows the peak temperature measured between the Marinite layers 1,020 s after fire initiation. The value of the peak temperatures decreased with distance away from the fuel pan, following the ceiling surface temperatures.

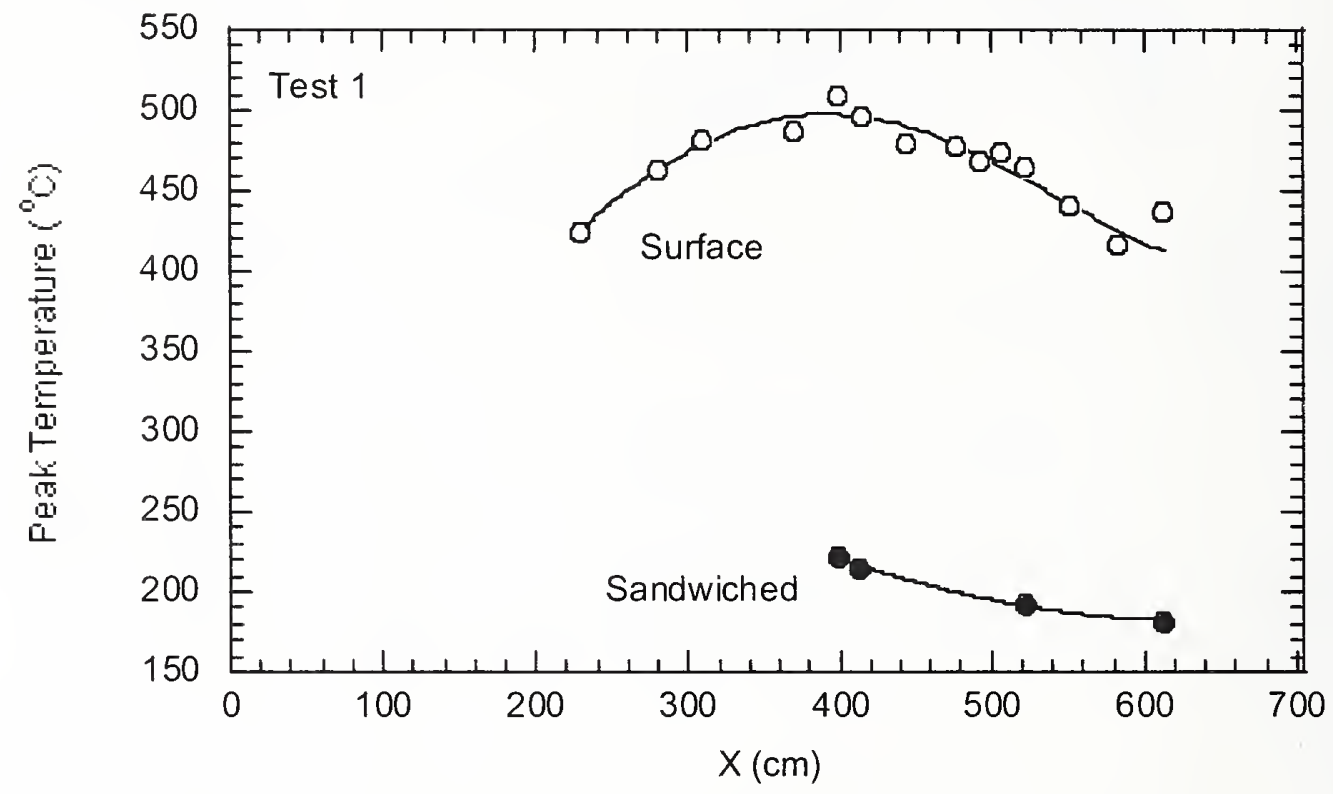

Figure $8-9$. The peak temperatures on the ceiling surface and sandwiched between
Marinite ceiling layers along the compartment centerline ( $x$ axis) during Test 1.

The ceiling surface temperature also varied along the y axis, in the north-south direction, due to the leaning of the fire toward the south wall. The reasons for asymmetry of the fire may be attributed to asymmetry in the placement of compartment contents such as the column and the instrumentation support, which were both located on the northern half of the compartment. Figure 8-10 shows the time varying ceiling surface temperatures for various locations on the $y$ axis at $x=456 \mathrm{~cm}$ during Test 5 . Similar results were seen in the other tests. The peak values of the ceiling surface temperature at $\mathrm{x}=456 \mathrm{~cm}$ (shown in Fig. 8-10 at 2,950 s) are re-plotted in Fig. 8-11 as a function of $\mathrm{y}$ location. The results at $\mathrm{x}=612 \mathrm{~cm}$ are also shown. Both sets of measurements are consistent with the observation that the flame was leaning toward the south wall. Similar results were obtained for the other tests.

Figures 8-12 through 8-21 show the peak surface and middle ceiling temperatures as a function of time after fire initiation for Tests 2 through 6 . The plots qualitatively resemble Figs. $8-7$ and $8-8$. The highest peak temperatures were attained during Tests 5 and 6 , when the fire duration was approximately $50 \mathrm{~min}$, the longest of all of the tests. 


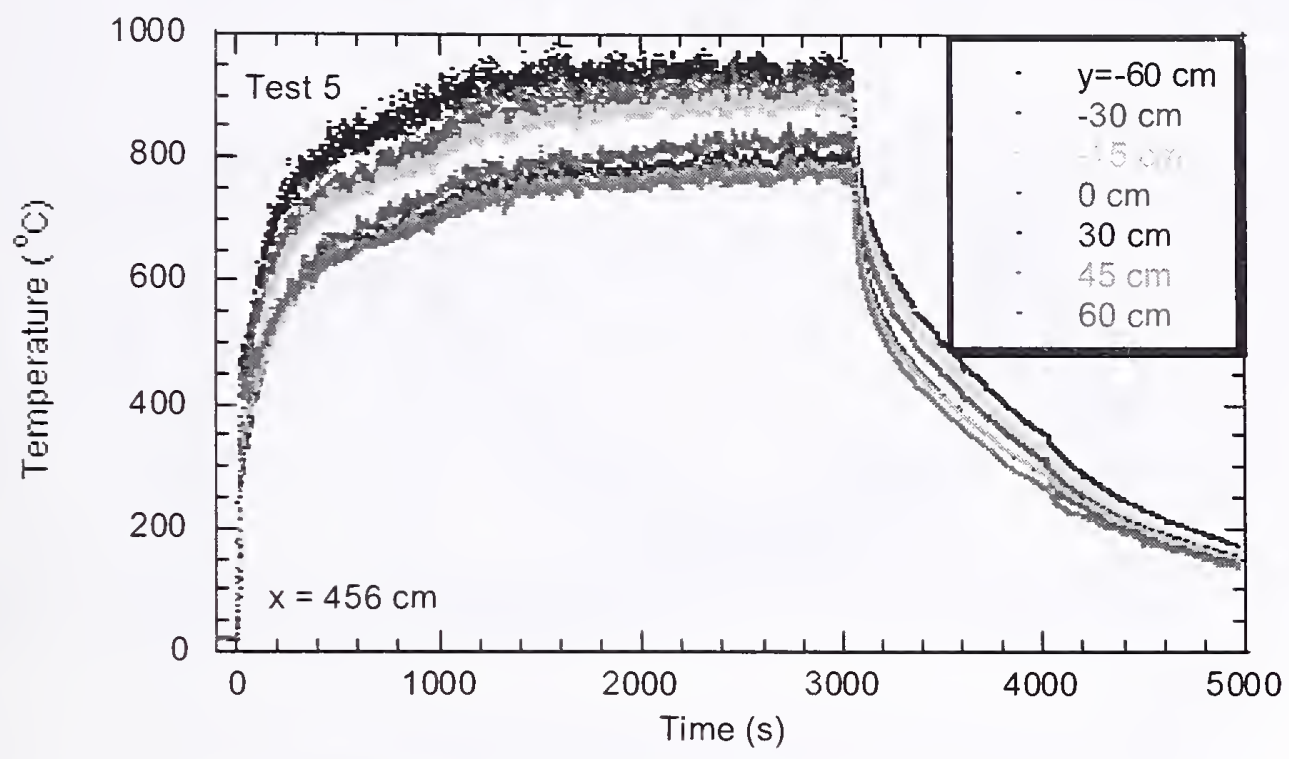

Figure 8-10. The measured ceiling surface temperatures as a function of time at seven locations along the $y$ axis at $x=456 \mathrm{~cm}$ during Test 5 .

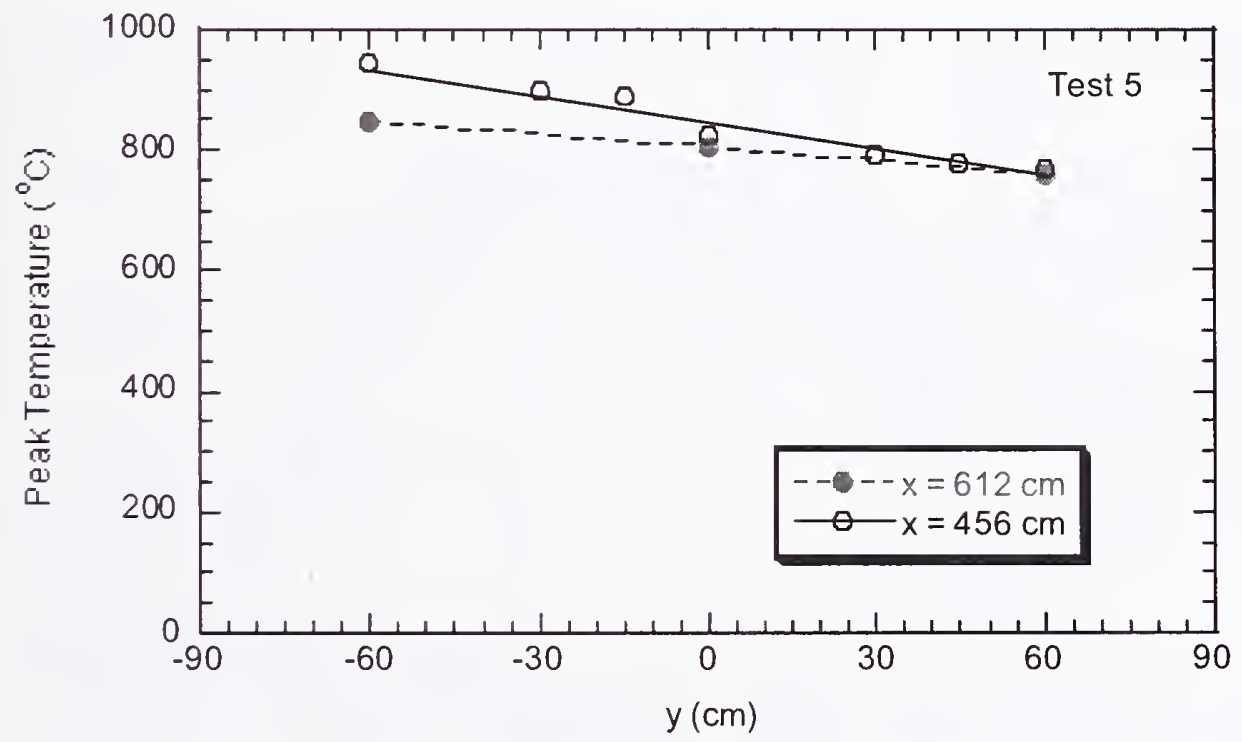

Figure 8-11. The measured peak ceiling surface temperatures as a function of location along the $y$ axis at two $x$ locations $(x=456 \mathrm{~cm}$ and $x=612 \mathrm{~cm})$ during Test 5 . 


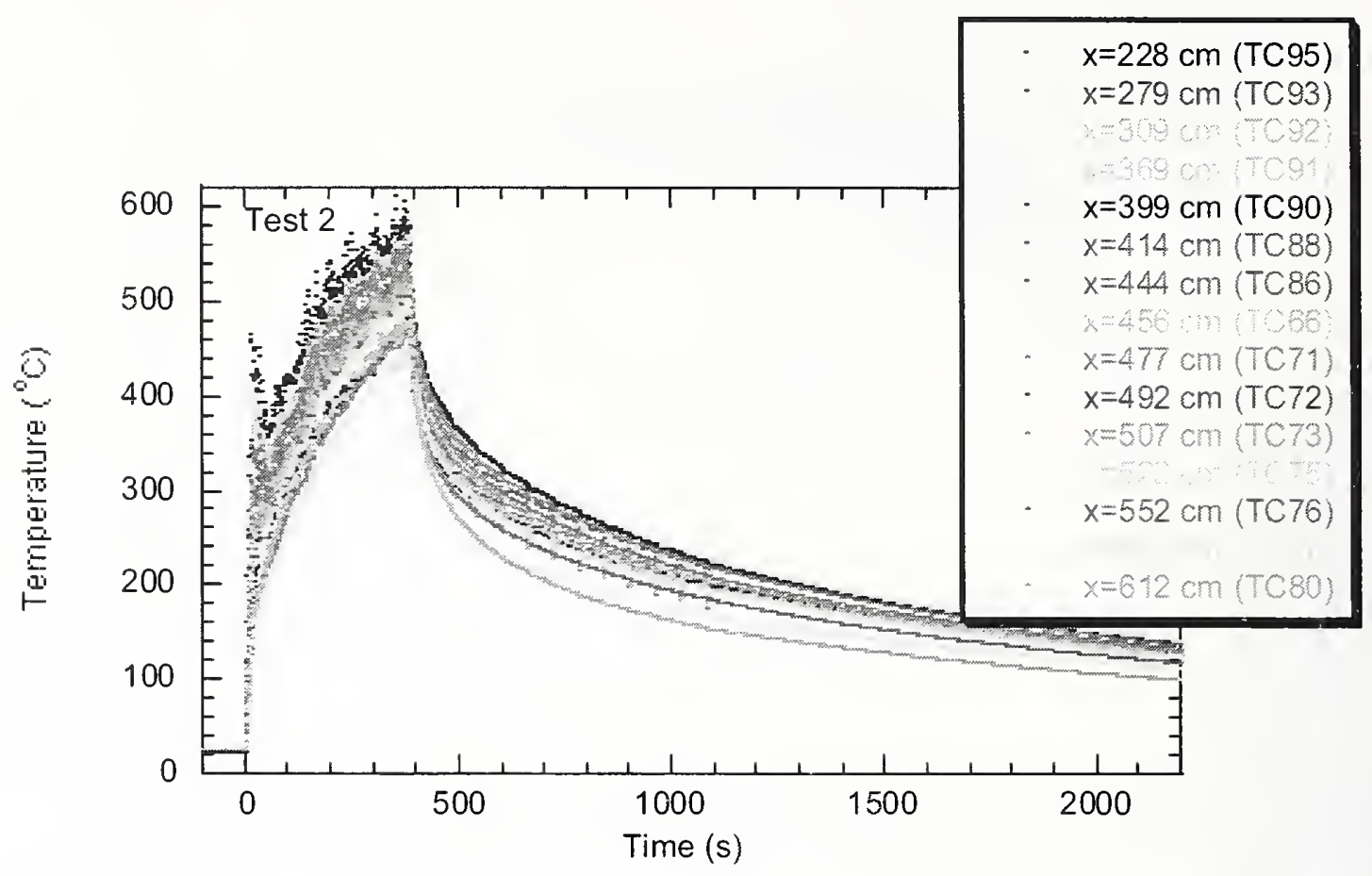

Figure 8-12. The measured ceiling temperatures as a function of time at 15 locations along the compartment centerline ( $x$ axis) during Test 2.

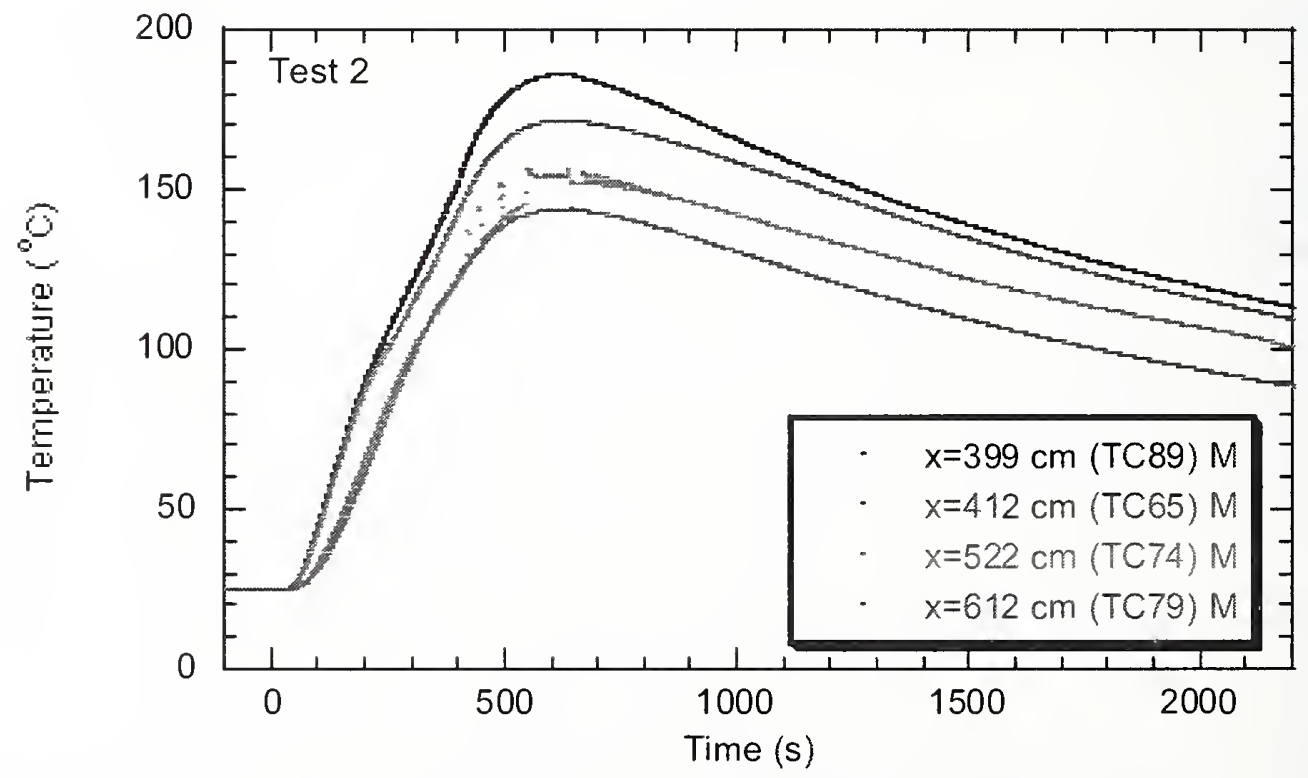

Figure 8-13. The measured temperatures between the two Marinite sheets in the ceiling along the compartment centerline ( $x$ axis) as a function of time at several locations during Test 2. 


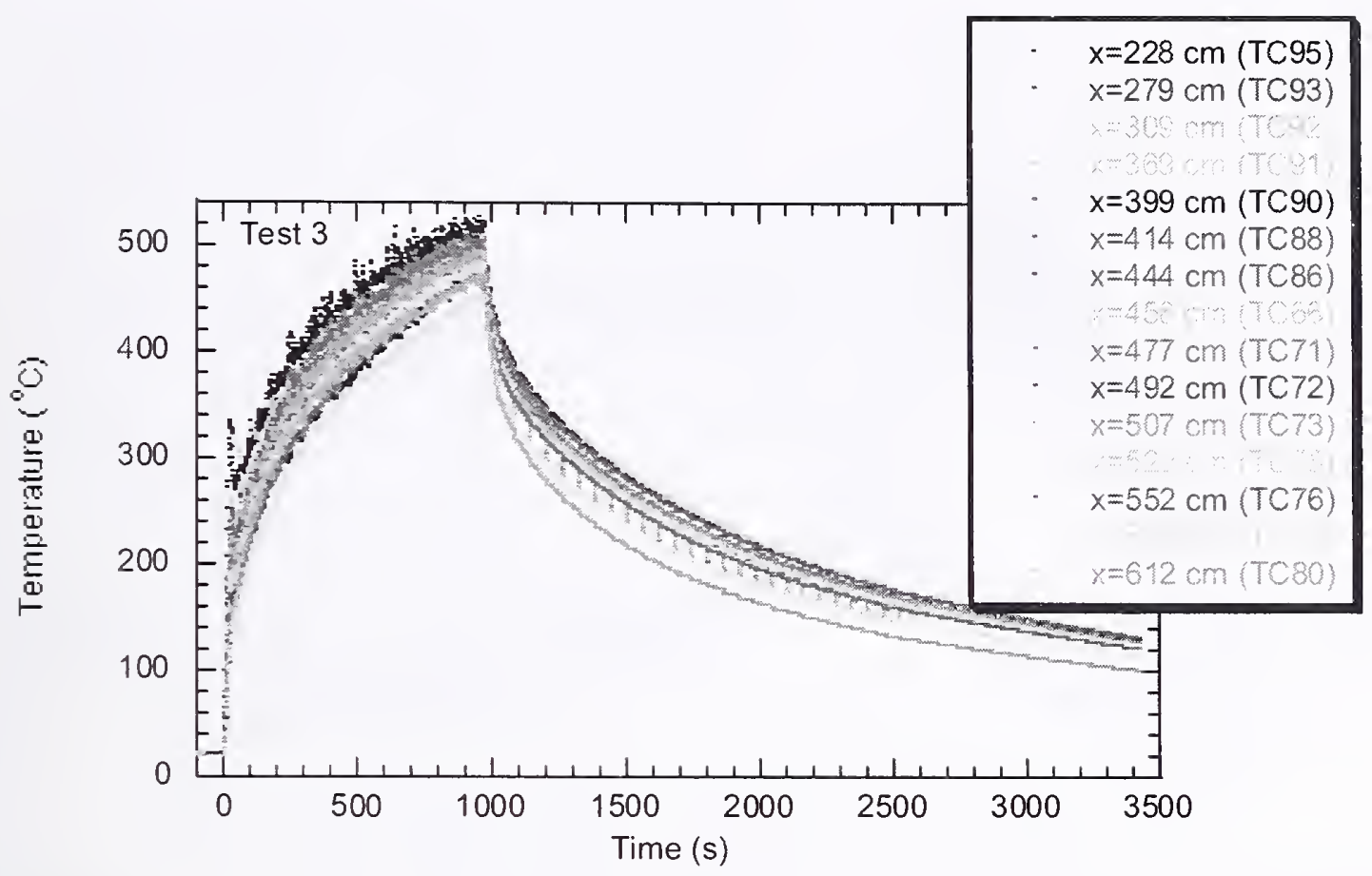

Figure 8-14. The measured ceiling temperatures as a function of time at 15 locations along the compartment centerline ( $x$ axis) during Test 3.

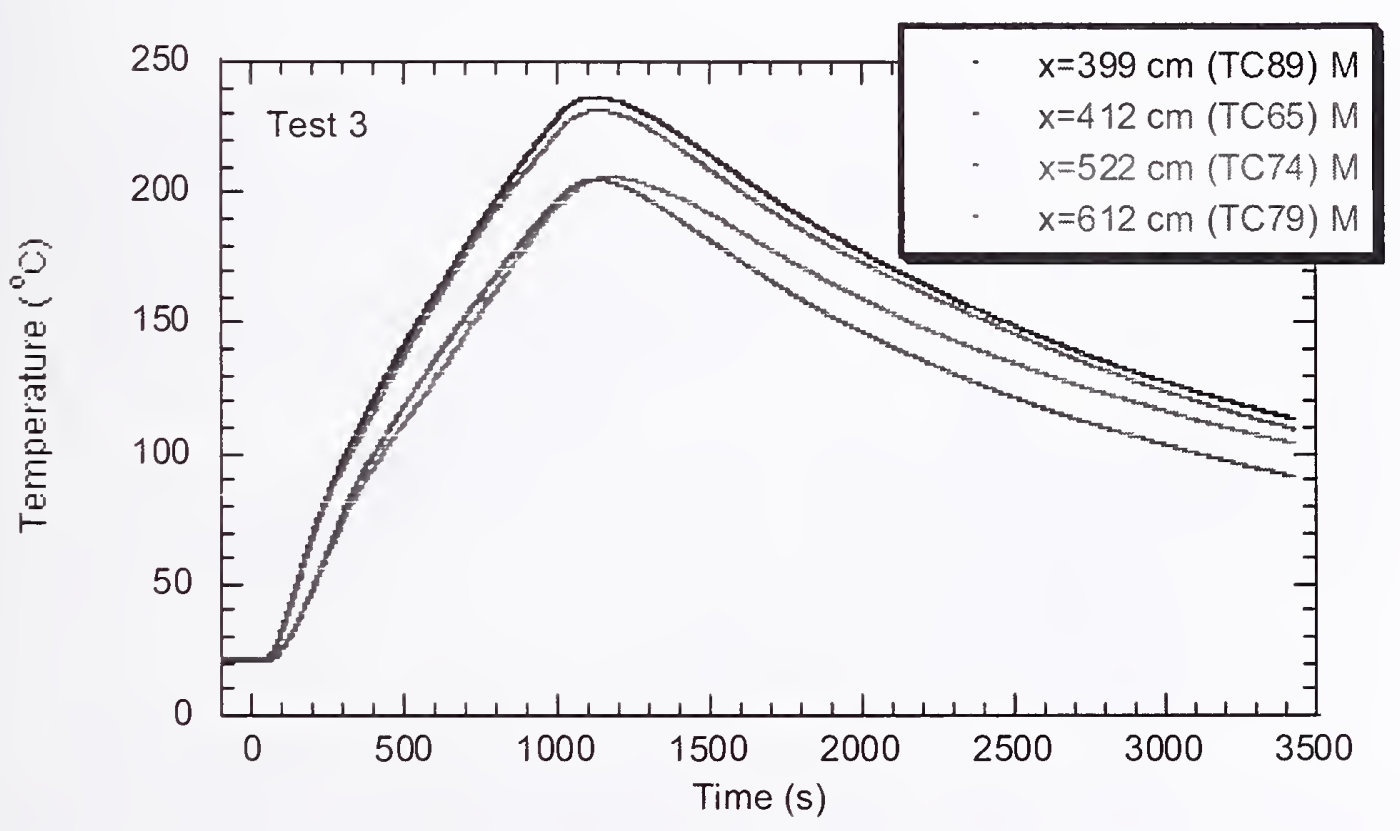

Figure 8-15. The measured temperatures between the two Marinite sheets in the ceiling along the compartment centerline ( $x$ axis) as a function of time at several locations during Test 3. 


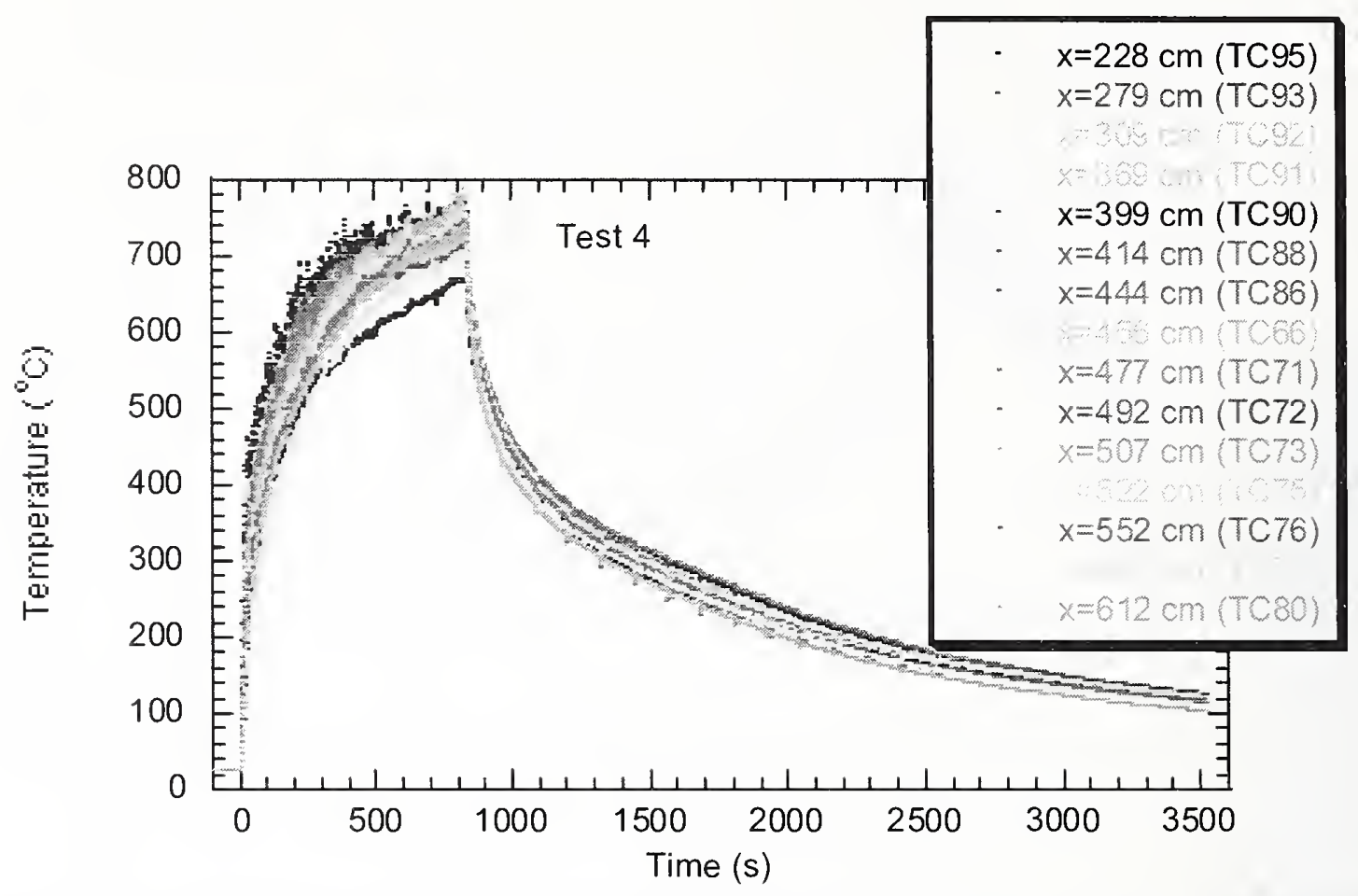

Figure 8-16. The measured ceiling temperatures as a function of time at 15 locations along the compartment centerline ( $x$ axis) during Test 4 .

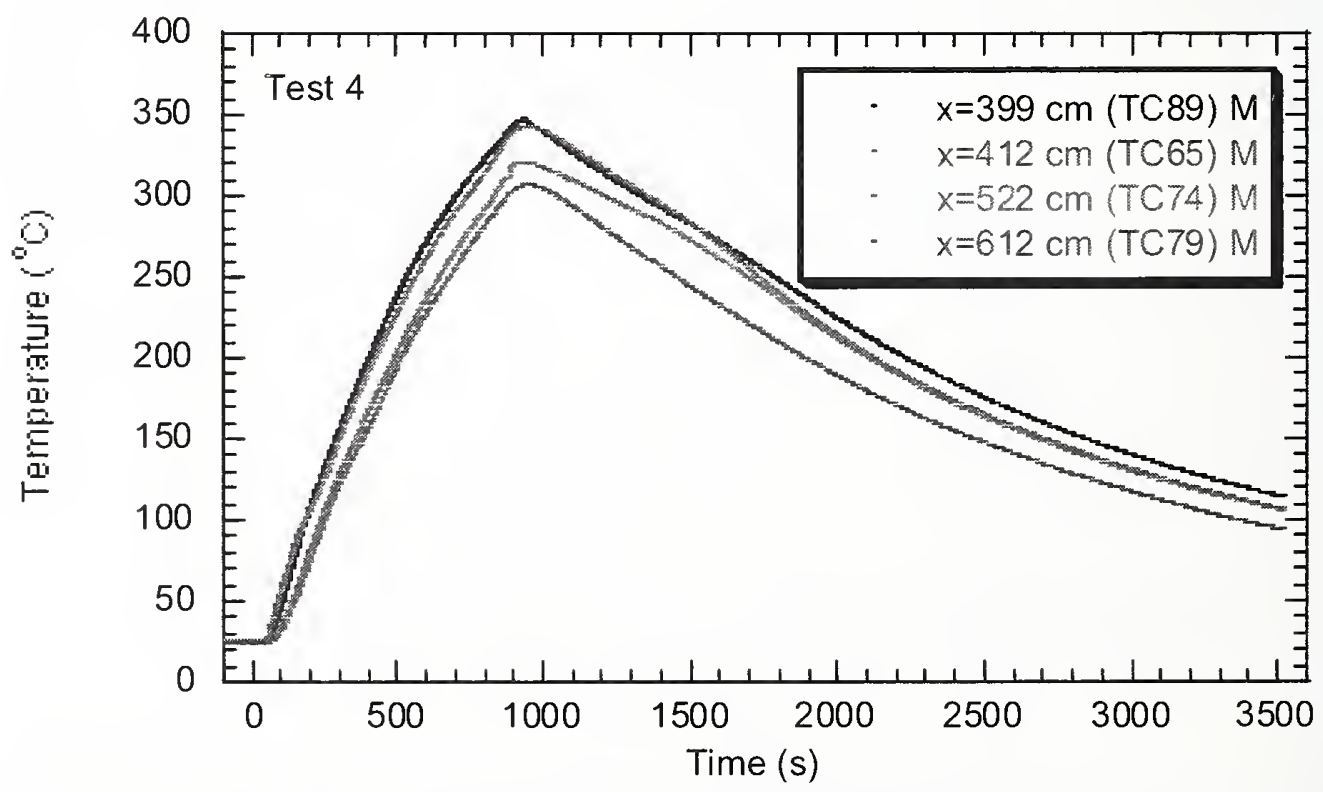

Figure 8-17. The measured temperatures between the two Marinite sheets in the ceiling along the compartment centerline ( $x$ axis) as a function of time at several locations during Test 4. 


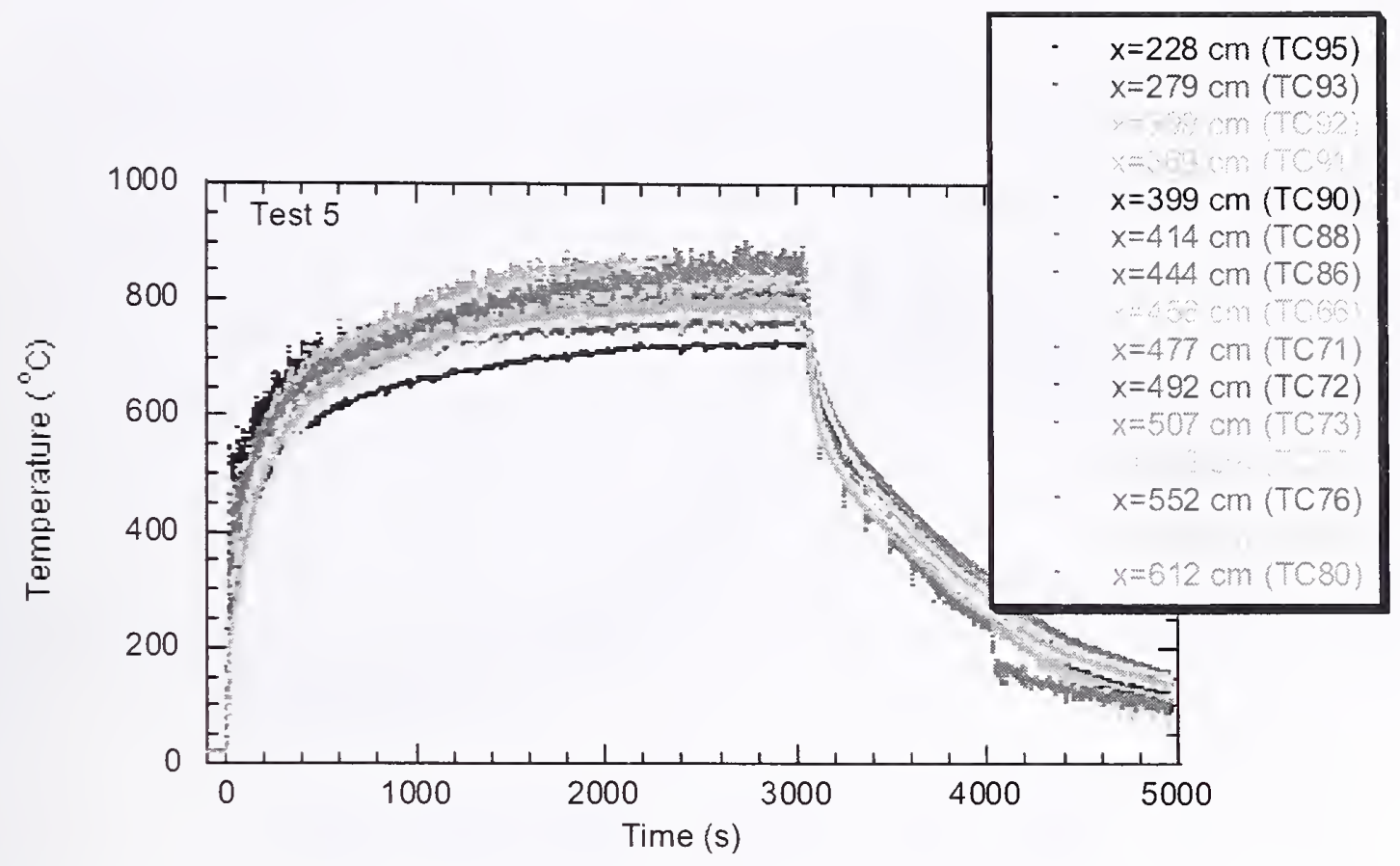

Figure 8-18. The measured ceiling temperatures as a function of time at 15 locations along the compartment centerline ( $x$ axis) during Test 5.

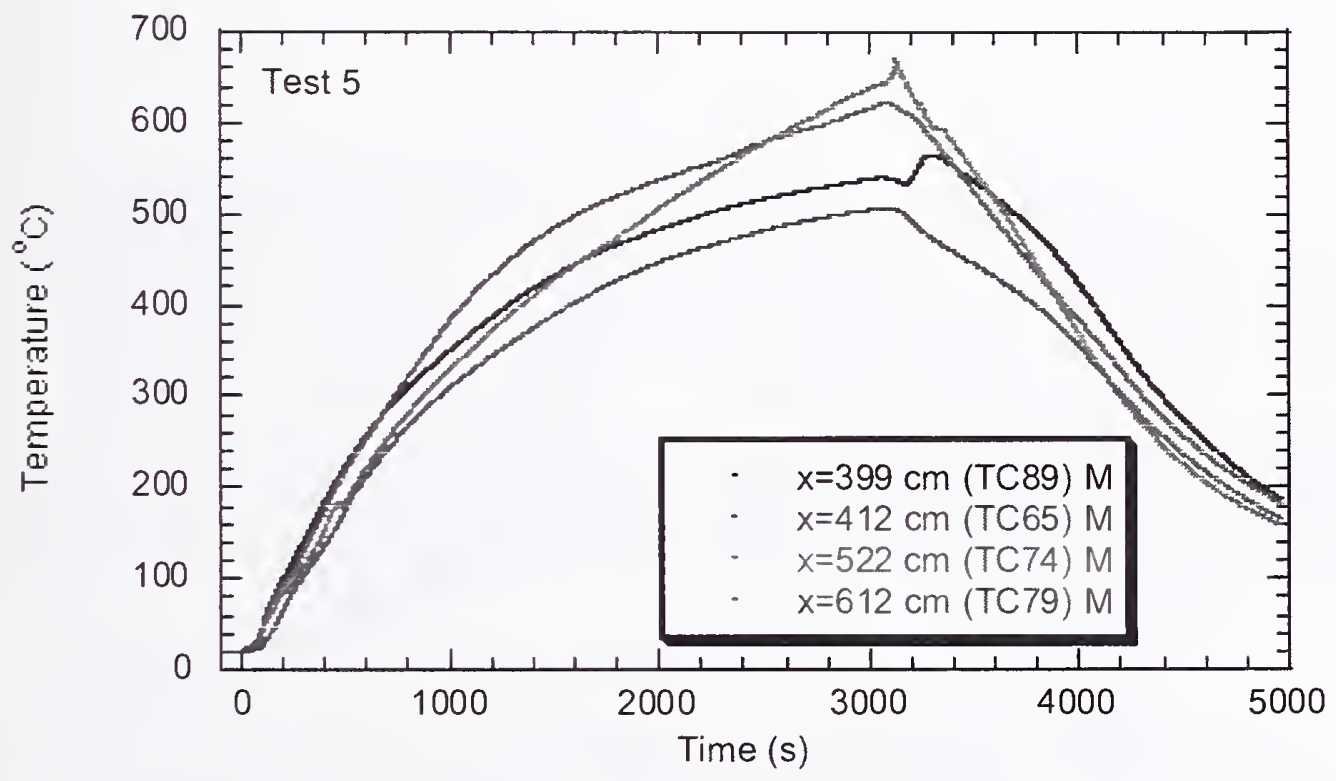

Figure 8-19. The measured temperatures between the two Marinite sheets in the ceiling along the compartment centerline ( $x$ axis) as a function of time at several locations during Test 5. 


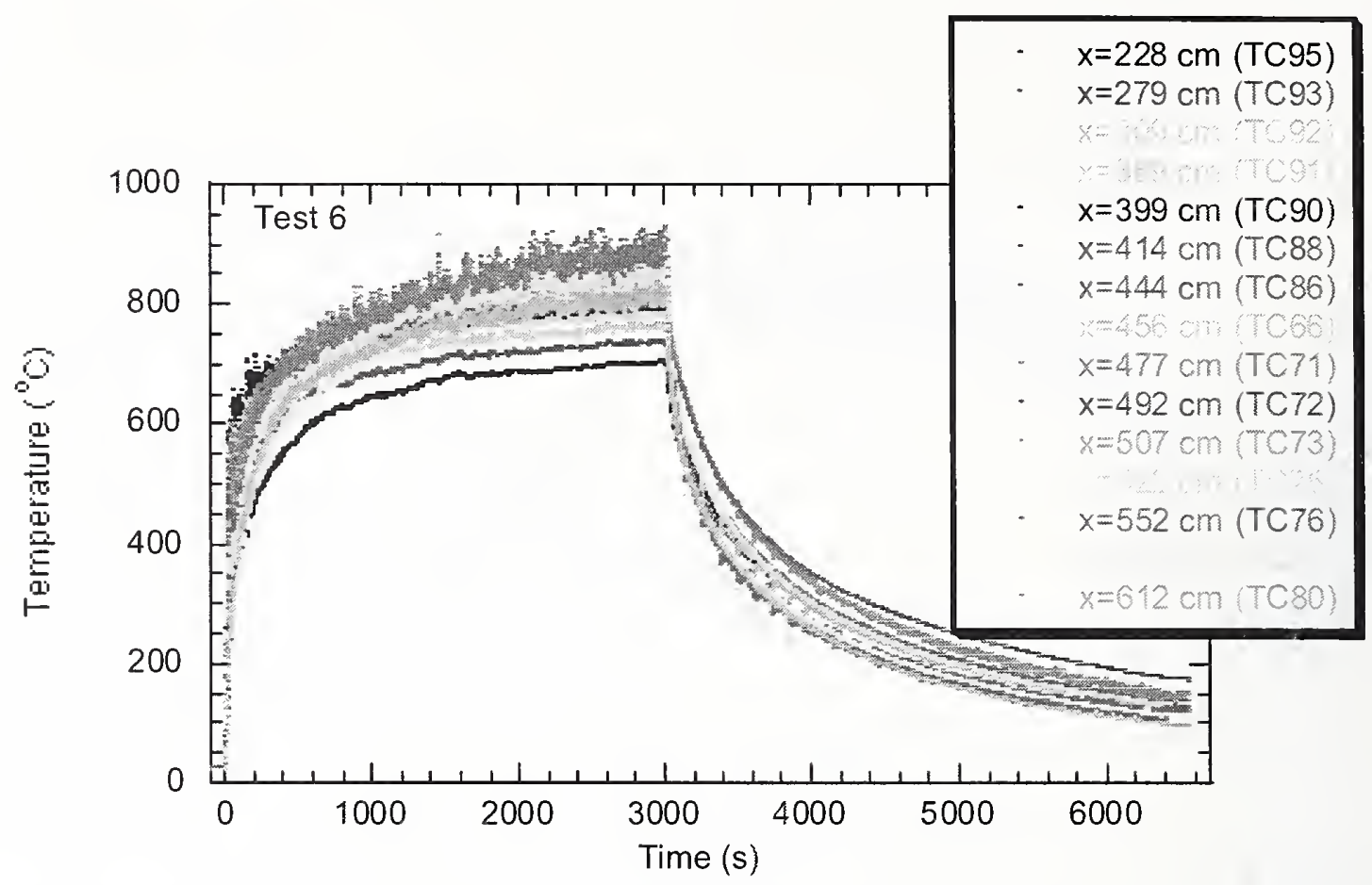

Figure 8-20. The measured ceiling temperatures as a function of time at 15 locations along the compartment centerline ( $x$ axis) during Test 6.

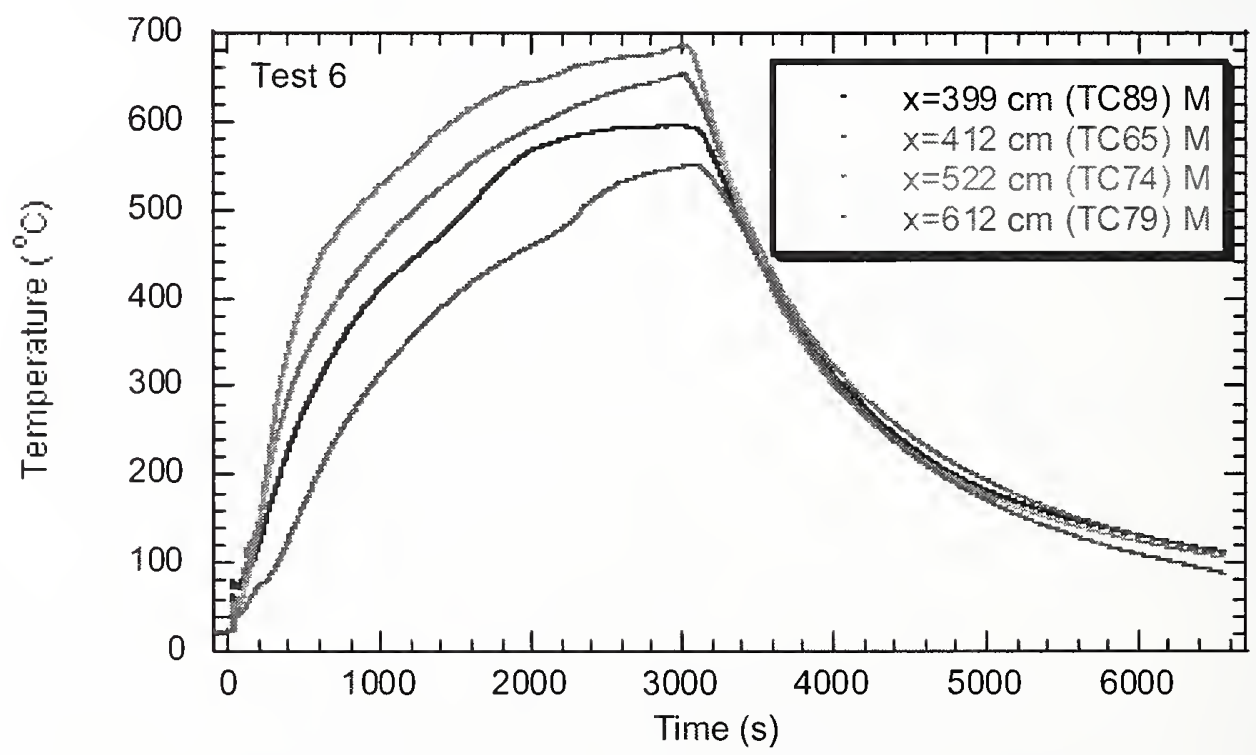

Figure 8-21. The measured temperatures between the two Marinite sheets in the ceiling along the compartment centerline ( $x$ axis) as a function of time at several locations during Test 6. 


\subsection{REPEATABILITY}

Figure 8-22 compares the temperatures measured along the compartment centerline ( $\mathrm{x}$ axis) on the ceiling surface and sandwiched between the two Marinite layers, 3,000 s and 3,080 s after fire initiation, respectively, during Tests 5 and 6 , which represent repeat experiments. These times were selected to compare the tests because the duration of Test 6 was 50 min $(3,000 \mathrm{~s})$, which was slightly shorter than Test 5. The fuel used was heptane, and the heat release rate was $3 \mathrm{MW}$ in both experiments. The repeatability of the ceiling temperature measurements should be considered in terms of the repeatability of the gas-phase temperatures in the upper layer of the compartment in Tests 5 and 6 (see Chapter 4), which drive the values of the compartment ceiling temperature. The average value of the expanded uncertainty limits in the gas-phase temperature was $21{ }^{\circ} \mathrm{C}$ and $23{ }^{\circ} \mathrm{C}$ from Table $4-4$ (Chapter 4) for Tests 5 and 6 , respectively. The average of the absolute value of the difference between the measured ceiling temperatures in Tests 5 and 6 was approximately $25^{\circ} \mathrm{C}$ for the surface and $24{ }^{\circ} \mathrm{C}$ between the Marinite layers. These differences were within the combined expanded gas-phase uncertainties. These results in concert with the measurement uncertainty described in Sec. 8.1 above demonstrate that the ceiling temperature measurements were repeatable within experimental uncertainty.

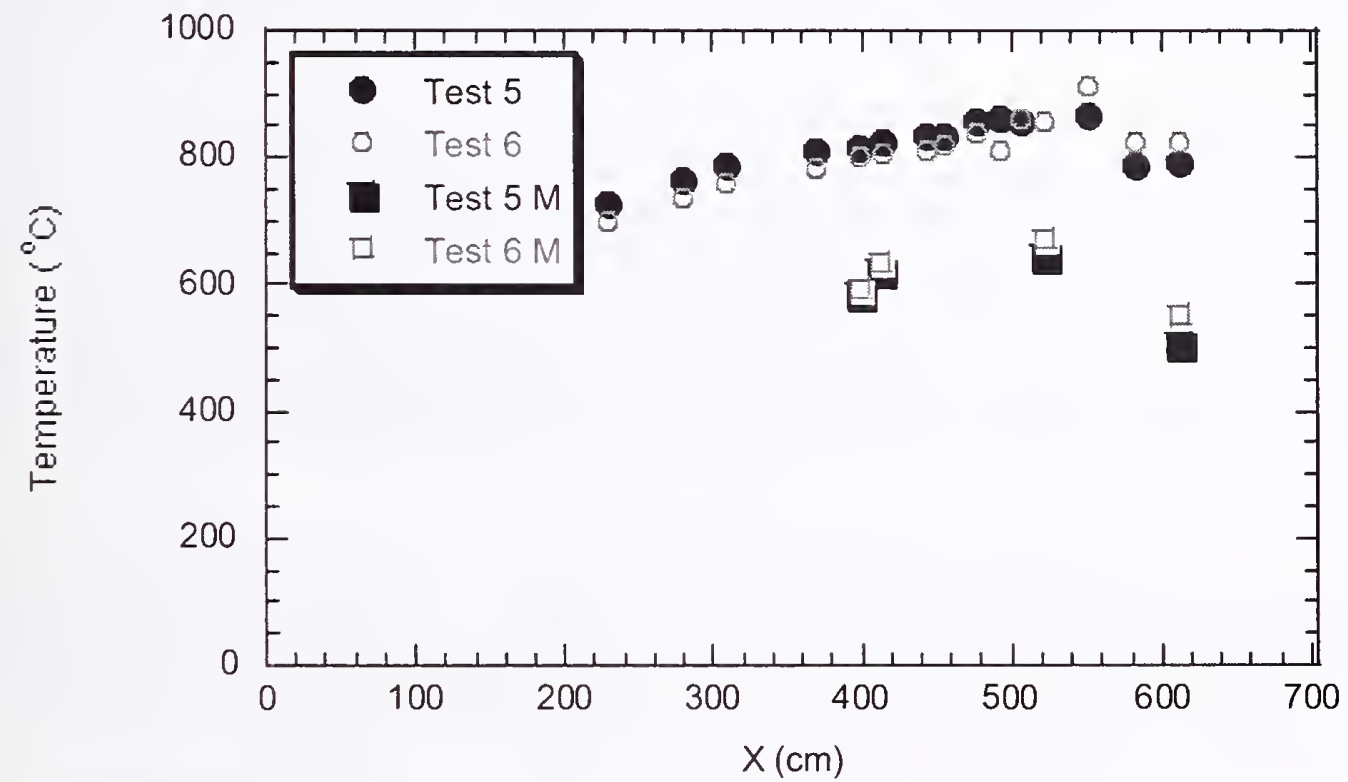

Figure 8-22. Comparison of the temperatures on the ceiling surface and sandwiched between the two Marinite ceiling layers $3,000 \mathrm{~s}$ and $3,080 \mathrm{~s}$ after fire initiation, respectively, along the compartment centerline ( $x$ axis) during Tests 5 and 6.

\subsection{EFFECT OF HEAT RELEASE RATE}

Figure 8-23 compares the temperatures measured along the compartment centerline ( $\mathrm{x}$ axis) on the ceiling surface and sandwiched between the Marinite layers, $830 \mathrm{~s}$ and 1,035 s after fire initiation, respectively, during Tests 1 and 5. These times were selected to compare the tests because the duration of Test 1 was only $14 \mathrm{~min}(840 \mathrm{~s})$ as compared to $50 \mathrm{~min}$ for Test 5 . Tests 1 and 5 were fires burning heptane with Test 1 having a heat release rate of $2 \mathrm{MW}$ as compared to $3 \mathrm{MW}$ in Test 5. As expected, the temperatures were larger in the higher heat release rate fire. 


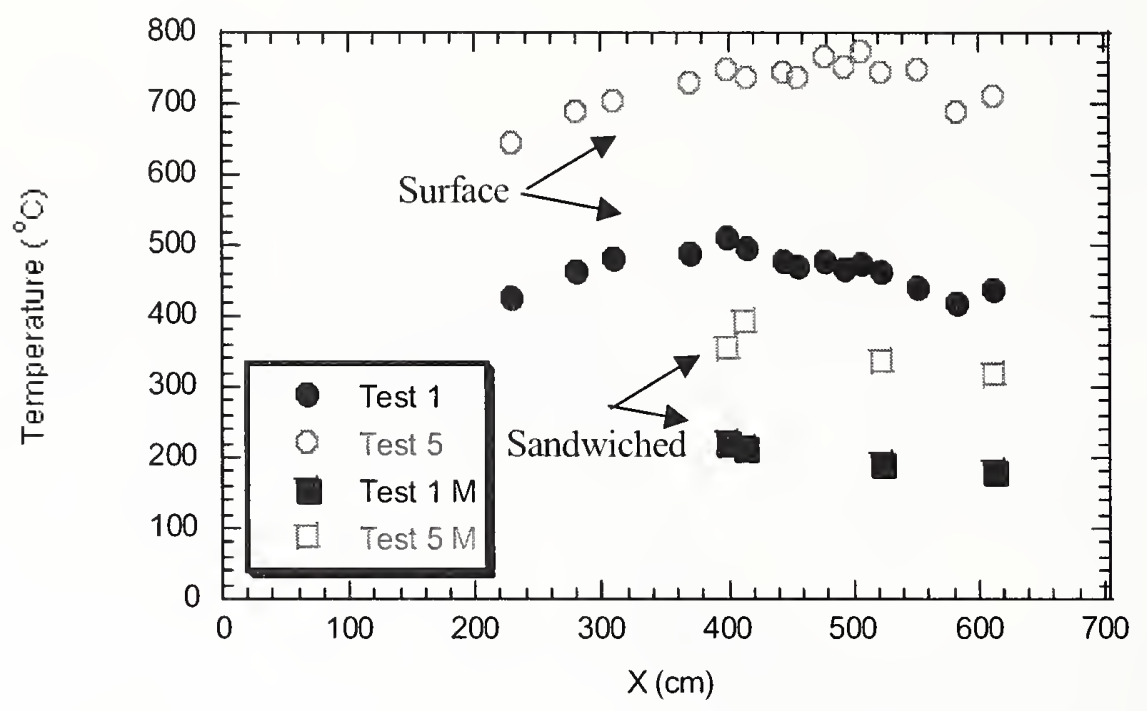

Figure 8-23. Comparison of the temperatures on the ceiling surface and sandwiched between the two Marinite ceiling layers $830 \mathrm{~s}$ and 1,035 s after fire initiation, respectively, along the compartment centerline ( $x$ axis) during Tests 1 and 5.

Figure 8-24 compares the temperatures measured along the compartment centerline ( $\mathrm{x}$ axis) on the ceiling surface and sandwiched between the two Marinite layers, $350 \mathrm{~s}$ and $660 \mathrm{~s}$ after fire initiation, respectively, during Tests 2 and 3. These times were selected to compare the tests because the duration of Test 2 was $6 \min (350 \mathrm{~s})$, which was shorter than Test 3 . Tests 2 and 3 were fires burning the heptane/toluene fuel mixture with Test 2 having a heat release rate of $2.4 \mathrm{MW}$ as compared to $2.0 \mathrm{MW}$ in Test 3. As seen in Fig. 8-24, the ceiling temperatures were larger in the higher heat release rate fire. As expected, the temperatures between the Marinite layers had smaller measured differences than the surface temperatures.

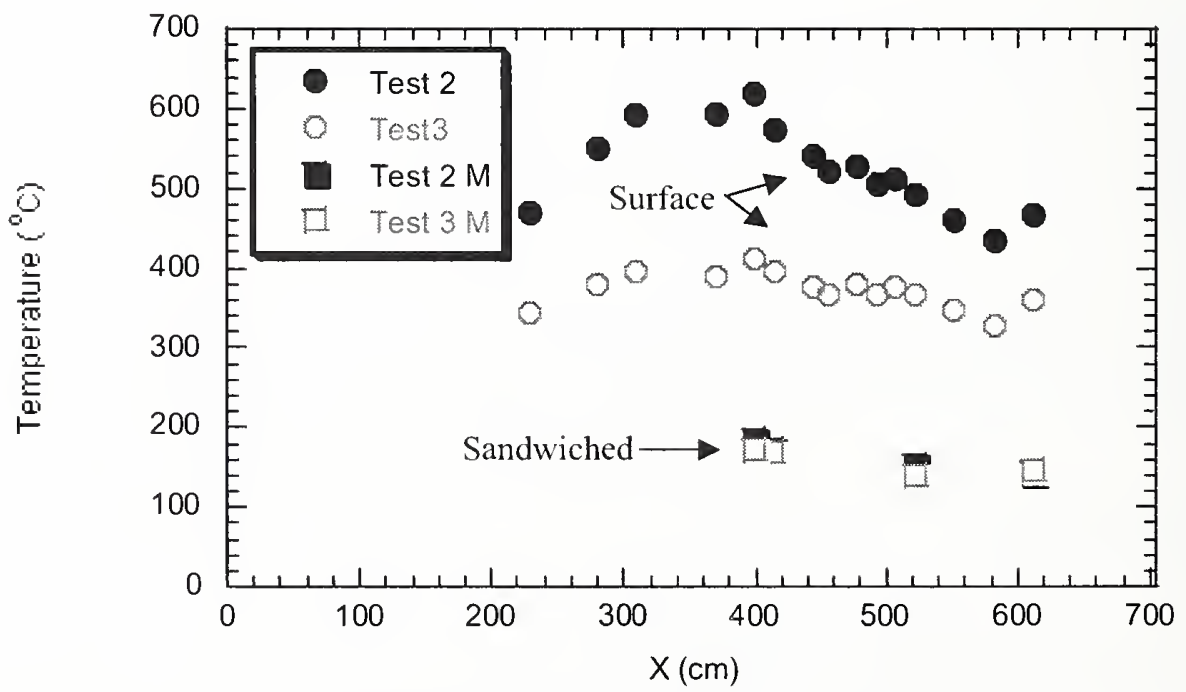

Figure 8-24. Comparison of the temperatures on the ceiling surface and sandwiched between the two Marinite ceiling layers $350 \mathrm{~s}$ and $660 \mathrm{~s}$ after fire initiation, respectively, along the compartment centerline ( $x$ axis) during Tests 2 and 3. 


\subsection{EFFECT OF FUEL TYPE}

Figure 8-25 compares the temperatures measured along the compartment centcrline ( $\mathrm{x}$ axis) on the ceiling surface and sandwiched between the two Marinite layers, $830 \mathrm{~s}$ and 1,040 s, after fire initiation,

respectively, during Tests 1 and 3 . The first time (830 s) was selected to compare the ceiling surface temperature for the two tests because the duration of Test 1 was $840 \mathrm{~s}(14 \mathrm{~min})$, which was shorter than Test 3. The second time (1,040 s) was selected to compare the sandwiched temperatures. Both tests had heat release rates of $2 \mathrm{MW}$. The fuel was heptane in Test 1 , whereas it was a mixture of heptane and toluene in Test 3. The difference in the measured ceiling temperatures between Tests 1 and 3 was about $7{ }^{\circ} \mathrm{C}$, consistent with the small temperature differences between Tests 1 and 3 observed for the East tree gas-phase thermocouple measurements for these two tests shown in Fig. 4-11. These results show that fuel type had little influence on the ceiling temperatures.

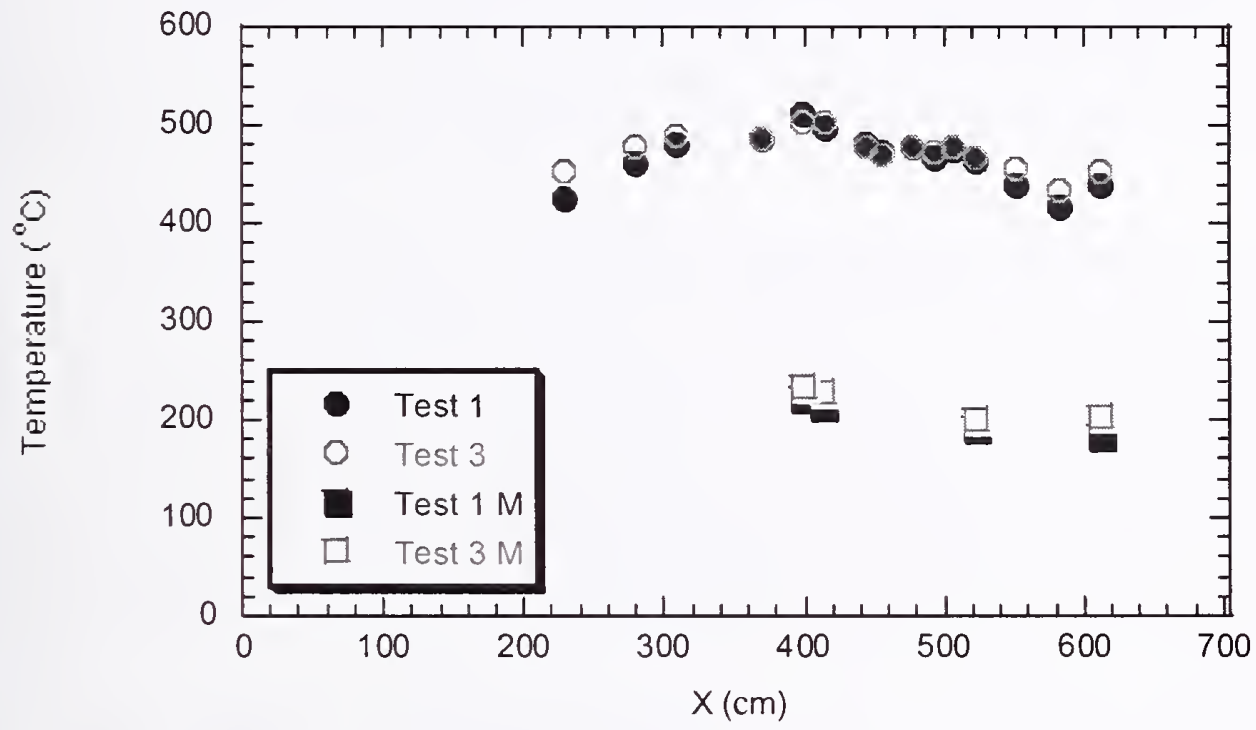

Figure 8-25. Comparison of the temperatures on the ceiling surface and sandwiched between the two Marinite ceiling layers $830 \mathrm{~s}$ and 1,040 s after fire initiation, respectively, along the compartment centerline ( $x$ axis) during Tests 1 and 3.

\subsection{REFERENCES}

ANSYS, Inc. 2003. ANSYS Release 8.0 Documentation.

Omega Engineering, Inc. 2000. Omega Temperature Handbook, Technical Refcrence Section, Section Z.

Siegel, R., and J.R. Howell. 2002. Thermal Radiation Heat Transfer, Taylor and Francis, NY.

Taylor, R.E., H. Groot, and J. Ferrier. 2003. Thermophysical Properties of PVC, PE, and Marinite, Report No. TPRL 2958, Thermophysical Properties Research Laboratory, Inc., April. 
This page intentionally left blank. 


\section{Chapter 9 \\ TEMPERATURES OF STEEL COMPONENTS}

\section{$9.1 \quad$ OBJECTIVE}

The time varying temperatures of the steel components were measured to determine the thermal response of structural steel components to controlled room fire conditions, including flame immersion, and to establish a data set to validate predictions of the temperature rise of insulated and uninsulated structural steel components. The components were tested in an uninsulated (unprotected bare) state in Tests 1, 2, and 3 and with an insulating coating of fireproofing, or fibrous sprayed fire-resistive material (SFRM), in Tests 4, 5, and 6. The SFRM was applied in two nominal thicknesses: $17 \mathrm{~mm}$ or $34 \mathrm{~mm}$. The steel components were not loaded or tested for strength; these tests were conducted primarily to measure the heat transfer to the steel. Chapter 11 compares the finite-element analysis predictions of the steel temperatures with the measurements presented here.

This chapter contains a description of the experimental measurements, an analysis of uncertainty, tabulation of key results, a statistical summary of the applied SFRM thickness on the steel components, and representative plots of the experimental results, including thermocouple measurements of the surface temperature of the bare and coated steel components during Tests 3 and 5. A complete record of the exact locations of the thermocouples on the steel components and the SFRM coating is documented in Appendix F. The complete record of time dependent measurements for Tests 1, 2, 3, 5, and 6 is presented in Appendix G. Test 4 was truncated after approximately 15 min due to a malfunction of the thermocouples that occurred a few minutes after the start of the test. As no useful steel temperature data was obtained during Test 4 , it is not included in this chapter or Appendix G.

\subsection{EXPERIMENTAL DESCRIPTION}

Steel components were selected to meet several criteria:

- Section thicknesses were sized so that $600{ }^{\circ} \mathrm{C}$ steel temperatures could be obtained with a fire heat release rate $(\dot{Q})$ of $2 \mathrm{MW}$ to $3 \mathrm{MW}$ in less than an hour,

- Components were sized to be similar to some of those in World Trade Center (WTC) 1 and WTC 2,

- A simplebar was included as a baseline case for analysis purposes, and

- Various types of structural components were selected to measure the heating effect of fires on horizontal and vertical steel components.

Three types of steel components were selected, a bar, a hollow steel tubular column, and a bar joist truss, and are shown in Figs. 9-1 through 9-3. The bars were nominally $3 \mathrm{~m}$ long ( $10 \mathrm{ft}$ ) and $25 \mathrm{~mm}$ ( 1 in.) in diameter; the columns were $0.26 \mathrm{~m}$ (10 in.) by $0.36 \mathrm{~m}$ (14 in.) tubular steel sections with a nominal $6 \mathrm{~mm}$ ( $1 / 4$ in.) wall thickness; and the trusses were $4.6 \mathrm{~m}$ (15 ft) long and $0.8 \mathrm{~m}(2.6 \mathrm{ft})$ deep with $64 \mathrm{~mm}$ to 
$76 \mathrm{~mm}$ (2.5 in. to $3 \mathrm{in}$.) double angles for the top and bottom chords and $25 \mathrm{~mm}$ ( $1 \mathrm{in}$.) bar for the web members.
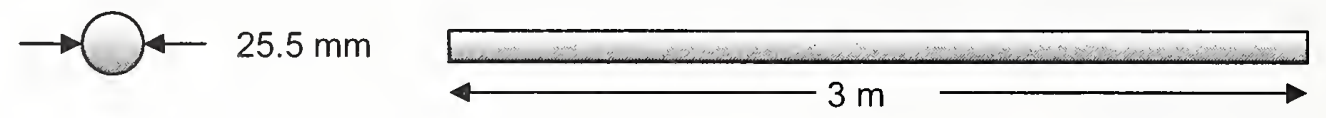

Figure 9-1. Bar dimensions.

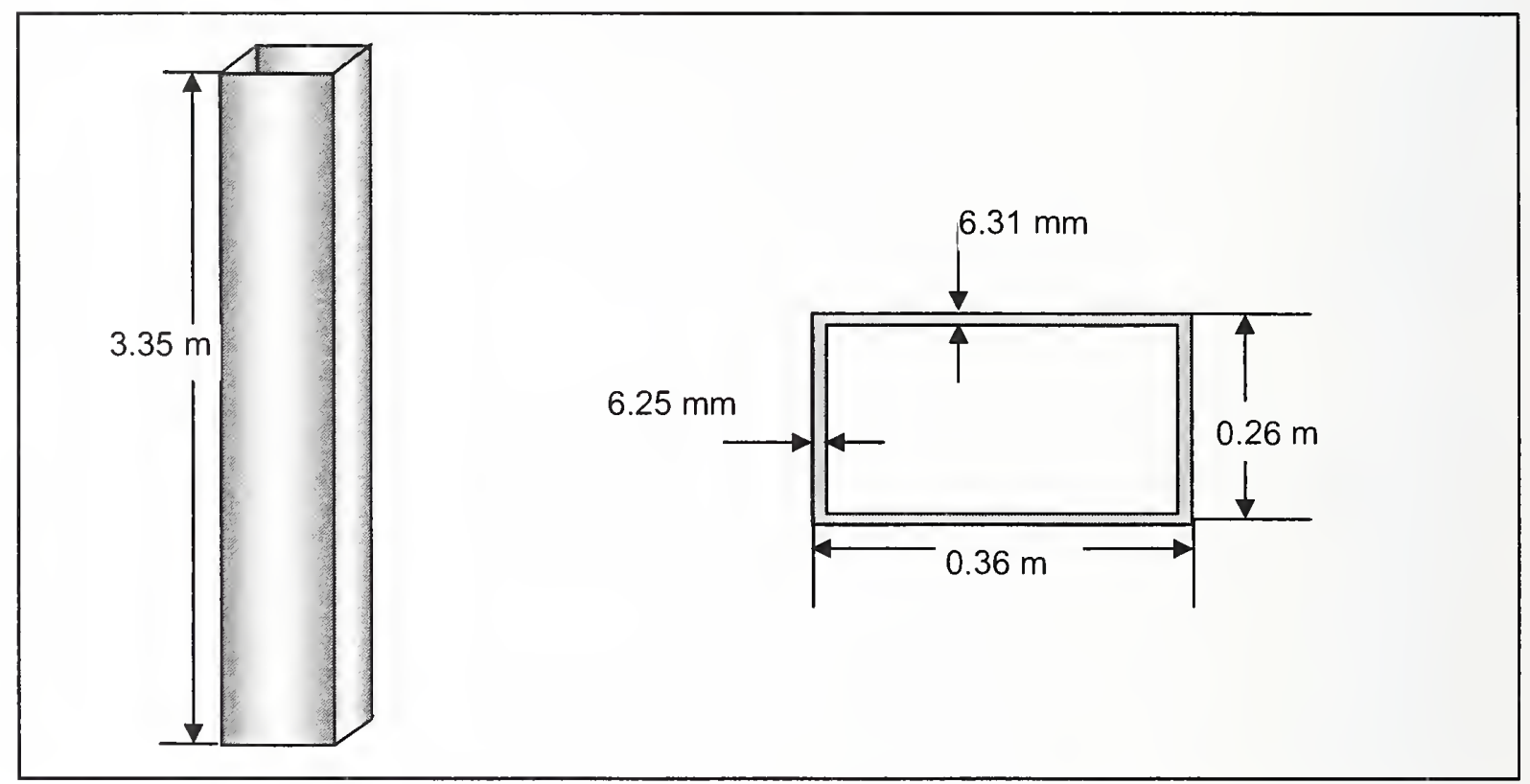

Figure 9-2. Tubular column dimensions.

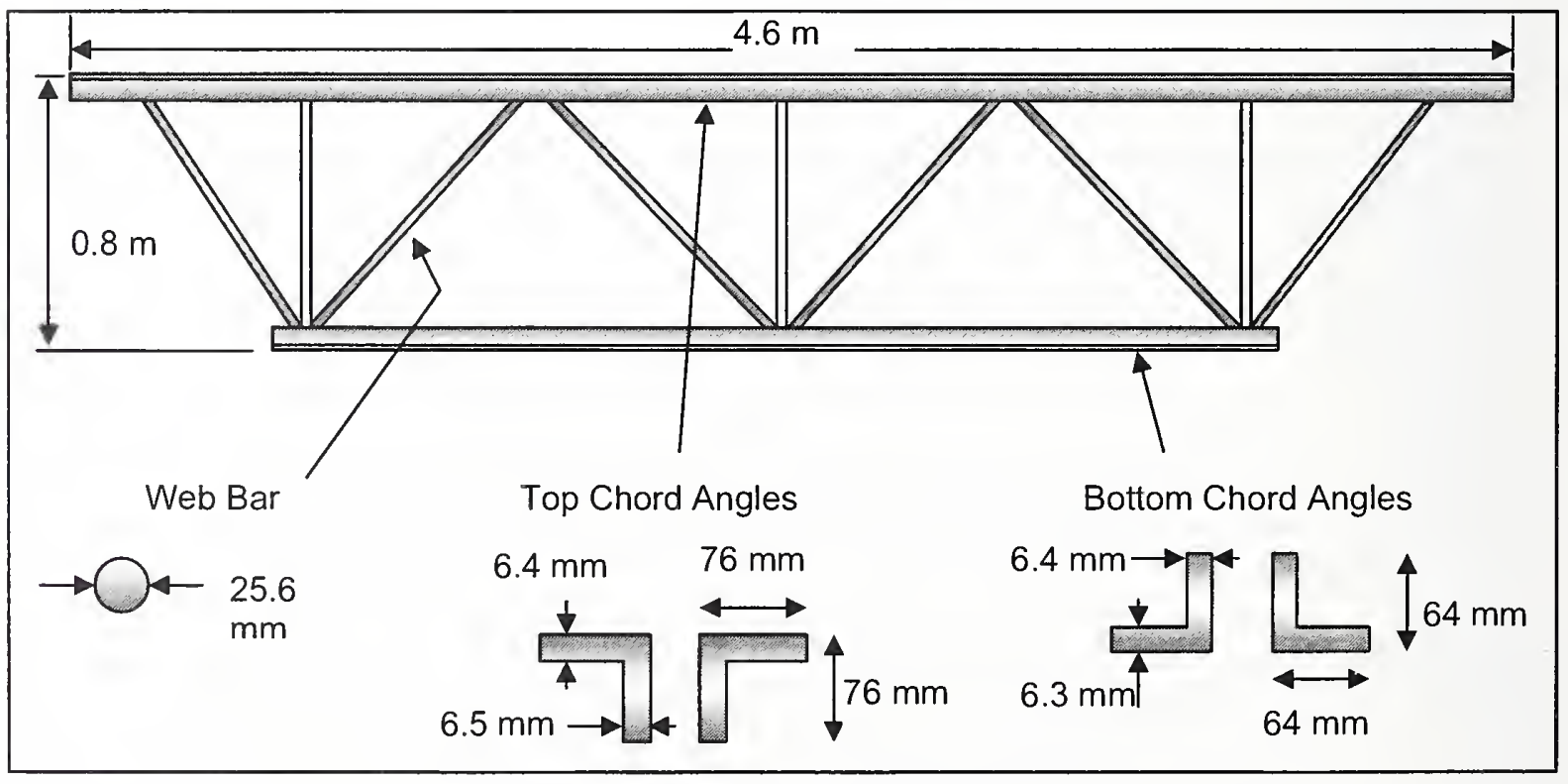

Figure 9-3. Truss dimensions. 
Bare-bead Type K 30-gauge thermocouples (TC) were selected to record the temperature time-histories at the steel and SFRM surfaces. Prior to application of SFRM to the steel components for Tests 4, 5, and 6, the thermocouple beads were spot welded to the bare steel surface of all components. The thermocouple locations on the bar, column, and truss components are illustrated in Figs. 9-4a, 9-5a, 9-5b, 9-5c, 9-6a, and 9-6b. The thermocouples that were to be positioned just under the SFRM surface were placed against the steel surface (under the SFRM) and supported on a wire tie at the intended thermocouple location. The wire tie minimized disruption to the SFRM after it cured and allowed sufficient thermocouple wire length for inserting the thermocouple bead just under the SFRM surface by hand while minimizing exposure of the thermocouple wire to the gas temperatures. Figure 9-6c shows a thermocouple wire supported on a wire tie, with the bead placed just under the SFRM surface. It is estimated that these thermocouple beads were within $1 \mathrm{~mm}$ to $5 \mathrm{~mm}$ of the surface. The wire tie was not considered to be a significant source of heat transfer to the steel since the wire only contacted the steel at occasional spots or corners where it was wrapped and twisted to provide support for the thermocouple wire.

The SFRM product used in the WTC and these experiments was BLAZE-SHIELD DC/F, which was manufactured and supplied by Isolatek International. BLAZE-SHIELD DC/F is a sprayed single-package factory controlled premix, based on a mixture of mineral wool fibers and cement binders. The manufacturer reported average density is $208 \mathrm{~kg} / \mathrm{m}^{3}\left(13 \mathrm{lb} / \mathrm{ft}^{3}\right)$ minimum and its thermal conductivity is $0.042 \mathrm{~W} / \mathrm{m}-\mathrm{K}$ at $24^{\circ} \mathrm{C}$. These values were confirmed by a testing laboratory, which reported a density of $240 \mathrm{~kg} / \mathrm{m}^{3}$ and a thermal conductivity of $0.046 \mathrm{~W} / \mathrm{m}-\mathrm{K}$ (NIST NCSTAR 1-6A). Uncertainty in the thermal properties impacts the prediction of the thermal-structural response of the insulated steel components. The SFRM was applied by an experienced applicator from Isolatek. A nominal thickness of SFRM was specified for each steel component, either $17 \mathrm{~mm}$ or $34 \mathrm{~mm}$. The applicator took considerable care to apply an even coating of the specified thickness of SFRM to the steel components. Figures 9-6d and 9-6e show the SFRM application process and steel components after the application. The $34 \mathrm{~mm}$ SFRM was applied in two coats. The first coating adhered to the bare steel and the second coating was applied the following day to obtain the required thickness. The SFRM was then allowed to dry in place for four weeks, as required by the manufacturer, before proceeding with thickness measurements, placement of thermocouple beads just under the SFRM surface, and verifying the thermocouple locations and function prior to testing.

A pin thickness gauge, specifically designed for SFRM products, was used to measure the applied coatings. This type of gauge can measure to the nearest $1 \mathrm{~mm}$; its measurement accuracy is $0.5 \mathrm{~mm}$. Figures 9-4b, 9-5b, and 9-6f show the location of the thermocouples and SFRM thickness measurements for steel components used in Tests 5 and 6. (The steel temperature data collected during Test 4 was disregarded due to problems with the thermocouple signals during the test, so the thermocouple and SFRM data are not presented.) The SFRM measurement statistics are summarized in Table 9-1. The SFRM mean thickness, $\mu$, was greater than the specified nominal thickness by 20 percent to 35 percent typically, but ranged in value from 5 percent to 42 percent greater. The standard deviation, $\sigma$, assuming a normal distribution of thicknesses, ranged from $3 \mathrm{~m}$ to $8.2 \mathrm{~m}$. The standard deviation was influenced by the steel shape and the lumpy nature of the fibrous SFRM; a smooth surface cannot be obtained when the product is sprayed (no tamping was allowed). The coefficient of variation $(\mathrm{COV})$, where $\mathrm{COV}=\sigma / \mu$, ranged from 0.17 to 0.27 for the bars, columns, and trusses, with the exception of the column in Test 5 which had a $\mathrm{COV}=0.07$. This lower COV occurred for the condition in which a thicker SFRM coat was 
applied to a smooth steel surface. The variation in SFRM thickness for these steel components should be considered as a lower bound of variance that would be expected for field applications.

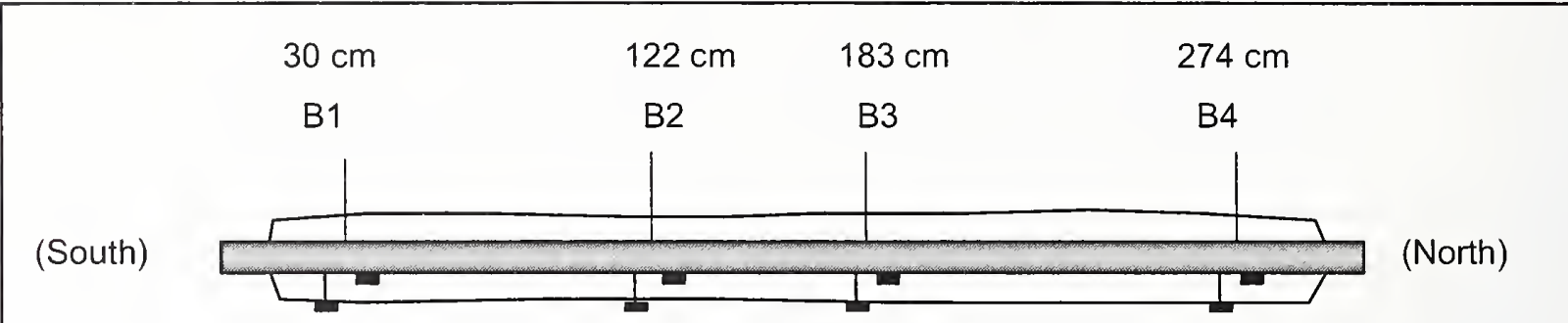

TCs were placed facing downward toward the floor.

Bar ends were used for handling and wrapped with Kaowool batting for testing.

Figure 9-4a. Thermocouple locations for bars.

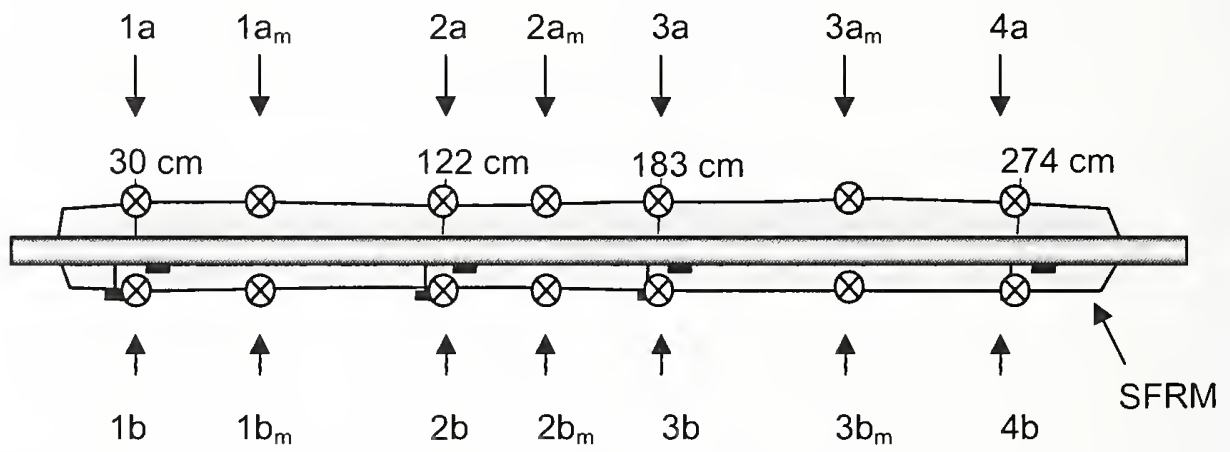

SFRM thickness was measured for two locations at each TC and at midpoints between the TCs.

Figure 9-4b. SFRM measurement locations for bars. 


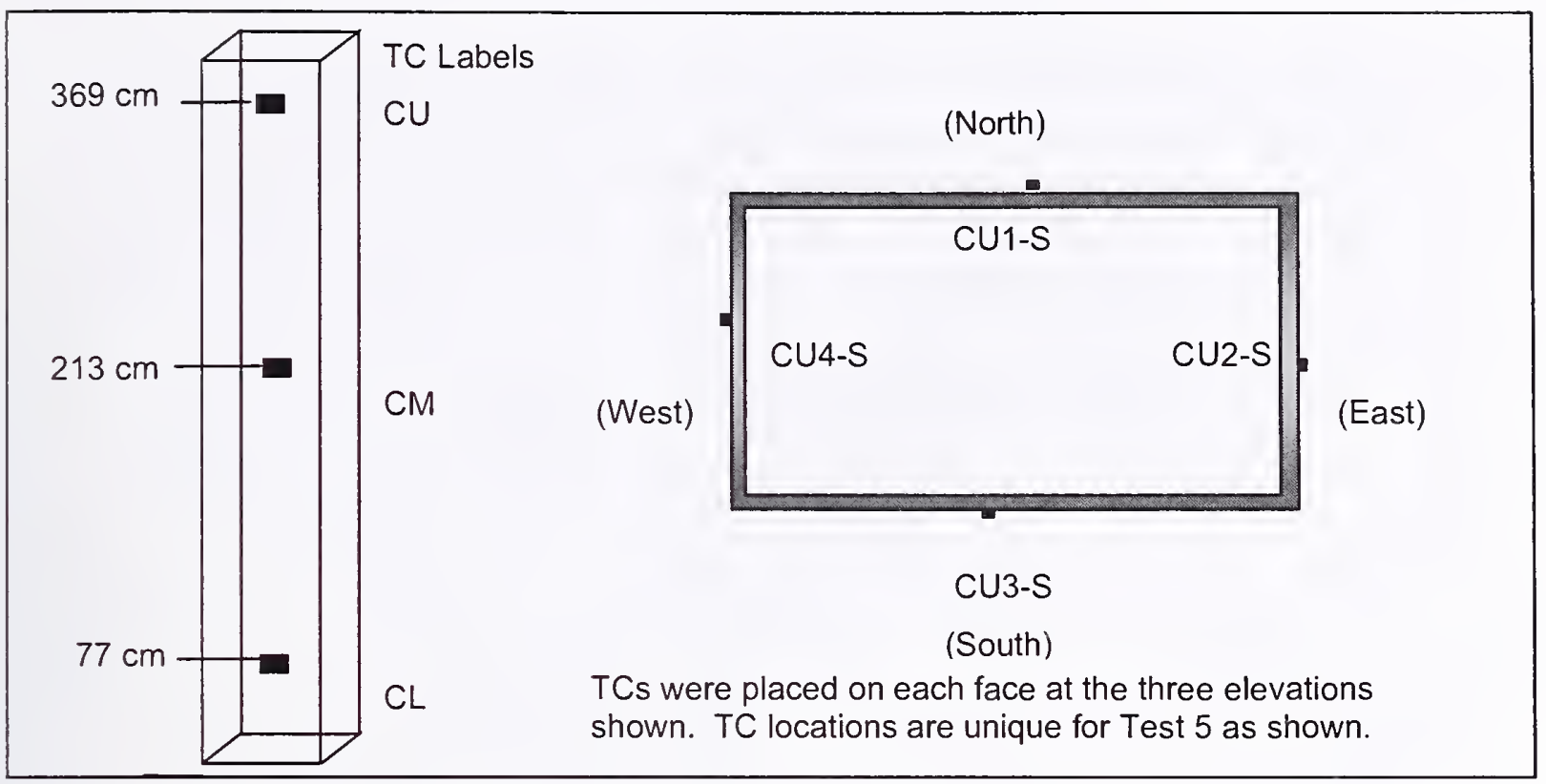

Figure 9-5a. Thermocouple locations for columns.

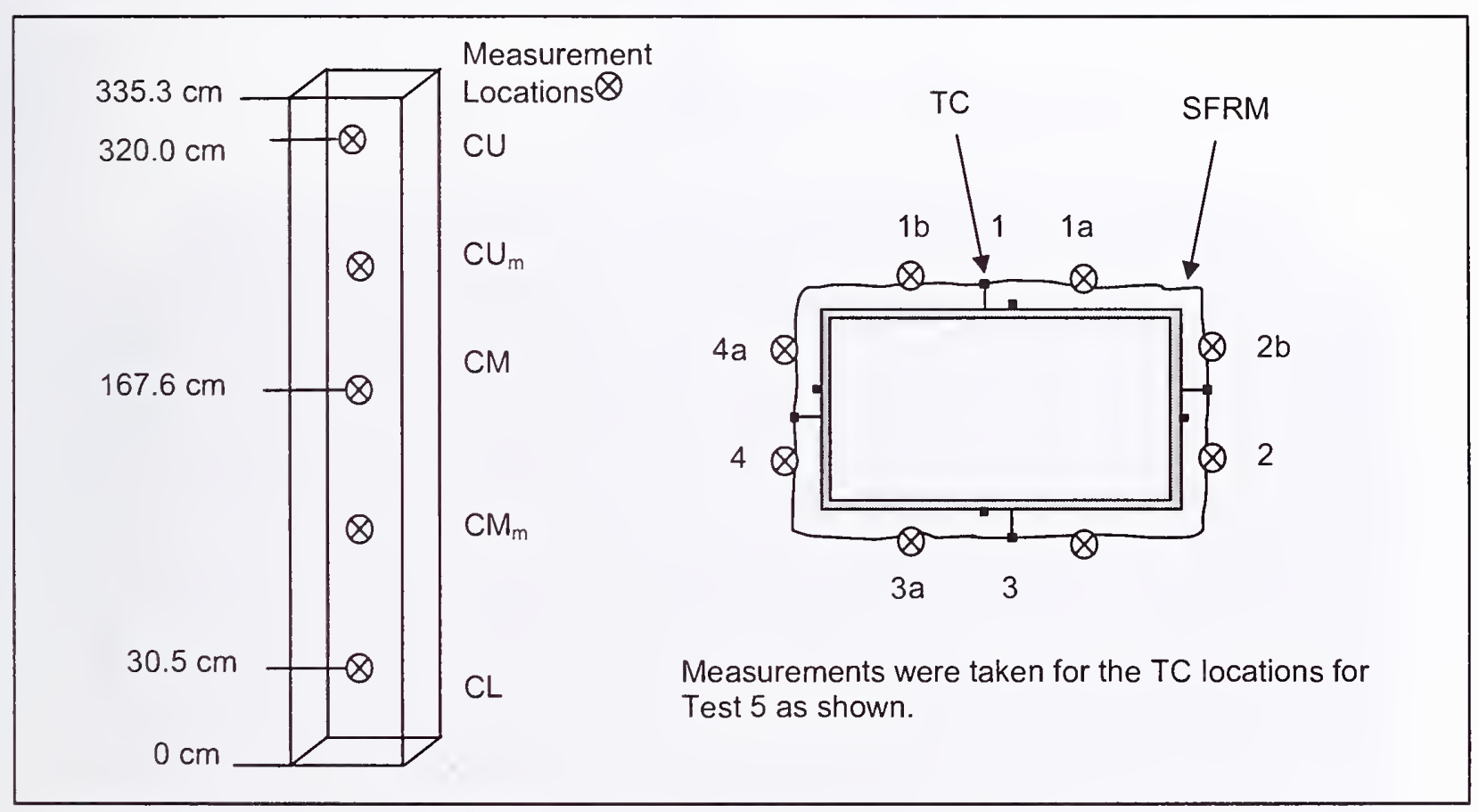

Figure 9-5b. SFRM measurement locations for column in Test 5 and 6. 


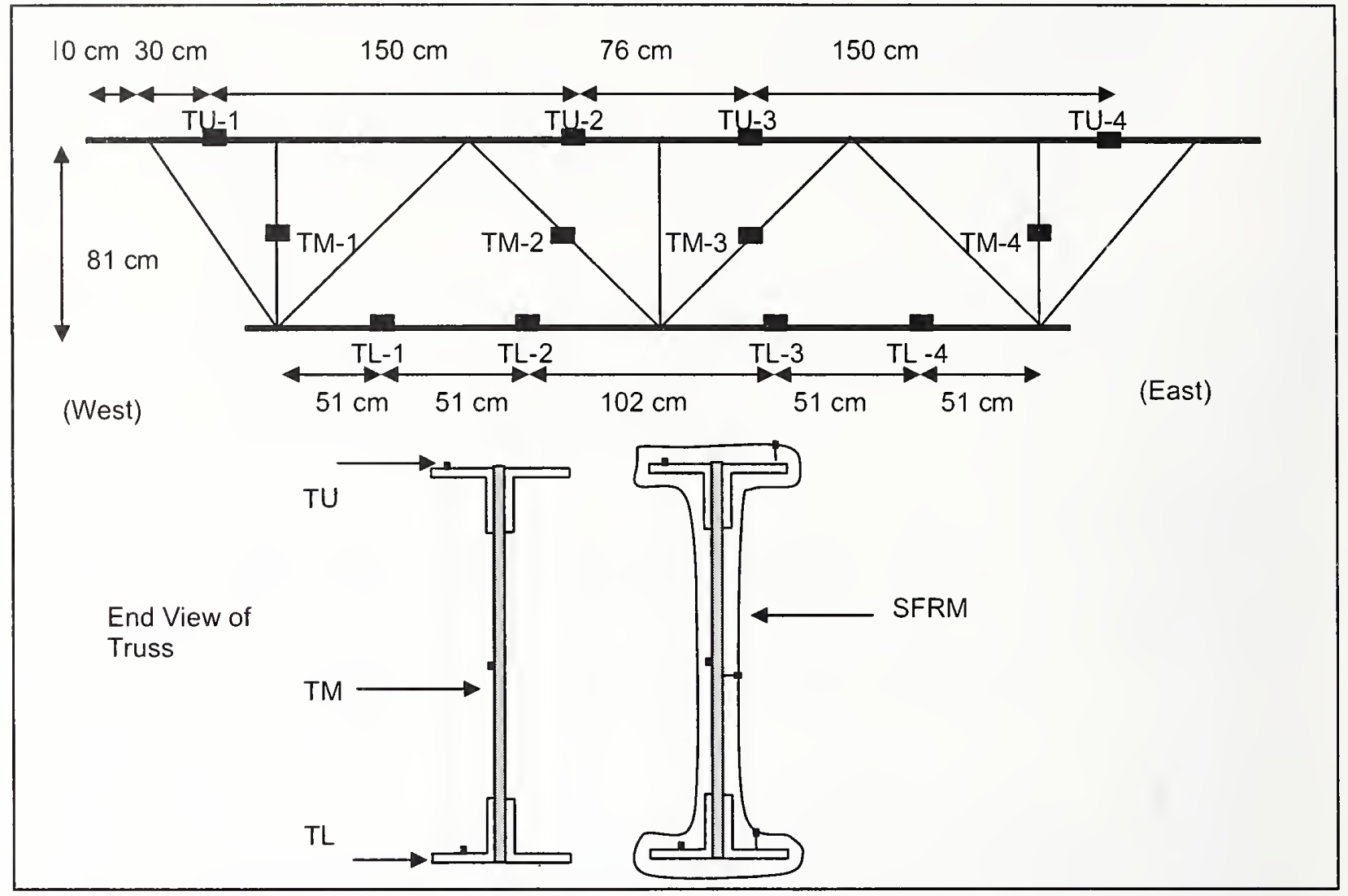

Figure 9-6a. Thermocouple locations on trusses.

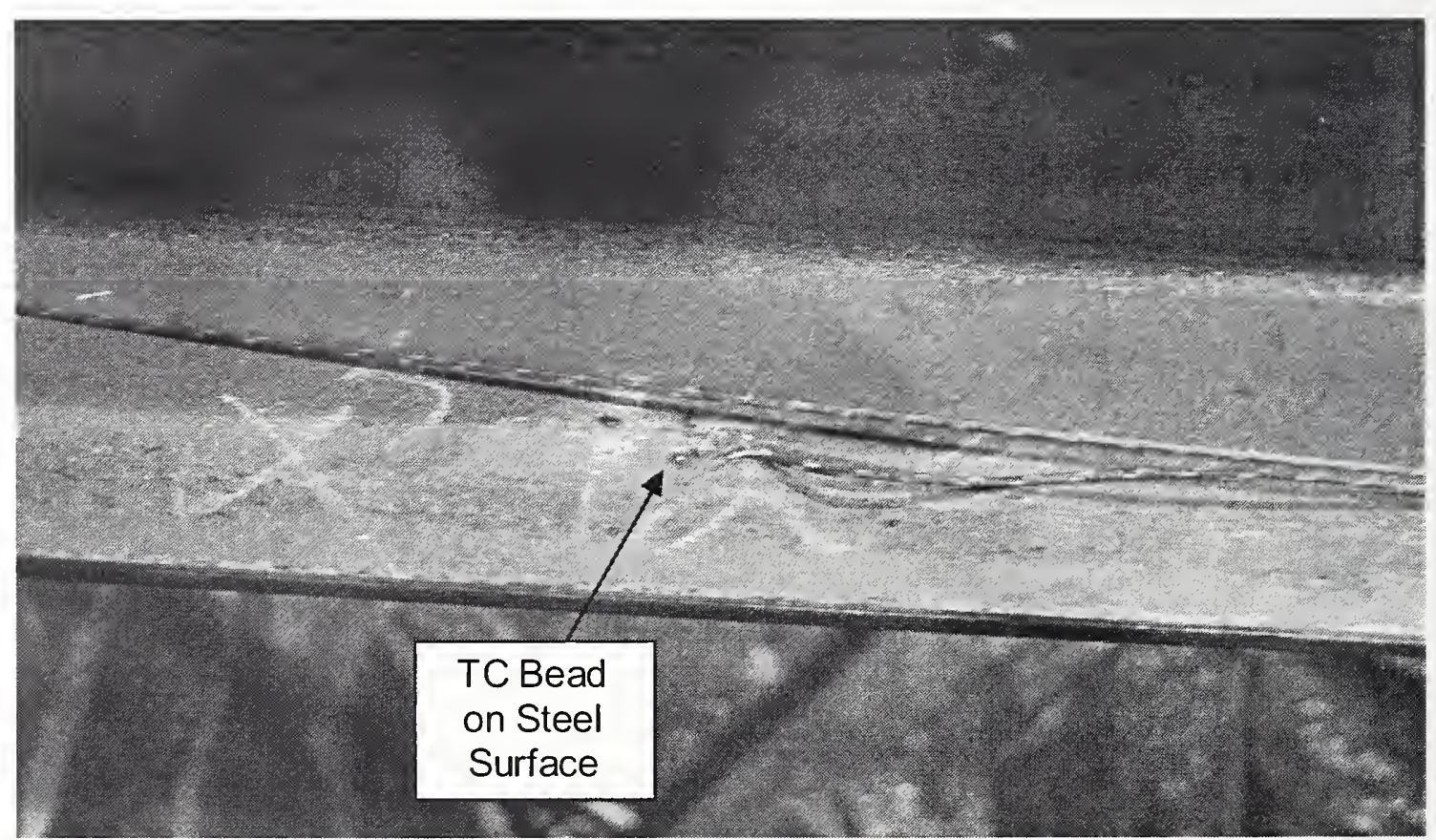

Source: NIST.

Figure 9-6b. Thermocouple bead spot welded onto the bottom chord of a steel truss with the wire running close to the steel surface. 


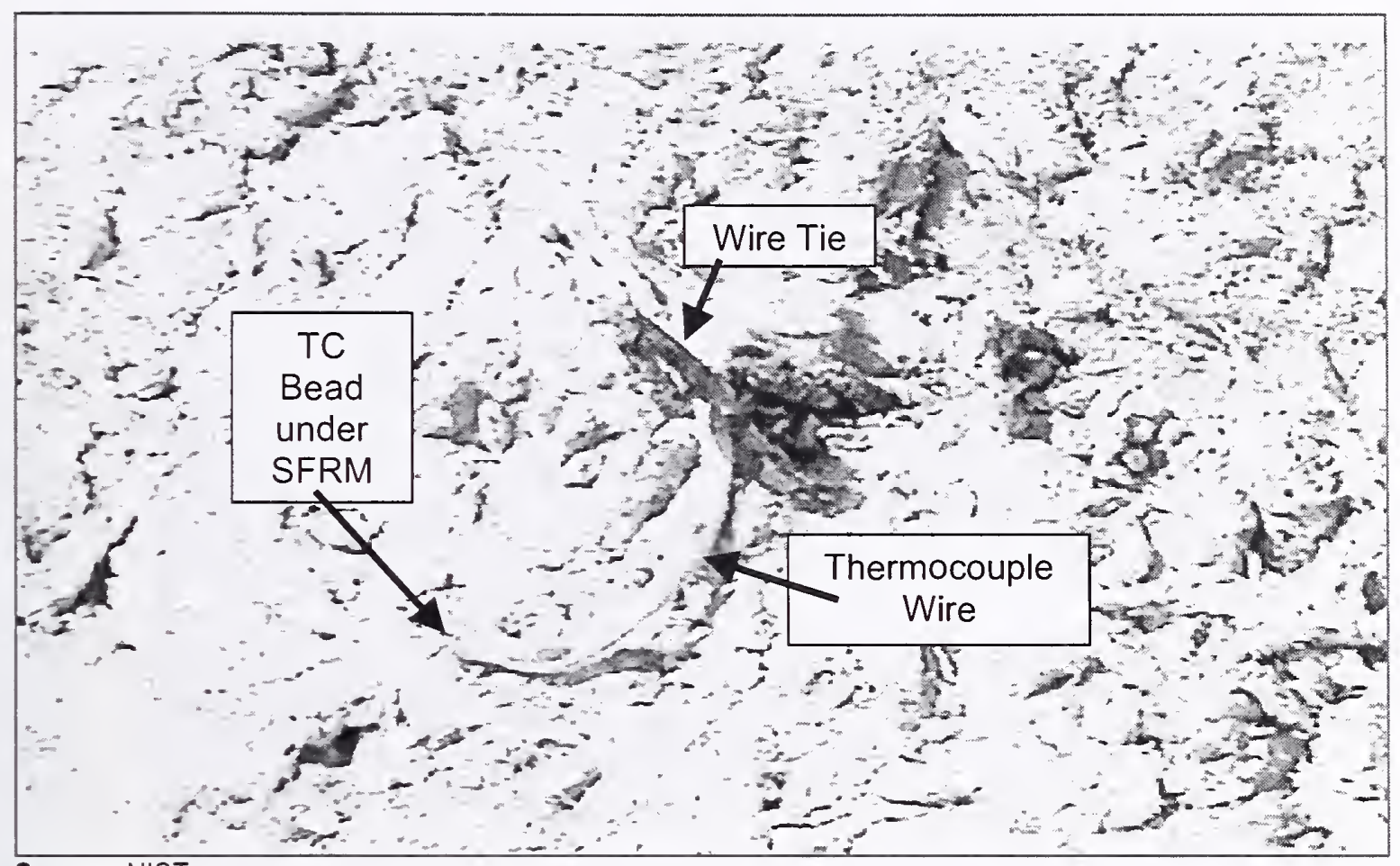

Source: NIST

Figure 9-6c. Color photograph of a thermocouple wire supported on a wire tie, with the thermocouple bead placed just under the SFRM surface.

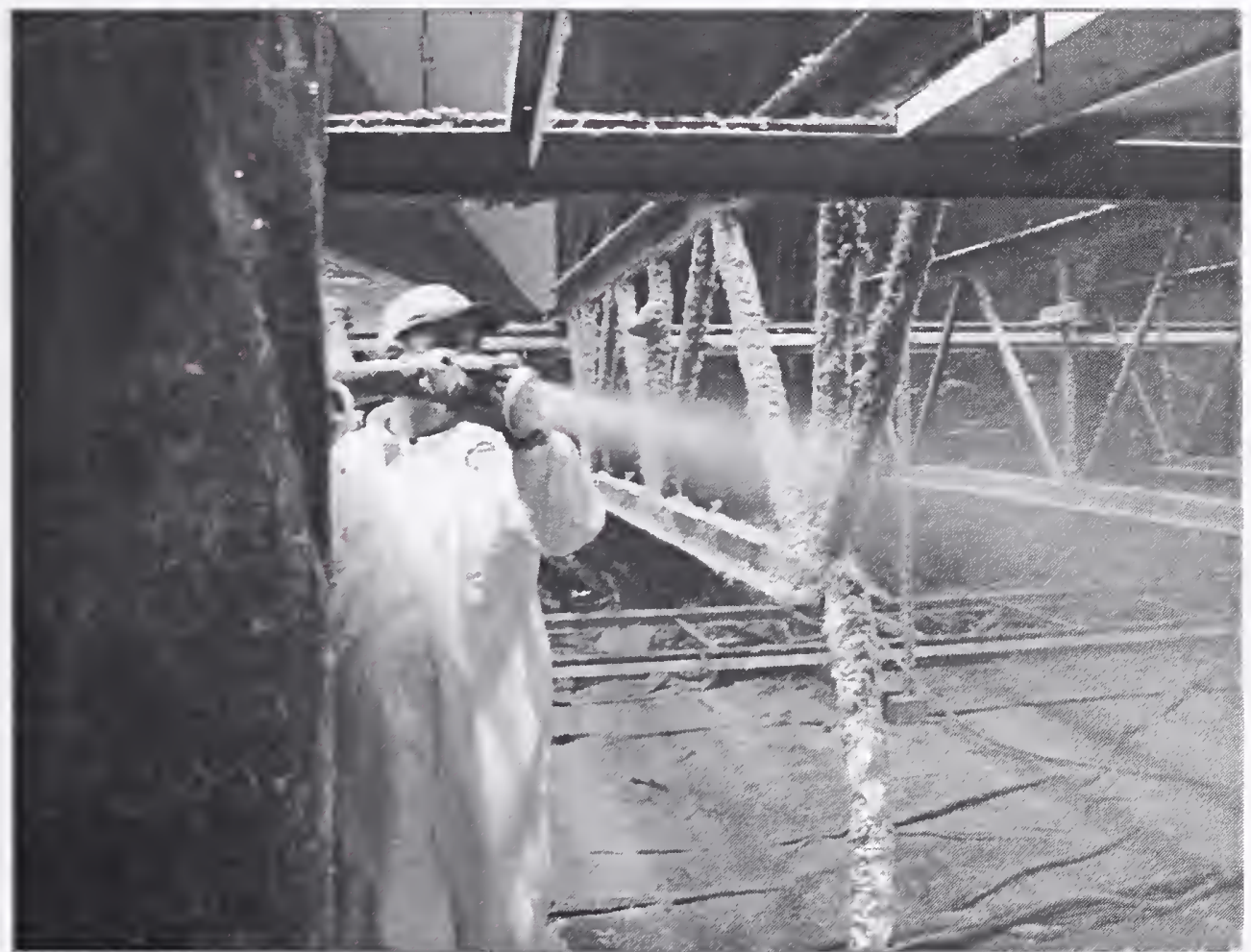

Source: NIST.

Figure 9-6d. Application of SFRM product to a truss. 


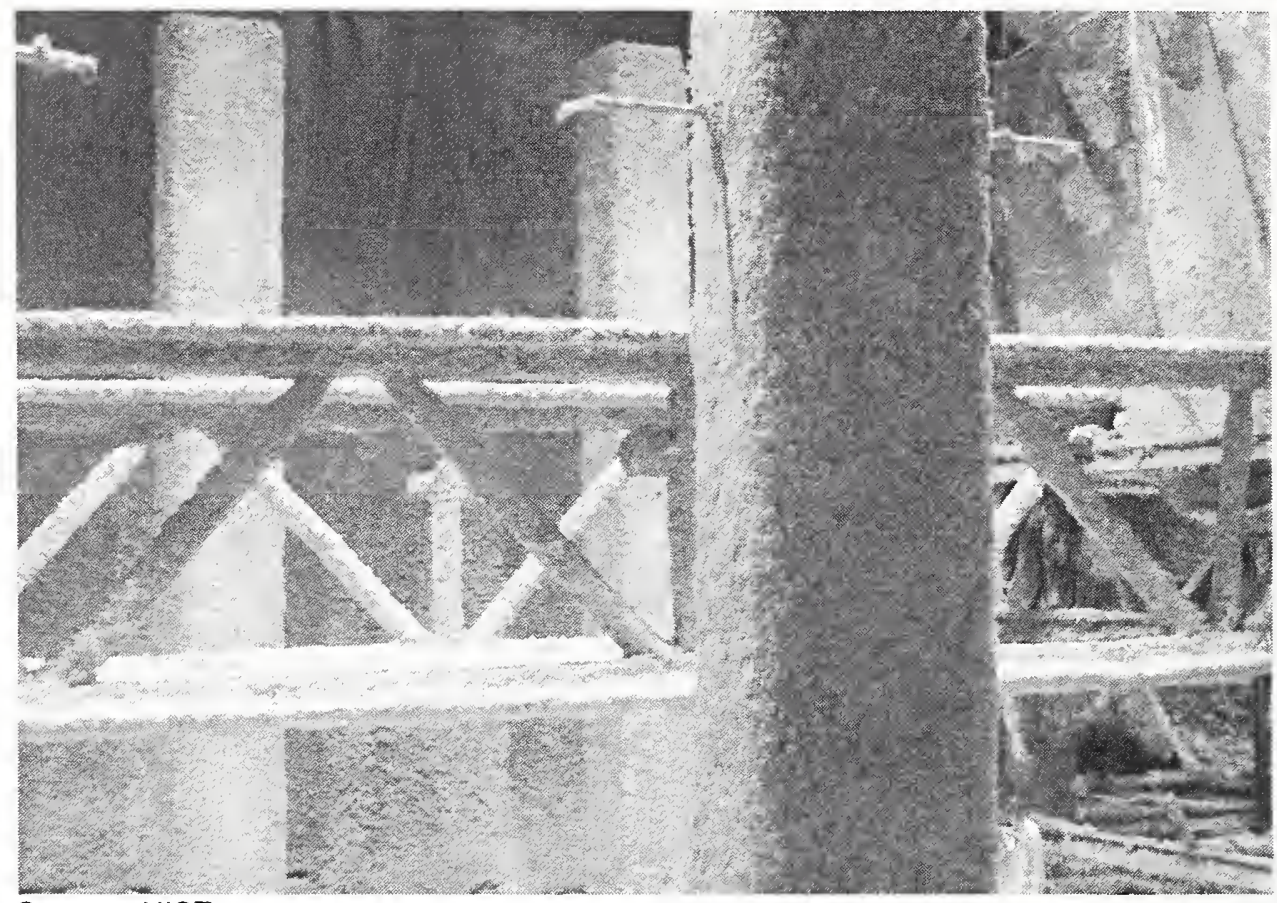

Source: NIST.

Figure 9-6e. Steel components with SFRM product prior to testing.

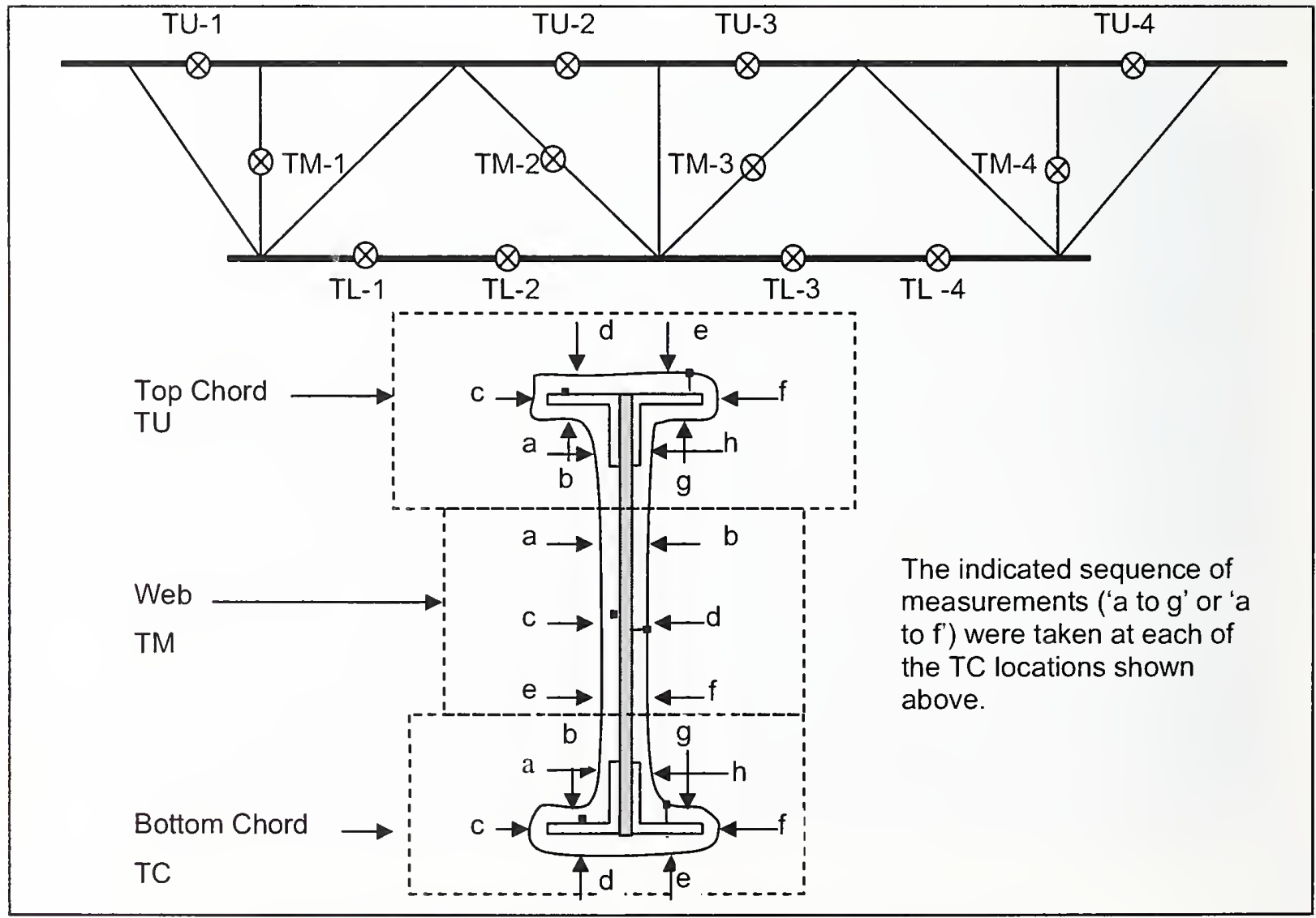

Figure 9-6f. SFRM measurement locations for trusses. 
Table 9-1. Statistical summary of SFRM thickness for steel components in Tests 5 and 6.

\begin{tabular}{|c|c|c|c|c|}
\hline & \multirow{2}{*}{$\begin{array}{c}\text { Specified } \\
\text { Thickness } \\
\text { Component }\end{array}$} & $\begin{array}{c}\text { Mean } \\
\text { (cm) }\end{array}$ & $\begin{array}{c}\text { Standard } \\
\text { Deviation } \\
(\mathbf{c m})\end{array}$ & COV \\
\hline Test 5 & & & & 0.55 \\
\hline Bar & 1.91 & 2.30 & 0.30 & 0.24 \\
\hline Column & 3.81 & 4.10 & 0.73 & 0.07 \\
\hline Truss A & 1.91 & 2.69 & 0.82 & 0.27 \\
\hline Truss B & 3.81 & 4.05 & & 0.20 \\
\hline Test 6 & & & 0.46 & 0.18 \\
\hline Bar & 1.91 & 2.53 & 0.35 & 0.17 \\
\hline Column & 1.91 & 2.14 & 0.69 & 0.26 \\
\hline Truss A & 1.91 & 2.60 & 0.69 & 0.27 \\
\hline Truss B & 1.91 & 2.56 & & \\
\hline
\end{tabular}

\subsubsection{SFRM Thickness}

The procedures to measure and evaluate SFRM thickness followed ASTM E 605-93, the Standard Test Method for Thickness and Density of Sprayed Fire-Resistive Material (SFRM) Applied to Structural Components, which is reproduced in italics below.

Selected areas to be measured for thickness shall be a predeternined, repetitive pattern to ensure obtaining representative average thickness. Determine the thickness by inserting the penetrating pin of the thickness gange perpendicular to and through the SFRM, to the substrate. When the point of the pin tonches the substrate, move the sliding disk to the SFRM sinface with sufficient force on the disk to register the average plane of the surface. Withdraw the gange to read the thickness in approximately $1 \mathrm{~mm}$ (1/16 in.) increments as shown by the position of the sliding clip indicator.

For the purpose of averaging measurements, any measurement $6 \mathrm{~mm}(1 / 4 \mathrm{in}$.) or nore, over the required design thickness, shall be recorded as the design thickness plus $6 \mathrm{~mm}$. No individnal measured thickness shall be more than $6 \mathrm{~mm}$ less, or more than 25 percent less, than the required design thickness.

Specific fire resistance rating criteria for beams, trusses, and columns may allow for a reduced thickness on flange tips. These thicknesses are to be averaged apart from other sections of the structural member.

An item (deck, column, beam, or joist) is deficient if:

- An individual measured thickness is more than $6 \mathrm{~mm}$ (1/4 in.) less, or more than 25 percent less, than the required fire resistance design thickness.

- The calculated average thickness of the SFRM is less than that required by the design. 
The applicable building code governs. Consult the applicable building code for exact requirenents and tolerances.

The International Building Code (IBC 2000) and the National Fire Protection Association in NFPA 5000 (NFPA 2003) both reference ASTM E 605 for determining adequate SFRM thickness. IBC 2000 further states that the minimum allowable thickness for a design thickness greater than or equal to $2.5 \mathrm{~cm}$ ( $1 \mathrm{in}$.) is the design thickness minus $0.6 \mathrm{~cm}(1 / 4 \mathrm{in}$.). Similarly, for a design thickness less than $2.5 \mathrm{~cm}$ ( $1 \mathrm{in}$.), the minimum allowable individual thickness is 75 percent of the design thickness.

Applying the IBC criteria to SFRM measurements that were less than the specified thickness would give a minimum allowable thickness of $1.43 \mathrm{~cm}$ for the specificd $1.91 \mathrm{~cm}$ coating and a minimum allowable thickness of $3.21 \mathrm{~cm}$ for the specified $3.81 \mathrm{~cm}$ coating. Individual thickness measurements are shown in Tables 9-2 through 9-7. Values that were less than the specified nominal thickness, but greater than the minimum allowable thickness, are highlighted in the tables. Bolded values were less than the minimum allowable thickness.

Table 9-2. SFRM thickness for bars in Tests 5 and 6.

\begin{tabular}{|c|c|c|c|c|c|c|c|c|c|}
\hline $\begin{array}{c}\text { Test 5 Bar } \\
(\mathbf{c m})\end{array}$ & $\mathbf{a}$ & $\mathbf{b}$ & $\mathbf{a}_{\mathbf{m}}$ & $\mathbf{b}_{\mathbf{m}}$ & $\begin{array}{c}\text { Test } \mathbf{6} \\
\text { Bar }(\mathbf{c m})\end{array}$ & $\mathbf{a}$ & $\mathbf{b}$ & $\mathbf{a}_{\mathbf{m}}$ & $\mathbf{b}_{\mathbf{m}}$ \\
\hline & \multicolumn{5}{|c|}{ Specified $1.91 \mathrm{~cm}$} & & \multicolumn{3}{c|}{ Specified $1.91 \mathrm{~cm}$} \\
\hline B1 & 3.02 & 2.70 & 1.91 & 2.54 & B1 & 1.91 & 3.18 & 2.06 & $\mathrm{x}$ \\
\hline B2 & 2.70 & 2.70 & 2.86 & 3.02 & B 2 & 2.86 & 2.70 & 2.54 & $\mathrm{x}$ \\
\hline B3 & 1.91 & 2.06 & 1.91 & 1.75 & B3 & 2.22 & 3.18 & 2.06 & $\mathrm{x}$ \\
\hline B4 & 1.91 & 1.27 & NA & NA & B4 & 2.22 & 2.86 & NA & NA \\
\hline \multicolumn{6}{|c|}{ COV $=0.24 ; \mu=2.30 \mathrm{~cm} ; \sigma=0.55 \mathrm{~cm}$} & \multicolumn{3}{c}{ COV $=0.18 ; \mu=2.53 \mathrm{~cm} ; \sigma=0.46 \mathrm{~cm}$} \\
\hline
\end{tabular}

Key: " $\mathrm{x}$ " indicates that measurements were not taken; NA, not applicable.

Note: Bold measurements were one standard deviation or more bclow specification; highlighted measurements were below specification. 
Table 9-3. SFRM thickness for columns in Tests 5 and 6.

\begin{tabular}{|c|c|c|c|c|c|c|c|}
\hline $\begin{array}{c}\text { Test } 5 \\
\text { Column } \\
(\mathrm{cm})\end{array}$ & $1 \mathbf{a}$ & lb & $1 \mathrm{~m}$ & $\begin{array}{c}\text { Test } 6 \\
\text { Column } \\
(\mathrm{cm})\end{array}$ & $1 \mathbf{a}$ & 1b & $1 \mathrm{~m}$ \\
\hline & \multicolumn{3}{|c|}{ Specified $3.81 \mathrm{~cm}$} & & \multicolumn{3}{|c|}{ Specified $1.91 \mathrm{~cm}$} \\
\hline $\mathrm{CU} 1$ & 4.29 & 4.29 & 4.29 & $\mathrm{CU} 1$ & 1.91 & 1.59 & 2.54 \\
\hline $\mathrm{CU} 2$ & 4.44 & 4.13 & 4.06 & CU 2 & 2.86 & 2.70 & 1.91 \\
\hline CU 3 & 4.13 & 4.13 & 3.81 & CU 3 & 2.54 & 1.91 & 1.91 \\
\hline $\mathrm{CU} 4$ & 4.44 & 3.96 & 4.44 & $\mathrm{CU} 4$ & 2.54 & 1.91 & 1.91 \\
\hline CM 1 & 4.13 & 4.29 & 4.13 & CM 1 & 1.91 & 2.54 & 2.22 \\
\hline CM 2 & 3.81 & 4.44 & 3.81 & CM 2 & 2.54 & 1.91 & 2.06 \\
\hline CM 3 & 4.44 & 4.44 & 4.13 & CM 3 & 1.43 & 1.75 & 1.91 \\
\hline $\mathrm{CM} 4$ & 4.44 & 4.06 & 4.13 & $\mathrm{CM} 4$ & 2.54 & 1.91 & 2.22 \\
\hline $\mathrm{CL} 1$ & 4.06 & 3.33 & $\mathrm{x}$ & $\mathrm{CL} 1$ & 1.75 & 1.91 & $\mathrm{x}$ \\
\hline CL 2 & 3.81 & 4.13 & $\mathrm{x}$ & CL 2 & 2.38 & 2.06 & $\mathrm{x}$ \\
\hline CL 3 & 4.13 & 3.18 & $\mathrm{x}$ & CL 3 & 2.38 & 2.54 & $x$ \\
\hline $\mathrm{CL} 4$ & 3.96 & 4.06 & $\mathrm{x}$ & CL 4 & 1.91 & 2.38 & $\mathrm{x}$ \\
\hline \multicolumn{4}{|c|}{$\mathrm{COV}=0.07 ; \mu=4.10 \mathrm{~cm} ; \sigma=0.30 \mathrm{~cm}$} & \multicolumn{4}{|c|}{$\operatorname{COV}=0.17 ; \mu=2.14 \mathrm{~cm} ; \sigma=0.35 \mathrm{~cm}$} \\
\hline
\end{tabular}

Key: " $x$ " indicates that measurements were not taken.

Note: Bold measurements were one standard deviation or more below specification; Highlighted measurements were below specification.

Table 9-4. SFRM thickness for truss A in Test 5.

\begin{tabular}{|c|c|c|c|c|c|c|c|c|}
\hline $\begin{array}{c}\text { Test 5 } \\
\text { Truss A } \\
(\mathbf{c m})\end{array}$ & $\mathbf{a}$ & $\mathbf{b}$ & $\mathbf{c}$ & $\mathbf{d}$ & $\mathbf{e}$ & $\mathbf{f}$ & $\mathbf{g}$ & $\mathbf{h}$ \\
\hline & \multicolumn{7}{|c|}{ Specified $1.91 \mathrm{~cm}$} \\
\hline TU 1 & 3.02 & 2.54 & 3.49 & 3.18 & 3.02 & 2.54 & 3.02 & 3.18 \\
\hline 2 & 2.54 & 2.38 & 2.06 & 3.81 & 2.54 & 2.54 & 2.54 & 3.18 \\
\hline 3 & 1.27 & 2.54 & 3.33 & 3.33 & 2.70 & 2.54 & 1.91 & 2.70 \\
\hline 4 & 2.22 & 2.70 & 2.86 & 1.75 & 2.54 & 1.75 & 3.18 & 2.38 \\
\hline TM 1 & 2.86 & 2.22 & 1.75 & 1.75 & 2.22 & 1.27 & NA & NA \\
\hline 2 & 2.86 & 2.86 & 2.54 & 1.91 & 2.54 & 2.70 & NA & NA \\
\hline 3 & 1.91 & 1.91 & 2.54 & 1.75 & 3.81 & 3.81 & NA & NA \\
\hline 4 & 2.08 & 3.81 & 3.81 & 2.70 & 2.72 & 5.08 & NA & NA \\
\hline TL 1 & 2.86 & 2.70 & 3.49 & 4.13 & 2.22 & 2.06 & 3.18 & 1.91 \\
\hline 2 & 3.81 & 3.81 & 1.27 & 1.75 & 2.54 & 3.18 & 3.02 & 3.18 \\
\hline 3 & 3.02 & 2.86 & 1.91 & 3.18 & 3.18 & 1.91 & 3.33 & 4.13 \\
\hline 4 & 3.18 & 1.59 & 1.59 & 1.91 & 2.54 & 2.54 & 3.02 & 3.18 \\
\hline
\end{tabular}

Note: Bold measurements were one standard deviation or more below specification; highlighted measurements were below specification. 
Table 9-5. SFRM thickness for truss B in Test 5.

\begin{tabular}{|c|c|c|c|c|c|c|c|c|}
\hline $\begin{array}{c}\text { Test 5 } \\
\text { Truss B } \\
\text { (cm) }\end{array}$ & $\mathbf{a}$ & $\mathbf{b}$ & $\mathbf{c}$ & $\mathbf{d}$ & $\mathbf{e}$ & $\mathbf{f}$ & $\mathbf{g}$ & $\mathbf{h}$ \\
\hline & \multicolumn{7}{|c|}{ Specified $3.81 \mathrm{~cm}$} \\
\hline TU 1 & $\mathbf{2 . 5 4}$ & $\mathbf{2 . 5 4}$ & $\mathbf{2 . 3 8}$ & 4.06 & 3.49 & $\mathbf{3 . 1 8}$ & 3.81 & 5.08 \\
\hline 2 & 4.76 & $\mathbf{3 . 1 8}$ & 3.49 & 3.81 & $\mathbf{3 . 1 8}$ & 3.81 & 3.81 & 3.81 \\
\hline 3 & 3.81 & 5.72 & $\mathbf{1 . 9 1}$ & 3.81 & 3.96 & $\mathbf{2 . 5 4}$ & 3.81 & 5.72 \\
\hline 4 & 5.72 & 4.06 & 3.96 & 4.44 & 3.96 & $\mathbf{3 . 1 8}$ & 4.44 & 4.92 \\
\hline TM 1 & $\mathbf{2 . 5 4}$ & 3.81 & 4.44 & 4.92 & 4.92 & 5.24 & NA & NA \\
\hline 2 & 3.81 & 3.81 & 3.81 & 4.44 & 5.72 & 4.44 & NA & NA \\
\hline 3 & 4.44 & 4.13 & 4.44 & 3.96 & 5.08 & 5.72 & NA & NA \\
\hline 4 & 3.81 & 4.44 & 4.06 & 4.44 & 5.08 & 5.24 & NA & NA \\
\hline TL 1 & 4.44 & 4.44 & 4.29 & 3.81 & 3.96 & $\mathbf{2 . 7 0}$ & 5.72 & 5.40 \\
\hline 2 & 3.81 & 3.49 & $\mathbf{3 . 1 8}$ & 4.44 & 4.13 & 3.81 & 4.44 & 4.13 \\
\hline 3 & 4.92 & 3.81 & $\mathbf{3 . 1 8}$ & 3.81 & 3.96 & $\mathbf{3 . 1 8}$ & 3.81 & 3.81 \\
\hline 4 & $\mathbf{3 . 1 8}$ & 3.81 & $\mathbf{3 . 1 8}$ & 4.13 & 4.13 & $\mathbf{3 . 1 8}$ & 4.44 & 4.44 \\
\hline
\end{tabular}

Key: NA, not applicable.

Note: Bold measurements were one standard deviation or more below specification; highlighted measurements were below specification.

Table 9-6. SFRM thickness for truss A in Test 6.

\begin{tabular}{|c|c|c|c|c|c|c|c|c|c|}
\hline $\begin{array}{c}\text { Test 6 } \\
\begin{array}{c}\text { Truss A } \\
\text { (cm) }\end{array}\end{array}$ & $\mathbf{a}$ & $\mathbf{b}$ & $\mathbf{c}$ & $\mathbf{d}$ & $\mathbf{e}$ & $\mathbf{f}$ & $\mathbf{g}$ & $\mathbf{h}$ \\
\hline Orange & \multicolumn{7}{|c|}{ Specified $1.91 \mathrm{~cm}$} \\
\hline TU 1 & 3.18 & 2.70 & 1.91 & 3.18 & 1.91 & 1.27 & 1.91 & 2.86 \\
\hline 2 & 2.86 & 1.43 & 2.38 & 2.70 & 3.18 & 1.91 & 1.59 & 2.54 \\
\hline 3 & 3.18 & 3.18 & 1.91 & 3.18 & 3.81 & 2.38 & 3.18 & 3.81 \\
\hline 4 & 2.54 & 1.91 & 1.59 & 1.91 & 2.38 & 1.43 & 1.91 & 2.86 \\
\hline TM 1 & 3.81 & 4.76 & 3.02 & 3.18 & 3.18 & 3.18 & NA & NA \\
\hline 2 & 2.86 & 3.18 & 2.38 & 3.18 & 3.33 & 2.86 & NA & NA \\
\hline 3 & 3.18 & 2.86 & 1.91 & 2.38 & 2.86 & 3.18 & NA & NA \\
\hline 4 & 2.86 & 3.18 & 2.70 & 2.38 & 3.81 & 3.02 & NA & NA \\
\hline TL 1 & 2.70 & 1.91 & 2.22 & 2.22 & 2.06 & 1.27 & 2.54 & 2.54 \\
\hline 2 & 3.33 & 3.18 & 1.91 & 3.81 & 2.54 & 1.11 & 1.43 & 1.91 \\
\hline 3 & 3.02 & 2.22 & 2.22 & 2.70 & 2.38 & 1.59 & 2.22 & 2.86 \\
\hline 4 & 2.86 & 2.86 & 2.06 & 3.18 & 2.70 & 1.75 & 2.54 & 2.70 \\
\hline
\end{tabular}

Key: NA, not applicable.

Note: Bold measurements were one standard deviation or more below specification; highlighted measurements were below specification. 
Table 9-7. SFRM thickness for truss B in Test 6.

\begin{tabular}{|c|c|c|c|c|c|c|c|c|}
\hline $\begin{array}{c}\text { Test 6 } \\
\text { Truss B } \\
\text { (cm) }\end{array}$ & $\mathbf{a}$ & $\mathbf{b}$ & $\mathbf{c}$ & $\mathbf{d}$ & $\mathbf{e}$ & $\mathbf{f}$ & $\mathbf{g}$ & $\mathbf{h}$ \\
\hline Yellow & \multicolumn{7}{|c|}{ Specified $1.91 \mathrm{~cm}$} \\
\hline TU 1 & 1.43 & 2.54 & 1.91 & 3.18 & 2.54 & $\mathbf{1 . 2 7}$ & 1.91 & 2.86 \\
\hline 2 & 1.91 & 2.54 & 1.59 & 2.54 & 3.18 & $\mathbf{1 . 2 7}$ & 1.91 & 1.91 \\
\hline 3 & 3.18 & 2.54 & 1.91 & 2.54 & 2.86 & $\mathbf{1 . 2 7}$ & 2.54 & 2.70 \\
\hline 4 & 2.38 & 1.91 & 1.59 & 2.70 & 1.91 & $\mathbf{1 . 2 7}$ & 1.91 & 2.38 \\
\hline TM 1 & 3.81 & 3.18 & 3.18 & 2.06 & 3.81 & 3.18 & NA & NA \\
\hline 2 & 3.18 & 3.81 & 3.18 & 2.86 & 3.96 & 3.81 & NA & NA \\
\hline 3 & 3.18 & 2.54 & 2.38 & 2.70 & 3.18 & 3.18 & NA & NA \\
\hline 4 & 3.18 & 3.18 & 2.38 & 2.70 & 3.18 & 2.38 & NA & NA \\
\hline TL 1 & 2.54 & 1.91 & 1.59 & 2.70 & 3.02 & 1.91 & 2.86 & 3.18 \\
\hline 2 & 2.54 & 1.43 & 1.43 & 2.86 & 3.81 & 1.91 & 2.54 & 2.54 \\
\hline 3 & 3.18 & 2.38 & 1.27 & 2.70 & 2.86 & 4.06 & 2.54 & 2.38 \\
\hline 4 & 3.18 & 2.22 & 1.91 & 2.22 & 2.70 & 2.22 & 3.18 & 3.18 \\
\hline
\end{tabular}

Key: NA, not applicable

Note: Bold measurements were one standard deviation or more below specification; highlighted measurements were below specification.

The measurements which fall below the minimum allowable thickness are highlighted and are listed in Tables 9-8 and 9-9 below (refer to Figs. 9-4b, 9-5b, and 9-6f for measurement locations):

Table 9-8. SFRM thickness measurements below allowable in Test 5.

\begin{tabular}{|c|c|c|c|}
\hline Component & $\begin{array}{c}\text { Number below Allowable/ } \\
\text { Total Number }\end{array}$ & $\begin{array}{c}\text { Percent below } \\
\text { Allowable }\end{array}$ & Location \\
\hline Bar & $1 / 14$ & $7 \%$ & B4 \\
\hline Column & $1 / 32$ & $3 \%$ & CL3 \\
\hline Truss A & $3 / 88$ & $3 \%$ & TU3 'a' \\
\hline & & & TM1 'f' \\
\hline & & & TL2 'c' \\
\hline Truss B & $17 / 96$ & $17 \%$ & TU1, TM1, TL4 'a' \\
\hline & & & TU1, TU2 'b' \\
\hline & & & TU1, TU3, TU4, TL1, TL3, TL4 'f \\
\hline
\end{tabular}


Table 9-9. SFRM thickness measurements below allowable in Test 6.

\begin{tabular}{|c|c|c|c|}
\hline Component & $\begin{array}{c}\text { Number below Allowable/ } \\
\text { Total Number }\end{array}$ & $\begin{array}{c}\text { Percent below } \\
\text { Allowable }\end{array}$ & Location \\
\hline Bar & None & 0 & B4 \\
\hline Column & None & 0 & - \\
\hline Truss A & $3 / 88$ & $3 \%$ & TU1, TL1, TL2, 'f'. \\
\hline Truss B & $5 / 88$ & $6 \%$ & TU1, TU2, TU3, TU4, 'f', TL3, 'c' \\
\hline
\end{tabular}

Most of the thickness measurements that were below the minimum allowable criteria occurred at the flange tips (locations ' $c$ ' and ' $f$ ' for the trusses), which is recognized as a difficult area to apply SFRM coatings (see Notc 1 of ASTM E 605, above). If the deficient flange tip measurements are removed from consideration, there remains one deficient thickness location in truss A and six in truss B for Test 5 and none for Test 6 . These steel components wcre carefully prepared in controlled conditions. They were tested without any attempt to address the noted thickness deficiencies.

The insulated steel components were handled carefully when thcy were placed in the test chamber. The trusses had short angle stubs attached to the center web member for lifting and positioning with a forklift. No thermocouples were attachcd to this web member. Once the trusses were placed within the chamber, the handling stubs and truss support ends were wrapped with Kaowool batting to prevent heat transfer into the truss through the bare steel areas, as the Kaowool batting thickness and thermal resistance propcrties were greater than that of the SFRM coating. The columns were lifted by grabbing removable bars inserted through holes that were pre-drilled through the columns. The column was seated on an elevated support designed to locate the column so that the top thermocouple was placed $15 \mathrm{~cm}$ below the cciling surface. The top and bottom of the columns were seated on Maranite supports to prevent heat transfer through the interior of the column. Aftcr an insulated column was positioned in the test chamber, the lifting bar was removed and the holes were filled with Kaowool batting. The bars were lifted by hand into position on the bottom chord of the two trusses (see Fig. 9-7a, 9-7b, 9-7c, and 9-7d). The bare ends were wrapped with Kaowool. 


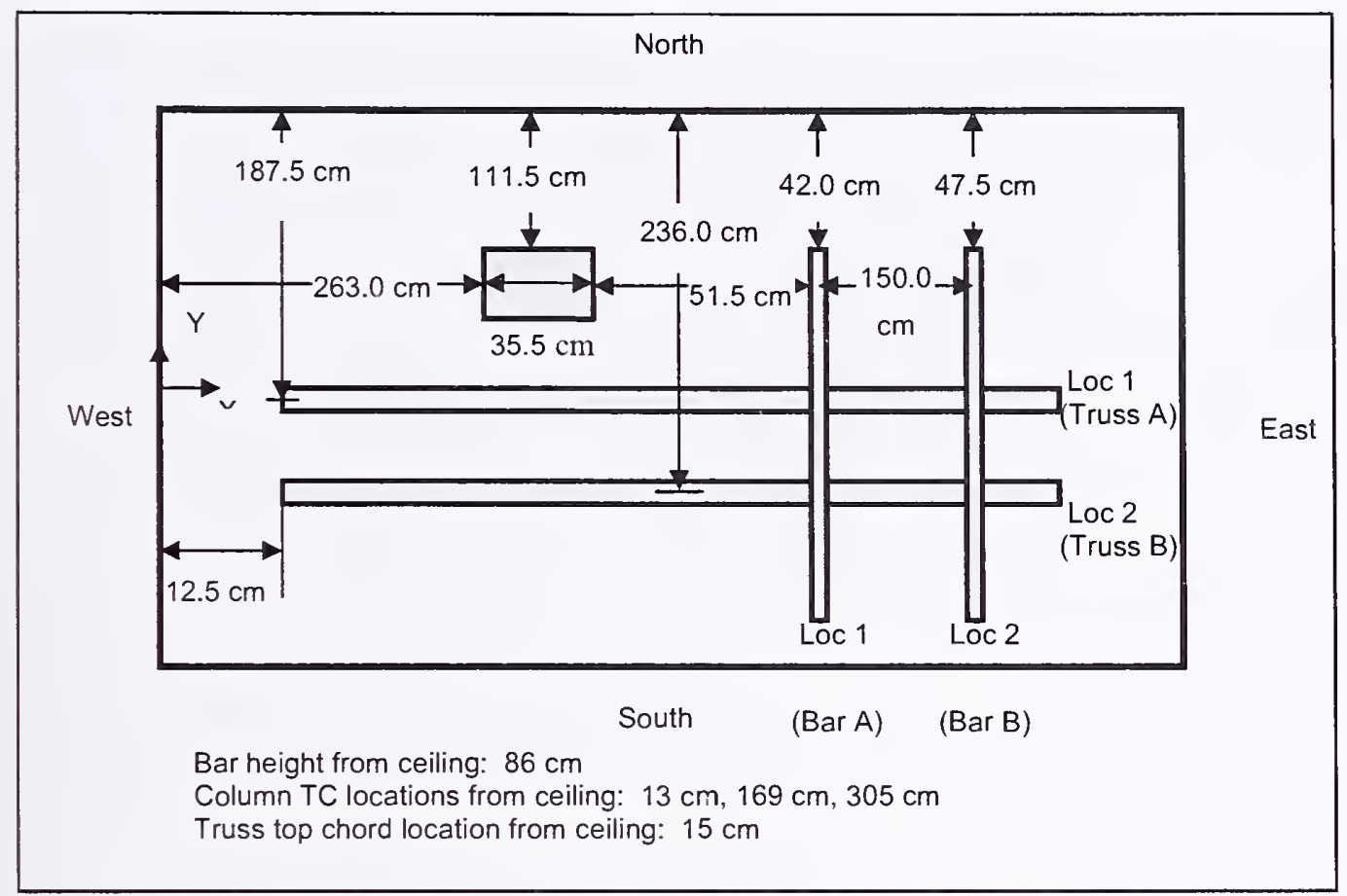

Figure 9-7a. Steel component locations for Tests 1, 2, and 3.

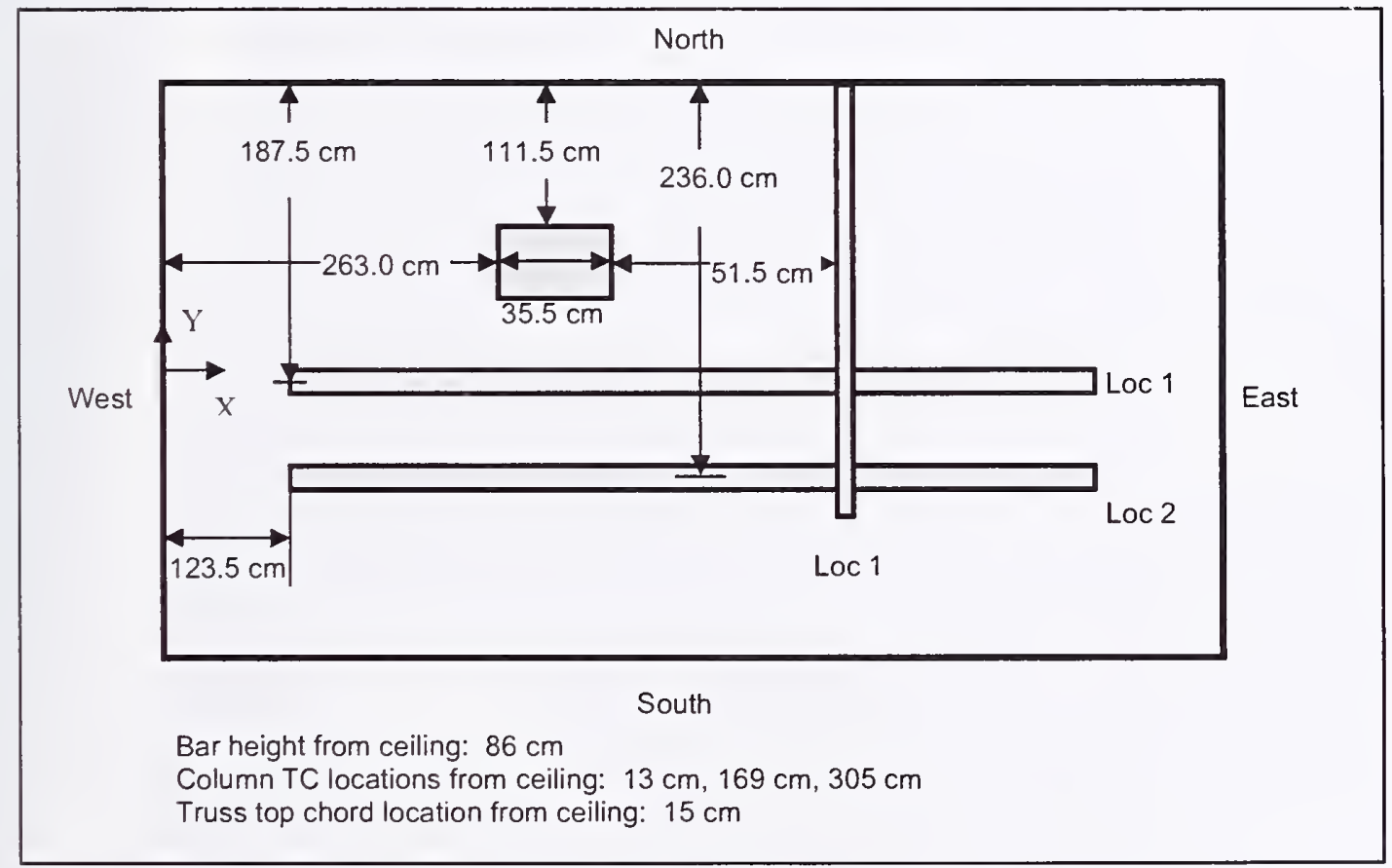

Figure 9-7b. Steel component locations for Tests 5 and 6. 


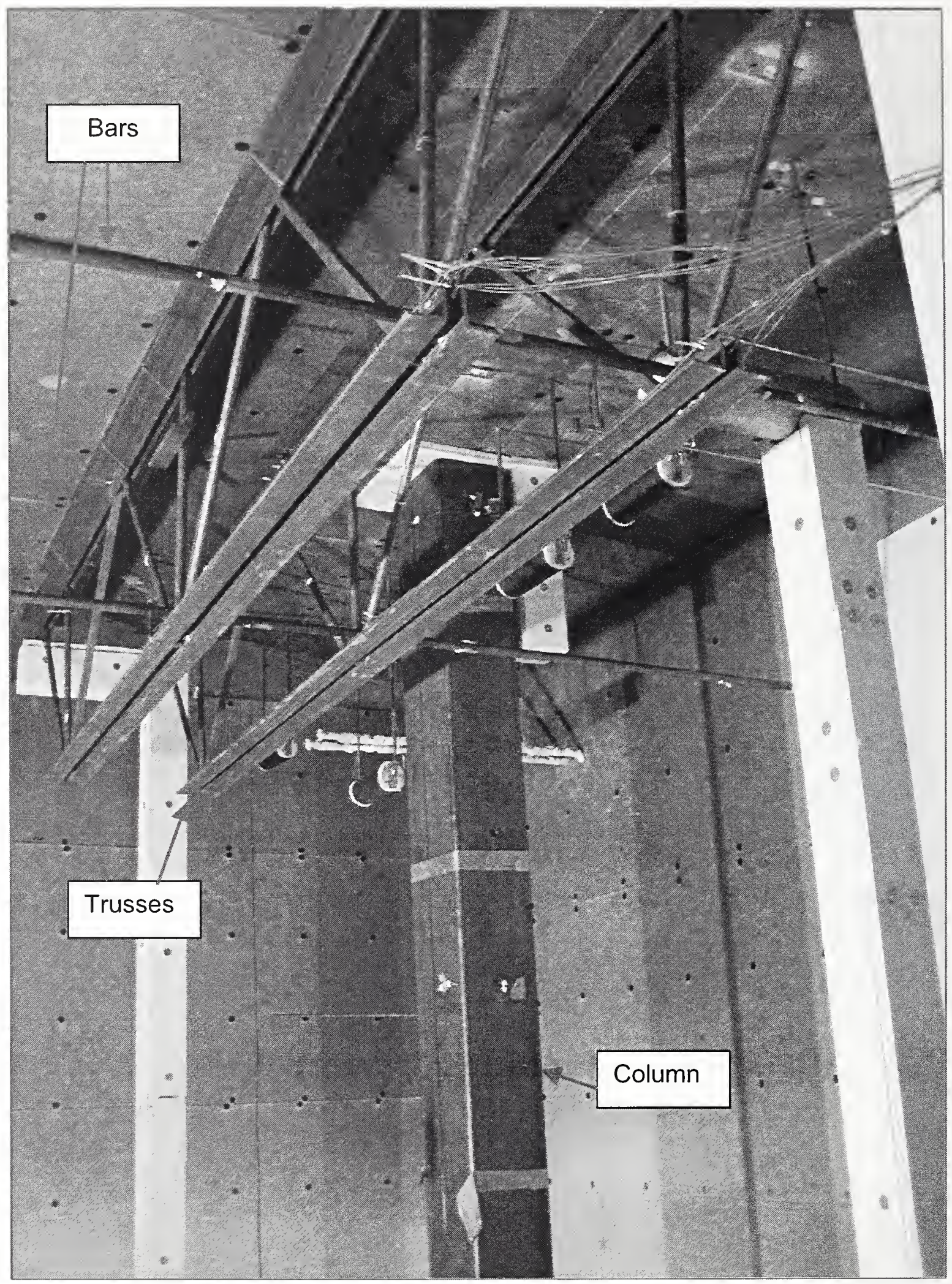

Source: NIST.

Figure 9-7c. Steel components in test compartment for Tests 1, 2, and 3. 


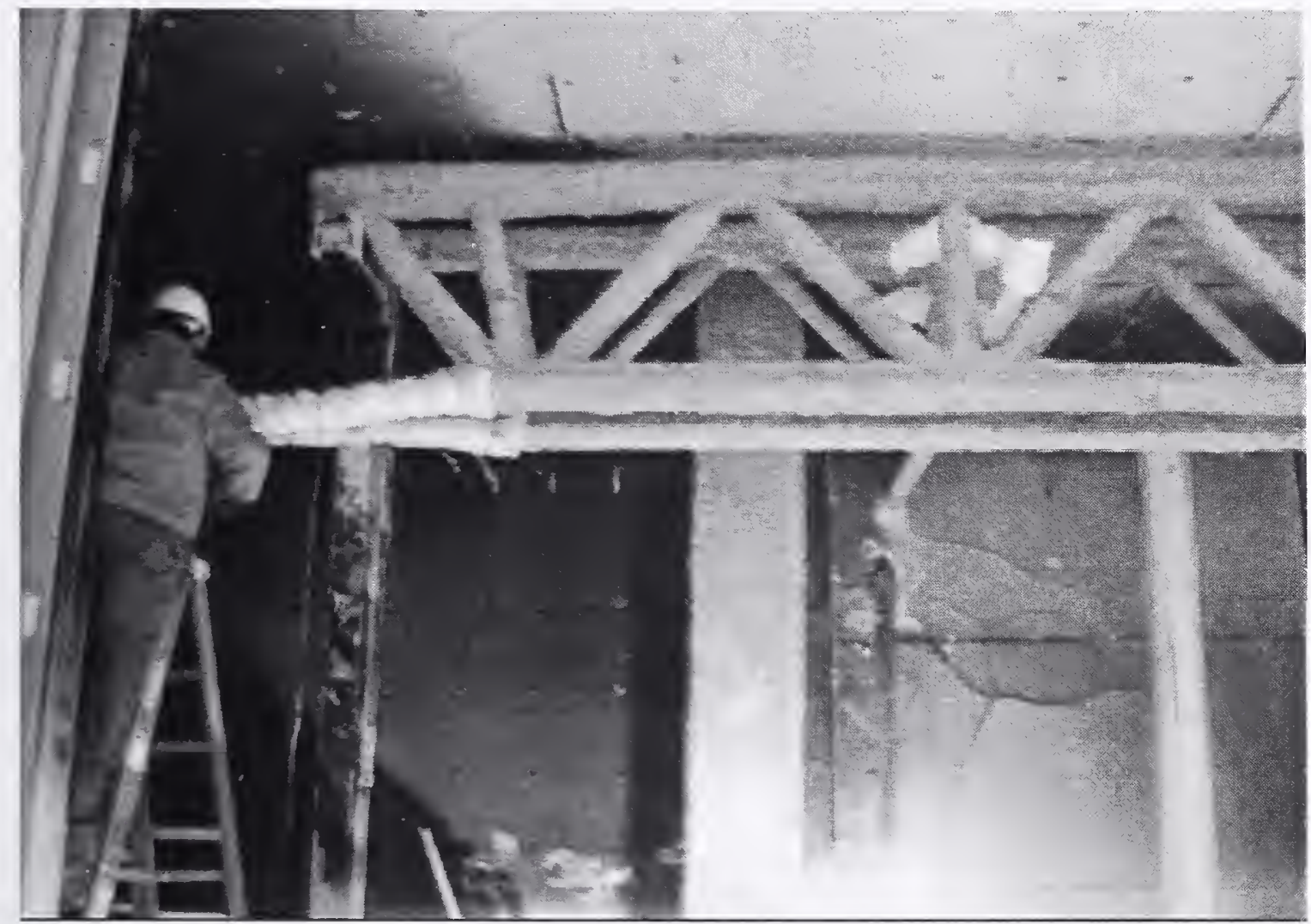

Source: NIST.

Figure 9-7d. Insulated steel components in test compartment for Tests 5 and 6.

\subsection{DESCRIPTION OF THE TEMPERATURE MEASUREMENTS}

The temperature measurements at the surface of the SFRM and the steel components are key for determining the amount of heat that is absorbed and conducted by these materials.

The controlling physical parameters of the solid and the density, $\rho$, the specific heat, $c$, and the thermal conductivity, $k$, can be combined into thermal diffusivity $\alpha(\equiv k / \rho c)$ (Holman 1976). The larger the value of $\alpha$, the faster heat will diffuse through the material. A large thermal diffusivity could occur with a high value of thermal conductivity $(k)$ or a low value of thermal heat capacity $(\rho c)$.

Steel and SFRM thermal properties vary with temperature, where c increases with temperature for both materials but, as the temperature increases, $\mathrm{k}$ decreases for steel, and $\mathrm{k}$ increases for SFRM. Steel density decreases slightly as thermal expansion increases the volume with increasing temperature, but this effect is often negligible for computing changes in thermal diffusivity.

While steel can be treated as a uniform solid, fibrous SFRM is a non-uniform composite material made up of fibers, cement, and other admixtures. When the packaged dry mix is combined with water and sprayed onto the steel surface, it dries and cures in place with air pockets distributed throughout the material. Furthermore, the SFRM composite material releases moisture as it is heated. While heat is transferred through the composite by a combination of conduction and radiation, reasonable results have been obtained by modeling the heat flow through SFRM solely with conduction heat transfer. Modeling analysis of heat transfer through the steel and SFRM is described in Chapter 11. 


\subsection{MEASUREMENT UNCERTAINTY}

An uncertainty analysis associated with the thermocouple measurement of the steel surface temperature is presented. Two contributions to the uncertainty are considered. The first contribution is the inherent uncertainty associated with a type $\mathrm{K}$ thermocouple, taken as approximately $5{ }^{\circ} \mathrm{C}$ (Omega 2000). The second contribution is the systematic and inherent difference between the measured temperature and the actual surface temperature due to the experimental configuration and the presence of a thermocouple attached to the surface of interest. This contribution may be further broken into two separate components, an error or offset in the measurement and an uncertainty of the measurement.

The error in the steel surface temperature measurement arises from the fact that the presence of the thermocouple bead and lead wires inherently influence the veracity of the measurement. While the thermocouple bead temperature is strongly influenced by the surface temperature of the steel, there is a difference due to the various heat transfer processes that occur. The condition of bare (uninsulated) steel leads to an upper bound in the temperature measurement as heat transfer to the bead and lead wires of the thermocouple from the hot gas layer via convection and radiation, as well as conductive transfer from the bead to the steel, from the lead wires to the bead, and along the lead wires all contribute to the actual temperature of the thermocouple bead.

Uncertainty in the measurement is from the distribution of temperature across the thermocouple bead. In thermoelectric thermometry, the electromotive force (e.m.f.) is dependent upon the material and the flow of heat from a region of one temperature to a region at a different temperature through the Seebeck effect (Bentley 1998). Joining two different materials whose Seebeck coefficient differs creates a thermocouple. The voltage measured across the open leads of the two materials is due to the temperature at the junction of the materials. For a beaded thcrmocouple, therefore, the measured temperature depends, in reality, on the geometry of the bead, the associated contact surfaces between the disparate metals of the thermocouple, and the temperature distribution across these contact surfaces. As it is not possible to ascertain the precise material distribution across the bead, it is possible that the measured temperature may be from any location within the bead. Typically, these distributions are small and can be neglected in comparison to other more dominant sources of uncertainty.

\subsubsection{Finite-Element Analysis}

Analysis of the systematic measurement error was considered using a finite-element code (ANSYS 2003) in a manner similar to that presented in Chapter 8 for thermocouple measurements of the temperature of the Marinite ceiling. Although an analytic steady-state solution to this problem may be simple, an analytic transient analysis is complex and is beyond the scope of this report. Furthermore, the transient problem is relatively more important than the steady state problem because it has a larger systematic measurement error than the steady-state problem. 
The simplified geometry considered here is presented in Fig. 9-8. The analysis is analogous to that considered for a thermocouple attached to an insulating wall material (see Fig. 8-2). An idealized hemispherical thermocouple bead is attached to the surface of a flat steel plate taken to be $2.5 \mathrm{~cm}$ thick. Thermocouple lead wires were attached to the bead and extend away from the steel surface. The lead wire diameter was $0.25 \mathrm{~mm}$ (30 gauge), and the bead diameter was initially taken to be twice the diameter of the wire leads, consistent with the thermocouples used in the experiment. Although composed of two different metals, the thermocouple was assumed to consist of only onc material so as to ease the computational burden through the application of symmetry conditions. Multiple calculations, using each of the component materials, were performed to assess the validity of this assumption.

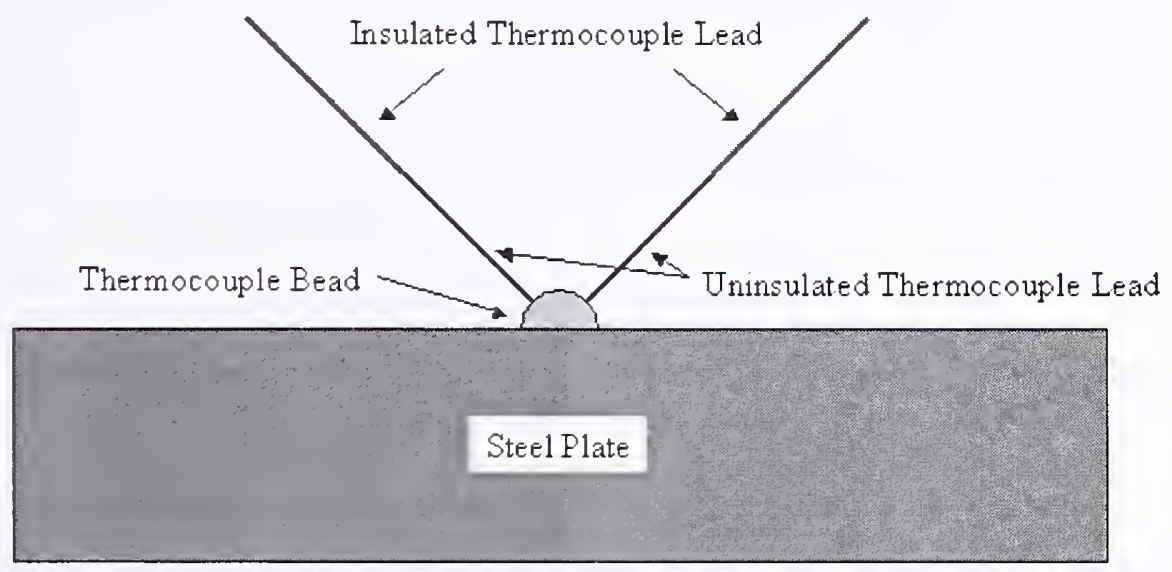

Figure 9-8. Simplified configuration used for the numerical analysis.

Representative thermophysical properties of the materials present were based on literature values. The temperature dependence of properties for Chromel and Alumel, the two materials comprising a Type K thermocouple, was neglected in the analysis; however, the temperature dependence of steel was considered (refer to NIST NCSTAR 1-3E). The properties of interest are listcd in Table 9-10. For steel, they are presented at room temperature. The emissivities of the steel and thermocouple surfaccs were taken to equal one, assuming that the surfaces were rapidly covered with soot during the experiment.

Table 9-10. Thermophysical properties of steel, Chromel, and Alumel.

\begin{tabular}{|l|c|c|c|}
\hline \multicolumn{1}{|c|}{ Material } & $\begin{array}{c}\text { Density } \\
\left(\mathbf{k g} / \mathbf{m}^{3}\right)\end{array}$ & $\begin{array}{c}\text { Heat Capacity } \\
(\mathbf{J} / \mathbf{k g ~ K})\end{array}$ & $\begin{array}{c}\text { Conductivity } \\
(\mathbf{W} / \mathbf{m ~ K})\end{array}$ \\
\hline Steel $^{\mathrm{a}}$ & 7,850 & 435 & 47.6 \\
\hline Alumel $^{\mathrm{b}}$ & 8,600 & 523 & 29.7 \\
\hline Chromel $^{\mathrm{b}}$ & 8,730 & 448 & 19.2 \\
\hline
\end{tabular}

a. Refer to NIST NCSTAR 1-3E, Physical Properties of Structural Steels.

b. Omega 2000.

The temperature of the thermocouple bead was taken as the average bead temperature. The distribution across the thermocouple bead and in the cross-section of the lead wires was neglected. This treatment presumes an idealized temperature measurement. The difference in temperature between the thermocouple bead attached to the steel plate and the steel surface some distance away from the 
thermocouple is denoted as the systematic error in the measurement. For these simulations, the lead wires were taken sufficiently long so that the end condition could be assumed to be at ambient conditions outside of the test compartment. The first $1 \mathrm{~cm}$ of lead wire off the thermocouple bead was considered to be uninsulated, whereas the remaining length was shielded with a perfect insulator.

\subsubsection{Simulation Results}

At time zero in the calculation, the steel plate and the thermocouple were immersed in a bath of hot gas simulating the upper layer of the compartment in the experiment. A uniform radiative flux similar in magnitude to that observed in the experiment $\left(20 \mathrm{~kW} / \mathrm{m}^{2}\right.$ to $\left.80 \mathrm{~kW} / \mathrm{m}^{2}\right)$ was applied to exposed surfaces, including the steel and the thermocouple, and the transient temperature field was calculated. In the experimental configuration, the thermocouple lead wires from the bead were held to the steel surface. The close proximity to the steel surface led to shadowing of portions of the lead wires from the full radiation field emitted by the hot upper gas layer. To approximate this, the radiative flux was only taken to be incident on half of the surface of the wire leads. Re-radiation from the surfaces was considered, but convective heat transfer was neglected. It is expected that similar results would be found if convection was considered in the analysis, although a determination of the localized convective heat transfer coefficients adds complexity to the model problem. Furthermore, at the temperatures realized in most fire situations, heat transfer from convection is typically much smaller than from radiation.

The simulation results showed that the thermocouple lead wires increased in temperature at a faster rate than did the surface of the steel. This can be attributed to the small thermal mass of the lead wire as compared to that of the steel. The rapid increase in temperature established a conductive flux along the wire to the thermocouple bead, which in turn increased the temperature of the bead. The high thermal conductivity of the steel helped dissipate the added heat flowing to the bead; nonetheless, a temperature gradient was established between the surface temperature of the steel (away from the thermocouple) and the thermocouple bead. The temperature difference arose from the conductive flux through the lead wires. As time progressed and the temperature of the steel plate and thermocouple approached steady state, the conductive flux diminished, and the temperature difference decreased to near zero at steady state.

A phase plot representing the systematic error associated with the measurement is presented in Fig. 9-9. The thermocouple temperature, plotted on the horizontal axis, is presented as a function of the difference in temperature between the steel surface and the thermocouple temperature, plotted on the vertical axis. For the various heat fluxes considered, as described above, there is an initial rise in the error observed early in the simulation. Maximum temperature differences of approximately $0.5^{\circ} \mathrm{C}, 1{ }^{\circ} \mathrm{C}, 2{ }^{\circ} \mathrm{C}$, and $4{ }^{\circ} \mathrm{C}$ were found for fluxes of $10 \mathrm{~kW} / \mathrm{m}^{2}, 20 \mathrm{~kW} / \mathrm{m}^{2}, 40 \mathrm{~kW} / \mathrm{m}^{2}$ and $80 \mathrm{~kW} / \mathrm{m}^{2}$, respectively. The differences remained nearly steady for some time and then rapidly decreased as steady state was reached. 


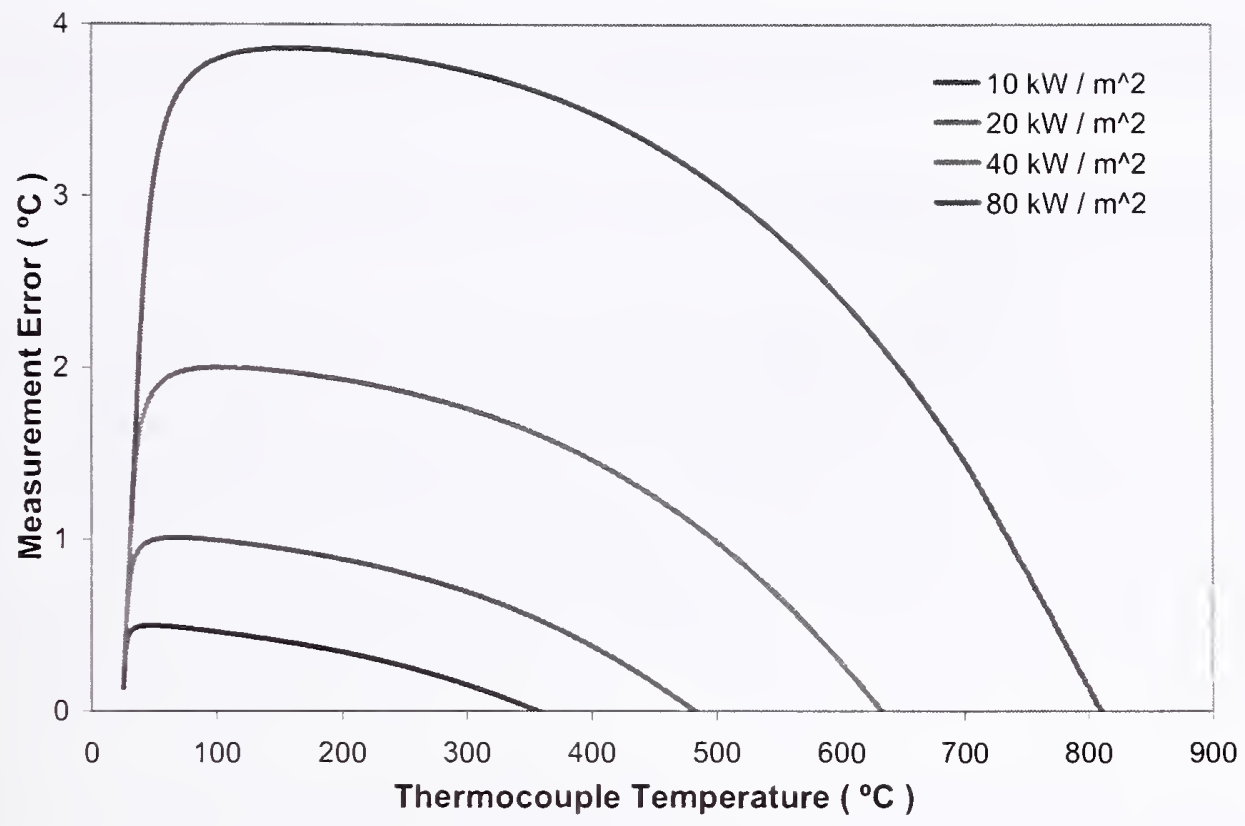

Figure 9-9. Calculated measurement error for thermocouples on uninsulated steel.

As stated above, both materials of a Type $\mathrm{K}$ thermocouple were considered in independent analyscs. The resulting calculated temperature differences between the thermocouple bead and the steel surface were found to be similar (within 10 percent) for both materials, justifying the earlier assumption that approximated the thermocouple using a single material. As expected, differences were slightly larger for simulations using Alumel as compared to Chromcl due to Alumel's higher thermal conductivity. The larger thermal conductivity increased the thermal flux from the wire to the bead, and rcsulted in a larger temperature difference.

Variation of the bead diameter was also considered. For simulations utilizing a bead diameter equal to four times the wire diameter, an increase of approximately 10 percent in the systematic error was calculated.

For very early times in the experiment, the thermocouple and steel surfaces may not be completely covered with soot. The emissivities would then be closer to the true emissivities of the respective materials, 0.8 for steel and 0.2 for Alumel (Smyth et al. 1985). The fluxes to the wire leads would be diminished, reducing the rate of temperature rise, and decreasing the associated conductivc flux between the wire and the bead. The temperature differences between the thcrmocouplc and the steel would be less than that described above as would the variation in temperature across the bead, reducing the uncertainty in the measurements.

In summary, the systematic error in the bare steel measurements is minimized as the temperature reaches steady state in the experiment and as the gradients between the thermocouple bead and the steel approach zero. For elevated steel temperatures $\left(\mathrm{T}>300^{\circ} \mathrm{C}\right)$, the analysis shows that the systematic error in the temperature measurement at steady state due to the experimental configuration is less than $4{ }^{\circ} \mathrm{C}$ even for high flux conditions $\left(80 \mathrm{~kW} / \mathrm{m}^{2}\right)$. If the systematic error is treated as a measurement uncertainty, then the total expanded measurement uncertainty is bounded by $+1{ }^{\circ} \mathrm{C}$ and $-9{ }^{\circ} \mathrm{C}$. A correction to the temperature 
measurements could be applied, provided that estimates of the local time varying heat flux are available. The value of the correction, however, is relatively small for conditions of interest here.

\subsection{MEASUREMENT UNCERTAINTY OF THE SFRM SURFACE TEMPERATURE}

The dominant contributor to the uncertainty in the measurcment of the SFRM is related to the exact location of the thermocouple bead. The coating is fibrous by nature, and the applied coating was uneven. Thermocouples were positioned onto the SFRM by pushing the lead wires and bead parallel to the steel surface and into the SFRM. A post-experiment assessment of the positions of the thermocouple bead relative to the surface of the coating showed that the thermocouple bead extended as far as $5 \mathrm{~mm}$ below the surface of the SFRM. The uncertainty in thermocouple position can lead to a systematic error in the measurement of the surface temperature. Calculations using the ANSYS finite-element software show that the magnitude of the error varies as a function of time. At early times in the calculation, the temperaturc gradient near the surface of the SFRM is very high, and the uncertainty in the position of the bead can lead to temperature measurements that are 30 percent less than the actual surface temperature. This error diminishes with time as the SFRM heats and the temperature gradient decreases. After long times, for example, the calculations showed that the systematic measurement error decreased to approximatcly $70{ }^{\circ} \mathrm{C}$ for the insulated bar exposed to $1,000{ }^{\circ} \mathrm{C}$ in the upper layer. Values of 7 percent less than the actual surface temperature are taken as representative of the systematic expanded uncertainty. The inherent thermocouple uncertainty of $5{ }^{\circ} \mathrm{C}$ provides an upper bound for the uncertainty, assuming that the thermocouples were positioned below the surface of the SFRM. Post-experiment inspection of representative thermocouples suggests that this was the case.

\subsection{DESCRIPTION OF EXPERIMENTAL RESULTS}

Tests 1,2, and 3 subjected the same set of two bars, one column, and two trusses to direct exposure of heat flux and temperatures from a fuel pan fire. In all three tests, the thermal response of these components to flame proximity or immersion was similar. The steel began to heat immediately upon initiation of the fire and to cool immediately after the fire was extinguished. The recorded response showed no lag time between the steel and heated gas for transferring radiant heat from the higher to lower temperature mediums.

Tests 5 and 6 exposed separate sets of one bar, one column, and two trusses that were insulated with SFRM to direct exposure of heat flux and temperatures from a fuel pan fire. In both tests, the thermal response of these components to flame proximity or immersion was similar. The SFRM surface began to heat immediately upon initiation of the fire and to cool immediately after the fire was extinguished. The protected steel responded more slowly, taking approximately $50 \mathrm{~min}$ with $1.91 \mathrm{~cm}(0.75 \mathrm{in}$.) of SFRM to reach $600{ }^{\circ} \mathrm{C}$ temperatures as compared to the $7 \mathrm{~min}$ when the steel was bare and subjected to similar $3 \mathrm{MW}$ fires. Steel temperatures continued to rise approximately $25^{\circ} \mathrm{C}$ to $50{ }^{\circ} \mathrm{C}$ for a $5 \mathrm{~min}$ to $10 \mathrm{~min}$ period after the fire was extinguished, before cooling began to take place by radiating heat through the insulation back into the relatively cooler gases.

Tables 9-11 and 9-12 summarize the minimum and maximum peak temperatures recorded during each test. Table $3-5$ in Chapter 3 lists the mean heat release rate $(\dot{Q})$ and duration for each test. The maximum steel temperatures occurred near the fire pan in areas where there was flame impingement on 
the bars (locations B3 and B4 in Fig. 9-4a) and trusses (location 3 or 4 in Fig. 9-6a) and on column surfaces facing the fire pan. The tests were stopped when one or more thermocouples on the steel surface reached approximately $600{ }^{\circ} \mathrm{C}$.

Table 9-11 lists temperatures recorded during Tests 1, 2, and 3 of bare steel components. Truss B at location TL3 recorded the highest temperature in each test $\left(615^{\circ} \mathrm{C}\right.$ to $\left.705^{\circ} \mathrm{C}\right)$, as this location was located directly over the fire pan and was often immersed in flames. The sequence of maximum temperatures (from highest to lowest peak temperature) is the same for each test-truss B, truss A, bar A, bar $\mathrm{B}$, and the column -indicating that radiation from the fire is the primary heat transfer mechanism.

The trusses and bars were immersed in a hot gas layer near the ceiling of the test chamber (see Chapter 4), and their peak minimum temperatures were within $60^{\circ} \mathrm{C}$ of each other. Note that the minimum temperatures were higher $\left(330^{\circ} \mathrm{C}\right.$ to $\left.390^{\circ} \mathrm{C}\right)$ for Tests 1 to 3 , which had a nominal $\dot{Q}$ of $2 \mathrm{MW}$ for approximately $15 \mathrm{~min}$, than the minimum temperatures recorded for Test $2\left(235^{\circ} \mathrm{C}\right.$ to $285^{\circ} \mathrm{C}$ ), which had a higher nominal $\dot{Q}$ of $3 \mathrm{MW}$ for $6 \mathrm{~min}$. The column components measured similar temperature ranges (maximum-minimum) of $150^{\circ} \mathrm{C}$ to $170{ }^{\circ} \mathrm{C}$.

Table 9-11. Summary of peak temperatures recorded during Tests 1, 2, and 3.

\begin{tabular}{|c|c|c|c|c|c|c|}
\hline Component & $\begin{array}{c}\text { Time } \\
(\mathbf{s})\end{array}$ & $\begin{array}{c}\text { Maximum } \\
\text { Temp } \\
\left({ }^{\circ} \mathbf{C}\right)\end{array}$ & $\begin{array}{c}\text { TC } \\
\text { Label }\end{array}$ & $\begin{array}{c}\text { Minimum } \\
\text { Temp } \\
\left({ }^{\circ} \mathbf{C}\right)\end{array}$ & $\begin{array}{c}\text { TC } \\
\text { Label }\end{array}$ & $\begin{array}{c}\text { Temp } \\
\text { Range } \\
\left({ }^{\circ} \mathbf{C}\right)\end{array}$ \\
\hline Test 1 $(14.5$ min) & 870 & & & & & \\
\hline Bar A & & 525 & B4 & 365 & B1 & 160 \\
\hline Bar B & & 440 & B4 & 365 & B1 & 75 \\
\hline Column & & 390 & CL2 & 240 & CL1 & 150 \\
\hline Truss A & & 560 & TL3 & 360 & TM1 & 200 \\
\hline Truss B & & 615 & TL3 & 370 & TM1 & 240 \\
\hline Test 2 (6.3 min) & 380 & & & & & \\
\hline Bar A & & 525 & B3 & 235 & B1 & 190 \\
\hline Bar B & & 370 & B4 & 260 & B1 & 110 \\
\hline Column & & 320 & CU3 & 150 & CL1, & 170 \\
\hline Truss A & & 600 & TL3 & 270 & TM1 & 230 \\
\hline Truss B & & 705 & TL3 & 285 & TM1 & 420 \\
\hline Test 3 (16.2 min) & 970 & & & & & \\
\hline Bar A & & 535 & B4 & 330 & B1 & 205 \\
\hline Bar B & & 435 & B4 & 350 & B1 & 85 \\
\hline Column & & 380 & CU3 & 225 & CL1 & 155 \\
\hline Truss A & & 545 & TU4 & 375 & TM1 & 170 \\
\hline Truss B & & 635 & TL3 & 390 & TM1 & 245 \\
\hline
\end{tabular}


Table 9-12. Summary of peak temperatures recorded during Tests 5 and 6.

\begin{tabular}{|c|c|c|c|c|c|c|c|c|}
\hline Component & $\begin{array}{l}\text { Time } \\
\text { (s) }\end{array}$ & $\begin{array}{c}\text { Maximum } \\
\text { Temp } \\
\left({ }^{\circ} \mathrm{C}\right)\end{array}$ & $\begin{array}{c}\text { Temp } \\
\text { Range at } \\
\text { Location } \\
\left({ }^{\circ} \mathrm{C}\right)\end{array}$ & $\begin{array}{c}\mathrm{TC} \\
\text { Label }\end{array}$ & $\begin{array}{c}\text { Minimum } \\
\text { Temp } \\
\left({ }^{\circ} \mathrm{C}\right)\end{array}$ & $\begin{array}{l}\text { Temp } \\
\text { Range at } \\
\text { Location } \\
\left({ }^{\circ} \mathrm{C}\right)\end{array}$ & $\begin{array}{c}\mathrm{TC} \\
\text { Label }\end{array}$ & $\begin{array}{l}\text { Temp } \\
\text { Range } \\
\left({ }^{\circ} \mathrm{C}\right)\end{array}$ \\
\hline Test $5(51.3 \mathrm{~min})$ & 3,075 & & & & & & & \\
\hline $\begin{array}{c}\text { Bar } \\
1.91 \mathrm{~cm} \text { SFRM }\end{array}$ & & 845 & \multirow{2}{*}{380} & B4 & 680 & \multirow{2}{*}{255} & B2 & 165 \\
\hline $\begin{array}{l}\text { Bar } \\
\text { Steel }\end{array}$ & & 465 & & B3 & 425 & & B2 & 40 \\
\hline $\begin{array}{c}\text { Column } \\
3.81 \mathrm{~cm} \text { SFRM }\end{array}$ & & 760 & \multirow{2}{*}{560} & CU3 & 425 & \multirow{2}{*}{305} & CLl & 335 \\
\hline $\begin{array}{l}\text { Column } \\
\text { Steel }\end{array}$ & & 200 & & CU2 & 120 & & CL4 & 80 \\
\hline $\begin{array}{c}\text { Truss A } \\
1.91 \mathrm{~cm} \text { SFRM }\end{array}$ & & 835 & \multirow{2}{*}{285} & TU4 & 625 & \multirow{2}{*}{225} & TL1 & 210 \\
\hline $\begin{array}{c}\text { Truss A } \\
\text { Steel }\end{array}$ & & 550 & & $\begin{array}{l}\text { TM4 } \\
\text { TU4 }\end{array}$ & 400 & & TU1 & 150 \\
\hline $\begin{array}{c}\text { Truss B } \\
3.81 \mathrm{~cm} \mathrm{SFRM}\end{array}$ & & 870 & \multirow{2}{*}{355} & TU4 & 660 & \multirow{2}{*}{485} & TU1 & 210 \\
\hline $\begin{array}{c}\text { Truss B } \\
\text { Steel }\end{array}$ & & 415 & & $\begin{array}{l}\text { TM4 } \\
\text { TU4 }\end{array}$ & 175 & & TL2 & 240 \\
\hline Test $6(50.2 \mathrm{~min})$ & 3,010 & & & & & & & \\
\hline $\begin{array}{c}\text { Bar } \\
1.91 \mathrm{~cm} \text { SFRM }\end{array}$ & & 865 & \multirow{2}{*}{355} & B4 & 730 & \multirow{2}{*}{285} & B1 & 135 \\
\hline $\begin{array}{l}\text { Bar } \\
\text { Steel }\end{array}$ & & 510 & & B4 & 445 & & B1 & 65 \\
\hline $\begin{array}{c}\text { Column } \\
1.91 \mathrm{~cm} \text { SFRM }\end{array}$ & & 745 & \multirow{2}{*}{360} & $\begin{array}{l}\mathrm{CM} 2 \\
\mathrm{CU} 2\end{array}$ & 495 & \multirow{2}{*}{220} & CL4 & 150 \\
\hline $\begin{array}{c}\text { Column } \\
\text { Steel }\end{array}$ & & 375 & & CUl & 275 & & CL1 & 100 \\
\hline $\begin{array}{c}\text { Truss A } \\
1.91 \mathrm{~cm} \mathrm{SFRM}\end{array}$ & & 950 & \multirow{2}{*}{285} & TM4 & 670 & \multirow{2}{*}{300} & TU1 & 280 \\
\hline $\begin{array}{c}\text { Truss A } \\
\text { Steel }\end{array}$ & & 665 & & TU4 & 370 & & TL1 & 295 \\
\hline $\begin{array}{c}\text { Truss B } \\
1.91 \mathrm{~cm} \text { SFRM }\end{array}$ & & 930 & \multirow{2}{*}{250} & TM4 & 655 & \multirow{2}{*}{240} & TM1 & 275 \\
\hline $\begin{array}{c}\text { Truss B } \\
\text { Steel }\end{array}$ & & 680 & & TU4 & 415 & & TL1 & 265 \\
\hline
\end{tabular}

Note: Steel temperatures for Tests 5 and 6 continued to rise approximately $25^{\circ} \mathrm{C}$ to $50^{\circ} \mathrm{C}$ after the fuel flow was halted. 
Figures 9-10 through 9-14 show the temperature histories recorded during Test 3 for all the thermocouples. The steel temperatures all rose rapidly for the first $8 \mathrm{~min}$ to $10 \mathrm{~min}$ at a nearly linear rate. As the steel reached $300{ }^{\circ} \mathrm{C}$ to $400^{\circ} \mathrm{C}$, the temperature rise continued at a slightly decreased rate. The recorded thermocouple temperatures for bar $\mathrm{B}$ and truss $\mathrm{A}$ subject to flame immersion are $50{ }^{\circ} \mathrm{C}$ to $75^{\circ} \mathrm{C}$ higher than similar locations on the other bar and truss and tend to have a high frequency signal imposed upon the average temperature. The columns were located next to the fire pan, but the airflow through the test chamber resulted in the fire leaning toward the exhaust outlet, away from the columns, so that the columns were heated primarily by radiation. The sides of the column facing the fire were heated more quickly, with thermocouples at the ceiling and floor level facing the fire pan recording maximum temperatures. There was a marked drop in steel temperatures when the fuel flow was shut off. As soon as the compartment gas temperatures fell, the steel temperature began to decrease as heat was transferred through radiation and convection to the surroundings.

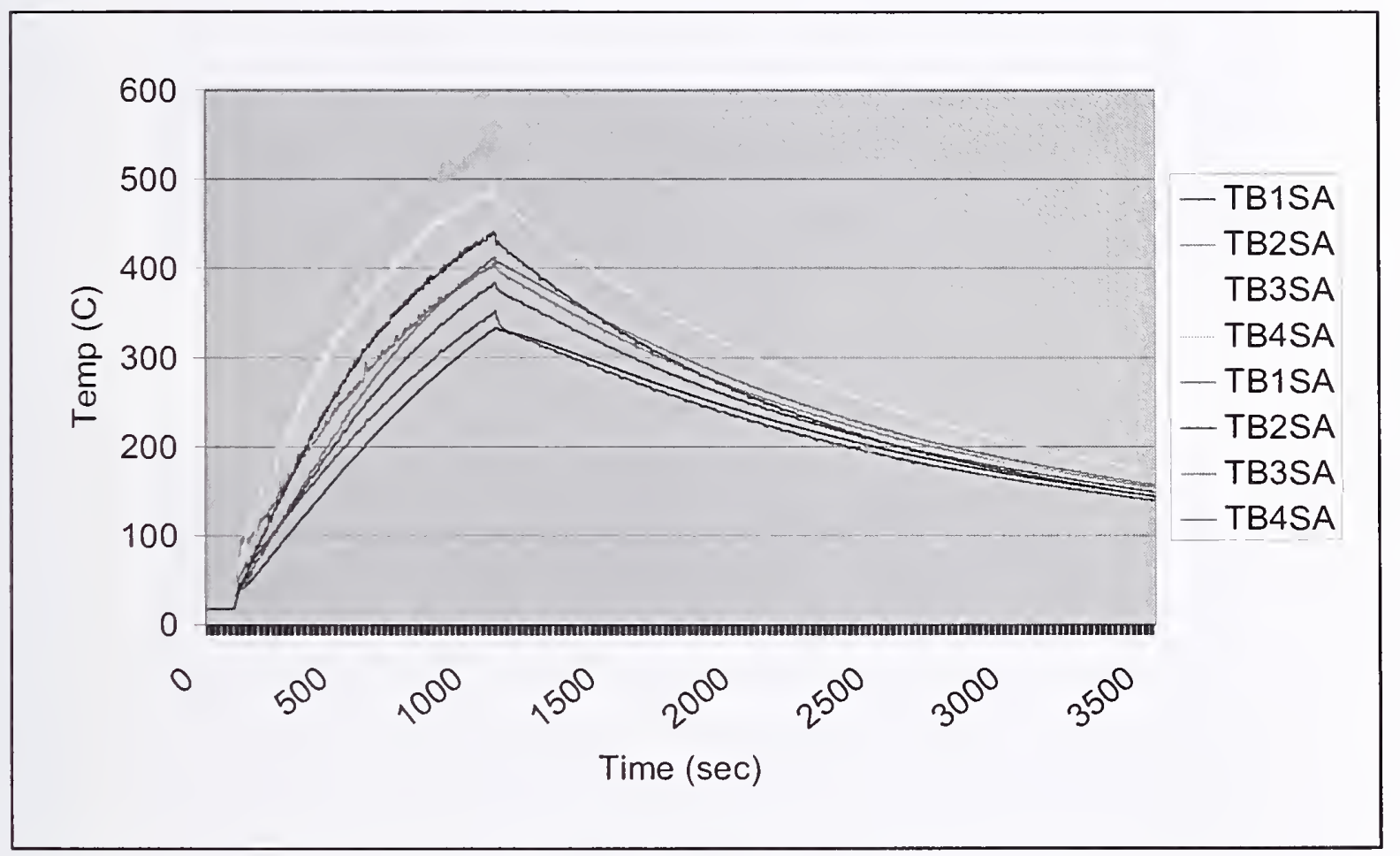

Figure 9-10. Temperature history for bar A in Test 3. 


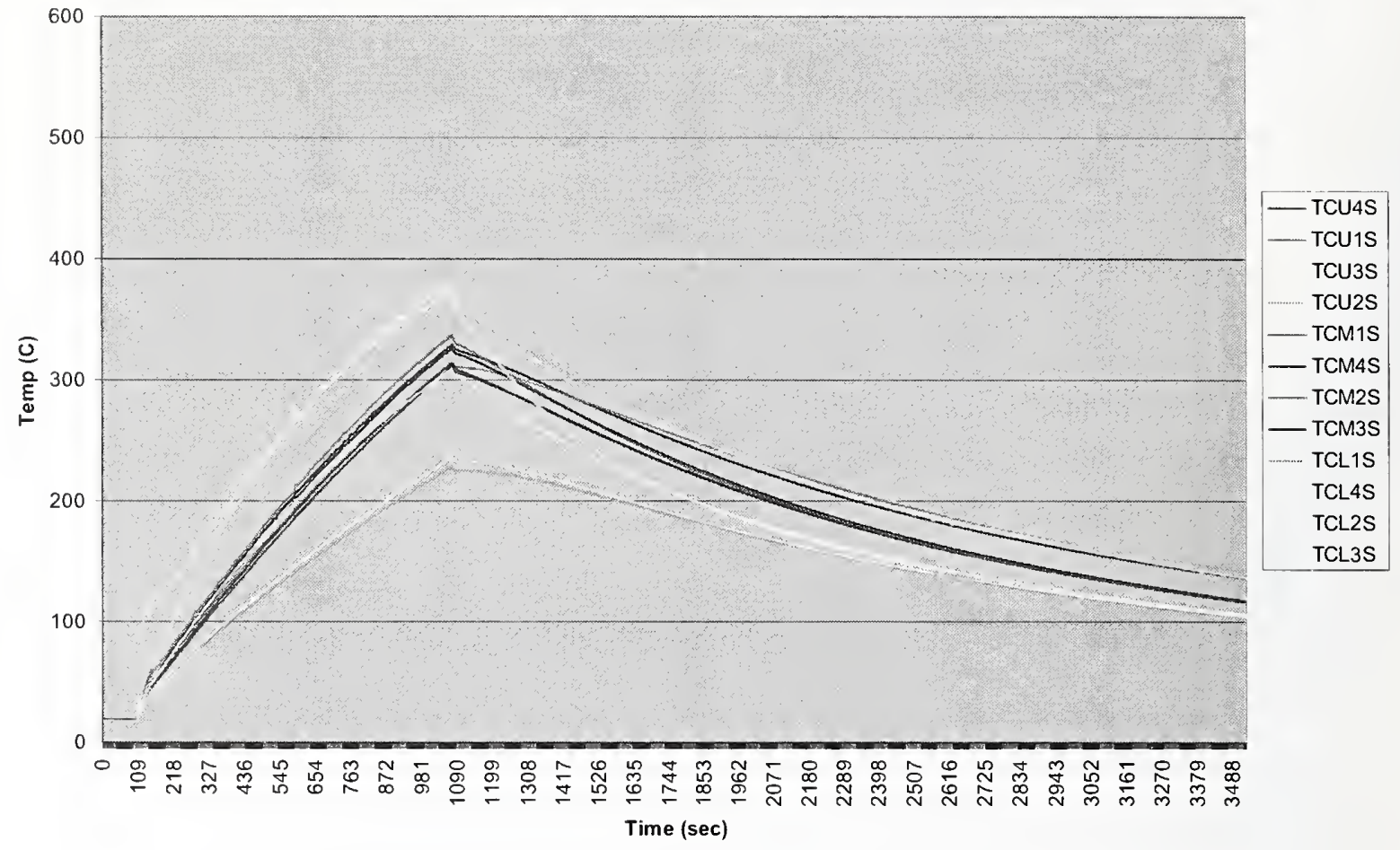

Figure 9-11. Temperature history for column in Test 3.

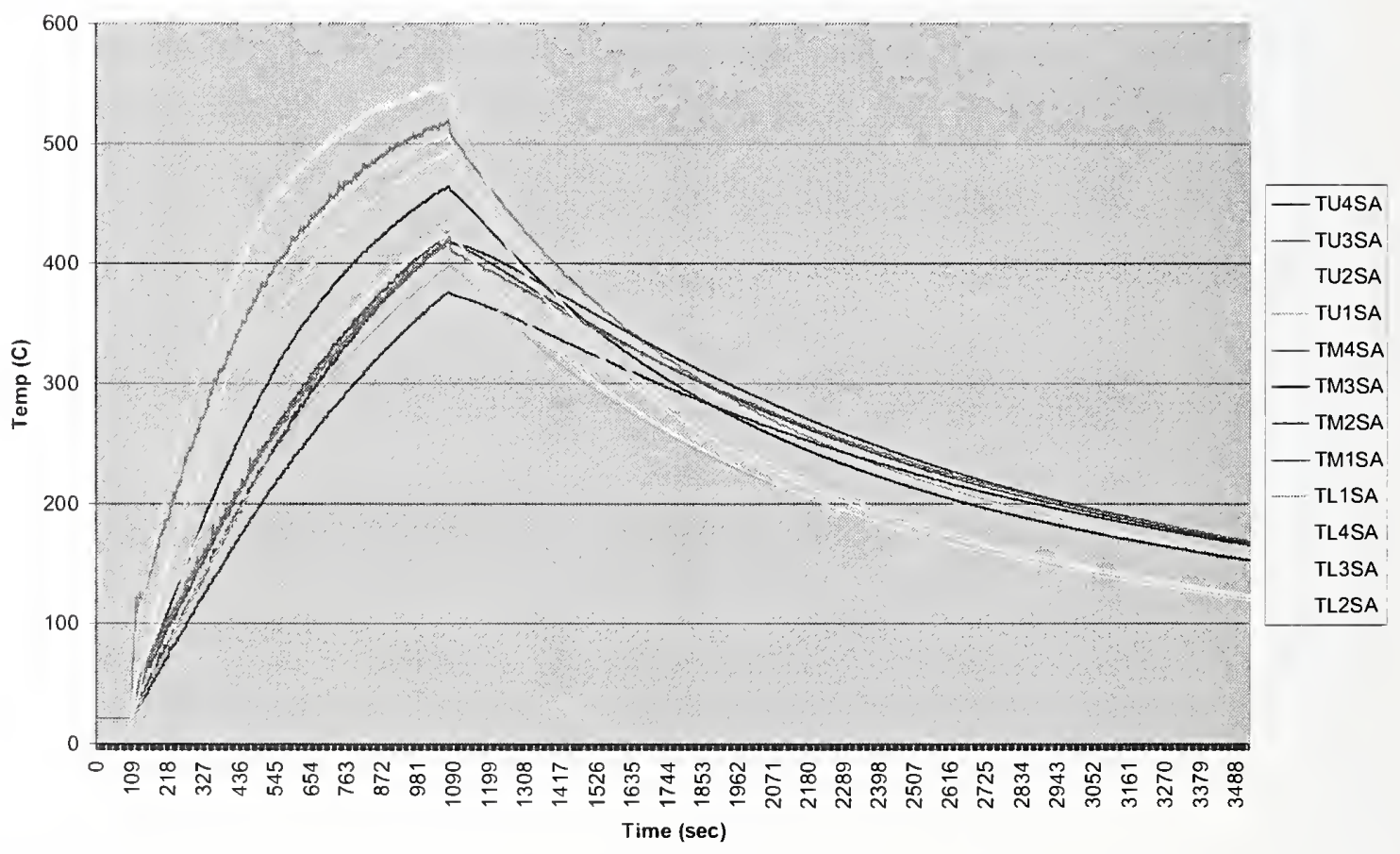

Figure 9-12. Temperature history for truss A in Test 3. 


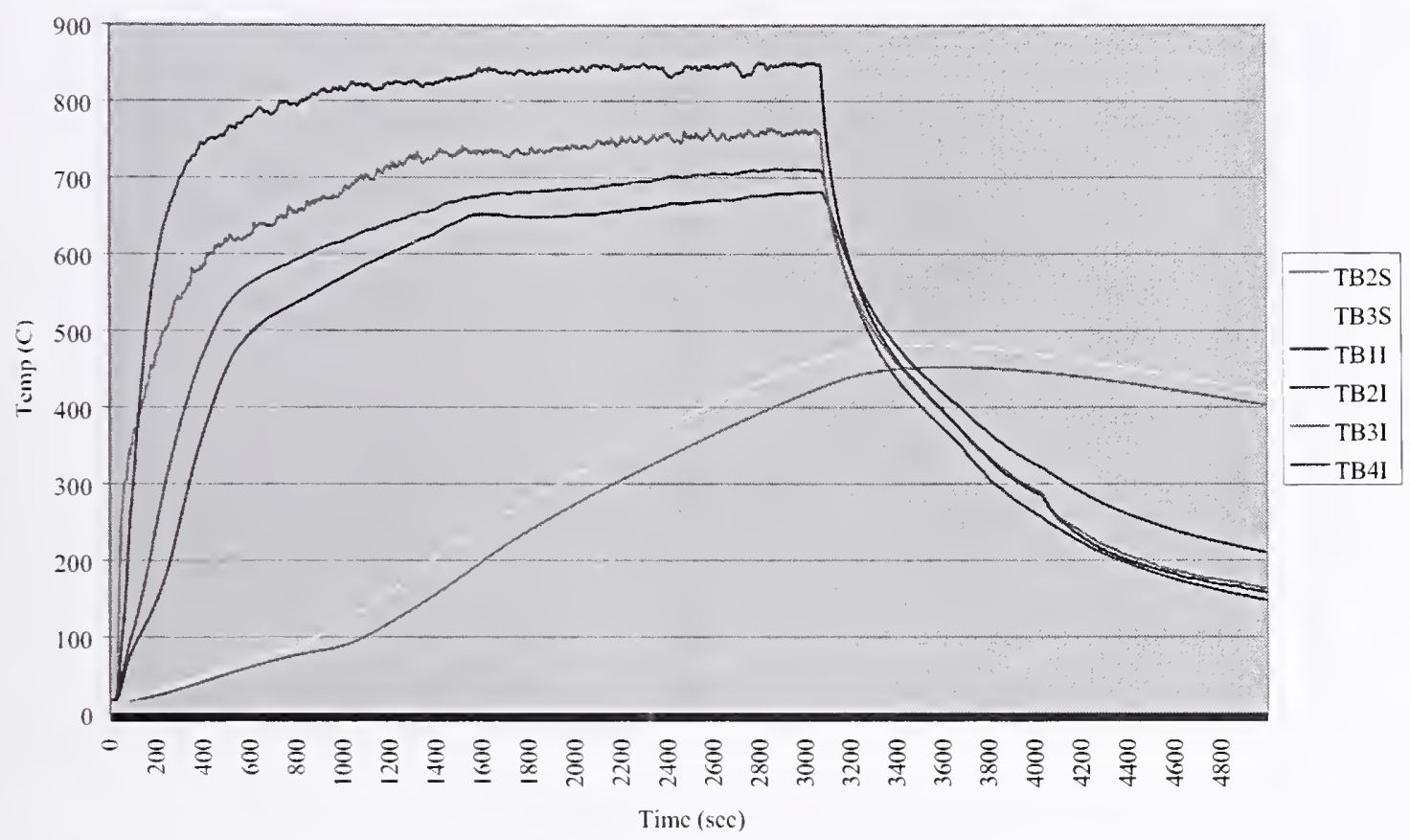

Figure 9-13. Temperature history for bar in Test 5.

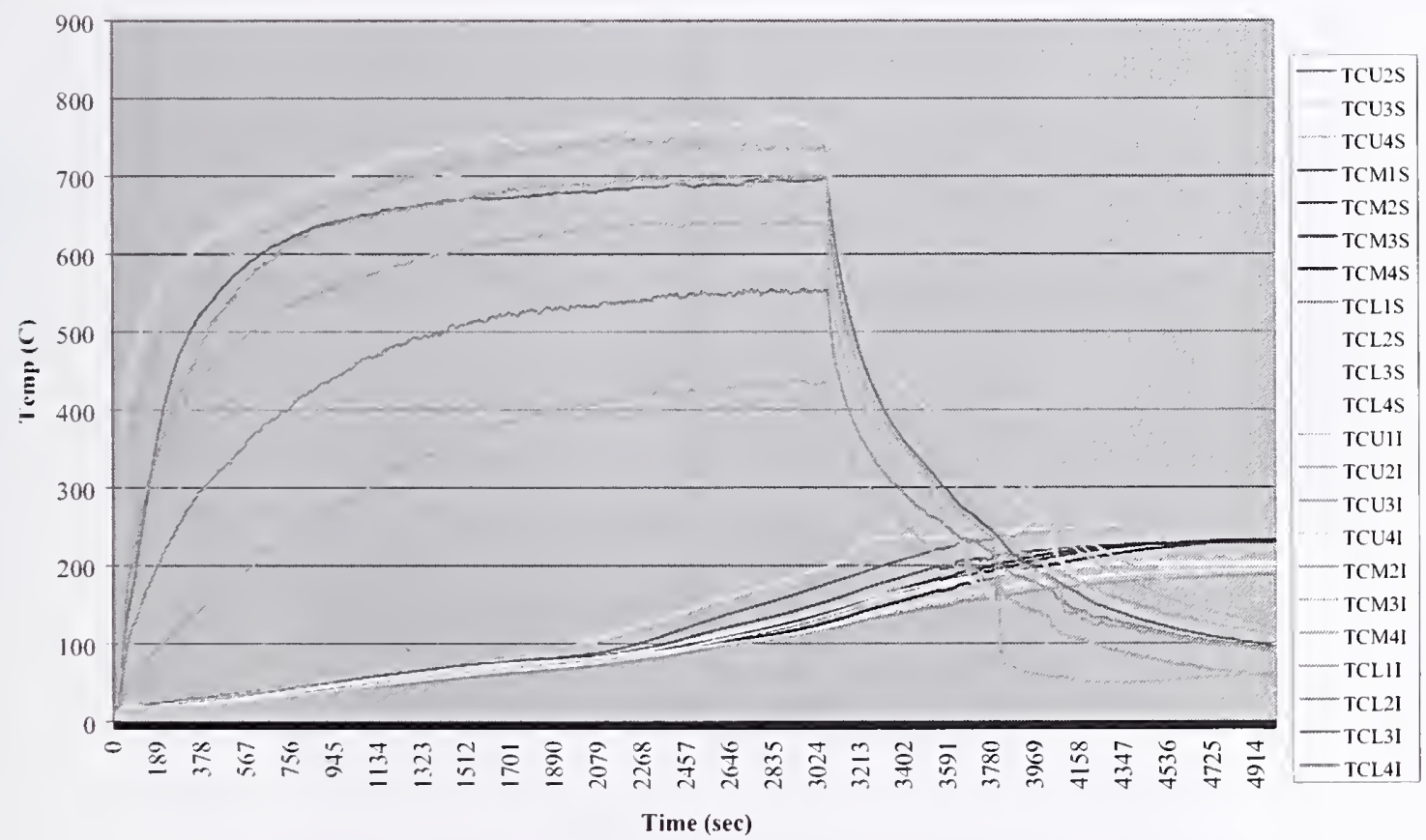

Figure 9-14. Temperature history for column in Test 5. 
Table 9-12 lists temperatures of SFRM protected components recorded during Tests 5 and 6 . Tests 5 and 6 are discussed separately to address the differences in the SFRM coatings. In Test 5, truss A $(1.91 \mathrm{~cm}$ SFRM) had peak maximum steel temperatures at locations TM4 and TU4, which were near, or immersed, in flames. The peak maximum steel temperature on truss B $\left(3.81 \mathrm{~cm}\right.$ SFRM) was $135{ }^{\circ} \mathrm{C}$ less at the same lateral (y axis) locations. The temperatures on the insulation surface rose sharply at the beginning of the test and were close to their peak temperatures after $5 \mathrm{~min}$ to $10 \mathrm{~min}$, whereas the steel surface temperatures rose more gradually. The maximum SFRM surface temperature was $835{ }^{\circ} \mathrm{C}$ to $870{ }^{\circ} \mathrm{C}$ at TU4 for both trusses. The peak minimum SFRM surface temperatures were similar $\left(625^{\circ} \mathrm{C}\right.$ to $\left.660^{\circ} \mathrm{C}\right)$, but the steel minimum temperatures differed by $225^{\circ} \mathrm{C}\left(400^{\circ} \mathrm{C}\right.$ vs. $\left.175^{\circ} \mathrm{C}\right)$. The difference in steel temperatures appears to be primarily duc to the difference in SFRM thickness, as the SFRM temperatures were within 5 percent. The bar $(1.91 \mathrm{~cm}$ SFRM) temperatures are similar to truss A, with the exception of the peak maximum steel temperature $\left(85^{\circ} \mathrm{C}\right.$ less $)$. The column $(3.81 \mathrm{~cm}$ SFRM) had markedly lower SFRM and steel temperatures than the trusses and bar. The peak maximum steel temperatures recorded at column location $\mathrm{CU} 3$, in the hot gas layer near the ceiling and facing the firc, were $100{ }^{\circ} \mathrm{C}$ to $300{ }^{\circ} \mathrm{C}$ less than the othcr components.

In Test 6, truss A (1.91 cm SFRM) and truss B (1.91 cm SFRM) recorded similar peak maximum and minimum temperatures for the steel and SFRM at locations TM4 and TU4. The bar (1.91 cm SFRM) temperatures are similar to the bar in Test 5 . The column (1.91 cm SFRM) had similar SFRM temperatures but higher steel temperatures than the column in Test 5. Figures 9-15 through 9-18 illustrate how the insulated stcel components responded to the fires. The SFRM surface thermocouples responded to the gas temperatures quickly, reaching their peak temperatures in $5 \mathrm{~min}$ to $10 \mathrm{~min}$. The steel temperature rise was essentially uniform for all thermocouples until the steel temperatures reach $100{ }^{\circ} \mathrm{C}$, when the rate of temperaturc rise increases for all thermocouples, but at different rates. The SFRM surface temperatures showed an immediate response to the drop in compartment gas temperatures. The steel temperatures continued to rise approximately $25{ }^{\circ} \mathrm{C}$ to $50^{\circ} \mathrm{C}$ after the fuel flow was shut. Figures 9-19 and 9-20 show the steel components before and during Test 6 , with flame impingement, through the exhaust opening.
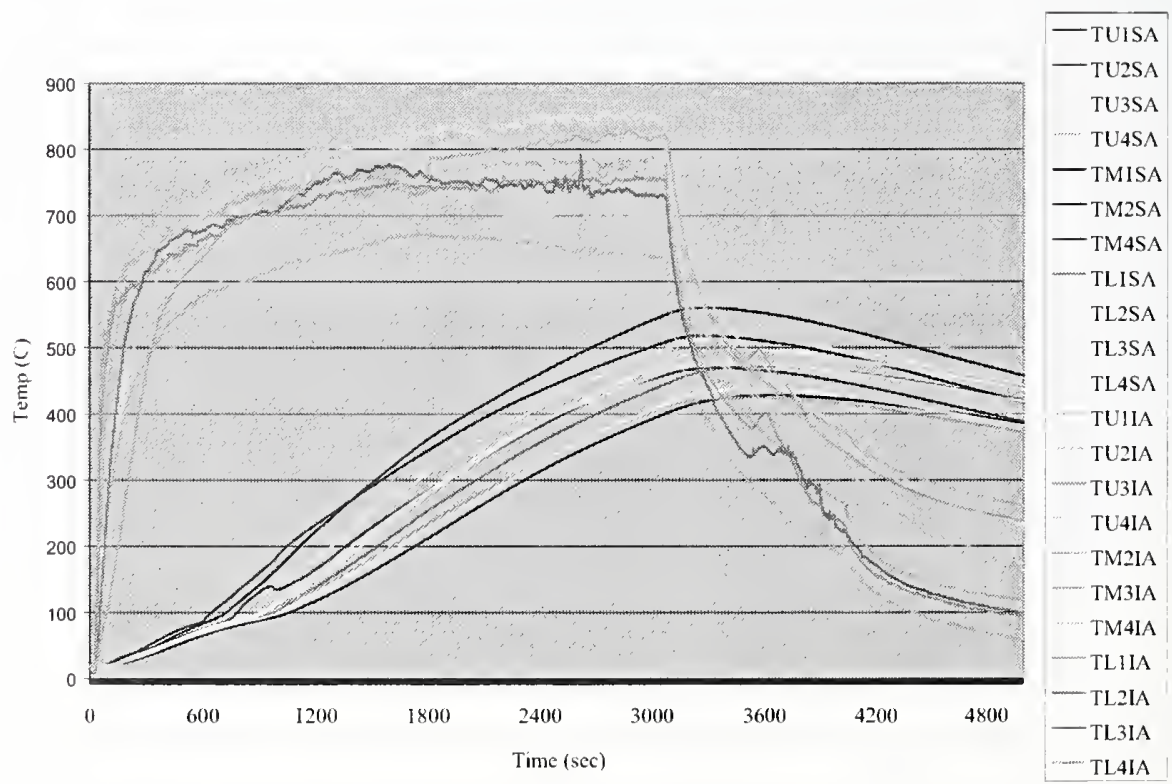

Figure 9-15. Temperature history for truss A in Test 5. 


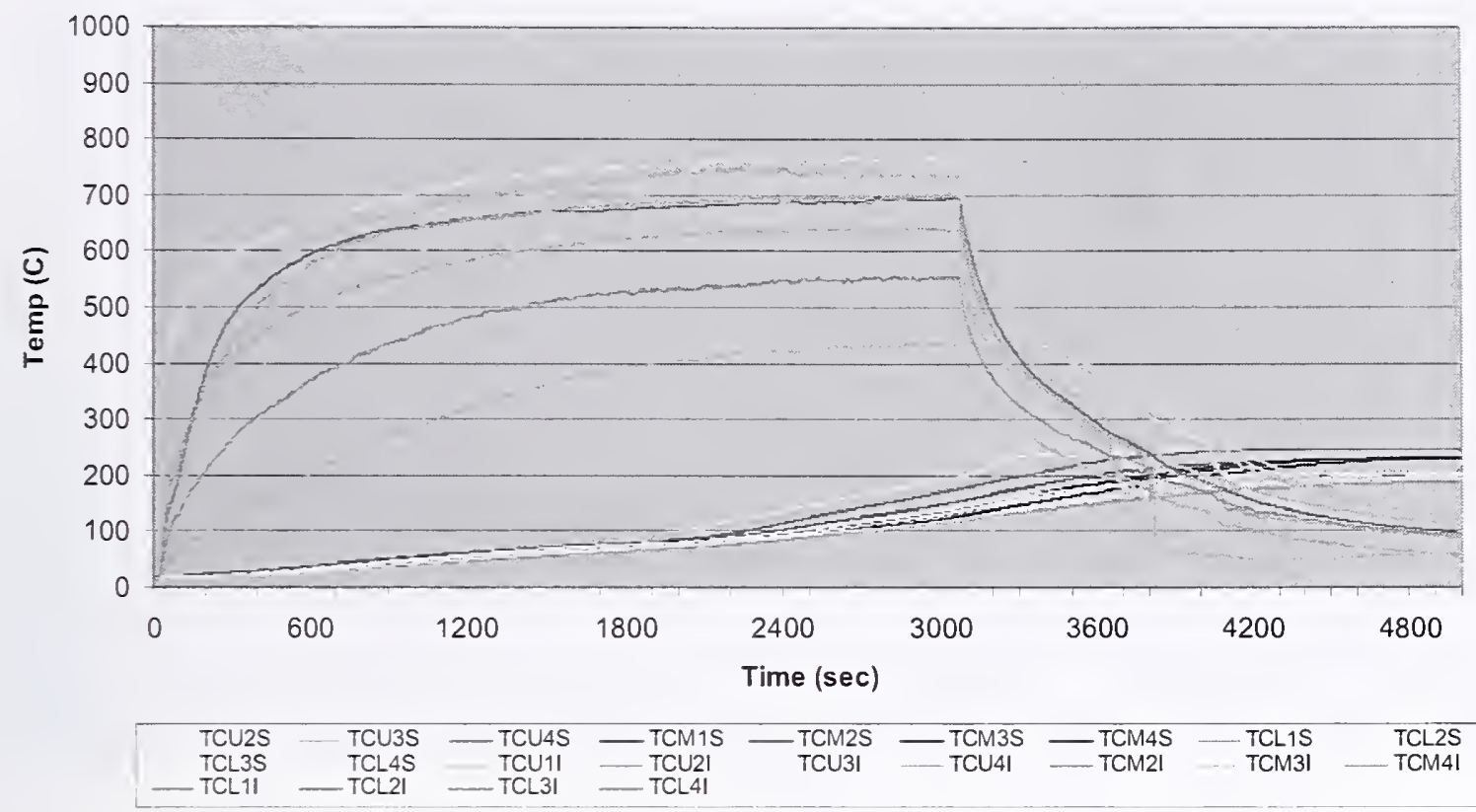

Figure 9-16. Temperature history for column in Test 5.

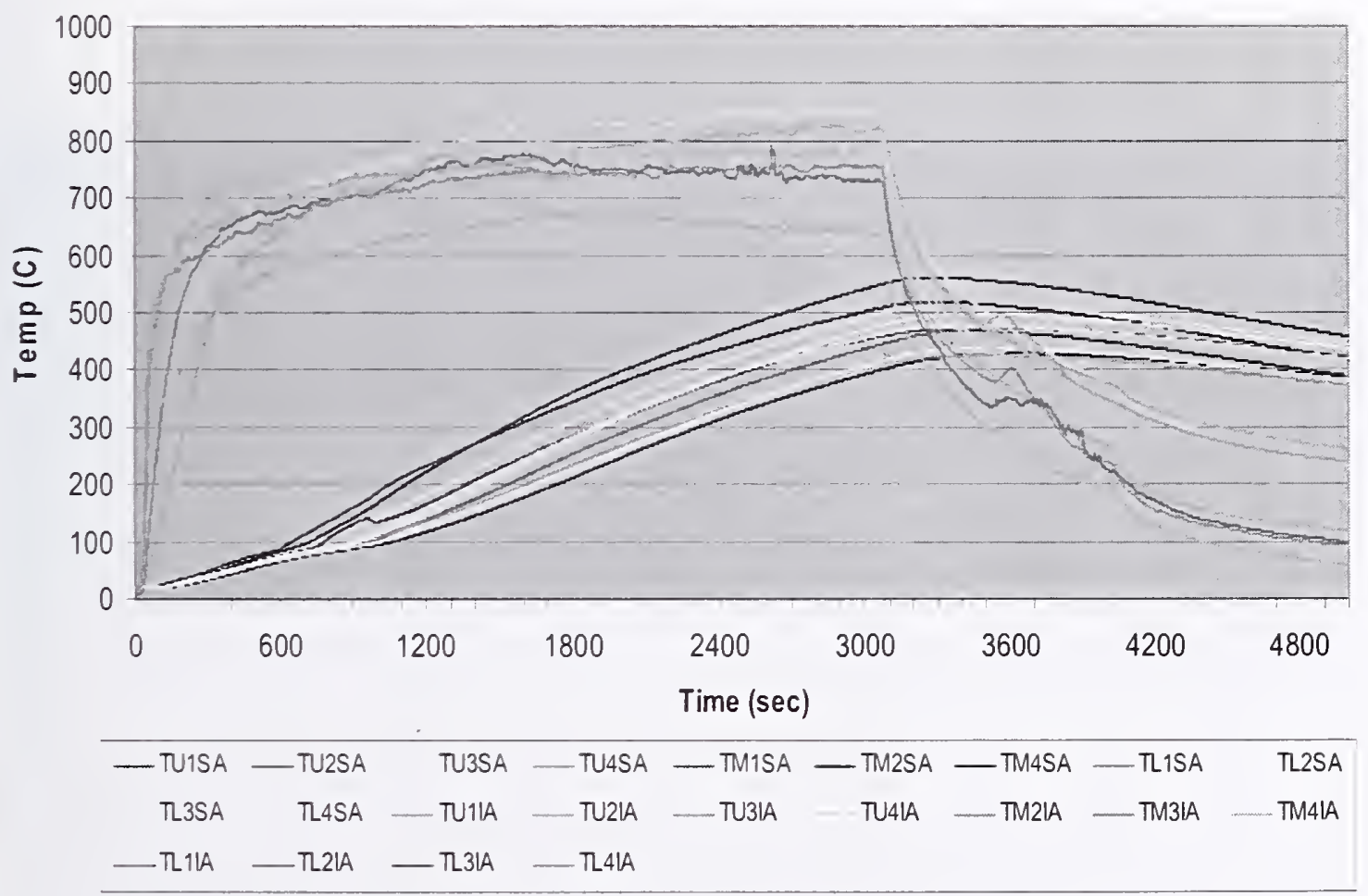

Figure 9-17. Temperature history for truss A in Test 5. 


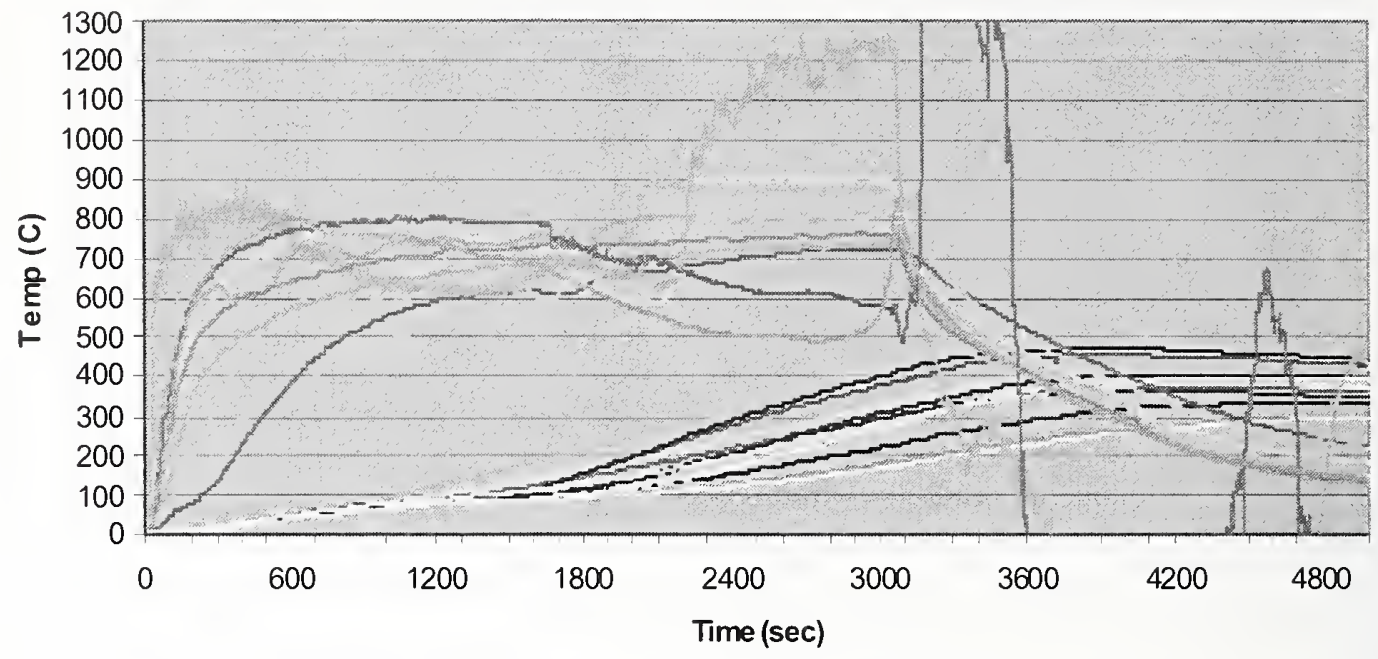

\begin{tabular}{|c|c|c|c|c|c|c|c|}
\hline - TU1SB & -TLRSB & TU3SB & TUASB & TM1SB & $-\mathrm{TM} 2 \mathrm{SB}$ & TMBSB & - TMASB \\
\hline TL1SB & TL2SB & TL3SB & TL4SB & TUIIB & TU2IB & TUBIB & TU4IB \\
\hline$-\mathrm{TM} 1 \mathrm{IB}$ & TM21B & $=$ TM31B & TMAIB & TL1/B & $-\mathrm{TL} 2 \mathrm{AB}$ & TL3B & $\mathrm{TL}$-4IB \\
\hline
\end{tabular}

Figure 9-18. Temperature history for truss B in Test 5.

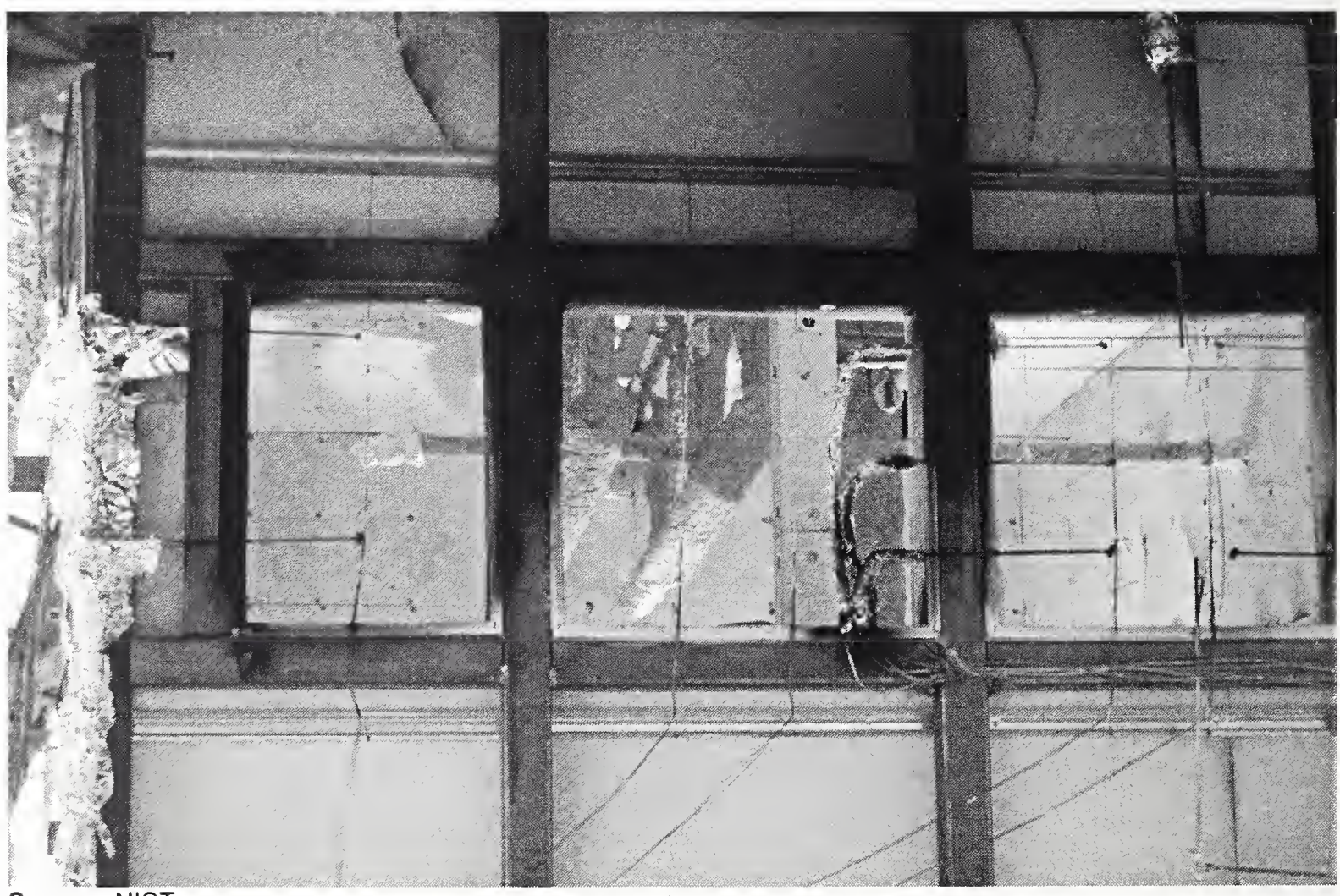

Source: NIST.

Figure 9-19. View of truss and bar components before Test 6. 


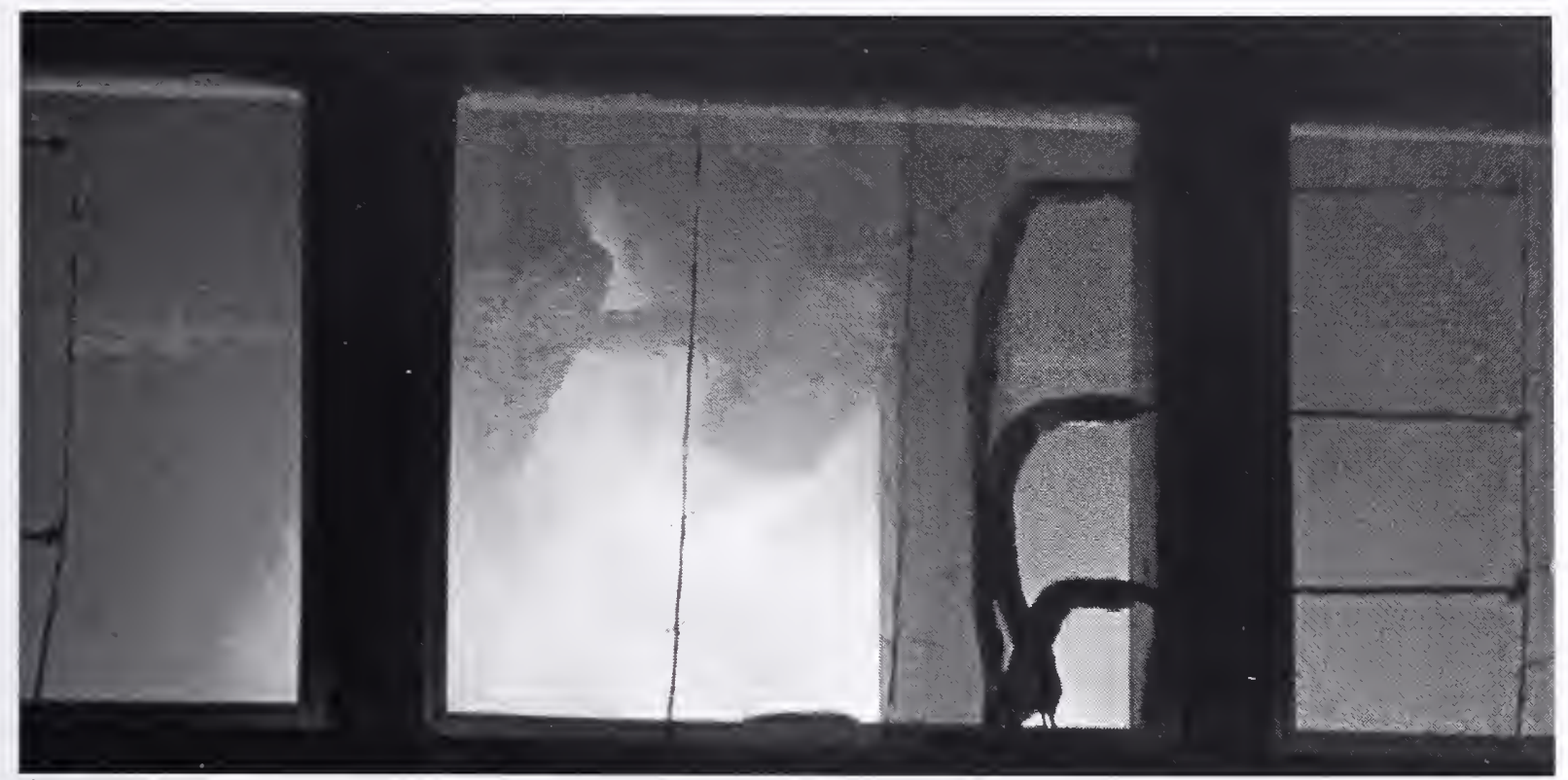

Source: NIST.

Figure 9-20. Flame impingement on trusses and bar during Test 6.

Table 9-13 lists the thermal lag in Tests 5 and 6 for the various insulated steel components. The time lag was defined as the difference between the time when the maximum temperature was reached in the SFRM, which occurred when the fuel was shut and the fire stopped, and the time when the maximum temperature in the steel components was reached. The data shows that the SFRM thickness, SFRM temperatures, and steel temperatures all affected the thermal wave or the rate at which heat traveled through the SFRM. For components with a nominal $1.91 \mathrm{~cm}$ SFRM thickness, the time lag ranged from $100 \mathrm{~s}$ to $800 \mathrm{~s}$. For components with a nominal $3.81 \mathrm{~cm}$ SFRM thickness, the time lag ranged from $1,000 \mathrm{~s}$ to over $1,900 \mathrm{~s}$. Further inspection of the table shows that larger temperature differences between the steel and SFRM also had a shorter time lag. This reflects the fact that conduction is directly dependent upon the temperature gradient between two points.

Table 9-13. Thermal lag in insulated steel components during Tests 5 and 6.

\begin{tabular}{|c|c|c|c|c|c|}
\hline \multirow{4}{*}{ Test } & Component & $\begin{array}{c}\text { SFRM Thickness } \\
(\mathbf{c m})\end{array}$ & $\begin{array}{c}\text { Time Lag } \\
(\mathbf{s})\end{array}$ & $\begin{array}{c}\text { SFRM Temp } \\
\left({ }^{\circ} \mathbf{C}\right)\end{array}$ & $\begin{array}{c}\text { Steel Temp } \\
\left({ }^{\circ} \mathbf{C}\right)\end{array}$ \\
\hline \multirow{4}{*}{5} & Bar & 1.91 & $200-300$ & $650-850$ & $400-550$ \\
\cline { 2 - 6 } & Column & 3.81 & $1,000-1,900$ & $650-900$ & $200-400$ \\
\cline { 2 - 6 } & Truss A & 3.81 & $1,900+$ & $425-775$ & $100-200$ \\
\cline { 2 - 6 } & Truss B & 1.91 & $400-600$ & $650-850$ & $400-500$ \\
\hline \multirow{3}{*}{6} & Bar & 1.91 & $300-800$ & $650-925$ & $375-675$ \\
\cline { 2 - 6 } & Column & 1.91 & $100-400$ & $650-925$ & $400-700$ \\
\cline { 2 - 6 } & Truss A & 1.91 & $600-1,000$ & $500-750$ & $275-375$ \\
\cline { 2 - 6 } & Truss B & 1.91 & $400-500$ & $700-850$ & $450-550$ \\
\hline
\end{tabular}




\subsection{SUMMARY OF RESULTS}

Insulated and uninsulated steel components were exposed to compartment fires with varying heat release rates, fuel type, and duration. The surface temperature of bare steel trusses that were subject to impingement or proximity of flames from fires with a nominal $3 \mathrm{MW}$ heat release rate reached $600{ }^{\circ} \mathrm{C}$ within $15 \mathrm{~min}$. In comparison, the insulated steel trusses with SFRM protection $(1.91 \mathrm{~cm}$ nominal thickness) reached $100{ }^{\circ} \mathrm{C}$ to $200{ }^{\circ} \mathrm{C}$ and the truss with $3.81 \mathrm{~cm}$ SFRM reached $50{ }^{\circ} \mathrm{C}$ to $100{ }^{\circ} \mathrm{C}$ after $15 \mathrm{~min}$ of exposure to a $3 \mathrm{MW}$ heat release rate fire. After $50 \mathrm{~min}$ of exposure to a $3 \mathrm{MW}$ nominal heat release rate, the trusses with SFRM protection $\left(1.91 \mathrm{~cm}\right.$ nominal thickncss) reached $550{ }^{\circ} \mathrm{C}$ to $680{ }^{\circ} \mathrm{C}$ and the truss with $3.81 \mathrm{~cm}$ SFRM protection reached $415^{\circ} \mathrm{C}$.

There is also a strong influence of SFRM thickness on steel temperatures. A significant variation in the thickness of the SFRM coating was measured. The $1.91 \mathrm{~cm}$ specified thickness average was measured to be $2.2 \mathrm{~cm}$ to $2.7 \mathrm{~cm}$ between components with a COV ranging from 0.17 to 0.27 . The $3.81 \mathrm{~cm}$ specified thickness average was measured to be $4.05 \mathrm{~cm}$ to $4.10 \mathrm{~cm}$ between components with a COV ranging from 0.07 to 0.20 . The lower COV values were measured for the columns; the higher COV values occurred for the bars and angles, which are more difficult shapes for uniform application of the SFRM product. These SFRM measurements may be considered as lower bound estimates of the variance that would be expected of field applications.

The uninsulated steel temperatures reached their maximum values approximately when the fuel flow was cut and the fire stopped. The same was true for the insulated steel components, except that the maximum temperatures were reached after the fuel was stopped due to lag of the thermal wave through the SFRM. The thermal lag varied between $100 \mathrm{~s}$ and $800 \mathrm{~s}$ for a nominal $1.91 \mathrm{~cm}$ SFRM thickness and 1,000 s to over $1,900 \mathrm{~s}$ for a nominal $3.81 \mathrm{~cm}$ SFRM thickness, depending upon the SFRM and steel temperatures and gradients.

The experimental results showed:

- SFRM coatings significantly delay the rise of steel temperatures when exposed to hot gases and flame impingement.

- The surface of the SFRM reached the gas temperatures within a few minutes after the start of the test. The SFRM temperatures closely matched the gas temperature variation along the chamber length.

- For uninsulated (bare) steel components, temperature variations existed along the length of the component throughout the test.

- For insulated components, the highest temperatures reached at steel surfaces were significantly lower than the temperature at the outside face of the insulation material, even at locations of flame impingement.

- Although steel has a high conductivity relative to the SFRM product, temperatures did not become uniform along the steel component lengths in either the bare or insulated state, indicating that the local gas temperature and the SFRM played a significant role in the temperature rise. 
- The surface temperature of uninsulated steel trusses that were subject to impingement or proximity of flames from fires with a nominal $3 \mathrm{MW}$ heat release rate reached $600{ }^{\circ} \mathrm{C}$ within $15 \mathrm{~min}$. In comparison, the insulated steel trusses with SFRM protection $(1.91 \mathrm{~cm}$ nominal thickness) reached $100{ }^{\circ} \mathrm{C}$ to $200{ }^{\circ} \mathrm{C}$ and the truss with $3.81 \mathrm{~cm}$ SFRM reached $50{ }^{\circ} \mathrm{C}$ to $100^{\circ} \mathrm{C}$ after $15 \mathrm{~min}$ of exposure to a $3 \mathrm{MW}$ heat release rate fire. The steel surface of an insulated steel truss with $1.91 \mathrm{~cm}$ (nominal) and $3.81 \mathrm{~cm}$ (nominal) SFRM obtained a temperature of $680^{\circ} \mathrm{C}$ and $415^{\circ} \mathrm{C}$, respectively, after $50 \mathrm{~min}$ of exposure to a $3 \mathrm{MW}$ fire.

- For the insulated steel components, the steel surface temperatures obtained a maximum sometime after the fire was stopped due to lag of the thermal wave through the SFRM. A thermal lag of between $100 \mathrm{~s}$ and $800 \mathrm{~s}$ for the nominal $1.91 \mathrm{~cm}$ SFRM thickness and 1,000 s to over $1,900 \mathrm{~s}$ for the nominal $3.81 \mathrm{~cm}$ SFRM thickness was observed, depending on the values of the temperature and the temperature gradients within the SFRM and the steel.

Chapter 11 compares the experimental measurements reported here with the FDS/FSI/ANSYS modeling results for the thermal behavior of the bare and insulated steel components. In particular, the measured steel and SFRM surface temperatures in Tests 1 and 5 are quantitatively compared with the modeling results.

\section{$9.8 \quad$ REFERENCES}

ANSYS, Inc. 2003. ANSYS Release 8.0 Documentation.

American Society for Testing and Materials. 2000. ASTM E 605-93, Standard Test Methods for Thickness and Density of Sprayed Fire-Resistive Material (SFRM) Applied to Structural Components, West Conshohocken, PA.

Bentley, R. E. 1998. Handbook of Temperature Measurement, Volume 3: Theory and Practice of Thermoelectric Thermometry. Springer-Verlag Singapore Pte. Ltd.

Hamins, A., A. Maranghides, and G. Mulholland. 2003. The Global Combustion Behavior of $1 \mathrm{MW}$ to 3 MW Hydrocarbon Spray Fires Burning in an Open Environment, NISTIR 7013, National Institute of Standards and Technology, Gaithersburg, MD, June.

Holman, J.P. 1976. Heat Transfer, Fourth Edition, McGraw-Hill Book Company.

IBC (International Building Code). 2000. International Code Council, Falls Church, VA.

Kay, T.R., B.R. Kirby, and R.R. Preston. 1996. Fire Safety J. 26, 327-350.

NFPA (National Fire Protection Association). 2003. NFPA 5000: Building Construction and Safety Code, 2003 edition, Quincy, MA.

Omega Engineering, Inc. 2000. Omega Temperature Handbook, Technical Reference Section, Section Z. 
Smyth, K., J.H. Miller, R.C. Dorfman, W.G. Mallard, and R.J. Santoro. 1985. Combust. Flame 62, 157-181. 


\section{Chapter 10 \\ SimUlation OF COMPARTMENT FiRE PHENOMENA}

\section{$10.1 \quad$ INTRODUCTION}

In cooperation with the fire protection engineering community, a computational fire model, the Fire Dynamics Simulator (FDS), has been developed at National Institute of Standards and Technology (NIST) to study fire behavior and to evaluate the performance of fire protection systems in buildings. The software was released into the public domain in 2000 , and since then has been used for a wide variety of analyses by fire protection engineers. Throughout its development, the model has been compared with a variety of fire experiments to ensure that the predictions are accurate. Most often, the experiments are not necessarily designed solely for the purpose of model validation, and as a result there are often sevcral features in the tests that are difficult to model. It is then difficult to assess the overall accuracy of the model because the uncertainty in modeling the difficult features dominates the error. The large-scale experiments described in this report were designed spccifically to test the accuracy of FDS.

The fire, itself, was relatively easy to model, and the heat release rate was mcasured. The compartment was heavily instrumented so that all of the energy from the fire could be accounted for and reported in terms of conductive losses to walls, convective flux through openings, etc. With the large number of measurements, it was possible to go beyond the traditional point by point comparison and discover why the model either over-predicted or under-predicted a given measurement. It was possible to compare the transport of energy, starting with the combustion of fuel and ending with effluent exiting into a large hood. Based on these integrated quantities, discrepancies in heat flux and gas concentration predictions could be tied to errors in the overall energy budget, allowing assessment of the accuracy of various components within the model.

Model calculations were performed before testing began to guide the design of the compartment and also to provide a baseline set of "blind" predictions. A complete description of the model can be found in McGrattan (2004). Briefly, FDS is a computational fluid dynamics code that solves the Navier-Stokes equations in low Mach number, or thermally-expandable, form. The transport algorithm is based on large eddy simulation techniques; radiation is modeled using a gray gas approximation, and a finite volume method is used to solve the radiation transport cquation. Combustion is modeled using a mixture fraction approach, in which a single transport equation is solved for a scalar variable representing the fraction of gas originating in the fuel stream.

\subsection{DESCRIPTION OF THE CALCULATIONS}

The geometry of the compartment was relatively simple and is described in detail in Chapter 2 . Figure 2-5 is a schematic drawing of the compartment contents. Figures 2-1 through 2-4 are photographs of the compartment. The enclosure was rectangular as were the vents and most of the obstructions. A uniform numerical grid, whose cells were $10 \mathrm{~cm}$ on a side, was chosen based on a grid resolution study (NIST NCSTAR 1-5F). Figure 10-1 is a snapshot of a simulation showing the isometric 
surface of stoichiometric mixture fraction, which is a representation of the flame surface. The figure also shows the major geometric features of the compartment as seen from the south wall looking toward the north. The inlets are evident on the left and the outlets on the right. It is useful to compare the snapshot with a photograph such as Figs. 2-2 and 2-3. Figure 10-2 shows the temperature profile through the centerline plane for one of the simulations as seen from the south wall looking toward the north.

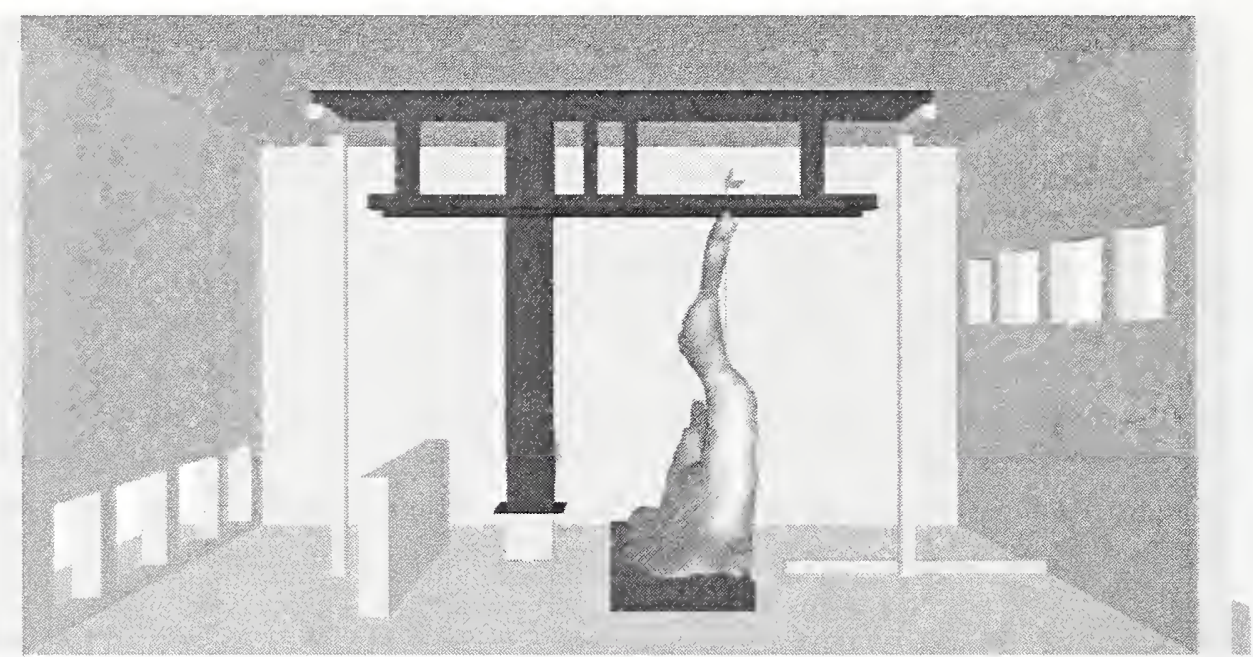

Figure 10-1. Snapshot of numerical simulation of Test 1 showing the fire as seen from a cutaway view looking towards the north wall.

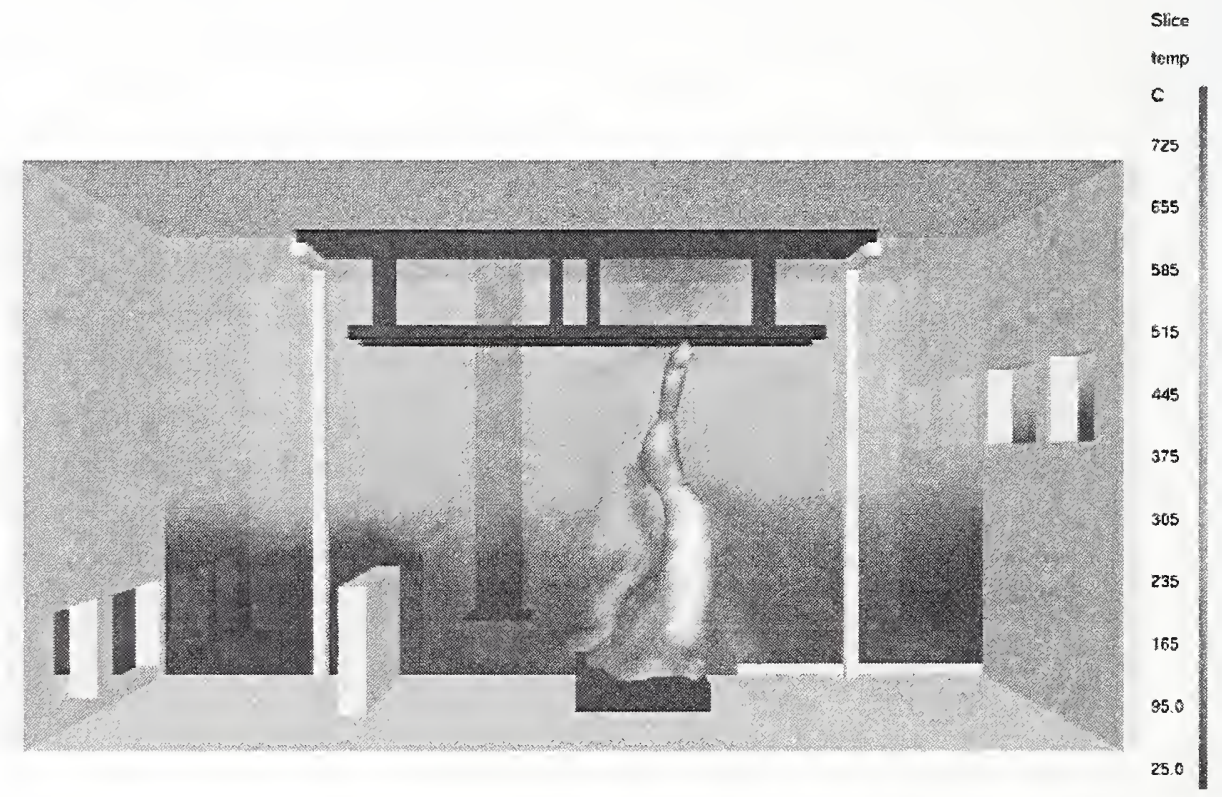

Figure 10-2. Snapshot of the numerical simulation of Test 1 showing the fire and a contour plot of gas temperature along the centerline of the compartment as seen from a cutaway view looking towards the north wall.

The compartment walls and ceiling were made of $2.54 \mathrm{~cm}(1 \mathrm{in}$.) thick Marinite 1 , a product of BNZ Materials, Inc. The manufacturer-provided thermal properties were given as a density of $737 \mathrm{~kg} / \mathrm{m}^{3}$ a conductivity of $0.12 \mathrm{~W} / \mathrm{m} / \mathrm{K}$. The specific heat range was given as $1,172 \mathrm{~J} / \mathrm{kg}-\mathrm{K}$ at $93{ }^{\circ} \mathrm{C}$ to 
$1,423 \mathrm{~J} / \mathrm{kg}-\mathrm{K}$ at $425^{\circ} \mathrm{C}$. These values differed somewhat from the values measured by Taylor et al. (2003), which are listed in Table 8-1. The calculation results were not sensitive to these differences as discussed below.

The steel used in the column and truss flanges for the experiments was $0.64 \mathrm{~cm}(1 / 4 \mathrm{in}$.) thick as described in Chapter 9. The density of the steel was assumed to be $7,860 \mathrm{~kg} / \mathrm{m}^{3}$, and its specific hcat $450 \mathrm{~J} / \mathrm{kg}-\mathrm{K}$ (NIST NCSTAR 1-3E). The steel was assumed in the FDS model to be thermally-thin; thus, no thermal conductivity was used. Note that FDS performs a simple one-dimensional calculation of the steel temperature to be used as a boundary condition in the calculation. More detailed calculations of the thermal behavior of the steel are discussed in Chapter 11 of this report.

Two fuels were used in the tests. The properties of the fuels were obtained from measurements made on a series of unconfined burns (Hamins 2003). The first fuel was a blend of heptane isomers. The soot yield was set at a constant value equal to 1.5 percent (Hamins et al. 2003). The present version of FDS does not adjust the soot yield based on compartment ventilation or combustion efficiency. The second fuel was a mixture (40 percent/ 60 percent by mass) of toluene, $\mathrm{C}_{7} \mathrm{H}_{8}$, and heptane as discussed in Chapters 2 and 3. Because FDS only considers the burning of a single hydrocarbon fuel, the mixture was taken to be $\mathrm{C}_{7} \mathrm{H}_{12}$ with a soot yield of 11.2 percent. The radiative fraction for the heptane blend is 0.44 ; for the heptane/toluene mixture it is 0.39. FDS does not use the measured radiative fraction of the fuel directly. Instead, FDS computes the radiative loss from the fire based on the temperature and gas composition. This calculation is subject to considerable uncertainty because of the fourth power dependence on temperature. As a consequence, FDS uses a user-prescribed lower bound for the radiative fraction, which in this case was 0.35 . This means that the simulated fire radiates at least 35 percent of its energy. For the simulations reported here, the radiative fraction was computed to be about 0.40 . A sensitivity analysis, described in Sec. 10.4.6, shows that the calculation results were insensitive to the prescribed lower bound of the radiative fraction. The FDS Technical Reference Guide (McGrattan 2004) provides a detailed discussion of how the output parameters are interpreted in the simulations.

The heat release rate of the simulated burner was set to that which was measured in the experiments. No attempt was made to model the spray burner. The heat release rate was assumed to be uniformly distributed over a $1 \mathrm{~m}$ by $1 \mathrm{~m}$ area in the fuel pan, consistent with observations of the hydrocarbon spray fire. With the exception of Tests 2 and 3, the target heat release rates for the experiments were achieved by adjusting the fuel flow rate to account for combustion inefficiencies that werc measured in a series of unconfined burns. During the simulation, values of temperature, heat flux, and gas species concentrations were reported as $5 \mathrm{~s}$ averages, consistent with the time response of the various instruments (see Table 2-3). Linear interpolation was used to approximate values between the $10 \mathrm{~cm}$ grid cells.

\subsection{DISCUSSION OF MODEL SIMULATIONS AND MEASUREMENTS}

In this section, the experimental measurements and the numerical simulations are presented. Comparison of the simulation results with the measurements should be considered in terms of the measurement uncertainty (which is summarized in Table 2-3) and a sensitivity analysis of the modeling results. In Sec. 10.4, a sensitivity analysis is presented, and comparisons are made with the measurements. 


\subsubsection{Gas Temperatures}

Upper and lower layer gas temperatures were measured in the experiments using both aspirated and barebead thermocouples, as discussed in Chapter 4 . For the purpose of model validation, the aspirated thermocouple measurements were used because measurement uncertainty was relatively small $\left(7^{\circ} \mathrm{C}\right)$ as the influence of external thermal radiation on the measurement was greatly reduced. Two vertical arrays of thermocouples were simulated, one on the inlet (west) side, near the centerline, and one on the outlet (east) side. Figures 10-3 through 10-12 display the time histories of both measured and predicted compartment gas temperatures. Note that in some of the experiments, the pumps drawing air through the aspiration tubes were not turned on until some time during the test. In these cases, the measured temperatures were noticeably lower than the predicted values.

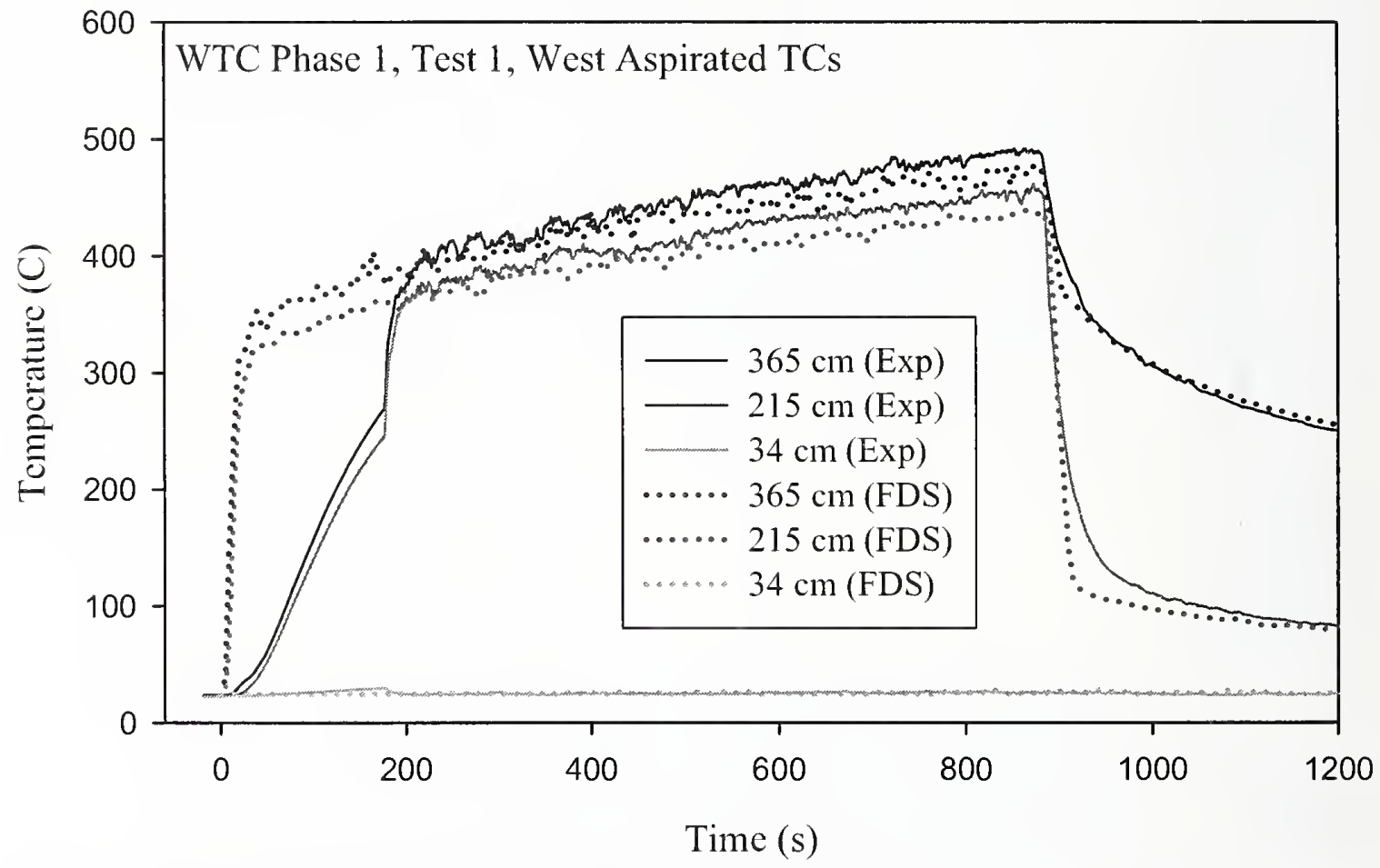

Figure 10-3. Comparison of gas temperatures, Test 1, intake side of compartment. The pumps connected to the aspirated thermocouples began to operate at $180 \mathrm{~s}$. 


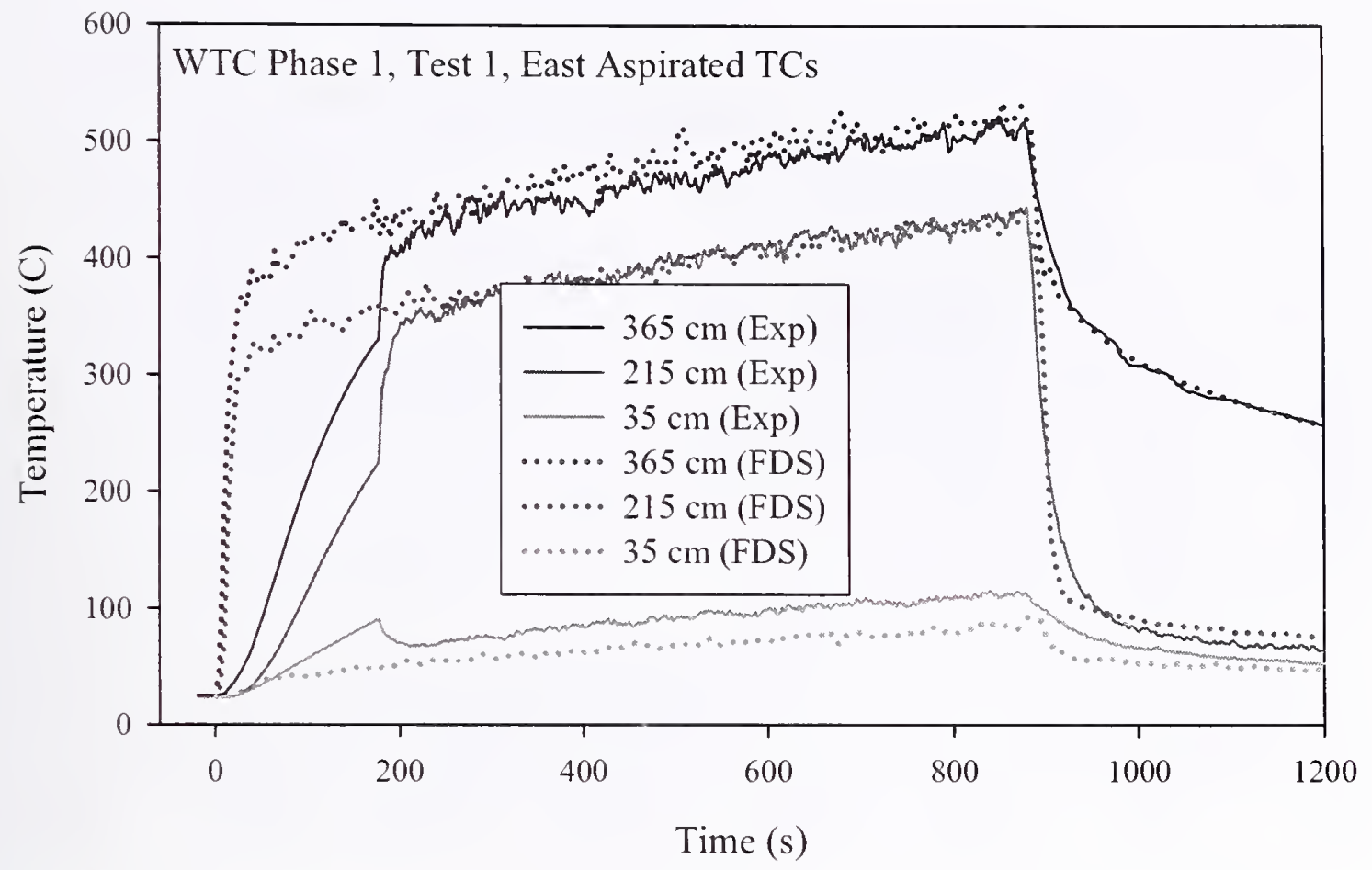

Figure 10-4. Comparison of gas temperatures, Test 1, exhaust side of compartment. The pumps connected to the aspirated thermocouples began to operate at $180 \mathrm{~s}$.

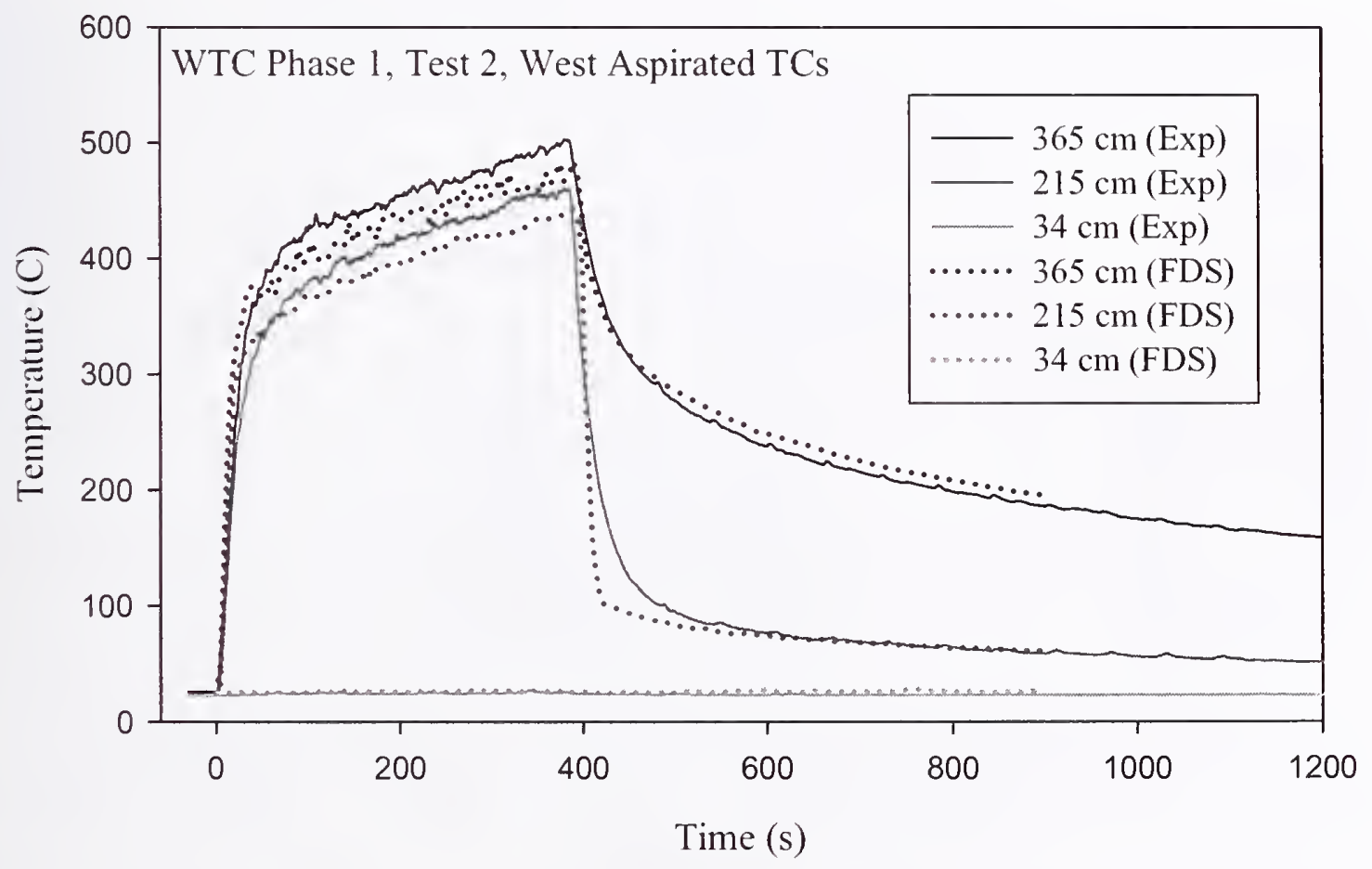

Figure 10-5. Comparison of gas temperatures, Test 2, intake side of compartment. 


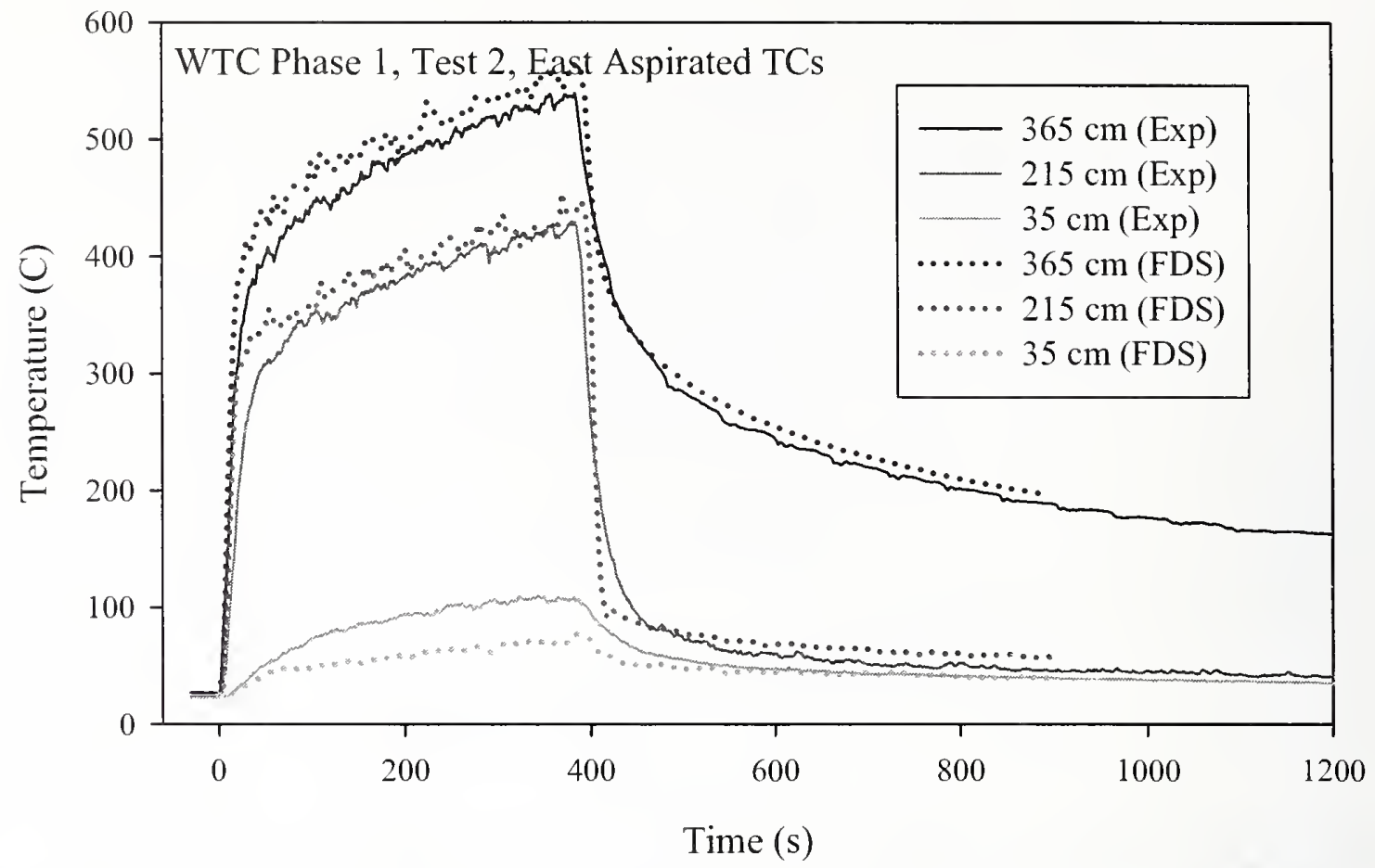

Figure 10-6. Comparison of gas temperatures, Test 2, exhaust side of compartment.

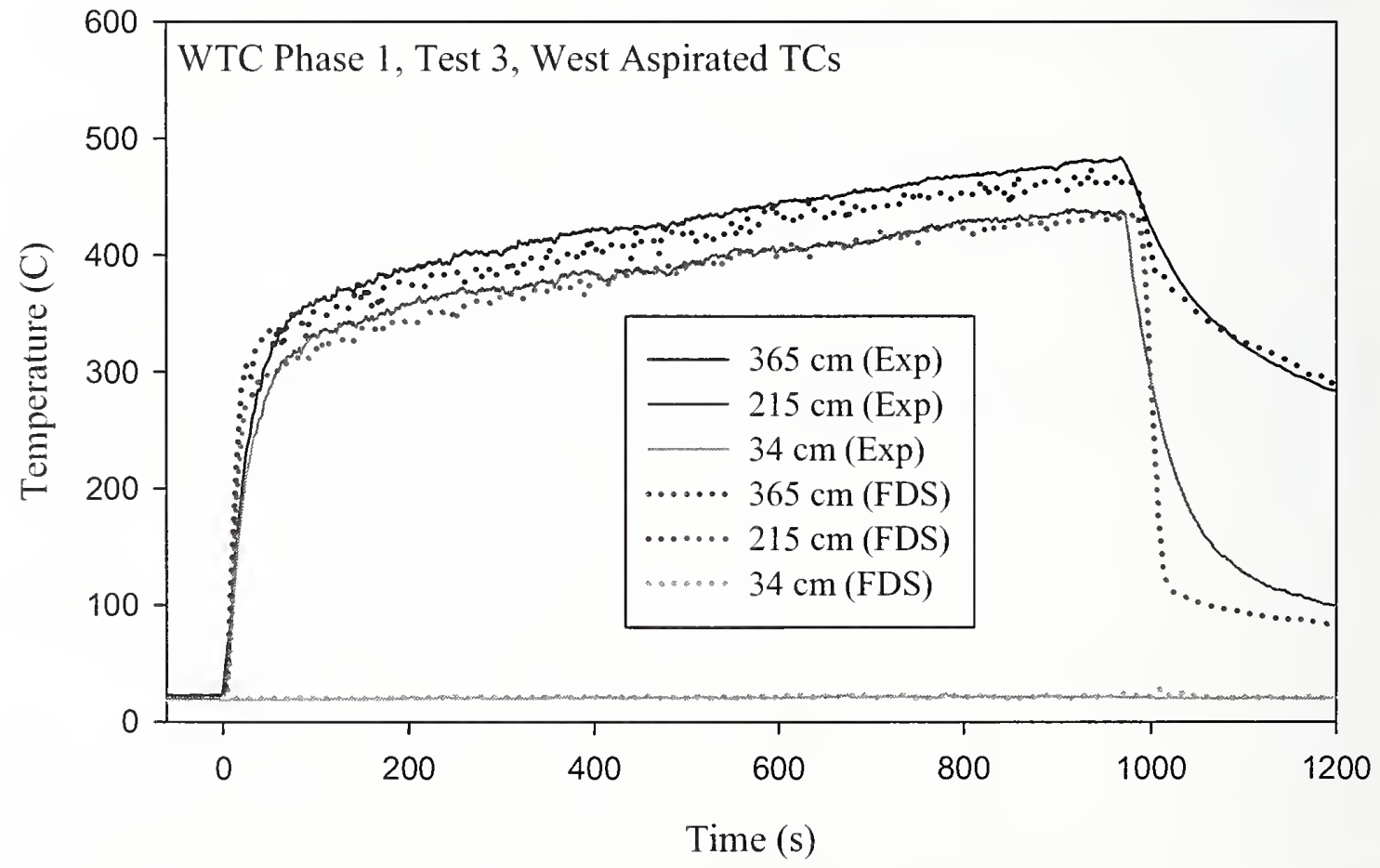

Figure 10-7. Comparison of gas temperatures, Test 3, intake side of compartment. 


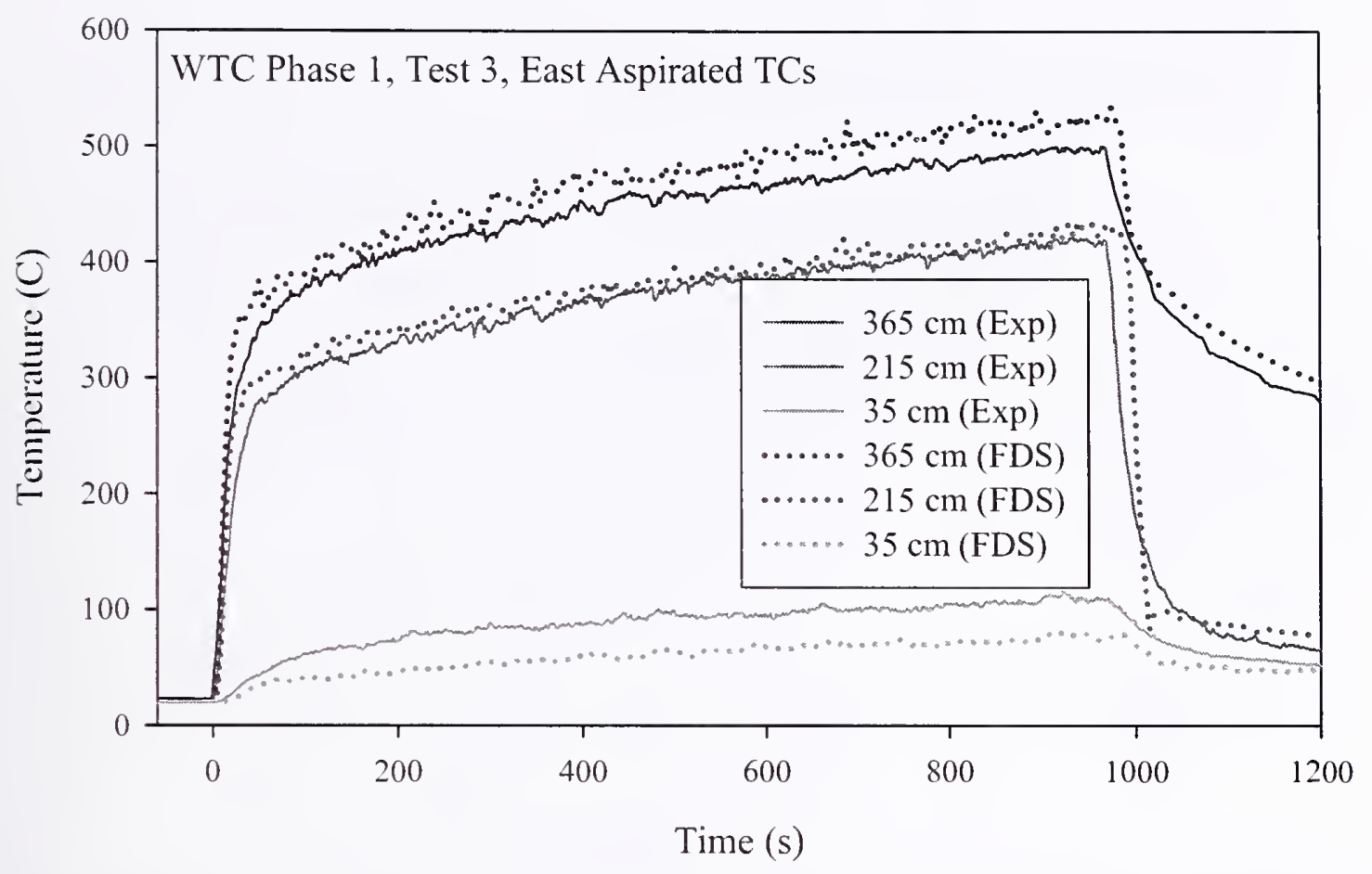

Figure 10-8. Comparison of gas temperatures, Test 3 , exhaust side of compartment.

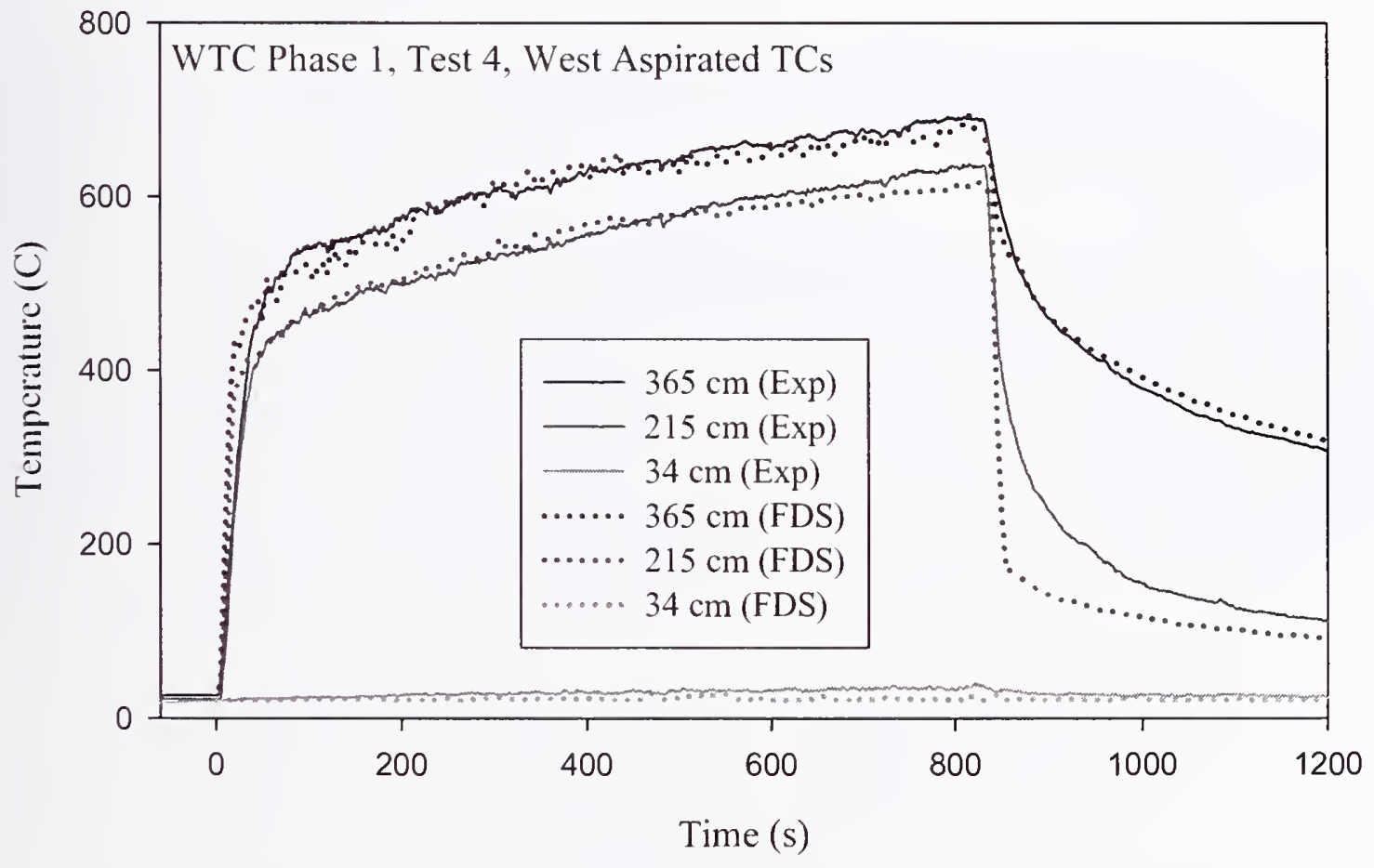

Figure 10-9. Comparison of gas temperatures, Test 4, intake side of compartment. 


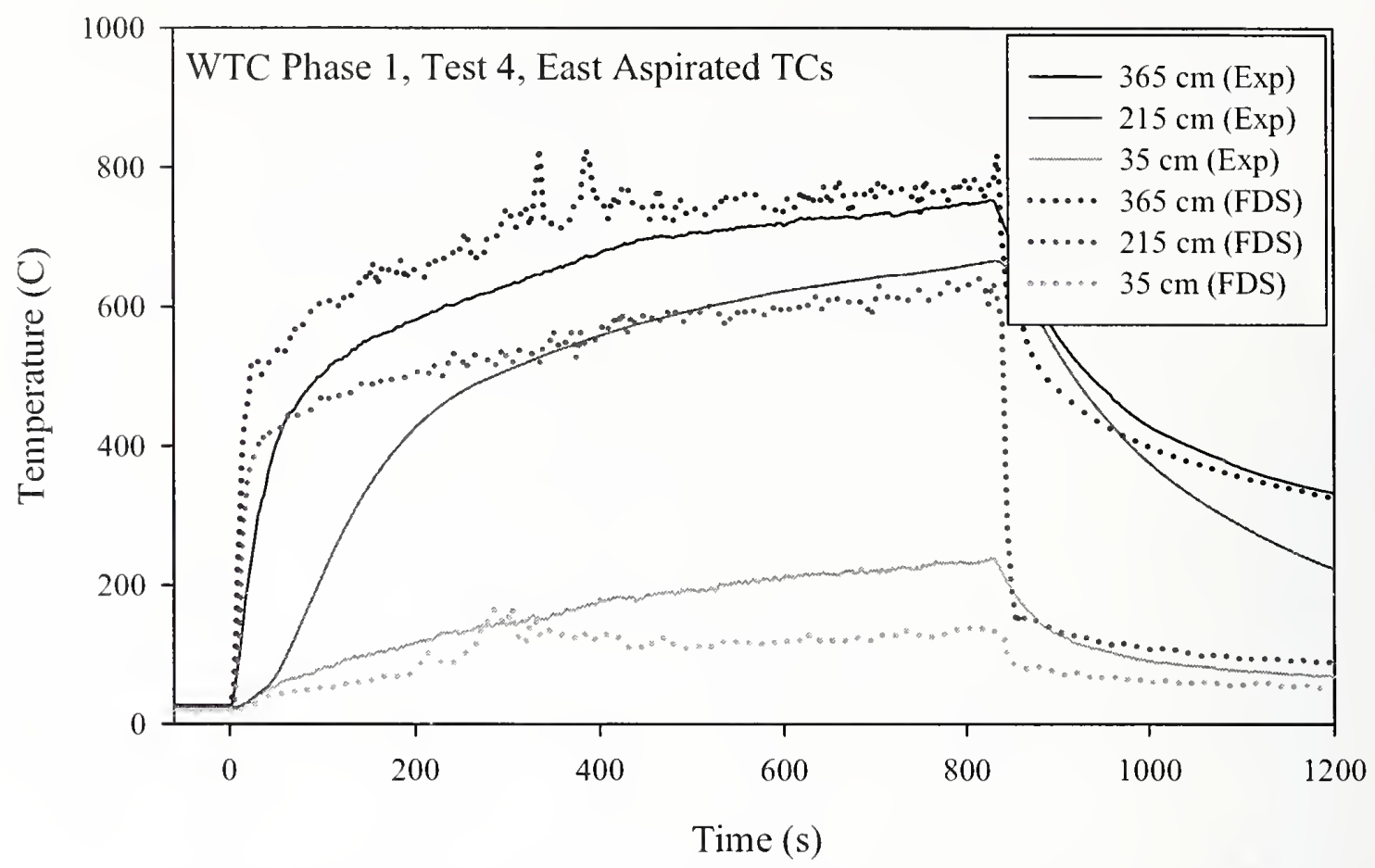

Figure 10-10. Comparison of gas temperatures, Test 4, exhaust side of compartment.

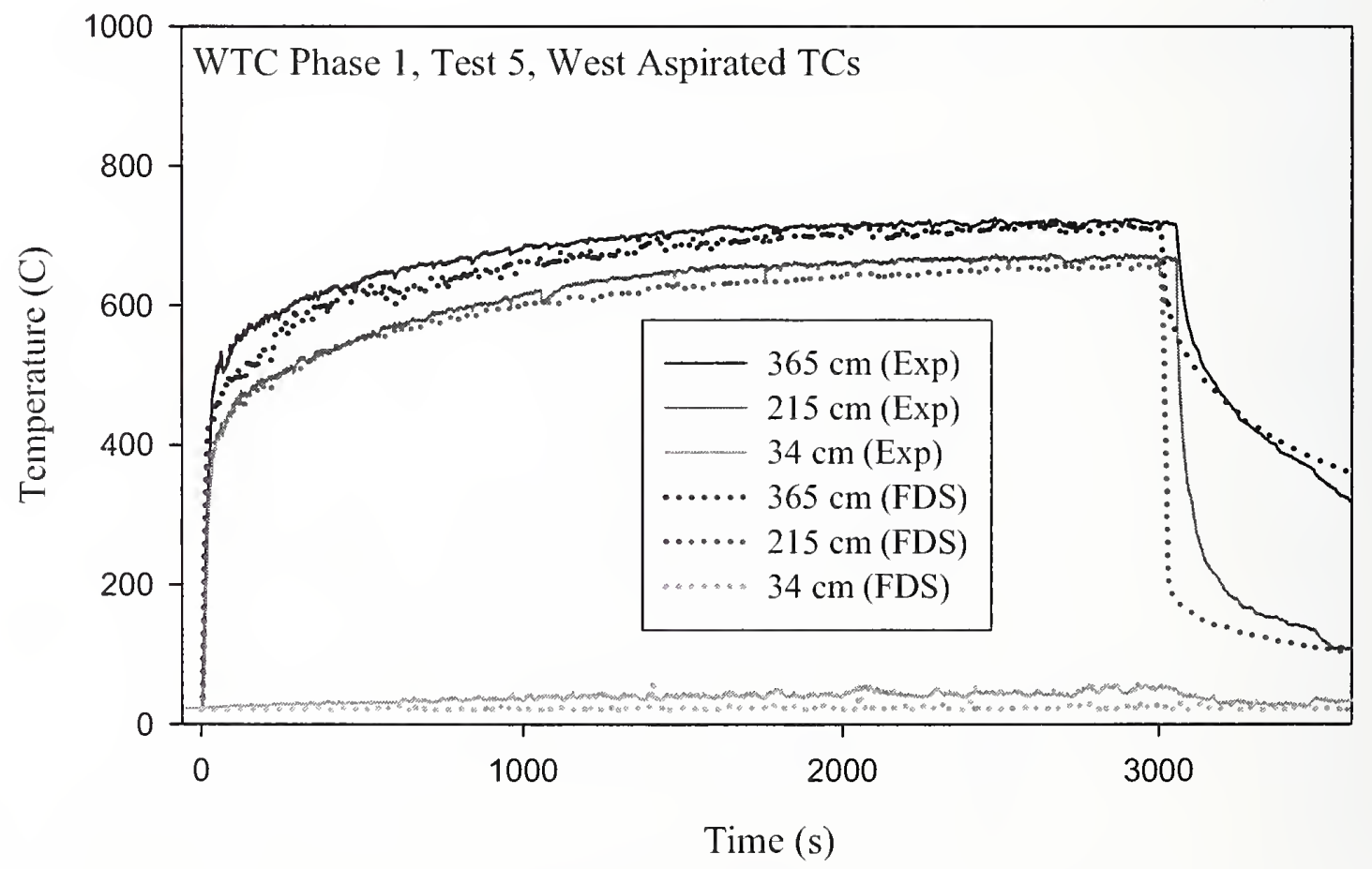

Figure 10-11. Comparison of gas temperatures, Test 5, intake side of compartment. 


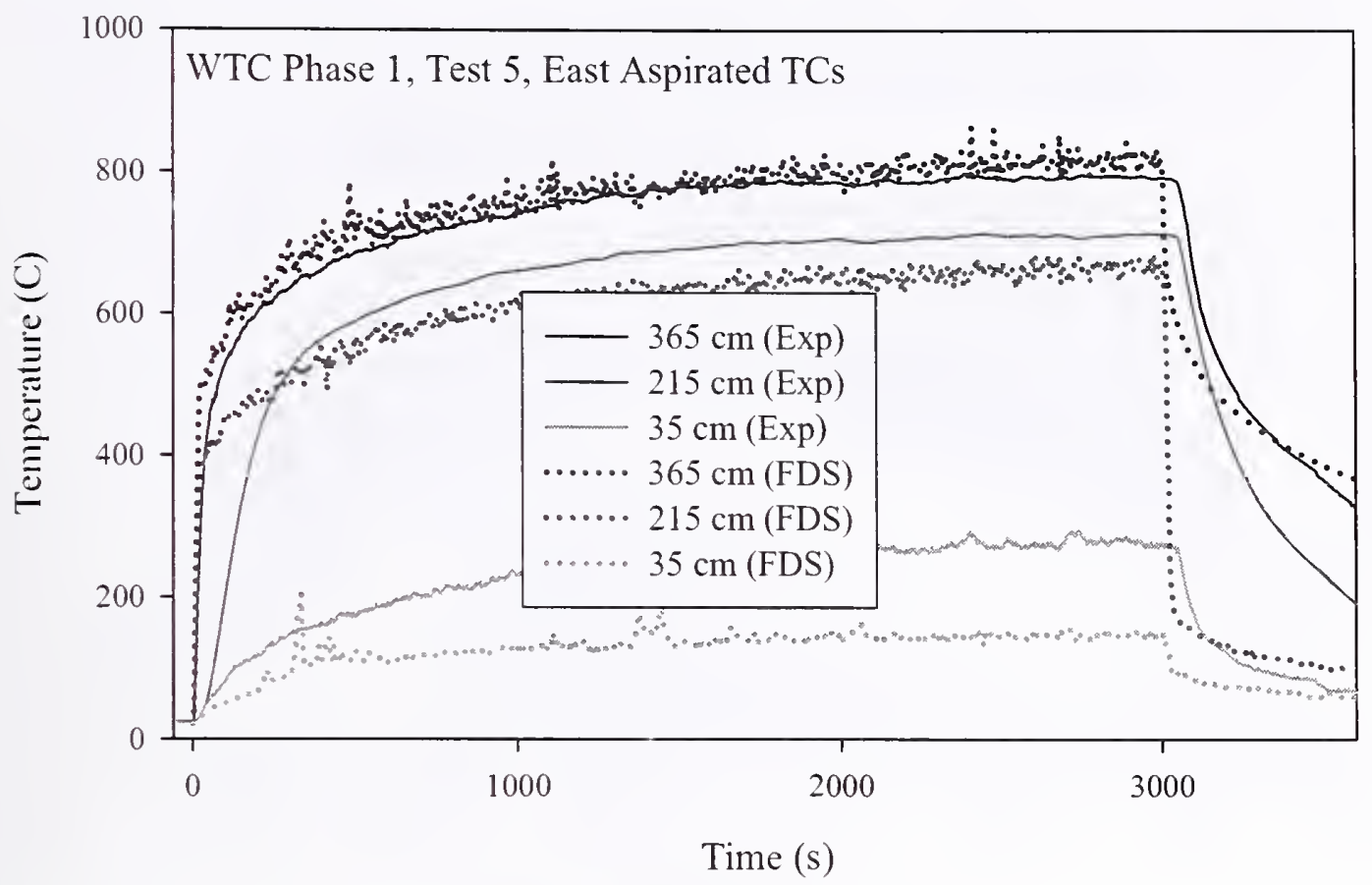

Figure 10-12. Comparison of gas temperatures, Test 5, exhaust side of compartment.

\subsubsection{Heat Flux to Solid Objects}

Heat flux gauges, some measuring total heat flux, some radiative, were positioned at various locations in both the upper and lower layers as discussed in Chapter 5. Heat fluxes to the upper and lower sections of the column are shown in Figs. 10-13 through 10-22. The large spikes in these figures were due to the $\mathrm{N}_{2}$ purge used to remove soot from the total heat flux gauges. Comparisons between measured and predicted heat fluxes at the floor are shown in Figs. 10-23 through 10-27.

It is worth noting that FDS predicted "cold wall" heat fluxes to the total flux gauges, thereby adding some uncertainty in the comparison due to convective heat transfer. It did so by using estimated convective heat transfer coefficients applied to each of the gauges. None of the flow situations in the compartment was a particularly clean example of a textbook case for which a heat transfer correlation is available. The flow velocity and gas temperature data that go into the correlations came from the model itself, not from experimental measurements. The uncertainties were difficult to quantify, but convection was typically a minor contributor to the total heat flux that the gauges recorded. 


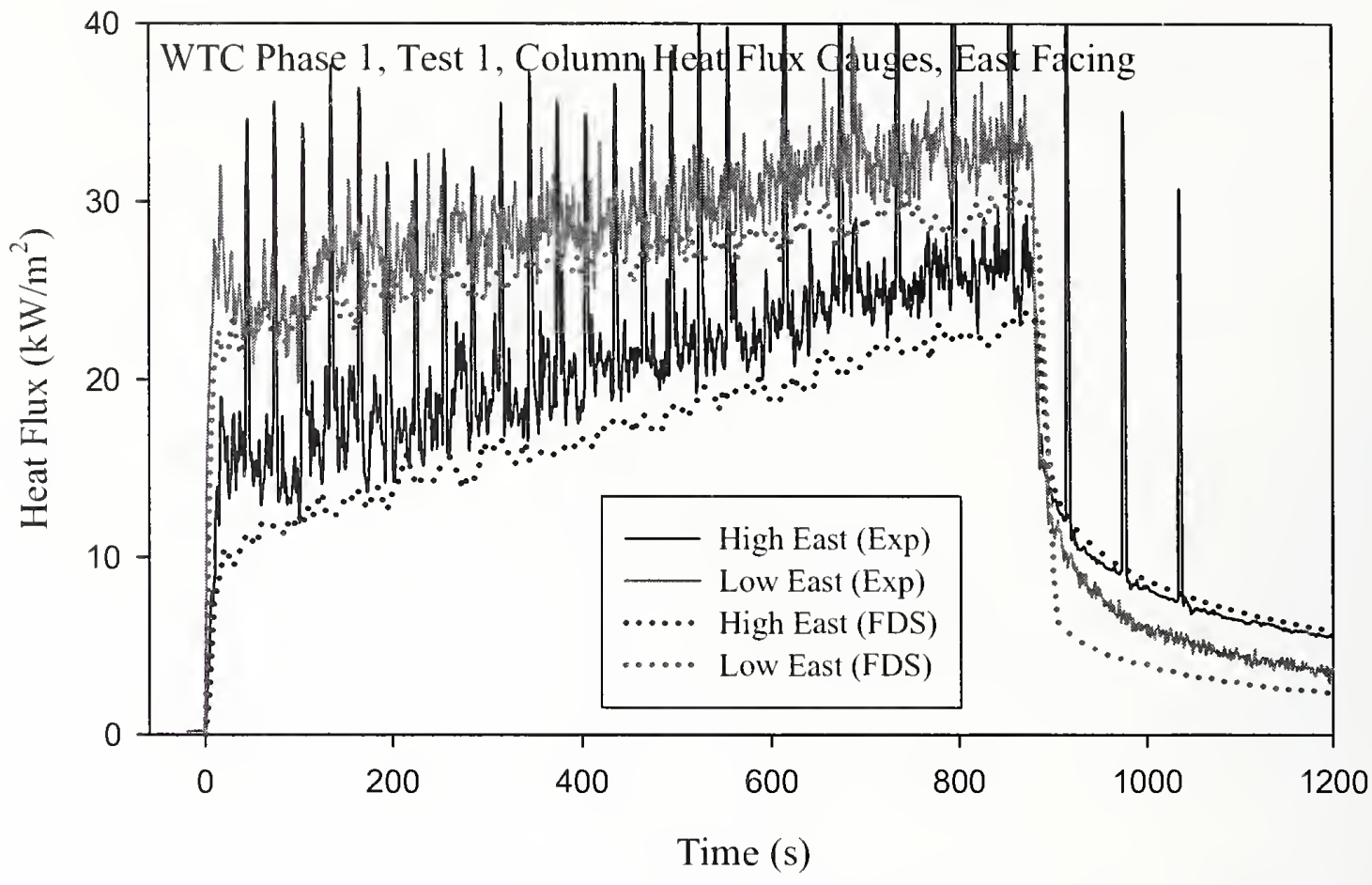

Figure 10-13. Comparison of heat fluxes to column, Test 1 . The periodic spikes in the measurements were due to the influence of a nitrogen purge.

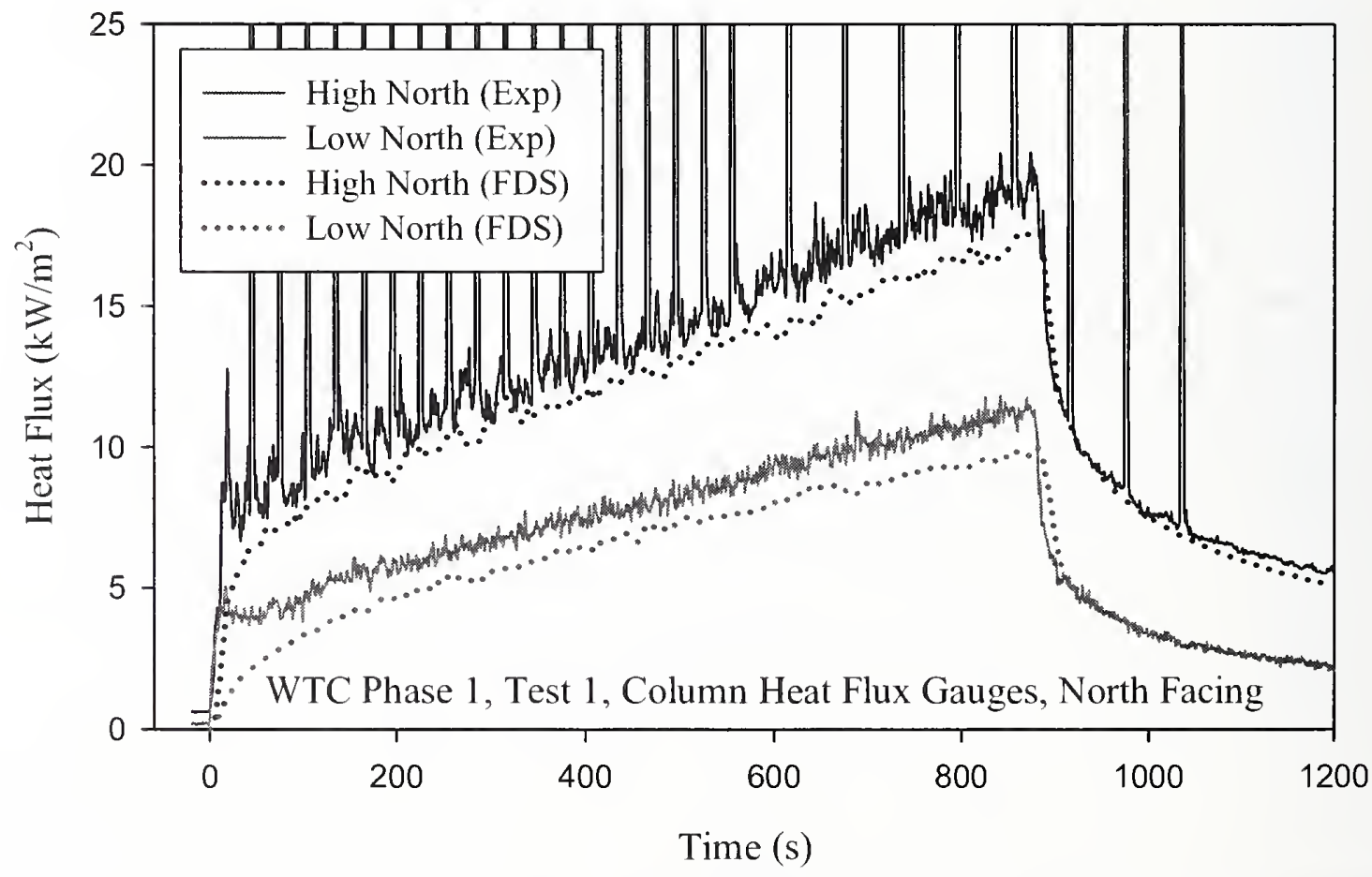

Figure 10-14. Comparison of heat fluxes to column, Test 1. The periodic spikes in the measurements were due to the influence of a nitrogen purge. 


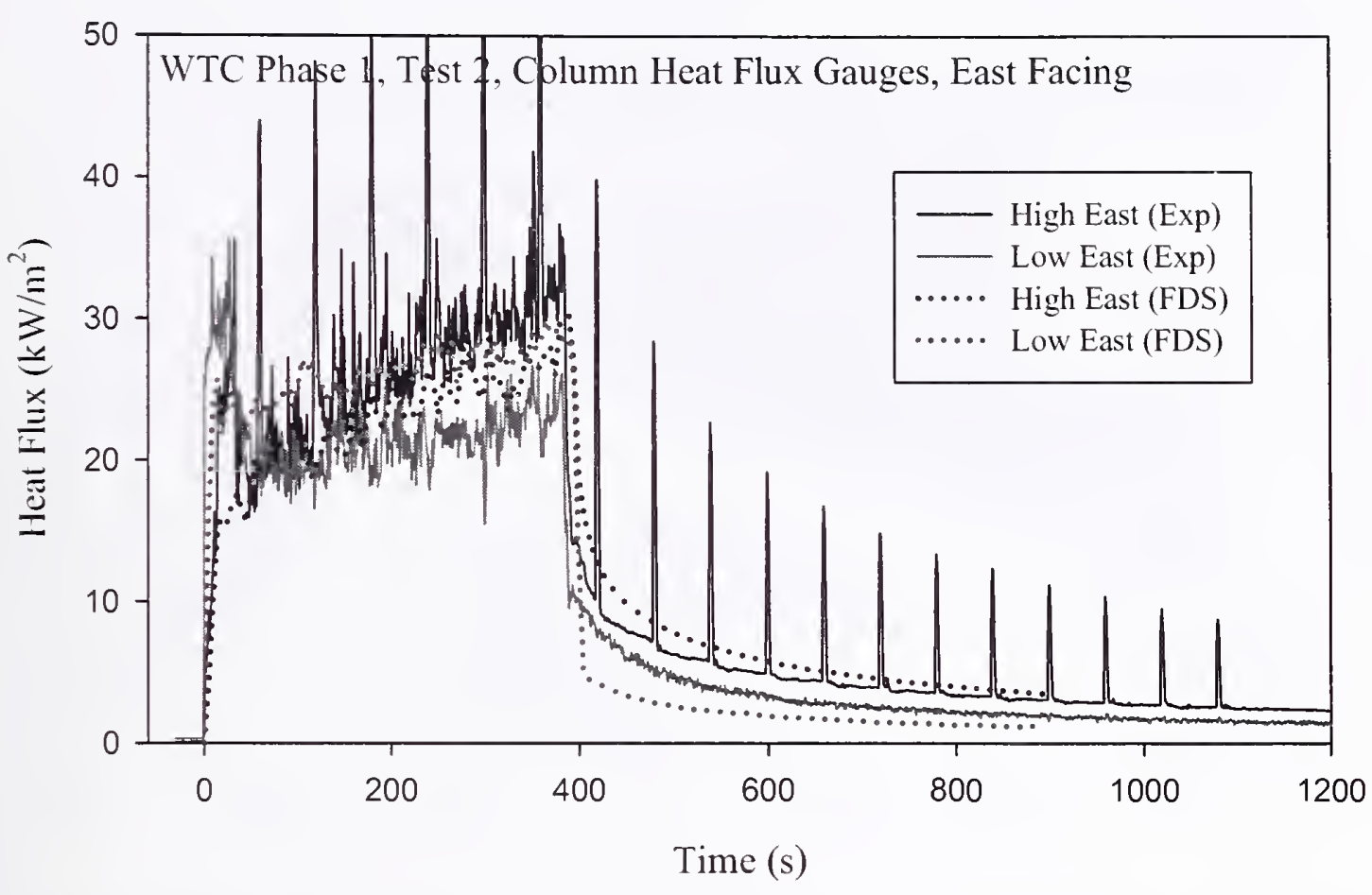

Figure 10-15. Comparison of heat fluxes to column, Test 2. The periodic spikes in the measurements were due to the influence of a nitrogen purge.

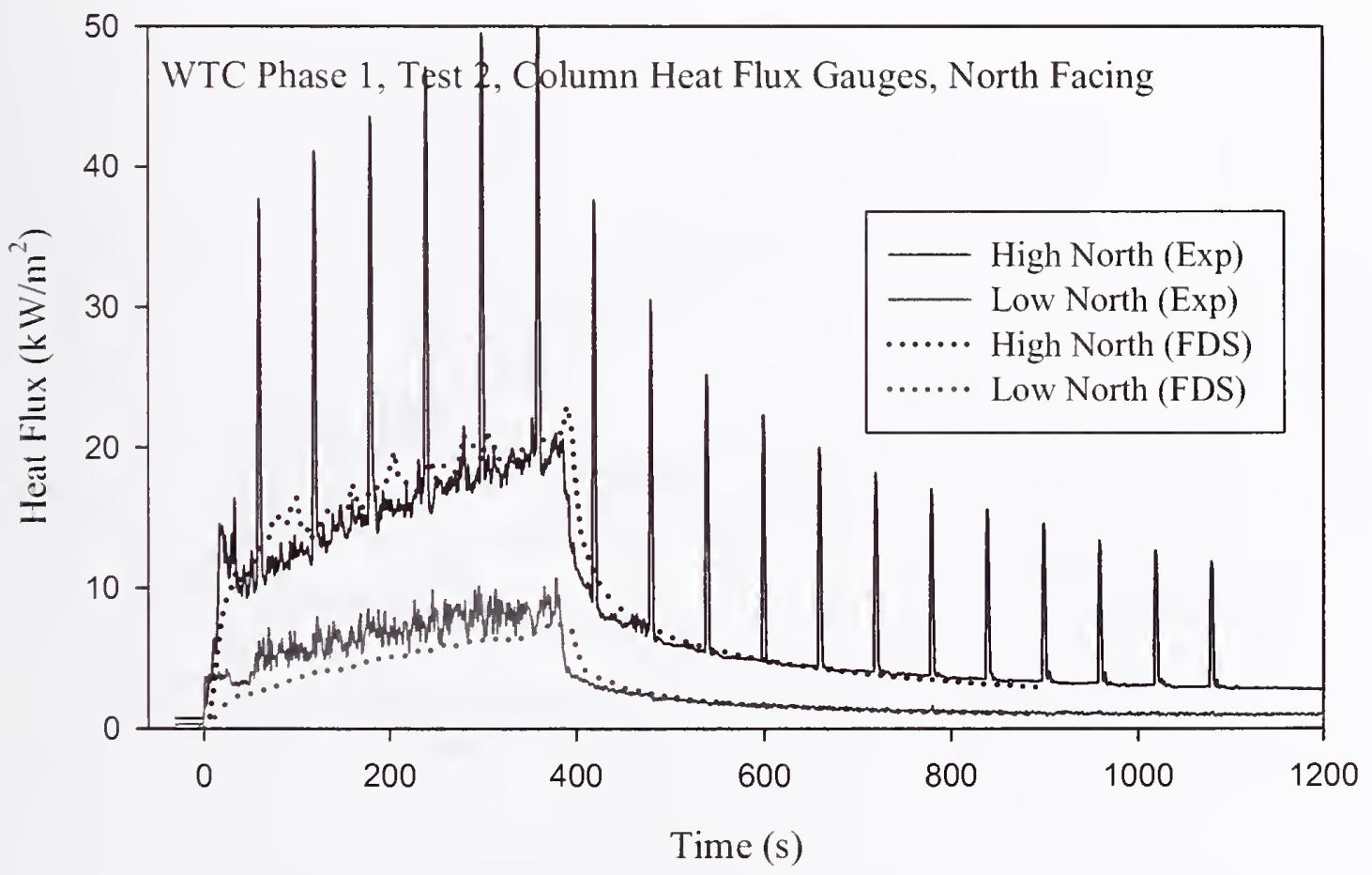

Figure 10-16. Comparison of heat fluxes to column, Test 2. The periodic spikes in the measurements were due to the influence of a nitrogen purge. 


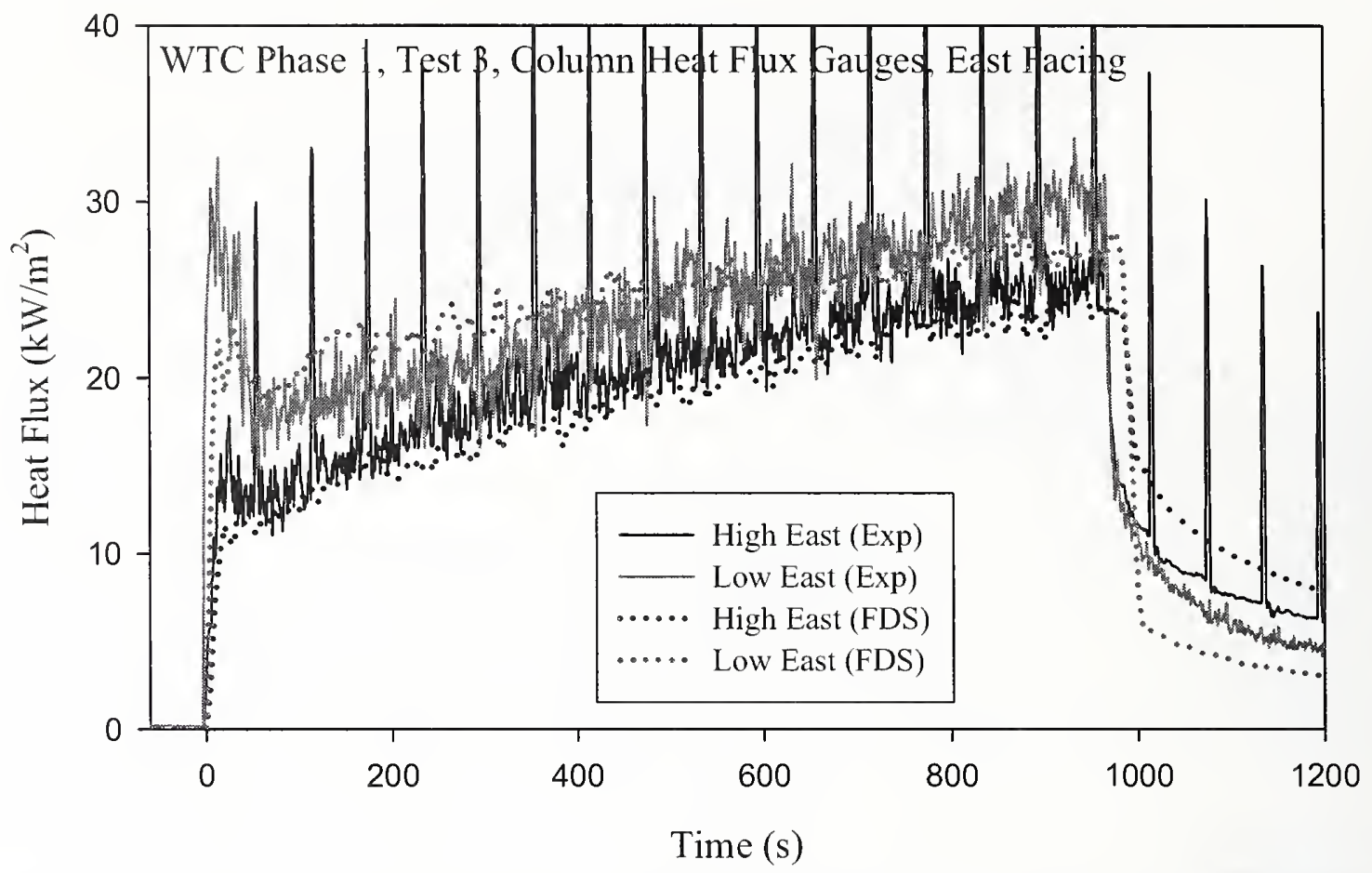

Figure 10-17. Comparison of heat fluxes to column, Test 3 . The periodic spikes in the measurements were due to the influence of a nitrogen purge.

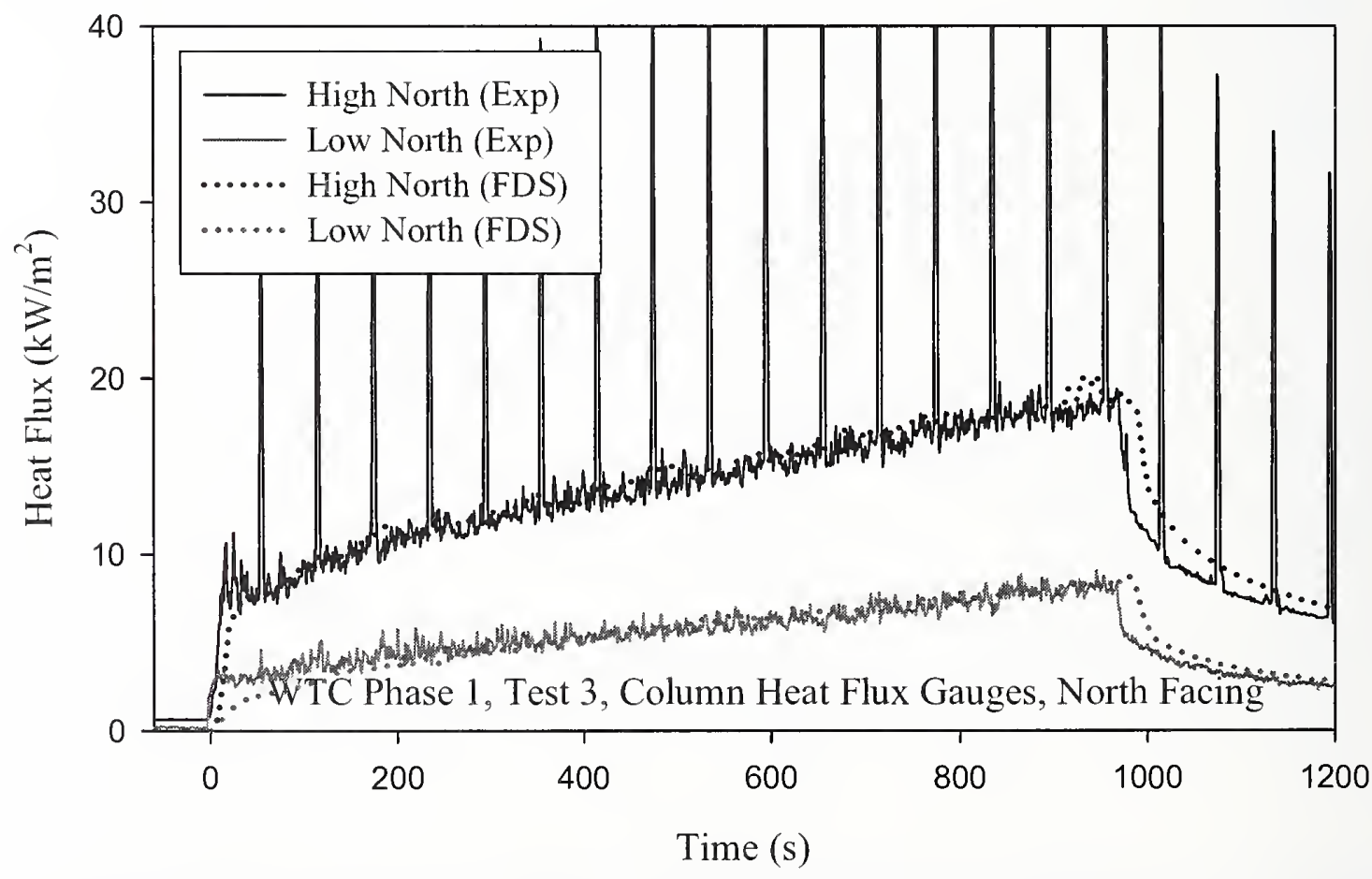

Figure 10-18. Comparison of heat fluxes to column, Test 3 . The periodic spikes in the measurements were due to the influence of a nitrogen purge. 


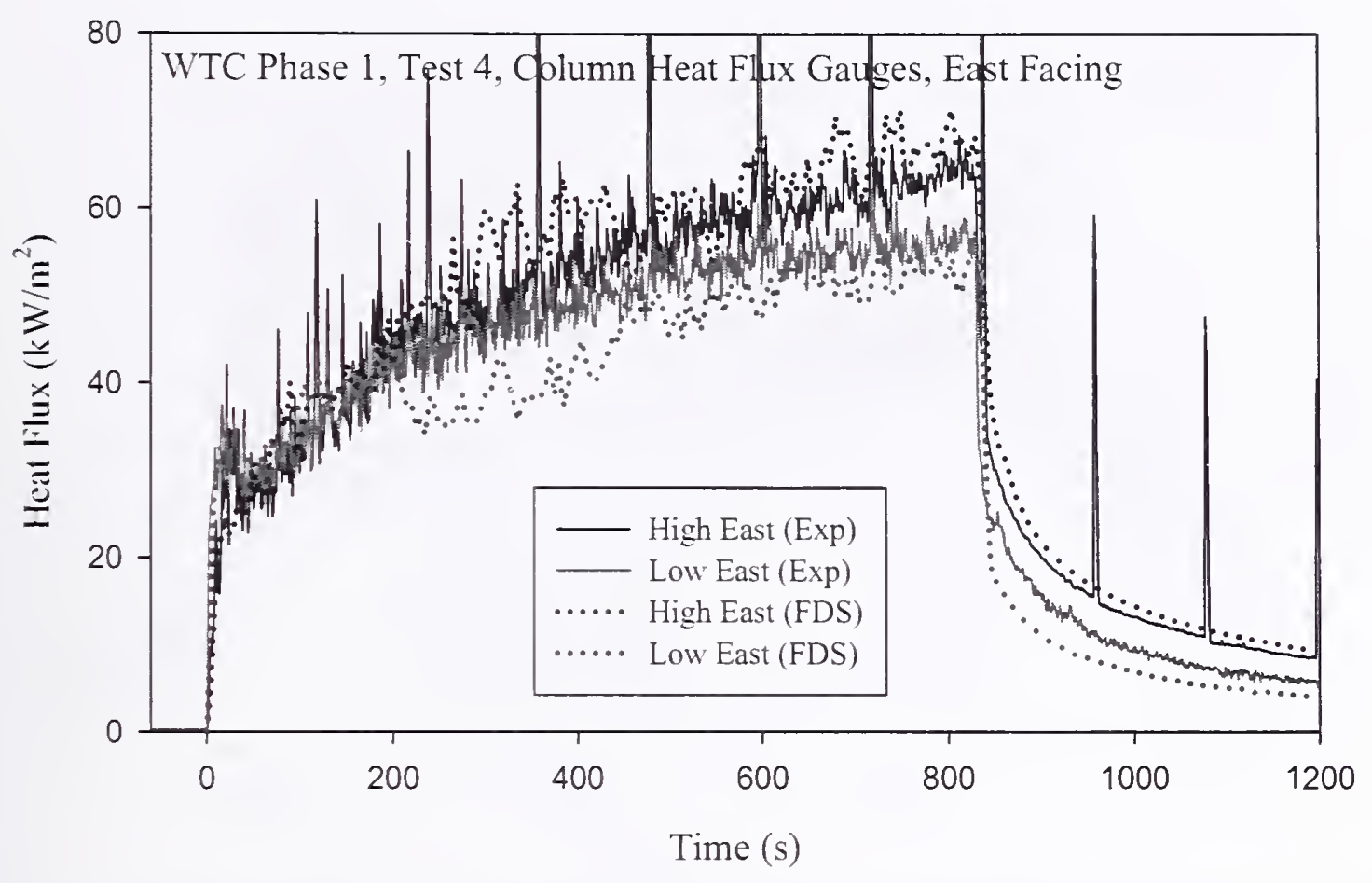

Figure 10-19. Comparison of heat fluxes to column, Test 4 . The periodic spikes in the measurements were due to the influence of a nitrogen purge.

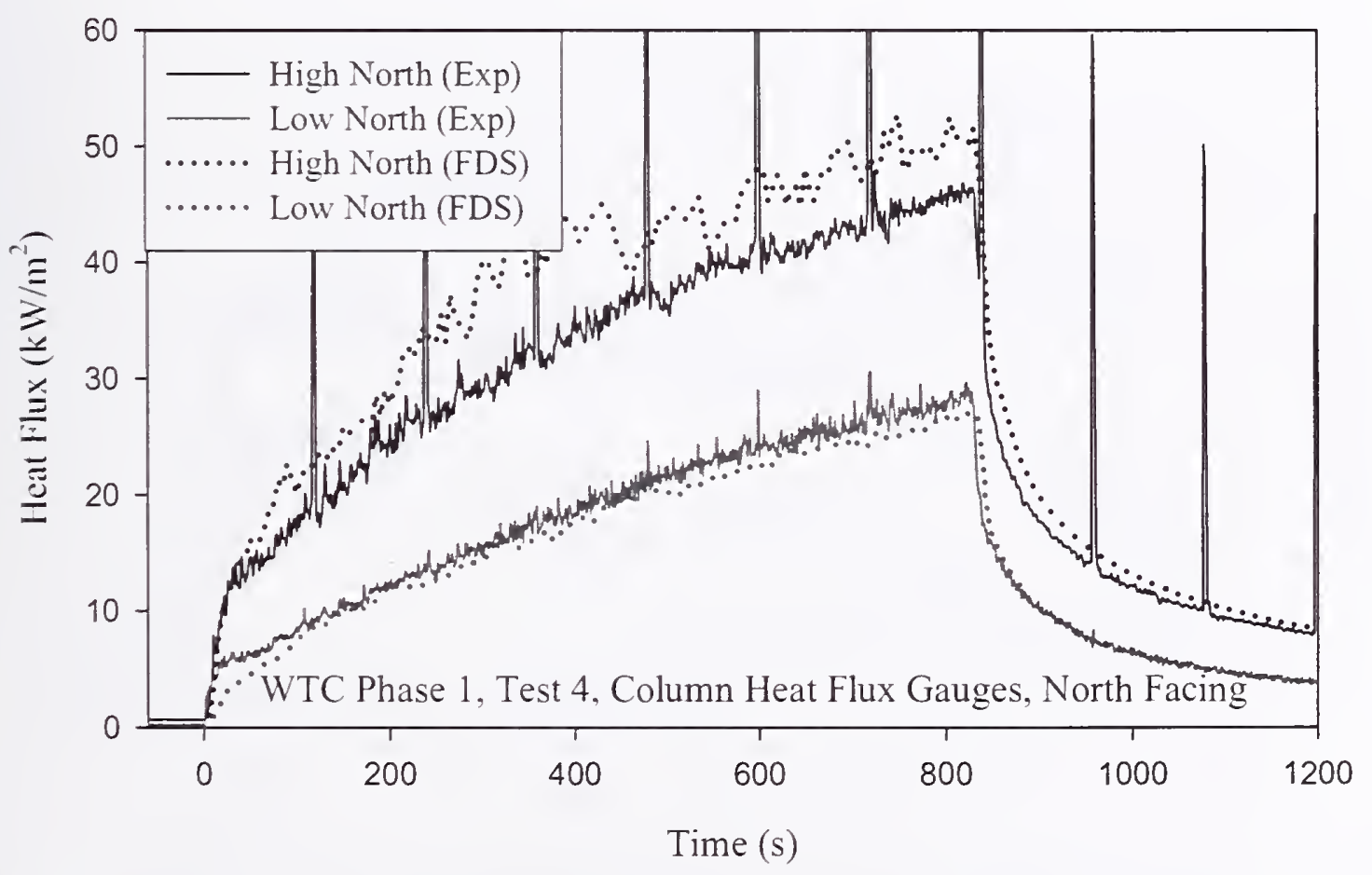

Figure 10-20. Comparison of heat fluxes to column, Test 4 . The periodic spikes in the measurements were due to the influence of a nitrogen purge. 


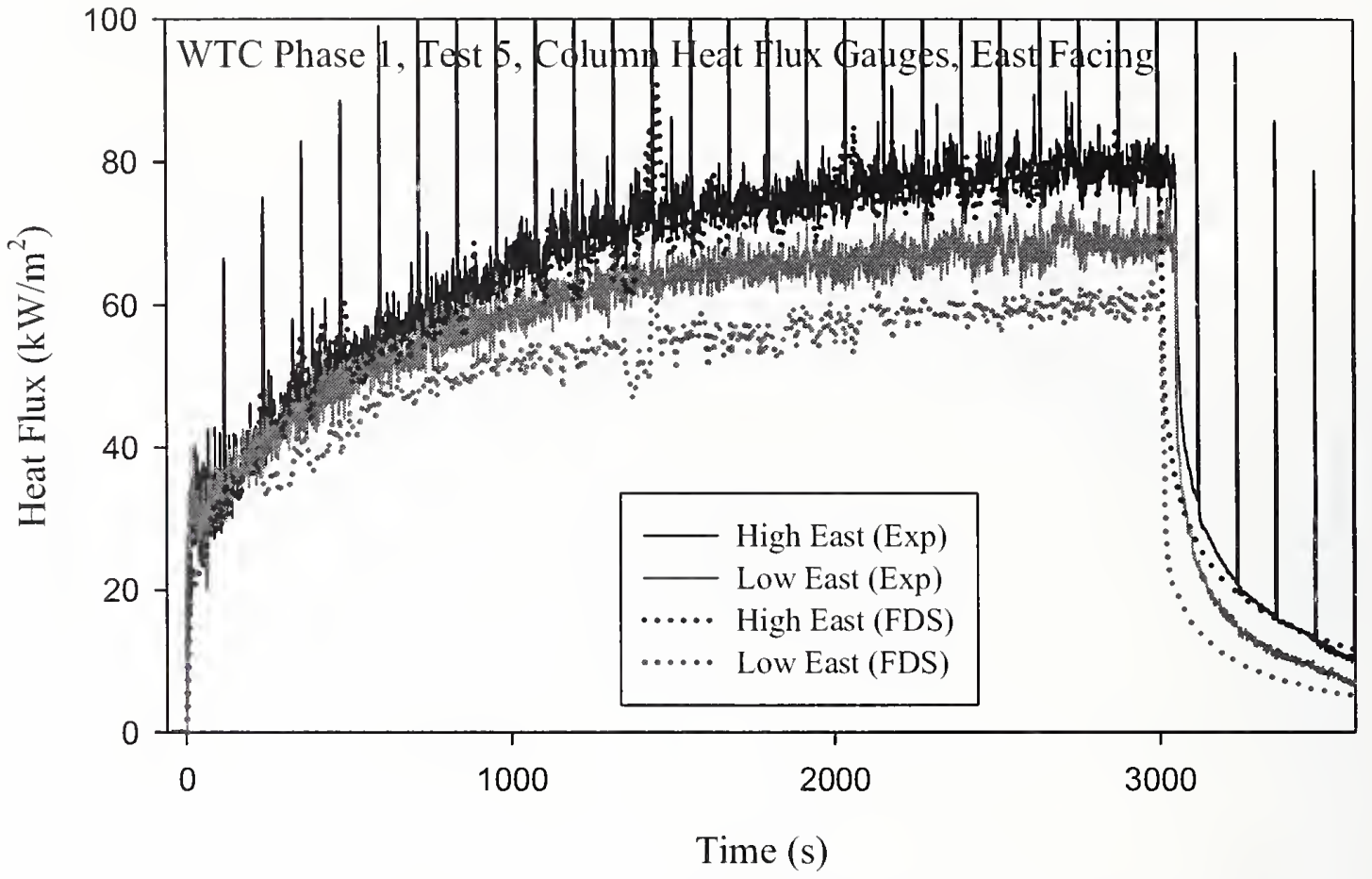

Figure 10-21. Comparison of heat fluxes to column, Test 5. The periodic spikes in the measurements were due to the influence of a nitrogen purge.

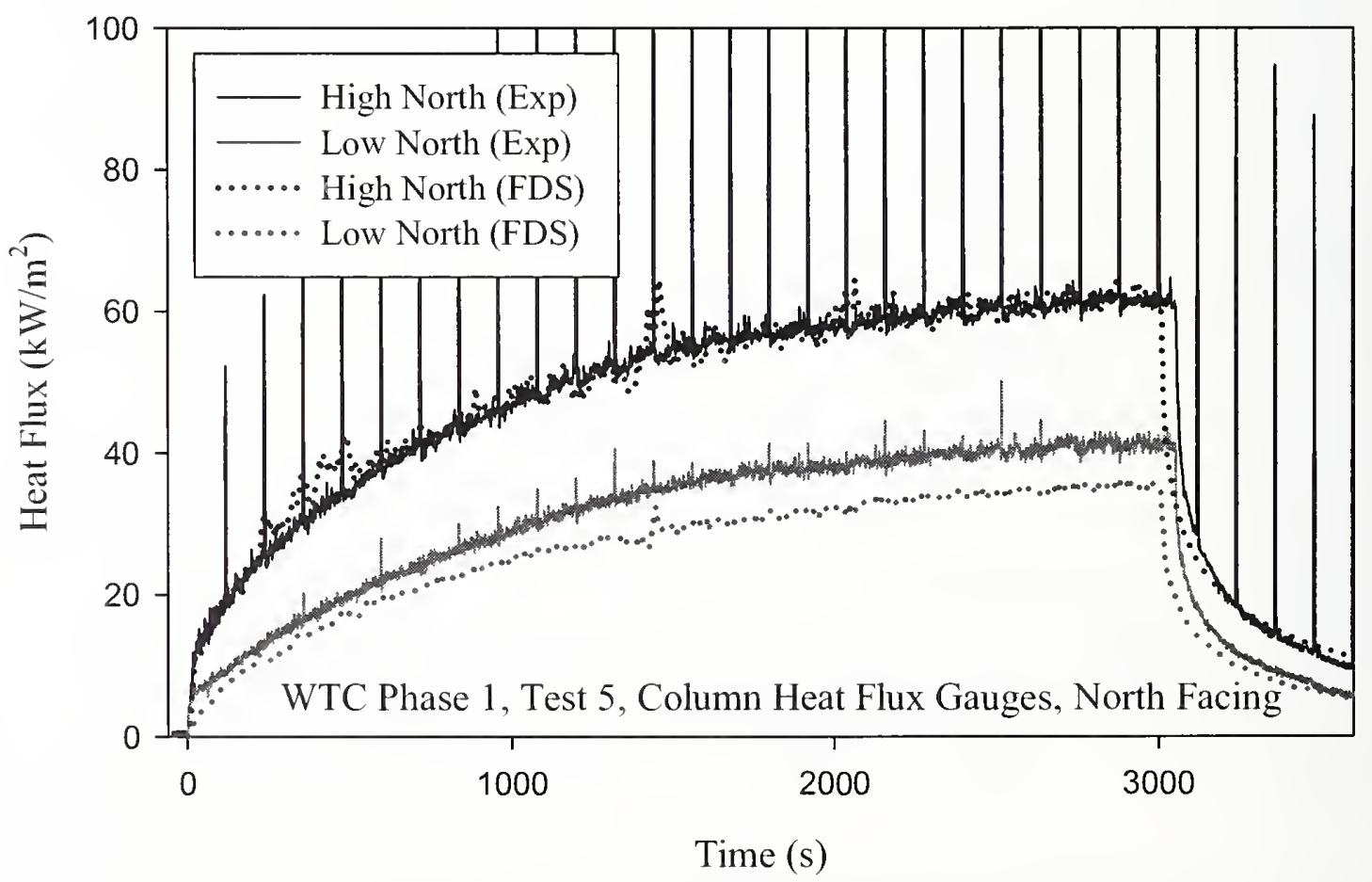

Figure 10-22. Comparison of heat fluxes to column, Test 5. The periodic spikes in the measurements were due to the influence of a nitrogen purge. 


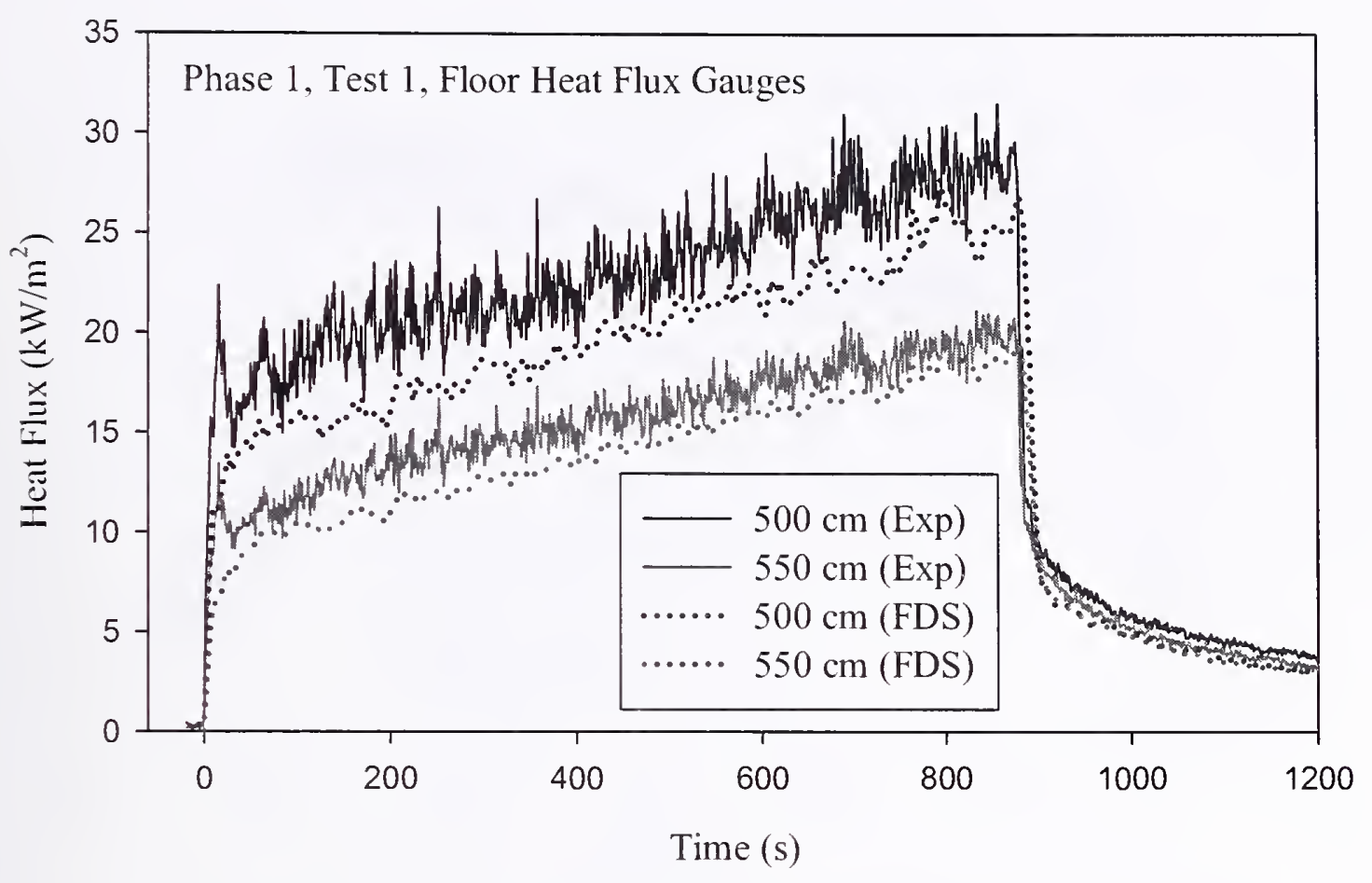

Figure 10-23. Comparison of heat fluxes to floor targets, Test 1.

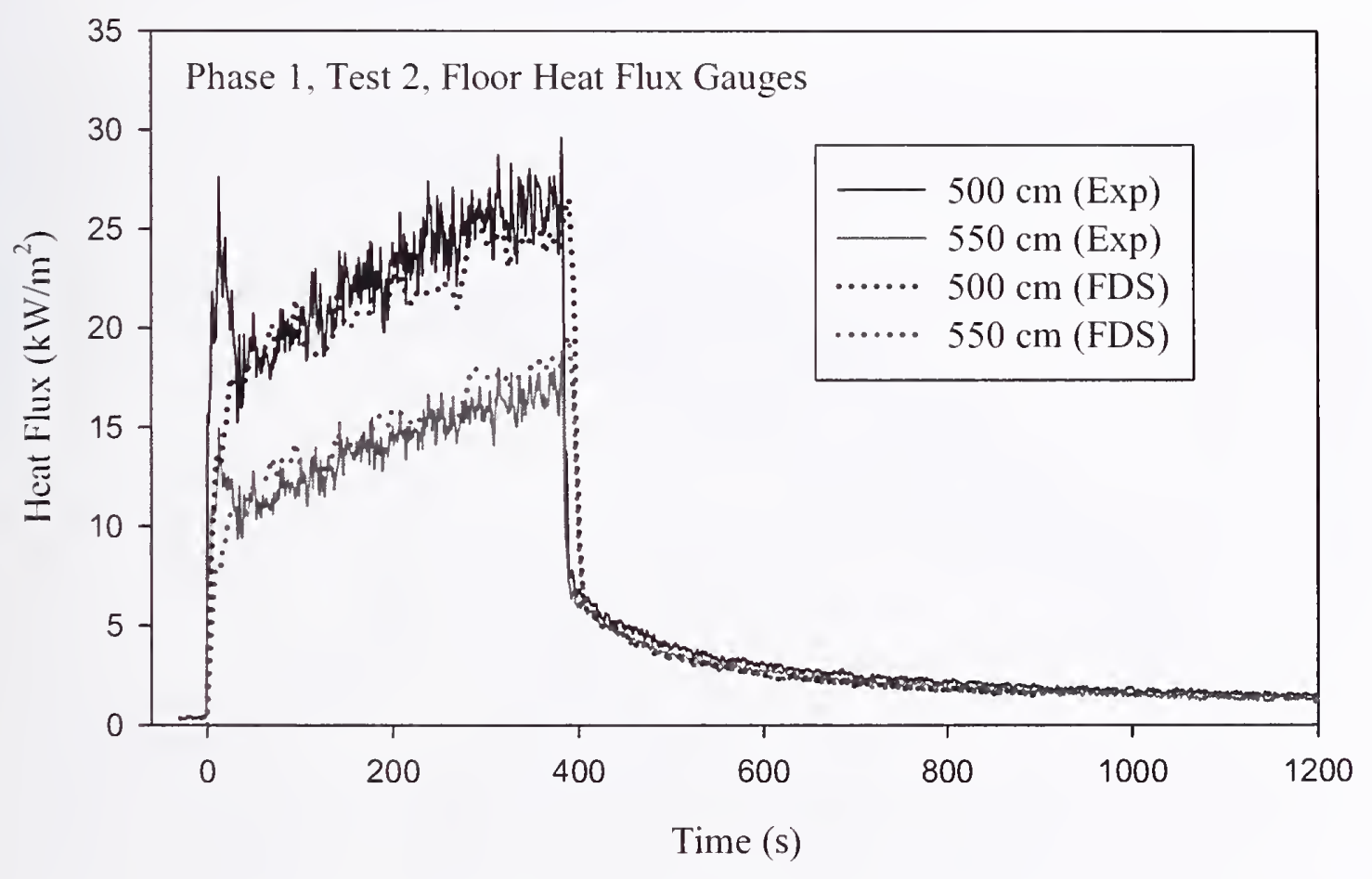

Figure 10-24. Comparison of heat fluxes to floor targets, Test 2. 


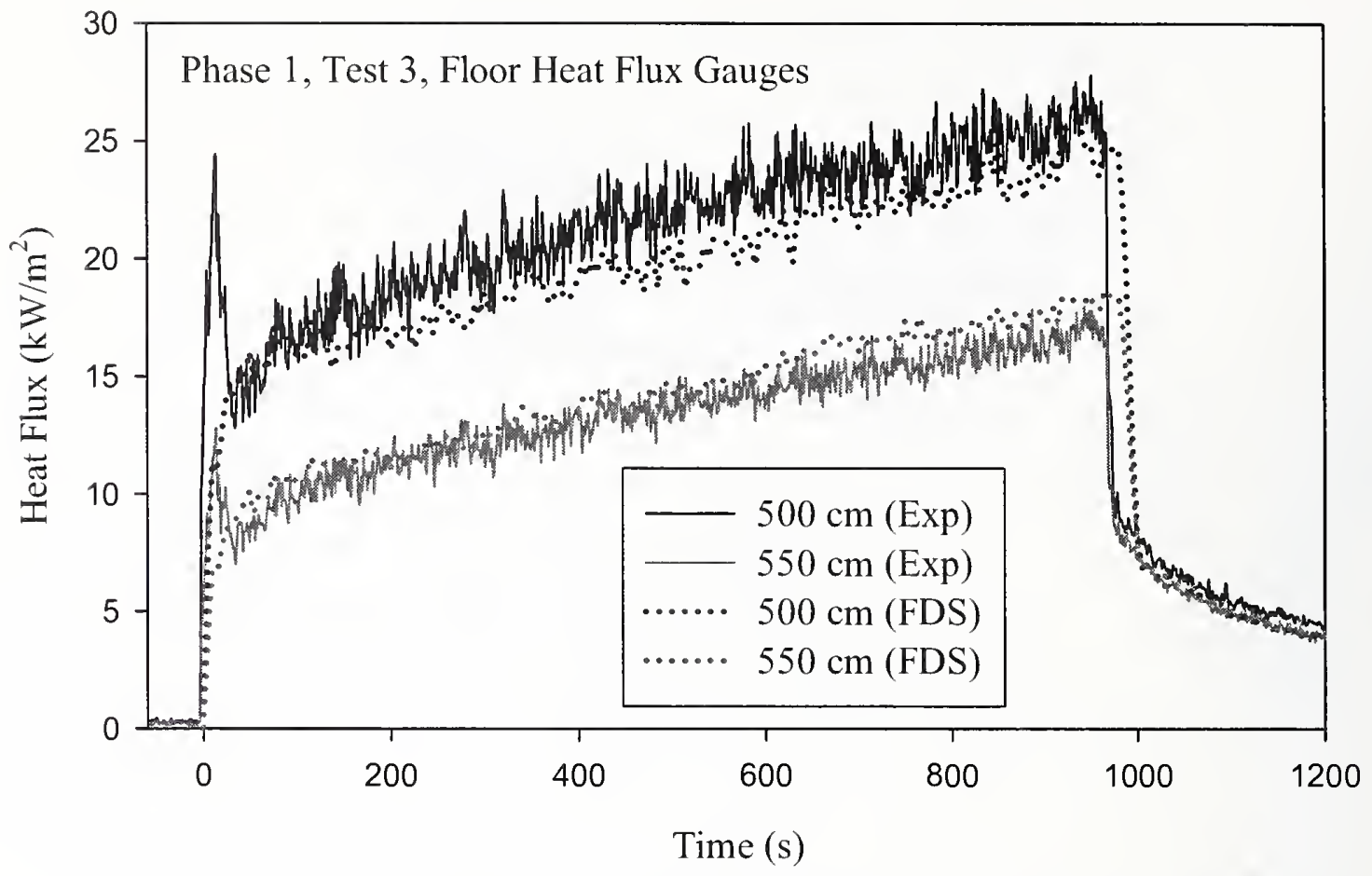

Figure 10-25. Comparison of heat fluxes to floor targets, Test 3.

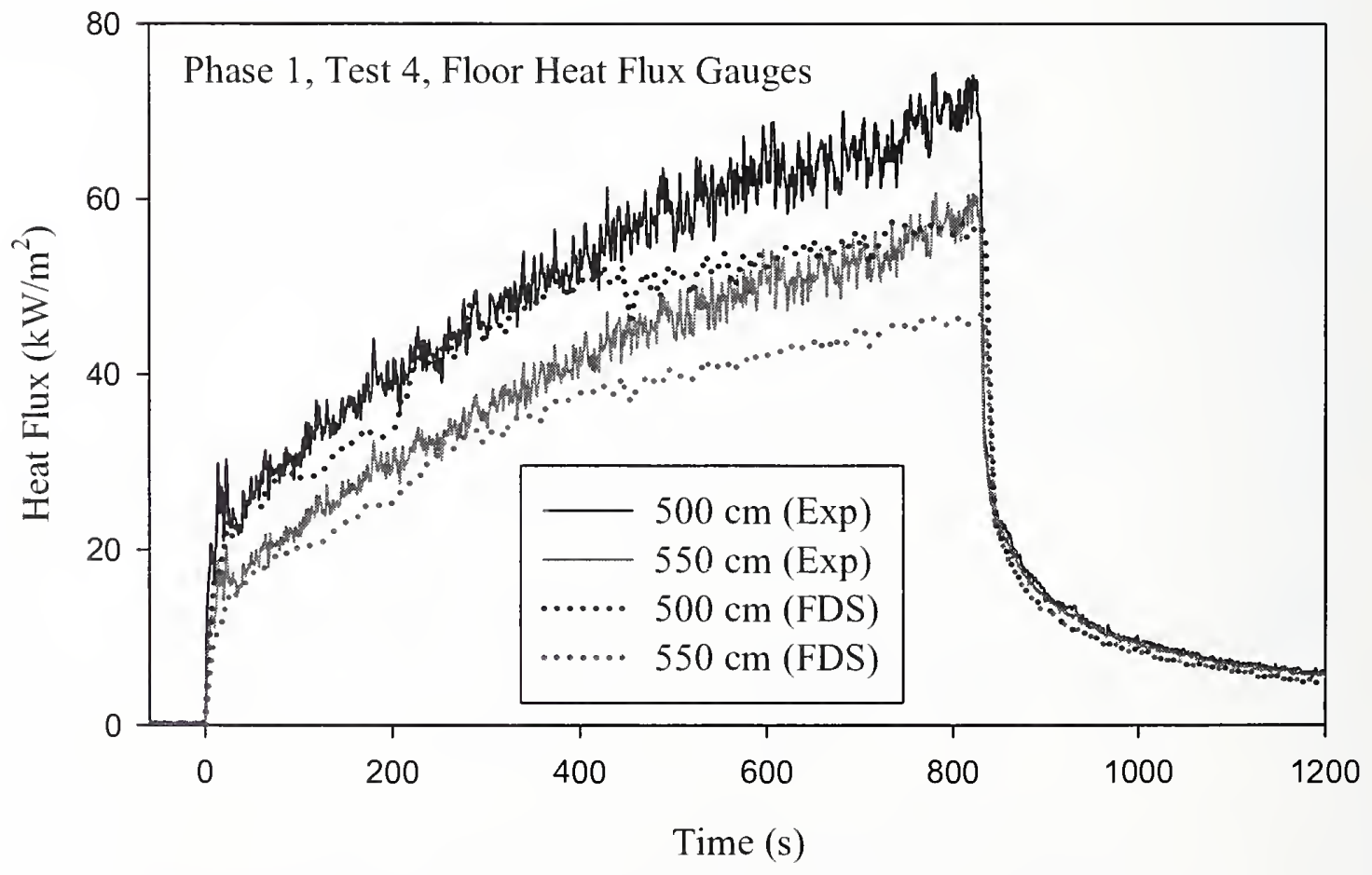

Figure 10-26. Comparison of heat fluxes to floor targets, Test 4. 


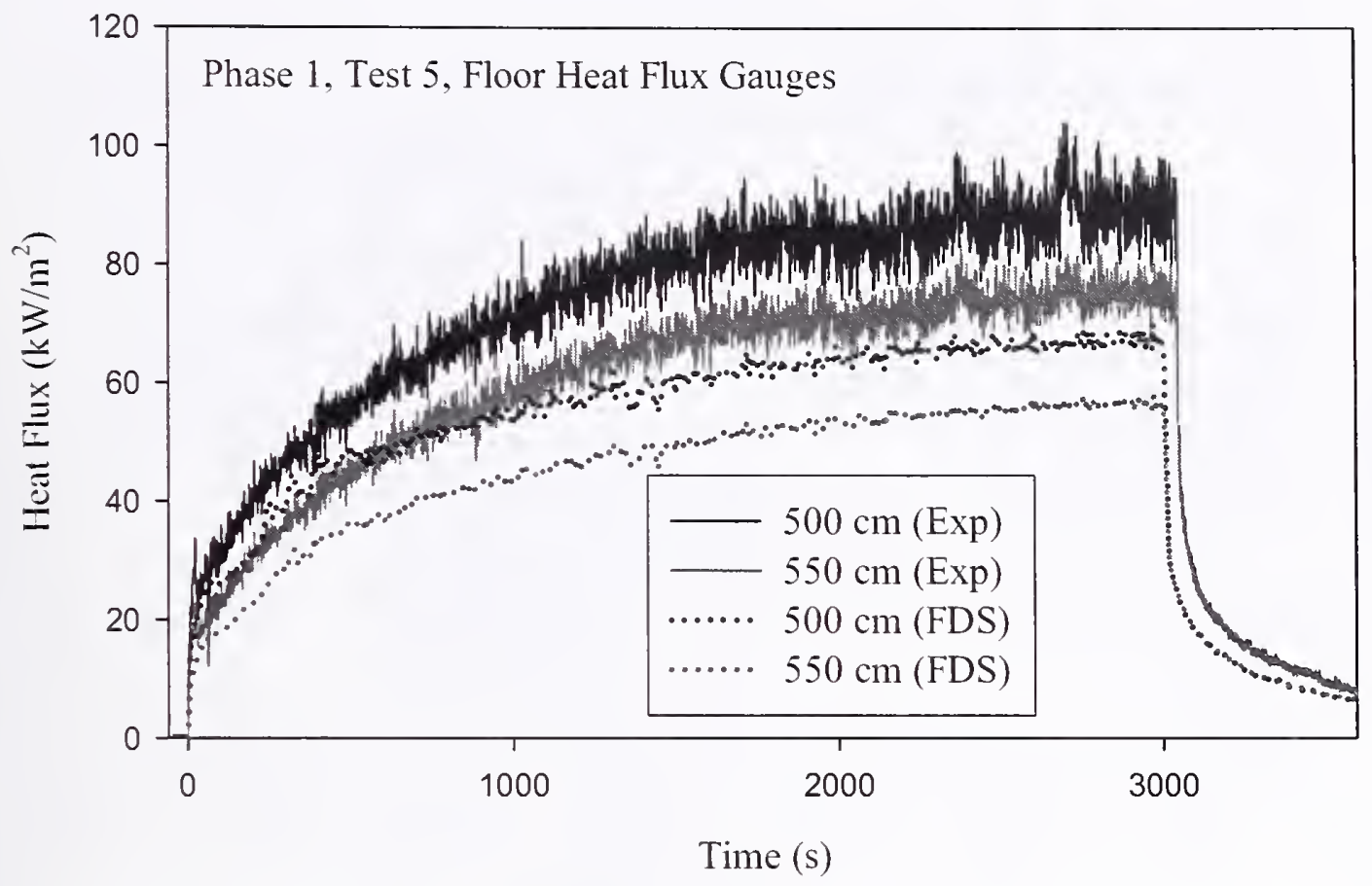

Figure 10-27. Comparison of heat fluxes to floor targets, Test 5.

\subsubsection{Compartment Surface Temperatures}

Bare-bead thermocouples were attached to the ceiling, walls, and other objects within the compartment as described in Chapter 8. In addition, several thermocouples were sandwiched between the two sheets of Marinite that made up the outer wall. These thermocouples were placed to test the model's prediction of conductive losses through the walls, an important component of the accounting of the overall energy budget. Ceiling surface temperatures and the corresponding inner temperatures are shown in Figs. 10-28 through 10-37. The three points chosen for comparison were along the centerline of the compartment: directly over the fire $(\mathrm{x}=399 \mathrm{~cm}), 0.5 \mathrm{~m}$ east of the fire $(\mathrm{x}=456 \mathrm{~cm})$, and beyond the fire plume towards the outlet $(\mathrm{x}=612 \mathrm{~cm})$. 


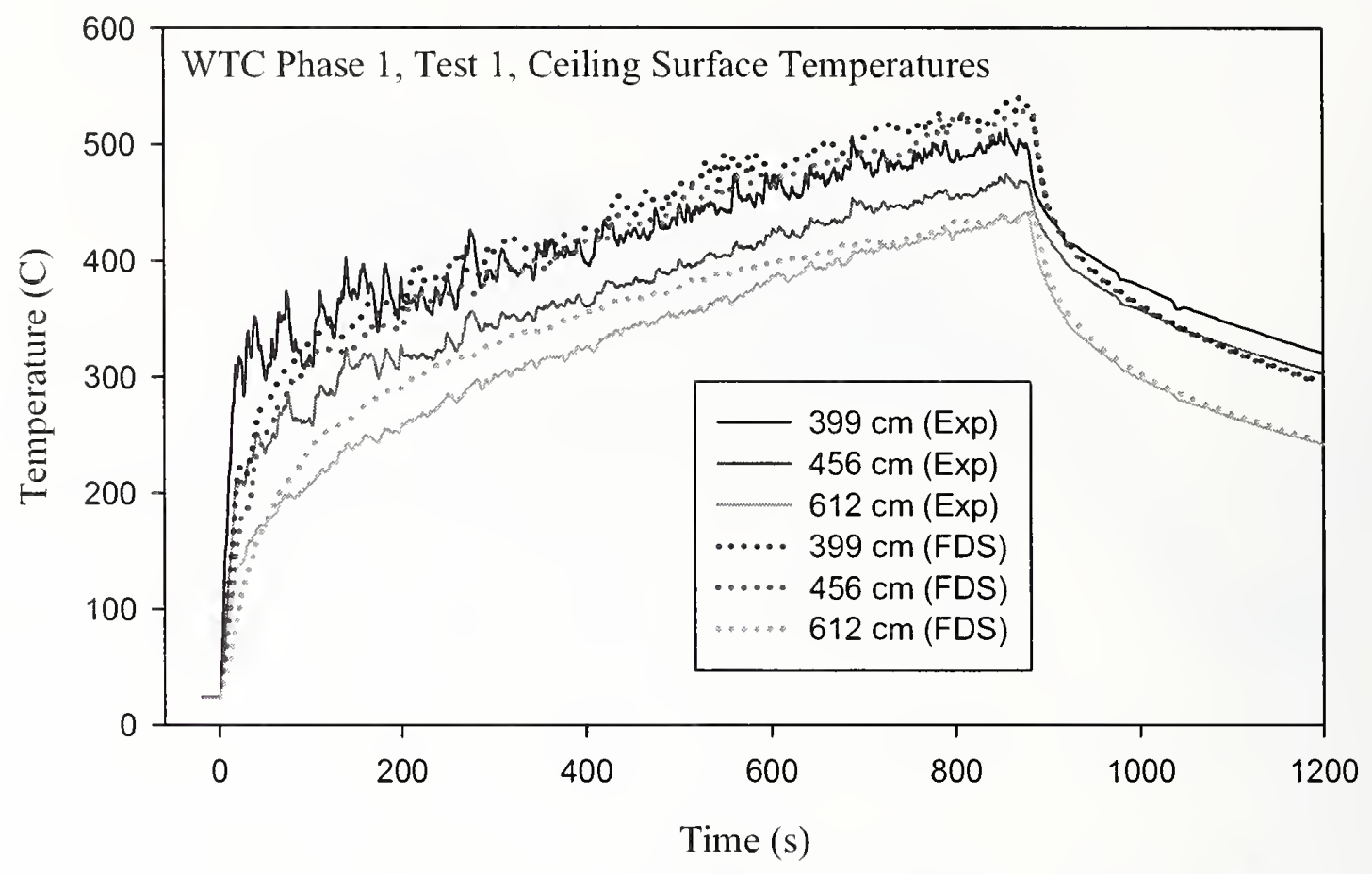

Figure 10-28. Comparison of ceiling temperatures, Test 1.

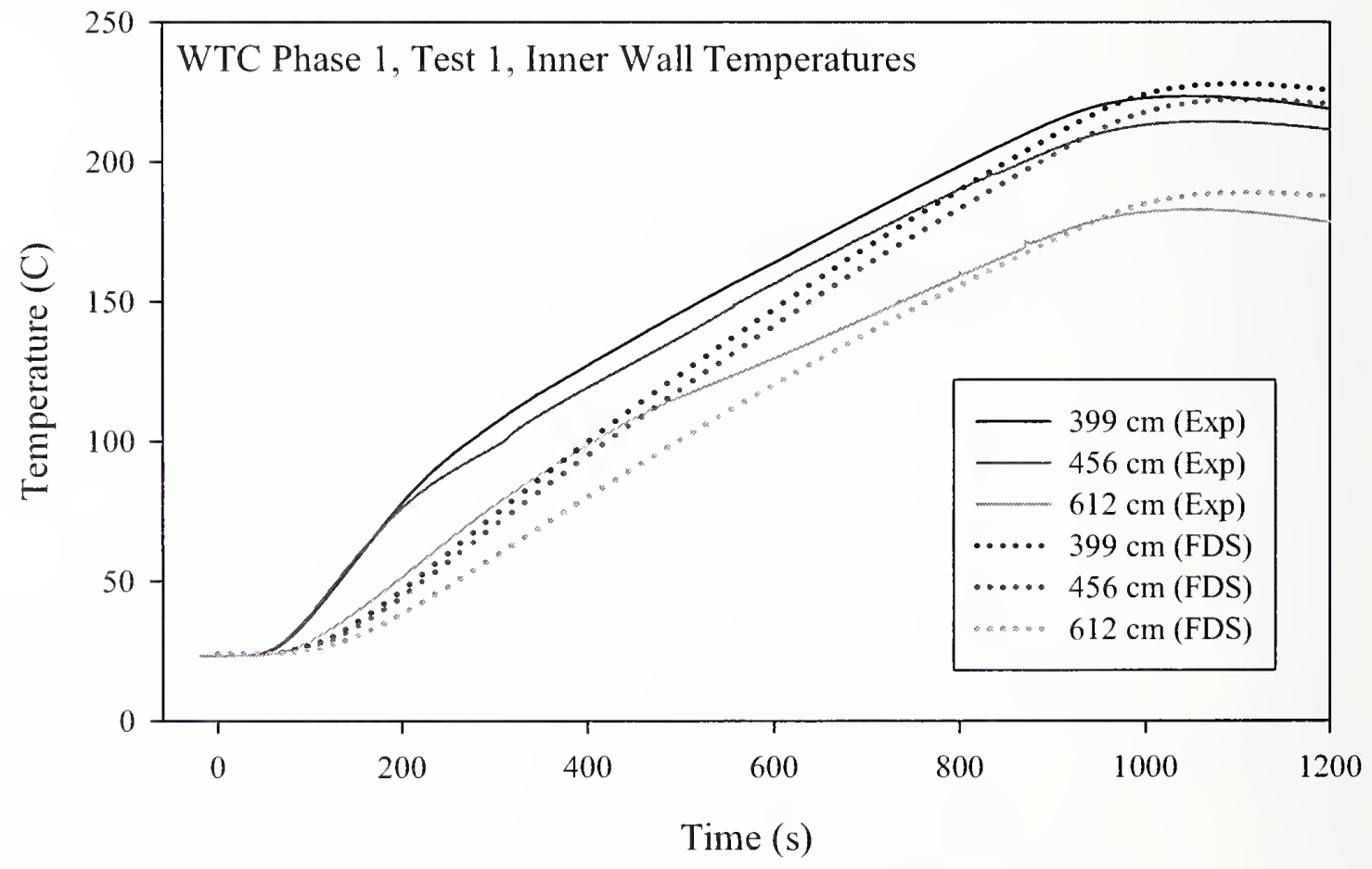

Figure 10-29. Comparison of inner ceiling temperatures, Test 1. 


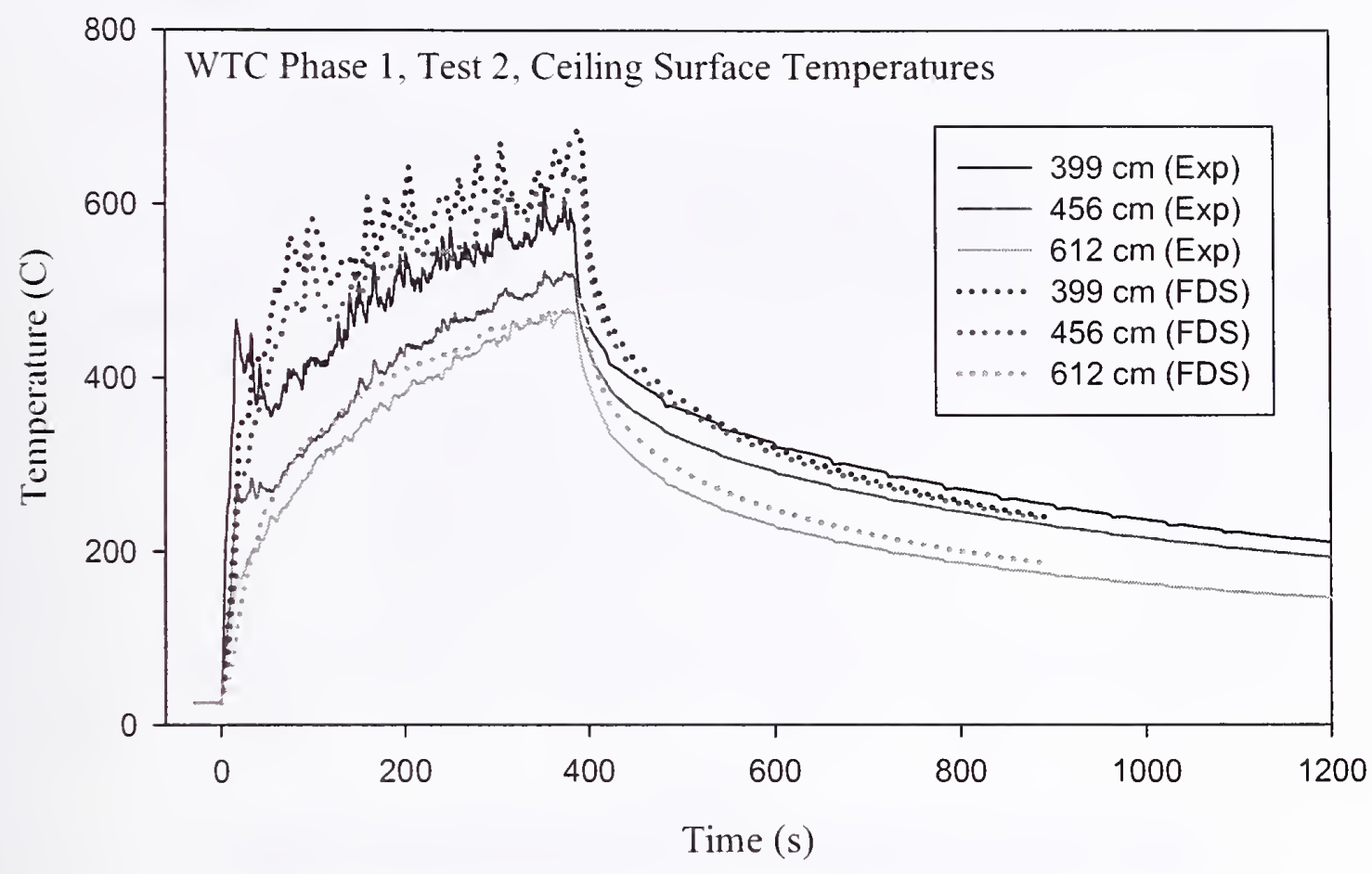

Figure 10-30. Comparison of ceiling temperatures, Test 2.

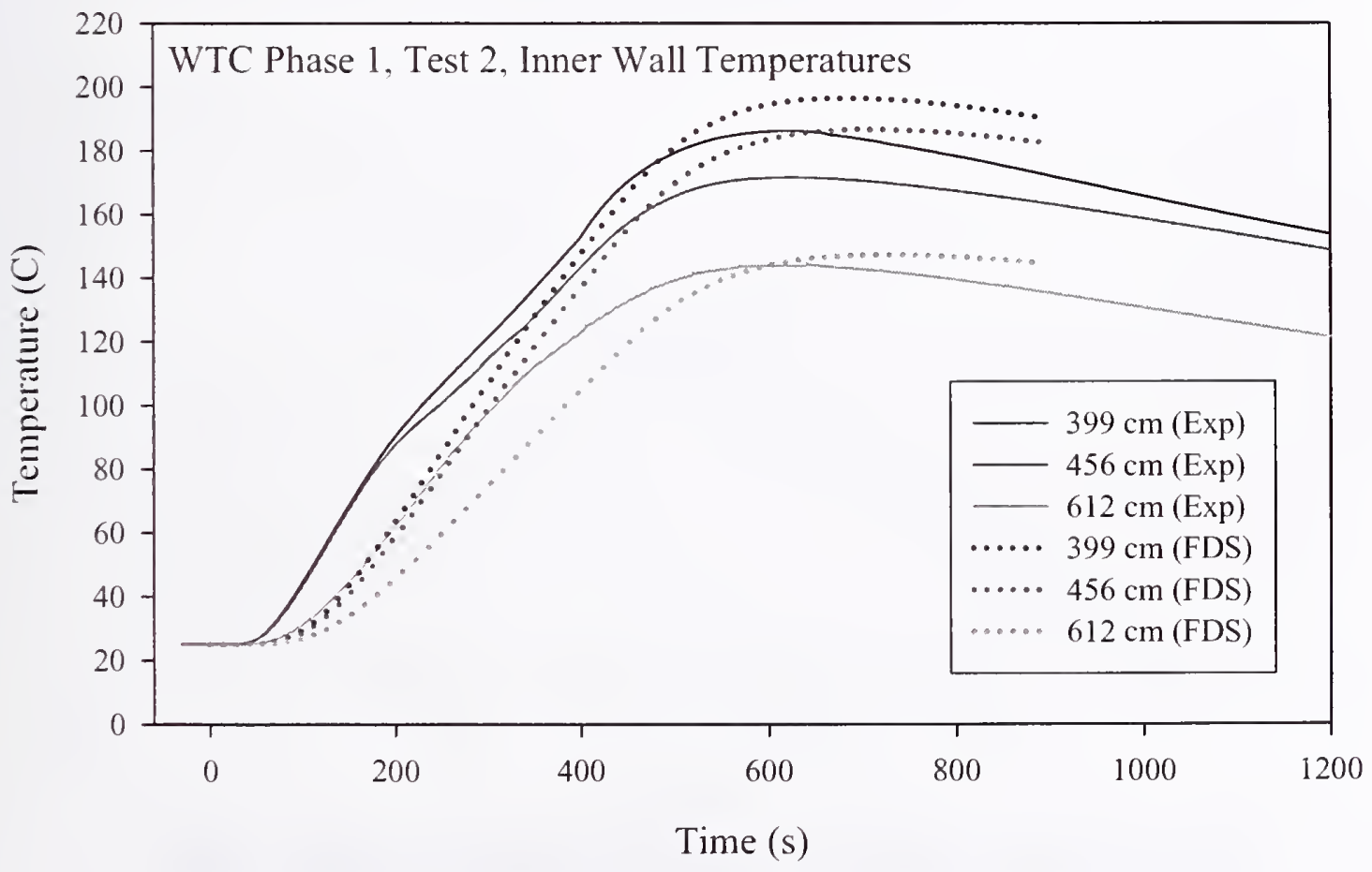

Figure 10-31. Comparison of inner ceiling temperatures, Test 2. 


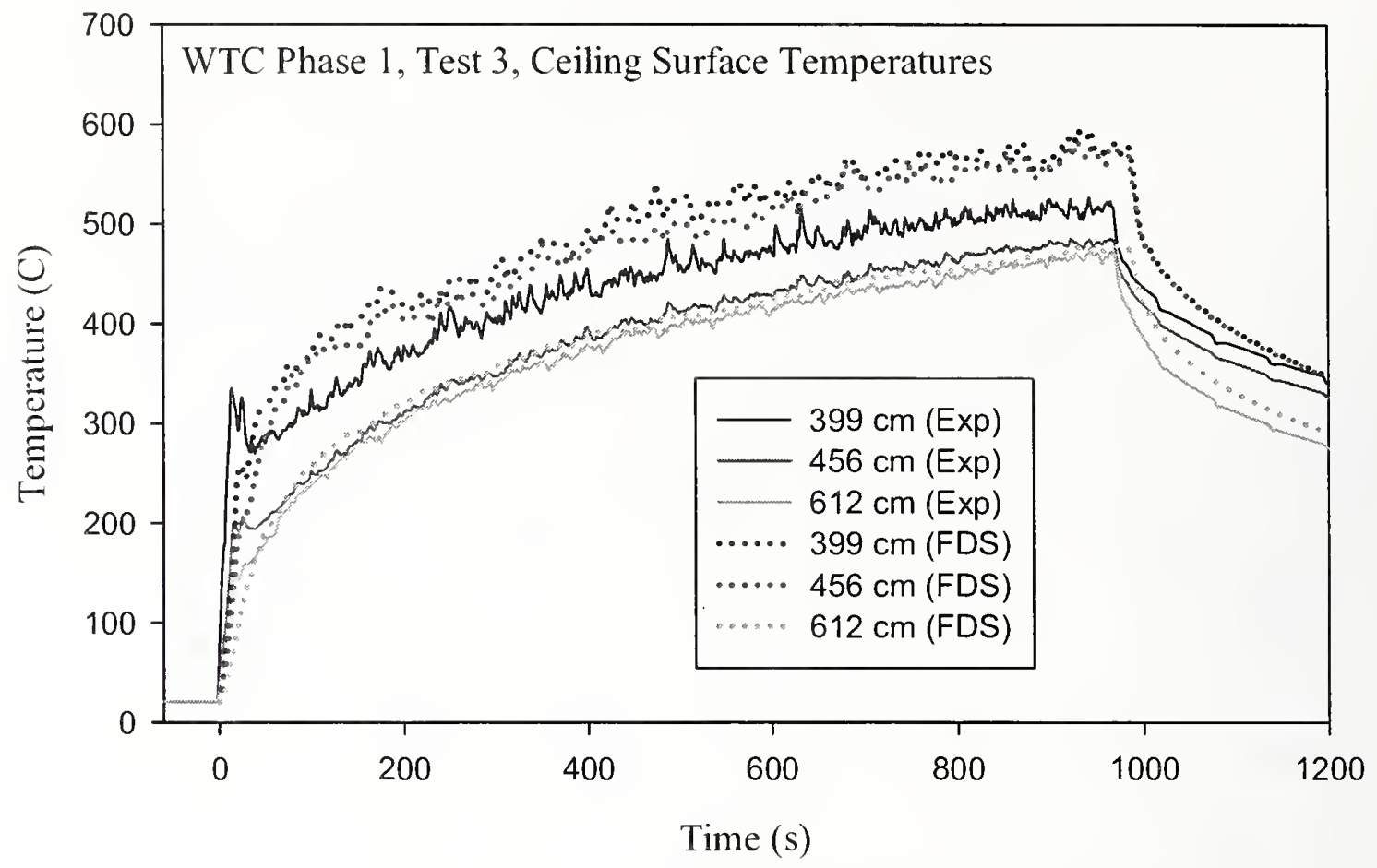

Figure 10-32. Comparison of ceiling temperatures, Test 3.

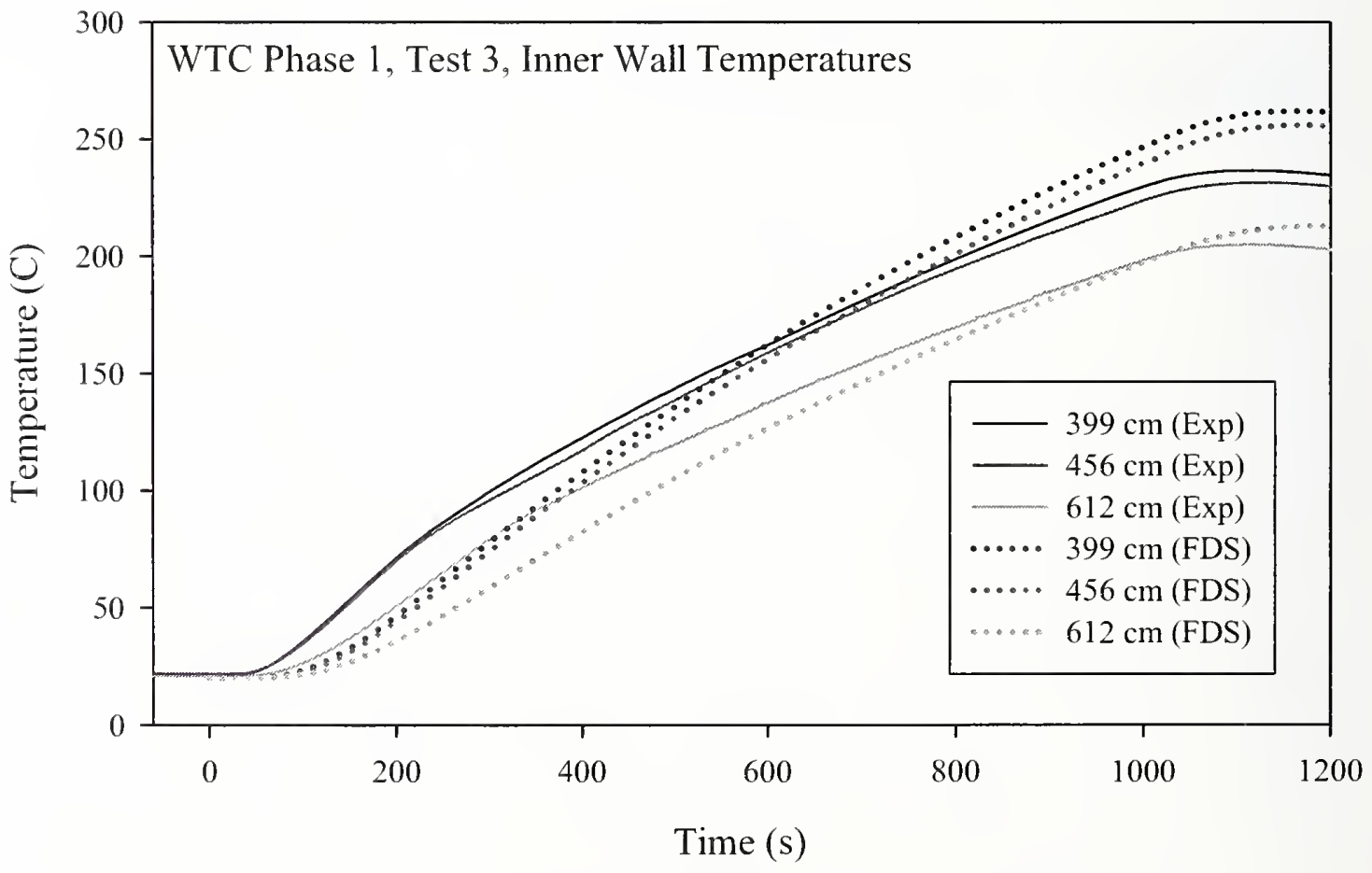

Figure 10-33. Comparison of inner ceiling temperatures, Test 3. 


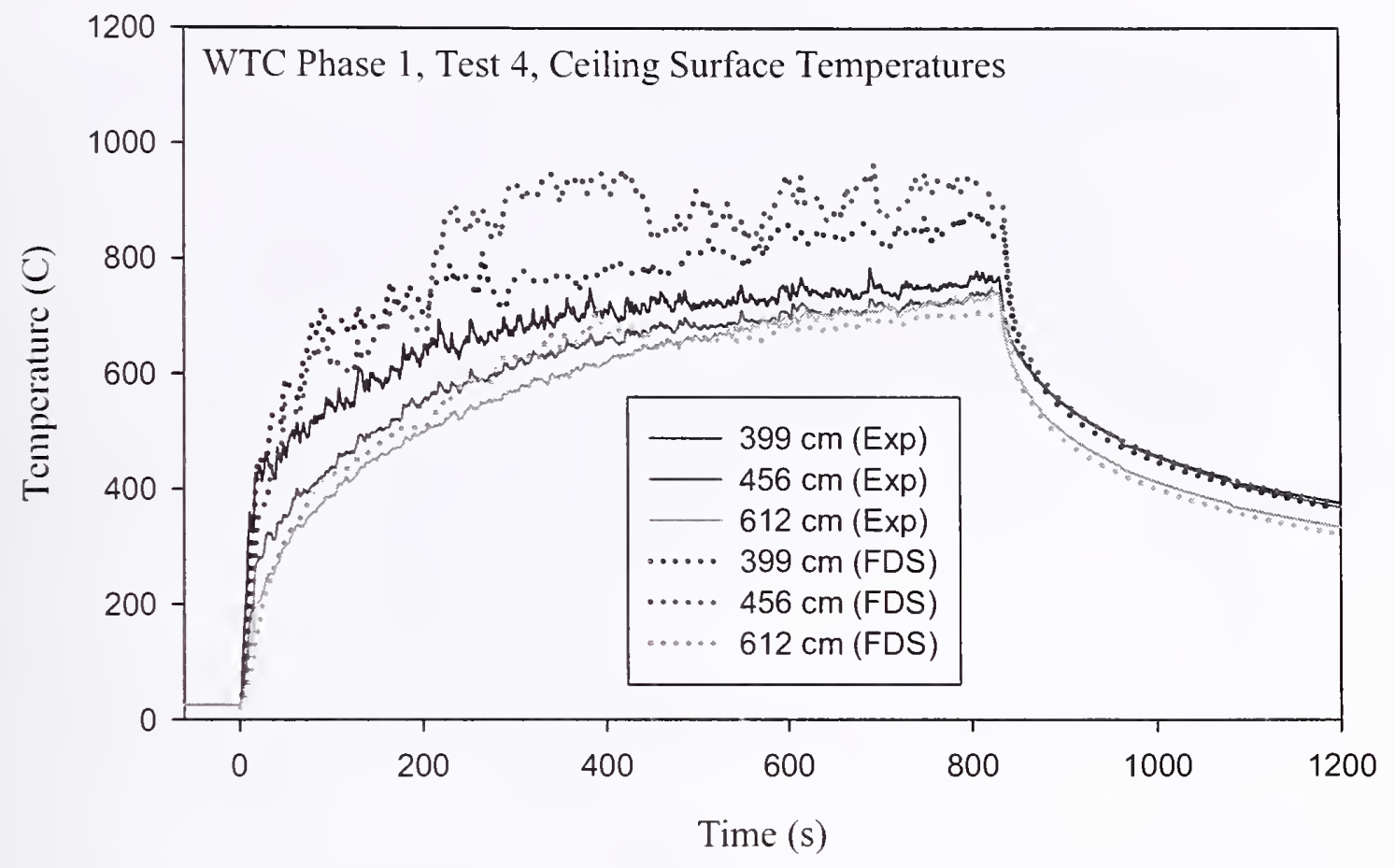

Figure 10-34. Comparison of ceiling temperatures, Test 4.

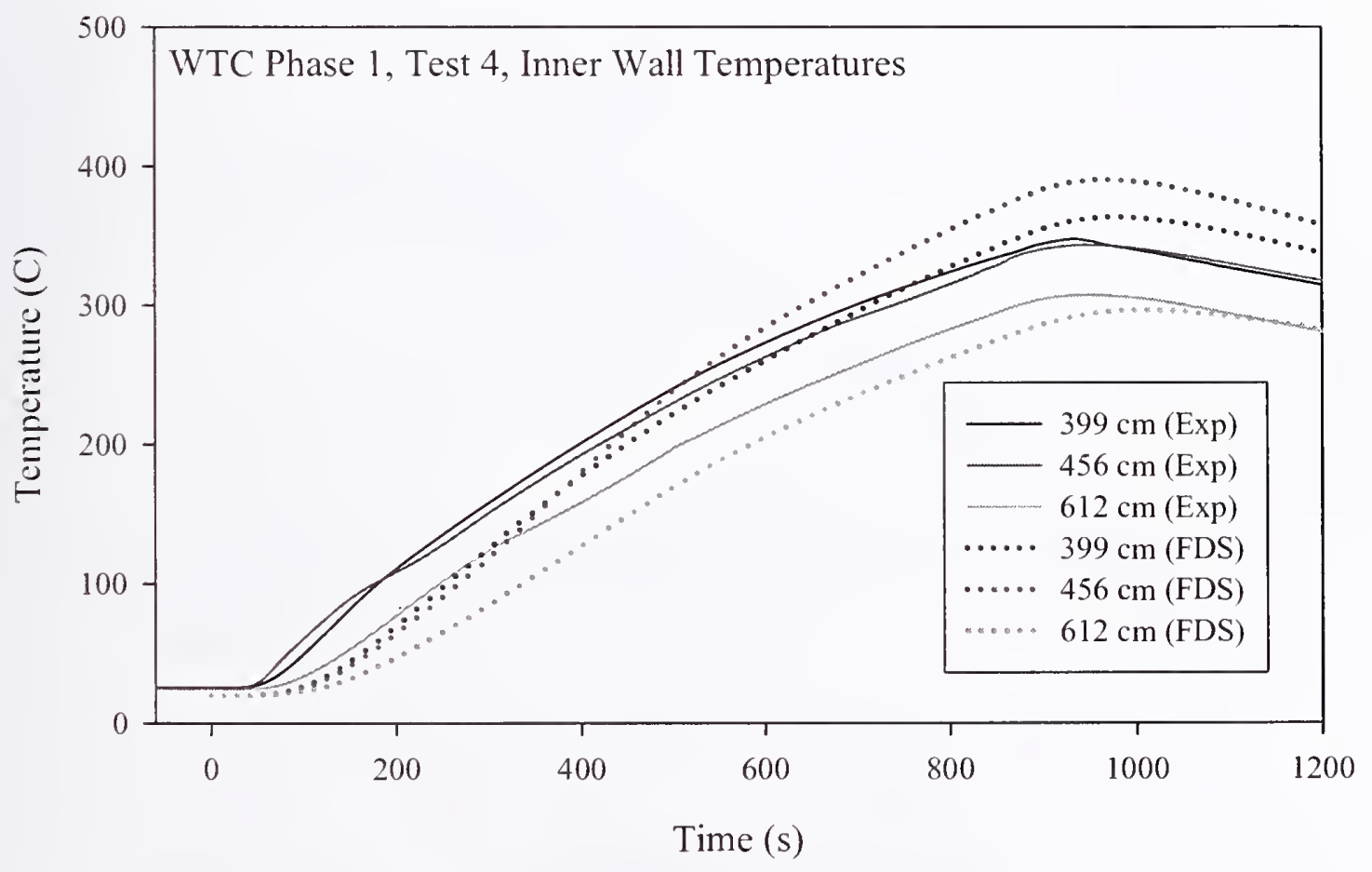

Figure 10-35. Comparison of inner ceiling temperatures, Test 4. 


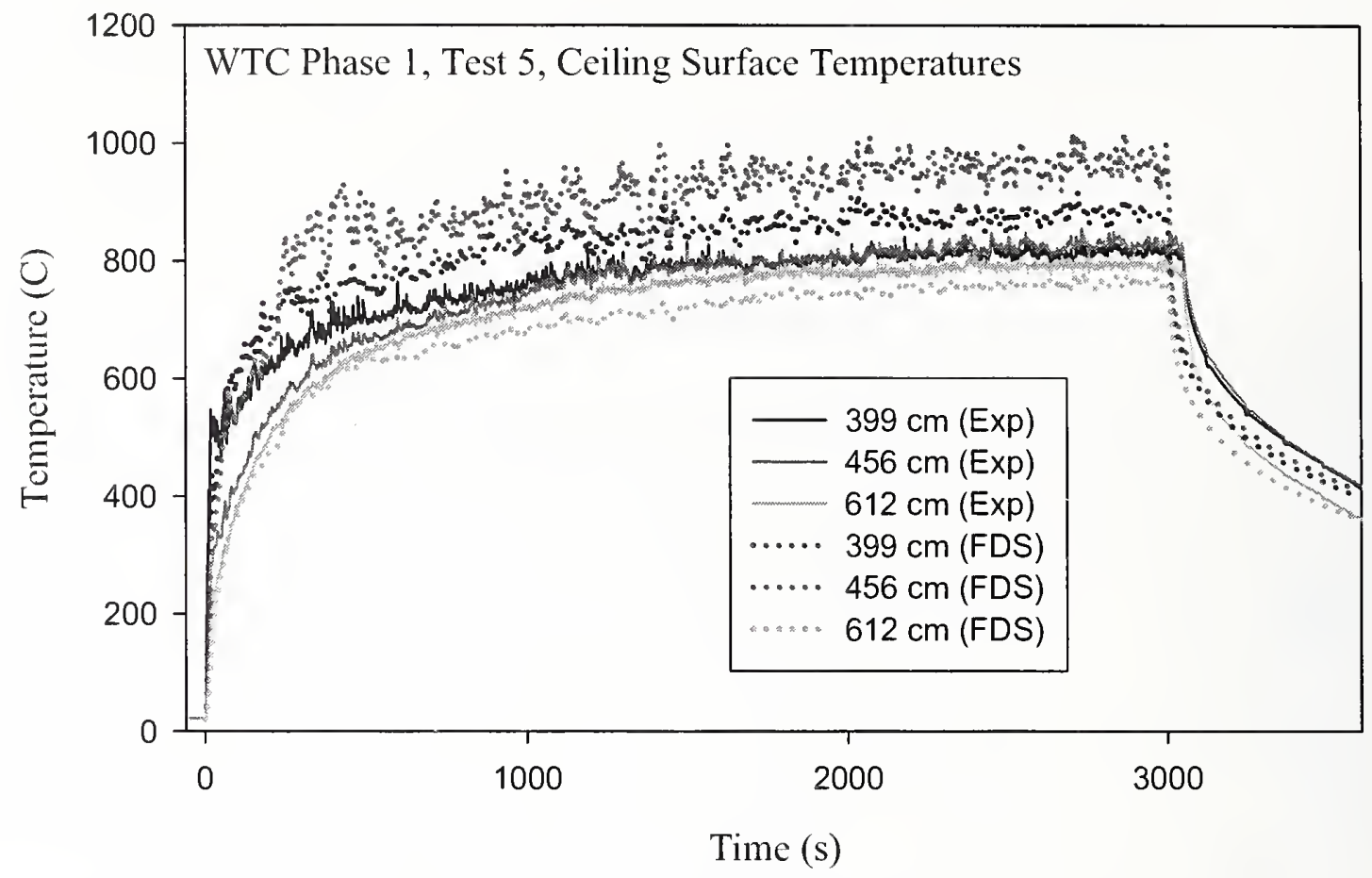

Figure 10-36. Comparison of ceiling temperatures, Test 5.

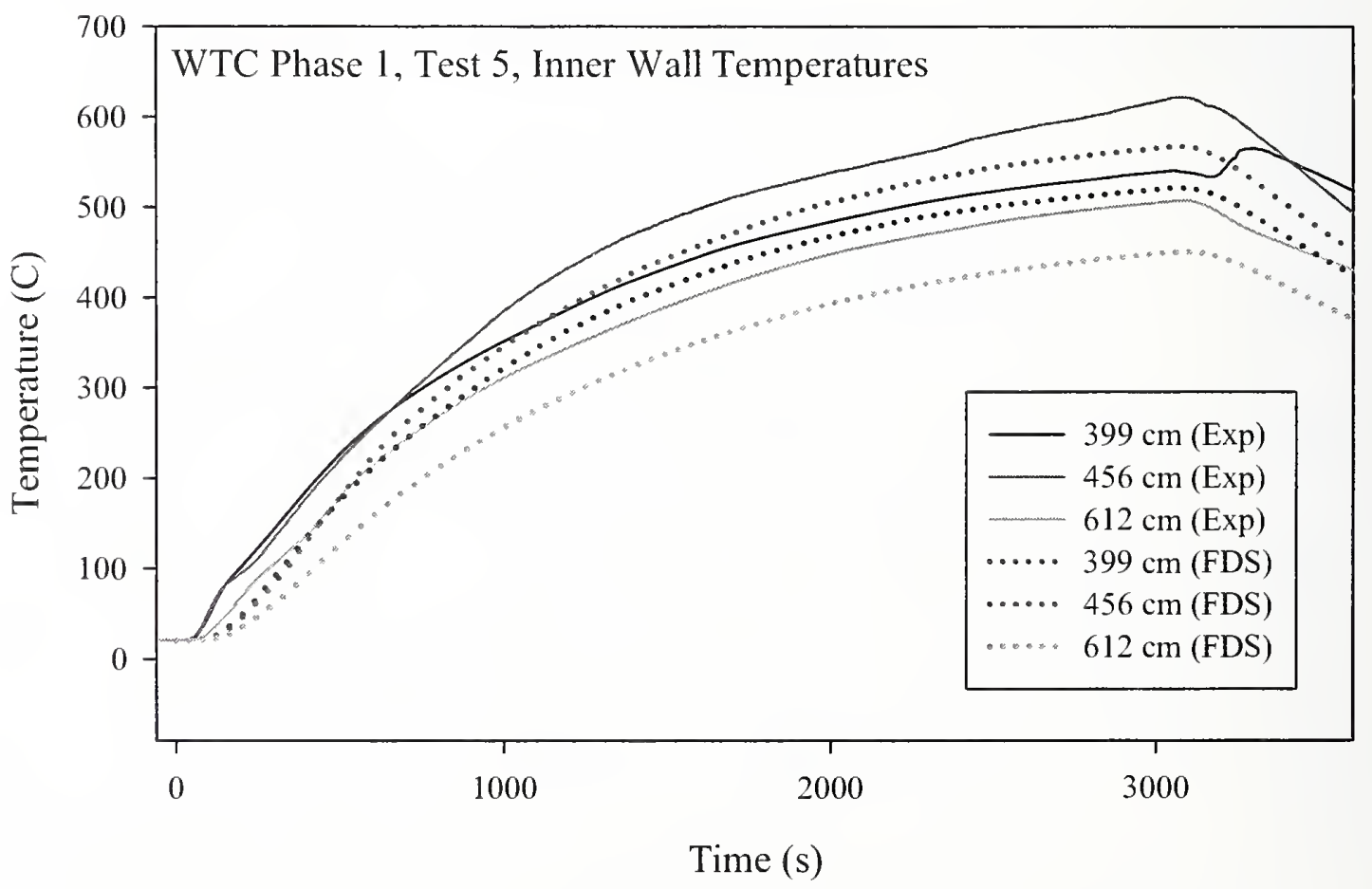

Figure 10-37. Comparison of inner ceiling temperatures, Test 5. 


\subsubsection{Gas Species Concentrations}

FDS uses a mixture fraction combustion model, meaning that all gas species within the compartment were assumed to be functions of a single scalar variable. FDS solves only one transport equation for this variable, and reports gas concentrations at any given point at any given time by extracting its value from a pre-computed table. For the major species, like carbon dioxide and oxygen, the calculation indicated how well FDS predicts the bulk transport of combustion products throughout the space. For minor species, like carbon monoxide, FDS at the present time, does not account for changes in combustion efficiency, relying only on a fixed yield of $\mathrm{CO}$ from the combustion product. In reality, the generation rate of $\mathrm{CO}$ changes depending on the ventilation conditions in the compartment. Figures 10-38 through 10-47 present comparisons of species concentration predictions with measurements. As part of the measurement procedure, water vapor was removed from the gas samples (see Chapter 6). For comparison with the measurements, a correction was made to the simulated gas concentrations to present them on a dry basis.

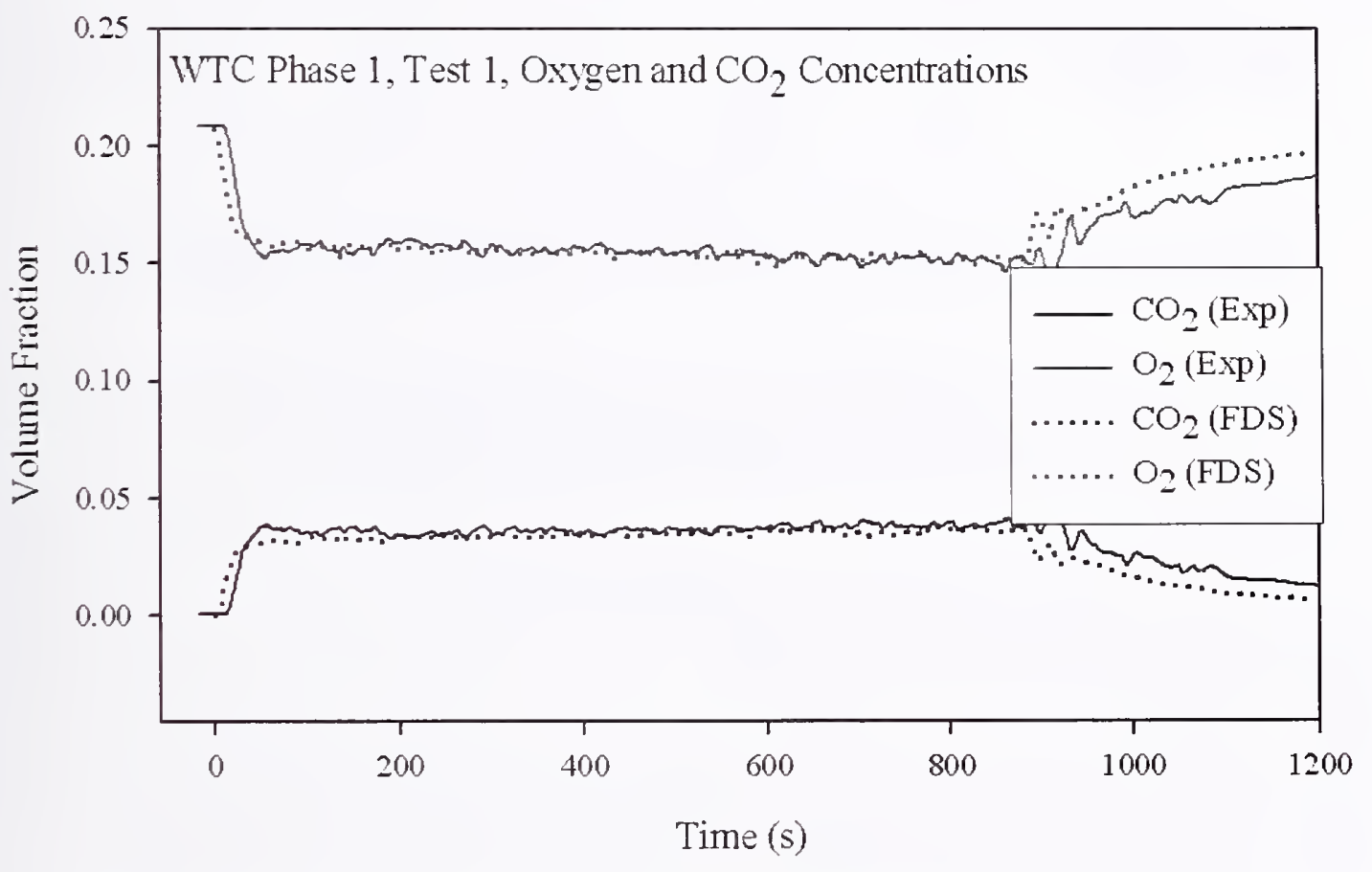

Figure 10-38. Comparison of gas concentrations on a dry basis, Test 1. 


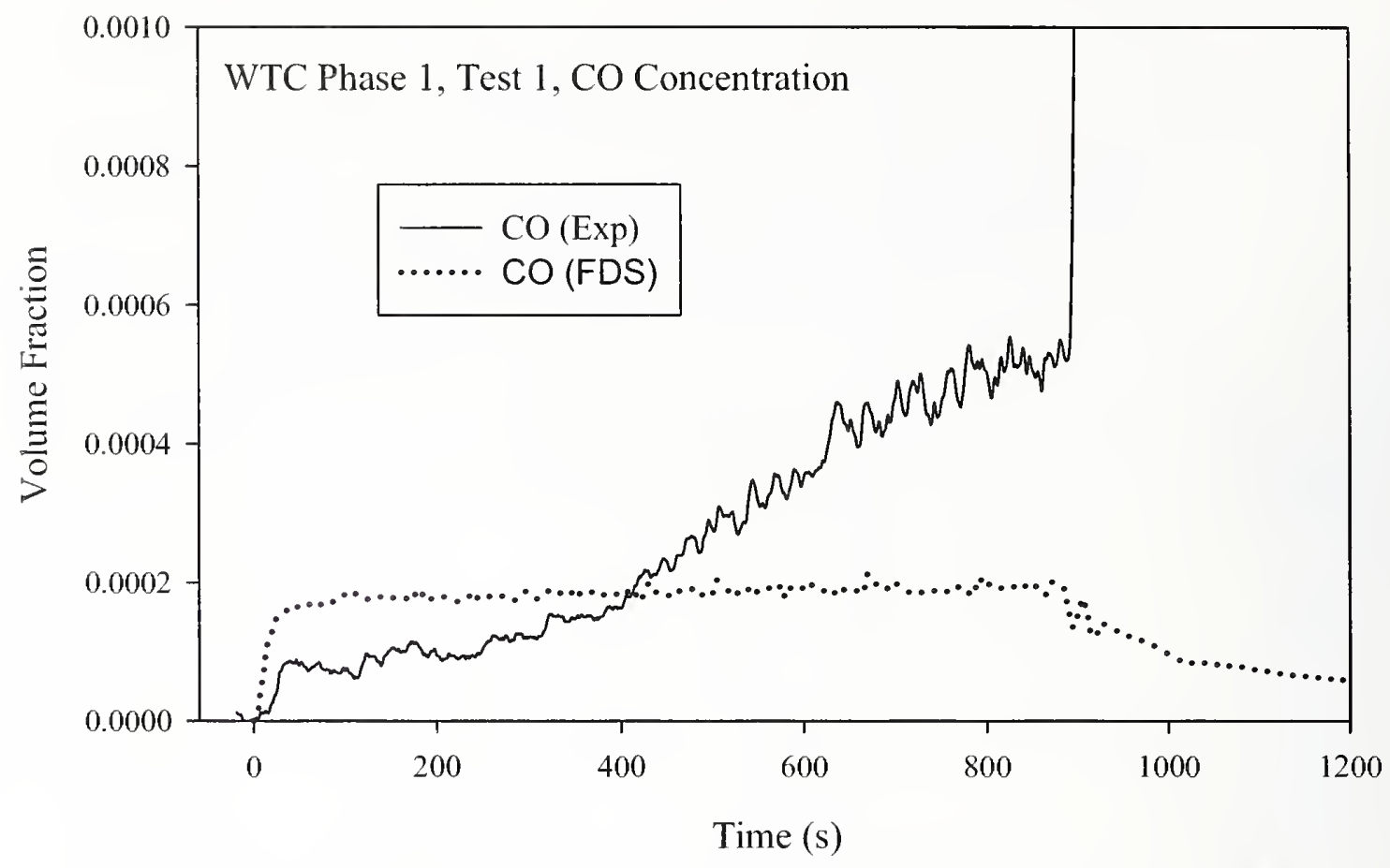

Figure 10-39. Comparison of gas concentrations on a dry basis, Test 1.

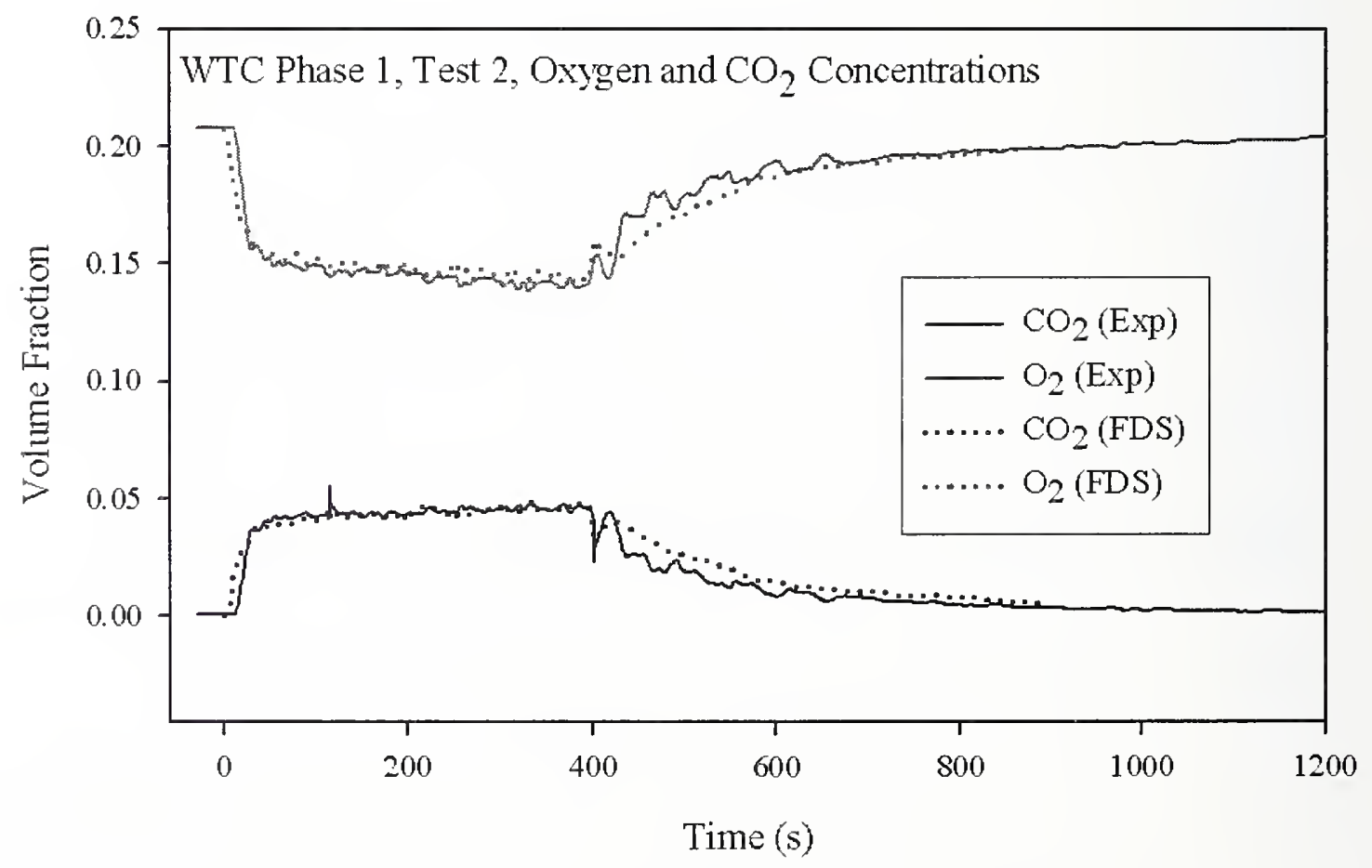

Figure 10-40. Comparison of gas concentrations on a dry basis, Test 2. 


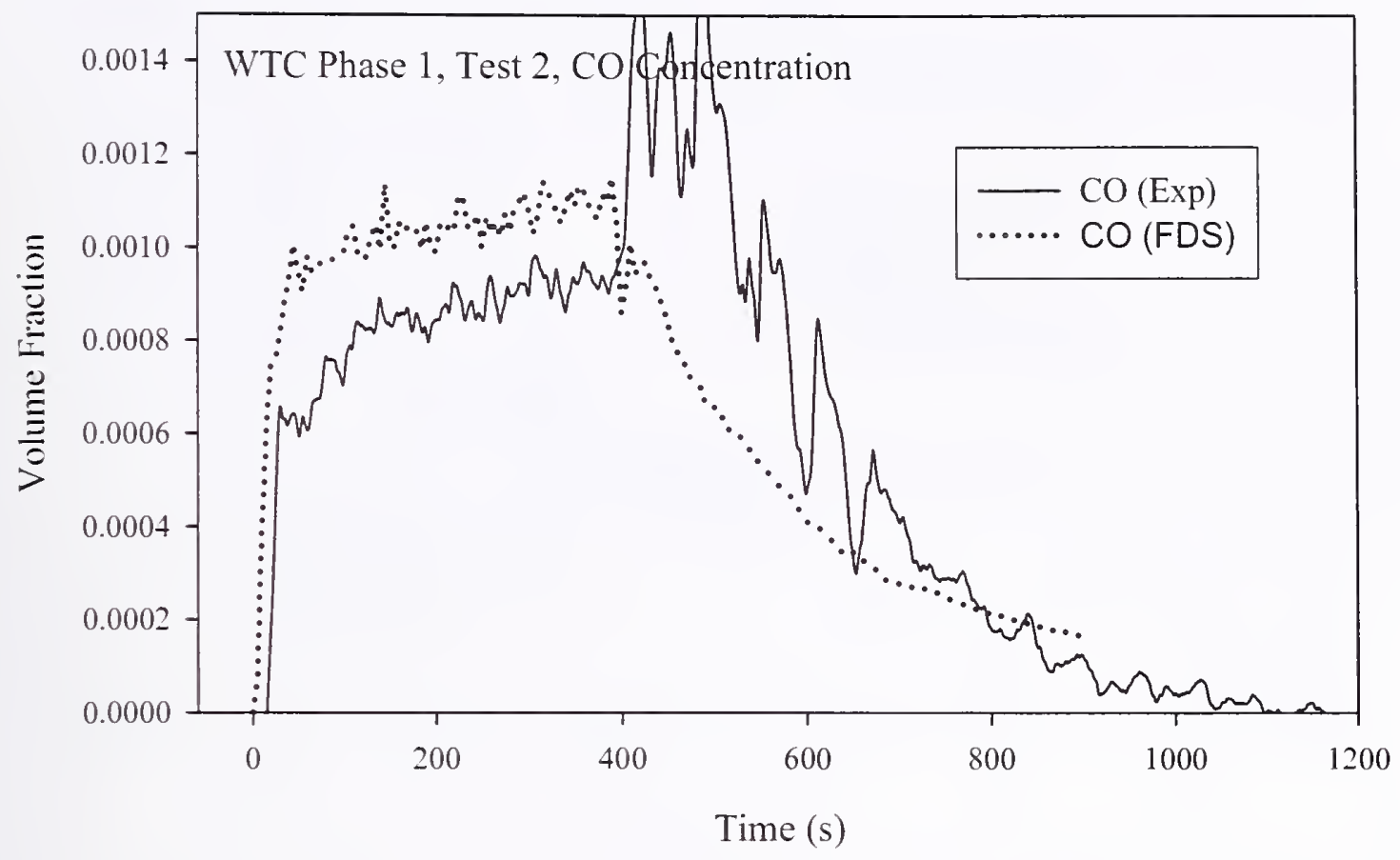

Figure 10-41. Comparison of gas concentrations on a dry basis, Test 2.

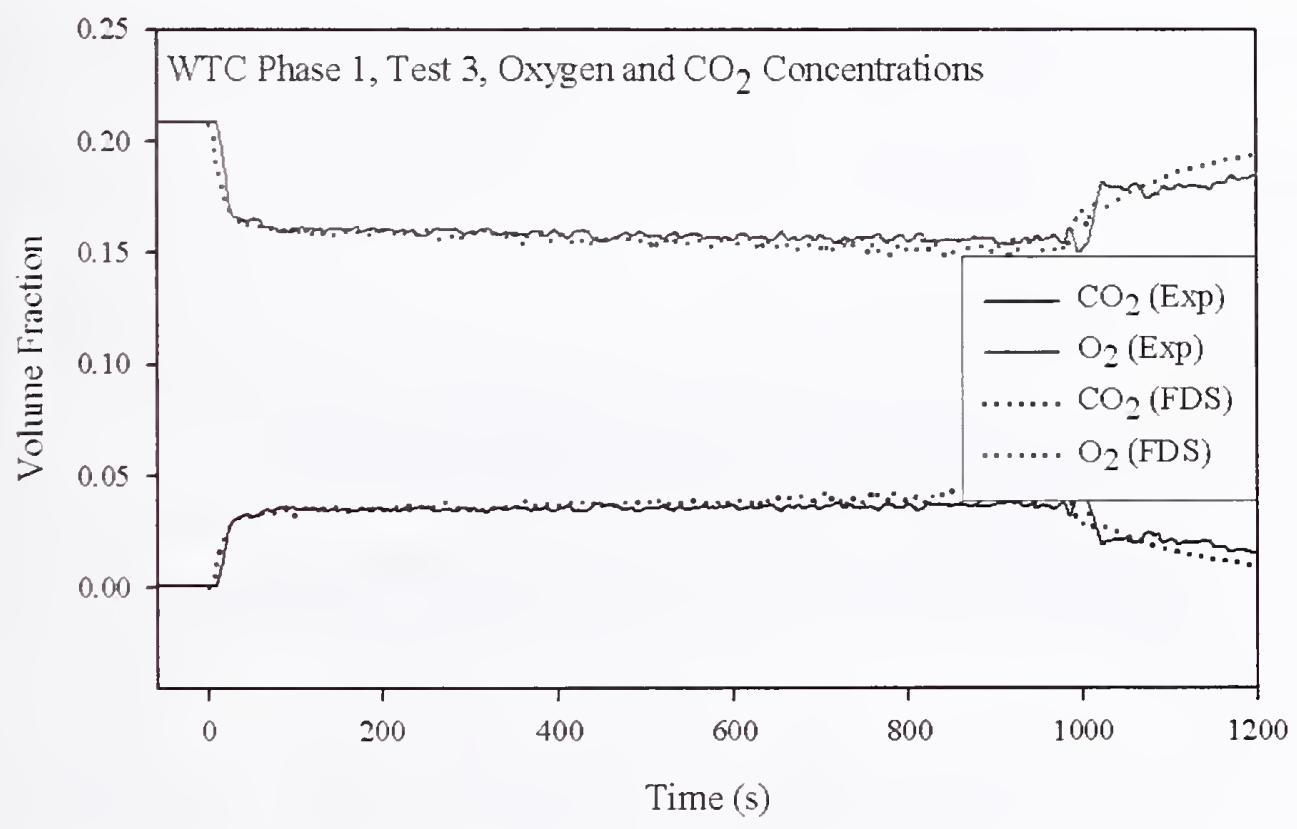

Figure 10-42. Comparison of gas concentrations on a dry basis, Test 3 . 


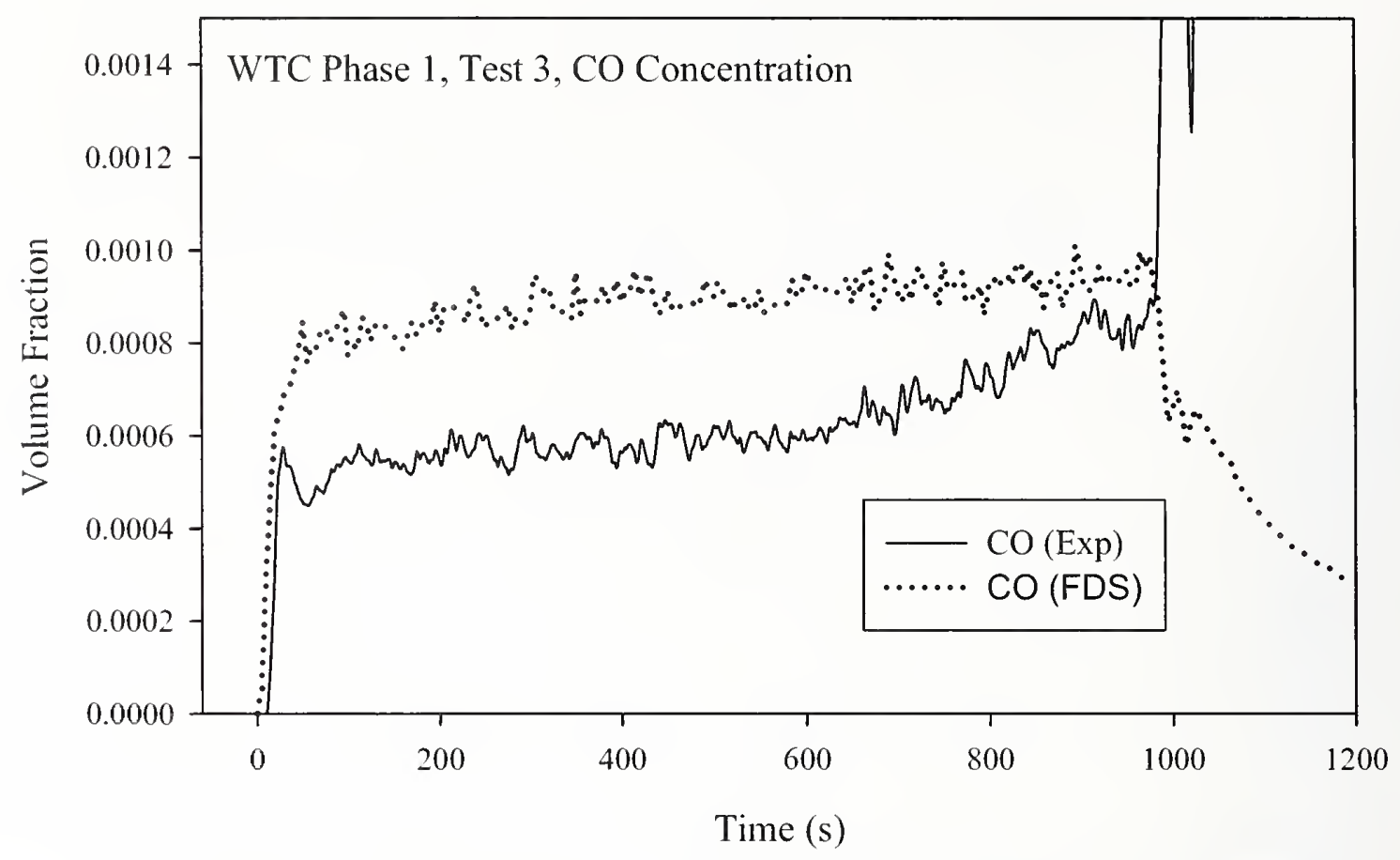

Figure 10-43. Comparison of gas concentrations on a dry basis, Test 3.

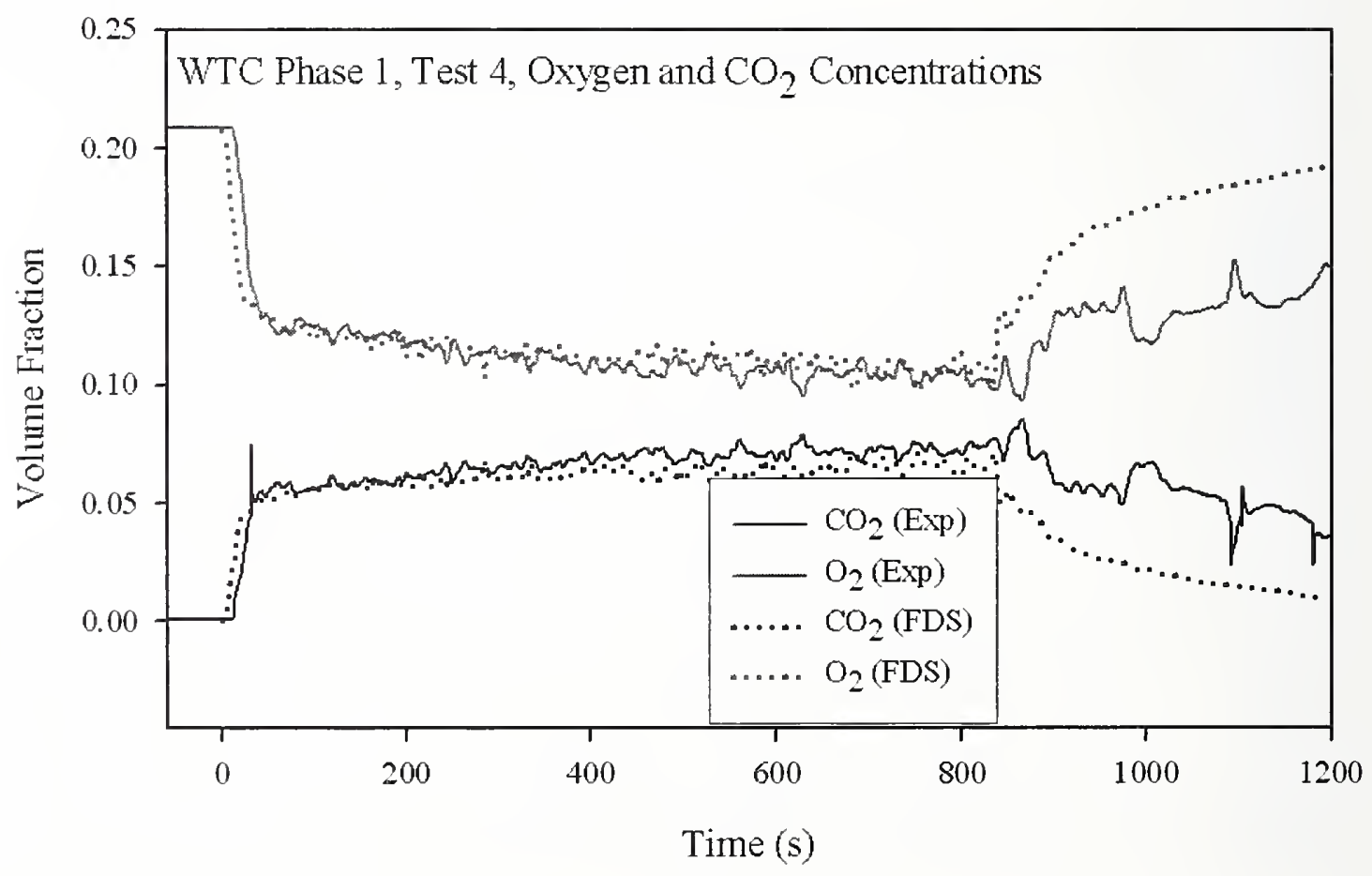

Figure 10-44. Comparison of gas concentrations on a dry basis, Test 4. 


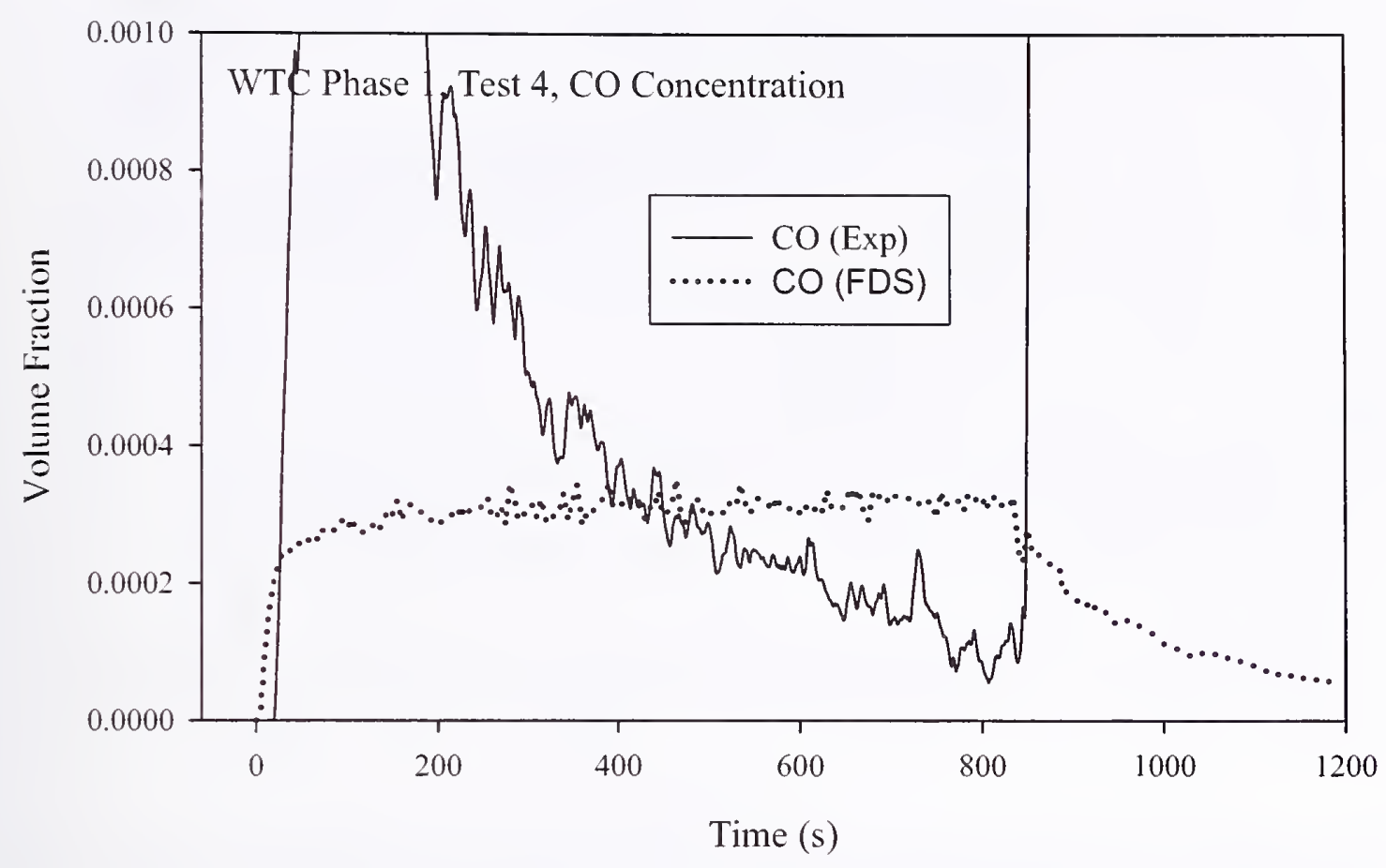

Figure 10-45. Comparison of gas concentrations on a dry basis, Test 4.

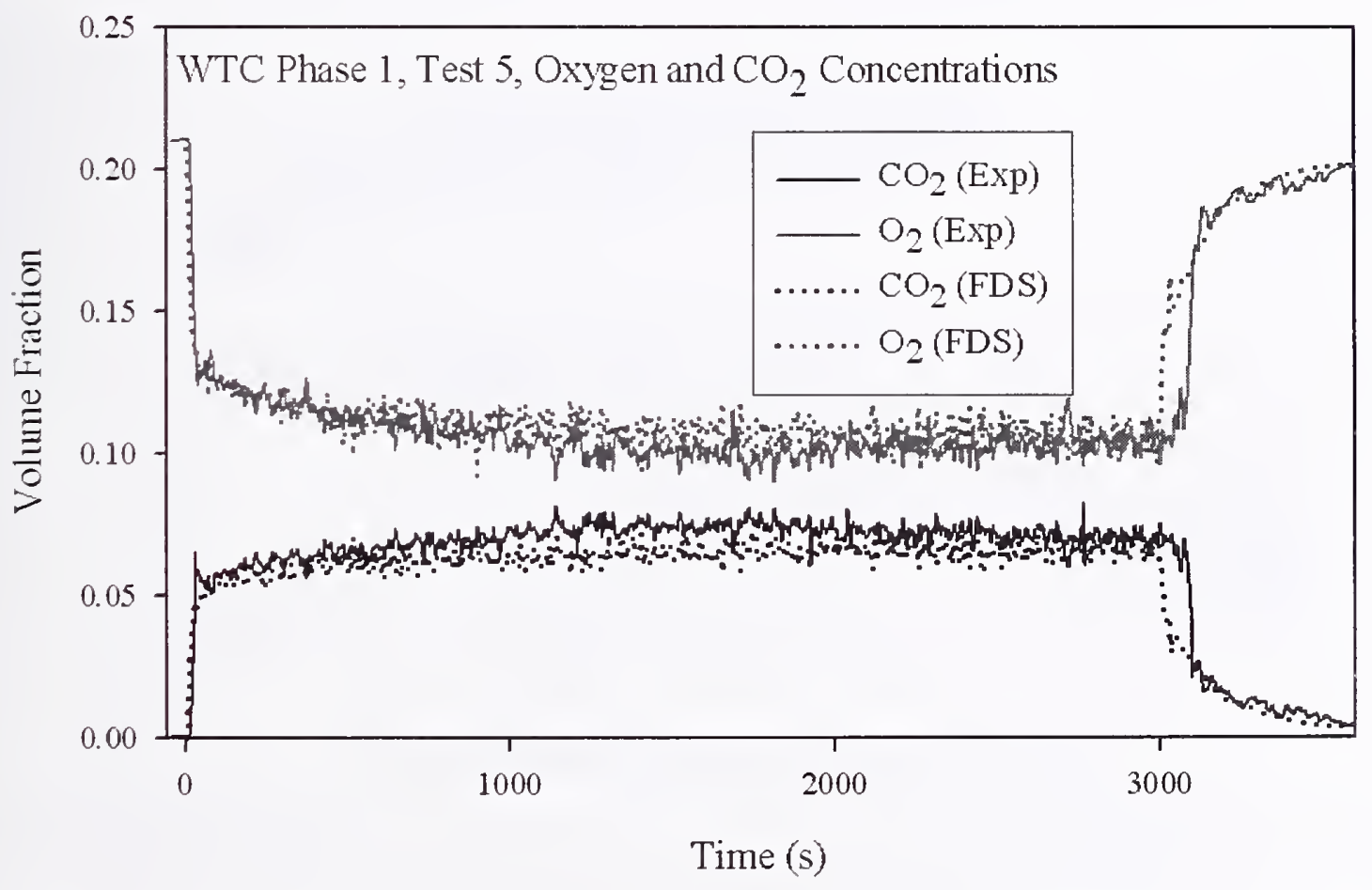

Figure 10-46. Comparison of gas concentrations on a dry basis, Test 5 . 


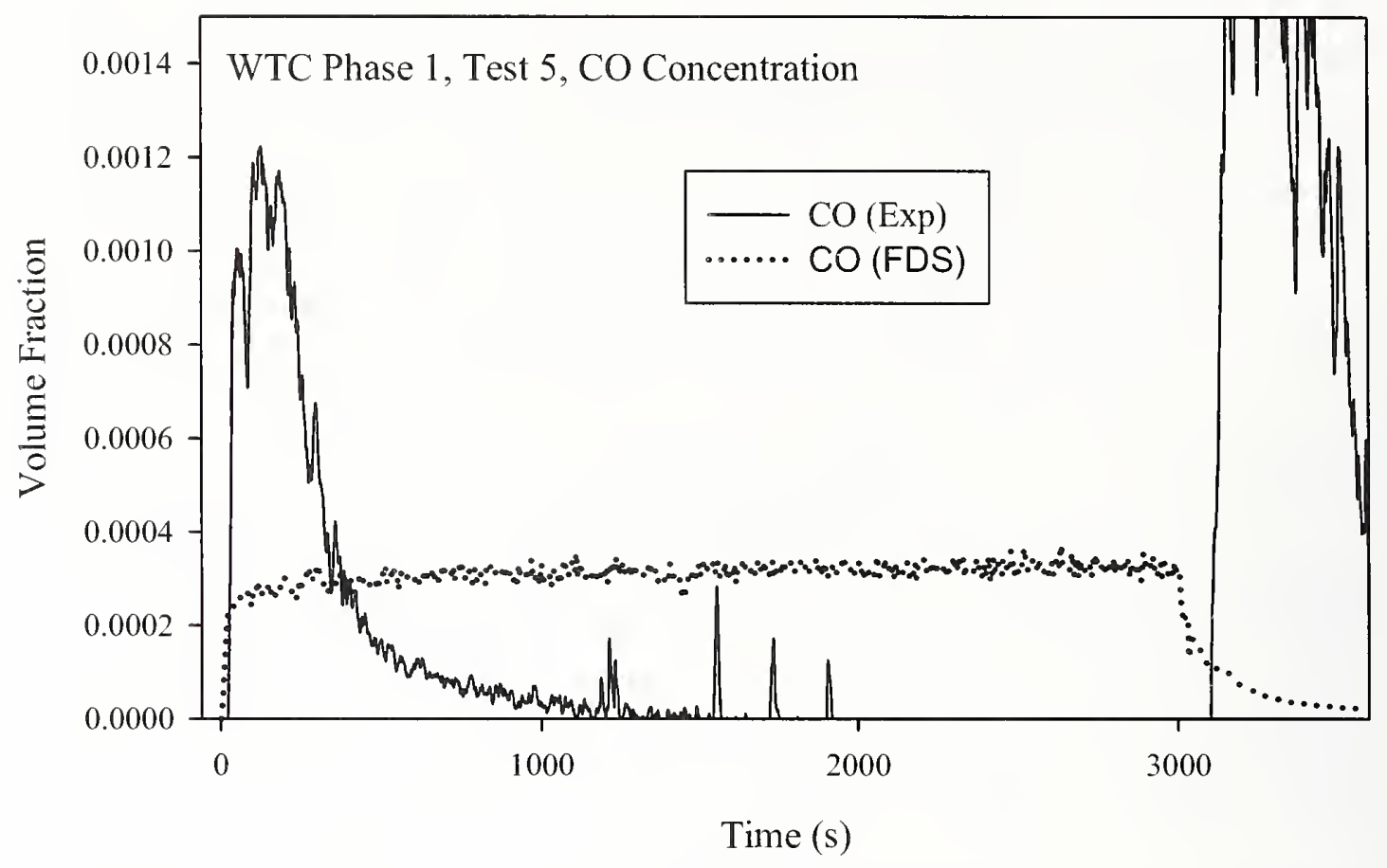

Figure 10-47. Comparison of gas concentrations on a dry basis, Test 5.

\subsubsection{Inlet and Outlet Velocities}

Velocity probes were placed in both the inlet and outlet vents. Comparisons of experimental measurement and model prediction for Test 1 are shown in Figs. 10-48 through 10-50. Station 1 was located $10 \mathrm{~cm}$ below the top of the vent just south of the compartment centerline. Station 2 was slightly above the midpoint of the vent. Station 3 was $15 \mathrm{~cm}$ above the base of the vent.

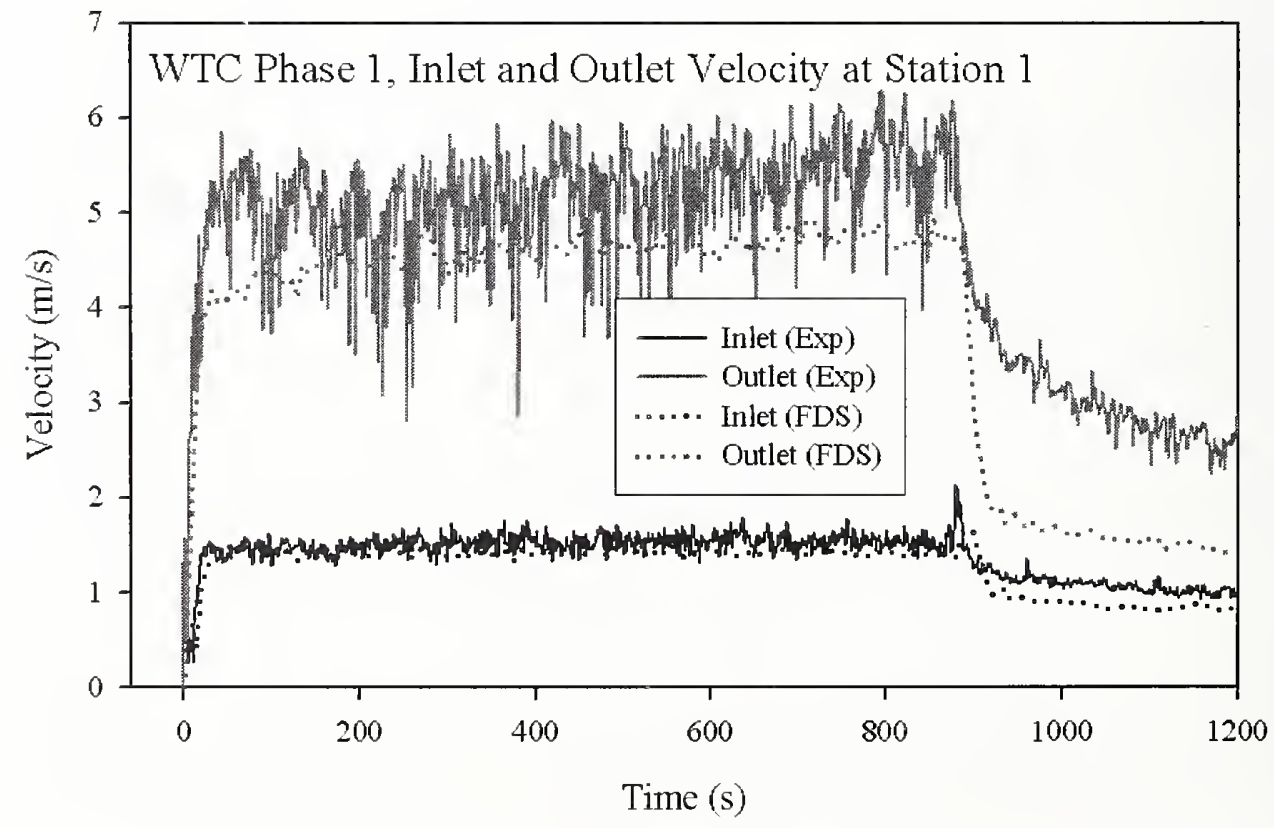

Figure 10-48. Comparison of velocity near top of vents, inlet and outlet in Test 1. 


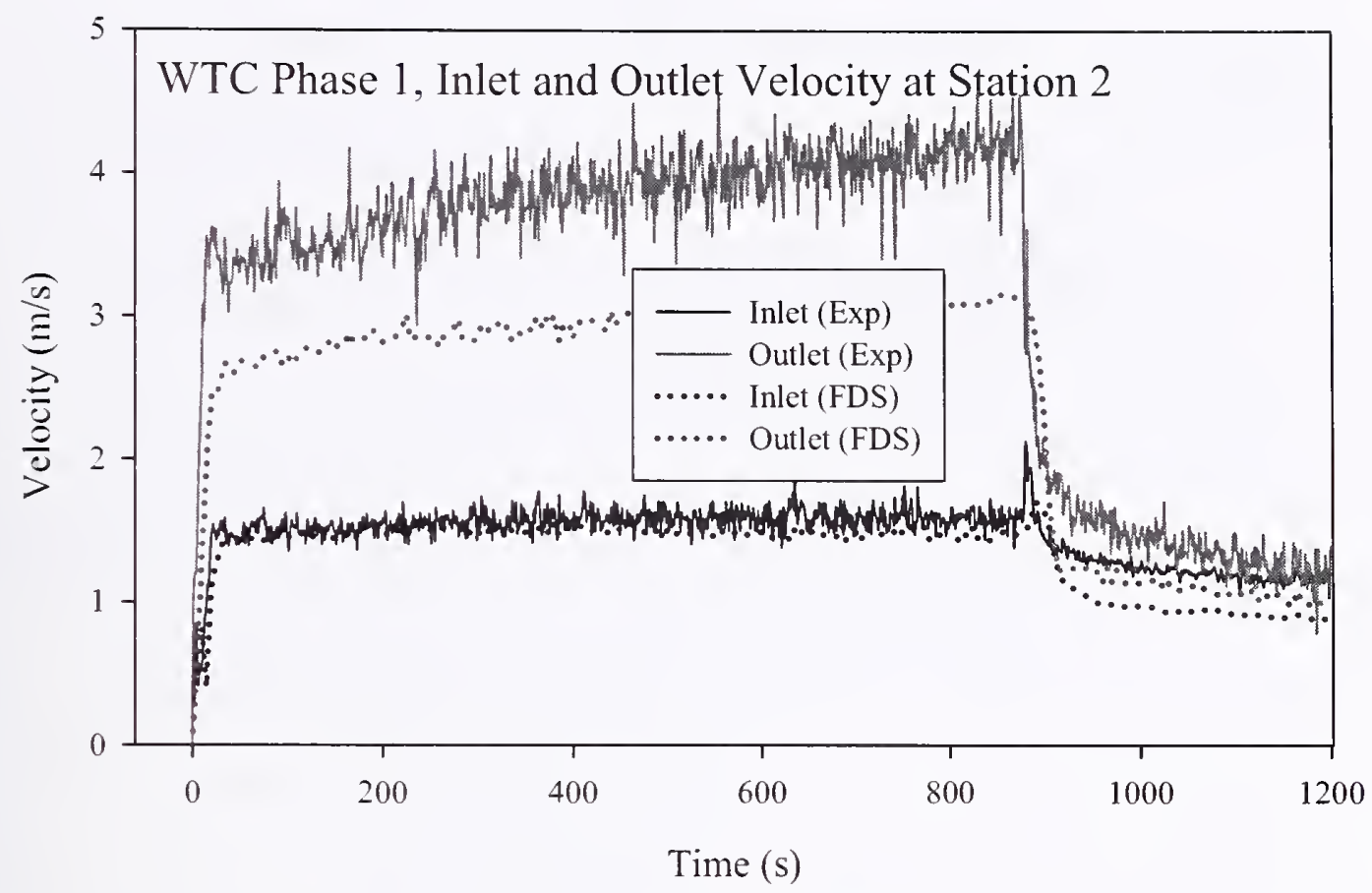

Figure 10-49. Comparison of velocity near center of vents, inlet and outlet in Test 1.

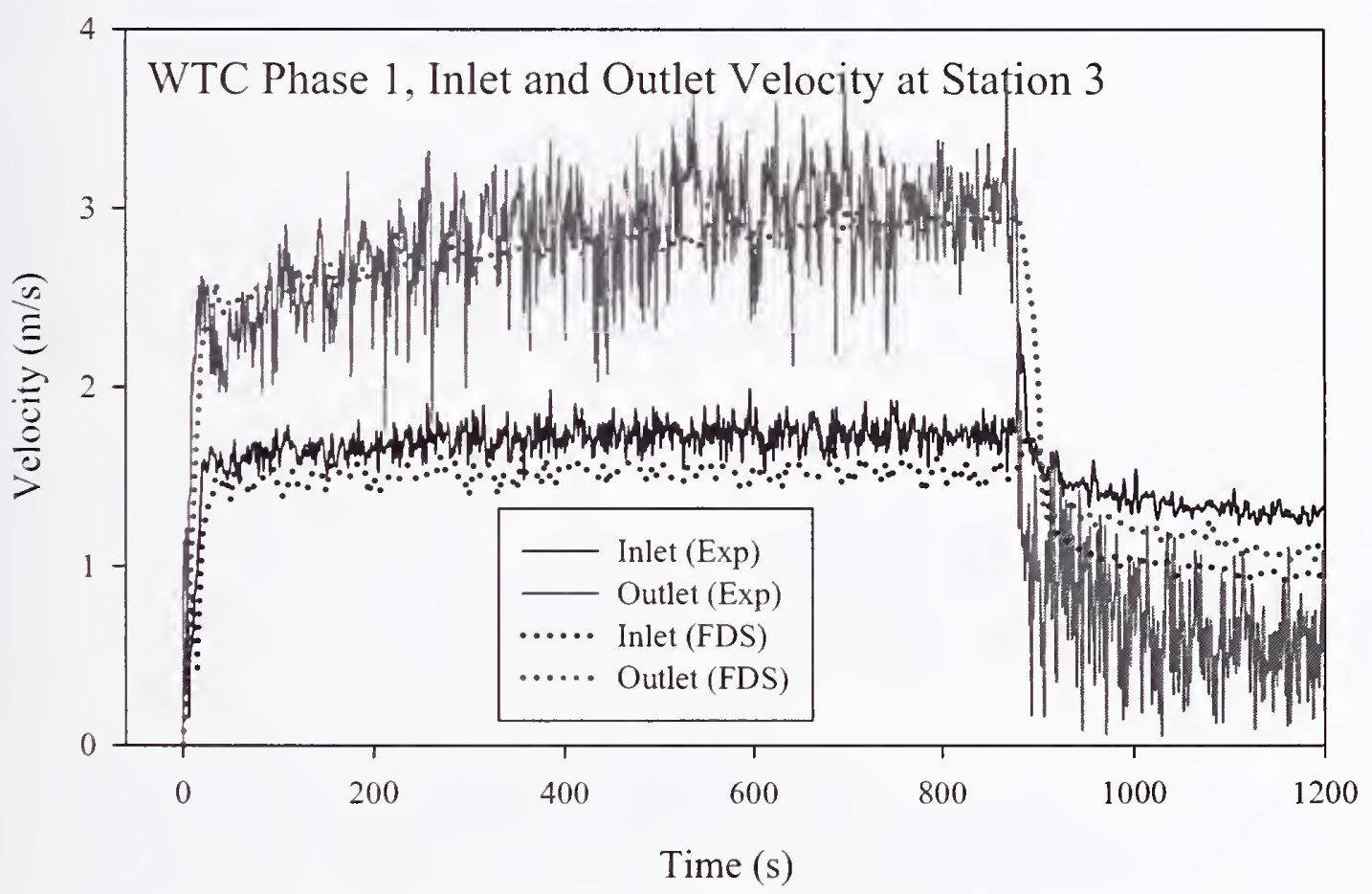

Figure 10-50. Comparison of velocity near bottom of vents, inlet and outlet in Test 1. 


\subsection{SENSITIVITY ANALYSIS AND COMPARISON TO MEASUREMENTS}

Overall, the agreement between the numerical predictions and the measurements was within experimental uncertainty. This was due to the fact that FDS predicted the upper layer temperature in most cases to within a few percent of the experiment. From the measurements of the gas temperature and the heat fluxes in the upper layer, it appeared that the emissivity was nearly 1 as steady state burning occurred. For example, this was seen to occur after approximately 1,500 $\mathrm{s}$ in Test 5 as seen in Fig. 8-5 (Sec. 8.2). At earlier times, the emissivity was less than 1 , but was monotonically increasing. The heat flux to the walls and objects within the upper layer was dependent on the upper layer temperature according to $\mathrm{q}=\varepsilon \sigma \mathrm{T}^{4}$, where $\mathrm{T}$ is the temperature, $\sigma$ is the Stefan-Boltzmann constant and $\varepsilon$ is the emissivity of the gas. This was a useful result because it tied the upper layer temperature to the heat flux to structural components in the upper layer. Of course, all the measurement locations needed to be examined to determine where it could be assumed that the emissivity was effectively unity. To better quantify the accuracy of the predictions, the sensitivity of the model output to the heat release rate was considered. The next sections consider the effect of the heat release rate on the FDS calculated gas temperature, heat flux to solid objects, compartment surface temperature, gas species concentrations, and inlet and outlet velocities.

\subsubsection{Sensitivity of Gas Temperatures to Heat Release Rate}

Accurate prediction of the upper layer of the compartment temperature depends on an accurate prescription of the heat release rate $(\dot{Q})$ of the fire. According to an empirical correlation by McCaffrey, Quintiere, and Harkleroad (Walton and Thomas 2003), the rise in the upper layer gas temperature $\Delta T_{g}$ in a compartment is related to the overall $Q$ by the relation:

$$
\Delta T_{g}=6.85\left(\frac{\dot{Q}^{2}}{A_{0} \sqrt{H_{0}} h_{k} A_{T}}\right)^{1 / 3}
$$

where:

$$
\begin{aligned}
& A_{0}=\text { area of openings }\left(\mathrm{m}^{2}\right) \\
& H_{0}=\text { height of openings }(\mathrm{m}) \\
& A_{T}=\text { total area of compartment surfaces }\left(\mathrm{m}^{2}\right) \\
& h_{k}=k / \delta \\
& k=\text { thermal conductivity of walls }(\mathrm{kW} / \mathrm{m} / \mathrm{K}) \\
& \delta=\text { wall thickness }(\mathrm{m})
\end{aligned}
$$

Equation 10-1 shows that the temperature rise is proportional to $\dot{Q}$ to the $2 / 3$ power. The reported expanded uncertainty in the heat release rate measurement was 11 percent (see Chapter 3 ). From Eq. 10-1, an 11 percent uncertainty in $\dot{Q}$ corresponds to a 7 percent uncertainty in the temperature rise $(=2 / 3 \times 11$ percent $)$. For upper layer temperatures of approximately $600{ }^{\circ} \mathrm{C}$, this translates to roughly $\pm 40^{\circ} \mathrm{C}$. The difference in upper layer temperatures (Figs. $10-3$ through $10-12$ ) ranged from $5^{\circ} \mathrm{C}$ to 
$20^{\circ} \mathrm{C}$. consistent with the sensitivity of the model to uncertainty in $\dot{Q}$. Even though there were uncertainties in the aspirated thermocouple measurement of the temperature of approximately $7{ }^{\circ} \mathrm{C}$, the discrepancy between measurement and prediction can be explained solely in terms of model uncertainty due to uncertainty in the $\dot{Q}$ measurement.

The McCaffrey, Quintiere, and Harkleroad correlation is based on fire test data with temperatures not exceeding $600^{\circ} \mathrm{C}$. In some of the experiments conducted here, however, the upper layer temperature was as high as $750^{\circ} \mathrm{C}$. For that reason, a simulation of Test 5 was re-run using a 5 percent increase in $\dot{Q}$. The results showed a 4.5 percent increase in the upper layer temperature, which wass higher than predicted by the correlation. Although larger than the hypothetical increase, this difference was not surprising given the simplifications made to derive Eq. 10-1 and the fact that it was not substantiated for higher temperatures. The sensitivity calculation confirms the idea that the upper layer temperature is nearly proportional to $\dot{Q}$, consistent with a widely accepted principle of fire protection engineering.

\subsubsection{Sensitivity of Heat Flux to Solid Objects to Heat Release Rate}

A comparison of simulations with measurements showed that the heat flux onto surfaces in the upper layer was very nearly given by $\sigma T^{4}$ where the value of $\sigma$ is $5.67 \times 10^{-11} \mathrm{~kW} / \mathrm{m}^{2}-\mathrm{K}^{4}$ and $T$ is the temperature in degrees $\mathrm{K}$. In other words, the emissivity of the upper layer gases was nearly 1 , not surprising given the high level of soot. Given a standard relative uncertainty in the upper layer temperature rise of 4.5 percent (see previous section), the standard uncertainty in absolute temperature at $600{ }^{\circ} \mathrm{C}$ was 3.1 percent, leading to an estimate for the standard relative uncertainty in heat flux of $4 \times 3.1$ percent $\cong 12$ percent.

Figures 10-13 through 10-22 compare the measured and predicted heat flux to the upper and lower faces of the vertical column. The relative standard (expansion factor of 1 ) uncertainty of the measurement was approximately 5.4 percent (see Table 5-1). The combined relative model and measurement uncertainty could then be estimated as 13 percent $\left(\approx \sqrt{ }\left[5.4^{2}+12^{2}\right]\right)$. In most instances, the difference between measurement and prediction was within 10 percent, confirming that the model was within experimental uncertainty.

Figures 10-23 through 10-27 compare the heat flux measurements and predictions at targets on the floor of the compartment. Because the targets were not within the upper layer, the simple $\sigma T^{4}$ estimate of the heat flux no longer applies and the assessment of experimental uncertainty was more difficult because it could not be traced back to the uncertainty in the $\dot{Q}$. Nevertheless, in most cases, the difference between measurement and prediction was within 10 percent. The measurement uncertainty was approximately 10 percent as discussed in Chapter 5. In cases where the difference was larger, as in Tests 4 and 5, it was possible that the model did not capture the near-field influence of the fire itself. One of the floor targets was near the fire pan, and subtle differences between the real and simulated fire could have made a substantial impact on the heat flux to a nearby target. Warping of the fire pan may also have played a role.

\subsubsection{Sensitivity of Compartment Surface Temperature to Heat Release Rate}

The accuracy of the ceiling surface temperatures was a function of the distance away from the plume impingement point. Predictions of surface temperatures at points outside of a circle of roughly $1 \mathrm{~m}$ radius 
agreed with measurements to about 5 percent. Predictions within the plume impingement zone had worse agreement with experiment and were accurate to about 20 percent. This is not surprising since the point of plume impingement changed throughout the test. Although the experiments were designed to be symmetric along the centerline of the compartment, the inclusion of the column and instrumentation tunnels on one side of the compartment apparently caused the flow in the compartment to be asymmetric, and the fire was observed to lean towards the trusses, which were positioned south of the centerline (foreground of Fig. 10-1). The simulation captured the asymmetry as well, but it did not appear to be as pronounced as in the experiment. As a result, the ceiling surface temperature predictions above the fire were noticeably higher than the experiment. Comparison of the temperatures measured between the two sheets of Marinite showed that the temperature-temperature history occurred at a similar rate, although the shape of the curves was somewhat different. This was attributed to uncertainty in thermophysical material properties and inaccuracy of the ceiling temperature simulations.

\subsubsection{Sensitivity of Gas Species Concentration to Heat Release Rate}

The comparison of oxygen and carbon dioxide prediction and measurement on a dry basis at one sampling point (Figs. 10-38 through 10-47) indicated that FDS was handled the bulk transport of gases well. In the first three tests, the $\mathrm{CO}_{2}$ prediction is indistinguishable from the experiment, and the oxygen prediction differed from the measurements by about 5 percent. The expanded measurement uncertainty was approximately 2 percent for $\mathrm{CO}_{2}$ and 5 percent for $\mathrm{O}_{2}$ as discussed in Chapter 6 . In the simulation, both oxygen and $\mathrm{CO}_{2}$ were tied to the mixture fraction, a single scalar for which FDS solves a transport equation. The prediction of $\mathrm{CO}$ is not expected to agree with the experiment since it is assumed in the model that its yield is constant. In reality, the yield of $\mathrm{CO}$ will change, usually increasing as the room fills with combustion products.

\subsubsection{Sensitivity of Inlet and Outlet Velocities to Heat Release Rate}

The comparison of inlet and outlet velocities revealed that the model predicted well the mass flow of air into the compartment, but it could not predict the details of the outlet velocity profile due to a lack of resolution. The model used $10 \mathrm{~cm}$ grid cells, which meant that seven cells in the vertical direction spanned the outlet vent. Whereas the calculated inlet velocity was fairly uniform over the height of the vent, the outlet velocity varied by at least $3 \mathrm{~m} / \mathrm{s}$ from top to bottom. Plus, the position of the probes relative to the depth of the opening mattered since the probes were designed to measure the velocity within a certain range of angular displacement.

\subsubsection{Model Sensitivity to Parameters other than Heat Release Rate}

In the discussion above, it was shown that the FDS predictions of upper layer temperatures and heat fluxes agreed with the experiment if model sensitivity and measurement uncertainty were considered. It was assumed that the sensitivity of the simulation was based solely on the uncertainty of the heat release rate measurement. Thus, it was shown how sensitive the upper layer temperature and heat flux measurements were to the heat release rate. In the numerical simulations there are dozens of input parameters prescribed by the model user. Often there is no way to assess the sensitivity of these parameters except by numerical experiment; that is, running the model with small changes to the base parameters to see what effect these have on the predictions. 
There are two types of input parameters: numerical and physical. Physical parameters describe the wall materials, fuel properties, reaction stoichiometry, etc. Numcrical parameters describe how the calculation is to be performed. The most important numerical parameters were the number of grid cells in each coordinate direction. CFD models solve an approximate form of the conservation equations of mass, momentum and energy. The error associated with the discretization of partial derivatives on a discrete grid is a function of the size of the grid cells and the type of differencing used. FDS uses second-order accurate approximations of both the temporal and spatial derivatives of the Navier-Stokes equations, meaning that the discretization error is proportional to the square of the cell size. In other words reducing the grid cell size by a factor of 2 reduces the discretization error by a factor of four. However, it also increases the computing time by a factor of 16 (a factor of two for the temporal and each spatial dimension). Clearly, there is a point of diminishing returns as one refines the numerical mesh. Determining what size grid cell to use in any given calculation is known as a grid sensitivity study.

\section{Sensitivity to Grid Size}

The simulations of these experiments were performed on a grid whose cells were $10 \mathrm{~cm}$ cubes. However, the simulations of the fires in the World Trade Center were performed with grid cells of dimension $0.5 \mathrm{~m}$ by $0.5 \mathrm{~m}$ by $0.4 \mathrm{~m}$ high. The selection of the mesh size may impact the calculation results for the configuration studied in this report. An obvious problem is that many of the obstructions in the test compartment cannot be described well on a $0.5 \mathrm{~m}$ grid. especially the small vents on either side of the space. A remedy for the problem is to maintain in the coarse calculations as many geometrical features as possible. For example, the exit vents in the coarse calculation have approximately the same total area and soffit height as in the refined calculations. The trusses, bars and column were removed from the coarse calculation, but the barrier in front of the fire remains. Figures 10-51 and 10-52 present a comparison of the predicted temperatures from the coarse calculation of Test 5 with the experimental measurements. The results are very encouraging, although it should be emphasized that as a rule coarsening a numerical grid to the extent done here will not yield such good results. ${ }^{1}$ The reason for the good agrecment is that in the experiment, a very stable, uniform layer of hot gases was established in the upper layer of the compartment over the course of an hour. Given a fixed $\dot{Q}$, and a comparable convective flux of energy through the vents, energy conservation dictates that the compartment temperaturcs also ought to be comparable between calculation and experiment. Even two-zone lumped parametcr models that are often used in fire protection engineering would yield a good prediction in this case due to the uniformity of the upper and lower layers within the compartment. In a stably stratified compartment with fairly uniform upper and lower layer, both a CFD model and zone model will make similar predictions of temperature because both assume conservation of mass and energy. The behavior of the flow ficld as predicted by the momentum conservation equation is not as important in this case, so long as the cnthalpy flow through the compartment vents is captured by both the fine and coarse meshes. However, the prediction of the temperature and heat flux to various objects in the compartment near the fire plume were subject to more uncertainty than suggested by the results shown in Figs. 10-51 and 10-52 because the flow dynamics have been simplified by the coarse mesh. This is less of a concern for the simulations done in conjunction with the WTC investigation because the heat flux to the structural components is being computed using the upper layer temperature field. Indeed, the FDS simulations of the WTC fires do not include the floor trusses because these objects cannot be resolved on the coarse grid.

\footnotetext{
${ }^{1}$ Simulation of the hour-long experiment on the coarse grid required $30 \mathrm{~min}$ on a Pentium 4, $240 \mathrm{MHz}$ personal computer.
} 


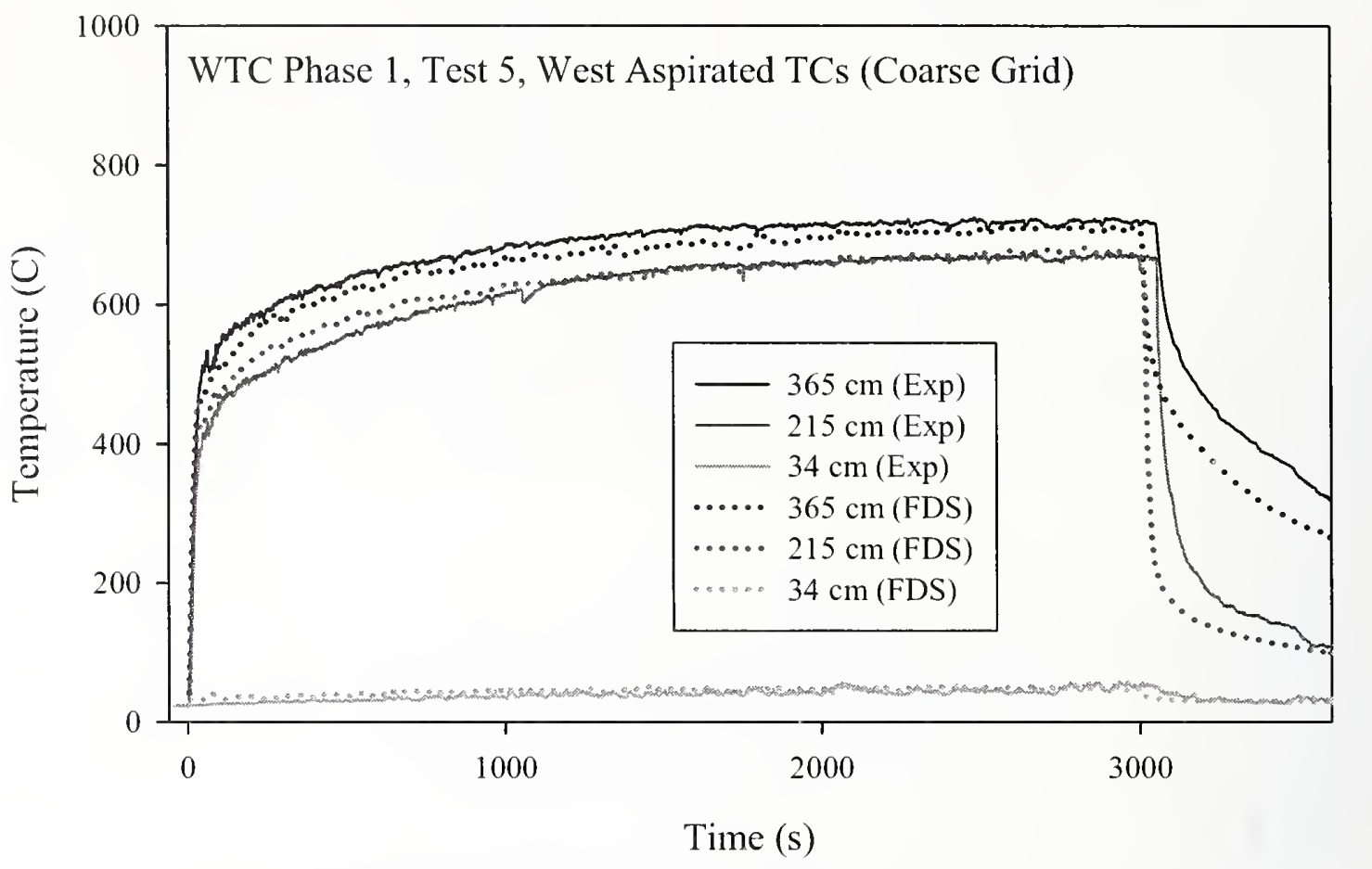

Figure 10-51. Coarse grid prediction of gas temperatures on the intake side of the compartment for Test 5.

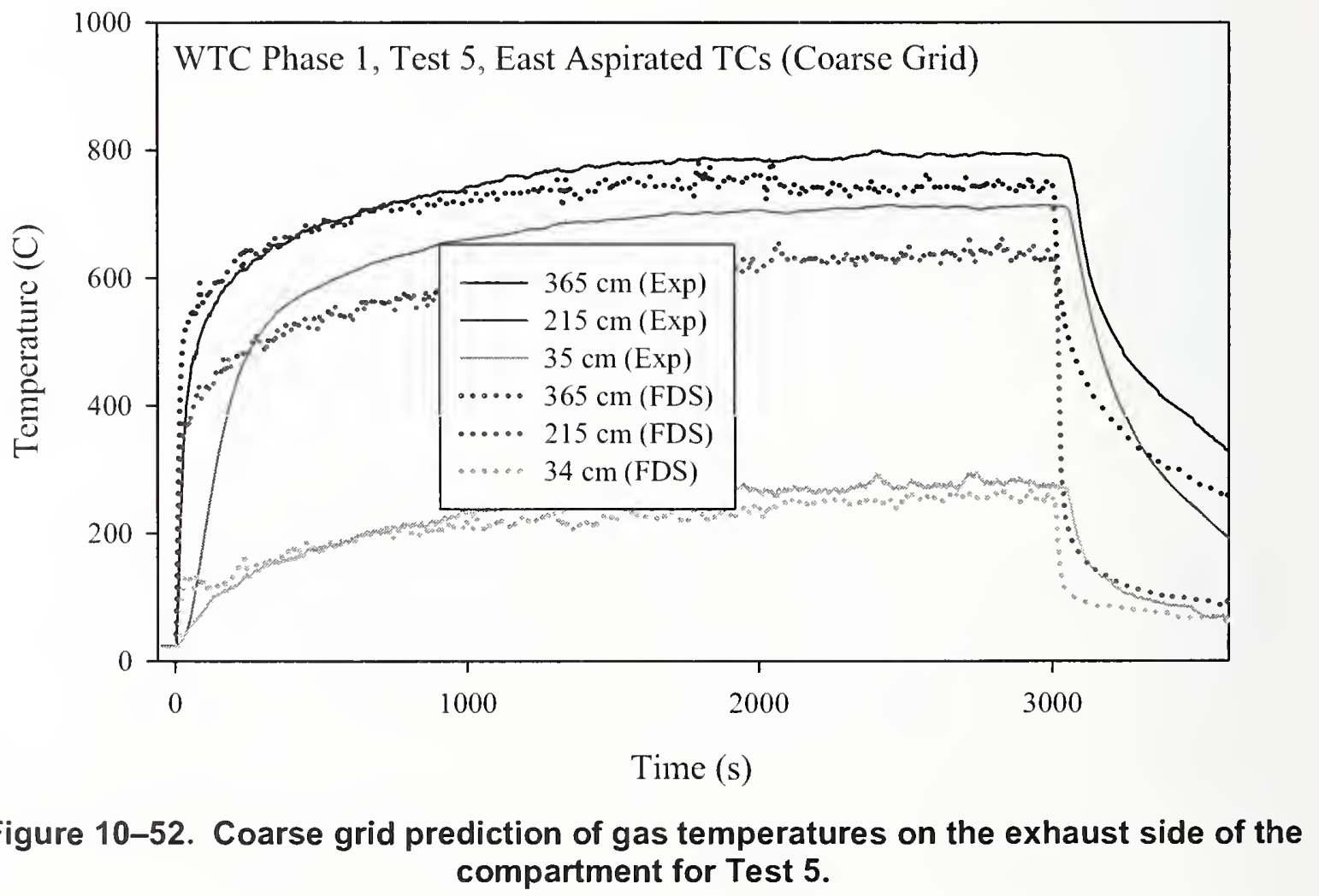


Beyond the numerical grid, there are numerous physical parameters that the user must prescribe to simulate the experiments. First, there are the physical dimensions of the compartment plus the objects within. Because one of the objectives of the experiments was model validation, the geometry was very simple. With a $10 \mathrm{~cm}$ numerical grid, the compartment was modeled to an accuracy of $\pm 5 \mathrm{~cm}$, and there were no detectable differences in results based on small adjustments made to objects to fit the nearest grid cell. With the $50 \mathrm{~cm}$ grid, however, there were significant differences in the results if proper attention was not paid to adjusting the vents to maintain the area and soffit height. A $20 \mathrm{~cm}$ shift in the height of the top of the vent lead to a change in the hot upper layer depth of the same amount, resulting in changes of upper layer temperature on the order of $100^{\circ} \mathrm{C}$. Based on these findings, the cell size for the WTC simulations was selected to maintain the window area and height. The external columns of WTC 1 and WTC 2 were spaced by the designers $1.016 \mathrm{~m} \mathrm{(40} \mathrm{in.)} \mathrm{apart.} \mathrm{The} \mathrm{horizontal} \mathrm{dimensions} \mathrm{of} \mathrm{the} \mathrm{grid} \mathrm{cells}$ used were $50 \mathrm{~cm}$, yielding an alternating pattern of solid column, vent, column, vent, etc.

\section{Sensitivity to Radiative Fraction}

Along with the $\dot{Q}$, another parameter of importance to fire models is the radiative loss from the fire. Room-scale fires typically radiate about $1 / 3$ of their energy, while the other $2 / 3$ of the energy rises to form the thermal plume. Often the radiative loss fraction is a user input to fire models because a prediction of it requires a fairly detailed model of the combustion processes. FDS uses a partial approach to the problem. Based on the predicted fire temperature and chemical composition. it computes the source term in the radiative transport equation, thus predicting the radiative loss from the fire. However, since the temperature and chemical composition within the fire were subject to uncertainty due to the coarseness of the numerical grid, the algorithm uses a user-prescribed radiative loss fraction instead of its own prediction, if that prediction is lower than what the user thinks it ought to be. In short, the user has the power to over-ride the FDS prediction if it is warranted. To ensure that the results of the simulations were not sensitive to the user-prescribed radiative loss fraction, several simulations were performed with prescribed loss fractions between 0.3 and 0.4. There was no discernable difference in the results. Again, this is not always the case. Compartment geometry is important, particularly the ceiling height. Also, in these tests, the hot upper layer is as important a radiator as the fire. The prescribed loss fraction only pertains to the fire.

\section{Sensitivity to Thermal Properties of the Compartment Surface Material}

Other physical parameters set by the user include the thermal properties of the wall material. In this case, the walls were lined with a $2.5 \mathrm{~cm}$ ( $1 \mathrm{in}$.) layer of calcium silicate board (Marinite). The manufacturer provided the thermal properties of the material, including the thermal conductivity. To determine the sensitivity of the model to this parameter, a simulation was performed with the thermal conductivity doubled from its listed value of $0.12 \mathrm{~W} / \mathrm{m}-\mathrm{K}$ to $0.24 \mathrm{~W} / \mathrm{m}-\mathrm{K}$. Measurements by Taylor et al. (2003) show that this is an order of magnitude larger than the uncertainty in the thermal conductivity of the Marinite. The predicted upper layer temperatures of Test 5 , the hour-long $3 \mathrm{MW}$ fire, decreased only 4 percent due to the doubling of the conductivity. This suggests that these simulations were not especially sensitive to the thermal properties of the wall materials, although this is not always true. In this case, of the $3 \mathrm{MW}$ of energy generated in the compartment by the fire, more than half flowed out the vents, either as thermal radiation or hot gases. The increase in conductivity means that more energy was being conducted through the walls, but since the walls were conducting only a small amount of the total energy, the increased loss 
did not affect the overall compartment temperature appreciably. If the compartment were of different dimension, aspect ratio, or ventilation, the thermal conductivity might play more of a role.

\section{Sensitivity to Smoke Yield}

Parameters associated with the combustion process were also tested. The smoke yields of the heptane and the heptane/toluene mixture were obtaincd during free burns of the two fuels. The smoke yicld is the fraction of fuel mass that is converted into soot via the combustion process. In a ventilation-limited fire, the soot yield will usually incrcase duc to the decrease in combustion efficiency. What effect can the increased soot yield have on the tcmperature predictions? The soot yield for the heptane fires was measured to be 0.014 . Increasing this value to 0.10 produced a 1 percent increasc in the upper layer temperature prediction. The reason for this is that the upper layer is nearly optically thick, that is, the emissivity of the smoke is nearly 1. Adding more soot to the layer only blackens what is already essentially black. The radiative heat transfer within the layer and to external targets is not affected.

\subsection{COUPLING WITH THERMAL-STRUCTURAL MODELS}

The computed values of the upper layer temperature, absorption coefficient, depth of the hot layer and the lower layer temperature were computed at a representative slice at a particular height above the floor, recorded at each $(\mathrm{x}, \mathrm{y})$ grid point, and saved in an ASCII file for utilization by the NIST Fire Structure Interface (FSI) (Prasad and Baum 2005), which used this information as input in the determination of heat flux boundary conditions for finite-element models that simulated the temperature distribution in the structural stcel components (sec discussion in Chapter 11). The FSI calculated the transfer of radiant and convective heat from FDS to a coupled, transient, three-dimensional finite-element model for the thermal response of structural components. The structural components were either simple (e.g., bare steel) or complcx (e.g., insulation-coatcd steel). A detailed description of the dcfinitions of the absorption coefficient and the depth of the hot layer are given in detail in the FDS user's guide (McGrattan 2004). To provide an estimate of model sensitivity on the calculated temperature distribution, FDS calculation results were also performed for varying heat releasc rate and grid resolution. The results of those calculations are discussed in Chapter 11.

\subsection{SUMMARY}

A series of geometrically and physically complex experiments were conducted to test the NIST FDS fire model. For the FSI methodology that was applied to determinc the temperature of structural steel that was in the fire compartment, the upper layer temperature calculated by FDS was a critical parameter. In general, most predictions were within 10 percent, except for some near-field quantities (20 percent). In particular,

- FDS predictions of the upper layer gas temperature were within 10 percent of the measurements. This difference can be attributed to the relative expanded uncertainty in the HRR measurement.

- FDS predictions were in agreement with measurcd gas velocities at the compartment inlets. 
- Because of limited spatial resolution at the outlet window, the steep gradient in velocity was not captured by the model, but the integrated mass flux was.

- FDS predictions were in agreement with the measured gas-phase volume fraction of $\mathrm{O}_{2}$ and $\mathrm{CO}_{2}$ in the upper layer.

- FDS predicted the leaning of the fire plume caused by asymmetric obstructions in the compartment, but underestimated the extent of the leaning. This adversely impacted FSI/ANSYS predictions of the thermal behavior of structural components at some locations near the fire.

- FDS predictions of heat flux in the upper layer were within 10 percent of the measurements. This difference can be attributed to the relative standard uncertainty in the HRR measurement.

- FDS predictions of the heat flux to the floor and the column were less accurate (within 20 percent) for surfaces facing the fire than surfaces facing away. This may be attributed to issues associated with prediction of the flame leaning and the radiative absorption of the surrounding gases.

\subsection{REFERENCES}

Hamins, A.. A. Maranghides. and G. Mulholland. 2003. The Global Combustion Behavior of 1 MW to 3 MW Hydrocarbon Spray Fires Burning in an Open Environment, NISTIR 7013, National Institute of Standards and Technology, Gaithcrsburg, MD, June.

McGrattan, K.B., ed. 2004. Fire Dynamics Simnlator (Version 4), Technical Reference Guide. NIST Special Publication 1018. National Institute of Standards and Technology, Gaithersburg, MD, July.

McGrattan, K.B., and Forney, G.P. 2004. FDS User's Guide. NIST Special Publication 1019. National Institute of Standards and Technology, Gaithersburg, MD.

Prasad, K., and H.R. Baum. 2005. "Coupled Fire Dynamics and Thermal Response of Complex Building Structures," Proc. Combustion Institute 30, 2255-2262.

Taylor, R.E., H. Groot, and J. Ferrier. 2003. Thermophysical Properties of PVC, PE, and Marinite, Report No. TPRL 2958, Thermophysical Properties Research Laboratory, Inc., April.

Walton, W.D., and P.H. Thomas. 2003. Estimating Temperatures in Compartment Fires. Fire Protection Handbook, $3^{\text {rd }}$ Ed. National Fire Protection Association, Quincy, MA. 
This page intentionally left blank. 


\section{Chapter 11 \\ SIMULATION OF THE THERMAL RESPONSE OF \\ STRUCTURAL COMPONENTS}

\section{$11.1 \quad$ INTRODUCTION}

The large-scale experiments measured the thermal response of structural steel components within a steel frame compartment lined with calcium silicate boards. As described in Chapter 3, the fire was gcnerated using liquid hydrocarbon fuels with nominal heat release rates of approximately $2 \mathrm{MW}$ to $3 \mathrm{MW}$. The layout of the steel components within the compartment and the location of the temperature measuremcnts on the structural components are described in detail in Chapter 9. Four steel components, consisting of two trusses, one thin-walled tubular column, and a simple rod, were placed in the compartment. The steel components were uninsulated in the first three experiments and were coated with a fibrous sprayed fireresistive material (SFRM) in the last three experiments. The temperatures of the surface of the steel components and the SFRM were measured and served as a data set to validate the prediction of the temperature rise of the structural steel components. In this chapter, a comparison is made betwecn the simulated and measured temperatures on the steel and the SFRM surfaces.

\subsection{METHODOLOGY}

Simulations of the effects of severe fires on the structural integrity of buildings requires a close coupling between the gas-phase enthalpy release and transport phenomena and the stress analysis in the load bearing materials. The connection between the two is established primarily through the interaction of the heat transfer between the solid and gas phase with the conduction of heat through the structural components. This process is difficult in large, geometrically complex buildings due to the wide disparity in length and time scales that must be accounted for in the simulations. Typical length scales range from $60 \mathrm{~m}$, characteristic of the WTC buildings, to $1 \mathrm{~cm}$ or $2 \mathrm{~cm}$, characteristic of structural components and insulation. Typical Fire Dynamics Simulator (FDS) time steps are on the order of $10^{-6} \mathrm{~s}$, whereas total simulation times for World Trade Center (WTC) 1 are about $10^{4} \mathrm{~s}$. These disparitics create a challenge both in terms of modeling and computational issues. The National Institute of Standards and Technology (NIST) Fire Structure Interface (FSI) has been developed to overcome these difficulties in the analysis of the collapse of the WTC buildings (Prasad and Baum 2005; NIST NCSTAR 1-5G). 
The FSI uses information predicted by the NIST FDS, described in Chapter 10 of this report, as boundary conditions for radiative and convective heat transfer to sub-grid scale structural components (Prasad and Baum 2005). The FSI uses a simple radiative transport model that assumes that the compartment is locally divided into a hot, soot laden upper layer and a cool relatively clear lower layer. The properties of the two layers are extracted from temporal averages of the results obtained from FDS. Explicit formulae for the heat flux were obtained as a function of temperature, hot layer depth, soot concentration, and orientation of each structural element. These formulae were used to generate realistic thermal boundary conditions for the coupled transient three-dimensional finite-element code. The code was then used to generate solutions for the heating of the complex structural assemblies. The goal of this portion of the study is to compare the numerically predicted temperature profiles within the structural steel components and the SFRM with the experimental measurements.

The computed upper layer temperature, absorption coefficient, depth of the hot layer, and ambient temperature, as computed by FDS, were recorded at $30 \mathrm{~s}$ intervals for grid points in the upper layer and stored as an ASCII text file for computing the combined radiative and convective fluxes incident on the structural components. The time constant for the temperature of the steel was on the order of minutes, so the $30 \mathrm{~s}$ time interval was sufficiently resolved. The file was subsequently read into the ANSYS (2004) finite-element program. Two major simplifications were introduced so that the radiative fluxes could be applied to the thermal analysis of structures. First, the concept of a gray gas whose properties are independent of spectral wavelength was employed. The second simplification was that the enclosure geometry induced a vertically stratified distribution of temperature and combustion products. As the fire developed in the enclosure, the hot layer had spatial variations in the above properties that varied much more rapidly in the vertical than in the horizontal direction. The radiative transport equations can be simplified, and the radiative flux to any surface can be computed. These radiative fluxes are a function of the location and orientation of the structural element. The radiative flux also depends on the upper layer temperature, the absorption coefficient, the hot layer depth, and the lower layer temperature that were obtained from the fire dynamics simulation in the form of an input file and were stored as a function of space and time. Figures 11-1 and 11-2 are representations of the FDS output values for these parameters after $500 \mathrm{~s}$ in Test 1. The radiative flux to the horizontal surface was obtained in terms of Exponential Integrals $E_{n}(z)$, whereas that to a vertical surface was obtained in terms of the rth iterated integral of the Modified Bessel function $\mathrm{K}_{0}(\mathrm{z})$ as described in detail in Prasad and Baum (2005). The numerical solution and post-processing procedures are also described in Prasad and Baum (2005).

The convective fluxes incident on the structural components were also considered and were obtained from the temperatures of the upper layer and the ambient temperature (Prasad and Baum 2005). Structural components in the hot layer were subject to convective fluxes, with bulk temperature values equal to the local instantaneous value of the temperature in the hot layer. Structural components not in the hot layer were subject to convective fluxes, with bulk temperature values equal to the local instantaneous value of the ambient temperature. A convective heat transfer coefficient value of $25 \mathrm{~W} / \mathrm{m}^{2}-\mathrm{K}$ was assumed for computing the convective fluxes to the structural components (Eurocode 1994). 


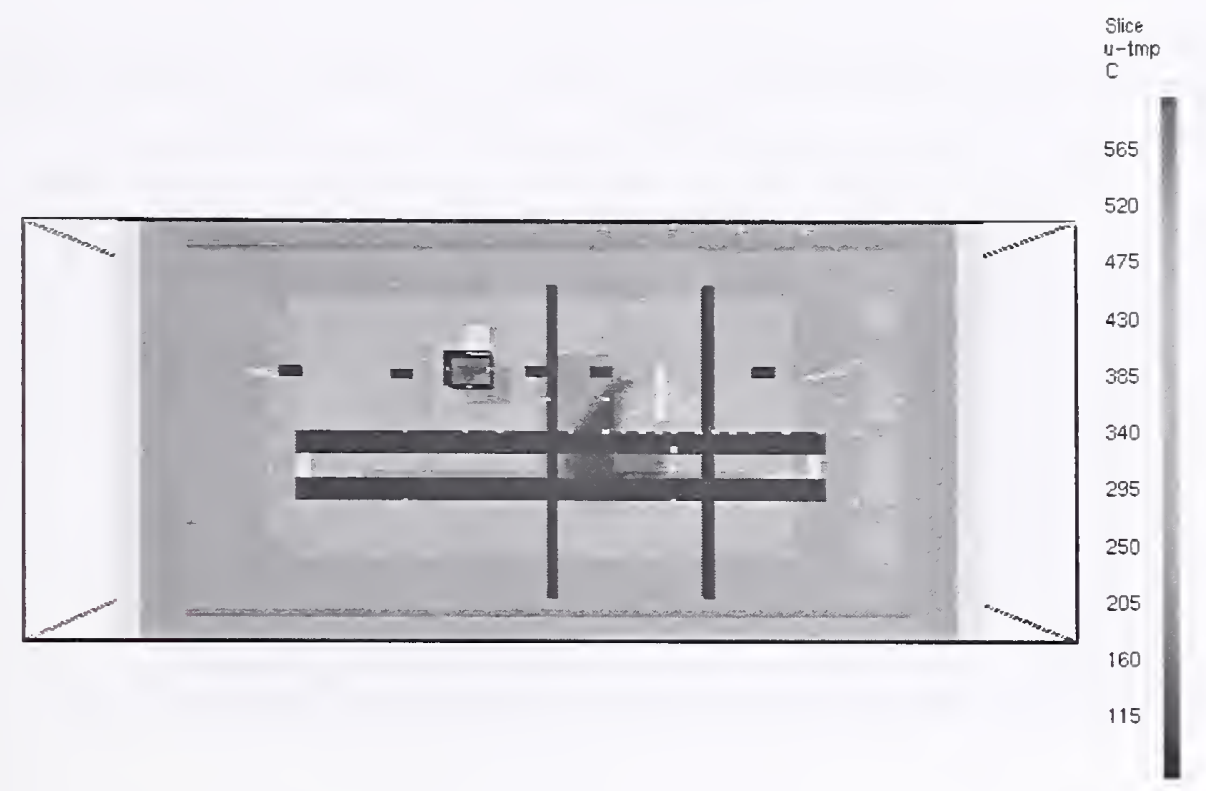

Time: 500.0

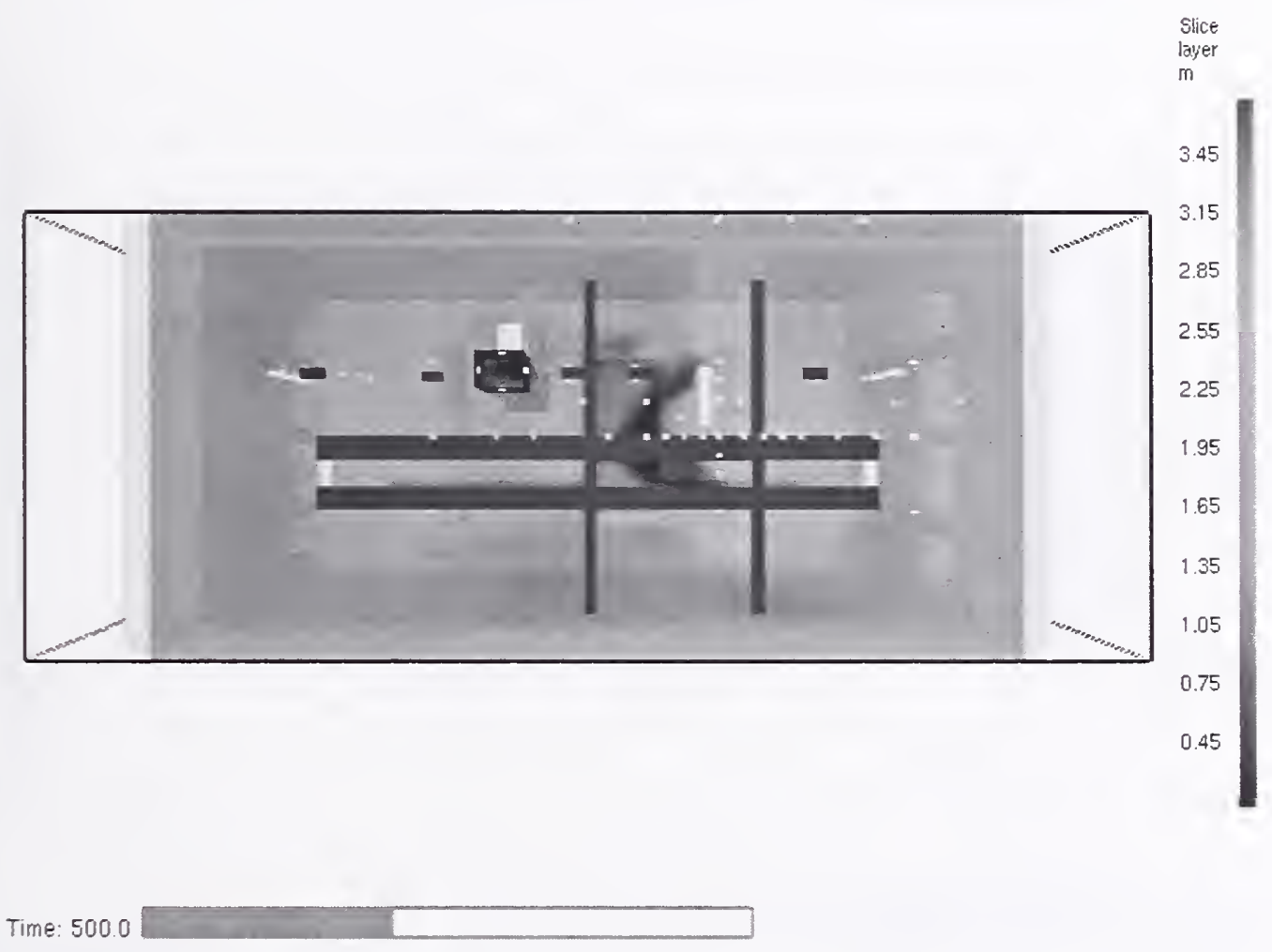

Figure 11-1. FDS simulation of the upper layer temperature on the plane $3.01 \mathrm{~m}$ above the floor (top figure) and the layer interface height (bottom figure) after $500 \mathrm{~s}$ in Test 1. 


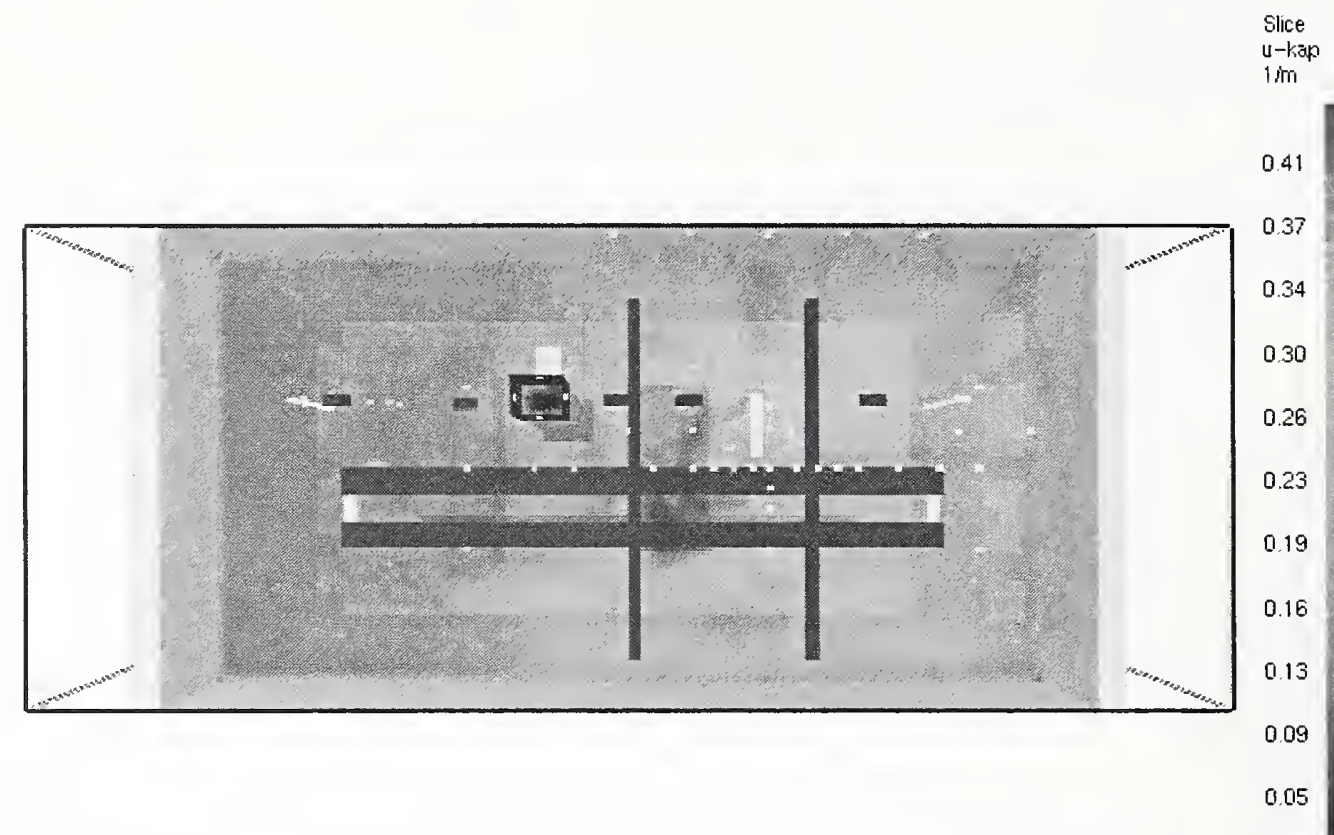

Time: 5000

Slice

I-trop

125

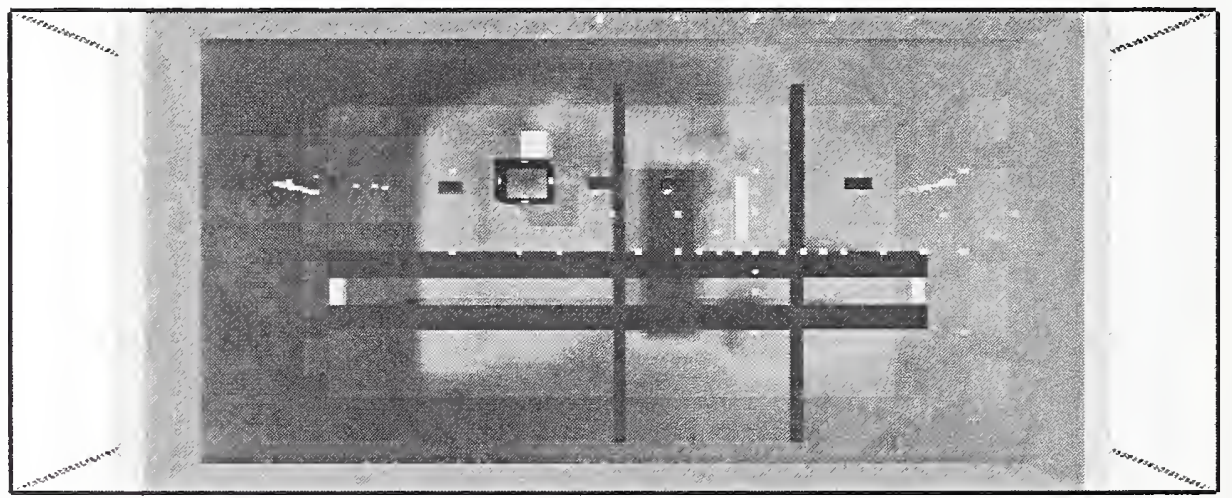

115

105

95.0

850

75.0

65.0

55.0

45.0

350

250

Time: 500.0

Figure 11-2. FDS simulation of the predicted absorption coefficients on the plane $3.01 \mathrm{~m}$ above the floor (top figure) and the lower layer temperature (bottom figure) after $500 \mathrm{~s}$ in Test 1. 
In order to perform a thermal analysis, the thermophysical properties of the steel and SFRM were needed, including the density, thermal conductivity, and heat capacity. These quantities are generally functions of temperature. The steel components were constructed of A572 steel, which has thermophysical properties very similar to A242 steel (NIST NCSTAR 1-3E). The thermophysical properties for A242 steel were obtained from NIST NCSTAR 1-3E. Figure 11-3 shows the A242 steel thermophysical properties as a function of temperature. The specific heat increases with temperature, whereas the thermal conductivity decreases as a function of temperature. Figure 11-4 shows the thermophysical properties obtained by Harmathy (1983) for the BLAZE-SHIELD D C/F SFRM used in the experiments. The thermophysical properties for Marinite, shown in Fig. 11-5, were obtained from Taylor et al. (2003).
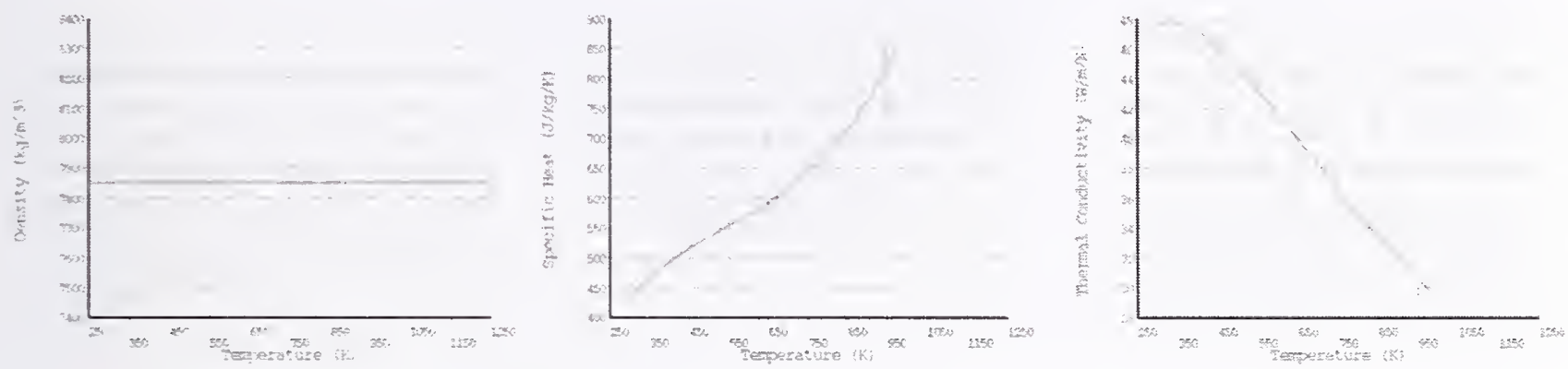

Figure 11-3. Temperature dependent thermophysical properties for A242 steel used in the thermal analysis.
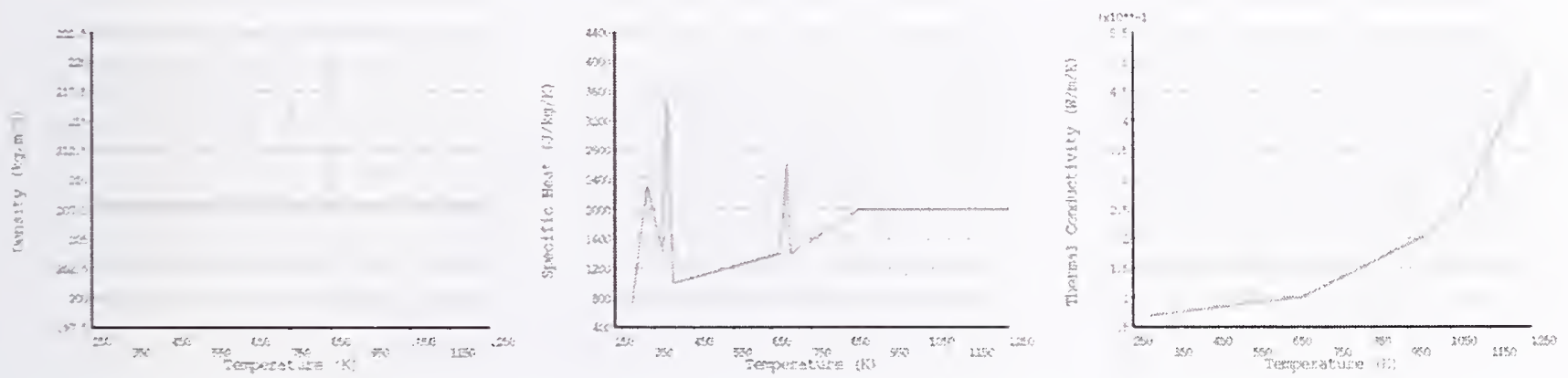

Figure 11-4. Temperature dependent thermophysical properties of the SFRM used in the experiments and thermal analysis.
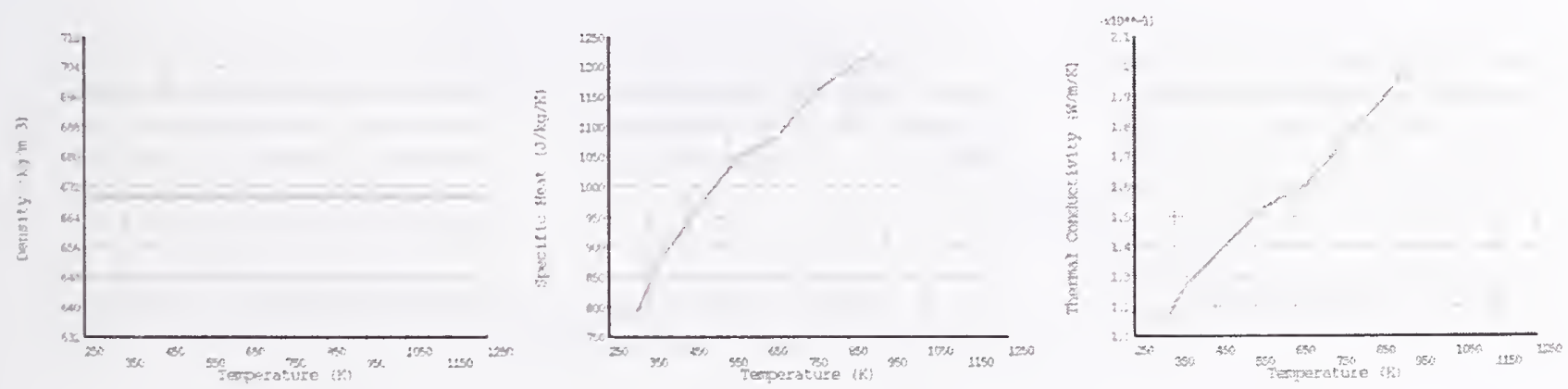

Figure 11-5. Temperature dependent thermophysical properties for Marinite. 
In order to perform the thermal analysis, initial and boundary conditions were applied on the structural components. The initial temperature of the steel and the SFRM was assumed to be $300 \mathrm{~K}$. The radiative and convective flux boundary conditions, as computed from the FSI plane layer analysis, were applied to the external faces of the structural components. The external faces were also covered with surface effect components to allow for re-radiation back to the ambient atmosphere. The ends of the bar were insulated for experimental purposes, and therefore, a zero flux boundary condition was applied in the computations. The initial time step was set to $1.0 \mathrm{~s}$, while the minimum and maximum time steps were set to $0.1 \mathrm{~s}$ and 20.0 s, respectively.

The finite-element model ANSYS 8.0 was used to model the thermal response of the structural components. Figure 11-6 is a finite-element representation of the $3.05 \mathrm{~m}$ (10.0 ft) long steel bar. The bar was meshed with "SOLID 70" brick components (an element with eight nodes each with a single degree of freedom). The element was used primarily for a three-dimensional transient thermal analysis. The bar was divided into 30 uniform divisions along its length. Figure 11-7 shows the components through a cross-section of the steel bar and SFRM. The bar diameter was $2.54 \mathrm{~cm}$ (1.00 in.). The thickness of the SFRM on the various components tested in the experiments was reported in Table 9-1. In Test 5, for example, the SFRM had a mean thickness of $2.30 \mathrm{~cm} \pm 0.55 \mathrm{~cm}$. In the calculations, the SFRM thickness was assumed to be uniform over the entire length of the component. A sensitivity analysis presented in Sec. 11.4.3 was performed to assess the validity of this assumption. The elements in Fig. 11-7 have been color coded with the components in blue representing the steel and those in violet representing the fire protective coating. Simulations were performed with approximately 6 to 10 elements through the thickness of the fire resistive coating. Surface elements were used to model the re-radiation back to the ambient atmosphere as well as to apply convective flux boundary conditions to the structural components. Figure 11-8 shows a typical calculated temperature distribution through a bar. The uncertainty in the predicted thermal response of the structural steel components is discussed in Sec. 11.4 in terms of model sensitivity to uncertainties of various input parameters used in FDS and the FSI models.

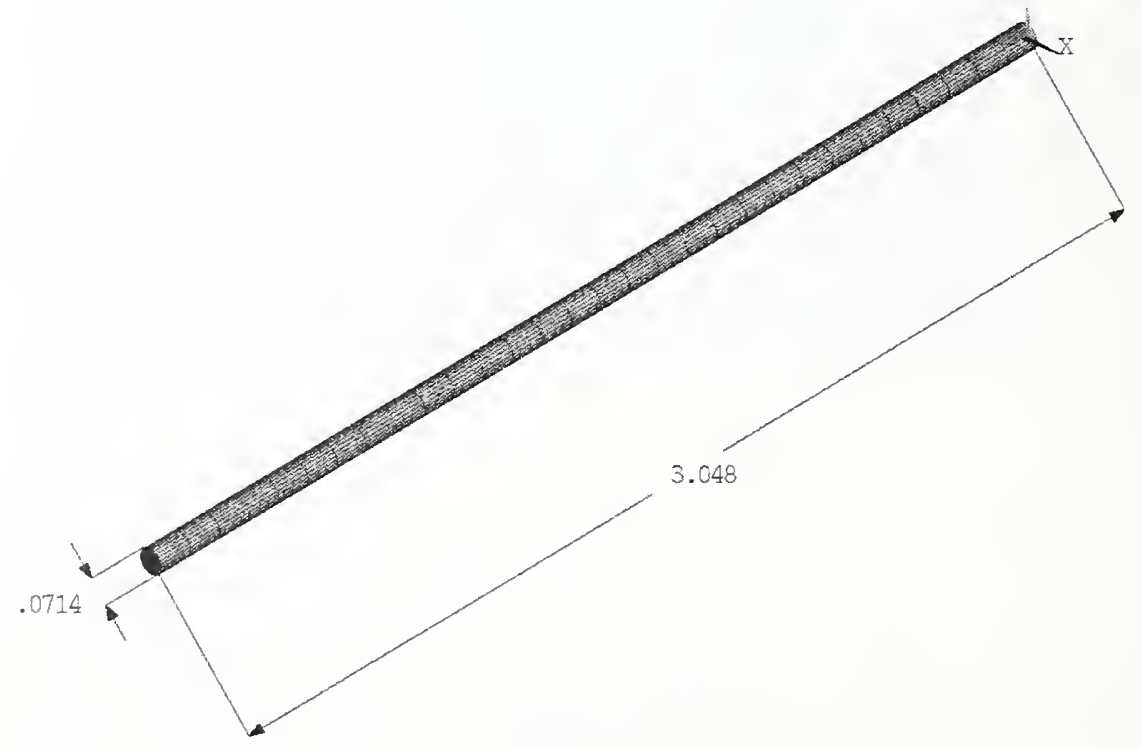

Figure 11-6. Finite-element model for the $3.05 \mathrm{~m}(10.0 \mathrm{ft})$ long steel bar, showing the elements distributed uniformly along the length of the bar. 


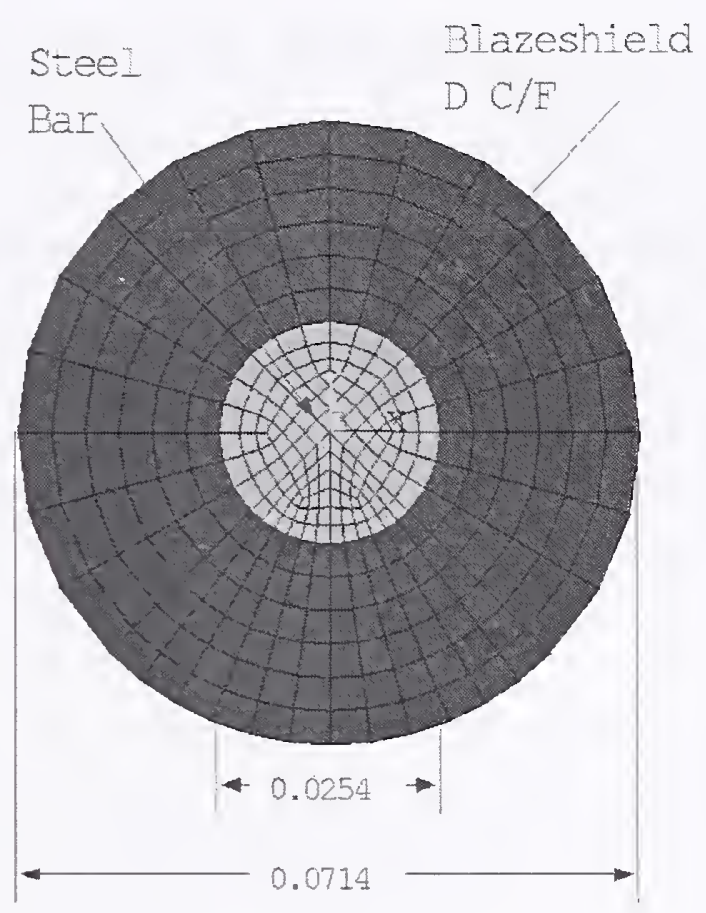

Figure 11-7. Cross section of bar showing the elements used to model the steel (in blue) and the SFRM (in violet).

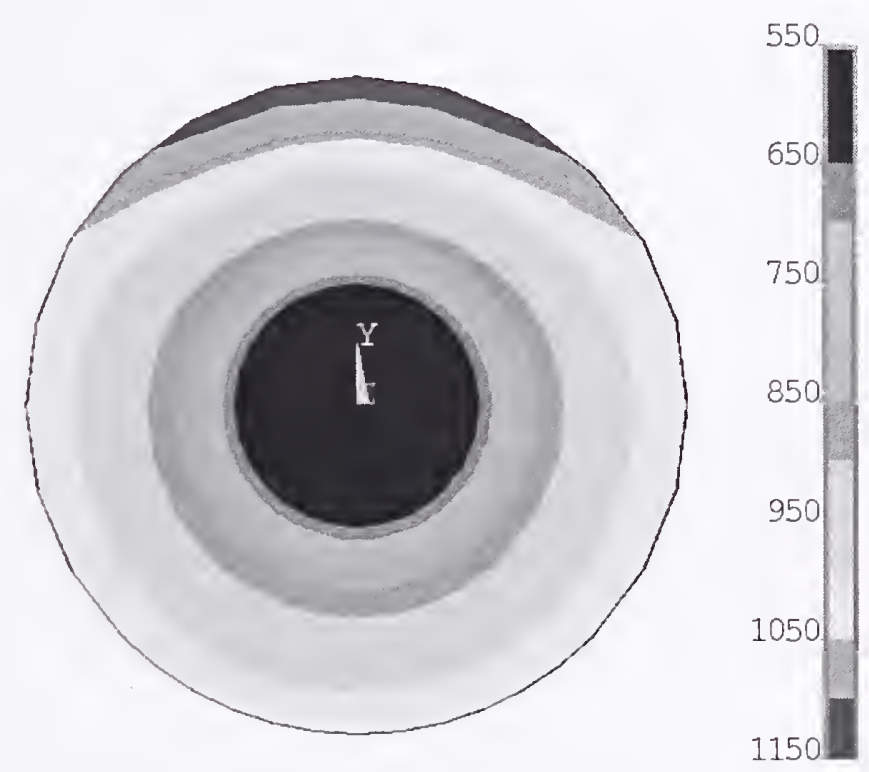

Temperature $K$

Figure 11-8. Typical temperature contours through the cross-section of the steel bar and the SFRM after 2,000 $\mathrm{s}$ in Test 5. 


\section{$11.3 \quad$ COMPARISON OF SIMULATIONS WITH MEASUREMENTS}

The simulations were compared to two representative experiments, namely Tests 1 and 5 . Test 1 was a $2 \mathrm{MW}$ heptane fire with a $15 \mathrm{~min}$ duration in which the steel components were bare (uncoated). Test 5 was a $3 \mathrm{MW}$ heptane fire with a 50 min duration in which the steel components were insulated with various thicknesses of SFRM (see Chapter 9). The comparisons between simulations and measurements focused on the peak temperatures attained by the steel rather than the amount of time it took to attain a particular temperature. This approach was taken because the peak steel temperatures varied widely from location to location and from test to test, making selection of a specific reference temperature impractical. In addition, the temperature rise in a given period of time was considered more important from the perspective of structural stability than from a study of component response.

\subsubsection{Test 1}

Figures 11-9 and 11-10 compare the numerical simulations (symbols) with the measured steel surface temperatures (solid lines) at four locations on bar A and bar B, respectively, during Test 1 . The location of the origin was taken as the north end of the bar (at the top of the bar in the figures). A detailed discussion of the steel temperature measurements, including the uncertainty, which was bounded from $-9{ }^{\circ} \mathrm{C}$ to $+1{ }^{\circ} \mathrm{C}$, is presented in Chapter 9 of this report. The shape of the simulated time-temperature results was similar to the measurements. Both curves increased in a monotonic fashion from ambient values at time equal to zero, to finite values, which obtained a maximum when the fuel was stopped, and subsequently decreased, also in a monotonic manner. The general character of these results was representative of all of the tests. For most locations, the absolute difference between the numerical predictions and the experimental data was less than $20^{\circ} \mathrm{C}$ at any time, whereas for other locations the difference was as large as $100^{\circ} \mathrm{C}$. This was because the asymmetry of the fire plume was not precisely predicted by FDS (see Fig. 8-11), so the difference between the temperature measurements and the model simulations differed along the bar at some locations. For the WTC fires that were severe enough to cause structural damage, the fire had a far wider spatial extent, and the calculation results will be less sensitive to the exact location of the fire plume.

Here, and subsequently in this chapter, the relative difference between the measured and simulated temperatures were compared by normalizing the temperature difference by the average of the measured and predicted temperature change from ambient conditions. The relative difference between the peak measured and simulated temperatures was approximately less than 20 percent for bar $\mathrm{A}$ and less than 10 percent for bar B. These differences are discussed in terms of model and measurement uncertainty in Sec. 11.4 below. 


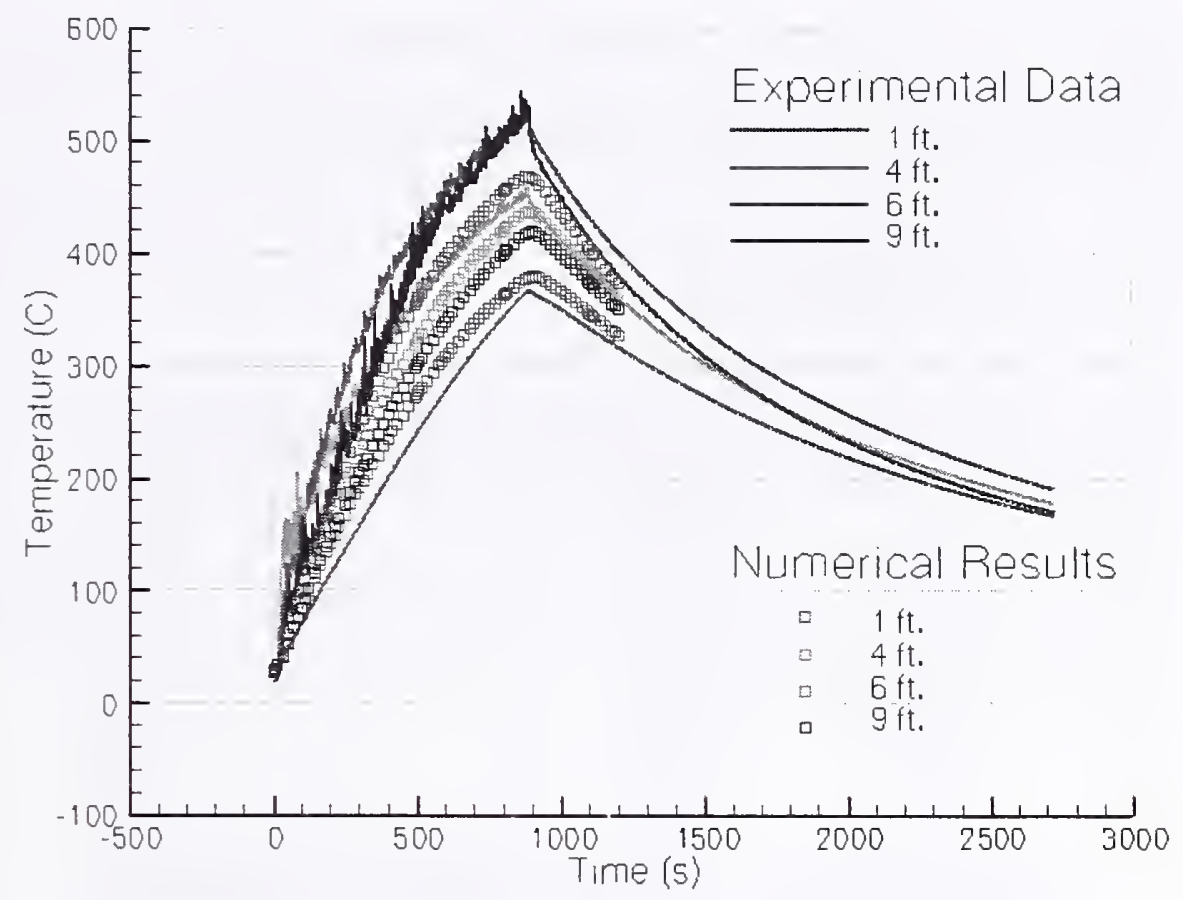

Figure 11-9. Comparison of numerical simulations with measurements for the steel surface temperature at four locations on bar $A$ in Test 1.

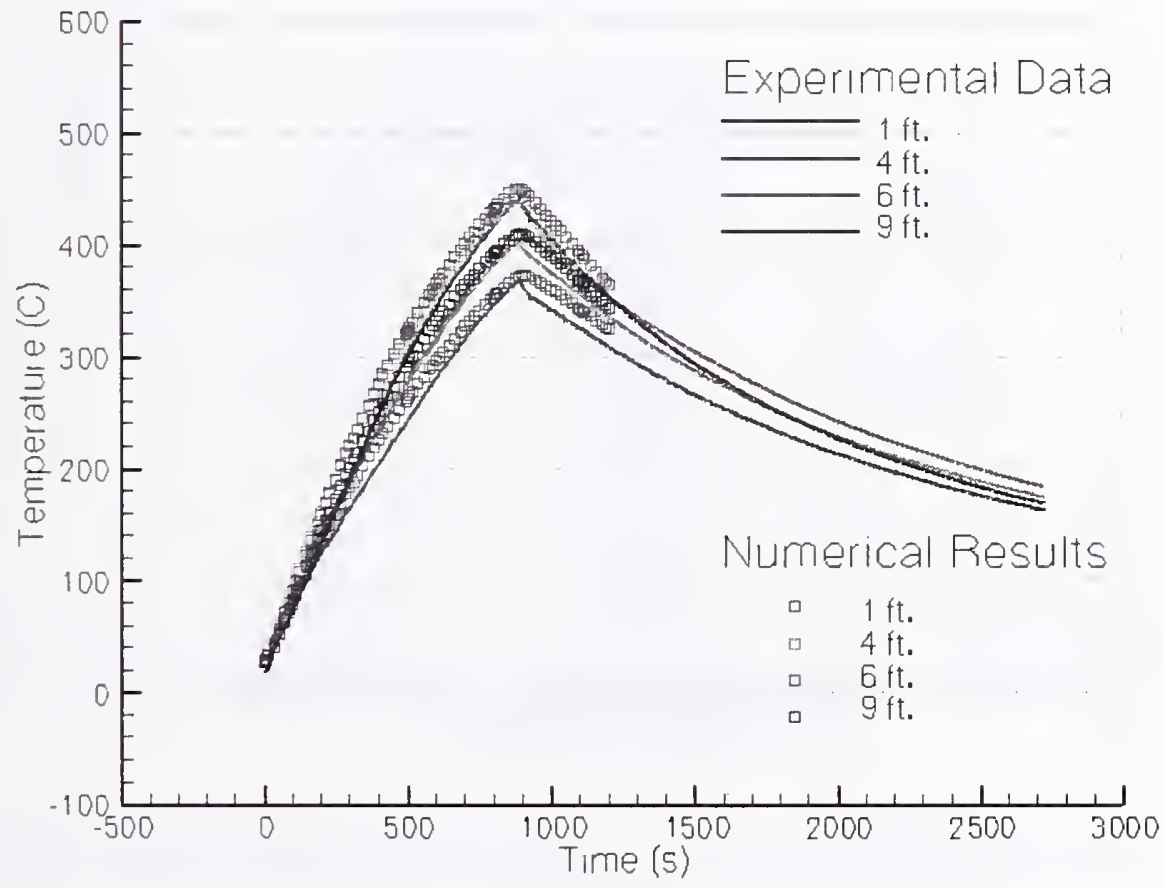

Figure 11-10. Comparison of numerical simulations with measurements for the steel surface temperature at four locations on bar B in Test 1. 
Figure 11-11 shows a perspective and a cross sectional view of the finite-element model that was used to model the thermal response of the column. The cross sectional view shows the stecl column with a uniform SFRM wrapped around it. A portion of the ceiling and floor were also included in the model in an effort to capture the radiative exchange between the column and these elements. Figure 11-12 shows typical calculation results for the temperature (in $\mathrm{K}$ ) plotted as isocontours on the surface of the SFRM and the Marinite ceiling 2,000 s into the simulation of Test 5.
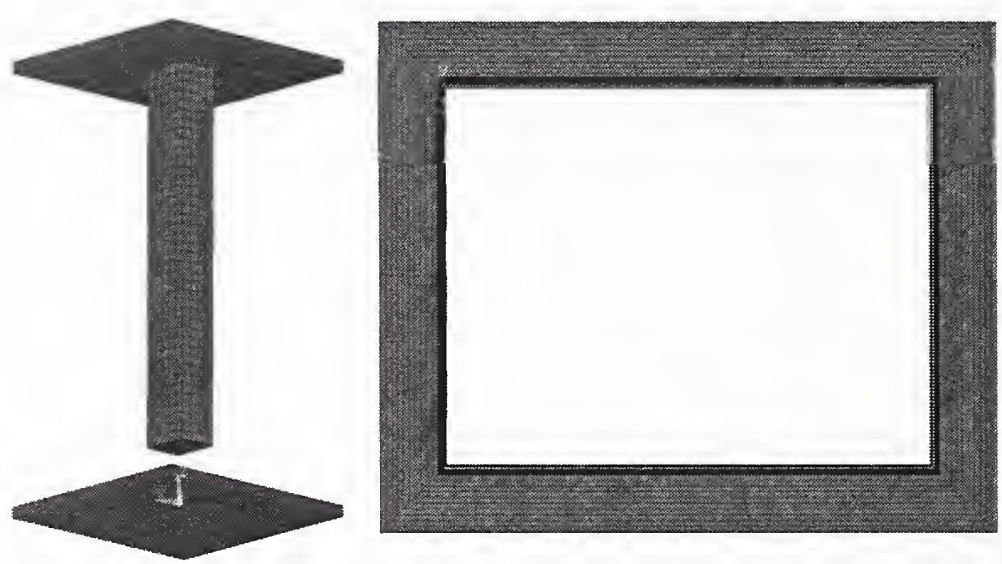

Figure 11-11. Perspective and top view of the finite-element model of the steel column with SFRM.

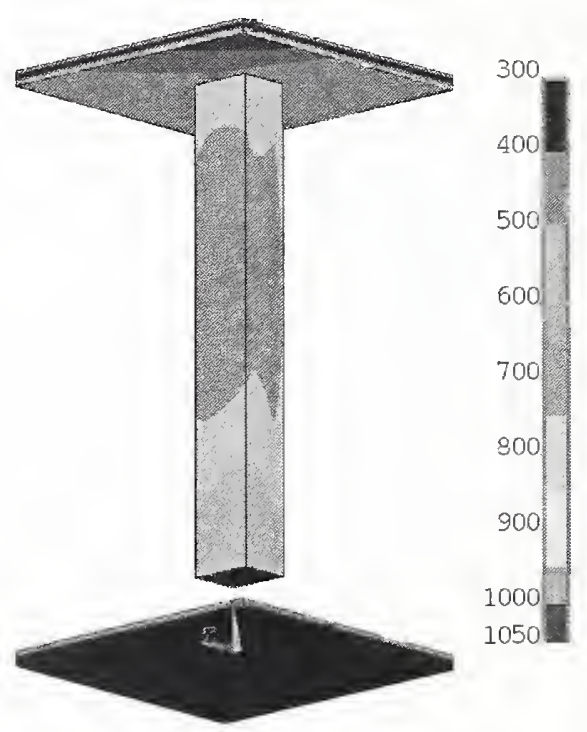

Figure 11-12. Temperature contours plotted on the surface of the SFRM and the ceiling after $2,000 \mathrm{~s}$ in Test 5. 
Figures 11-13 and 11-14 compare the numerical predictions with measurements of the steel surface temperature for locations on the North, South, East, and West faces of the bare column during Test 1 at heights of $3.69 \mathrm{~m}$ and $2.13 \mathrm{~m}$ above the floor, respectively. The location of the column relative to the compartment is shown in Figs. 11-1 and 11-2 and is schematically shown in Figs. 2-5 and 5-3 in Chapters 2 and 5, respectively. In Figs. 11-13 and 11-14, both the numerical predictions and the experimental measurements have been color coded for the four faces of the column. (The west face of the column faced the compartment inlet.) The highest predicted and measured temperatures occurred on the south face of the column. At one location on the south face ( $3.69 \mathrm{~m}$ above the floor), the largest difference between the simulations and measurements was immediately after the start of the test, when the temperatures were still relatively low, but the rate of temperature change was large. The largest temperature difference generally occurred. however, just before the fuel flow was stopped. In Test 1, this was $900 \mathrm{~s}$ after ignition. For most locations, the relative differences between the peak measured and simulated temperatures was less than 5 percent, whereas for some locations the differences were as large as 10 percent. These results are discussed in terms of model and measurement uncertainty in Sec. 11.4 below.

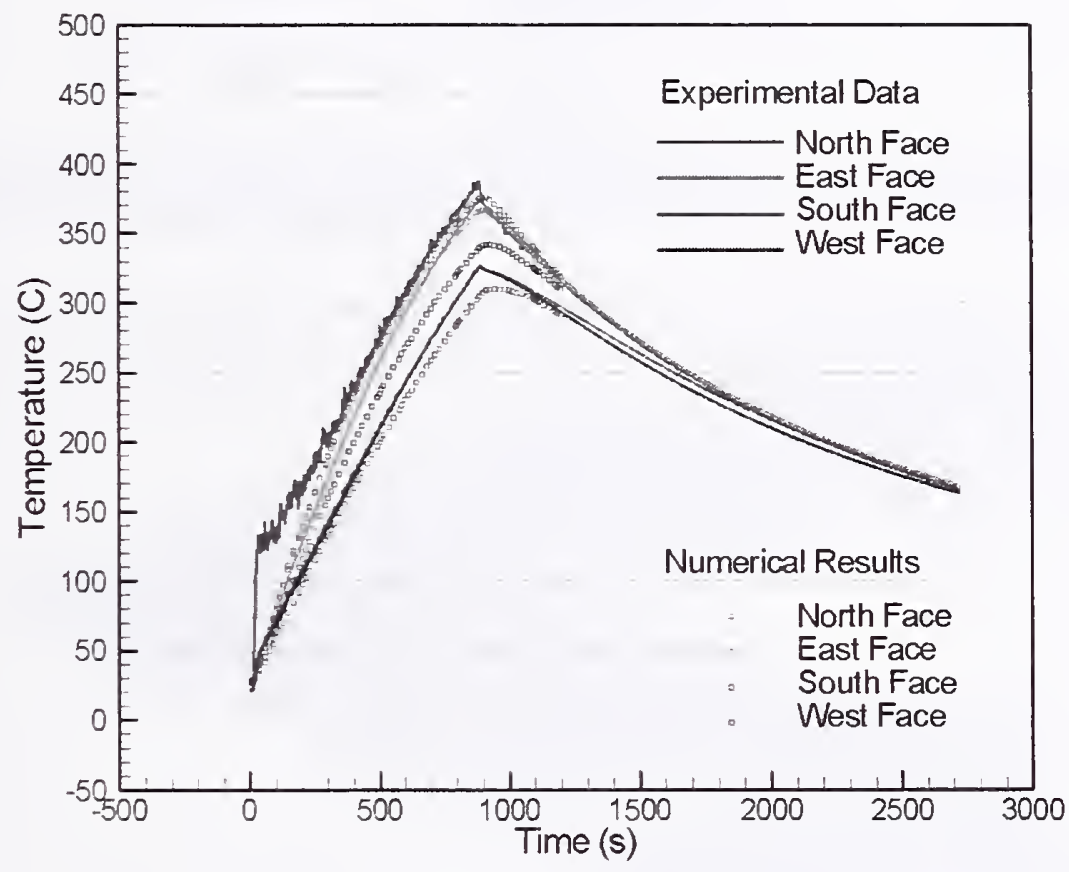

Figure 11-13. Comparison of numerical simulations with measurements for the steel surface temperature at four locations $3.69 \mathrm{~m}$ above the floor on the column in Test 1. 


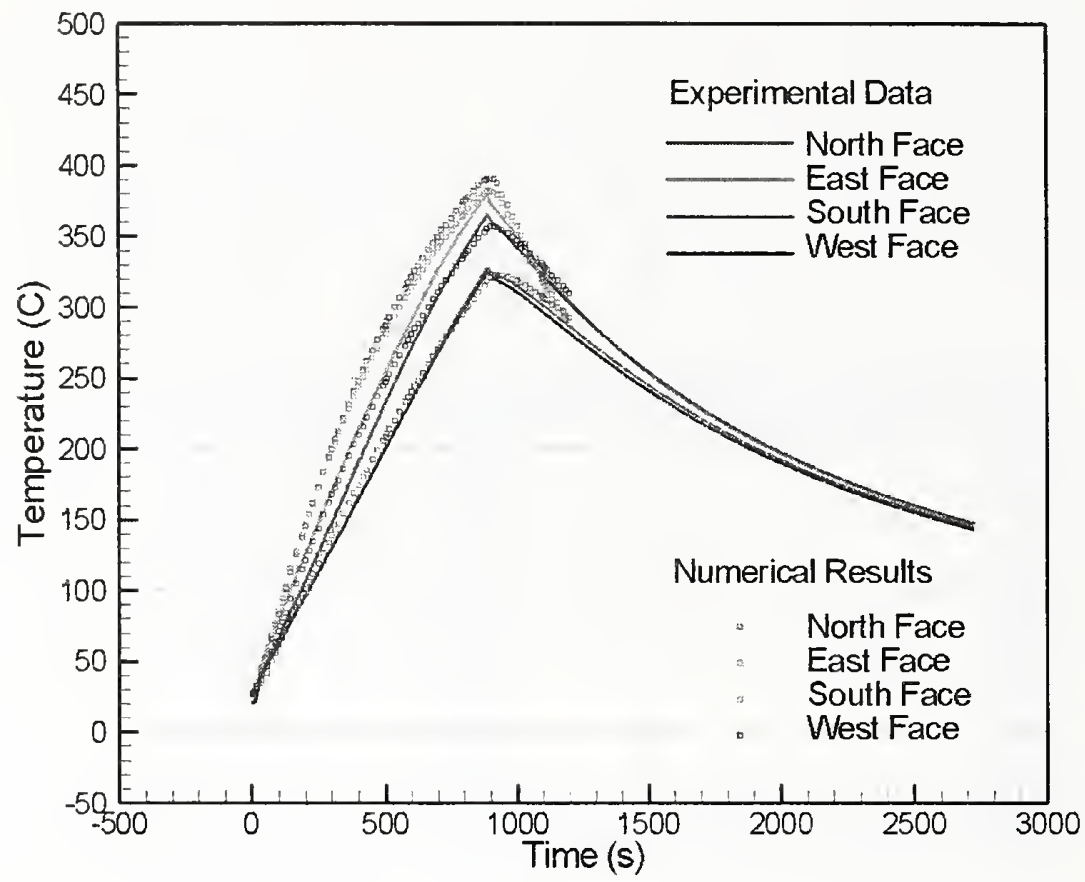

Figure 11-14. Comparison of numerical simulations with measurements for the steel surface temperature at four locations $2.13 \mathrm{~m}$ above the floor on the column in Test 1.

Figures 11-15 and 11-16 show the finite-element representation of the truss used in the thermal analysis. Figure 11-15 is a cross-sectional view of the truss, showing the top and bottom steel flanges (L-shaped sections). Typical calculation results are shown in Fig. 11-17 plotted as temperature contours on the surface of the SFRM for truss A $1,000 \mathrm{~s}$ into Test 5 .
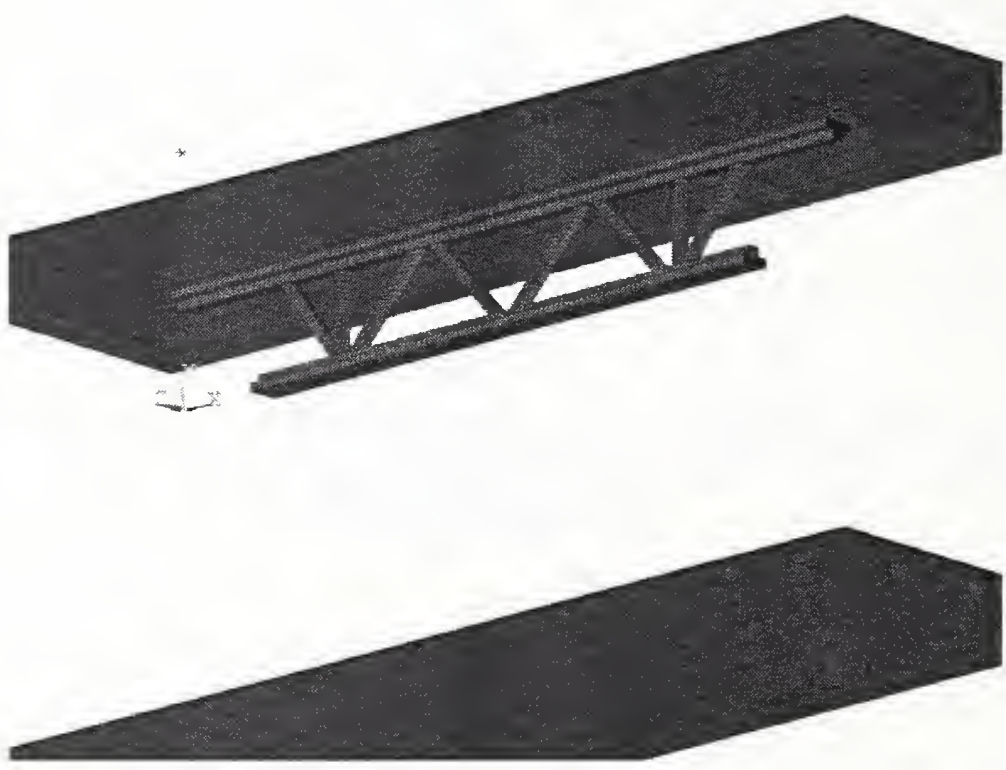

Figure 11-15. Finite-element model of the insulated steel truss, the ceiling and the floor used in the thermal analysis of Test 5. 


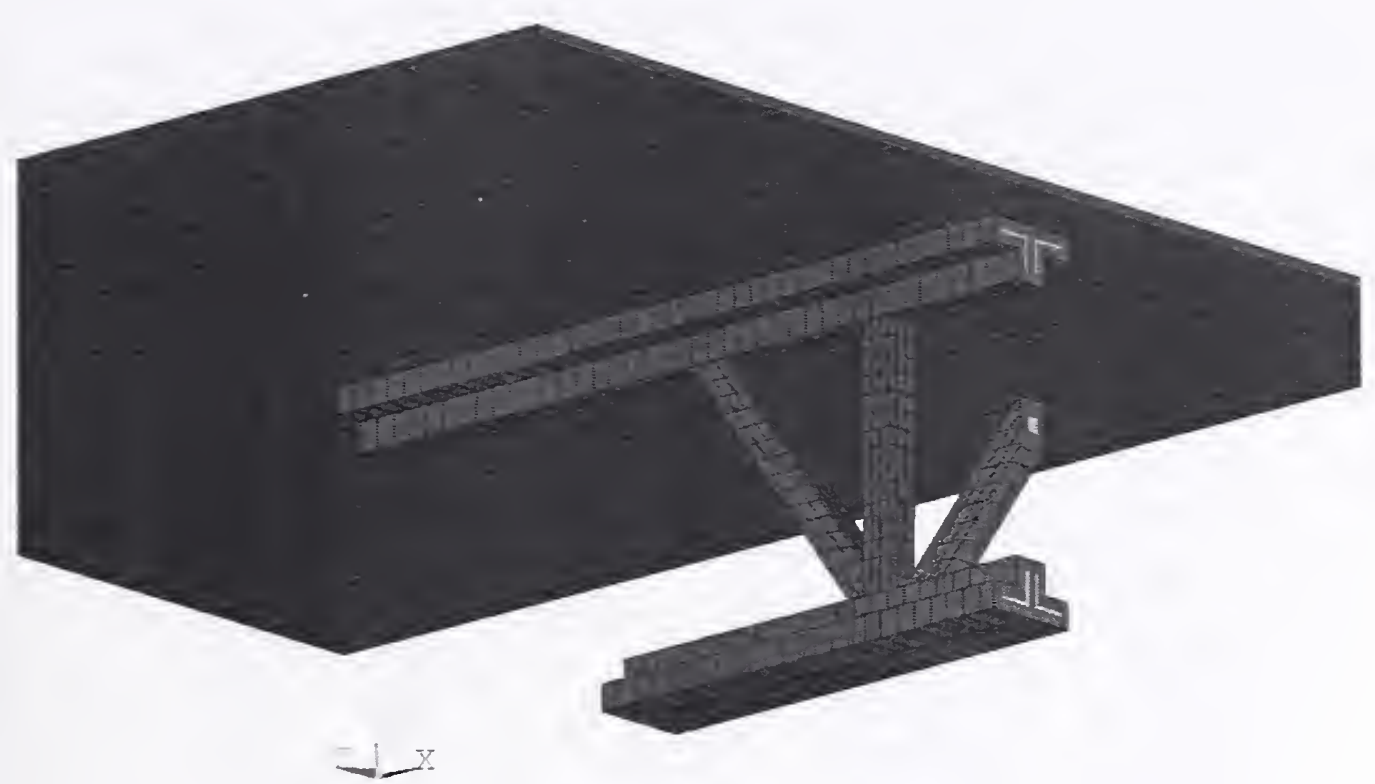

Figure 11-16. Finite-element representation of the insulated steel truss (blue), the SFRM (violet), and the ceiling (red) used in the thermal analys is of Test 5.
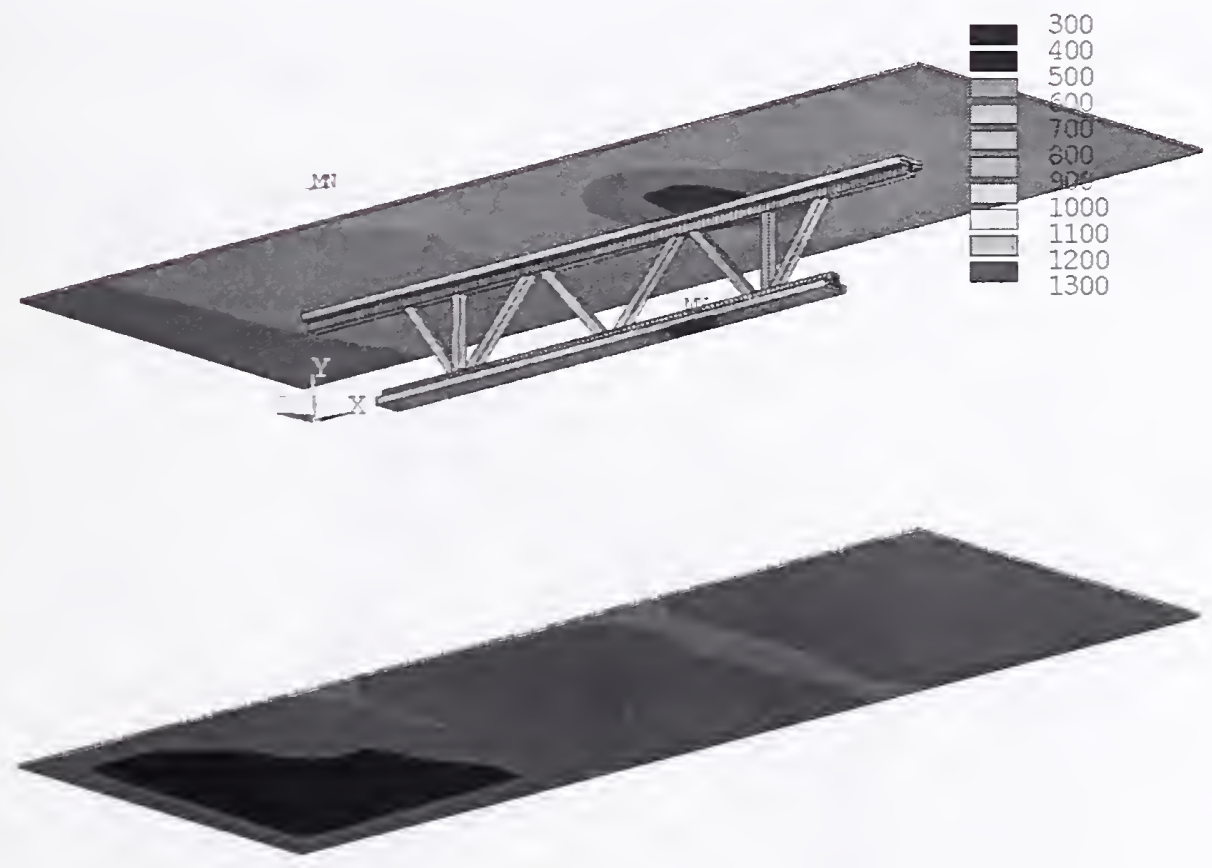

Figure 11-17. Temperature contours (in K) on the ceiling, floor, and the surface of the SFRM on truss $A$ after $1,000 \mathrm{~s}$ in Test 5. 
Figures 11-18 through 11-23 compare the numerical simulations and the temperature measurements for various locations on the surface of the steel trusses during Test 1. Figures 11-18 through 11-20 show results at various locations for three heights $(2.89 \mathrm{~m}, 3.29 \mathrm{~m}$ and $3.70 \mathrm{~m})$ on truss A. Figures $11-21$ through 11-23 show analogous results for truss B. The locations of the thermocouples are illustrated in Figs. 9-6a and 9-6b. For most locations, the maximum difference between the measurements and the simulations was less than 10 percent, which typically occurred when the fuel flow was stopped. For a small number of locations, the difference was as large as 27 percent.

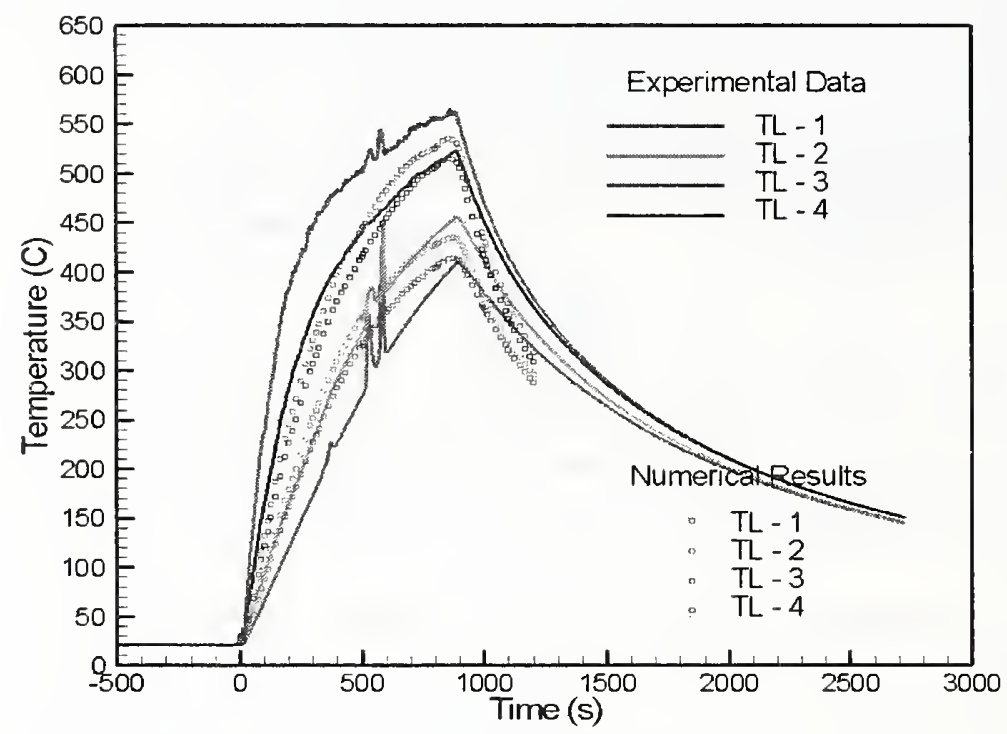

Figure 11-18. Comparison of numerical simulations with measurements for the steel surface temperature at four locations $2.89 \mathrm{~m}$ above the floor on truss $A$ in Test 1.

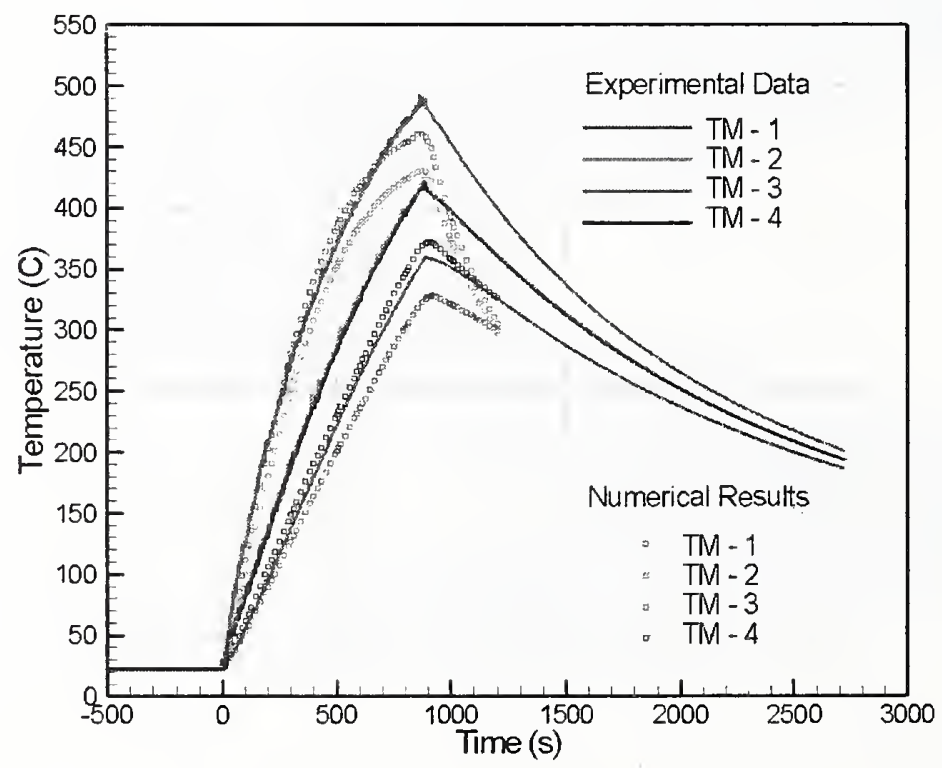

Figure 11-19. Comparison of numerical simulations with measurements for the steel surface temperature at four locations $3.29 \mathrm{~m}$ above the floor on truss $A$ in Test 1. 


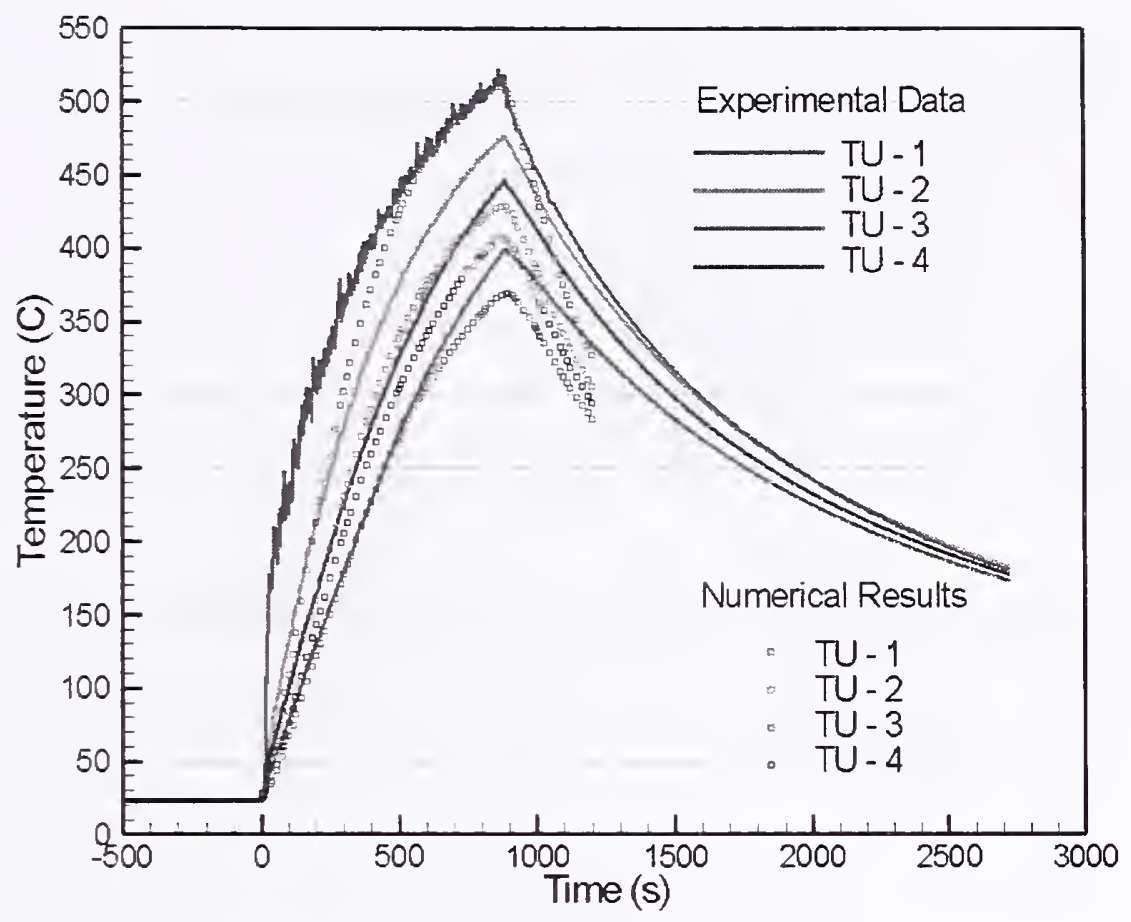

Figure 11-20. Comparison of numerical simulations with measurements for the steel surface temperature at four locations $3.70 \mathrm{~m}$ above the floor on truss $A$ in Test 1.

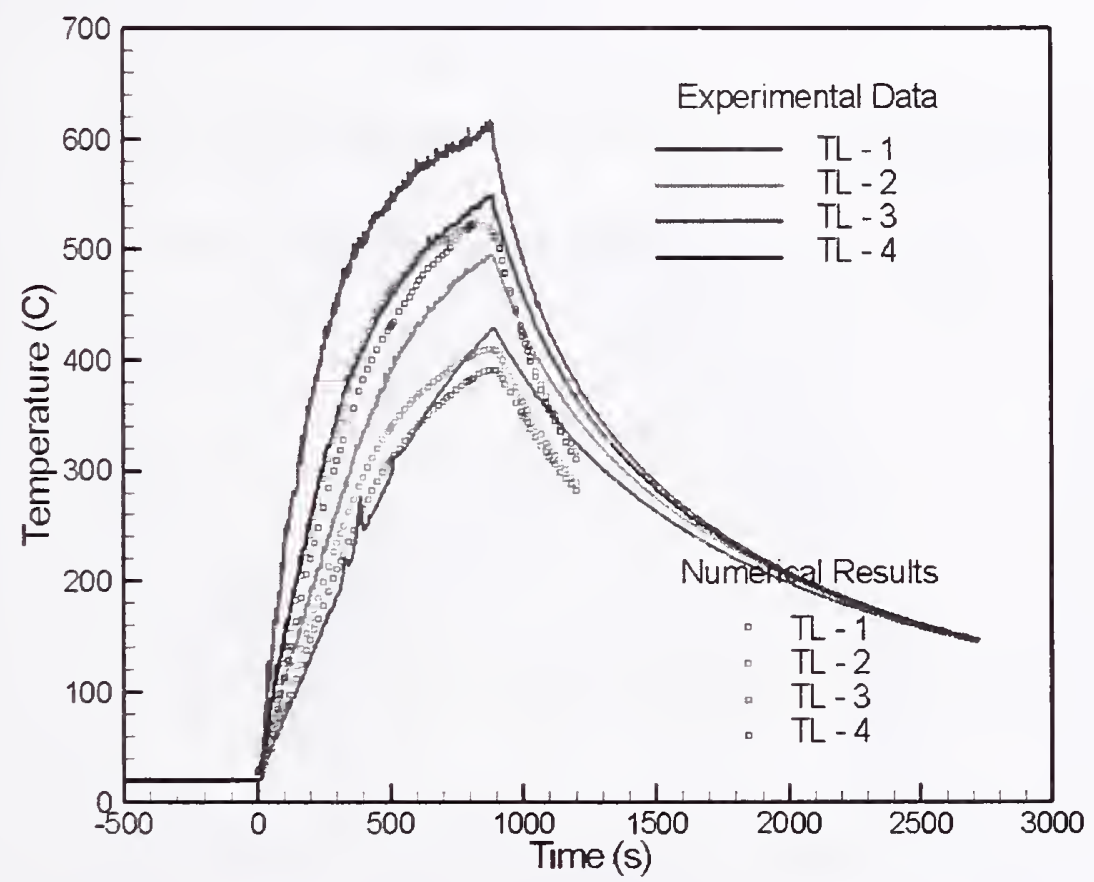

Figure 11-21. Comparison of numerical simulations with measurements for the steel surface temperature at four locations $2.89 \mathrm{~m}$ above the floor on truss B in Test 1. 


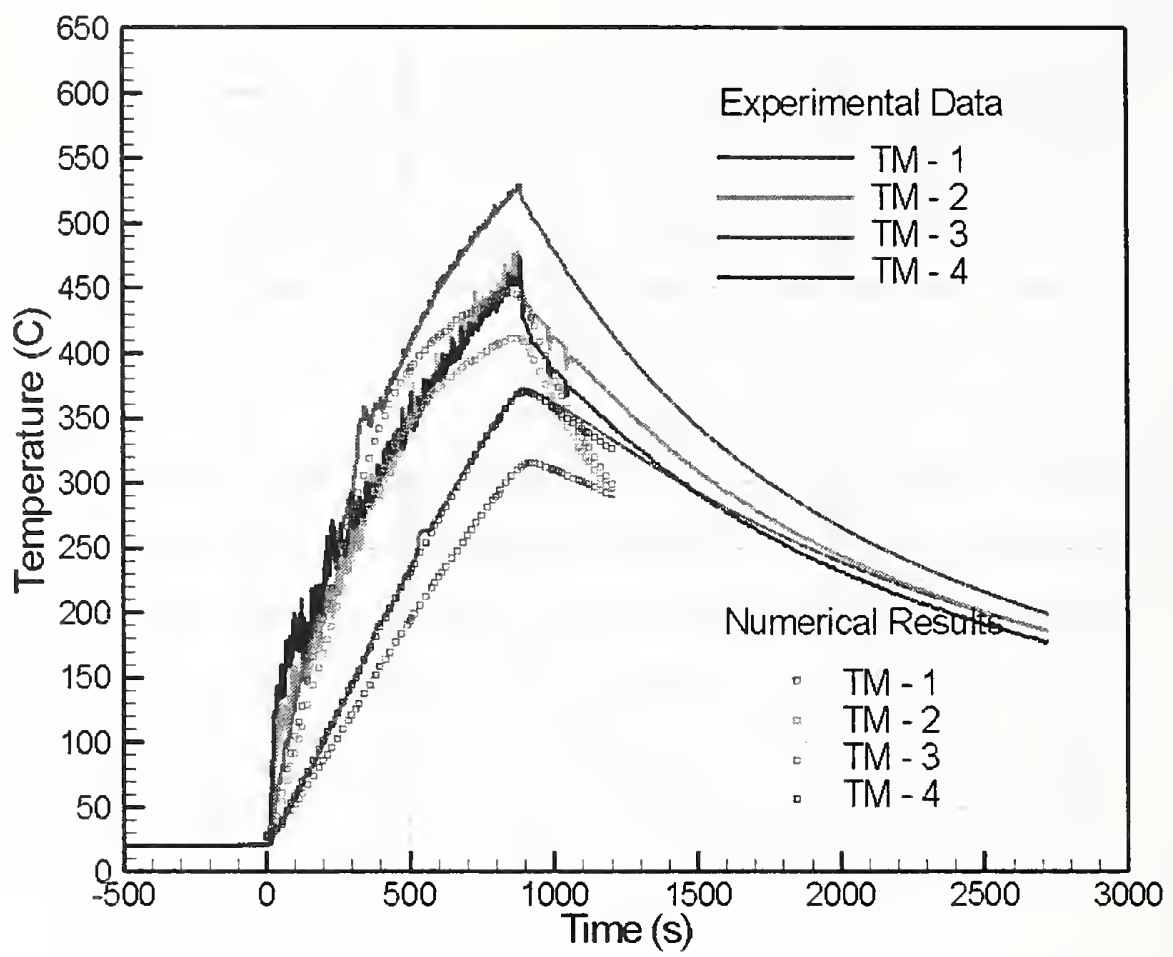

Figure 11-22. Comparison of numerical simulations with measurements for the steel surface temperature at four locations $3.29 \mathrm{~m}$ above the floor on truss B in Test 1 .

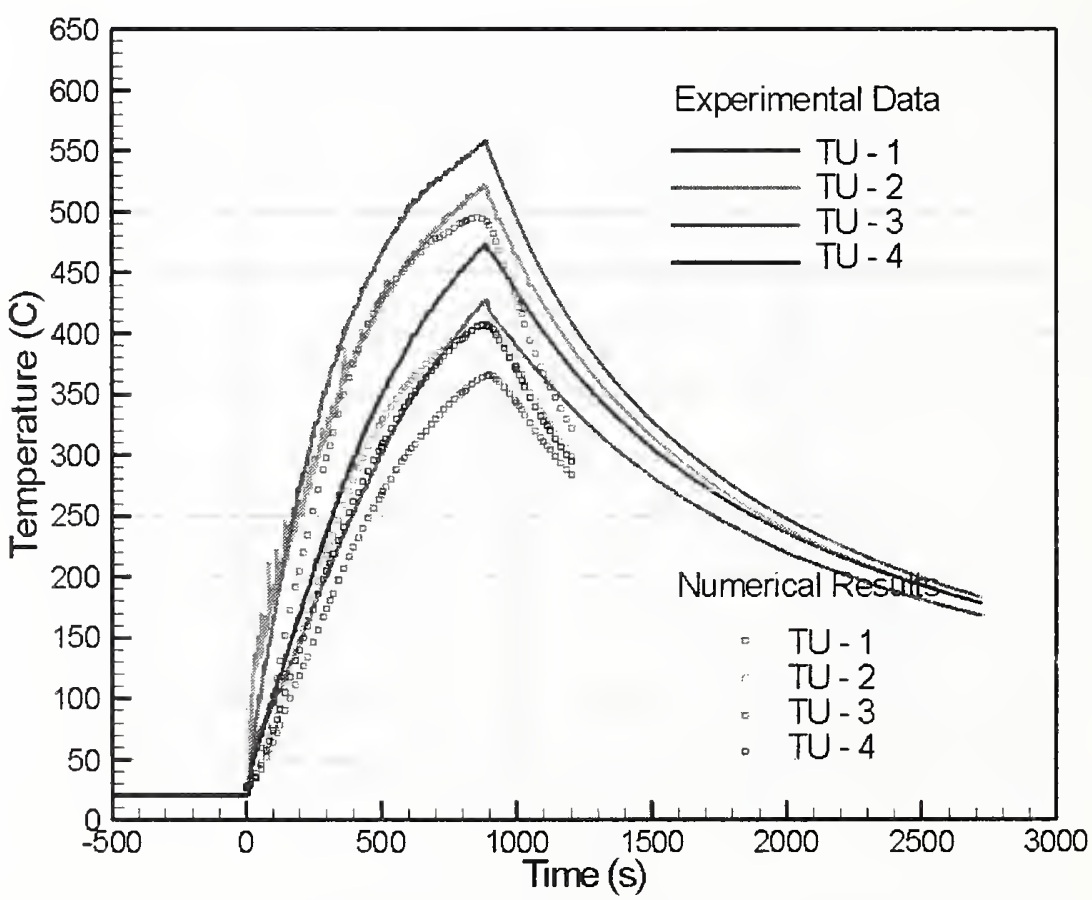

Figure 11-23. Comparison of numerical simulations with measurements for the steel surface temperature at four locations $3.70 \mathrm{~m}$ above the floor on truss B in Test 1 . 


\subsubsection{Test 5}

Figures 11-24 through 11-37 compare the numerical simulations and the temperature measurements for various locations on the surface of the steel components and on the SFRM surface in Test 5. Figures 11-24, 11-26 through 11-28, and 11-32 through 11-34 compare the simulations with measurements at locations on the surface of the SFRM for the bar, column and truss. Although these results have less direct bearing on the stability of a steel component subjected to a fire. they are of interest because the SFRM surface temperature is related to the steel surface temperature. For most locations, the maximum difference between the measurements and the simulations of the SFRM surface temperature typically occurred during the first $600 \mathrm{~s}$ after ignition, when the measurement uncertainty was largest (see Chapter 8). During the steady burning period, 1,000 s after ignition, the temperature difference was typically less than 10 percent. although it was as large as 20 percent to 30 percent in a small number of cases.

The rate of temperature rise on the steel was significantly reduced when the SFRM was present. Figures 11-25, 11-29 through 11-31, and 11-35 through 11-37 compare the simulations with measurements at locations on the steel surface for the bar, column, and truss in Test 5. For the bar and the column, the maximum difference between the measurements and the simulations was less than 15 percent, which generally occurred shortly after the fuel flow was stopped. For truss A, the maximum difference between the measurements and the simulations was typically less than 20 percent. At one location, however, the temperature difference was as large as approximately 30 percent. The reason for the magnitude of this difference appears to be subtleties associated with predicting the exact location of the flame, as mentioned previously. Other reasons for the differences between the numerical simulations and the temperature measurements are discussed in Sec. 11.4 in terms of the uncertainty in the measurements and a sensitivity analysis of the model.

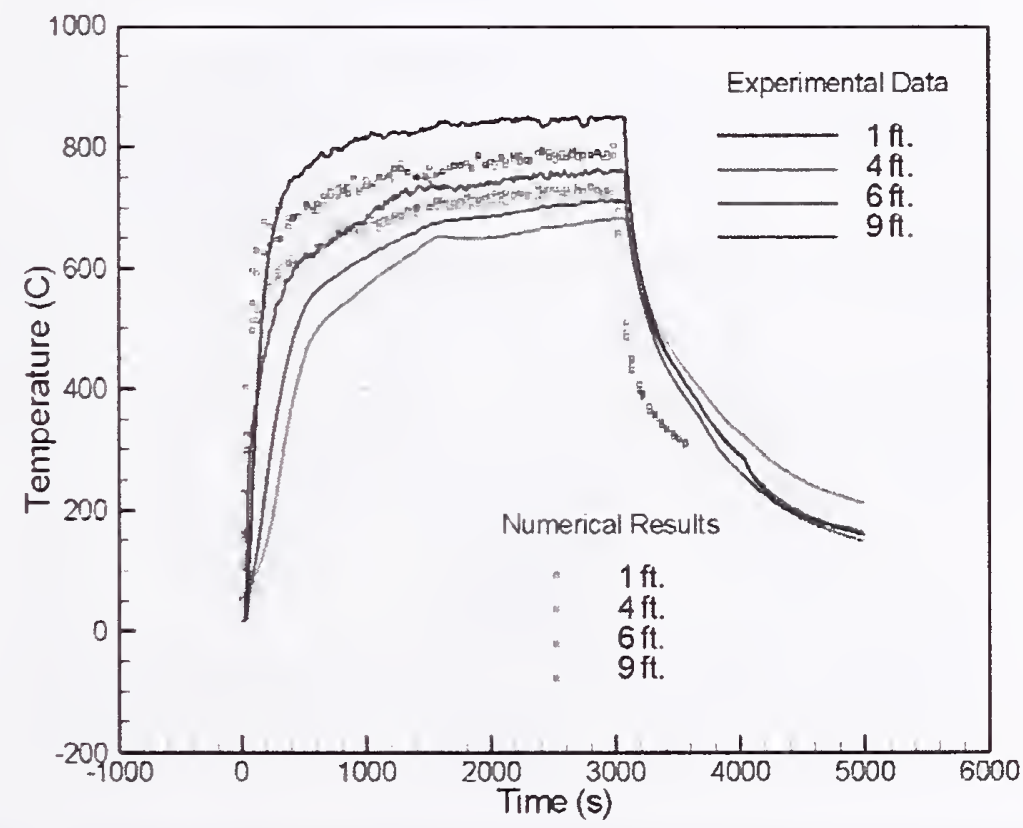

Figure 11-24. Comparison of numerical simulations with measurements for the temperature of the SFRM surface at four locations on the insulated bar in Test 5. 


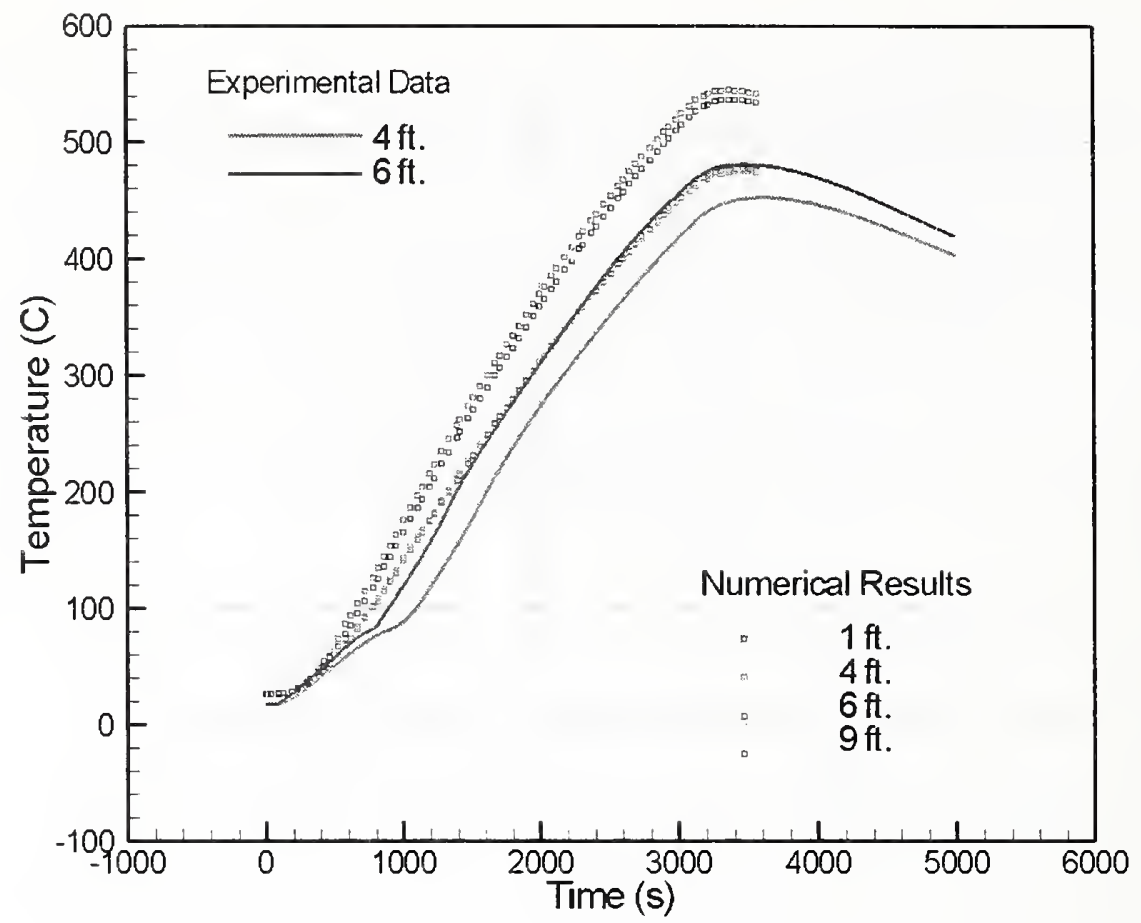

Figure 11-25. Comparison of numerical simulations with measurements for the temperature of the steel surface at four locations on the insulated bar in Test 5 .

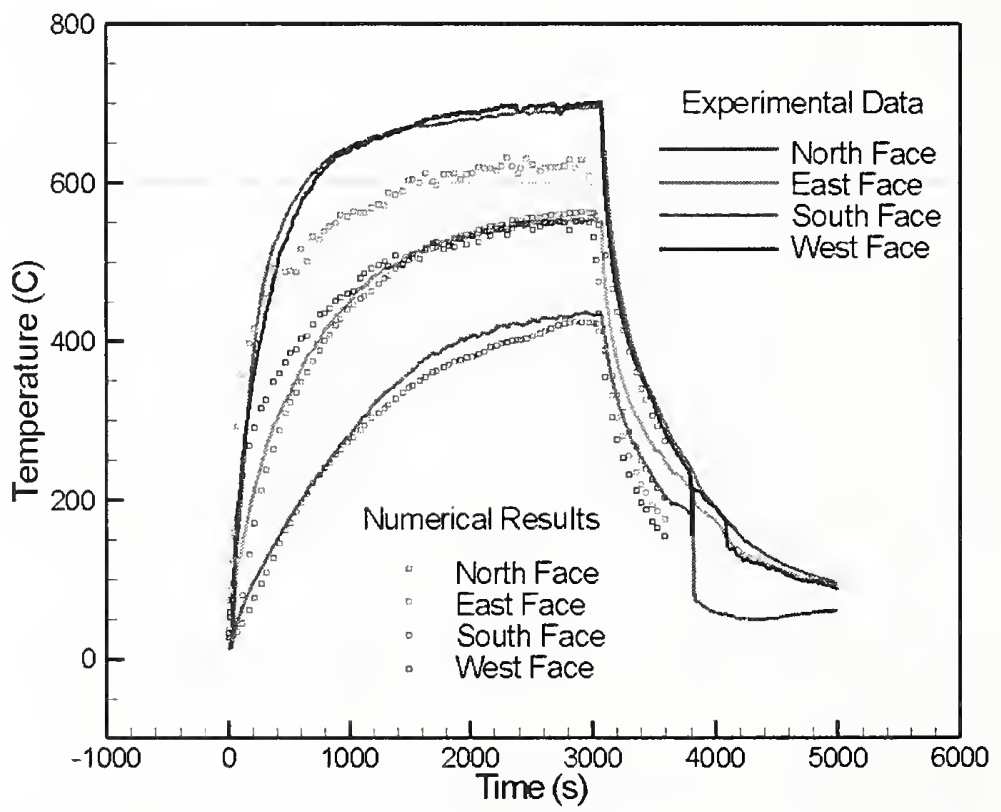

Figure 11-26. Comparison of numerical simulations with measurements for the temperature of the SFRM surface at four locations $0.77 \mathrm{~m}$ above the floor on the insulated steel column in Test 5. 


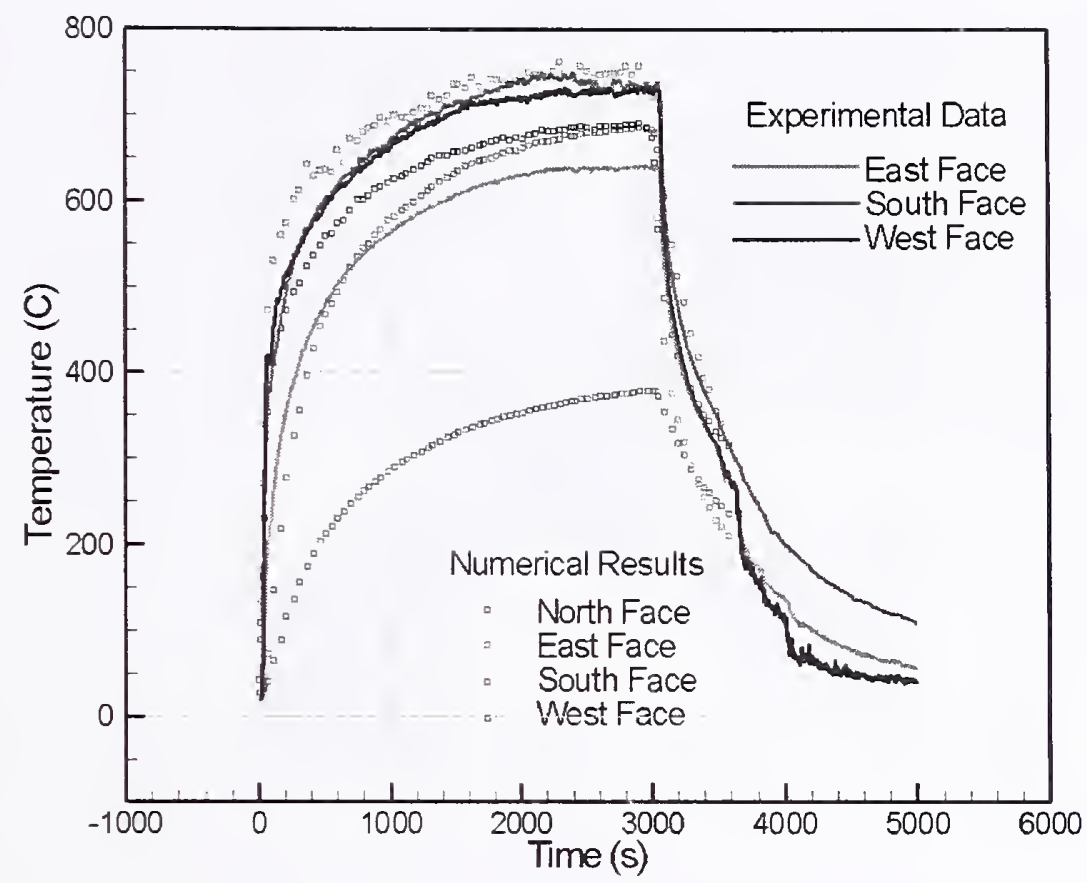

Figure 11-27. Comparison of numerical simulations with measurements for the temperature of the SFRM surface at four locations $2.13 \mathrm{~m}$ above the floor on the insulated steel column in Test 5.

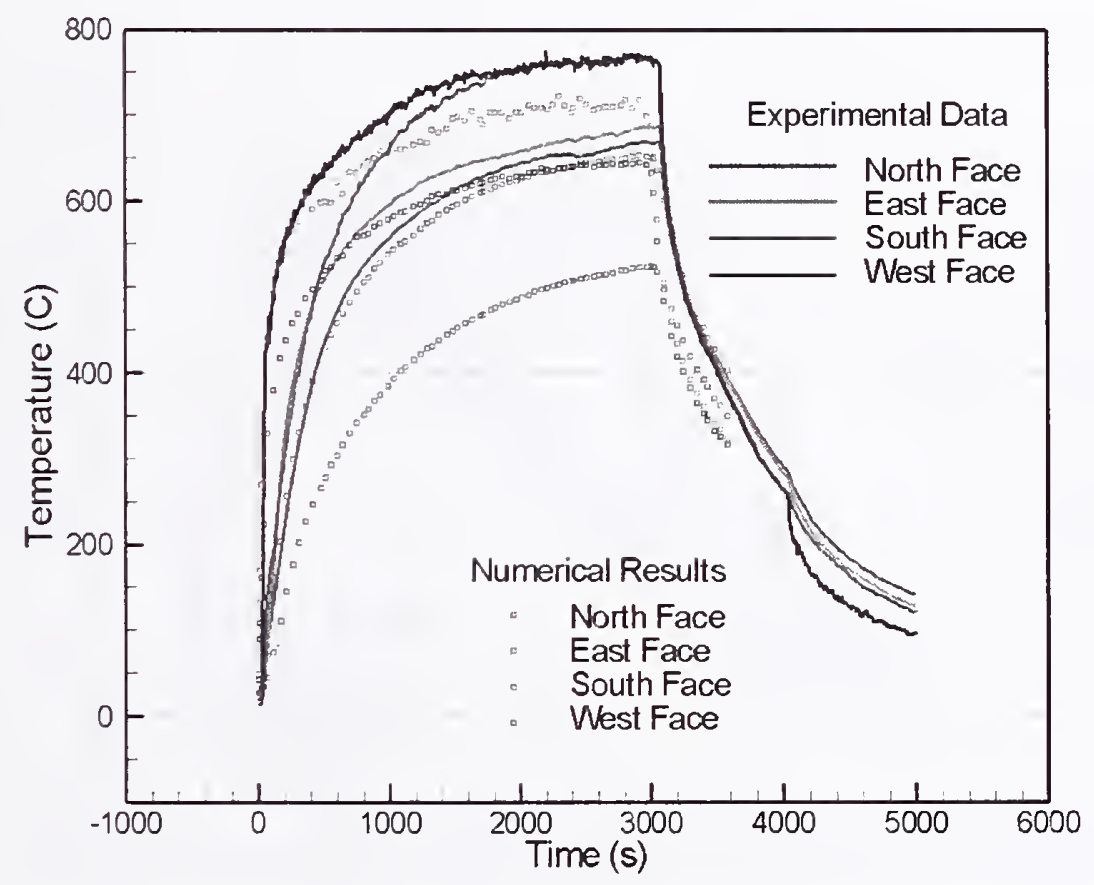

Figure 11-28. Comparison of numerical simulations with measurements for the temperature of the SFRM surface at four locations $3.69 \mathrm{~m}$ above the floor on the insulated steel column in Test 5. 


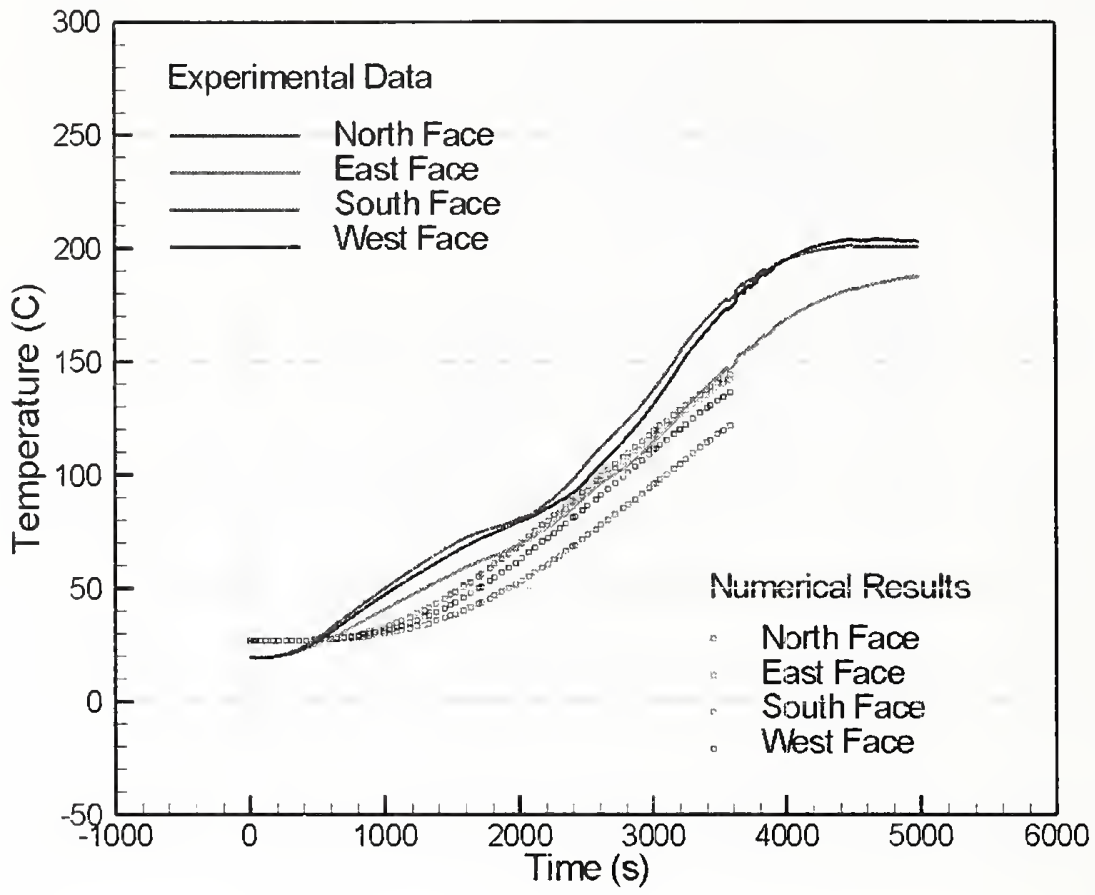

Figure 11-29. Comparison of numerical simulations with measurements for the temperature of the steel surface at four locations $0.77 \mathrm{~m}$ above the floor on the insulated column in Test 5.

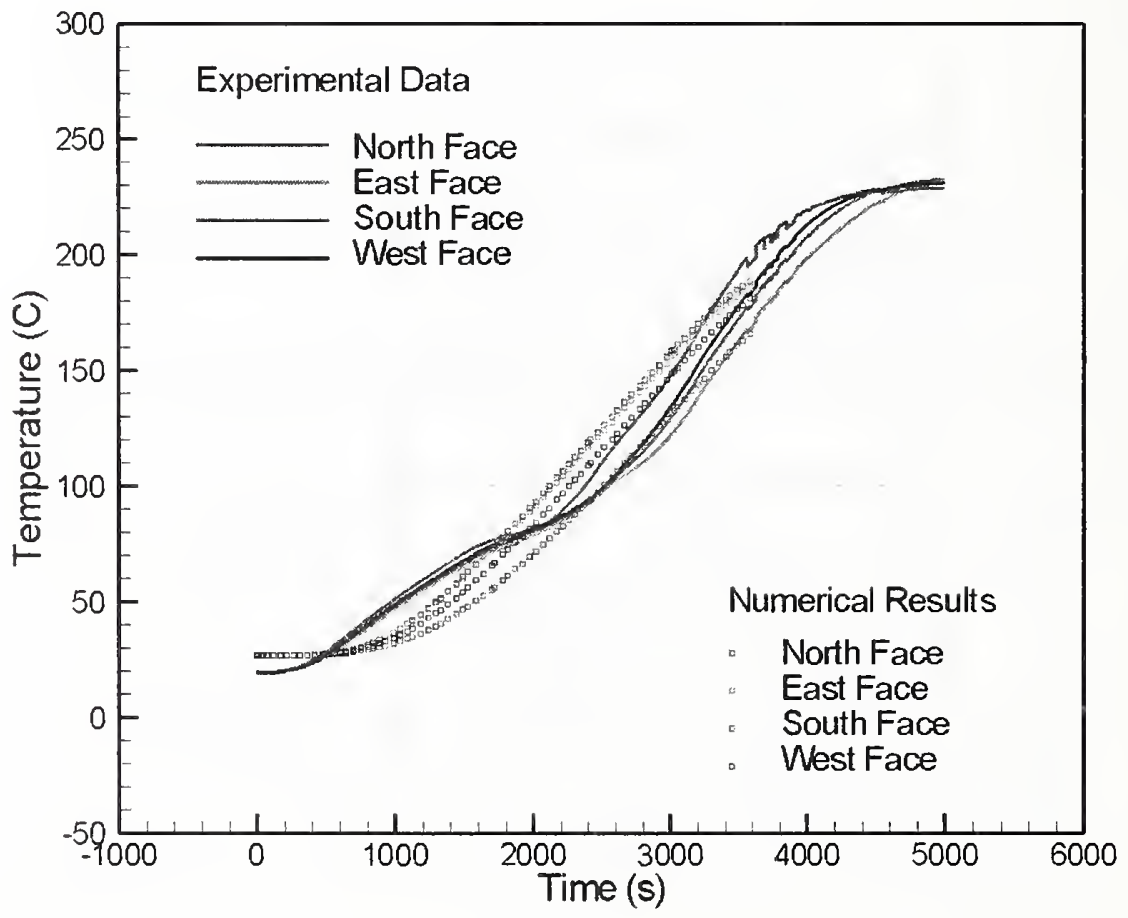

Figure 11-30. Comparison of numerical simulations with measurements for the temperature of the steel surface at four locations $2.13 \mathrm{~m}$ above the floor on the insulated column in Test 5. 


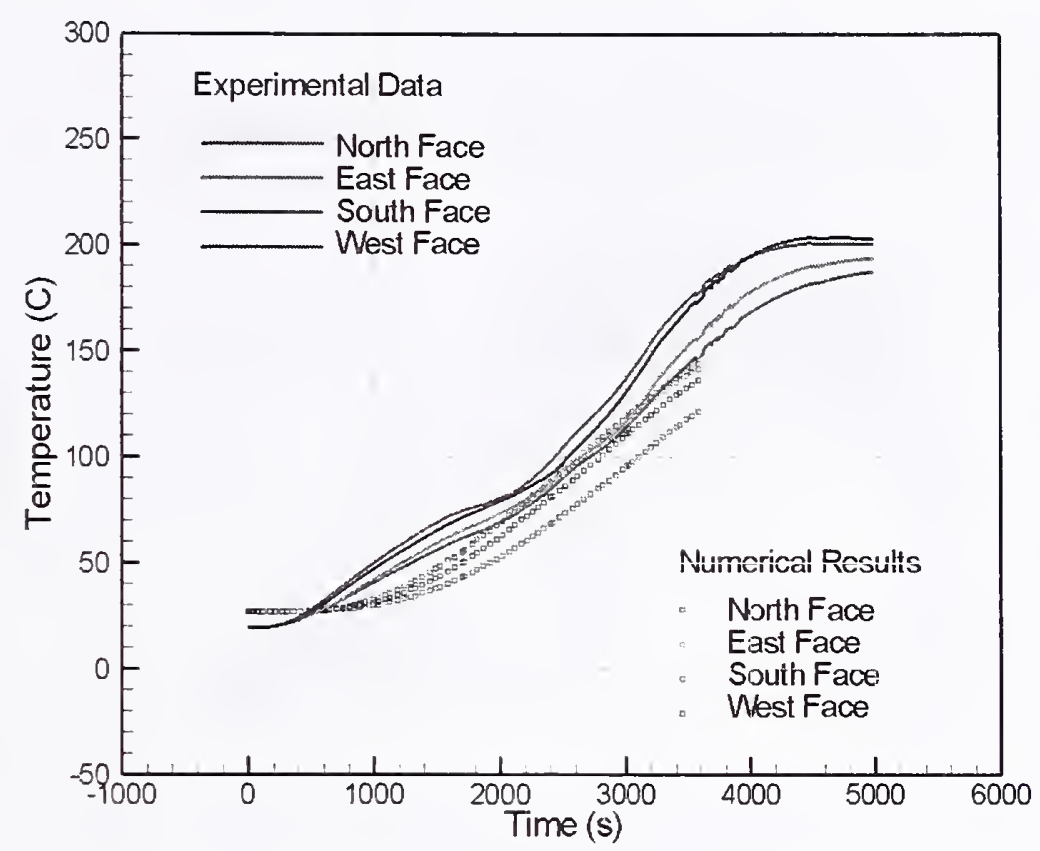

Figure 11-31. Comparison of numerical simulations with measurements for the temperature of the steel surface at four locations $3.69 \mathrm{~m}$ above the floor on the insulated steel column in Test 5.

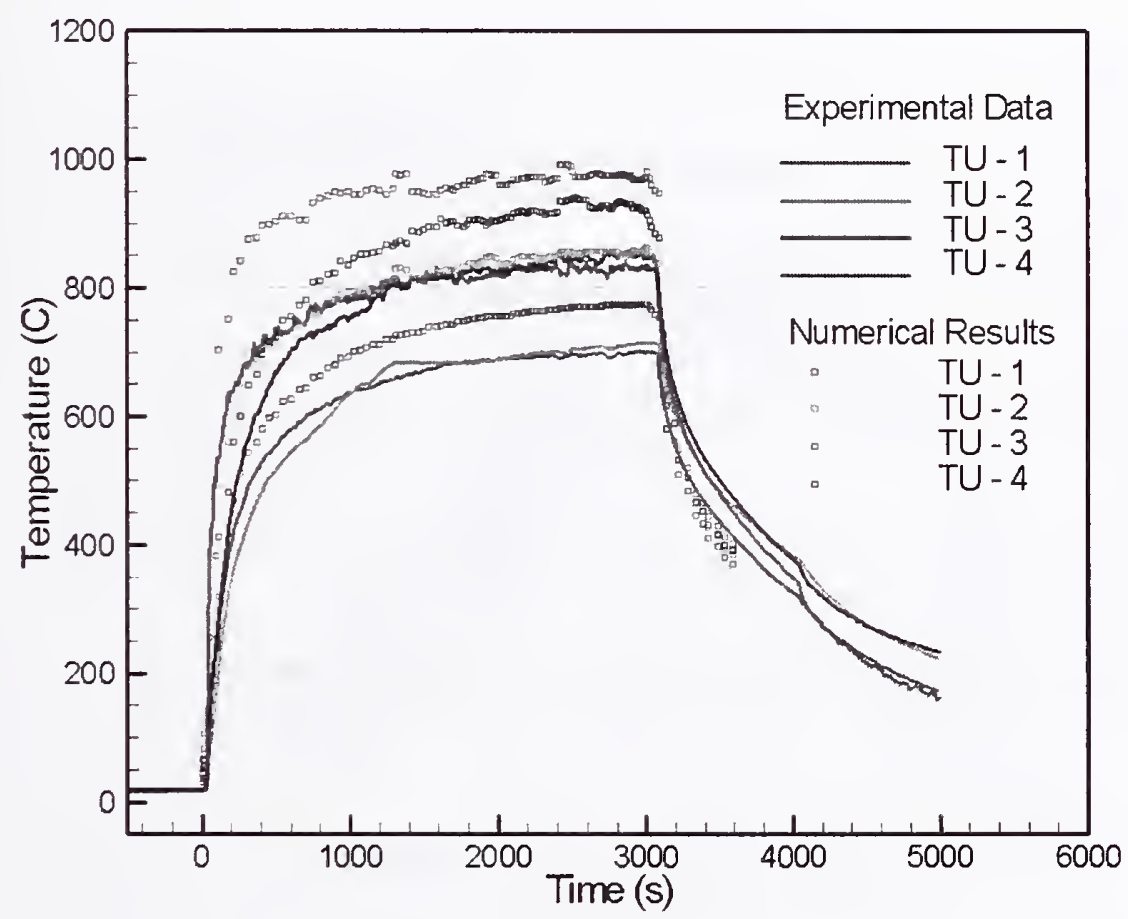

Figure 11-32. Comparison of numerical simulations with measurements for the temperature of the SFRM surface at four locations $3.70 \mathrm{~m}$ above the floor on truss A in Test 5. 


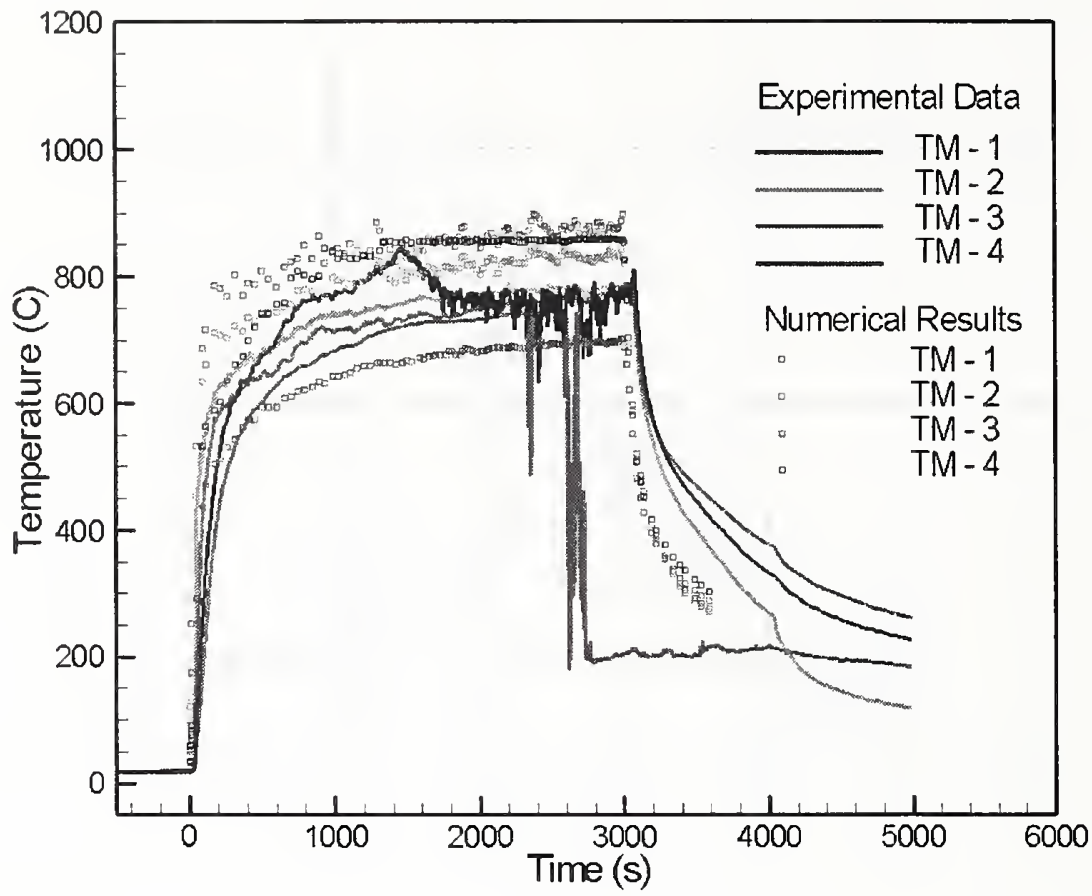

Figure 11-33. Comparison of numerical simulations with measurements for the temperature of the SFRM surface at four locations $3.29 \mathrm{~m}$ above the floor on truss $A$ in Test 5.

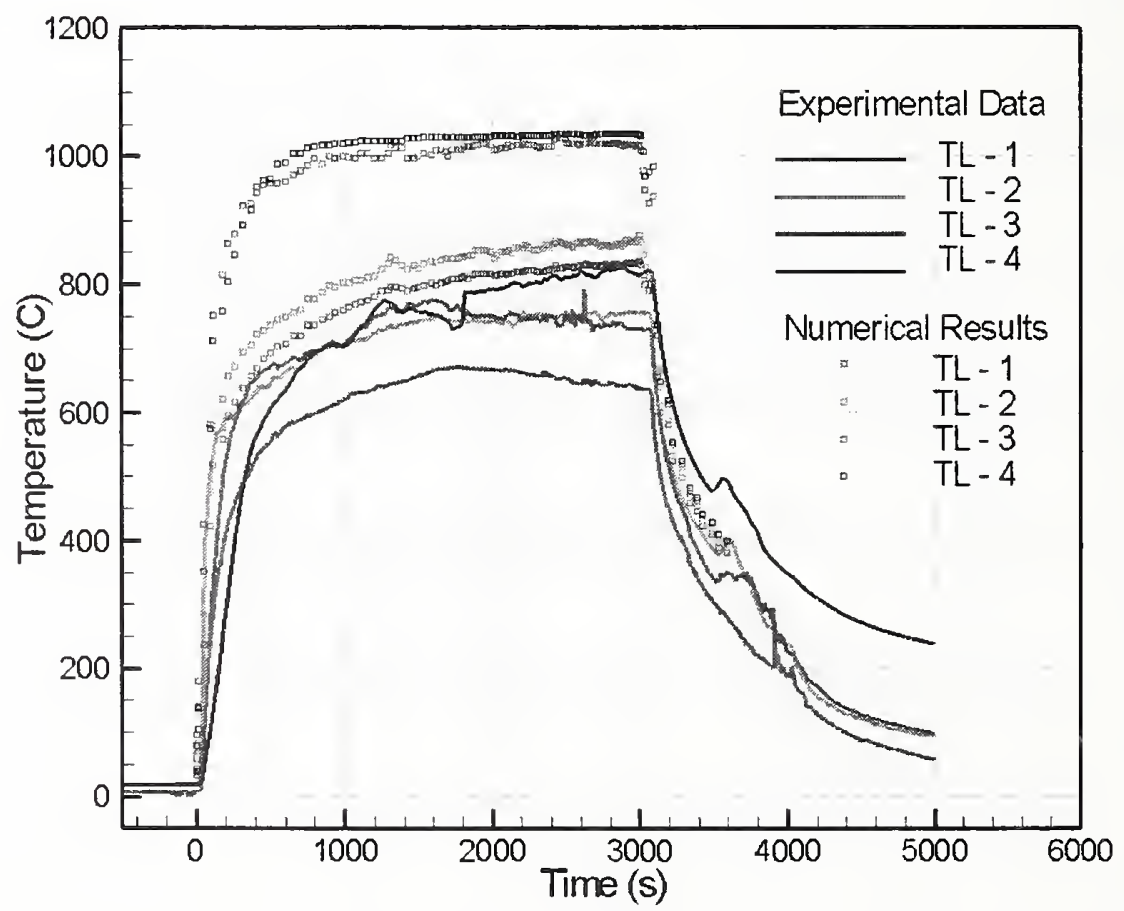

Figure 11-34. Comparison of numerical simulations with measurements for the temperature of the SFRM surface at four locations $2.89 \mathrm{~m}$ above the floor on truss $A$ in Test 5. 


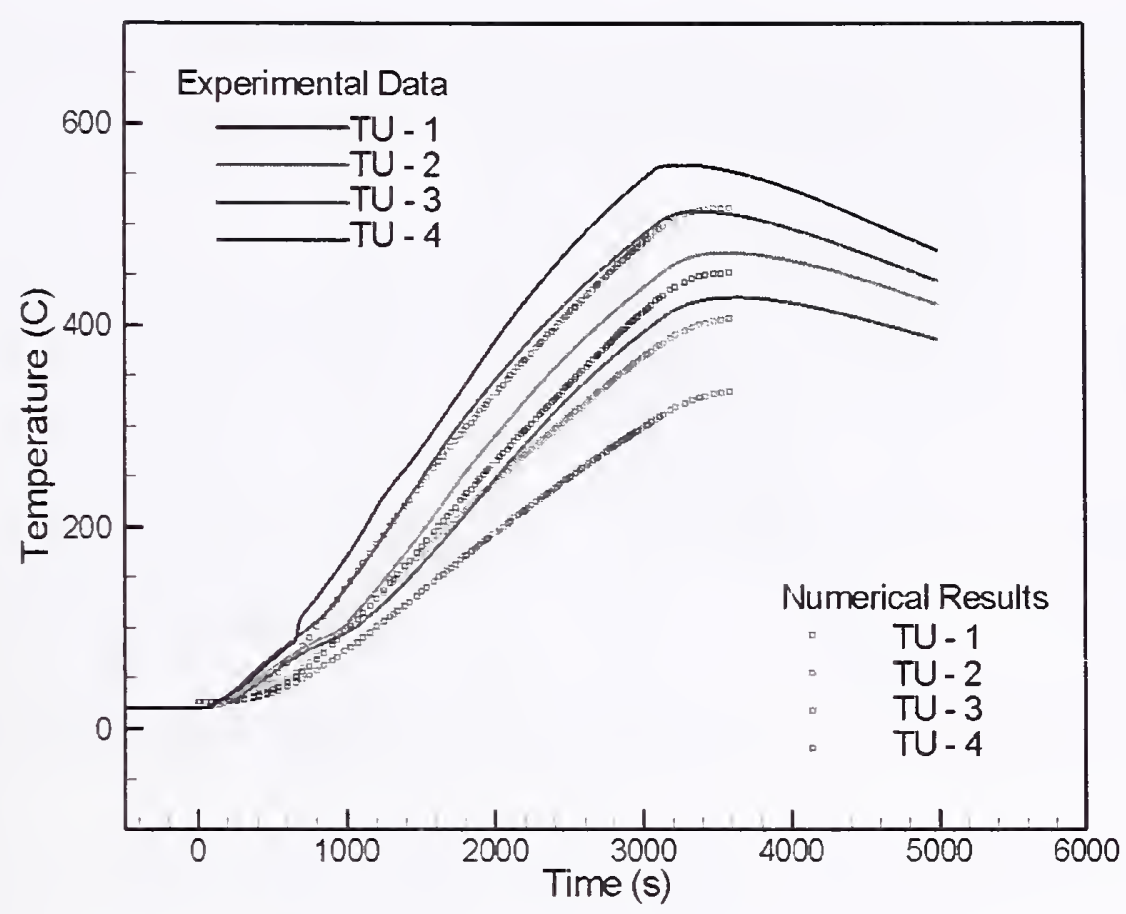

Figure 11-35. Comparison of numerical simulations with measurements for the temperature of the steel surface at four locations $3.70 \mathrm{~m}$ above the floor on truss $A$ in Test 5.

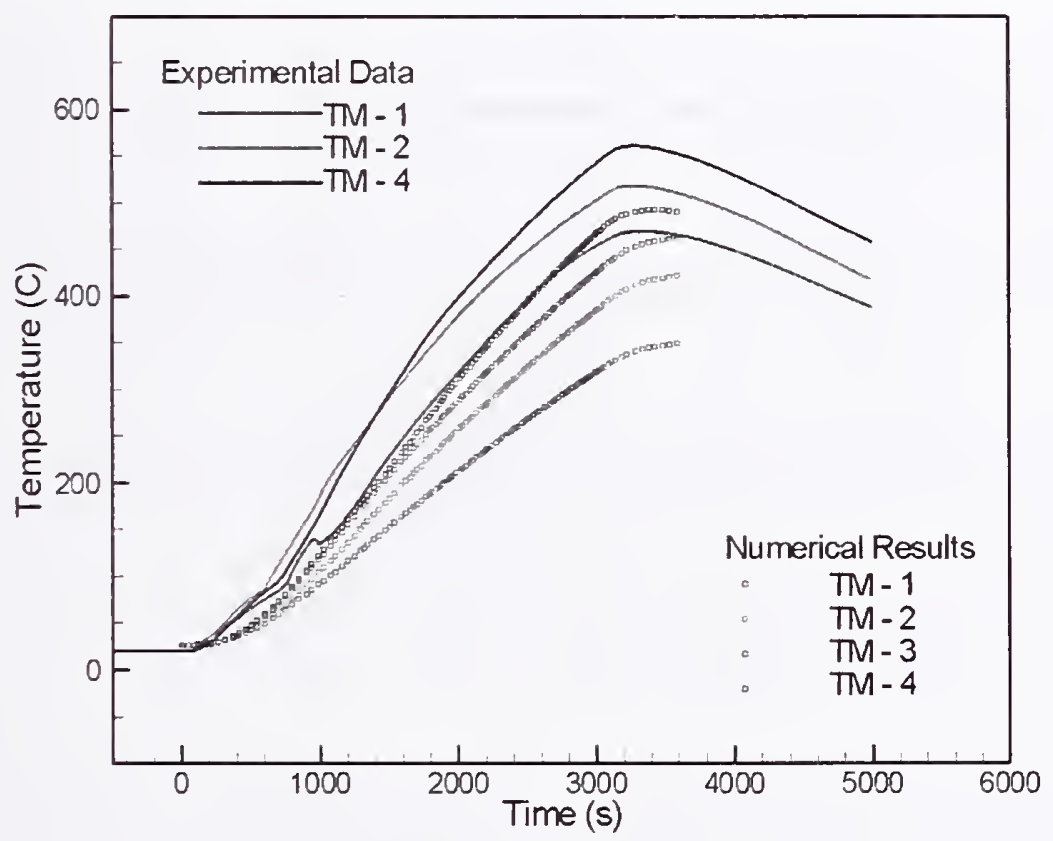

Figure 11-36. Comparison of numerical simulations with measurements for the temperature of the steel surface at four locations $3.29 \mathrm{~m}$ above the floor on truss $A$ in Test 5. 


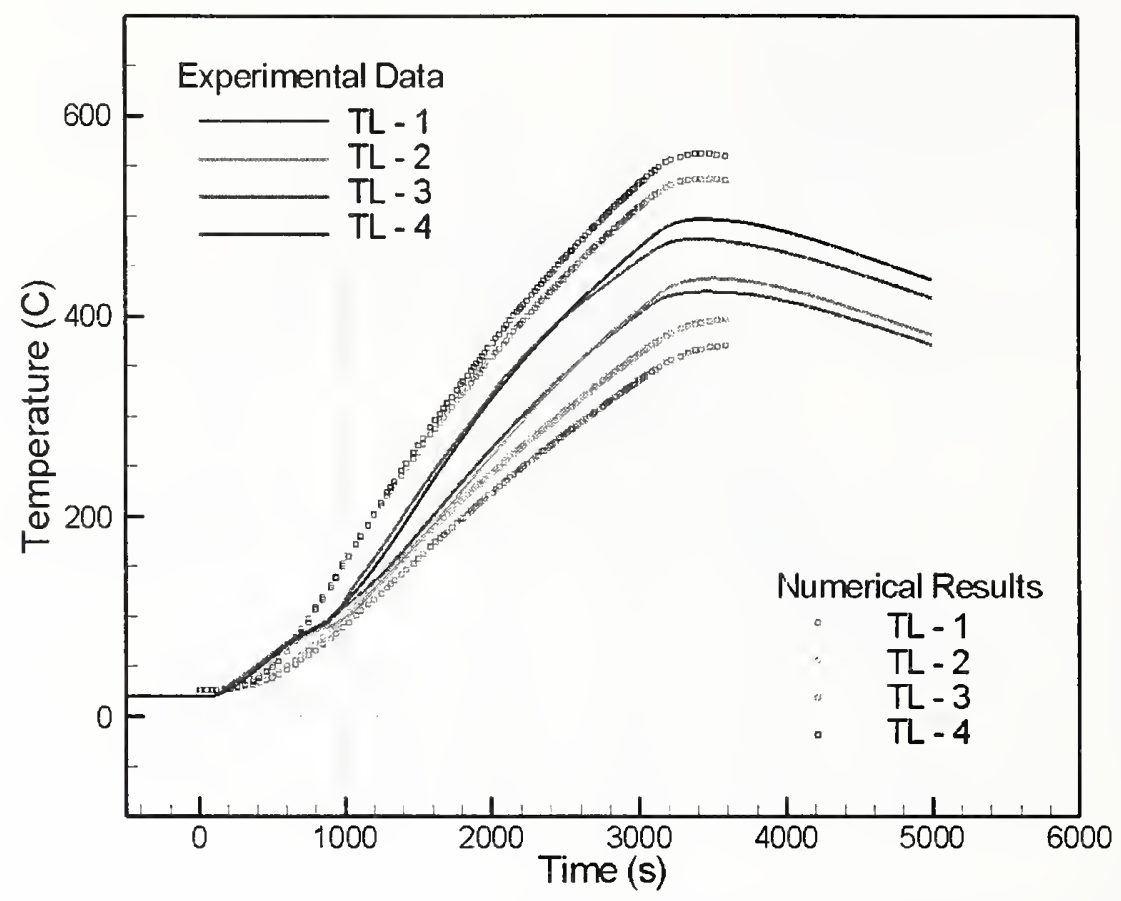

\section{Figure 11-37. Comparison of numerical simulations with measurements for the temperature of the steel surface at four locations $2.89 \mathrm{~m}$ above the floor on truss $\mathrm{A}$ in Test 5.}

The levels of agreement between the calculated and the measured values of the peak temperature for the various steel components in Tests 1 and 5 are summarized in Tables $11-1$ and 11-2, respectively. The table lists the difference between the peak values of the measured and the stimulated steel surface temperatures, normalized by the average of those temperatures on the bare or insulated steel surface. The peak temperatures typically occurred $850 \mathrm{~s}$ after ignition in Test 1 (see, for example, Fig. 11-10) and 3,300 s after ignition in Test 5 (see, for example, Fig. 11-36). In terms of thermal load on a structural element, both the maximum temperature and the temperature gradient may be important. The data in the tables represent the percentage agreement for the hottest and coolest temperature locations on each element. A negative percentage in the tables indicates that the numerical simulation was less than the measured value, and a positive percentage indicates that the simulation was greater than the measured value. The average of the absolute values of the percentages is given at the bottom of each table. The average of the percentages are shown in parenthesis. These values were negative for all four cases, indicating that the numerical predictions consistently underpredicted the measurements by a finite, but small, perccntage. For the uninsulated steel components in Test 1 , the average of the absolute value of the differences was less than 8 percent, although some individual differences were as large as 12 percent to 15 percent for the hottest temperature locations and as large as 16 percent to 20 percent for the coolest temperature locations. For the steel components with SFRM in Test 5, the average of the absolute values of the differences was less than 20 percent, although some individual differences were as large as 20 percent to 30 percent for the hottest temperature locations and as large as 30 percent to 33 percent for the coolest temperature locations. 
Table 11-1. Percentage difference between peak values of the measured and the simulated steel surface temperatures at the hottest and coolest locations on various uninsulated components in Test 1.

\begin{tabular}{|l|c|c|}
\hline \multicolumn{1}{|c|}{ Element (Vertical Position) } & Hottest Location & Coolest Location \\
\hline Bar A & $-10 \%$ & $3 \%$ \\
\hline Bar B & $8 \%$ & $-2 \%$ \\
\hline Column (2.13 m above floor) & $2 \%$ & $-2 \%$ \\
\hline Column (3.69 $\mathrm{m}$ above floor) & $-3 \%$ & $-6 \%$ \\
\hline Truss A (2.89 $\mathrm{m}$ above floor) & $-4 \%$ & $2 \%$ \\
\hline Truss A (3.29 $\mathrm{m}$ above floor) & $-6 \%$ & $-8 \%$ \\
\hline Truss A (3.70 $\mathrm{m}$ above floor) & $1 \%$ & $-10 \%$ \\
\hline Truss B (2.89 $\mathrm{m}$ above floor) & $-12 \%$ & $10 \%$ \\
\hline Truss B (3.29 $\mathrm{m}$ above floor) & $-15 \%$ & $-20 \%$ \\
\hline Truss B (3.70 $\mathrm{m}$ above floor) & $-6 \%$ & $-16 \%$ \\
\hline Absolute Value of Average (Average) & $6.7 \%(-4.5 \%)$ & $7.9 \%(-5.1 \%)$ \\
\hline
\end{tabular}

Table 11-2. Percentage difference between peak values of the measured and the simulated steel temperatures for the hottest and coolest locations on the steel surface of various components with SFRM in Test 5.

\begin{tabular}{|l|c|c|}
\hline \multicolumn{1}{|c|}{ Element } & Hottest Location & Coolest Location \\
\hline Bar $^{\text {a }}$ & $8 \%$ & $3 \%$ \\
\hline Column $(0.77 \mathrm{~m}$ above floor $)$ & $-20 \%$ & $3 \%$ \\
\hline Column $(2.13 \mathrm{~m}$ above floor $)$ & $-11 \%$ & $-13 \%$ \\
\hline Column (3.69 $\mathrm{m}$ above floor) & $-30 \%$ & $25 \%$ \\
\hline Truss A (2.89 $\mathrm{m}$ above floor) & $15 \%$ & $-15 \%$ \\
\hline Truss A (3.29 m above floor) & $-15 \%$ & $-33 \%$ \\
\hline Truss A (3.70 $\mathrm{m}$ above floor) & $-10 \%$ & $-30 \%$ \\
\hline Absolute Value of Average (Average) & $16 \%(-9 \%)$ & $20 \%(-11 \%)$ \\
\hline
\end{tabular}

a. Only one bar was tested in Test 5 .

The temperatures of the steel surfaces in Tests 1 and 5 were controlled by the transient heat flux boundary conditions, which were driven mainly by the upper layer gas temperature. The magnitude of the disagreement shown in Tables 11-1 and 11-2 cannot be explained solely by uncertainty in the measurement of the surface temperature of the uninsulated steel in Test 1, which was approximately 2 percent (bounded by $+1{ }^{\circ} \mathrm{C}$ and $-9^{\circ} \mathrm{C}$ ), nor by the uncertainty in the measurement of the surface temperature of the steel with the SFRM in Test 5 , which was approximately 1 percent $\left( \pm 5^{\circ} \mathrm{C}\right)$ for the highest temperature measured.

Table 11-2 shows the percentage difference between peak values of the measured and the simulated steel surface temperatures at the hottest and coolest locations on various uninsulated components in Test 5 . The percentage differences were much higher than analogous comparisons for Test 1 (shown in Table 11-1). Test 1 and Test 5 were somewhat similar. Although both tests used heptane as a fuel, Test 5 had a higher heat release rate ( $3 \mathrm{MW}$ rather than $2 \mathrm{MW}$ ) and was longer in duration (50 min rather than $14 \mathrm{~min}$ ) than Test 1. Other experimental parameters did not change from Test 1 to Test 5 . The agreement between 
FDS simulations of the upper layer gas temperature and the experimental measurements was very similar for Test 1 and Test 5. A review of the data in Chapter 10 shows that the percentage difference in the peak value of the upper layer gas-phase temperatures on the intake and exhaust sides of the compartment was 2 percent and 5 percent in Test 5 (see Figs. 10-11 and 10-12), and 5 percent and 3 percent in Test 1 (see Figs. 10-3 and 10-4). The difference in the nature of the agreement between the FSI and the measurements for Test 1 and Test 5 is attributed to the effects of the SFRM, which was present in Test 5 , but not in Test 1. Variation in the SFRM thickness was highlighted in Chapter 9 in which the coefficient of variation was reported to be 24 percent, 7 percent, and 27 percent for the bars, column, and truss $\mathrm{A}$ in Test 5, respectively (see Tables 9-2, 9-3, and 9-4a.). The uncertainty in SFRM thickness can have a large impact on the predicted steel temperatures.

\subsection{MODEL SENSITIVITY}

Model sensitivity was considered in an effort to understand the effect of uncertainty of the various input parameters used in the NIST FDS and FSI models on the calculated thermal response of the structural steel components. This information is useful for understanding the differences between the simulated and measured temperature behavior of the steel members in the fire tests. A key focus of the sensitivity study was the effect of the gas-phase heat release rate and the FDS grid resolution on the calculated thermal response of the structural components. The FSI used the upper layer temperature, absorption coefficient, layer height, and the lower layer temperature obtained from FDS simulations as model input. All of these parameters are controlled by the fire heat release rate. Other effects, such as the impact of the SFRM thickness on the calculated temperature, are also considered below.

To determine the effect of variation of the fire heat release rate on the calculated thermal response of the structural steel components, the results of the FDS calculations presented in Chapter 10 for the case of a 10 percent higher heat release rate and reduced grid resolution for Test 1 were considered. The results of the FDS calculations for upper layer temperature, absorption coefficient, layer interface height, and the lower layer temperature are shown in Figs. 11-38 through 11-41. These simulation results should be compared to the results for the baseline case shown in Figs. 11-1 and 11-2. For the increased heat release rate, the FDS rcsults showed that the upper layer temperature increased (see Sec. 10.4.1 for a complete discussion), whereas the absorption coefficient, the layer height, and the lower layer temperatures exhibited only small changes. For the coarse grid FDS calculation, all of the parameters exhibited significant changes. For example, the upper layer temperature decreased approximately $100{ }^{\circ} \mathrm{C}$, and the absorption coefficient decreased approximately 10 percent. The coarse grid calculations tended to create upper layer temperature and layer height distributions that were nearly uniform. These two sets of FDS results were used as input in the NIST FSI to predict the thermal behavior of the steel components. 


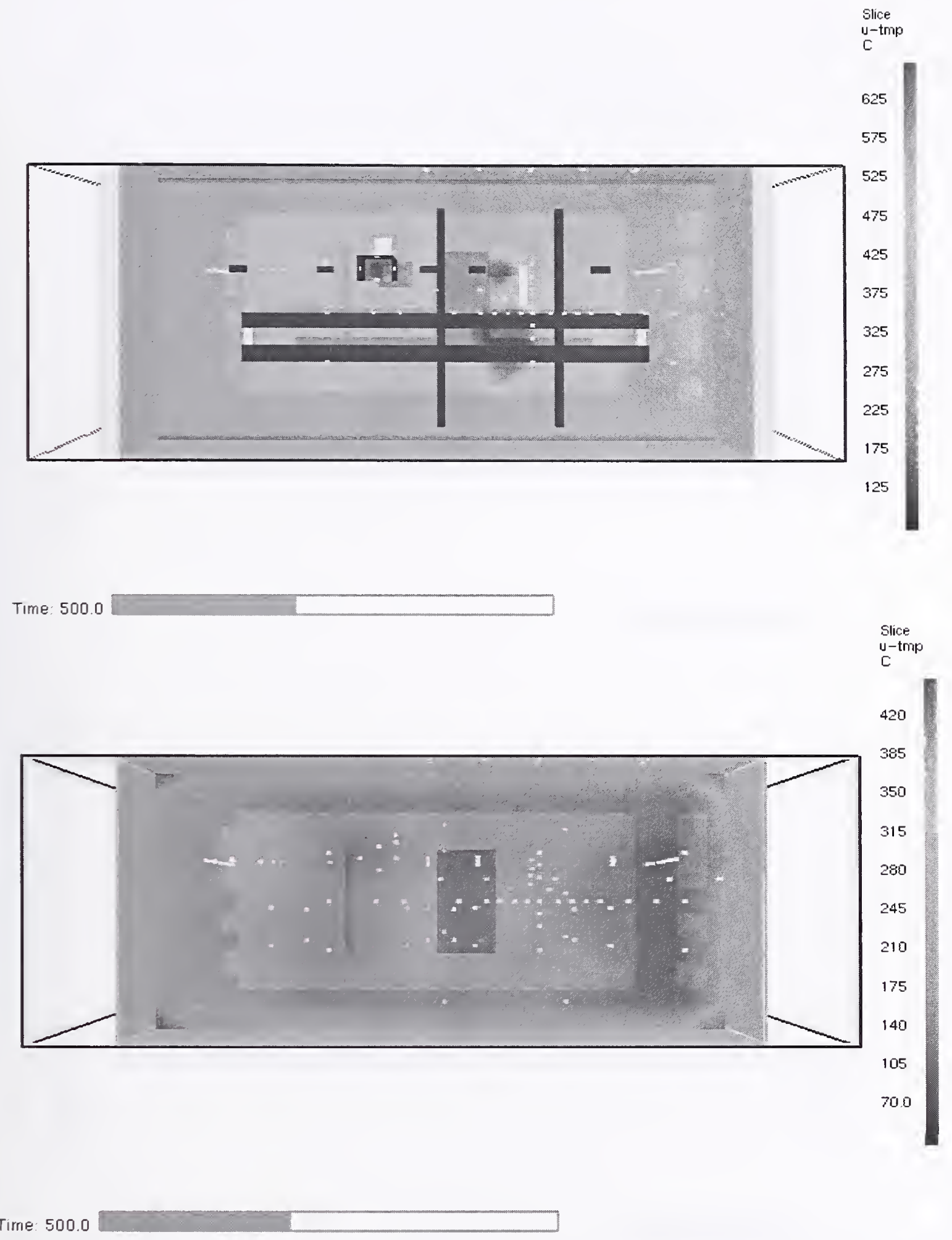

Figure 11-38. FDS simulation of the upper layer temperature on a plane $3.01 \mathrm{~m}$ above the floor after $500 \mathrm{~s}$ in Test 1 using a heat release rate increased by 10 percent (top figure) and a crude mesh with $50 \mathrm{~cm}$ resolution (bottom figure). 

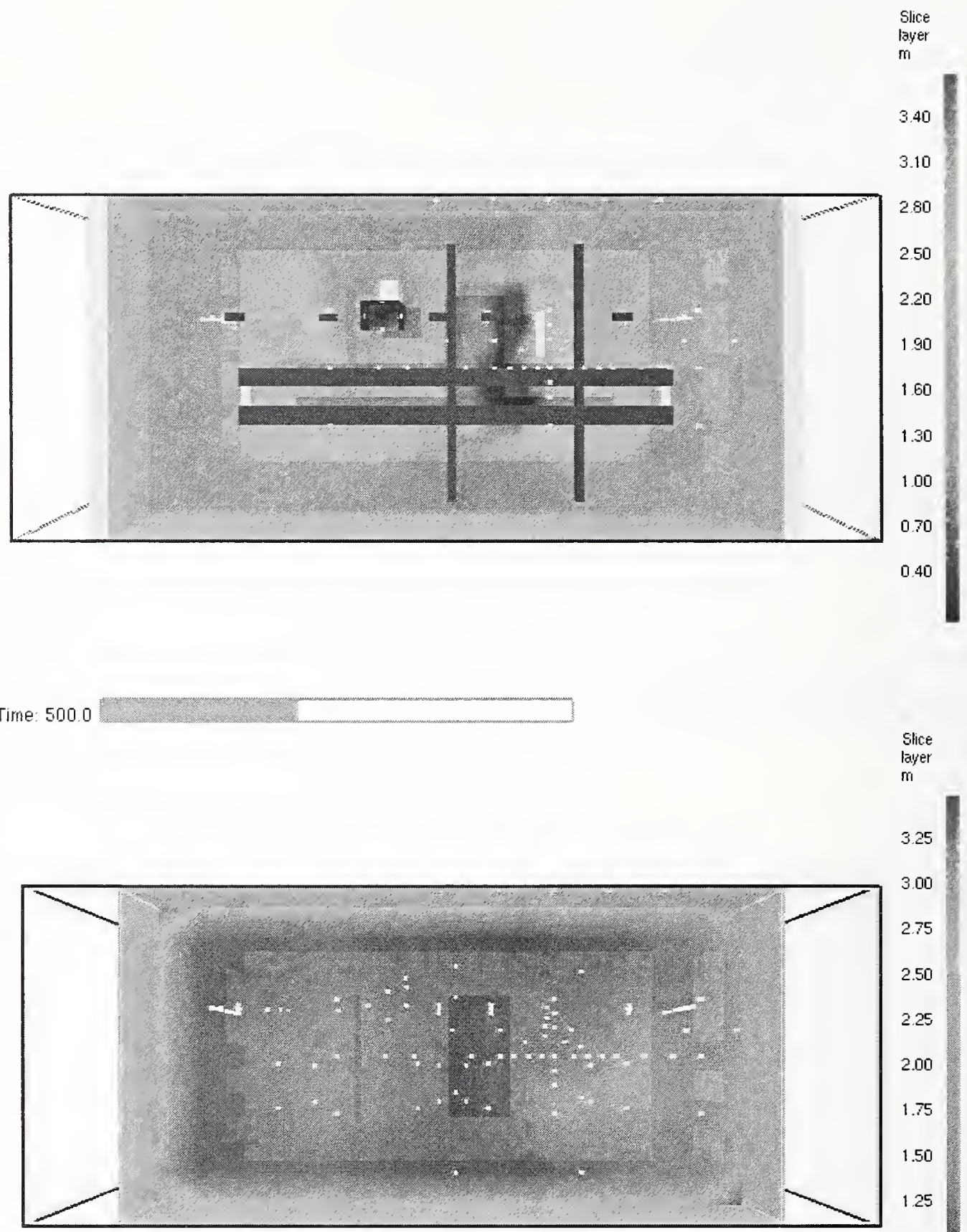

3.00

Figure 11-39. FDS simulation of the layer interface height after $500 \mathrm{~s}$ in Test 1 using a heat release rate increased by 10 percent (top figure) and a crude mesh with $50 \mathrm{~cm}$ resolution (bottom figure). 

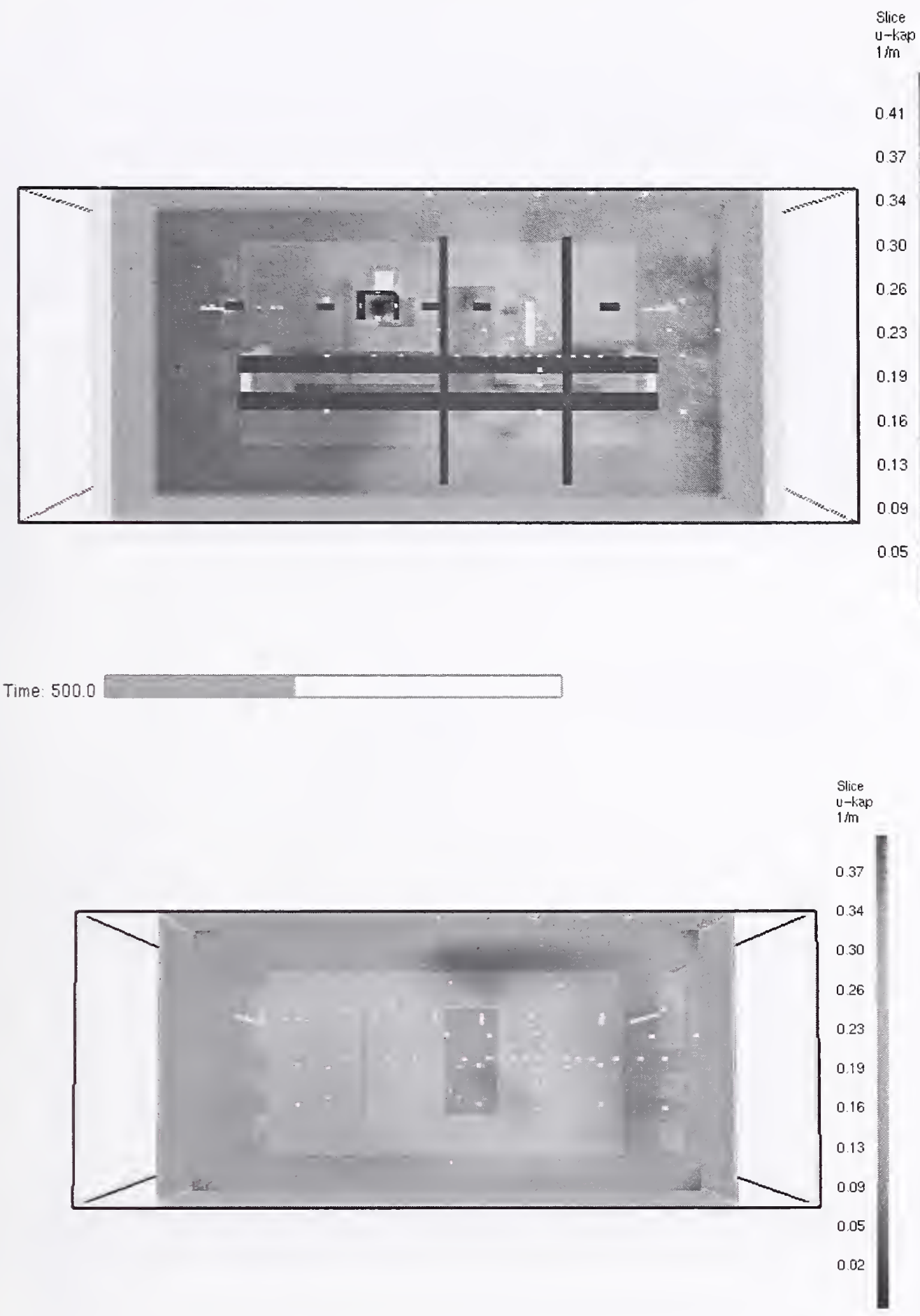

Time: 5000

Figure 11-40. FDS simulation of the absorption coefficient on a plane $3.01 \mathrm{~m}$ above the floor after $500 \mathrm{~s}$ in Test 1 using a heat release rate increased by 10 percent (top figure) and a crude mesh with $50 \mathrm{~cm}$ resolution (bottom figure). 

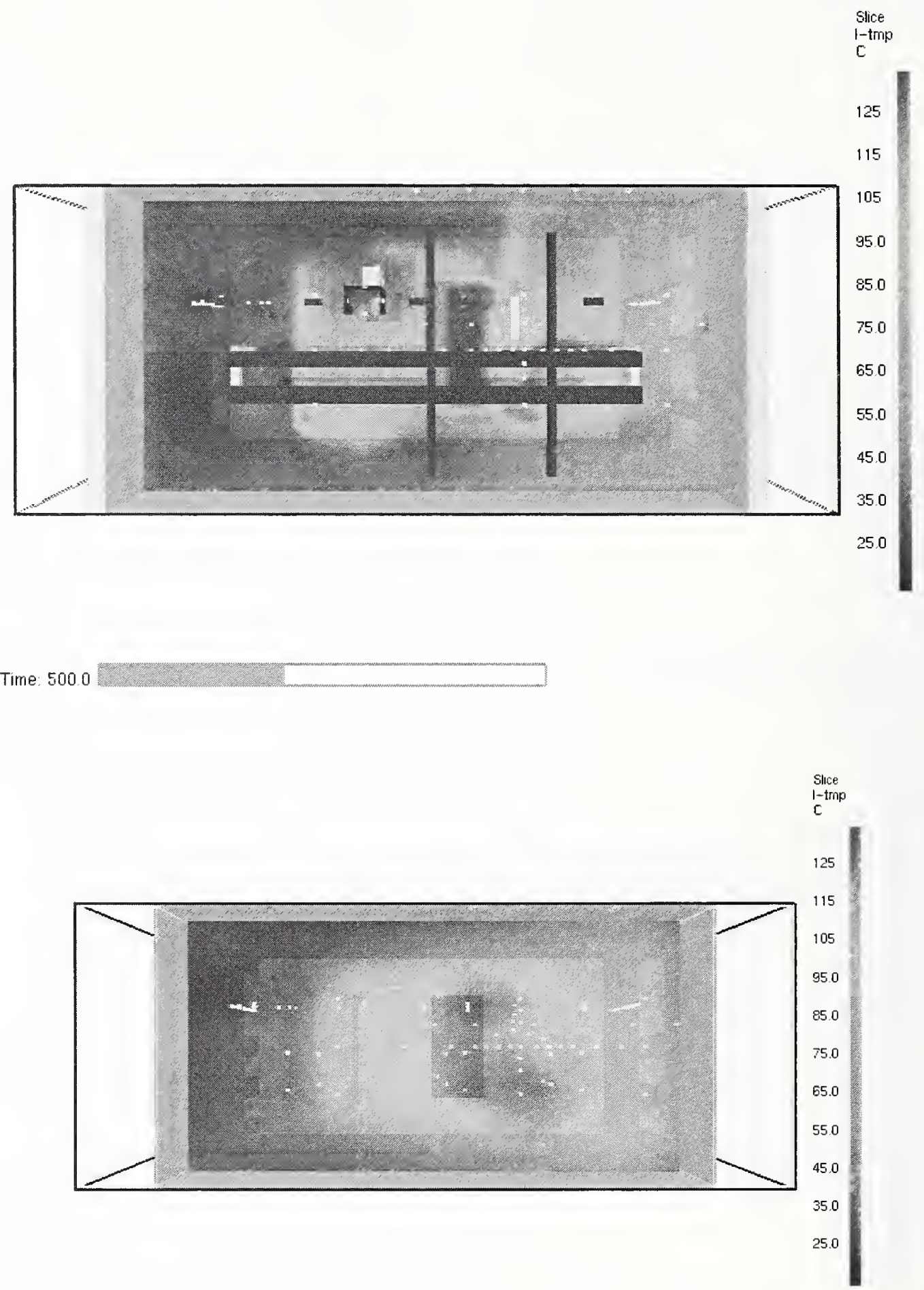

Figure 11-41. FDS simulation of the lower layer temperature after $500 \mathrm{~s}$ in Test 1 using a heat release rate increased by 10 percent (top figure) and a crude mesh with $50 \mathrm{~cm}$ resolution (bottom figure). 


\subsubsection{Sensitivity to Heat Release Rate}

Figures 11-42 and 11-43 show the predicted steel temperatures for bars A and B in Test 1, respectively, corresponding to the FDS simulation with a heat release rate 10 percent higher than the baseline value. The computed transient steel temperatures for the higher heat release rate fire were similar in shape to those computed using the baseline heat release rate (shown in Figs. 11-9 and 11-10), but the rate of the temperature increase was always larger. This led to simulated temperatures that were 5 percent to 21 percent higher than values in the baseline case, depending on location, which either improved or worsened agreement with the measurements.

Figures 11-44 and 11-45 show the predicted steel surface temperature at two different heights on the column in Test 1 for a 10 percent higher heat release rate than that used in the baseline simulations shown in Figs. 11-13 and 11-14. In this case, the elevated steel temperatures were paradoxically lower for the increased gas-phase heat release rate. This occurred because the flame tended to bend away from the column for the simulated fire with the higher heat release rate.

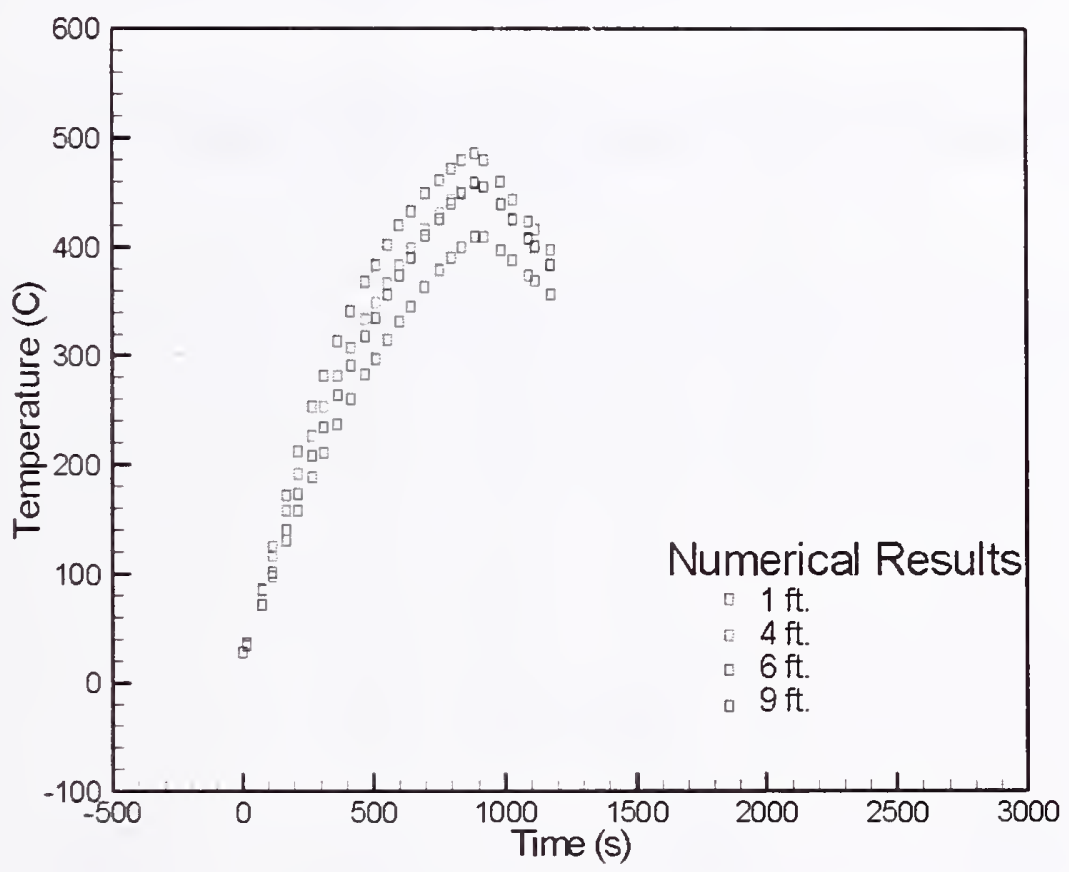

Figure 11-42. Numerical predictions of the steel surface temperature on bar $A$ in Test 1 for an FDS calculation performed with a heat release rate 10 percent above baseline. 


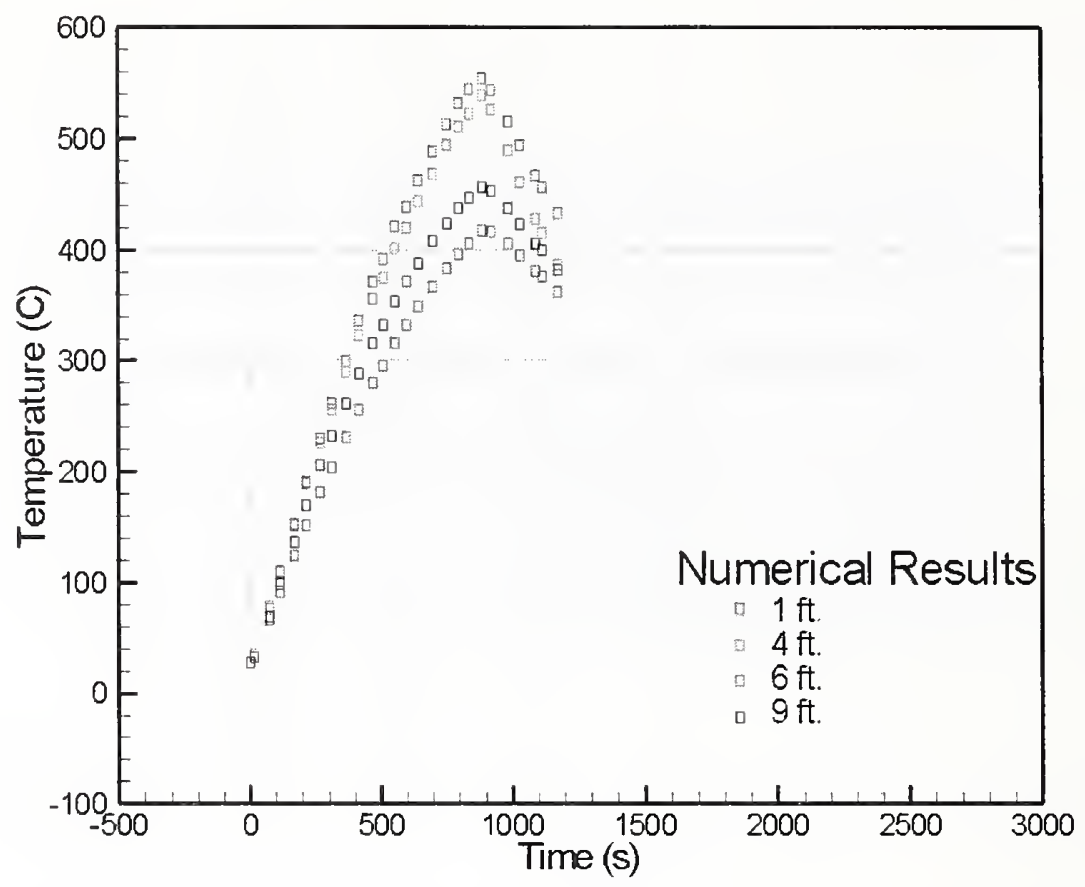

Figure 11-43. Numerical predictions of the steel surface temperature on bar B in Test 1 for an FDS calculation performed with a heat release rate 10 percent above baseline.

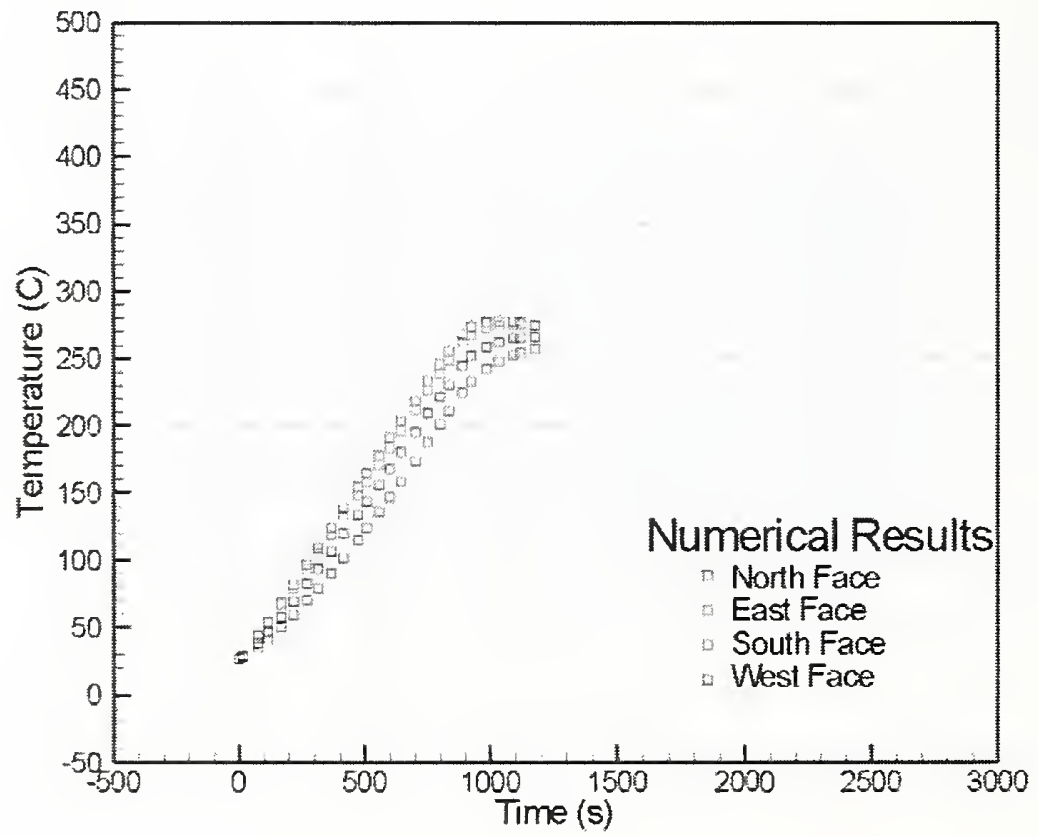

Figure 11-44. Numerical predictions of the steel surface temperature for the column in Test 1 at $3.69 \mathrm{~m}$ above the floor for an FDS calculation performed with a heat release rate 10 percent above baseline. 


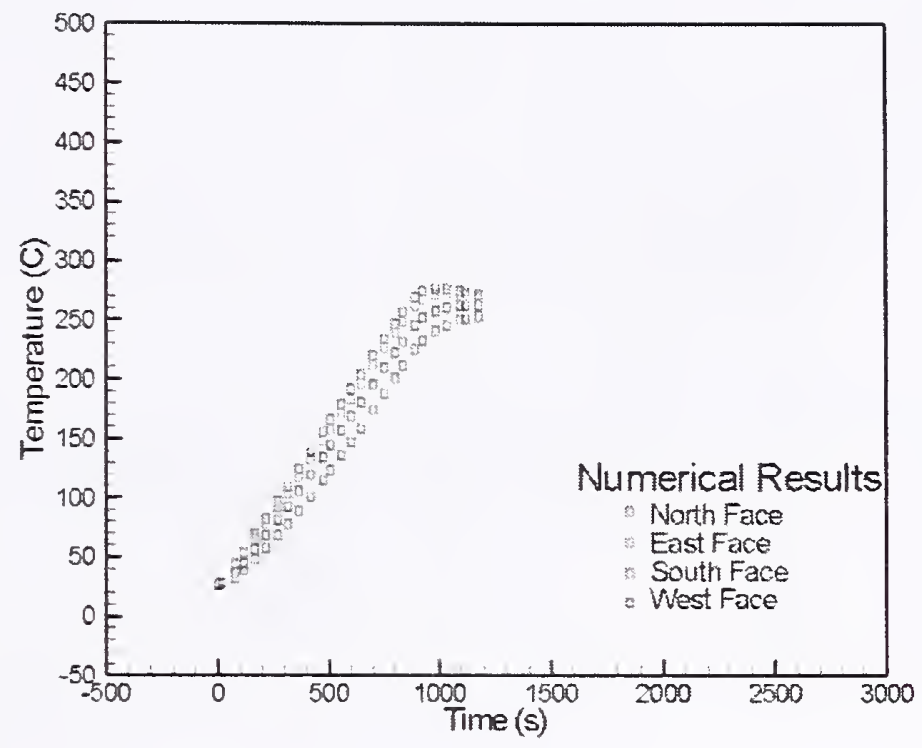

Figure 11-45. Numerical predictions of steel surface temperature for the column in Test 1 at $2.13 \mathrm{~m}$ above the floor for an FDS calculation performed with a heat release rate 10 percent above baseline.

Figures 11-46 through 11-48 show the simulated steel surface temperature on truss $\mathrm{A}$ in Test 1 for a 10 percent higher heat release rate than that used in the baseline calculations (which are shown in Figs. 11-17 through 11-19, respectively). The simulations showed that the temperature of the steel on truss $\mathrm{A}$ increased 4 percent to 29 percent for the higher heat release rate, depending on the exact location.

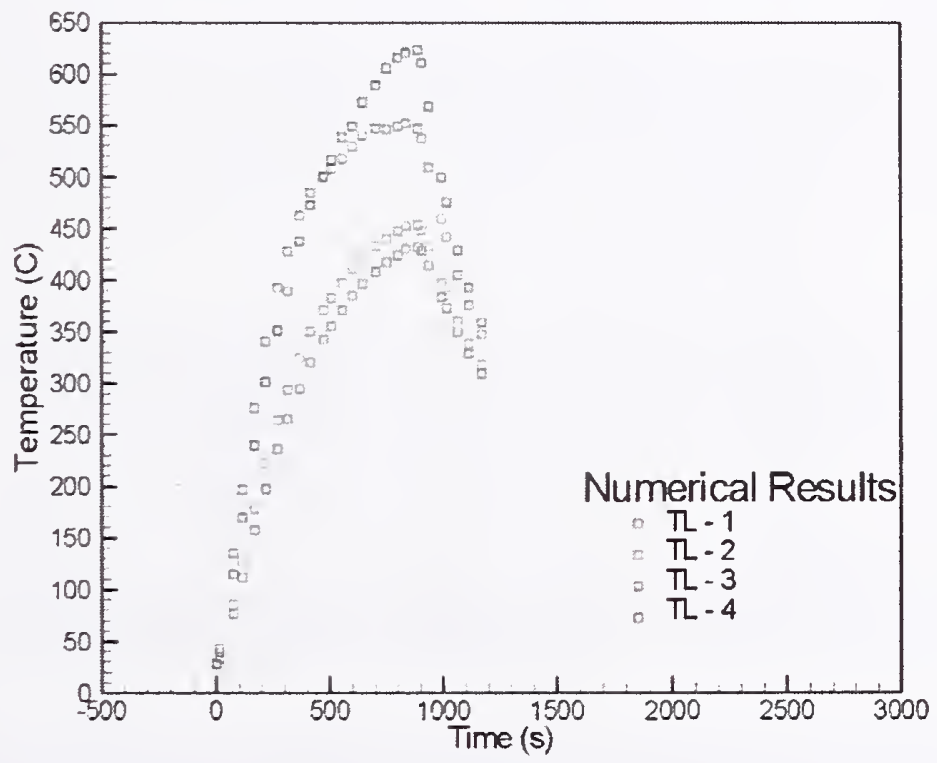

Figure 11-46. Numerical predictions of steel surface temperature at four locations $2.89 \mathrm{~m}$ above the floor on truss $\mathrm{A}$ in Test 1 for an FDS calculation performed with a heat release rate 10 percent above baseline. 


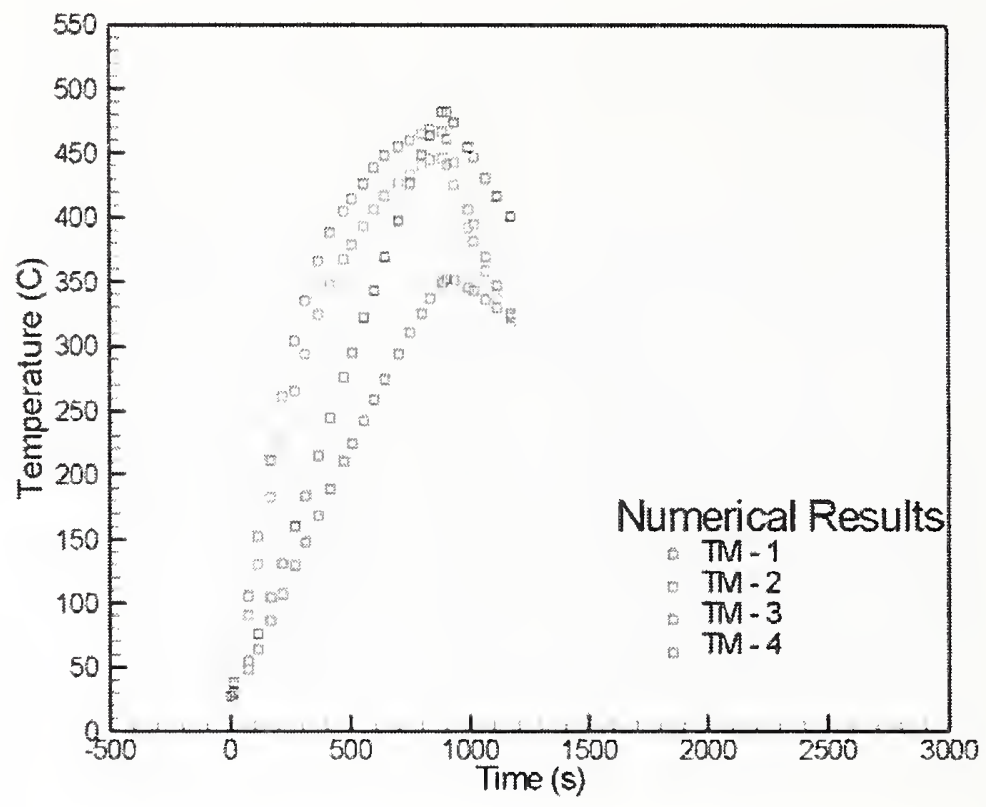

Figure 11-47. Numerical predictions of steel surface temperature at four locations $3.29 \mathrm{~m}$ above the floor on truss A in Test 1 for an FDS calculation performed with a heat release rate 10 percent above baseline.

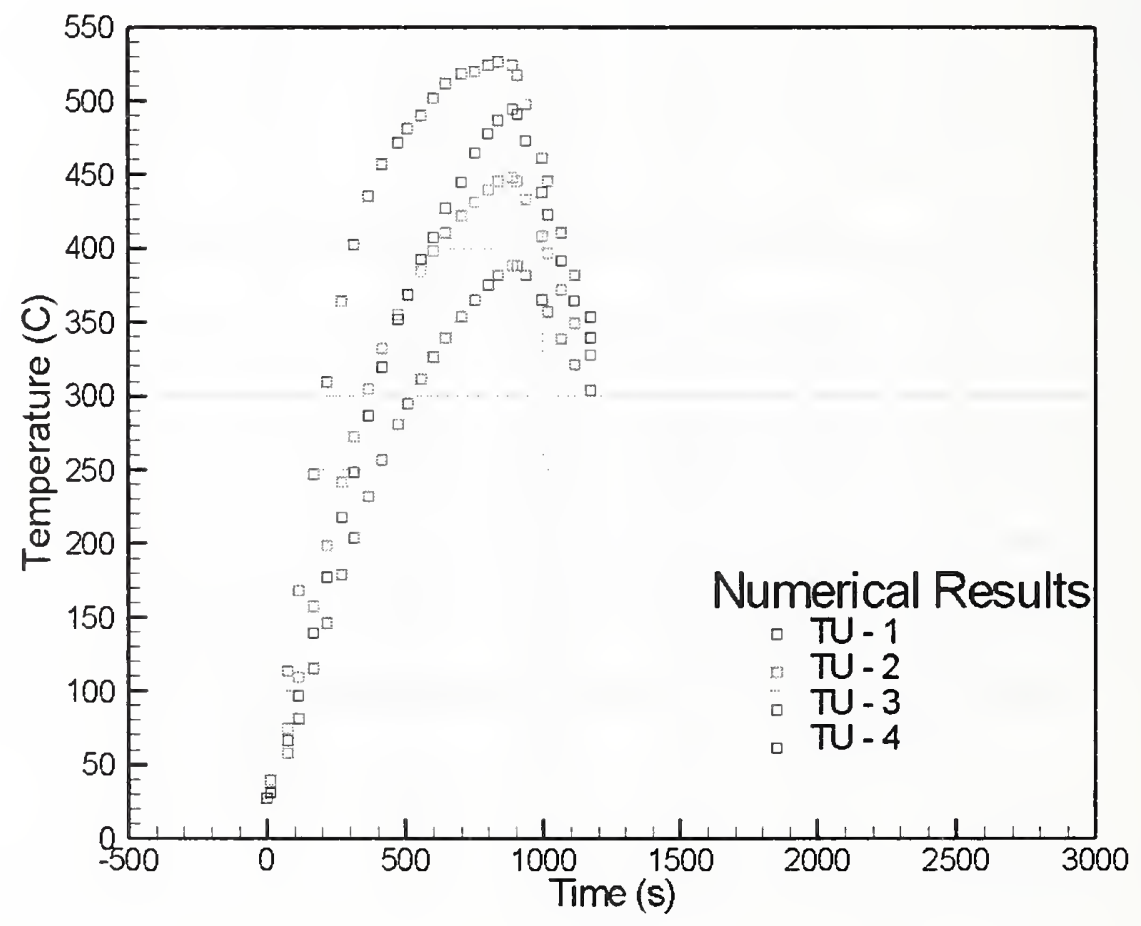

Figure 11-48. Numerical simulations of the steel surface temperature at four locations $3.70 \mathrm{~m}$ above the floor on truss A in Test 1 for an FDS calculation performed with a heat release rate 10 percent above baseline. 
Table 11-3 summarizes the FSI simulation results shown in Figs. 11-42 through 11-48. The table lists the percentage difference in the peak value of the simulated temperature profiles betwcen the baseline simulations and those with a 10 percent higher heat release rate (and consequent 9 percent increase in the upper layer temperature) at the hottest and coolest locations on the steel surface of various uninsulated components in Test 1. The increased heat release rate and upper layer temperature led to changes in the simulated steel surface temperature of 21 percent on average at the hottest locations on each of the components, with a range from -38 percent to +29 percent. Table 11-3 shows that the percentage change at the coolest locations was smaller on average than at the hottest locations.

Table 11-3. Percentage difference in the peak value of temperatures between the baseline simulations and those with a 10 percent higher heat release rate at the hottest and coolest locations on the steel surface of various uninsulated components in Test 1.

\begin{tabular}{|l|c|c|}
\hline \multicolumn{1}{|c|}{ Element (Vertical Position) } & Hottest Location & Coolest Location \\
\hline Bar A & $5 \%$ & $5 \%$ \\
\hline Bar B & $21 \%$ & $14 \%$ \\
\hline Column (3.69 m above floor) & $-33 \%$ & $-22 \%$ \\
\hline Column (2.13 m above floor) & $-38 \%$ & $-26 \%$ \\
\hline Truss A (2.89 m above floor) & $20 \%$ & $5 \%$ \\
\hline Truss A (3.29 m above floor) & $29 \%$ & $8 \%$ \\
\hline Truss A (3.70 $\mathrm{m}$ above floor) & $4 \%$ & $4 \%$ \\
\hline Absolute Value of Average & $21 \%$ & $12 \%$ \\
\hline
\end{tabular}

The increase in the maximum calculated steel temperatures seen in Figs. 11-42 through 11-45 for locations on the bars, column, and truss A should be compared with the change in the upper layer gas temperatures calculated by FDS, which increased by 9 percent on average for the 10 percent increase in the heat release rate above baseline (see Sec. 10.4.1). The change in the simulated steel surface temperature did not change linearly with the upper layer gas temperature. The difference in the temperature increases on the steel can be attributed to subtle changes in the character of the simulated fire, including its physical location. its size, and its extent, all of which impacted the calculated flux onto the structural steel components and, subsequently, the calculated temperature distribution in the steel components.

Chapter 10 showed that the FDS simulations were in agreement with upper layer gas temperature measurements. The absolute difference between the measured and (FDS) simulated upper layer gas temperatures for Tests 1 and 5 was 4 percent on average (see Figs. 10-3 through 10-12) for locations near the east and west walls of the compartment. FDS tended to underpredict the gas temperature on the intake side of the compartment (west) and overpredict the gas temperature on the exhaust side of the compartment. The differences could be accounted for by a combination of measurcment uncertainty and sensitivity of FDS to various physical and numerical parameters, most importantly the input heat release rate, which had an expanded $(2 \sigma)$ uncertainty of 11 percent.

The difference between the measured and predicted steel surface temperatures (see Table 11-1) cannot be explained solely by measurement uncertainty, which was estimated as approximately $5{ }^{\circ} \mathrm{C}$ (or 1 percent to 2 percent depending on the absolute value of the steel surface temperature). The difference, however, can be explained through consideration of FSI model sensitivity to uncertainty in physical input parameters, 
the most important of which was the heat release rate. A sensitivity study showed that a 10 percent increase in the heat release rate led to a 21 percent higher steel surface temperature on average at the hottest locations, as compared to the baseline results for Test 1. The FSI simulation exhibited a non-linear sensitivity of the steel temperature to the fire heat release rate and associated upper layer temperatures.

The simulated thermal behavior of the steel was also sensitive to the proximity of the structural components to the fire. Chapter 10 describes how FDS did a better job predicting the heat flux to locations far from the fire, because the size, spatial extent, and precise location of the fire had less influence on the results.

\subsubsection{Sensitivity to Grid Size}

Figures 11-49 and 11-50 show the predicted steel temperature for bars A and B in Test 1 using the FDS coarse grid simulations. These results are of interest because the WTC fire calculations (NIST NCSTAR 1-5F) must be completed using a coarse grid due to computational costs. The computed steel temperatures using the coarse mesh were similar in shape to those computed using the finer mesh shown in Figs. 11-9 and 11-10, but the maximum calculated temperatures were shifted by approximately 10 percent to either larger or smaller values. The coarse mesh calculations displayed uniform temperatures along the length of the bar, which was in contrast to the fine mesh calculations, which led to finite temperature differences (15 percent) along the length of the bar. The calculations show that FDS grid resolution has a finite effect on the thermal-structural analysis, although it is not greater than the effect of model sensitivity to various model input parameters.

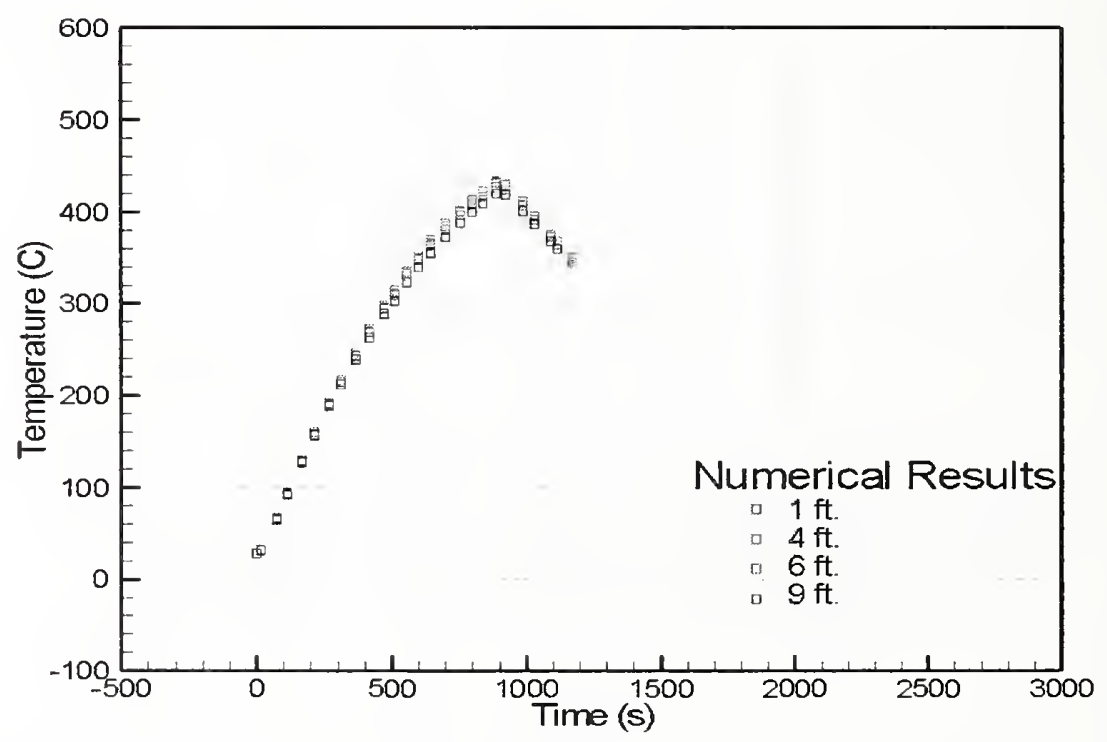

Figure 11-49. Predicted numerical results for steel temperature for bar A in Test 1. These results correspond to an FDS calculation performed with a crude mesh (50 $\mathrm{cm}$ resolution). 


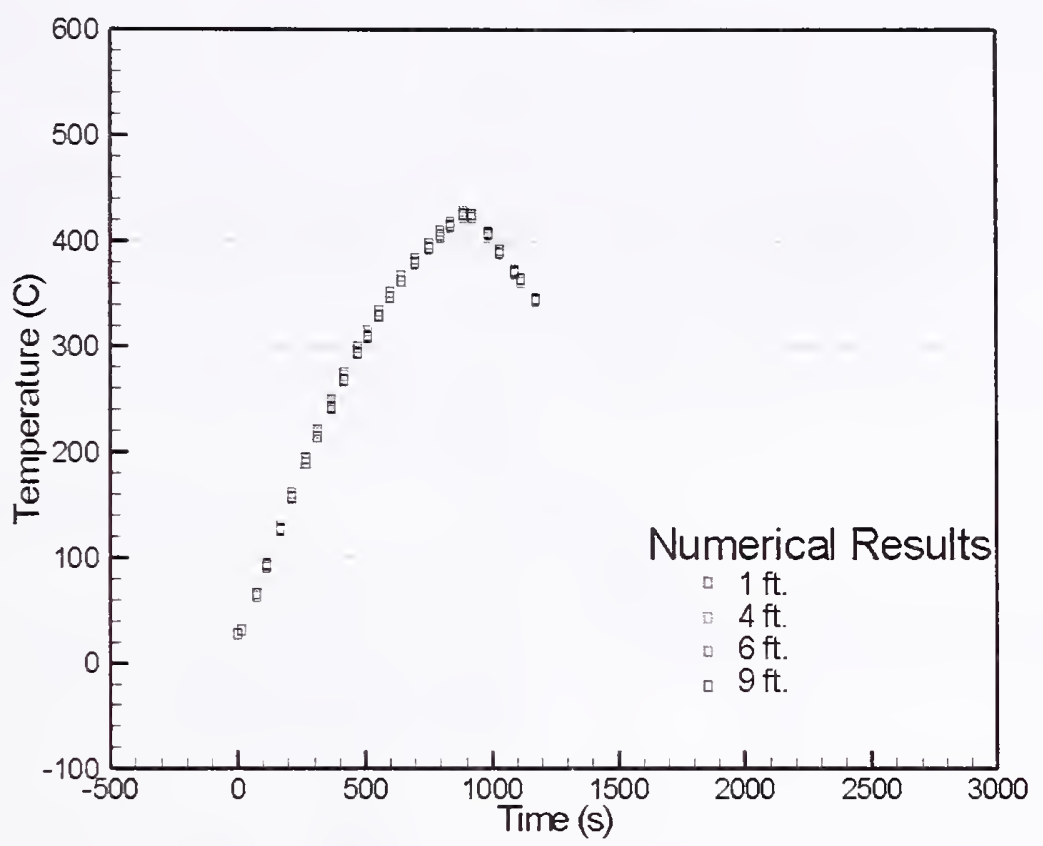

Figure 11-50. Predicted numerical results for steel temperature on bar B in Test 1. These results correspond to an FDS calculation performed with a crude mesh (50 $\mathrm{cm}$ resolution).

\subsection{SENSITIVITY TO THE THICKNESS AND THERMO-PHYSICAL PROPERTIES OF THE SPRAYED FIRE-RESISTIVE MATERIAL}

There were additional factors that may have influenced the thermal response of the steel when the SFRM was present, including variability in the thickness of the SFRM and the thermo-physical properties of the steel and the SFRM. The optical properties of the steel and the SFRM, however, probably did not play an important role, as soot rapidly coated the steel components upon ignition of the fire, as is typical of fires burning materials that produce copious amounts of soot.

The SFRM thickness was not uniform about a structural element, even a simple symmetric element such as a bar. Table 9-2 shows that on the bars, for example, the SFRM thickness was not uniform about all sides of the bar-even at a single location along the axis of the bar. The nonuniform thickness led to three-dimensional effects that impacted the thermal behavior of the SFRM, effectively increasing the uncertainty in the simulated steel temperature underneath the SFRM. The importance of this effect can be characterized by the coefficient of variation (COV) of the SFRM thickness (the ratio of the standard deviation to the mean thickness; see Sec. 9.2) and is bounded by the maximum and minimum values of the SFRM thickness. The coefficient of variation ranged from 0.17 to 0.27 for the bars, columns, and trusses.

The SFRM thickness in the calculations presented here was based on this mean value, which was assumed to be uniform over the entire length of the bar. In Test 5 for example, the mean thickness of the SFRM on the bars was measured as $2.31 \mathrm{~cm}$ and the COV was 0.24 (see Table 9-2). Figure 11-51 shows the numerical simulation of the steel surface temperature for bar A in Test 5, assuming a 25 percent 
decrease in the thickness of the SFRM. The resulting temperatures increased by approximately 10 percent as compared to the baseline results shown in Fig. 11-25. Table 9-2 also shows that locally, the SFRM thickness on some sections of the bars was smaller than the mean by as much as 45 percent. This indicates that the variation in the calculated steel surface temperature was as much as 20 percent simply from uncertainty in the SFRM thickness. NIST NCSTAR 1-5G and NIST NCSTAR 1-6A present a comprehensive sensitivity study of the role of the variation of the SFRM thickness on its effectiveness.

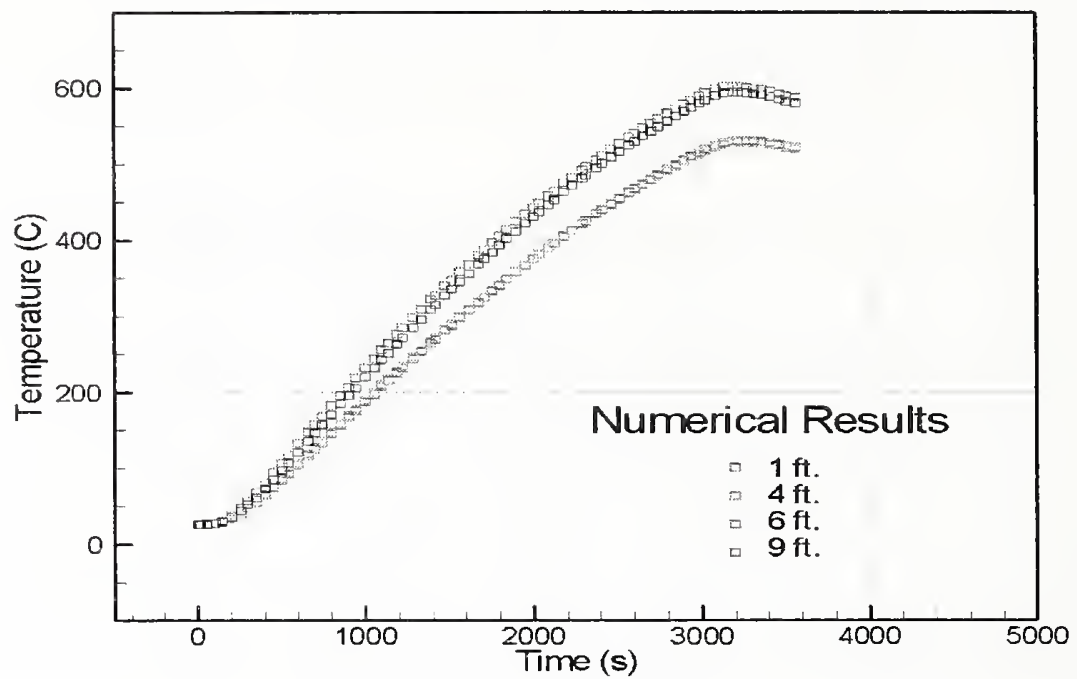

\section{Figure 11-51. Numerical predictions of steel surface temperature for bar $A$ in Test 5 assuming a SFRM thickness 25 percent below baseline.}

The effect of uncertainty in the thermal conductivity of the SFRM will also play a role. Typical uncertainty in the determination of thermal conductivity using the ASTM standard method is not better than \pm 6 percent (ASTM 2000). For insulation materials like BLAZE-SHIELD DC/F SFRM, the measurement uncertainty may be considerably larger, although it has not been quantified. According to the manufacturer, the thermal conductivity for BLAZE-SHIELD DC/F was $0.042 \mathrm{~W} / \mathrm{m}-\mathrm{K}$ at $24{ }^{\circ} \mathrm{C}$, which was quite different from Harmathy's temperature-dependent data shown in Fig. 11-4 that was used in the baseline calculations reported here. A third set of thermophysical data was obtained for the SFRM (NIST NCSTAR 1-6A). In that data set, the thermal conductivity was determined to be about 10 percent higher than the value reported by the manufacturer. The sensitivity of the calculation results to the thermophysical properties was investigated by considering the idealized situation where a $2.5 \mathrm{~cm}$ bar with $2.5 \mathrm{~cm}$ of insulation was exposed to a constant source of heat flux. The results showed a 7 percent lower steel temperature for the calculations that used the Harmathy data as compared to the calculations that used the data from NIST NCSTAR 1-6A. The sensitivity of FSI to the thermophysical properties of the SFRM increased uncertainty in the simulation (NIST NCSTAR 1-5G and NIST NCSTAR 1-6A). The results suggest that the sensitivity of FSI to the thermophysical properties was significant, but much less so than the uncertainty associated with the SFRM thickness.

\subsection{SUMMARY}

The behavior of the simulated and measured uninsulated steel temperatures was similar. Both increased in a monotonic fashion from ambient values at time equal to zero, to finite values that obtained a maximum approximately when the fuel flow and the fire stopped. The same was true for the insulated 
steel components, except that the temperatures obtained a maximum after the fuel was stopped due to lag of the thermal wave through the SFRM. In both cases, the temperatures decreased after the fire was stopped, also in a monotonic manner.

On average, the numerical predictions of the steel surface temperature were within 7 percent of the experimental measurements for the case of bare steel and within 17 percent for the steel components with SFRM with the maximum difference reading 38 percent. For the bare steel, a series of calculations showed that the differences could be attributed to model sensitivity to the heat release rate in the fire model. For the insulated steel, the differences could be attributed to model sensitivity to the SFRM coating thickness.

\subsection{REFERENCES}

ASTM International. 2000. Standard Test Method for Thermal Conductivity of Refractories by Hot Wire (Platinum Resistance Thermometer Technique), vol. 15.01. ASTM C 1113-99, Annual Book of ASTM Standards. West Conshohocken, PA.

Eurocode 4. 1994. Design of Composite Steel and Concrete Structures, ENV 1993-1-2: General, EC4, Rules - Structural Fire Design. European Committee for Standardization, Brussels, Belgium.

Harmathy. T.Z. 1983. "Properties of Building Materials at Elevated Temperatures," paper NRCC-20956 (DBR-P-1080), Division of Building Research, National Research Council, Canada, (1080), pp. 72 , March.

Prasad, K., and H.R. Baum. 2005. "Coupled Fire Dynamics and Thermal Response of Complex Building Structures," Proc. Combustion Institute 30, 2255-2262.

Taylor, R.E., H. Groot, and J. Ferrier. 2003. Thermophysical Properties of PVC, PE, and Marinite, Report No. TPRL 2958, Thermophysical Properties Research Laboratory, Inc., April. 
This page intentionally left blank. 


\section{Chapter 12 \\ SUMMARY OF RESULTS}

A series of experiments was conducted to assess the models that were developed to determine the temperature rise of structural components within a compartment fire. The well-controlled large-scale experiments described in this report were designed specifically to validate aspects of the National Institute of Standards and Technology (NIST) Fire Dynamic Simulator (FDS), the NIST Fire Structure Interface (FSI), and the commercially available finite-element program ANSYS, which were used to simulate the fires and their impact on the thermal behavior of structural components as applied to the investigation of the World Trade Center (WTC) fire and collapse. Measurements were conducted to assess the accuracy of each of the model calculations. The fire and thermal models exercised here were used to generate input for a set of structural analyses to determine the collapse sequence of the WTC towers. The experiments reported here provide a basis for understanding the uncertainties associated with these models, and thereby, constraints on the limits of accuracy of the structural calculations.

Each experiment was heavily instrumented so that many aspects of the fire model were tested. Many assumptions went into the design of the experiments, including details associated with the test matrix, the experimental configuration, and the test conditions. It was impossible to recreate every feature of the actual fire conditions in the WTC buildings, and that was not the primary goal of the work presented here. In this work, a number of important aspects of the WTC fires were recreated to compare model predictions with measurements. The measurements led to findings regarding the thermal behavior of the compartment and its contents, including the steel components, as they were exposed to fires of various size, fuel sootiness, and proximity to the fire plume. Noteworthy results included the following:

- The temperature and flux measurements showed that, in general, the experiments were very repeatable.

- Most measured quantities (temperatures, gas concentrations, soot, fluxes, velocities, etc.) showed rapid changes during the first $100 \mathrm{~s}$ in the experiments and then were fairly steady or slowly varied, as the temperature of the compartment walls slowly increased.

- The value of the heat flux about the compartment was dependent on location and test conditions. For example, at the floor in front of the fire pan, the heat flux varied from $20 \mathrm{~kW} / \mathrm{m}^{2}$ to $90 \mathrm{~kW} / \mathrm{m}^{2}$. In the upper layer near the ceiling, the heat flux was measured to be as high as $90 \mathrm{~kW} / \mathrm{m}^{2}$.

- Higher temperatures $\left(200^{\circ} \mathrm{C}\right.$ to $300^{\circ} \mathrm{C}$ higher) were measured in the upper layer of fires with larger heat release rates ( $3 \mathrm{MW}$ versus $2 \mathrm{MW}$ ). In addition, fire size had a large influence on the heat flux impinging on structural components in both the hot upper layer and elsewhere in the compartment.

- Ceiling surface temperatures obtained values as high as $700{ }^{\circ} \mathrm{C}$ to $800{ }^{\circ} \mathrm{C}$ and $800{ }^{\circ} \mathrm{C}$ to $900{ }^{\circ} \mathrm{C}$ after $15 \mathrm{~min}$ and $50 \mathrm{~min}$, respectively, of exposure to a $3 \mathrm{MW}$ heat release rate fire with peak temperatures observed to occur above the fuel pan. 
- The measured yields of soot and $\mathrm{CO}_{2}$ in the hot upper layer of the compartment were very similar to those measured in the downstream plume of spray fires burning in the open. The results for $\mathrm{CO}$ were more complex, with the yield varying with location and changing with time, depending on the experimental conditions.

- Gas velocity measurements at the vents showed that the velocity was largest near the top of the vent and decreased with hcight.

- The experimental results showed that the SFRM significantly delayed the rise in the steel temperature. The highest temperatures obtained at the stecl surface were significantly lower than the temperature on the outside face of the insulation material.

- The surface temperature of uninsulated steel trusses that were subject to impingement or proximity of flames from fires with a nominal $3 \mathrm{MW}$ heat release rate reached $600{ }^{\circ} \mathrm{C}$ within $15 \mathrm{~min}$. In comparison, the insulated steel trusses with SFRM protection $(1.91 \mathrm{~cm}$ nominal thickness) reached $100^{\circ} \mathrm{C}$ to $200^{\circ} \mathrm{C}$ and the truss with $3.81 \mathrm{~cm}$ SFRM reached $50^{\circ} \mathrm{C}$ to $100{ }^{\circ} \mathrm{C}$ after $15 \mathrm{~min}$ of exposure to a $3 \mathrm{MW}$ heat release rate fire. The steel surface of an insulated steel truss with $1.91 \mathrm{~cm}$ (nominal) and $3.81 \mathrm{~cm}$ (nominal) SFRM obtained a temperature of $680^{\circ} \mathrm{C}$ and $415^{\circ} \mathrm{C}$, respectively, after $50 \mathrm{~min}$ of exposure to a $3 \mathrm{MW}$ fire.

- For the insulated steel components, the steel surface temperatures obtained a maximum sometimc after the fire was stopped due to lag of the thermal wave through the SFRM. A thermal lag of between $100 \mathrm{~s}$ and $800 \mathrm{~s}$ for the nominal $1.91 \mathrm{~cm}$ SFRM thickncss and 1,000 s to over $1,900 \mathrm{~s}$ for the nominal $3.81 \mathrm{~cm}$ SFRM thickness was observed, depending on the values of the temperature and the temperature gradients within the SFRM and the steel.

Before testing began, model calculations were performed to guide the design of the compartment and to provide a baseline set of "blind" predictions. The accuracy of the models was assessed in terms of sensitivity to a number of parameters. The sensitivity analysis yielded estimates of uncertainty for model output that facilitated quantitative evaluation of the agreement between models and measurements. Using a well-known correlation between compartment temperature and the heat release rate of the fire, it was possible to propagate the uncertainty in the measurement of the heat release rate to the measurement of the upper layer temperature, and then to the measurement of the heat flux to the walls and the structural components. These uncertainties provided bounds for the numerical simulations. A comparison of the predictions with the measurements showed that:

- The FDS predictions fell within the uncertainty bounds of the gas temperature and heat flux measurements. FDS predictions of the upper layer gas temperature agreed with measurements to within 10 percent, which was fairly accurate considering model sensitivity to input parameters such as the heat release rate. Since the heat flux to the walls and objects within the upper layer is highly dependent on the upper layer temperature, these predictions were also accurate. The model accuracy decreased near the fire. Greater uncertainty in nearfield predictions was due to a combination of limited spatial resolution of the numerical grid, simplification of the combustion and radiation processes, and differences between model and actual burner geometries. 
- The sootier-burning fuel led to similar temperature rise in the ceiling and the steel above the fire plume, while the measured and predicted fluxes to the lower layer was smaller.

- FDS predicted asymmetry of the fire plume caused by obstructions to uniform flow through the compartment, but did not accurately predict the extent of the asymmetry, which adverscly impacted the FSI prediction of structural components very close to the fire. Away from the fire, small differences in the exact flame position were not as important.

- The behaviors of the simulated and the measured uninsulated steel temperatures were similar. Both increased from ambient values to finite values in a monotonic fashion that obtained a maximum approximately when the fuel flow was stopped. The same was true for the insulated steel components, except that the temperatures obtained a maximum after the fuel was stopped due to lag of the thermal wave through the SFRM.

- On average, the numerical predictions of the steel surface temperature were within 8 percent of the experimental measurements for the case of bare steel and within 20 percent for the steel components with SFRM. For the bare steel, a series of calculations showed that these differences could be attributed to model sensitivity to the fire heat release rate used in the fire model. For the insulated steel, the differences could be attributed mainly to model sensitivity to the SFRM coating thickness.

In addition to checking the accuracy of the model, the experiments served as a means to check the sensitivity of the model to changes in input parameters, both numerical and physical. One of the most important parameters prescribed by the model user is the size of the numerical grid. Simulations of all the tests were performed with grid cells $10 \mathrm{~cm}$ by $10 \mathrm{~cm}$ by $10 \mathrm{~cm}$. Several tests were also simulated using a coarse grid $50 \mathrm{~cm}$ by $50 \mathrm{~cm}$ by $40 \mathrm{~cm}$, the same as was used to perform the simulations of the WTC fires. The upper layer temperature predictions did not differ appreciably from those of the fine grid simulation, justifying the use of the coarse grid in the WTC simulations. Changes in various other physical parameters also did not significantly change the results. This is important because the initial and boundary conditions in the WTC simulations are far less certain than those of the experiments presented here.

In summary, measurements in a series of specially designed, large-scale fire expcriments were compared with predictions from the FDS/FSI/ANSYS modeling methodology to quantify uncertainties and the parameters to which the models are most sensitive. The sensitivity analysis for FDS was extended to the steel temperature calculations, providing the bounds for quantifying the accuracy of the FSI/ANSYS model. Quantitative disagreement between the models and the experiments were attributed to model sensitivities to input parameters that had experimental uncertainties. The study provides the level of confidence necessary to apply the modeling methodology to the investigation of the WTC disaster. 
This page intentionally left blank. 


\section{Appendix A \\ SELECTION OF FUELS}

\section{A.1 COMPOSITION OF OFFICE FURNISHINGS}

It was assumed that there were two generic types of furniture present in the World Trade Center (WTC) offices, namely wood based or modern. The first type was predominantly composed of cellulosic materials, such as books, conglomerate bookshelves, wooden desks, and lots of paper. Some amount of thermoplastics would also be present. The second type of furniture considered was composed of materials that were less cellulosic and more thermoplastic in composition. Table $\mathrm{A}-\mathrm{l}$ shows the assumed composition of the two office types. Nylon is essentially ignored because that carpeting would play only a minor role in the total heat release of an office.

Table A-1. Assumed composition of office furnishings.

\begin{tabular}{|l|c|c|c|}
\hline \multicolumn{1}{|c|}{ Office Type } & Cellulose & ABS & Polystyrene \\
\hline Wood-based & $2 / 3$ & $1 / 6$ & $1 / 6$ \\
\hline Modern & $1 / 3$ & $1 / 3$ & $1 / 3$ \\
\hline
\end{tabular}

Key: ABS, copolymer of acrylonitrile-butadiene-styrene

The smoke yield is defined as the number of grams of smoke emitted per gram of fuel combustcd. The smoke yield from fires burning cellulose (representative of woody materials), copolymer of acrylonitrilebutadiene-styrene (ABS), and polystyrene are $0.015,0.105$, and 0.164 , respectively. The smoke yield from fires burning heptane and toluene are 0.037 and 0.178 , respectively (Tewarson 2002). Jet A (fuel from the aircraft) is composed essentially of kerosene, which has a smoke yield of 0.215 .

Assuming a linear relationship between composition and smoke yield, a wood-based office would be expected to have a smoke yield of:

$$
2 / 3(0.015)+1 / 6(0.105)+1 / 6(0.164)=0.056
$$

whereas, a modern type office would be expected to have a smoke yield of:

$$
1 / 3(0.015)+1 / 3(0.105)+1 / 3(0.164)=0.095
$$

This can be compared to a mixture of 50 percent heptane and 50 percent toluene (by mass) (assuming a linear relation); the yields would be expected to have a comparable smoke yield:

$$
1 / 2(0.037)+1 / 2(0.178)=0.11,
$$

which is somewhat larger than the smoke yield of the modern office type. A mixture of 60 percent heptane and 40 percent toluene (by mass), assuming a linear relation would be expected to have a smoke yield of:

$$
0.6(0.037)+0.4(0.178)=0.0934
$$


which is similar to the smoke yield of the modern office type. To cover the range of soot yields during the validation experiments, the fuels used were heptane and a mixture of 60 percent heptane and 40 percent toluene (by mass). Pure toluene would yield a fire too heavily laden with soot as compared to materials that are typically present in office buildings such as the WTC towers. Although jet fuel may have becn present during the WTC fires, the majority of the mass combusted during the WTC fires was due to office furnishings. Heptane and toluene are miscible with highly similar boiling points (Hamins 1985). Preferential burning is not significant as the fuels were injected in the form of a spray.

\section{A.2 REFERENCES}

Hamins, A. 1985. The Structure and Extinction of Diffusion Flames, Ph.D. Dissertation, University of California at San Diego.

Tewarson, A. 2002. "Generation of Heat and Chemical Compounds in Fires," pp. 3-82 to 3-161 in the SFPE Handbook of Fire Protection Engineering, 3rd ed. (P.J. DiNenno, ed.), Society of Fire Protection Engineers, Bethesda, MD. 


\section{Appendix B \\ INSTRUMENT LOCATIONS}

Table B-1 is a detailed list of instrumentation location and channel assignment in the data acquisition system. The location of the instrument is given when a measurement was made within the experimental compartment. Many measurements were made outside of the compartment (e.g., calorimetry) or were used to monitor instrument function and do not have coordinate locations listed in the table. The reference location $(0.0 .0)$ was the floor at the center of the west wall, as described in Chapter 2 . The location of the thermocouples on the steel components changed from test to test and is described in detail in Chapter 9.

Table B-1. Instrument locations and channel assignments.

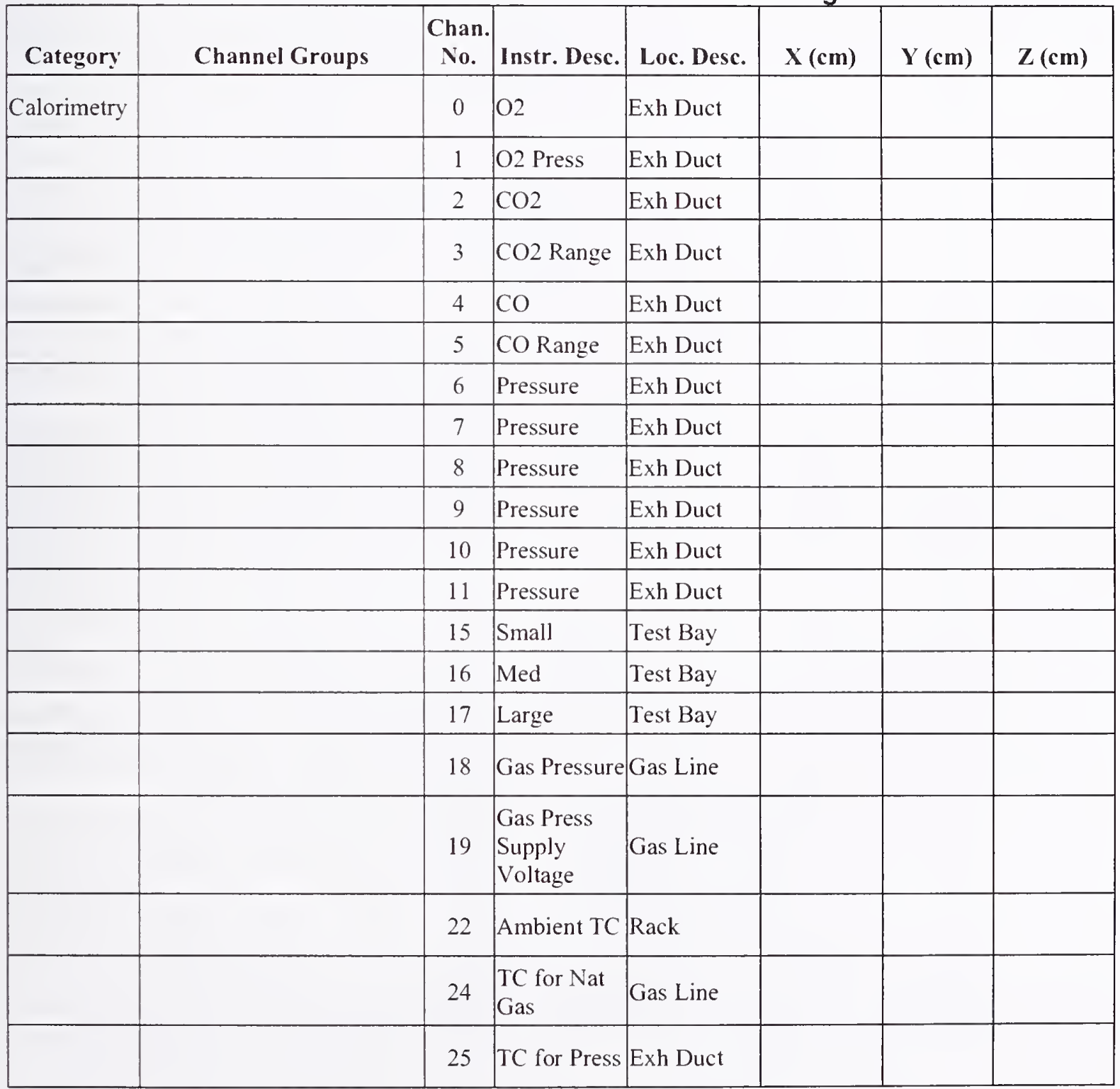




\begin{tabular}{|c|c|c|c|c|c|c|c|}
\hline Category & Channel Groups & $\begin{array}{c}\text { Chan. } \\
\text { No. }\end{array}$ & Instr. Desc. & Loc. Desc. & $X(\mathrm{~cm})$ & $Y(\mathrm{~cm})$ & $\mathrm{Z}(\mathrm{cm})$ \\
\hline & & 26 & TC for Press & Exh Duct & & & \\
\hline & & 27 & TC for Press & Exh Duct & & & \\
\hline & & 28 & TC for Press & Exh Duct & & & \\
\hline & & 29 & $\mathrm{TC}$ for Press & Exh Duct & & & \\
\hline & & 30 & TC for Press & Exh Duct & & & \\
\hline \multirow[t]{9}{*}{$\begin{array}{l}\text { Gas } \\
\text { Analyzers }\end{array}$} & $\mathrm{O} 2$ & 33 & $\mathrm{O} 2$ & & 604.0 & 28.0 & 365.0 \\
\hline & $\mathrm{CO} 2$ & 34 & $\mathrm{CO} 2$ raw & & 604.0 & 28.0 & 365.0 \\
\hline & & 35 & $\mathrm{CO} 2$ range & & 604.0 & 28.0 & 365.0 \\
\hline & $\mathrm{CO}$ & 36 & CO raw & & 604.0 & 28.0 & 365.0 \\
\hline & & 37 & CO range & & 604.0 & 28.0 & 365.0 \\
\hline & $\mathrm{CO} 2$ & 38 & $\mathrm{CO} 2 \mathrm{raw}$ & & 138.0 & 54.0 & 324.0 \\
\hline & & 39 & $\mathrm{CO} 2$ range & & 138.0 & 54.0 & 324.0 \\
\hline & $\mathrm{CO}$ & 40 & CO raw & & 153.0 & 54.0 & 324.0 \\
\hline & & 41 & $\mathrm{CO}$ range & & 153.0 & 54.0 & 324.0 \\
\hline \multirow[t]{18}{*}{ Pressure } & Inlet & 42 & Press & Inlet & -17.8 & -33.0 & 71.1 \\
\hline & & 43 & Press & Inlet & -17.8 & -33.0 & 45.7 \\
\hline & & 44 & Press & Inlet & -17.8 & -33.0 & 25.4 \\
\hline & & 45 & Press & Inlet & -17.8 & -59.7 & 71.1 \\
\hline & & 46 & Press & Inlet & -17.8 & -59.7 & 25.4 \\
\hline & & 47 & Press & Inlet & -17.8 & -127.0 & 71.1 \\
\hline & & 48 & Press & Inlet & -17.8 & -127.0 & 45.7 \\
\hline & & 49 & Press & Inlet & -17.8 & -127.0 & 25.4 \\
\hline & Outlet & 50 & Press & Outlet & 721.4 & 33.0 & 261.6 \\
\hline & & 51 & Press & Outlet & 721.4 & 33.0 & 236.2 \\
\hline & & 52 & Press & Outlet & 721.4 & 33.0 & 215.9 \\
\hline & & 53 & Press & Outlet & 721.4 & 59.7 & 261.6 \\
\hline & & 54 & Press & Outlet & 721.4 & 59.7 & 215.9 \\
\hline & & 55 & Press & Outlet & 721.4 & 125.7 & 261.6 \\
\hline & & 56 & Press & Outlet & 721.4 & 125.7 & 236.2 \\
\hline & & 57 & Press & Outlet & 721.4 & 125.7 & 215.9 \\
\hline & Near Metal & 58 & Press & Heat Flux & 435.0 & 17.0 & 320.0 \\
\hline & & 59 & Press & Heat Flux & 481.0 & 17.0 & 320.0 \\
\hline
\end{tabular}




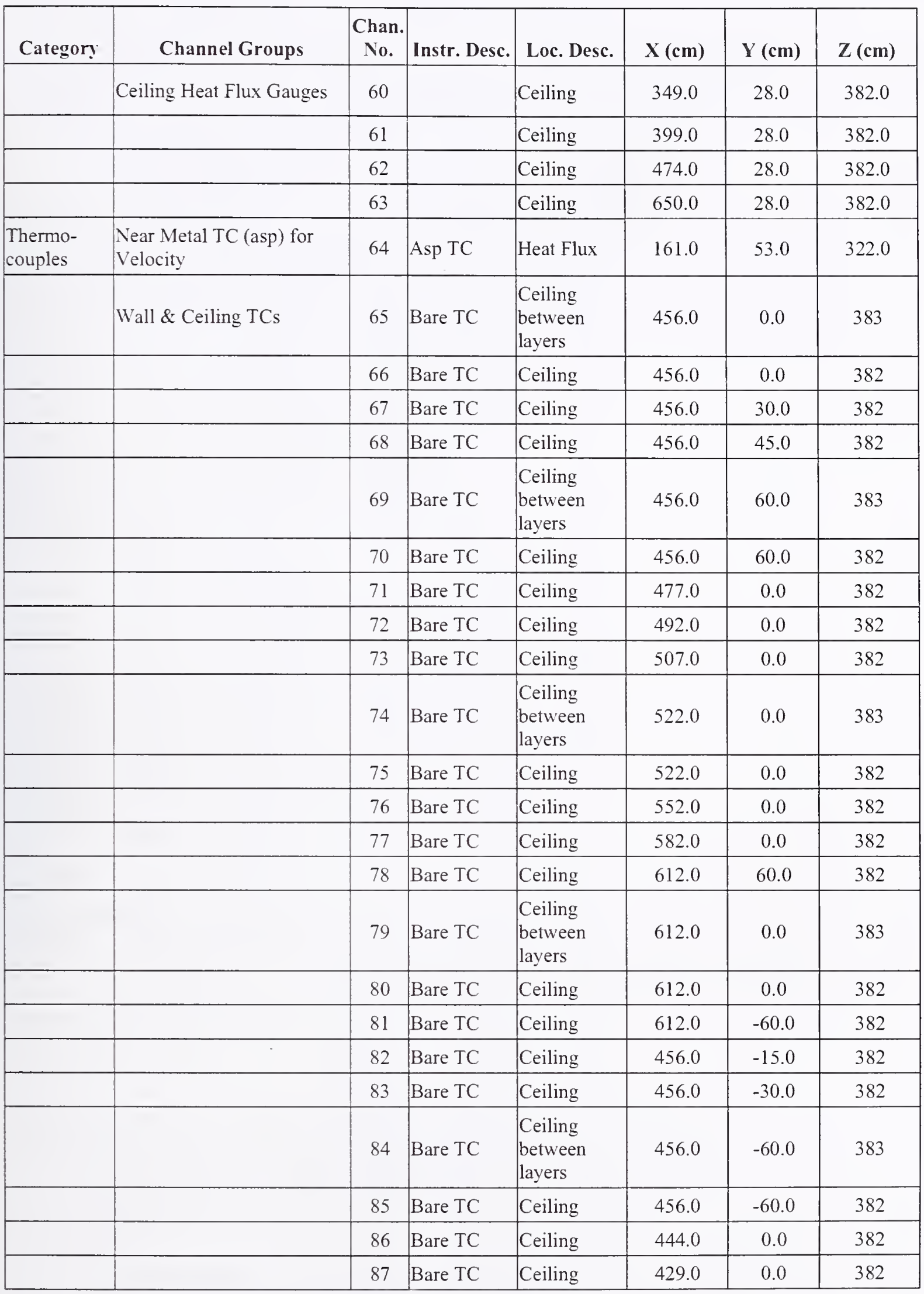




\begin{tabular}{|c|c|c|c|c|c|c|c|}
\hline Category & Channel Groups & $\begin{array}{c}\text { Chan. } \\
\text { No. }\end{array}$ & Instr. Desc. & Loc. Desc. & $X(\mathrm{~cm})$ & $\mathrm{Y}(\mathrm{cm})$ & $\mathrm{Z}(\mathbf{c m})$ \\
\hline & & 88 & Bare TC & Ceiling & 414.0 & 0.0 & 382 \\
\hline & & 89 & Bare TC & $\begin{array}{l}\text { Ceiling } \\
\text { between } \\
\text { layers }\end{array}$ & 399.0 & 0.0 & 383 \\
\hline & & 90 & Bare TC & Ceiling & 399.0 & 0.0 & 382 \\
\hline & & 91 & Bare TC & Ceiling & 369.0 & 0.0 & 382 \\
\hline & & 92 & Bare TC & Ceiling & 309.0 & 0.0 & 382 \\
\hline & & 93 & Bare TC & Ceiling & 279.0 & 0.0 & 382 \\
\hline & & 94 & Bare TC & Ceiling & 228.0 & -60.0 & 382.0 \\
\hline & & 95 & Bare TC & Ceiling & 228.0 & 0.0 & 382.0 \\
\hline & & 96 & Bare TC & Ceiling & 228.0 & 60.0 & 382.0 \\
\hline & North Wall TCs & 97 & Bare TC & $\begin{array}{l}\text { Ceiling } \\
\text { between } \\
\text { layers }\end{array}$ & 459.0 & 181.0 & 377 \\
\hline & & 98 & Bare TC & & 459.0 & 180.0 & 377 \\
\hline & & 99 & Bare TC & & 459.0 & 181.0 & 367.0 \\
\hline & & 100 & Bare TC & & 459.0 & 180.0 & 367.0 \\
\hline & & 101 & Bare TC & & 459.0 & 181.0 & 357.0 \\
\hline & & 102 & Bare TC & & 459.0 & 180.0 & 357.0 \\
\hline & & 103 & Bare TC & & 519.0 & 180.0 & 367.0 \\
\hline & & 104 & Bare TC & & 579.0 & 181.0 & 367.0 \\
\hline & & 105 & Bare TC & & 579.0 & 180.0 & 367.0 \\
\hline & & 106 & Bare TC & & 579.0 & 180.0 & 357.0 \\
\hline & & 107 & Bare TC & & 399.0 & 180.0 & 367.0 \\
\hline & & 108 & Bare TC & & 339.0 & 181.0 & 367.0 \\
\hline & & 109 & Bare TC & & 339.0 & 180.0 & 367.0 \\
\hline & & 110 & Bare TC & & 339.0 & 180.0 & 357.0 \\
\hline & Truss 1 Uninsulated TCs & 113 & Bare TC & Steel Surf & * & * & * \\
\hline & & 114 & Bare TC & Steel Surf & * & $*$ & $*$ \\
\hline & & 115 & Bare TC & Steel Surf & $*$ & $*$ & * \\
\hline & & 116 & Bare TC & Steel Surf & $*$ & $*$ & $*$ \\
\hline & & 117 & Bare TC & Steel Surf & $*$ & $*$ & $*$ \\
\hline & & 118 & Bare TC & Steel Surf & * & $*$ & * \\
\hline & & 118 & Bare TC & Steel Surf & $*$ & $*$ & * \\
\hline & & 120 & Bare TC & Steel Surf & $*$ & $*$ & $*$ \\
\hline & & 121 & Bare TC & Steel Surf & $*$ & $*$ & * \\
\hline & & 122 & Bare TC & Steel Surf & * & $*$ & $*$ \\
\hline
\end{tabular}




\begin{tabular}{|c|c|c|c|c|c|c|c|}
\hline Category & Channel Groups & $\begin{array}{c}\text { Chan. } \\
\text { No. }\end{array}$ & Instr. Desc. & Loc. Desc. & $\mathrm{X}(\mathrm{cm})$ & $Y(\mathrm{~cm})$ & $\mathrm{Z}(\mathrm{cm})$ \\
\hline & & 123 & Bare TC & Steel Surf & * & $*$ & * \\
\hline & & 124 & Bare TC & Steel Surf & $*$ & $*$ & * \\
\hline & Truss 1 Insulated TCs & 125 & Bare TC & Insul Surf & * & * & * \\
\hline & & 126 & Bare TC & Insul Surf & * & * & * \\
\hline & & 127 & Bare TC & Insul Surf & * & * & * \\
\hline & & 128 & Bare TC & Insul Surf & $*$ & $*$ & $*$ \\
\hline & & 129 & Bare TC & Insul Surf & $*$ & * & * \\
\hline & & 130 & Bare TC & Insul Surf & * & * & * \\
\hline & & 131 & Bare TC & Insul Surf & * & * & $*$ \\
\hline & & 132 & Bare TC & Insul Surf & $*$ & * & * \\
\hline & & 133 & Bare TC & Insul Surf & $*$ & * & $*$ \\
\hline & & 134 & Bare TC & Insul Surf & * & * & * \\
\hline & & 135 & Bare TC & Insul Surf & * & * & $*$ \\
\hline & & 136 & Bare TC & Insul Surf & $*$ & $*$ & $*$ \\
\hline & Column Uninsulated TCs & 137 & Bare TC & Steel Surf & * & $*$ & * \\
\hline & & 138 & Bare TC & Steel Surf & * & $*$ & $*$ \\
\hline & & 139 & Bare TC & Steel Surf & * & * & * \\
\hline & & 140 & Bare TC & Steel Surf & * & $*$ & $*$ \\
\hline & & 141 & Bare TC & Steel Surf & * & $*$ & $*$ \\
\hline & & 142 & Bare TC & Steel Surf & $*$ & $*$ & $*$ \\
\hline & & 143 & Bare TC & Steel Surf & * & * & * \\
\hline & & 144 & Bare TC & Steel Surf & $*$ & $*$ & $*$ \\
\hline & & 145 & Bare TC & Steel Surf & * & * & * \\
\hline & & 146 & Bare TC & Steel Surf & * & $*$ & * \\
\hline & & 147 & Bare TC & Steel Surf & * & * & * \\
\hline & & 148 & Bare TC & Steel Surf & $*$ & * & * \\
\hline & Column Insulated TCs & 149 & Bare TC & Insul Surf & * & * & * \\
\hline & & 150 & Bare TC & Insul Surf & * & * & $*$ \\
\hline & & 151 & Bare TC & Insul Surf & $*$ & * & $*$ \\
\hline & & 152 & Bare TC & Insul Surf & * & * & * \\
\hline & & 153 & Bare TC & Insul Surf & * & * & $*$ \\
\hline & & 154 & Bare TC & Insul Surf & * & $*$ & * \\
\hline & & 155 & Bare TC & Insul Surf & * & * & * \\
\hline & & 156 & Bare TC & Insul Surf & * & * & $*$ \\
\hline & & 157 & Bare TC & Insul Surf & $*$ & * & * \\
\hline
\end{tabular}




\begin{tabular}{|c|c|c|c|c|c|c|c|}
\hline Category & Channel Groups & $\begin{array}{c}\text { Chan. } \\
\text { No. }\end{array}$ & Instr. Desc. & Loc. Desc. & $X(\mathrm{~cm})$ & $Y(\mathbf{c m})$ & $\mathrm{Z}(\mathrm{cm})$ \\
\hline & & 158 & Bare TC & Insul Surf & $*$ & $*$ & * \\
\hline & & 159 & Bare TC & Insul Surf & * & * & $*$ \\
\hline & & 160 & Bare TC & Insul Surf & $*$ & $*$ & $*$ \\
\hline & Rod Uninsulated TCs & 161 & Bare TC & Steel Surf & $*$ & * & * \\
\hline & & 162 & Bare TC & Steel Surf & $*$ & $*$ & * \\
\hline & & 163 & Bare TC & Steel Surf & * & * & $*$ \\
\hline & & 164 & Bare TC & Steel Surf & $*$ & $*$ & $*$ \\
\hline & Rod Insulated TCs & 165 & Bare TC & Insul Surf & $*$ & $*$ & $*$ \\
\hline & & 166 & Bare TC & Insul Surf & $*$ & $*$ & $*$ \\
\hline & & 167 & Bare TC & Insul Surf & $*$ & $*$ & $*$ \\
\hline & & 168 & Bare TC & Insul Surf & * & * & $*$ \\
\hline & Truss 2 Uninsulated TCs & 169 & Bare TC & Steel Surf & * & $*$ & $*$ \\
\hline & & 170 & Bare TC & Steel Surf & $*$ & $*$ & $*$ \\
\hline & & 171 & Bare TC & Steel Surf & * & $*$ & $*$ \\
\hline & & 172 & Bare TC & Steel Surf & $*$ & $*$ & $*$ \\
\hline & & 173 & Bare TC & Steel Surf & $*$ & * & $*$ \\
\hline & & 174 & Bare TC & Steel Surf & $*$ & * & $*$ \\
\hline & & 175 & Bare TC & Steel Surf & $*$ & $*$ & $*$ \\
\hline & & 176 & Bare TC & Steel Surf & $*$ & $*$ & $*$ \\
\hline & & 177 & Bare TC & Steel Surf & * & * & $*$ \\
\hline & & 178 & Bare TC & Steel Surf & $*$ & * & $*$ \\
\hline & & 179 & Bare TC & Steel Surf & $*$ & $*$ & $*$ \\
\hline & & 180 & Bare TC & Steel Surf & $*$ & $*$ & $*$ \\
\hline & Truss 2 Insulated TCs & 181 & Bare TC & Insul Surf & $*$ & * & $*$ \\
\hline & & 182 & Bare TC & Insul Surf & $*$ & $*$ & $*$ \\
\hline & & 183 & Bare TC & Insul Surf & $*$ & * & $*$ \\
\hline & & 184 & Bare TC & Insul Surf & $*$ & $*$ & * \\
\hline & & 185 & Bare TC & Insul Surf & * & * & * \\
\hline & & 186 & Bare TC & Insul Surf & $*$ & $*$ & * \\
\hline & & 187 & Bare TC & Insul Surf & $*$ & $*$ & $*$ \\
\hline & & 188 & Bare TC & Insul Surf & $*$ & $*$ & $*$ \\
\hline & & 188 & Bare TC & Insul Surf & * & * & $*$ \\
\hline & & 190 & Bare TC & Insul Surf & $*$ & $*$ & $*$ \\
\hline & & 191 & Bare TC & Insul Surf & $*$ & $*$ & $*$ \\
\hline & & 192 & Bare TC & Insul Surf & $*$ & $*$ & $*$ \\
\hline
\end{tabular}




\begin{tabular}{|c|c|c|c|c|c|c|c|}
\hline Category & Channel Groups & $\begin{array}{l}\text { Chan. } \\
\text { No. }\end{array}$ & Instr. Desc. & Loc. Desc. & $\mathrm{X}(\mathrm{cm})$ & $Y(\mathrm{~cm})$ & $\mathrm{Z}(\mathrm{cm})$ \\
\hline & Inlet TCs ( 12 bare \& 2 asp) & 193 & Bare TC & Inlet & -25.4 & -31.8 & 73.7 \\
\hline & & 194 & Bare TC & Inlet & -25.4 & -31.8 & 63.5 \\
\hline & & 195 & Bare TC & Inlet & -25.4 & -31.8 & 49.5 \\
\hline & & 196 & Bare TC & Inlet & -25.4 & -31.8 & 30.5 \\
\hline & & 197 & Bare TC & Inlet & -25.4 & -57.2 & 73.7 \\
\hline & & 198 & Bare TC & Inlet & -25.4 & -57.2 & 63.5 \\
\hline & & 199 & Bare TC & Inlet & -25.4 & -57.2 & 49.5 \\
\hline & & 200 & Bare TC & Inlet & -25.4 & -57.2 & 30.5 \\
\hline & & 201 & Bare TC & Inlet & -25.4 & -125.7 & 73.7 \\
\hline & & 202 & Bare TC & Inlet & -25.4 & -125.7 & 63.5 \\
\hline & & 203 & Bare TC & Inlet & -25.4 & -125.7 & 49.5 \\
\hline & & 204 & Bare TC & Inlet & -25.4 & -125.7 & 30.5 \\
\hline & & 205 & Asp TC & Inlet & -17.8 & -50.8 & 45.7 \\
\hline & & 206 & Asp TC & Inlet & -17.8 & -119.4 & 30.5 \\
\hline & $\begin{array}{l}\text { Outlet TCs ( } 30 \text { bare \& } 4 \\
\text { asp) }\end{array}$ & 207 & Bare TC & Outlet & 711.2 & -127.0 & 265.4 \\
\hline & & 208 & Bare TC & Outlet & 711.2 & -127.0 & 256.5 \\
\hline & & 209 & Bare TC & Outlet & 711.2 & -127.0 & 242.6 \\
\hline & & 210 & Bare TC & Outlet & 711.2 & -127.0 & 223.5 \\
\hline & & 211 & Bare TC & Outlet & 711.2 & -127.0 & 210.8 \\
\hline & & 212 & Bare TC & Outlet & 711.2 & -57.2 & 265.4 \\
\hline & & 213 & Bare TC & Outlet & 711.2 & -57.2 & 256.5 \\
\hline & & 214 & Bare TC & Outlet & 711.2 & -57.2 & 242.6 \\
\hline & & 215 & Bare TC & Outlet & 711.2 & -57.2 & 223.5 \\
\hline & & 216 & Bare TC & Outlet & 711.2 & -57.2 & 210.8 \\
\hline & & 217 & Bare TC & Outlet & 711.2 & -35.6 & 265.4 \\
\hline & & 218 & Bare TC & Outlet & 711.2 & -35.6 & 256.5 \\
\hline & & 219 & Bare TC & Outlet & 711.2 & -35.6 & 242.6 \\
\hline & & 220 & Bare TC & Outlet & 711.2 & -35.6 & 223.5 \\
\hline & & 221 & Bare TC & Outlet & 711.2 & -35.6 & 210.8 \\
\hline & & 222 & Bare TC & Outlet & 711.2 & 35.6 & 265.4 \\
\hline & & 223 & Bare TC & Outlet & 711.2 & 35.6 & 256.5 \\
\hline & & 224 & Bare TC & Outlet & 711.2 & 35.6 & 242.6 \\
\hline & & 225 & Bare TC & Outlet & 711.2 & 35.6 & 223.5 \\
\hline & & 226 & Bare TC & Outlet & 711.2 & 35.6 & 210.8 \\
\hline & & 227 & Bare TC & Outlet & 711.2 & 57.2 & 265.4 \\
\hline
\end{tabular}




\begin{tabular}{|c|c|c|c|c|c|c|c|}
\hline Category & Channel Groups & $\begin{array}{c}\text { Chan. } \\
\text { No. } \\
\end{array}$ & Instr. Desc. & Loc. Desc. & $X(\mathrm{~cm})$ & $Y(\mathrm{~cm})$ & $\mathrm{Z}(\mathrm{cm})$ \\
\hline & & 228 & Bare TC & Outlet & 711.2 & 57.2 & 256.5 \\
\hline & & 229 & Bare TC & Outlet & 711.2 & 57.2 & 242.6 \\
\hline & & 230 & Bare TC & Outlet & 711.2 & 57.2 & 223.5 \\
\hline & & 231 & Bare TC & Outlet & 711.2 & 57.2 & 210.8 \\
\hline & & 232 & Bare TC & Outlet & 711.2 & 127.0 & 265.4 \\
\hline & & 233 & Bare TC & Outlet & 711.2 & 127.0 & 256.5 \\
\hline & & 234 & Bare TC & Outlet & 711.2 & 127.0 & 242.6 \\
\hline & & 235 & Bare TC & Outlet & 711.2 & 127.0 & 223.5 \\
\hline & & 236 & Bare TC & Outlet & 711.2 & 127.0 & 210.8 \\
\hline & & 237 & Asp TC & Outlet & 721.4 & 50.8 & 254.0 \\
\hline & & 238 & Asp TC & Outlet & 721.4 & 50.8 & 210.8 \\
\hline & $\begin{array}{l}\text { West Tree TCs ( } 15 \text { bare \& } 2 \\
\text { asp) }\end{array}$ & 239 & Bare TC & West Tree & 95.0 & 51.0 & 377.0 \\
\hline & & 240 & Bare TC & West Tree & 95.0 & 51.0 & 365.0 \\
\hline & & 241 & Bare TC & West Tree & 95.0 & 51.0 & 350.0 \\
\hline & & 242 & Bare TC & West Tree & 95.0 & 51.0 & 335.0 \\
\hline & & 243 & Bare TC & West Tree & 95.0 & 51.0 & 320.0 \\
\hline & & 244 & Bare TC & West Tree & 95.0 & 51.0 & 305.0 \\
\hline & & 245 & Bare TC & West Tree & 95.0 & 51.0 & 289.0 \\
\hline & & 246 & Bare TC & West Tree & 95.0 & 51.0 & 274.0 \\
\hline & & 247 & Bare TC & West Tree & 95.0 & 51.0 & 244.0 \\
\hline & & 248 & Bare TC & West Tree & 95.0 & 51.0 & 216.0 \\
\hline & & 249 & Bare TC & West Tree & 95.0 & 51.0 & 183.0 \\
\hline & & 250 & Bare TC & West Tree & 95.0 & 51.0 & 153.0 \\
\hline & & 251 & Bare TC & West Tree & 95.0 & 51.0 & 124.0 \\
\hline & & 252 & Bare TC & West Tree & 95.0 & 51.0 & 91.0 \\
\hline & & 253 & Bare TC & West Tree & 95.0 & 51.0 & 33.0 \\
\hline & & 254 & Asp TC & West Tree & 100.0 & 53.0 & 364.5 \\
\hline & & 255 & Asp TC & West Tree & 100.0 & 53.0 & 214.5 \\
\hline & & 256 & Asp TC & West Tree & 100.0 & 53.0 & 33.5 \\
\hline & $\begin{array}{l}\text { East Tree TCs ( } 15 \text { bare \& } 2 \\
\text { asp) }\end{array}$ & 257 & Bare TC & East Tree & 604.0 & 52.0 & 379.0 \\
\hline & & 258 & Bare TC & East Tree & 604.0 & 52.0 & 364.0 \\
\hline & & 259 & Bare TC & East Tree & 604.0 & 52.0 & 349.0 \\
\hline & & 260 & Bare TC & East Tree & 604.0 & 52.0 & 334.0 \\
\hline & & 261 & Bare TC & East Tree & 604.0 & 52.0 & 319.0 \\
\hline & & 262 & Bare TC & East Tree & 604.0 & 52.0 & 304.0 \\
\hline
\end{tabular}




\begin{tabular}{|c|c|c|c|c|c|c|c|}
\hline Category & Channel Groups & \begin{tabular}{|c|} 
Chan \\
No.
\end{tabular} & Instr. Desc. & Loc. Desc. & $X(\mathrm{~cm})$ & $Y(\mathrm{~cm})$ & $\mathrm{Z}(\mathrm{cm})$ \\
\hline & & 263 & Bare TC & East Tree & 604.0 & 52.0 & 289.0 \\
\hline & & 264 & Bare TC & East Tree & 604.0 & 52.0 & 274.0 \\
\hline & & 265 & Bare TC & East Tree & 604.0 & 52.0 & 244.0 \\
\hline & & 266 & Bare TC & East Tree & 604.0 & 52.0 & 214.0 \\
\hline & & 267 & Bare TC & East Tree & 604.0 & 52.0 & 183.0 \\
\hline & & 268 & Bare TC & East Tree & 604.0 & 52.0 & 152.0 \\
\hline & & 269 & Bare TC & East Tree & 604.0 & 52.0 & 122.0 \\
\hline & & 270 & Bare TC & East Tree & 604.0 & 52.0 & 92.0 \\
\hline & & 271 & Bare TC & East Tree & 604.0 & 52.0 & 62.0 \\
\hline & & 272 & Bare TC & East Tree & 604.0 & 52.0 & 34.0 \\
\hline & & 273 & Bare TC & East Tree & 604.0 & 52.0 & 3.0 \\
\hline & & 274 & Asp TC & East Tree & 604.0 & 53.0 & 365.0 \\
\hline & & 275 & Asp TC & East Tree & 604.0 & 53.0 & 215.0 \\
\hline & & 276 & Asp TC & East Tree & 604.0 & 53.0 & 35.0 \\
\hline & Ceiling Heat Flux TCs & 277 & Bare TC & Ceiling & 349.0 & 28.0 & 382.0 \\
\hline & & 278 & Bare TC & Ceiling & 399.0 & 28.0 & 382.0 \\
\hline & & 279 & Bare TC & Ceiling & 474.0 & 28.0 & 382.0 \\
\hline & & 280 & Bare TC & Ceiling & 650.0 & 28.0 & 382.0 \\
\hline & $\begin{array}{l}\text { Flux Station } 2 \text { Heat Flux } \\
\text { TCs }\end{array}$ & 285 & Bare TC & Flux St 2 & 458.0 & 56.0 & 330.0 \\
\hline & & 286 & Bare TC & Flux St 2 & 458.0 & 44.0 & 330.0 \\
\hline & & 287 & Bare TC & Flux St 2 & 458.0 & 23.0 & 315.0 \\
\hline & & 288 & Bare TC & Flux St 2 & 458.0 & 35.0 & 315.0 \\
\hline & Column Heat Flux TCs & 289 & Bare TC & Column & 304.0 & 77.0 & 346.0 \\
\hline & & 290 & Bare TC & Column & 297.0 & 85.0 & 327.0 \\
\hline & & 291 & Bare TC & Column & 304.0 & 77.0 & 92.0 \\
\hline & & 292 & Bare TC & Column & 297.0 & 85.0 & 102.0 \\
\hline & Floor Heat Flux TCs & 293 & Bare TC & Floor & 500.0 & 6.0 & 13.0 \\
\hline & & 294 & Bare TC & Floor & 550.0 & 3.0 & 13.0 \\
\hline & Slug $1 \mathrm{TCs}$ & 299 & $\mathrm{TC}$ & & 102.0 & 53.0 & 329.0 \\
\hline & & 300 & $\mathrm{TC}$ & & 102.0 & 53.0 & 329.0 \\
\hline & & 301 & $\mathrm{TC}$ & & 102.0 & 53.0 & 329.0 \\
\hline & & 302 & $\mathrm{TC}$ & & 102.0 & 53.0 & 329.0 \\
\hline & Slug 2 TCs & 303 & $\mathrm{TC}$ & & 212.0 & 53.0 & 291.0 \\
\hline & & 304 & TC & & 212.0 & 53.0 & 291.0 \\
\hline & & 305 & $\mathrm{TC}$ & & 212.0 & 53.0 & 291.0 \\
\hline & & 306 & $\mathrm{TC}$ & & 212.0 & 53.0 & 291.0 \\
\hline
\end{tabular}




\begin{tabular}{|c|c|c|c|c|c|c|c|}
\hline Category & Channell Groups & $\begin{array}{c}\text { Chan. } \\
\text { No. }\end{array}$ & Instr. Desc. & Loc. Desc. & $X(\mathrm{~cm})$ & $Y(\mathrm{~cm})$ & $Z(\mathrm{~cm})$ \\
\hline & Slug 3 TCs & 307 & $\mathrm{TC}$ & & 337.0 & 53.0 & 329.0 \\
\hline & & 308 & $\mathrm{TC}$ & & 337.0 & 53.0 & 329.0 \\
\hline & & 309 & $\mathrm{TC}$ & & 337.0 & 53.0 & 329.0 \\
\hline & & 310 & $\mathrm{TC}$ & & 337.0 & 53.0 & 329.0 \\
\hline & Slug 4 TCs & 311 & $\mathrm{TC}$ & & 397.0 & 53.0 & 329.0 \\
\hline & & 312 & $\mathrm{TC}$ & & 397.0 & 53.0 & 329.0 \\
\hline & & 313 & $\mathrm{TC}$ & & 397.0 & 53.0 & 329.0 \\
\hline & & 314 & $\mathrm{TC}$ & & 397.0 & 53.0 & 329.0 \\
\hline & Slug 5 TCs & 315 & $\mathrm{TC}$ & & 550.0 & 53.0 & 329.0 \\
\hline & & 316 & $\mathrm{TC}$ & & 550.0 & 53.0 & 329.0 \\
\hline & & 317 & $\mathrm{TC}$ & & 550.0 & 53.0 & 329.0 \\
\hline & & 318 & $\mathrm{TC}$ & & 550.0 & 53.0 & 329.0 \\
\hline & $\begin{array}{l}\text { Near Metal TC (asp) for } \\
\text { Velocity }\end{array}$ & 325 & Asp TC & Heat Flux & 604.0 & 53.0 & 365.0 \\
\hline & Soot TCs & 326 & Bare TC & Filter & & & \\
\hline & & 327 & Bare TC & Filter & & & \\
\hline & & 328 & Bare TC & Gas & & & \\
\hline & & 329 & Bare TC & Gas & & & \\
\hline & & 330 & Bare TC & Probe & & & \\
\hline & & 331 & Bare TC & Probe & & & \\
\hline & & 332 & Bare TC & Bath Inlet & & & \\
\hline & & 333 & Bare TC & Bath Outlet & & & \\
\hline \multicolumn{8}{|l|}{ Heat Flux } \\
\hline & $\begin{array}{l}\text { Flux Station } 2 \text { Heat Flux } \\
\text { Gauges }\end{array}$ & 338 & & Flux St 2 & 458.0 & 56.0 & 330.0 \\
\hline & & 339 & & Flux St 2 & 458.0 & 44.0 & 330.0 \\
\hline & & 340 & & Flux St 2 & 458.0 & 23.0 & 315.0 \\
\hline & & 341 & & Flux St 2 & 458.0 & 35.0 & 315.0 \\
\hline & Column Heat Flux Gauges & 342 & & Column & 304.0 & 77.0 & 346.0 \\
\hline & & 343 & & Column & 297.0 & 85.0 & 327.0 \\
\hline & & 344 & & Column & 304.0 & 77.0 & 92.0 \\
\hline & & 345 & & Column & 297.0 & 85.0 & 102.0 \\
\hline & Floor Heat Flux Gauges & 346 & & Floor & 500.0 & 6.0 & 13.0 \\
\hline & & 347 & & Floor & 550.0 & 3.0 & 13.0 \\
\hline
\end{tabular}

Key: location of thermocouples on structural components varied from test to test. See Chapter 9 and Appendix F for detailed information. 


\section{Appendix C \\ Gas-Phase Temperature Measurements}

This appendix contains data on the gas-phase temperatures measured using aspirated and bare bead thermocouples (see Figs. C-1 through $\mathrm{C}-15$ ). Further information on these measurements can be found in Chapter 4 of this report.

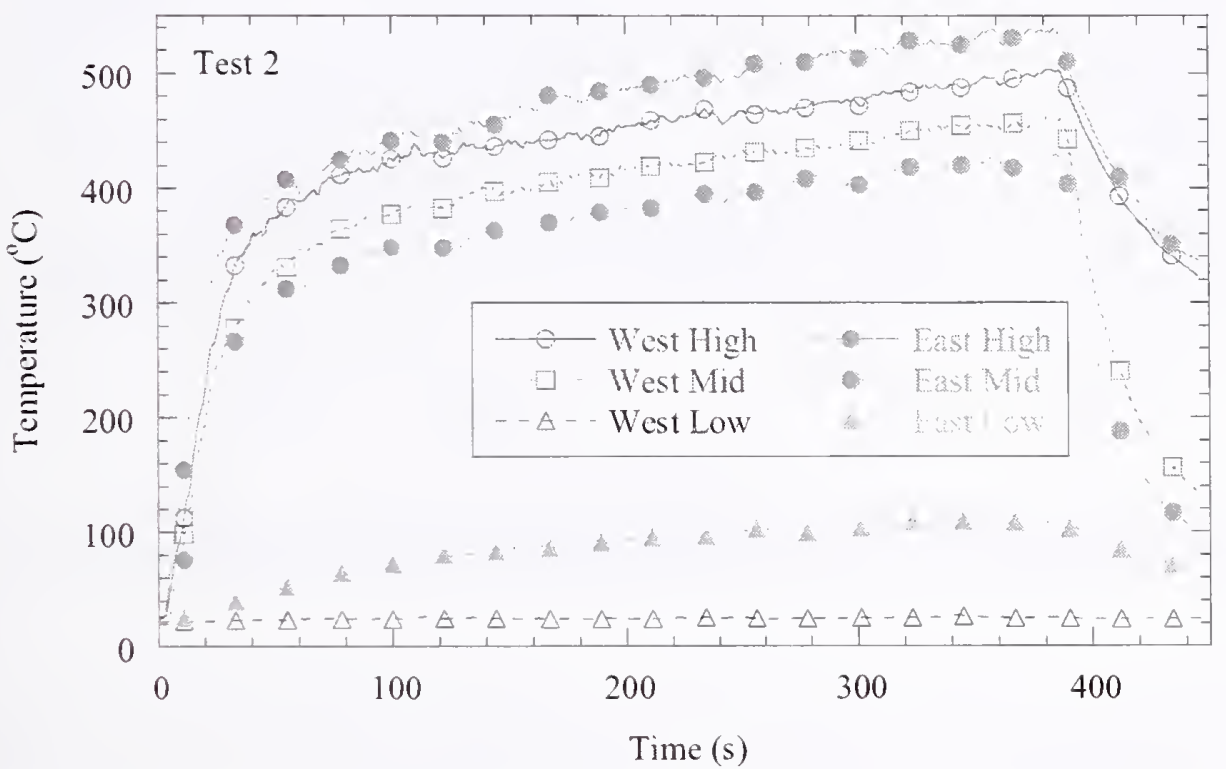

Figure C-1. Aspirated thermocouple temperatures as a function of time for Test 2.

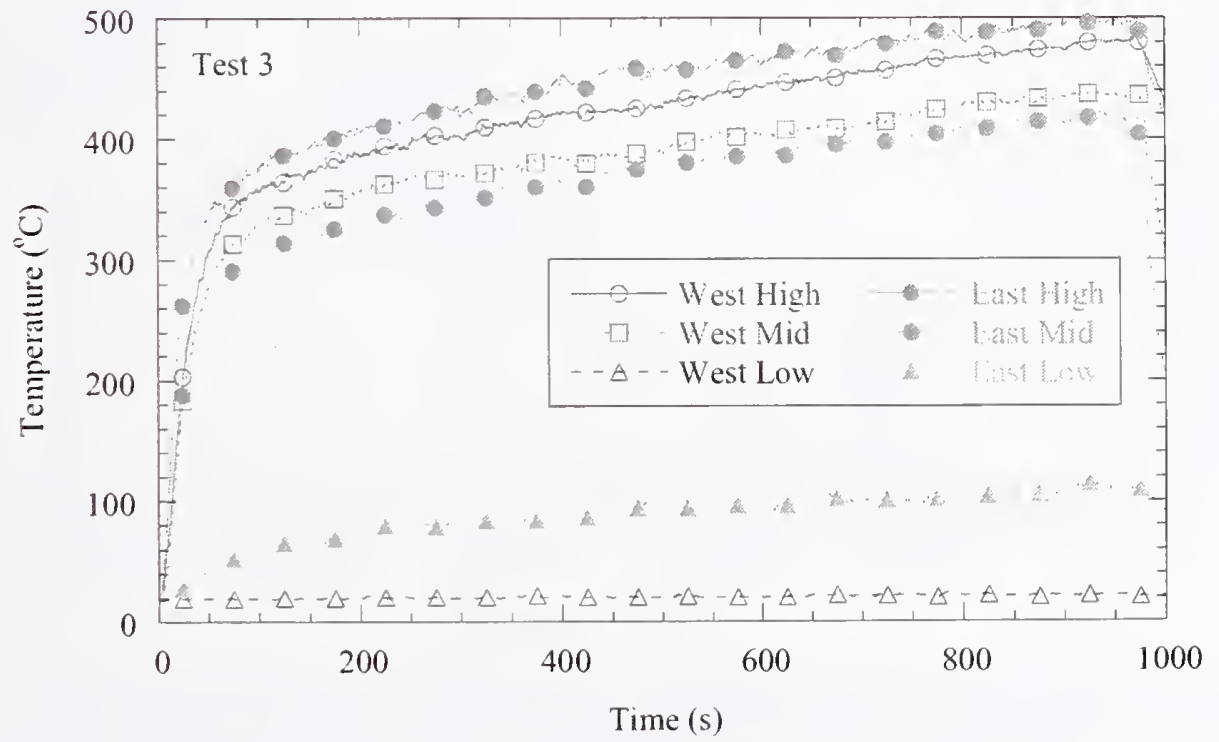

Figure C-2. Aspirated thermocouple temperatures as a function of time for Test 3. 


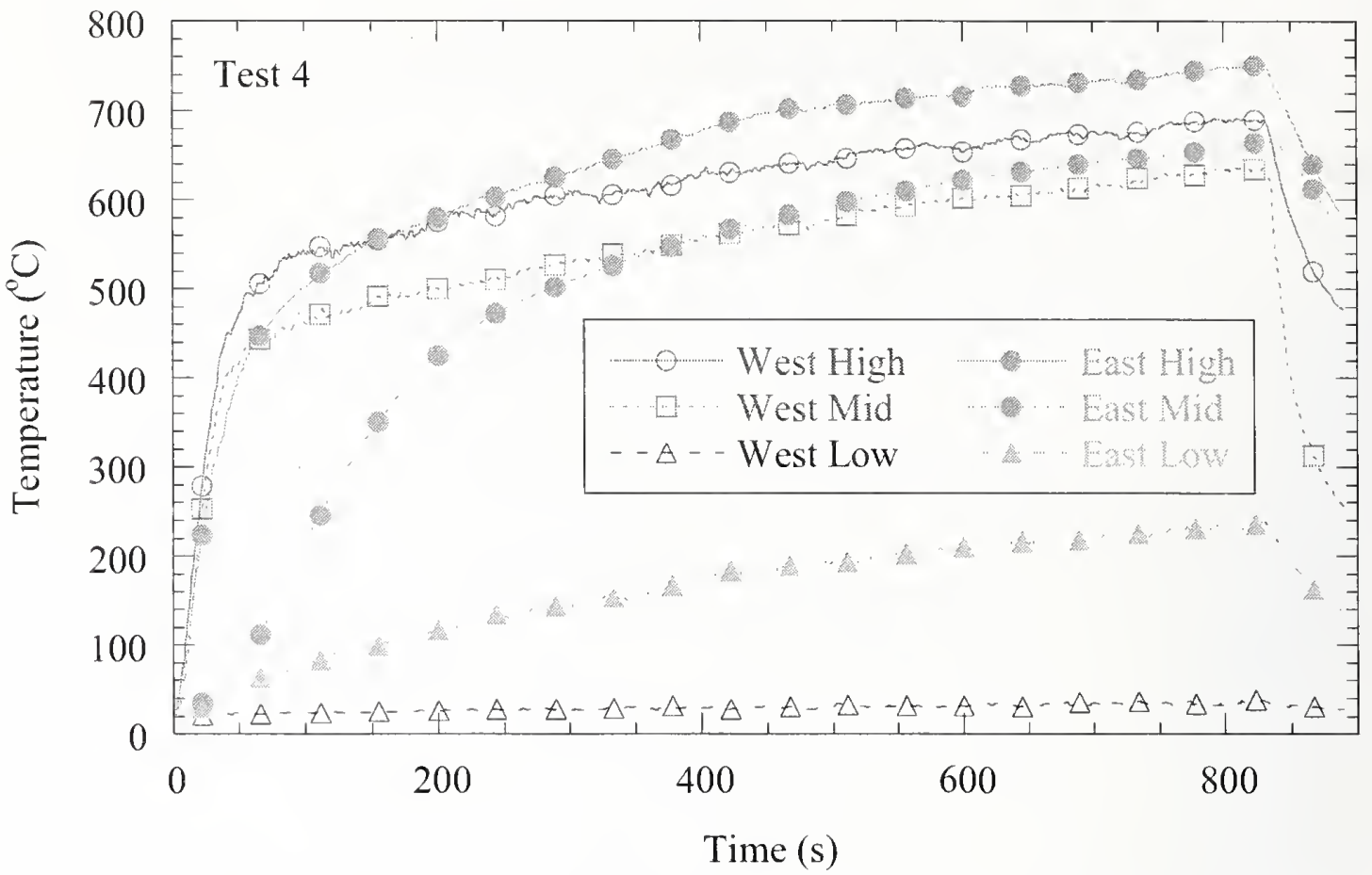

Figure C-3. Aspirated thermocouple temperatures as a function of time for Test 4.

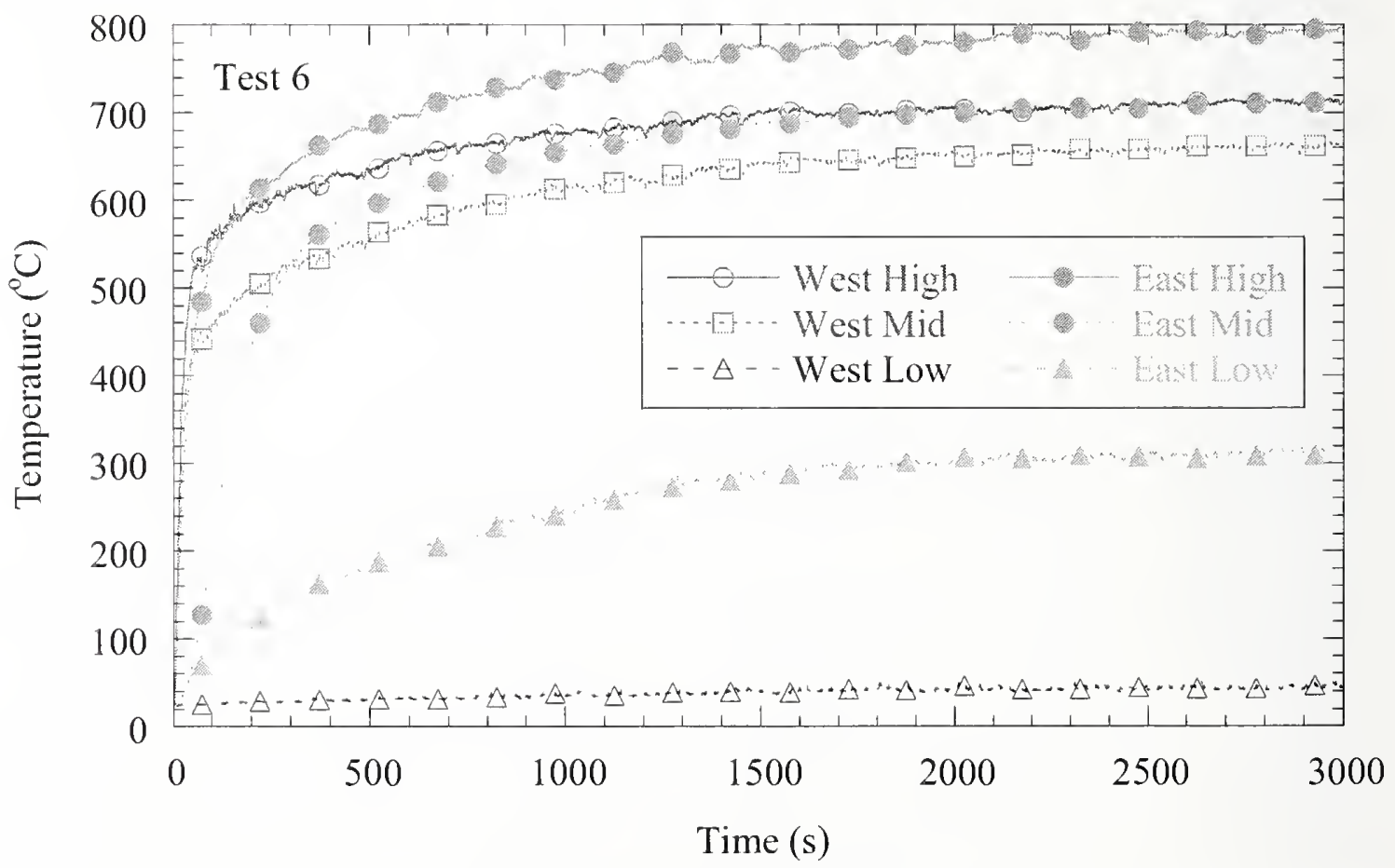

Figure C-4. Aspirated thermocouple temperatures as a function of time for Test 6. 


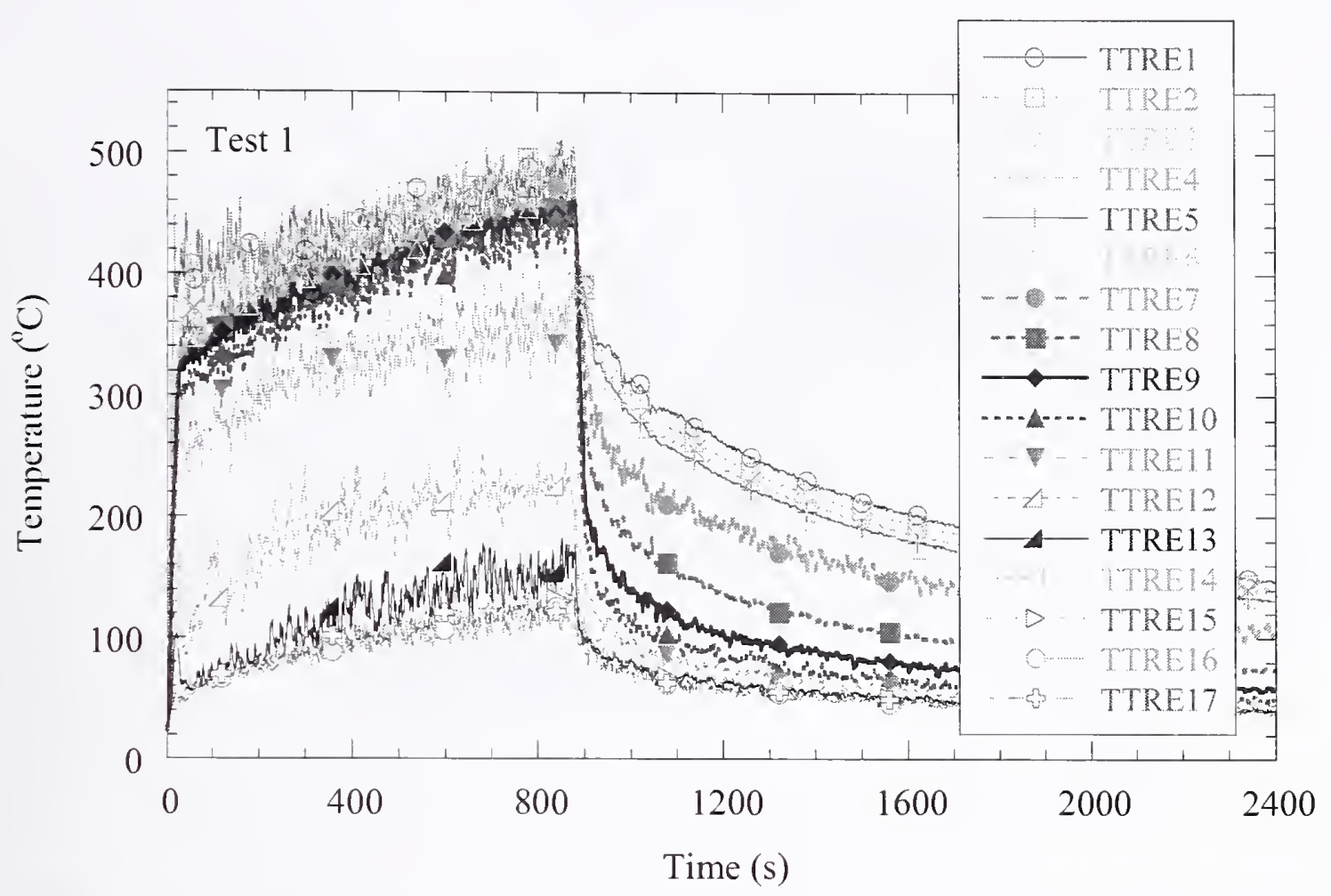

Figure C-5. East thermocouple tree temperatures as a function of time in Test 1.

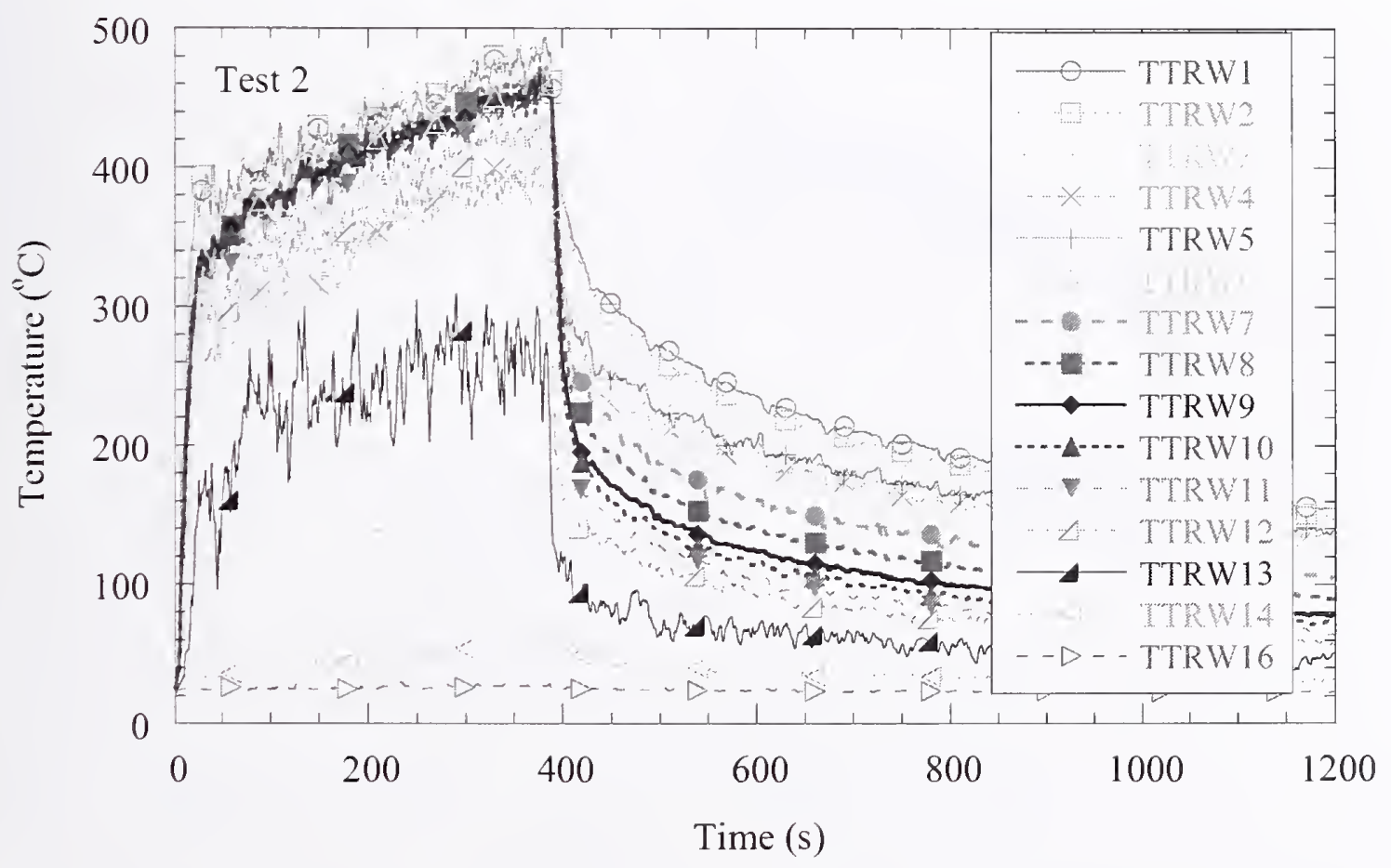

Figure C-6. West thermocouple tree temperatures as a function of time in Test 2. 


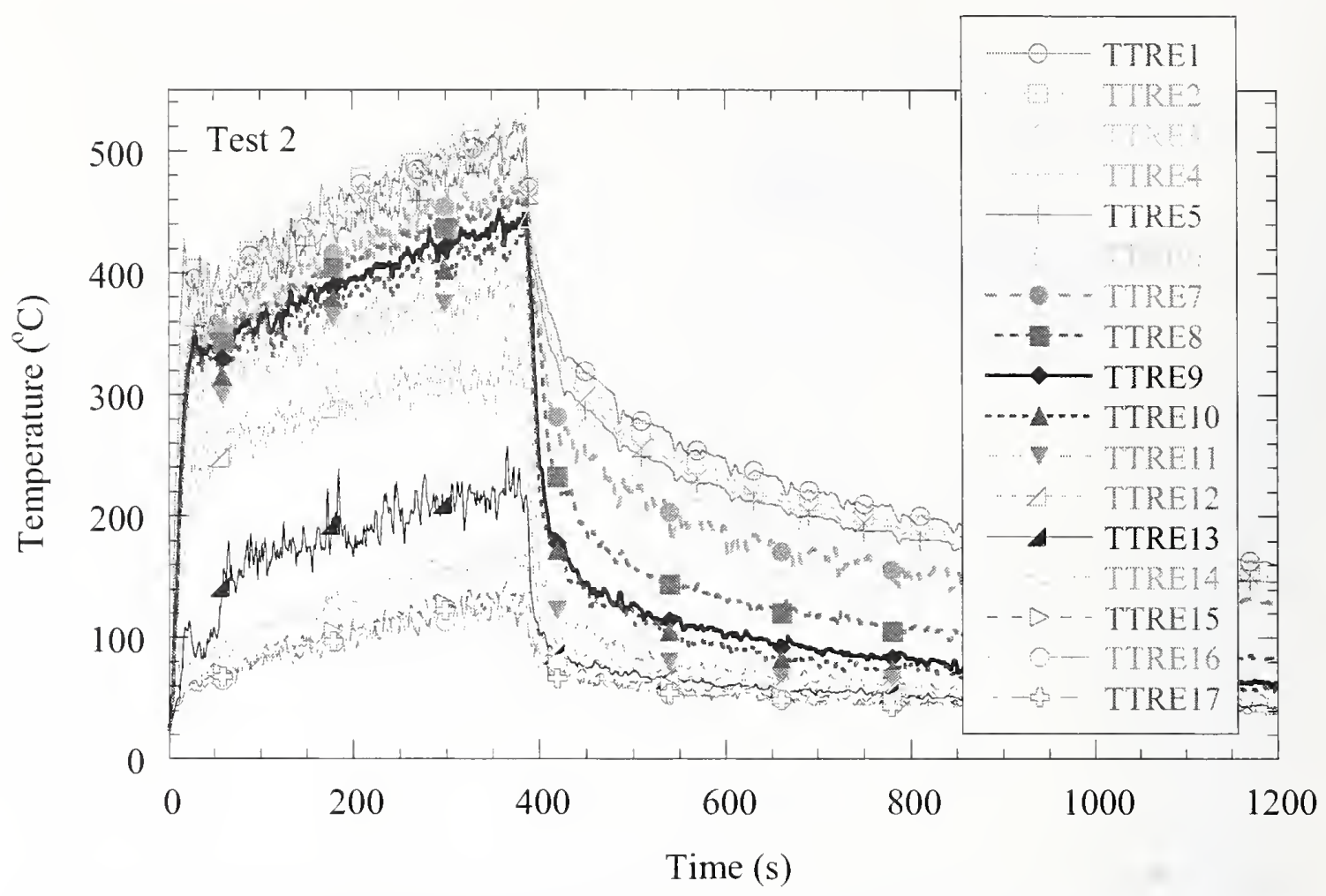

Figure C-7. East thermocouple tree temperatures as a function of time in Test 2.

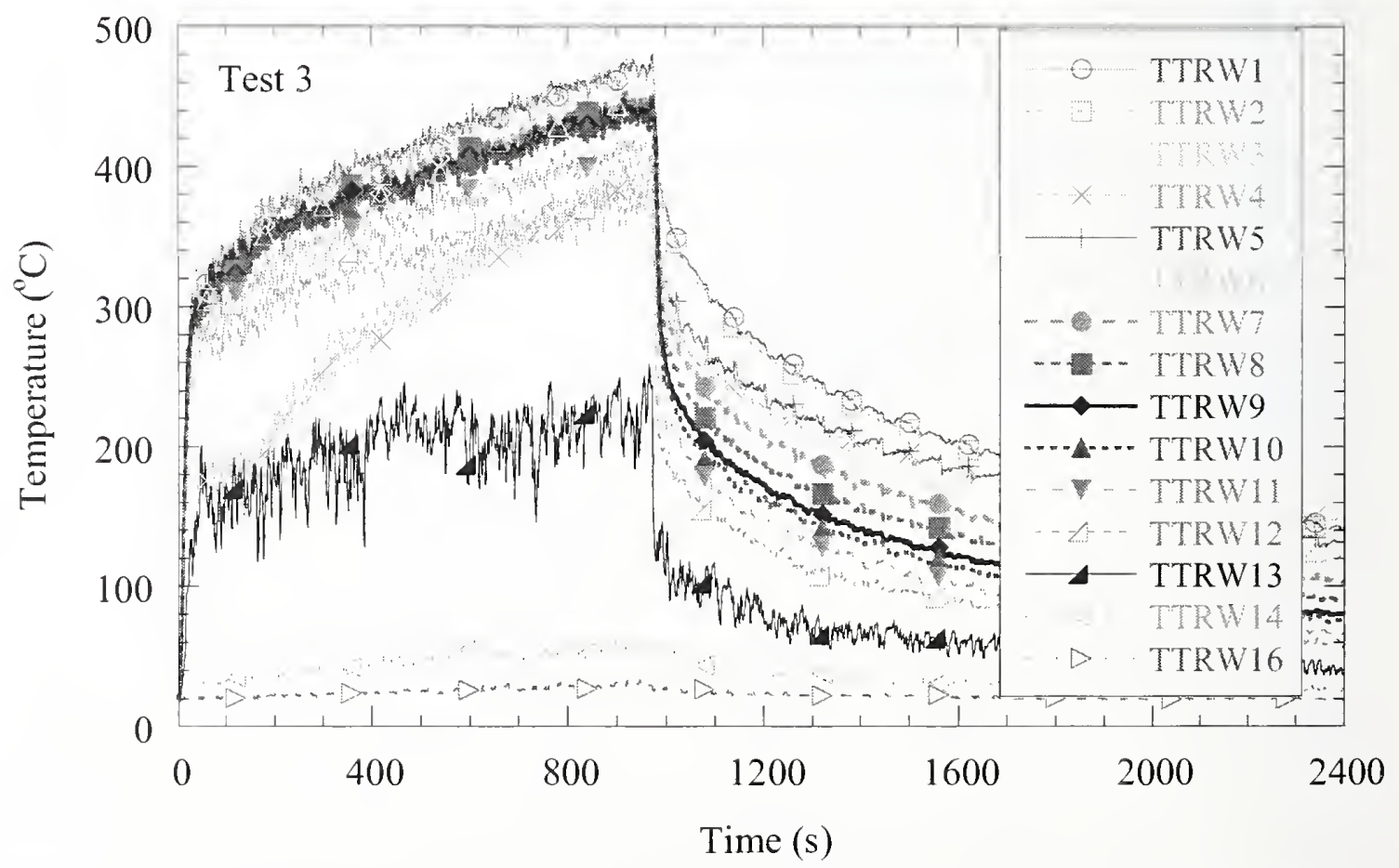

Figure C-8. West thermocouple tree temperatures as a function of time in Test 3. 


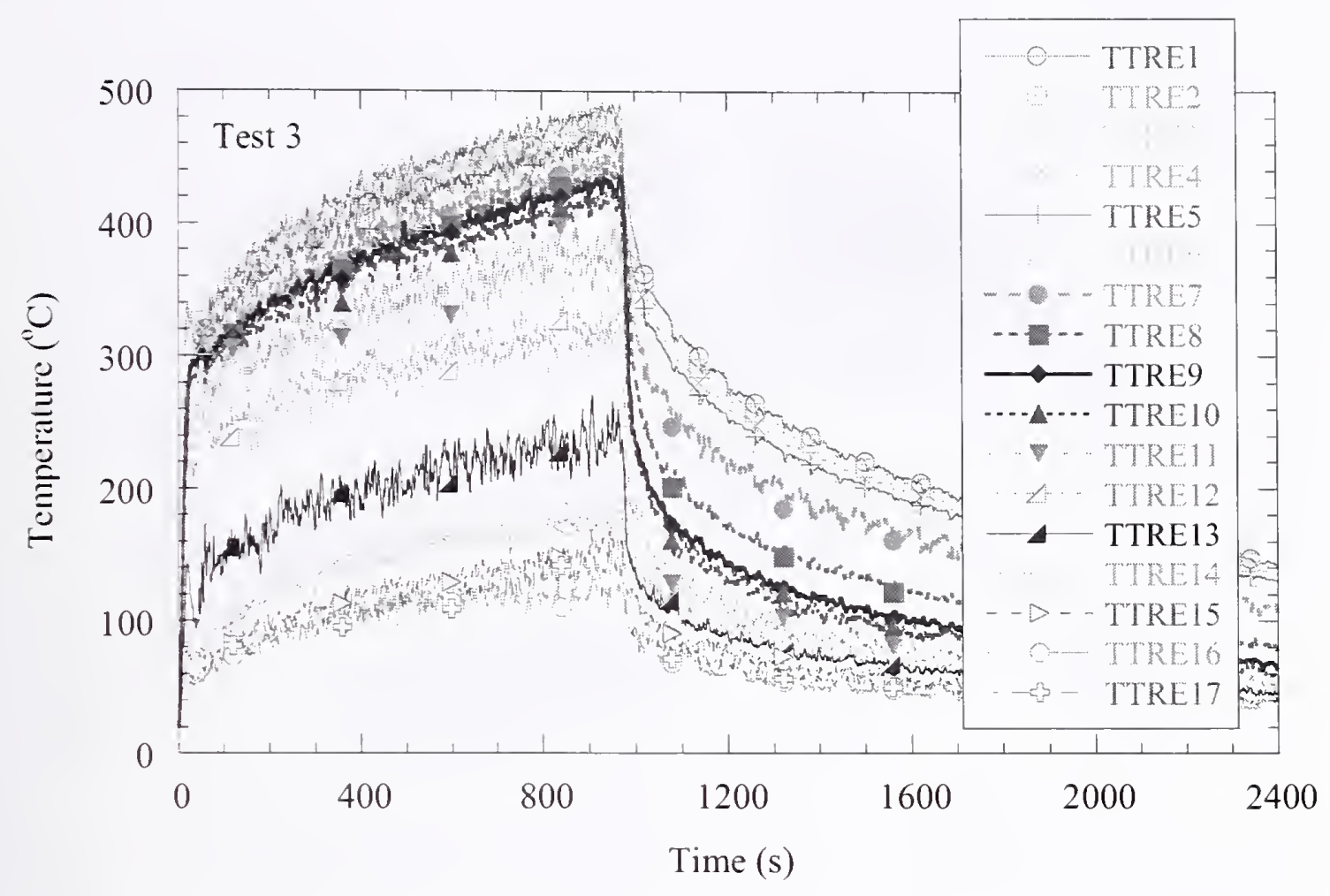

Figure C-9. East thermocouple tree temperatures as a function of time in Test 3.

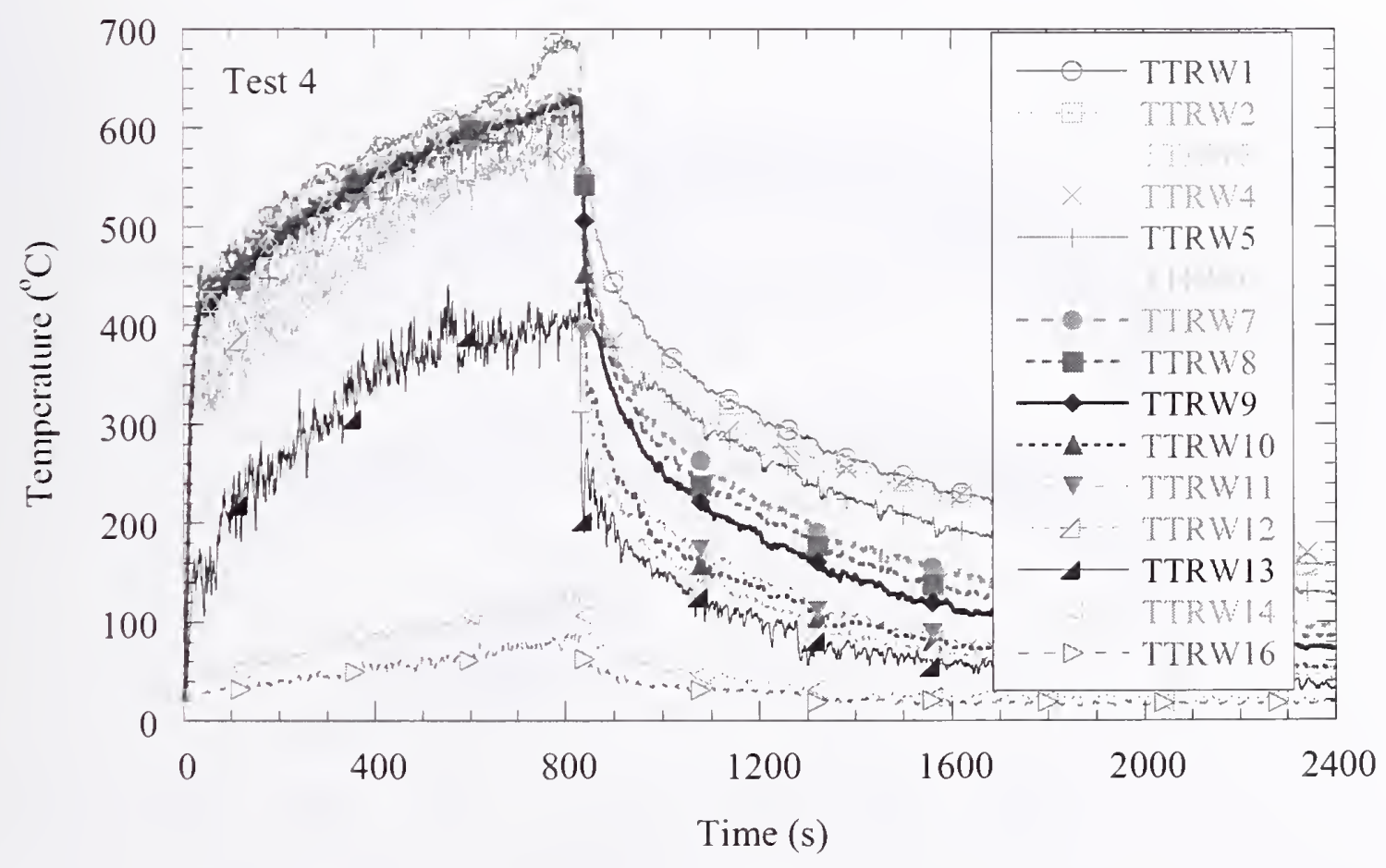

Figure $\mathrm{C}-10$. West thermocouple tree temperatures as a function of time in Test 4. 


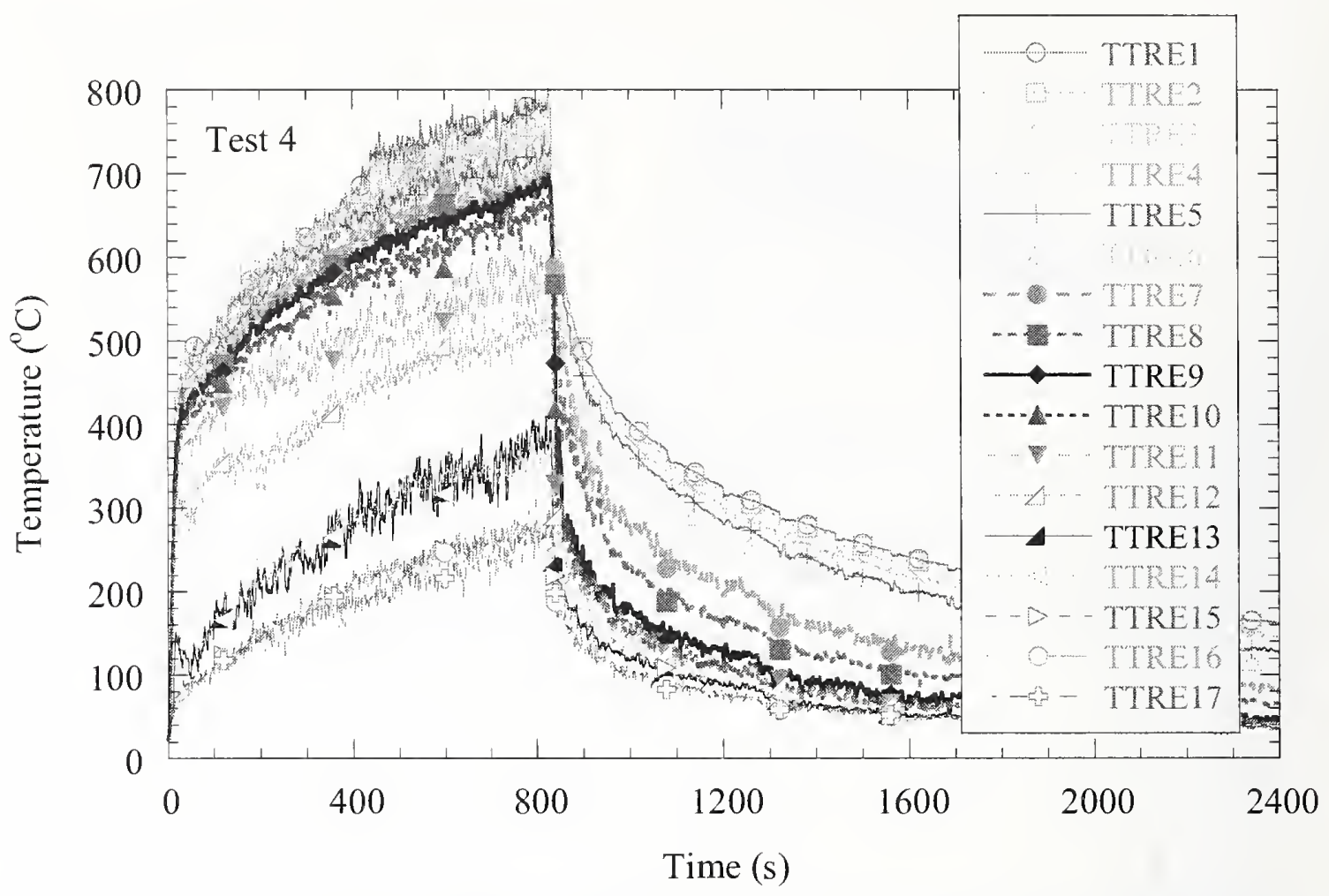

Figure $\mathrm{C}-11$. East thermocouple tree temperatures as a function of time in Test 4.

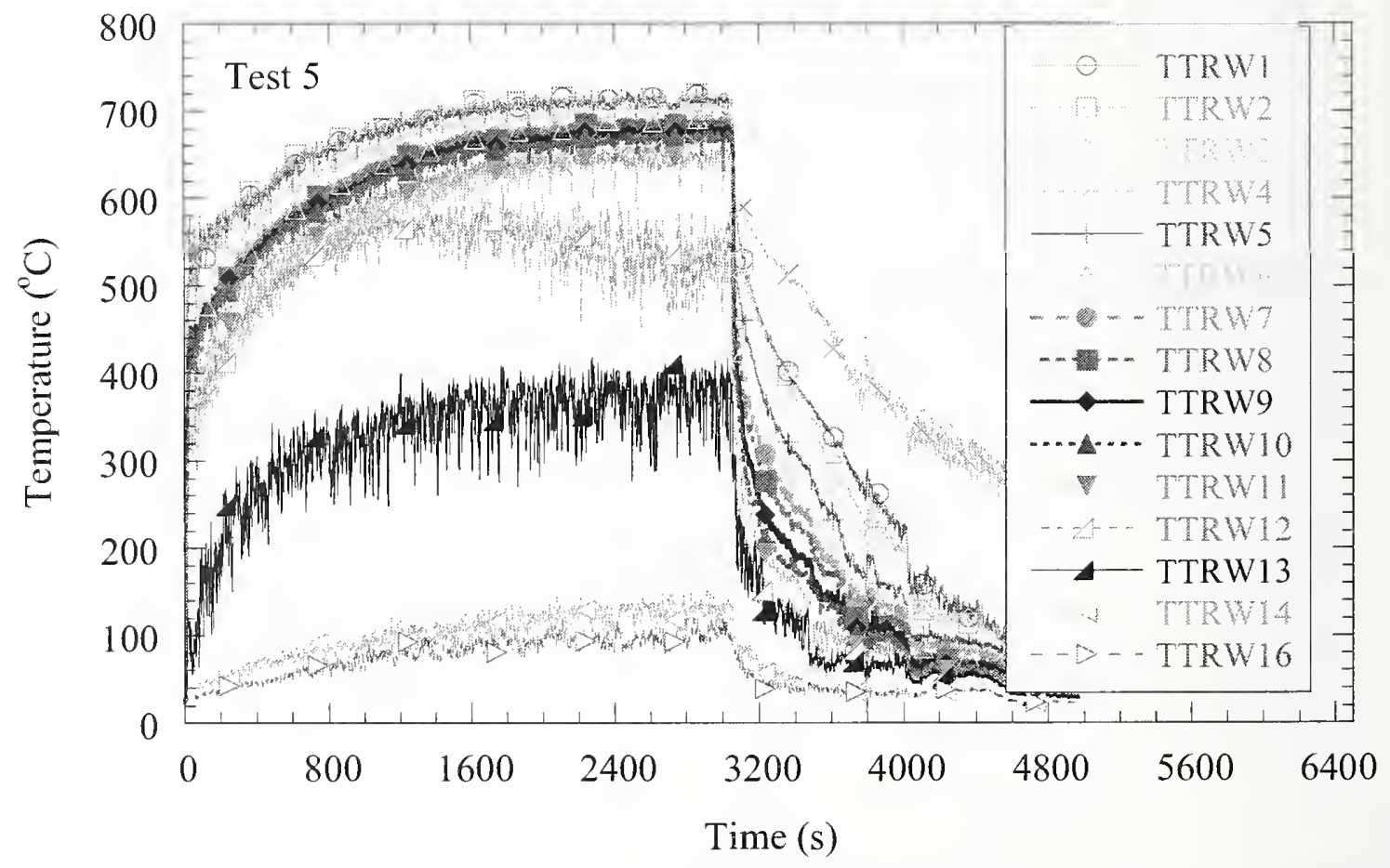

Figure $\mathrm{C}-12$. West thermocouple tree temperatures as a function of time in Test 5. 


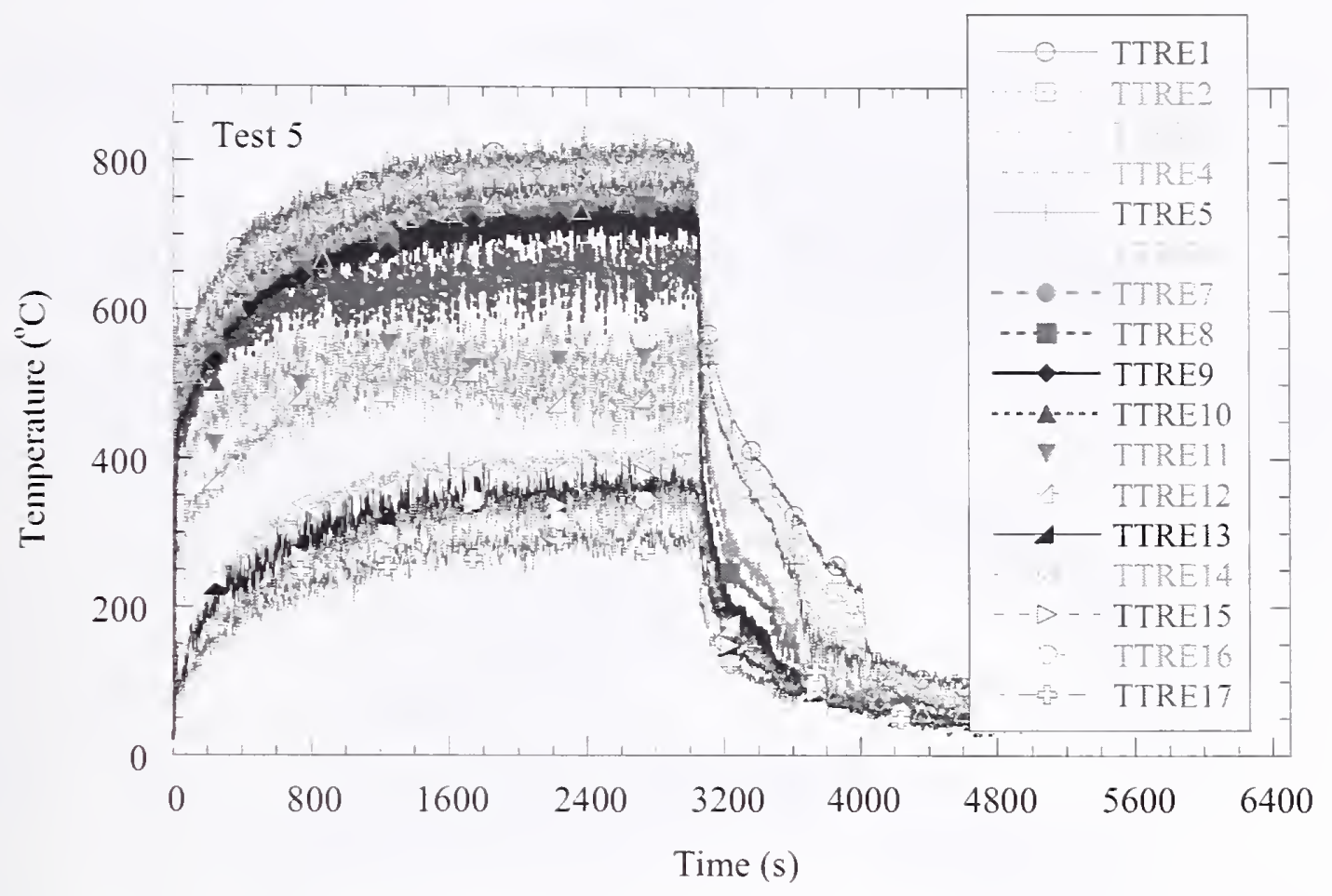

Figure $\mathrm{C}-13$. East thermocouple tree temperatures as a function of time in Test 5.

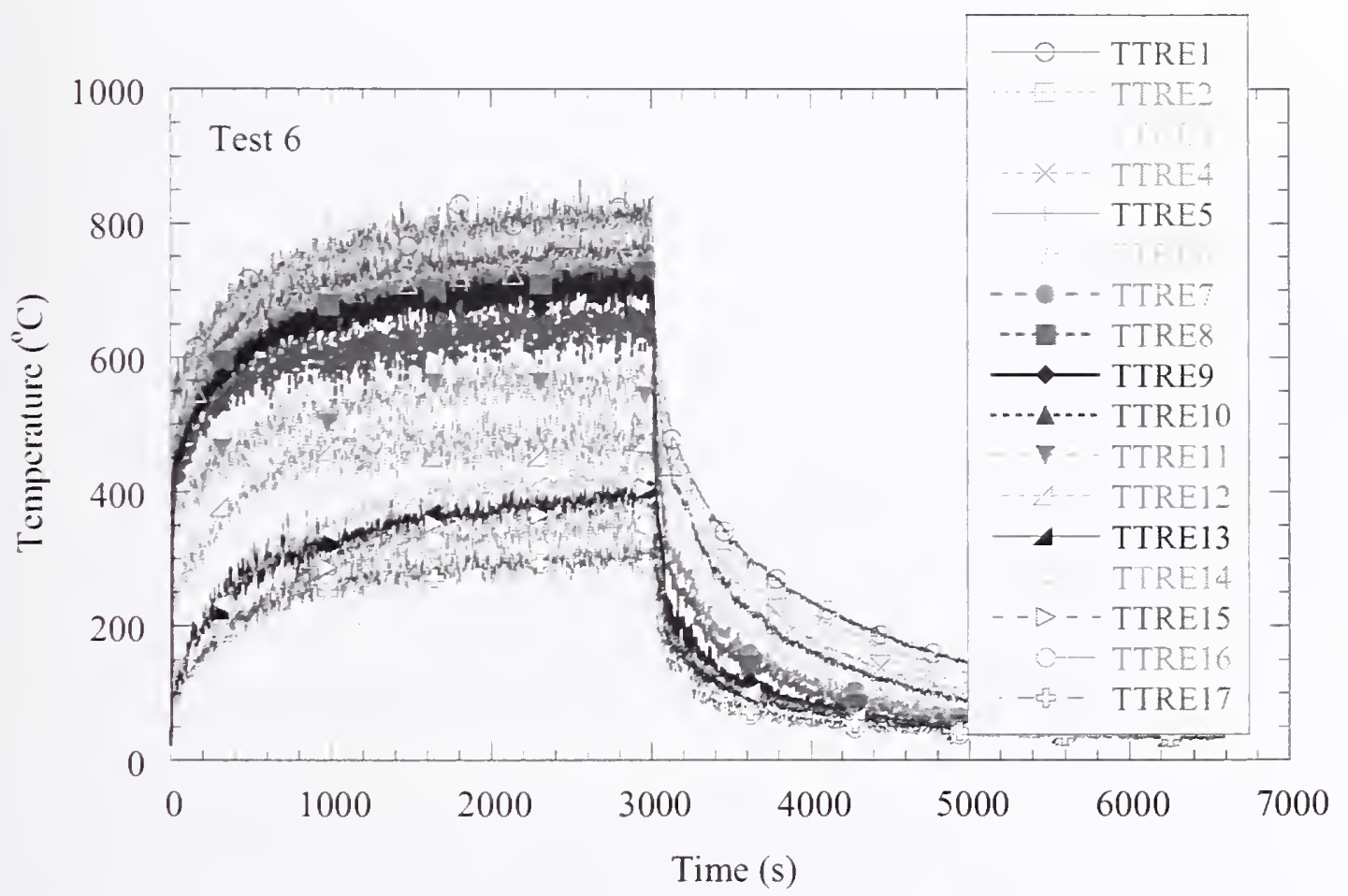

Figure C-14. East thermocouple tree temperatures as a function of time in Test 6. 


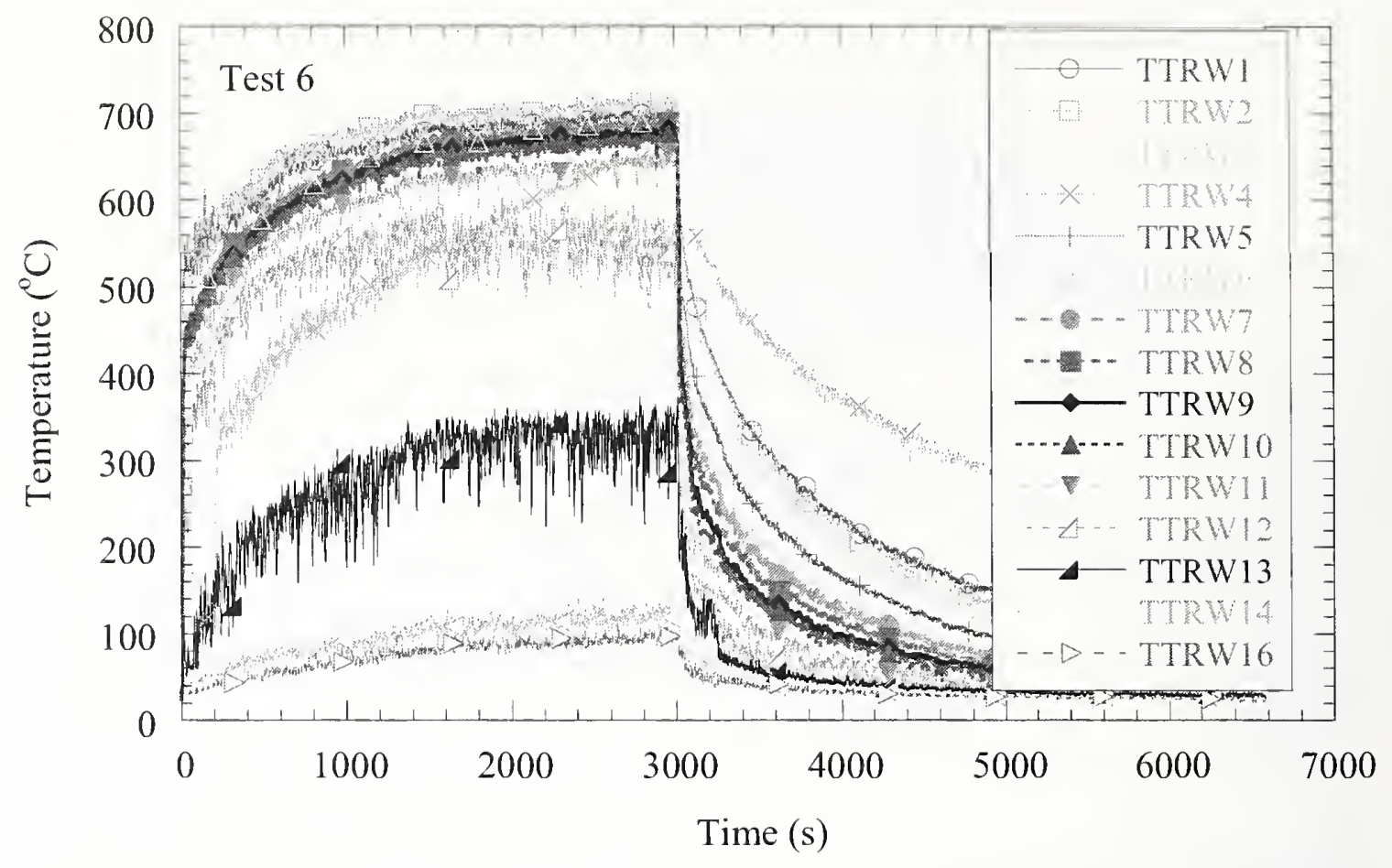

Figure $\mathrm{C}-15$. West thermocouple tree temperatures as a function of time in Test 6. 


\section{Appendix D \\ Velocity MeAsurements at THE Compartment INLET AND OUTLET}

This appendix presents data on the inlet and outlet velocities and the corresponding corrected temperature measurements that was not presented in Chapter 7 of this report (see Figs. D-1 through D-42). Further information on these measurements can be found in Chapter 7.

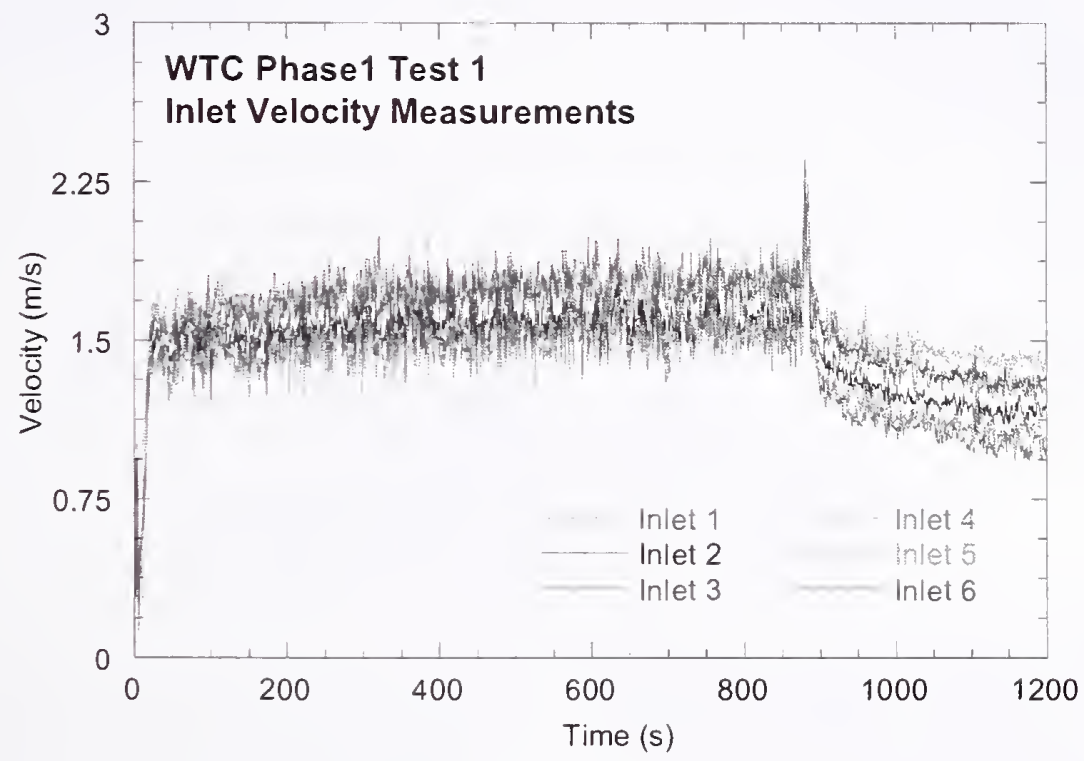

Figure D-1. Inlet velocities for Test 1.

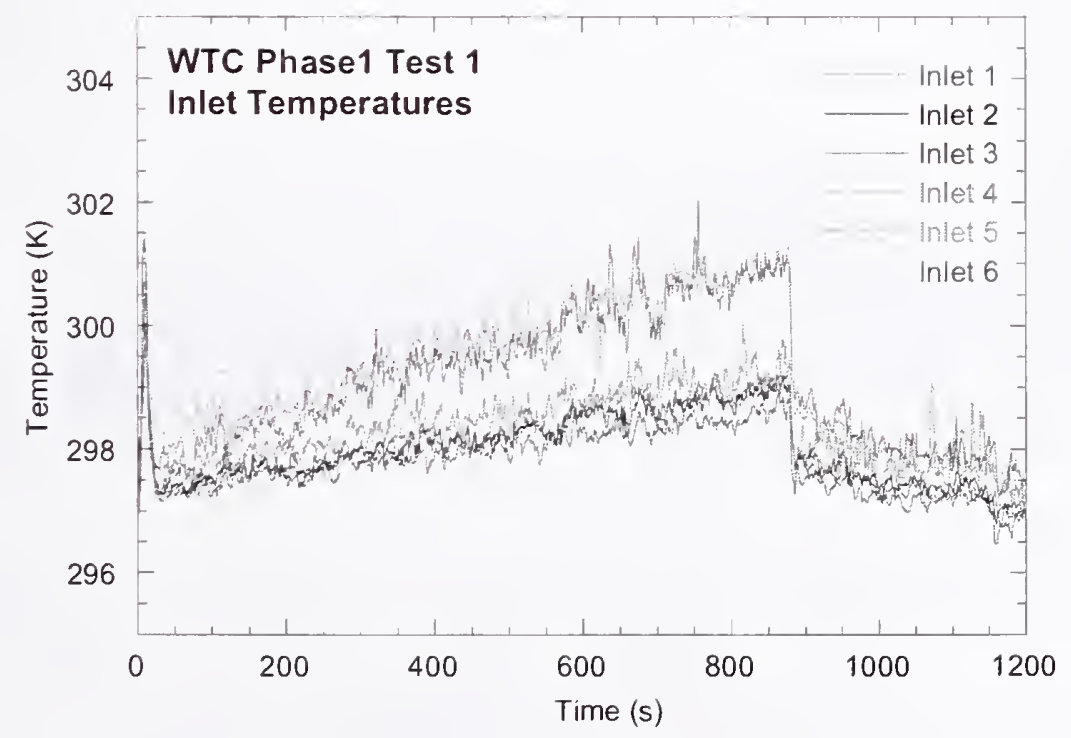

Figure D-2. Inlet temperatures for Test 1. 


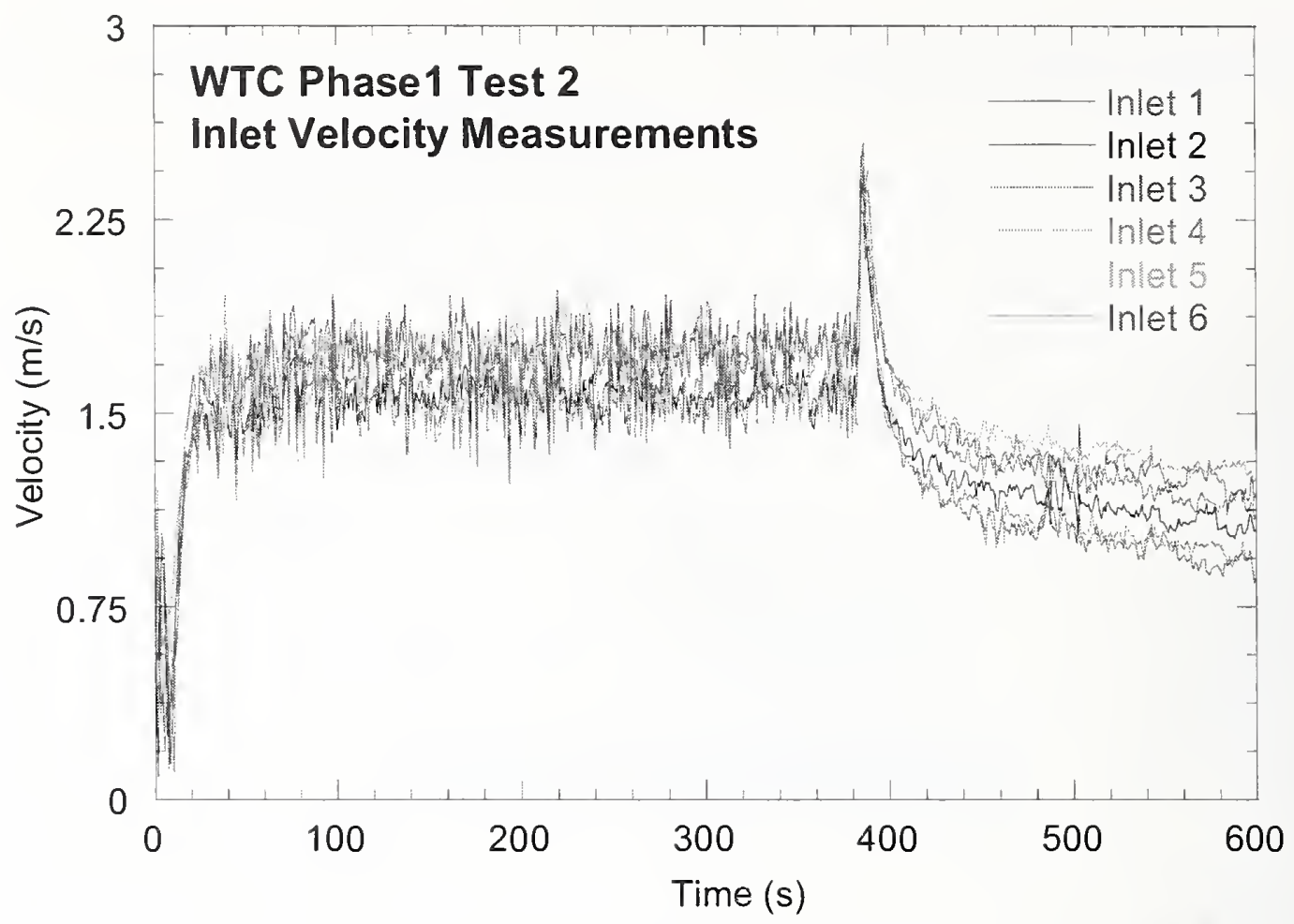

Figure D-3. Inlet velocities for Test 2.

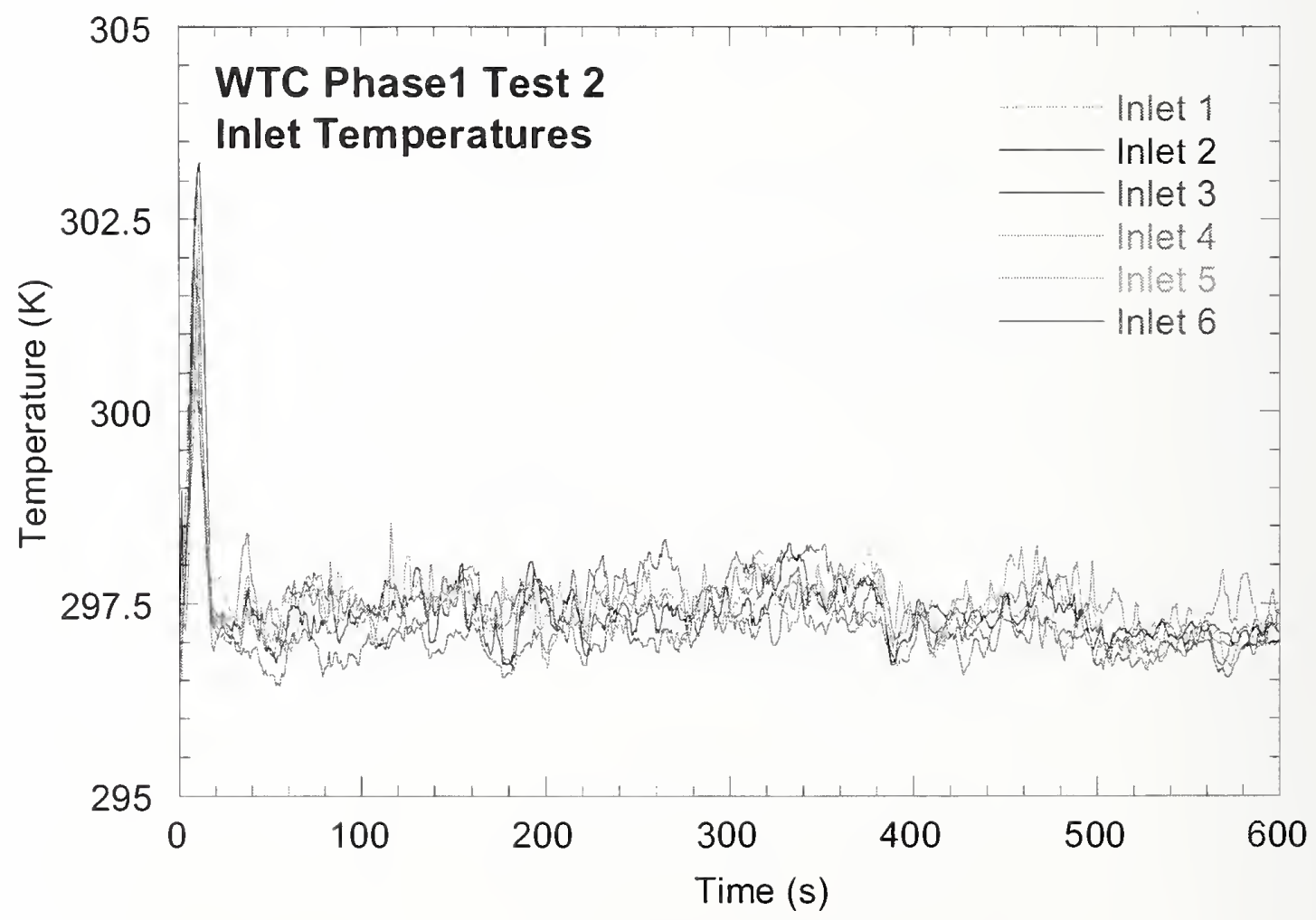

Figure D-4. Inlet temperatures for Test 2. 


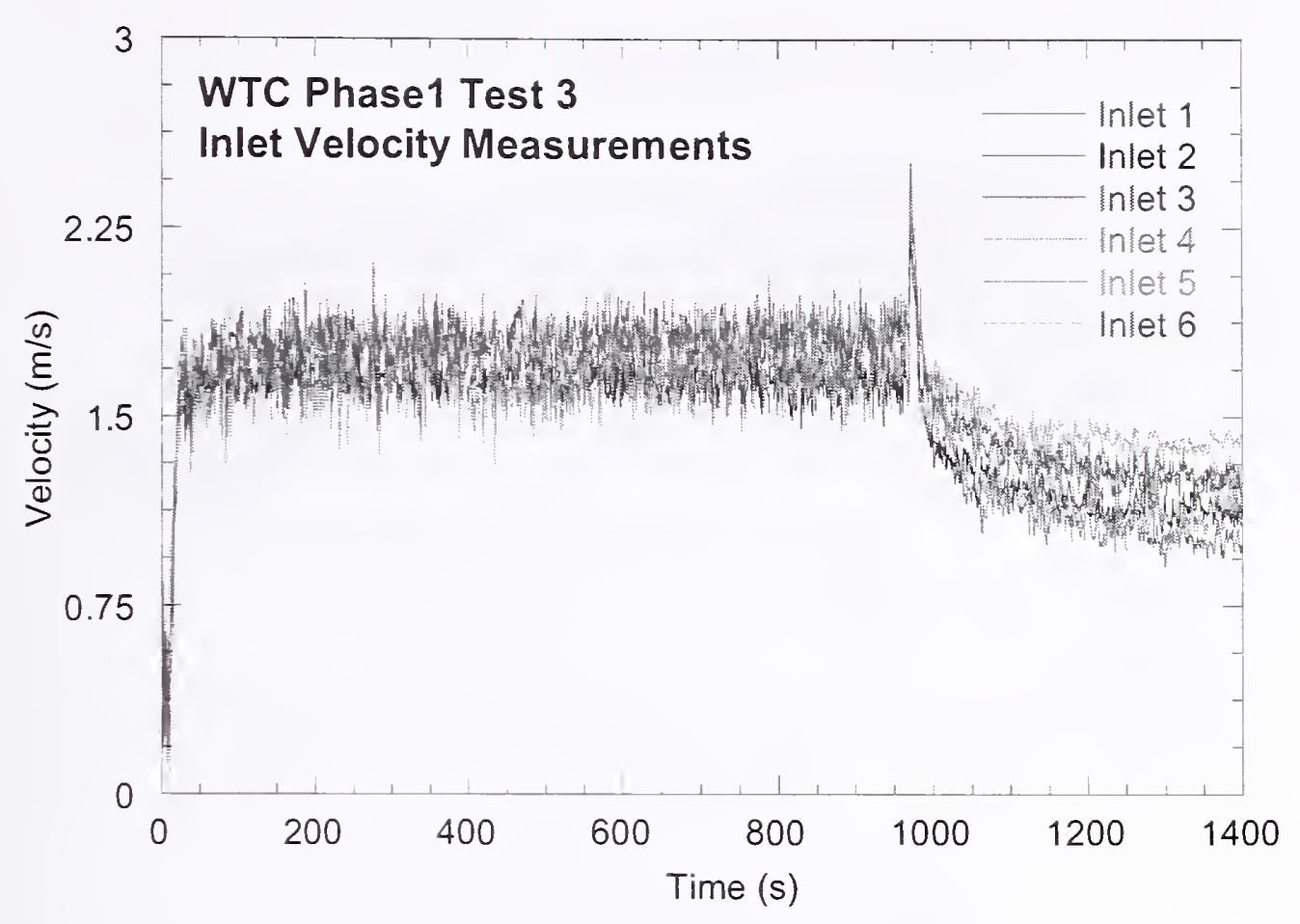

Figure D-5. Inlet velocities for Test 3.

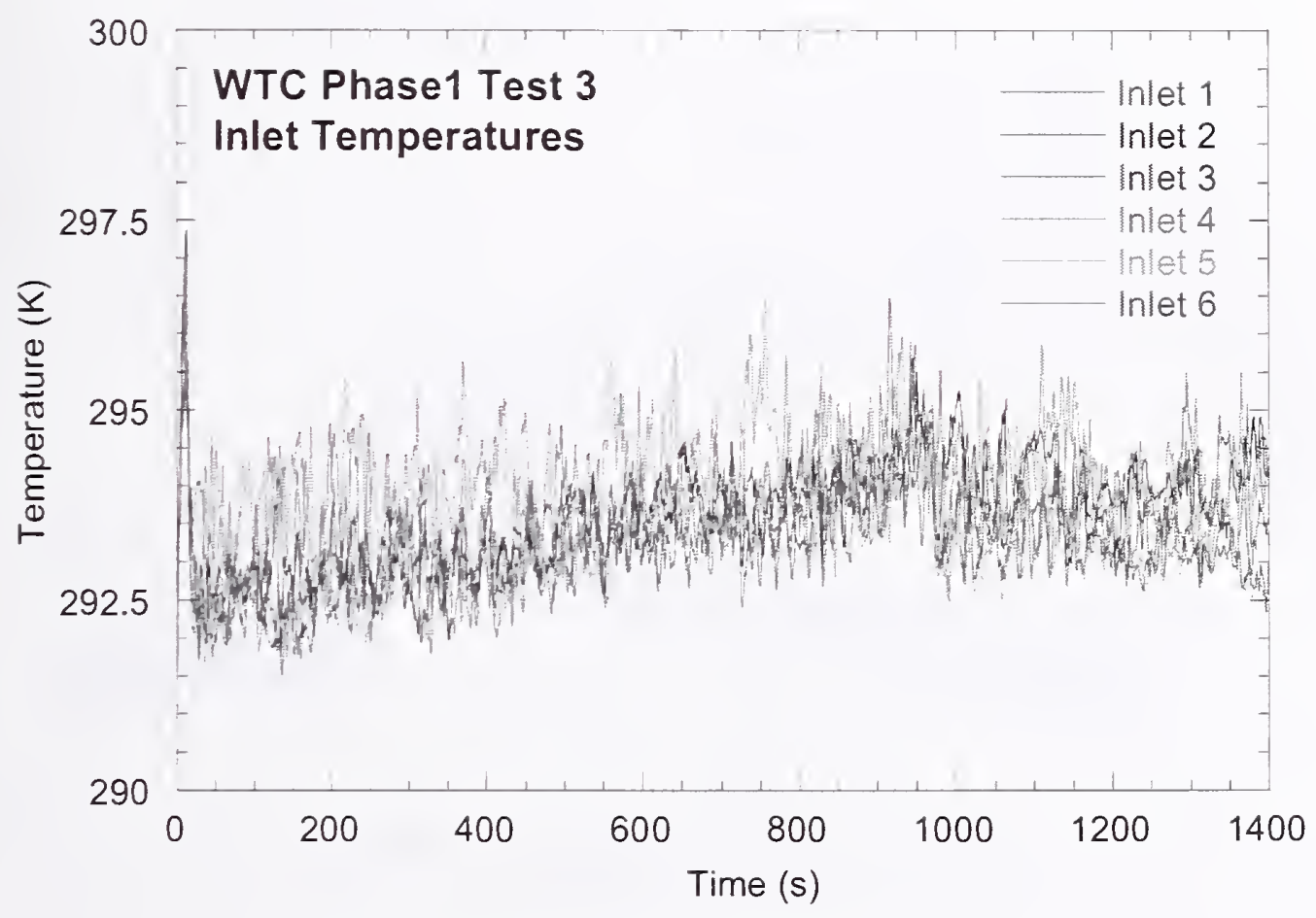

Figure D-6. Inlet temperatures for Test 3. 


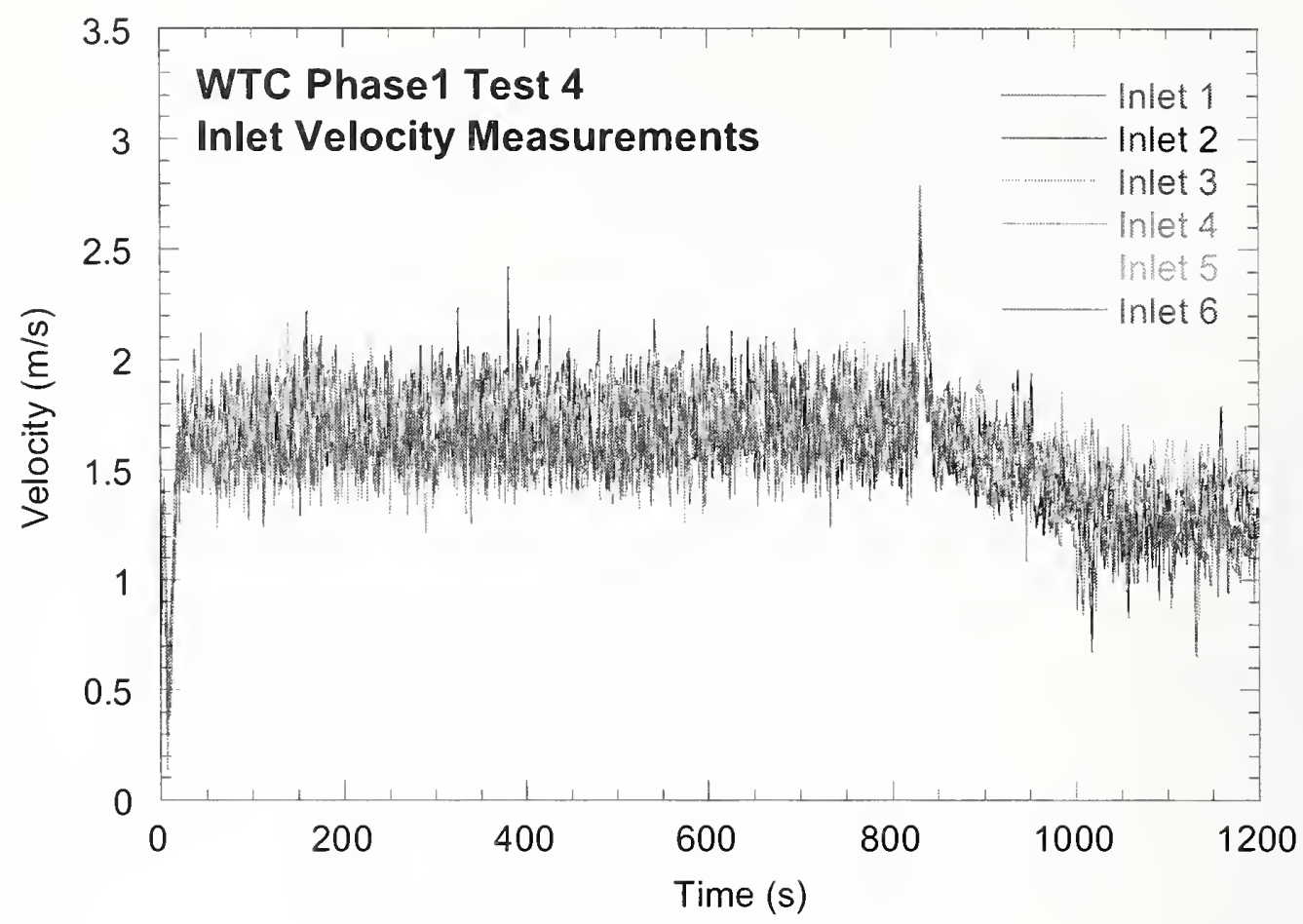

Figure D-7. Inlet velocities for Test 4.

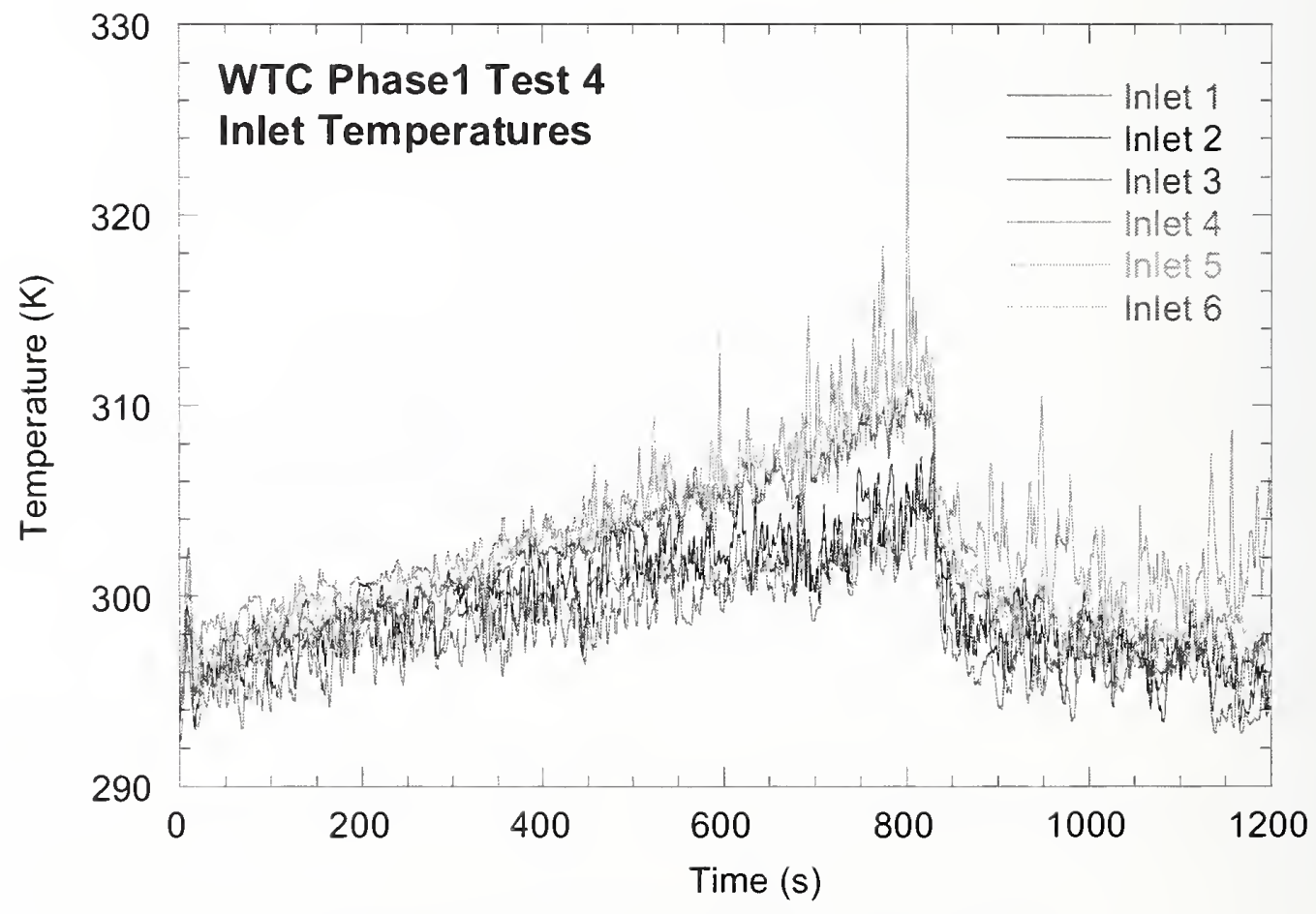

Figure D-8. Inlet temperatures for Test 4. 


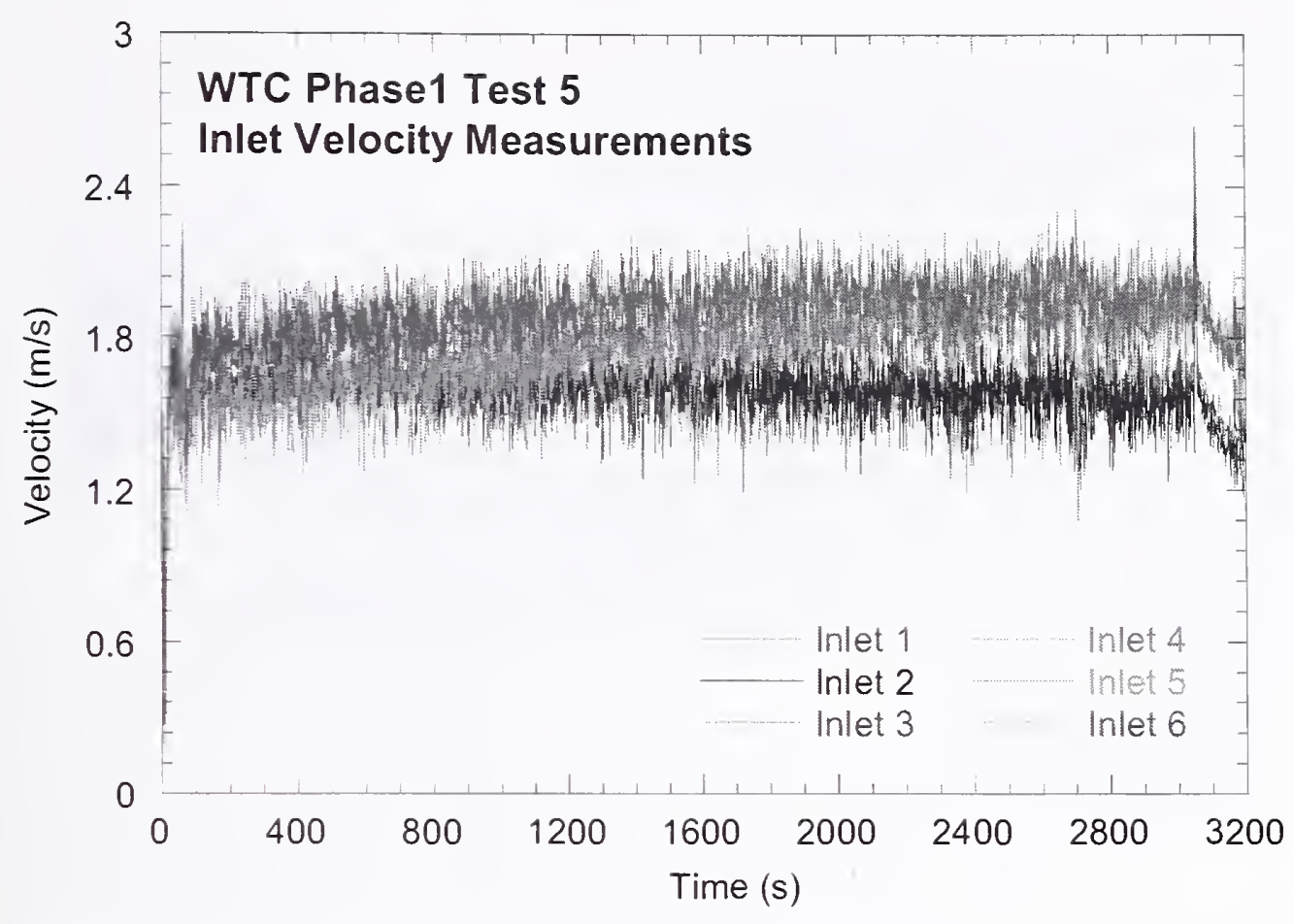

Figure D-9. Inlet velocities for Test 5.

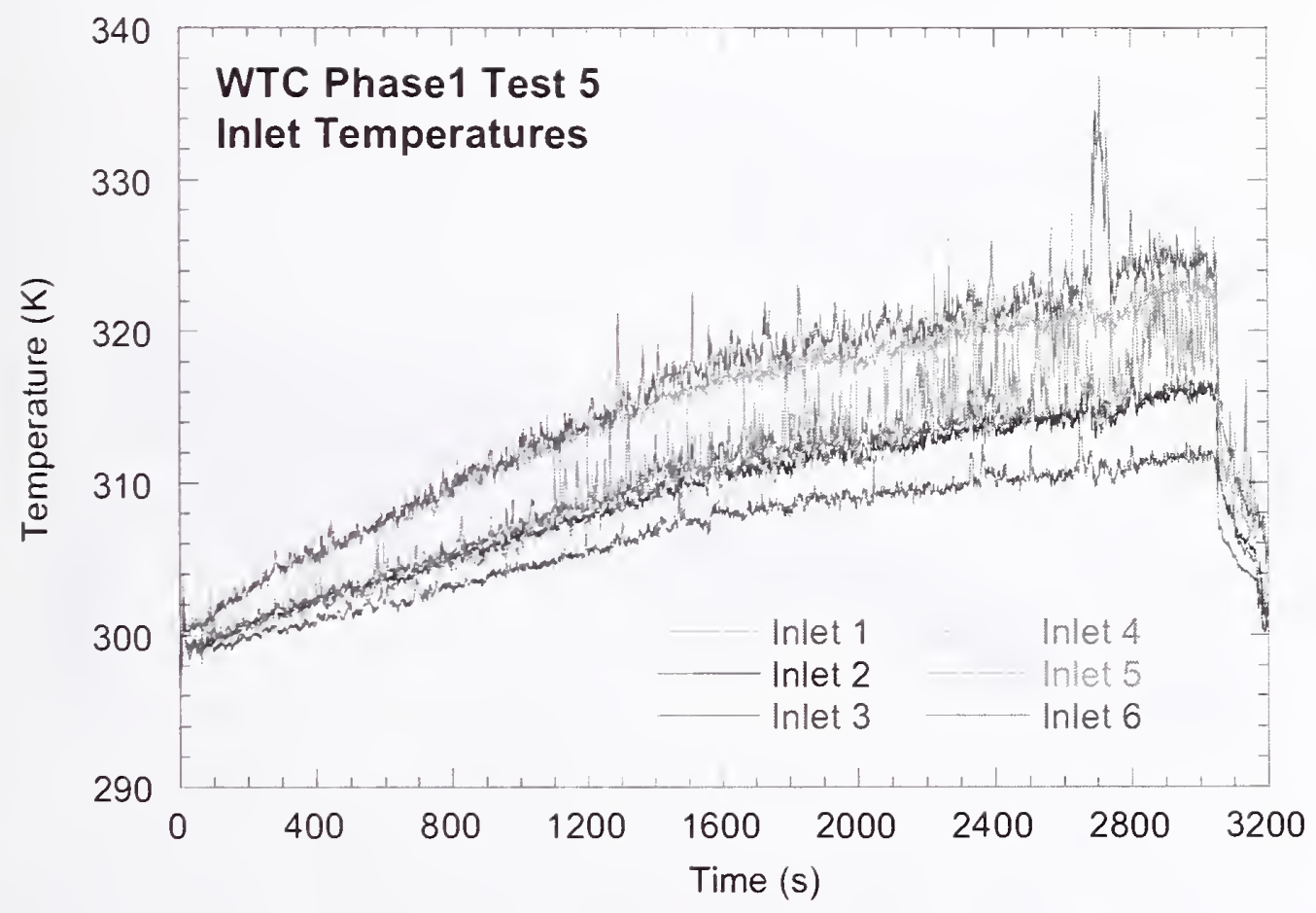

Figure D-10. Inlet temperatures for Test 5. 


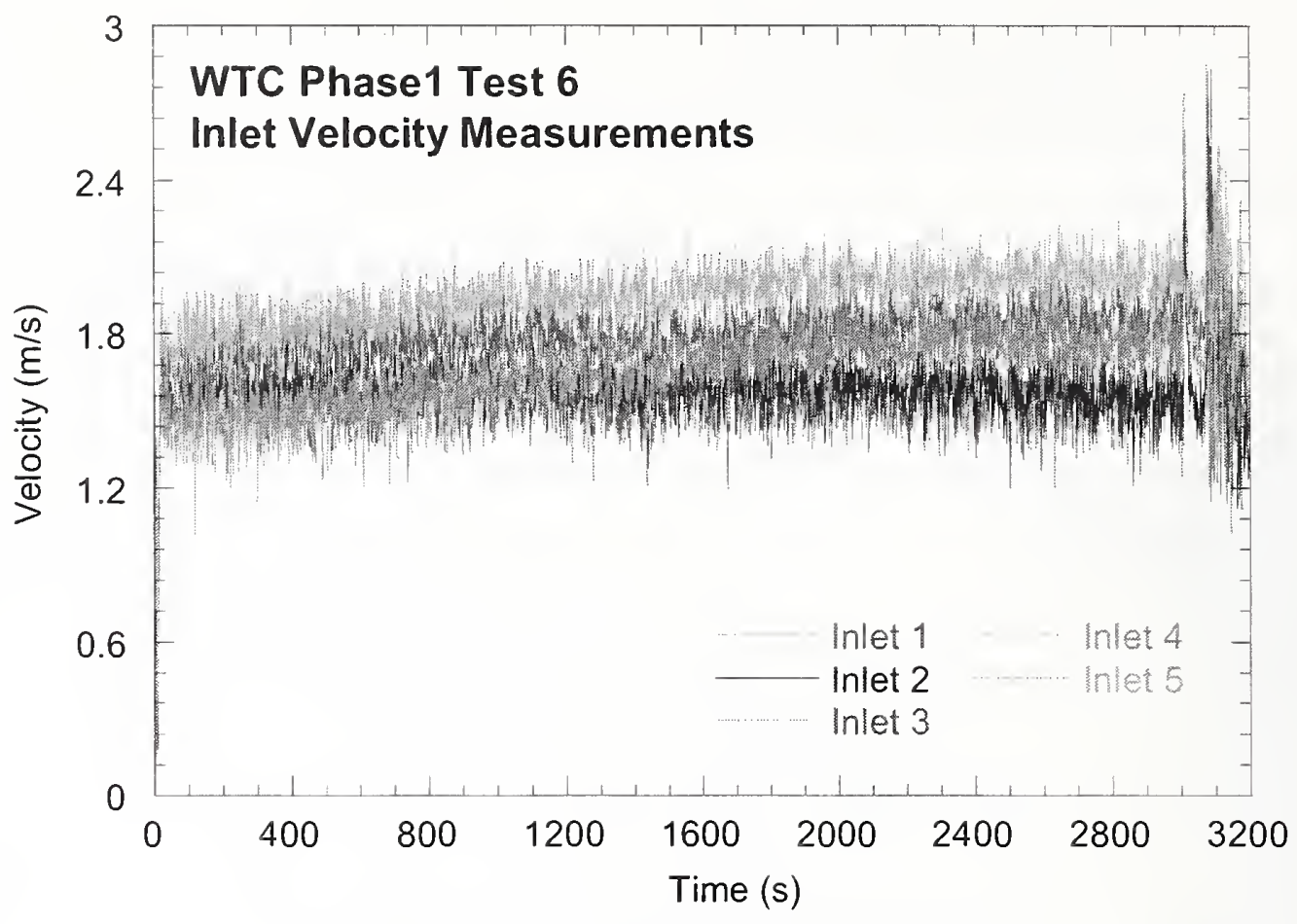

Figure D-11. Inlet velocities for Test 6.

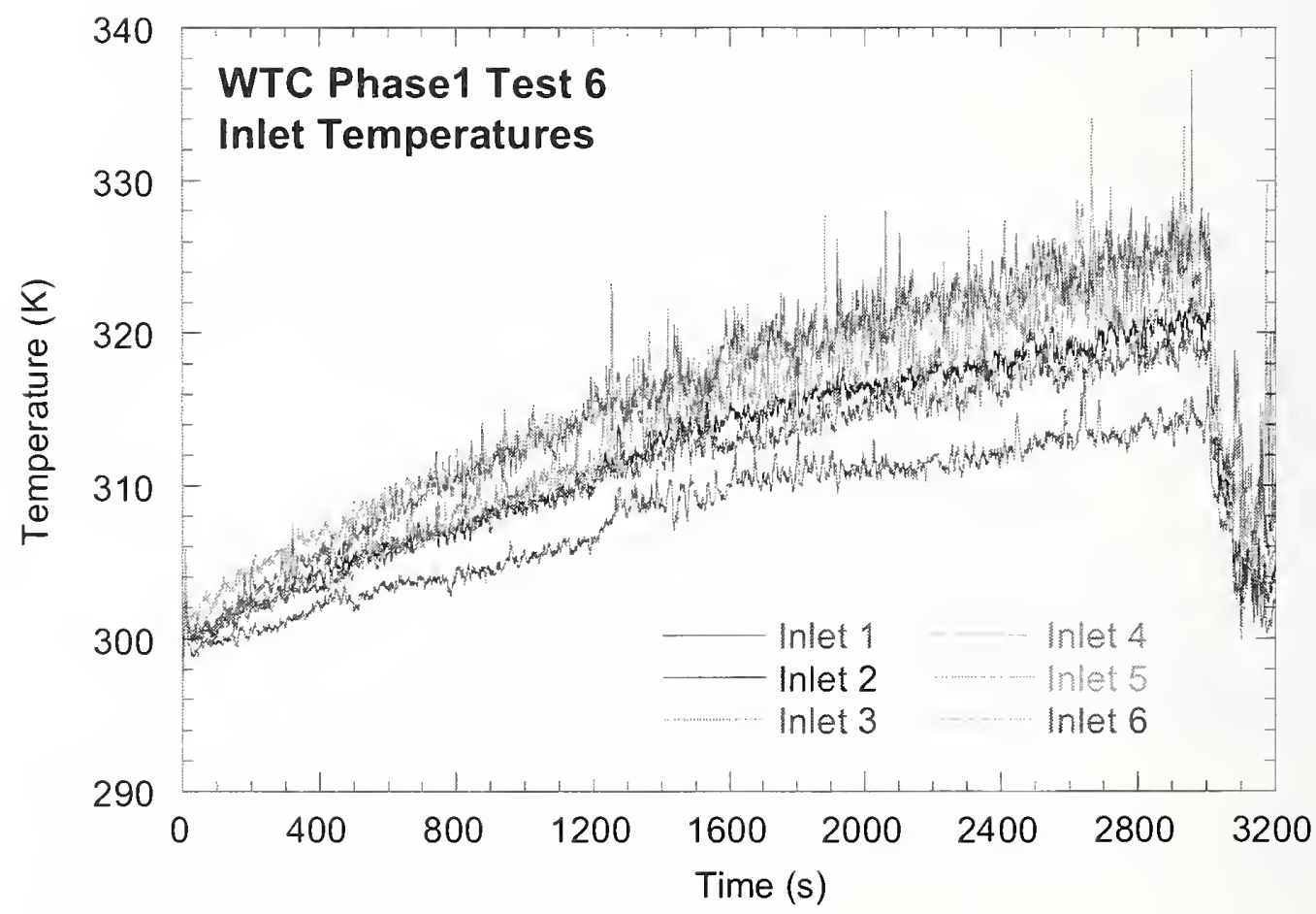

Figure D-12. Inlet temperatures for Test 6. 


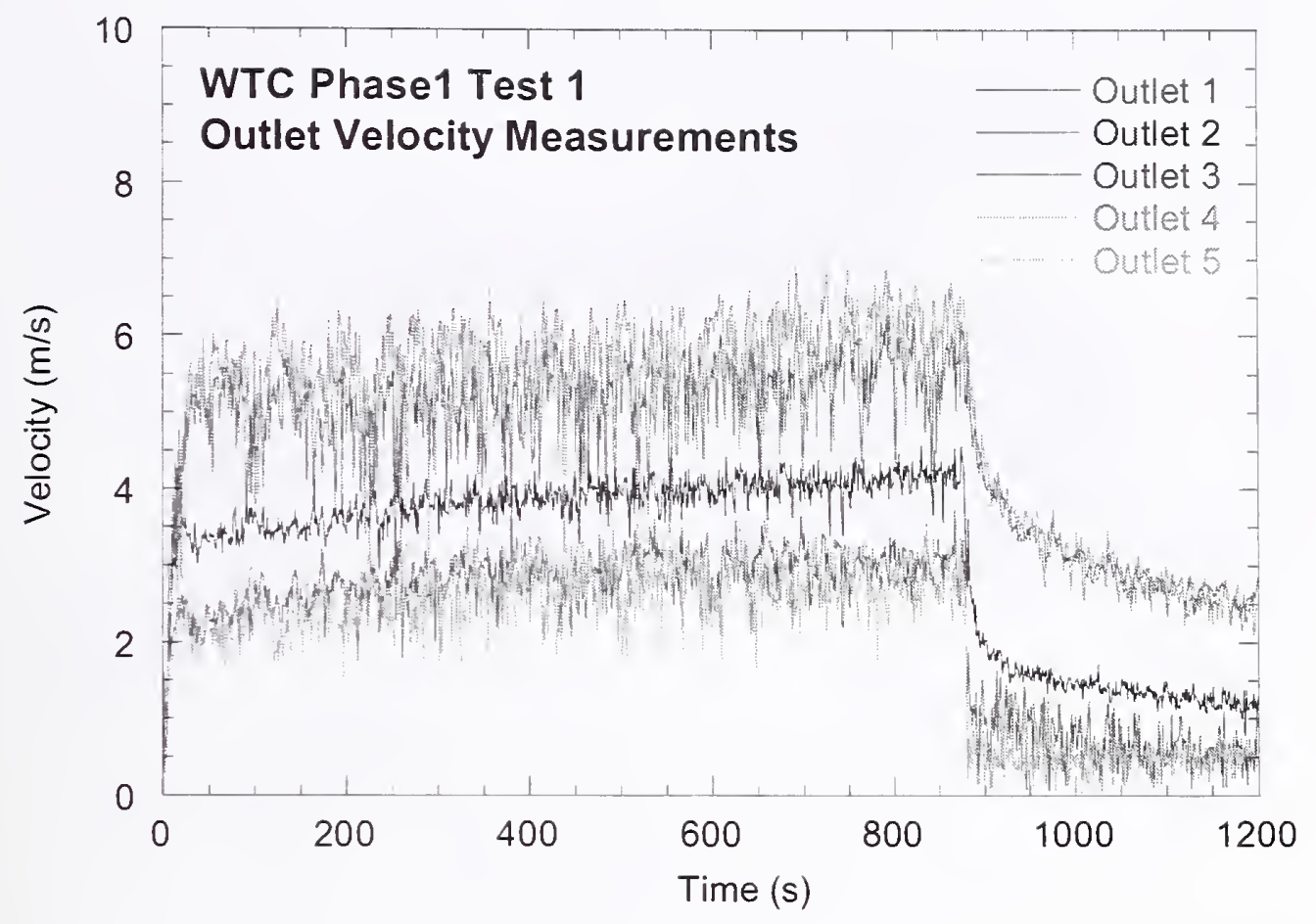

Figure D-13. Outlet velocities for Test 1, outlet locations 1, 2, 3, 4, and 5.

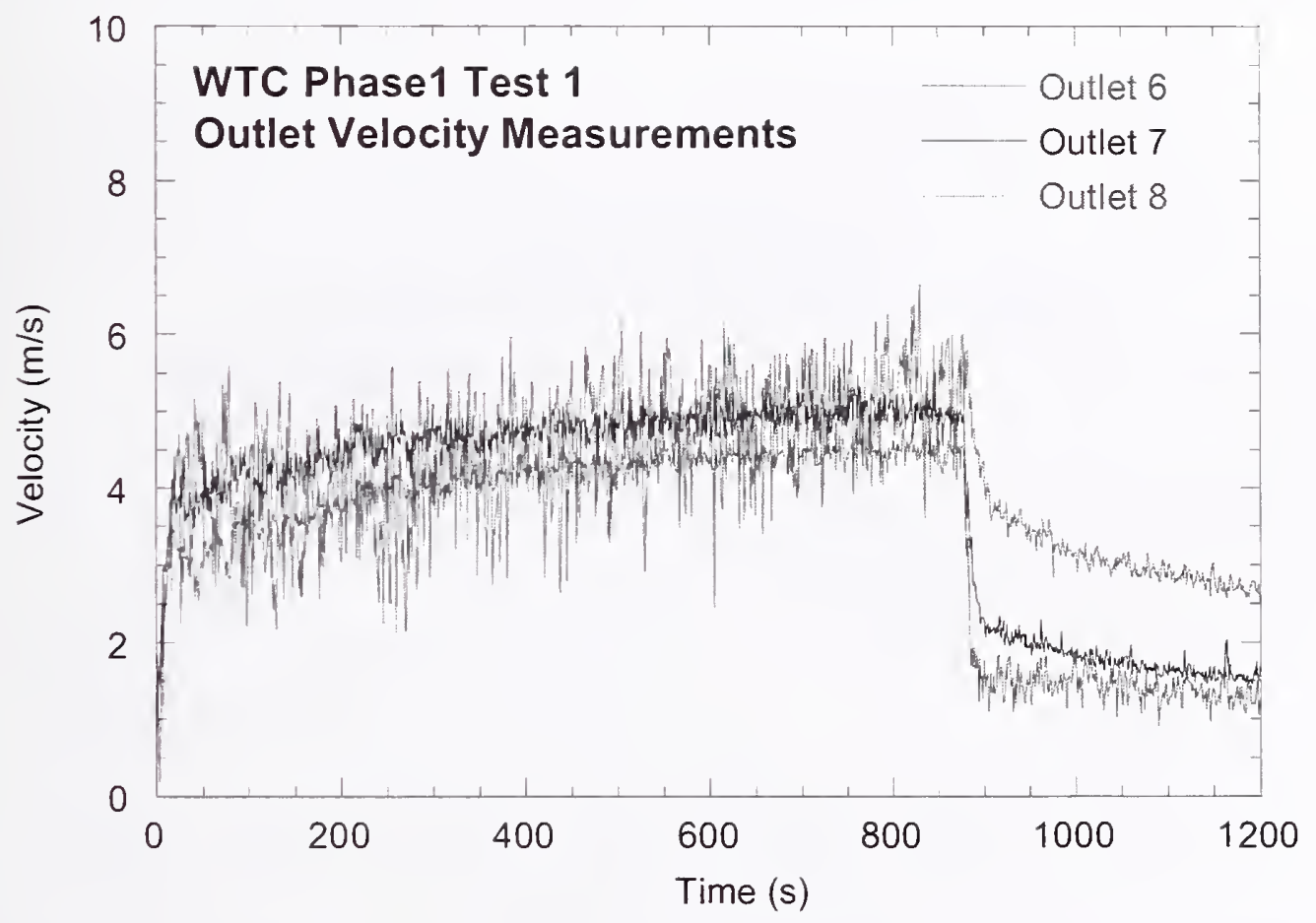

Figure D-14. Outlet velocities for Test 1, outlet locations 6, 7, and 8. 


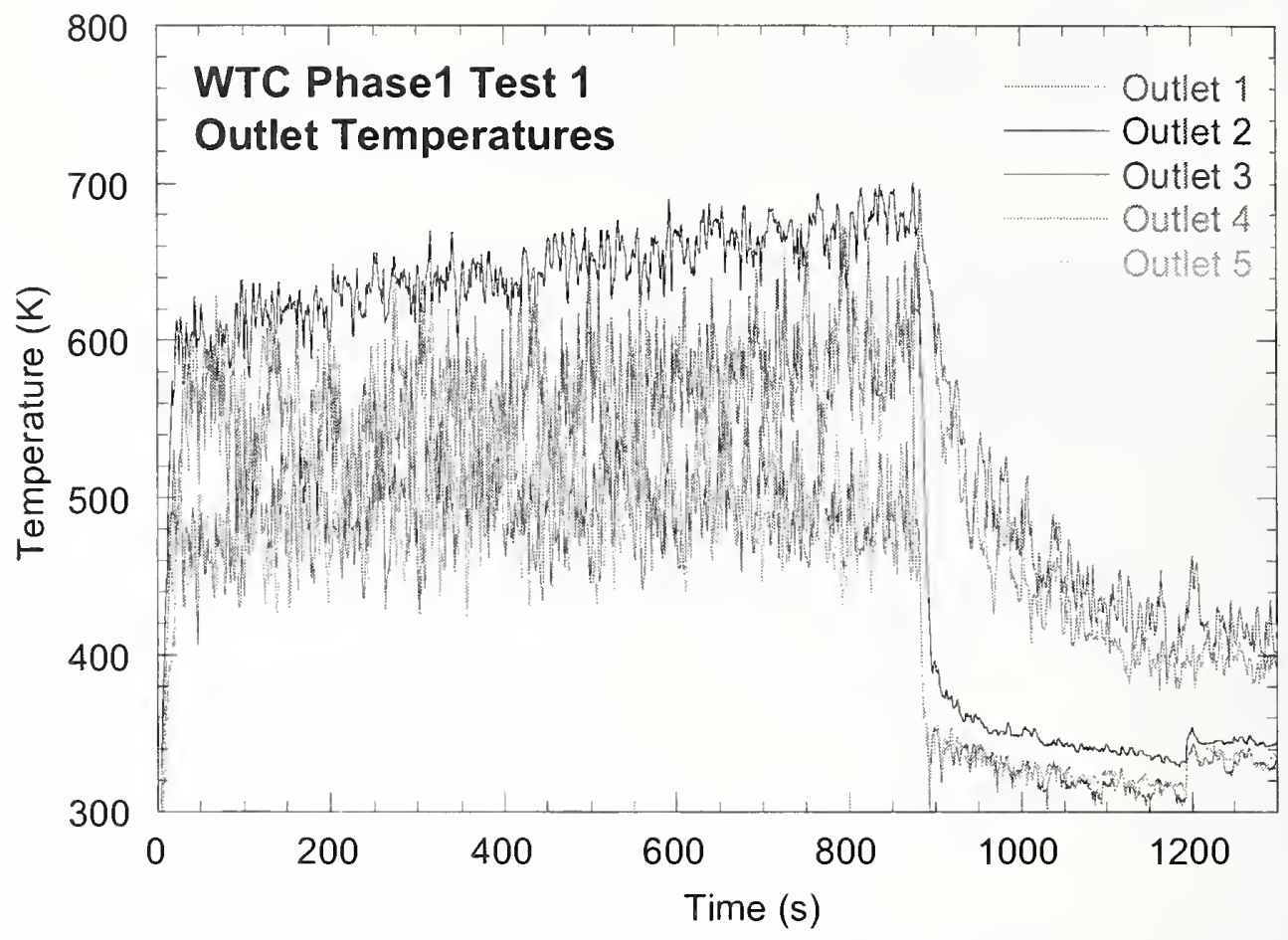

Figure D-15. Outlet temperatures for Test 1, outlet locations 1, 2, 3, 4, and 5.

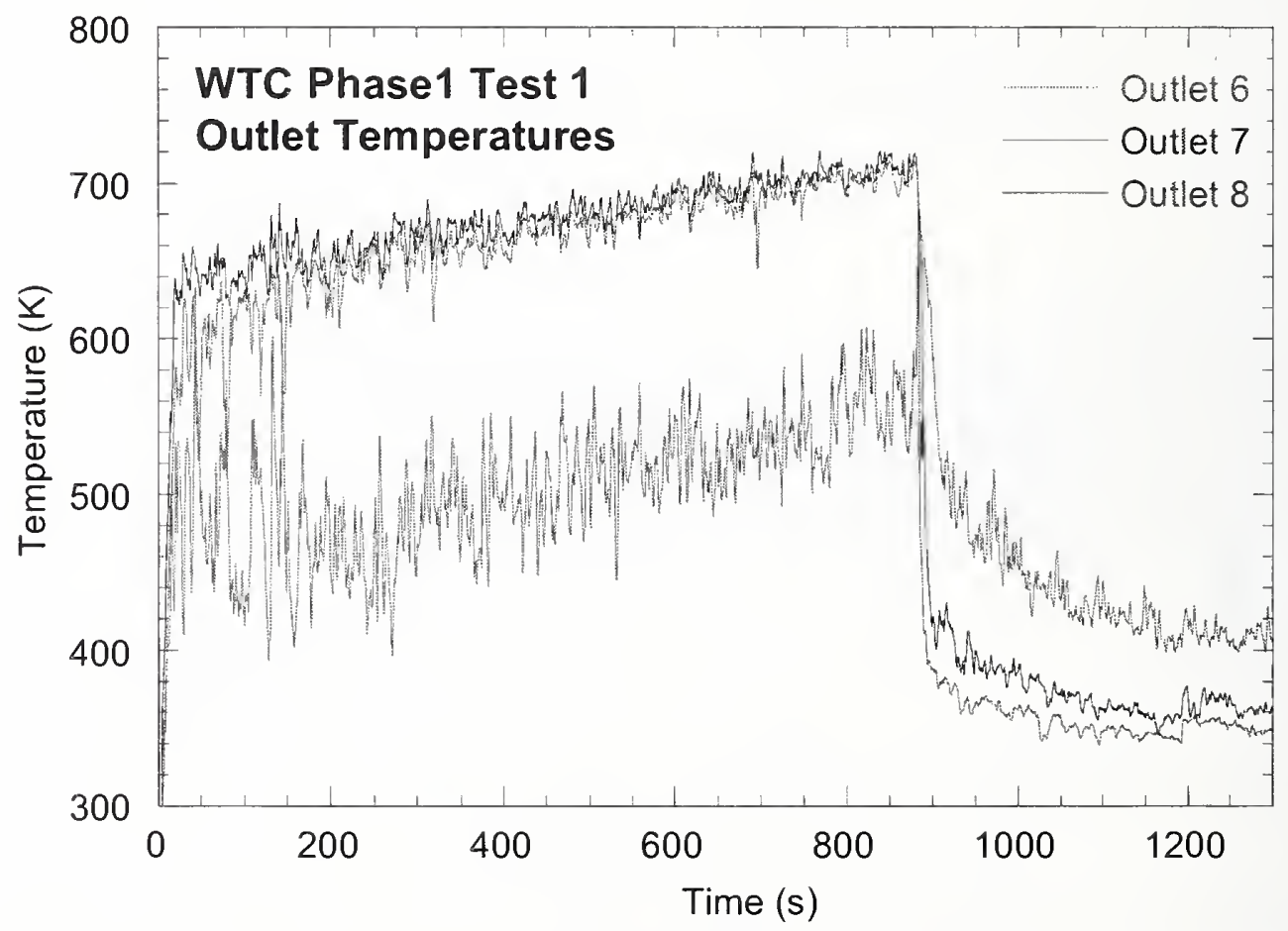

Figure D-16. Outlet temperatures for Test 1, outlet locations 6, 7, and 8. 


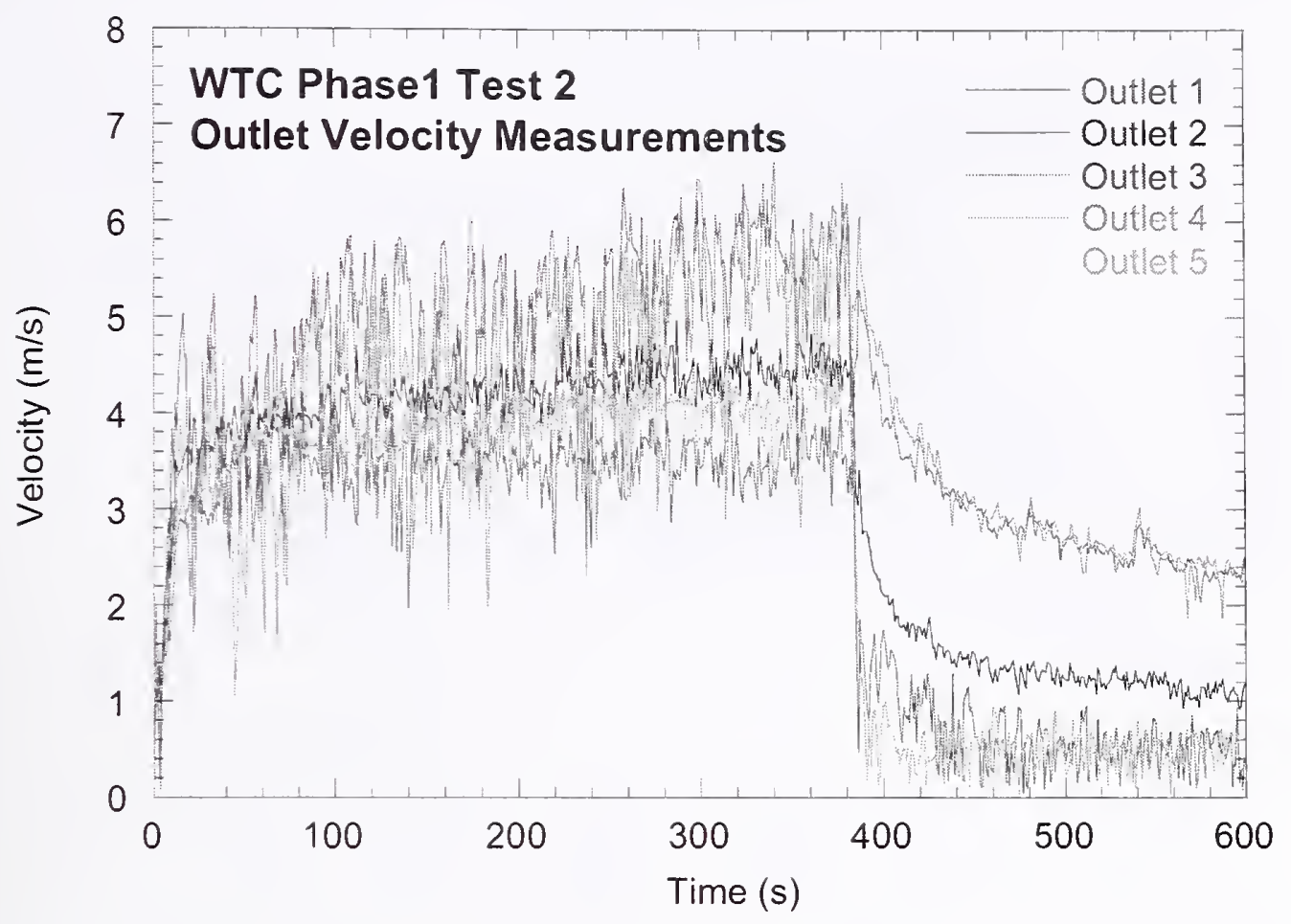

Figure D-17. Outlet velocities for Test 2, outlet locations 1, 2, 3, 4, and 5.

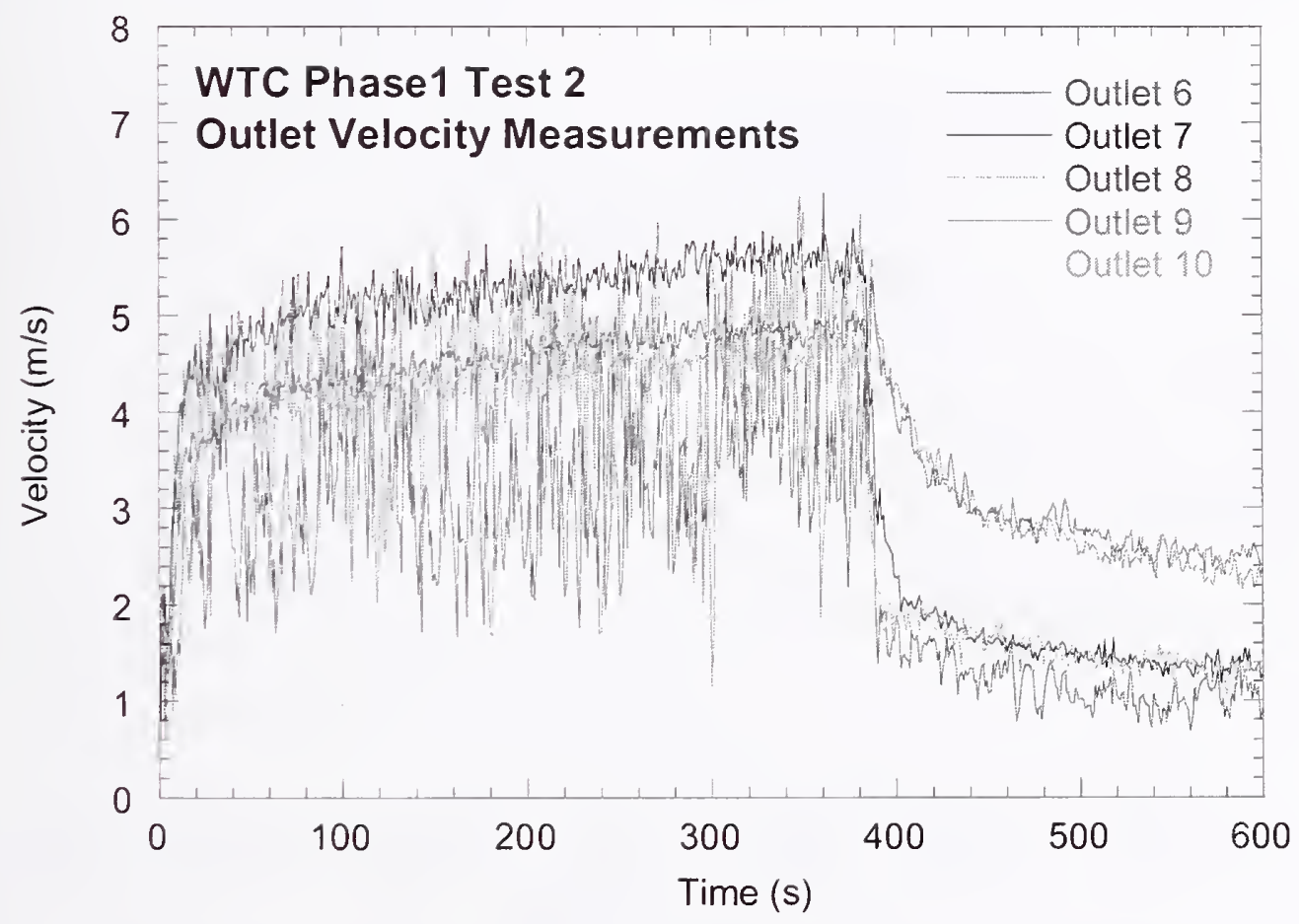

Figure D-18. Outlet velocities for Test 2, outlet locations 6, 7, 8, 9, and 10. 


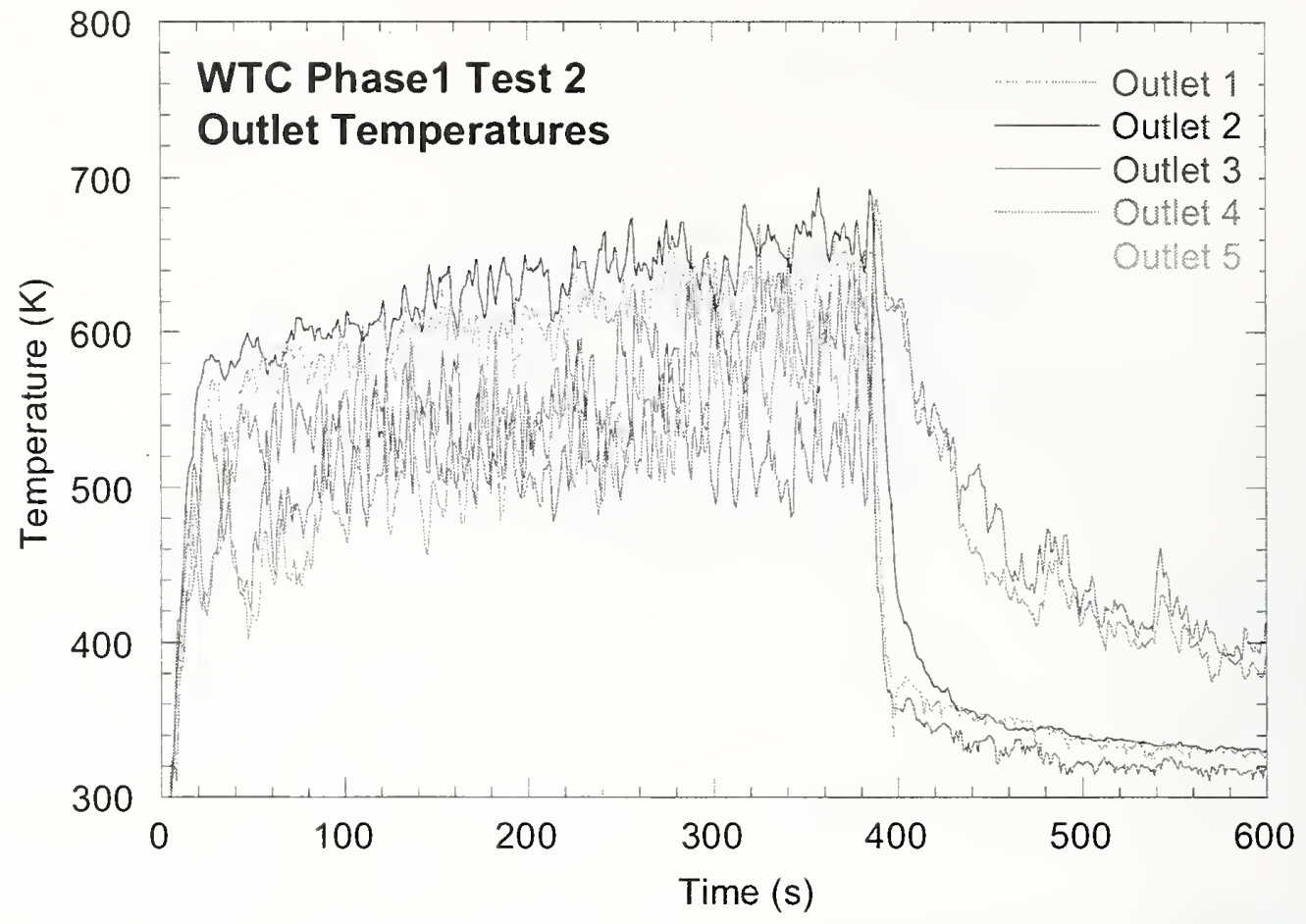

Figure D-19. Outlet temperatures for Test 2, outlet locations 1, 2, 3, 4, and 5.

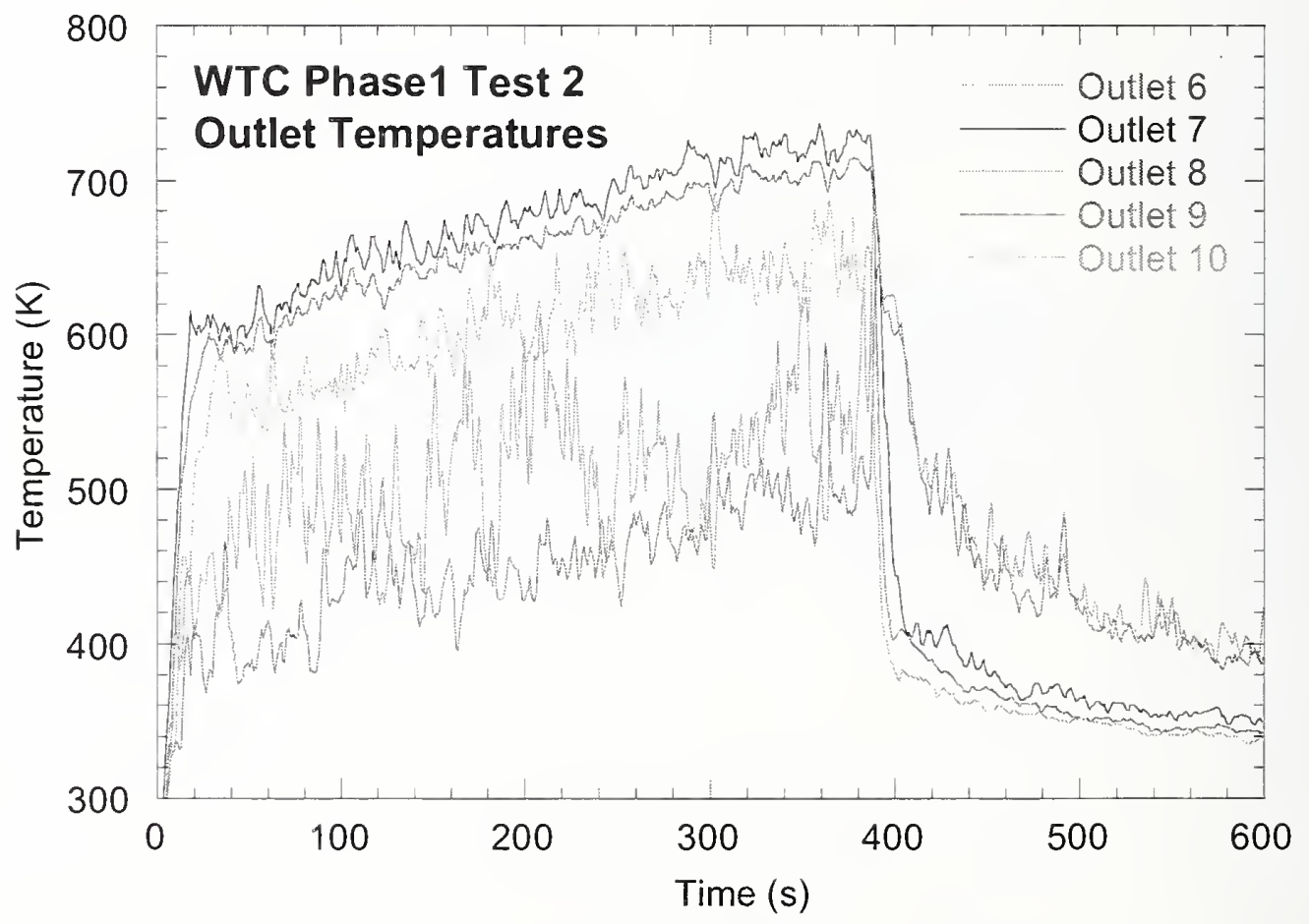

Figure D-20. Outlet temperatures for Test 2, outlet locations 6, 7, 8, 9, and 10. 


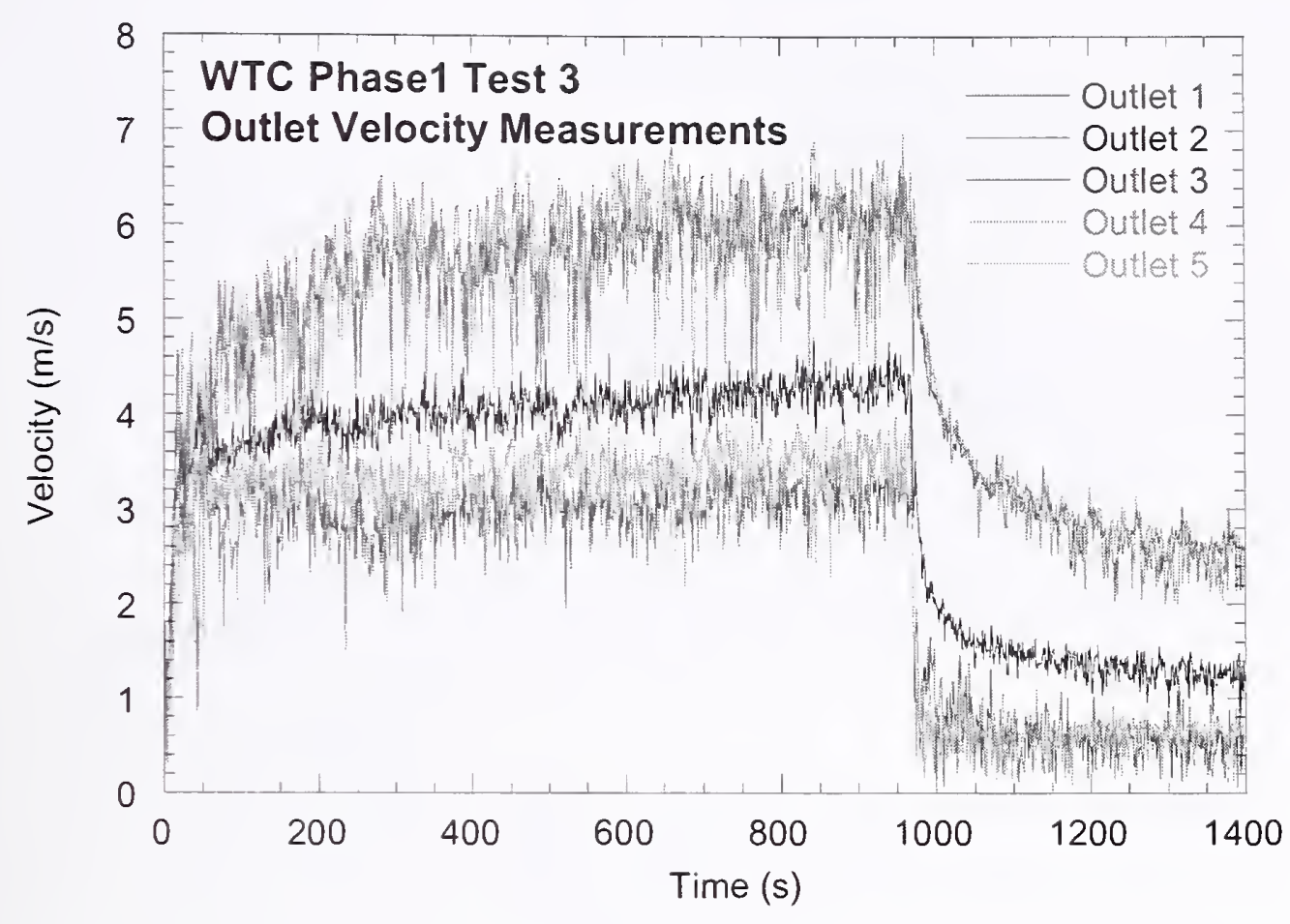

Figure D-21. Outlet velocities for Test 3, outlet locations 1, 2, 3, 4, and 5.

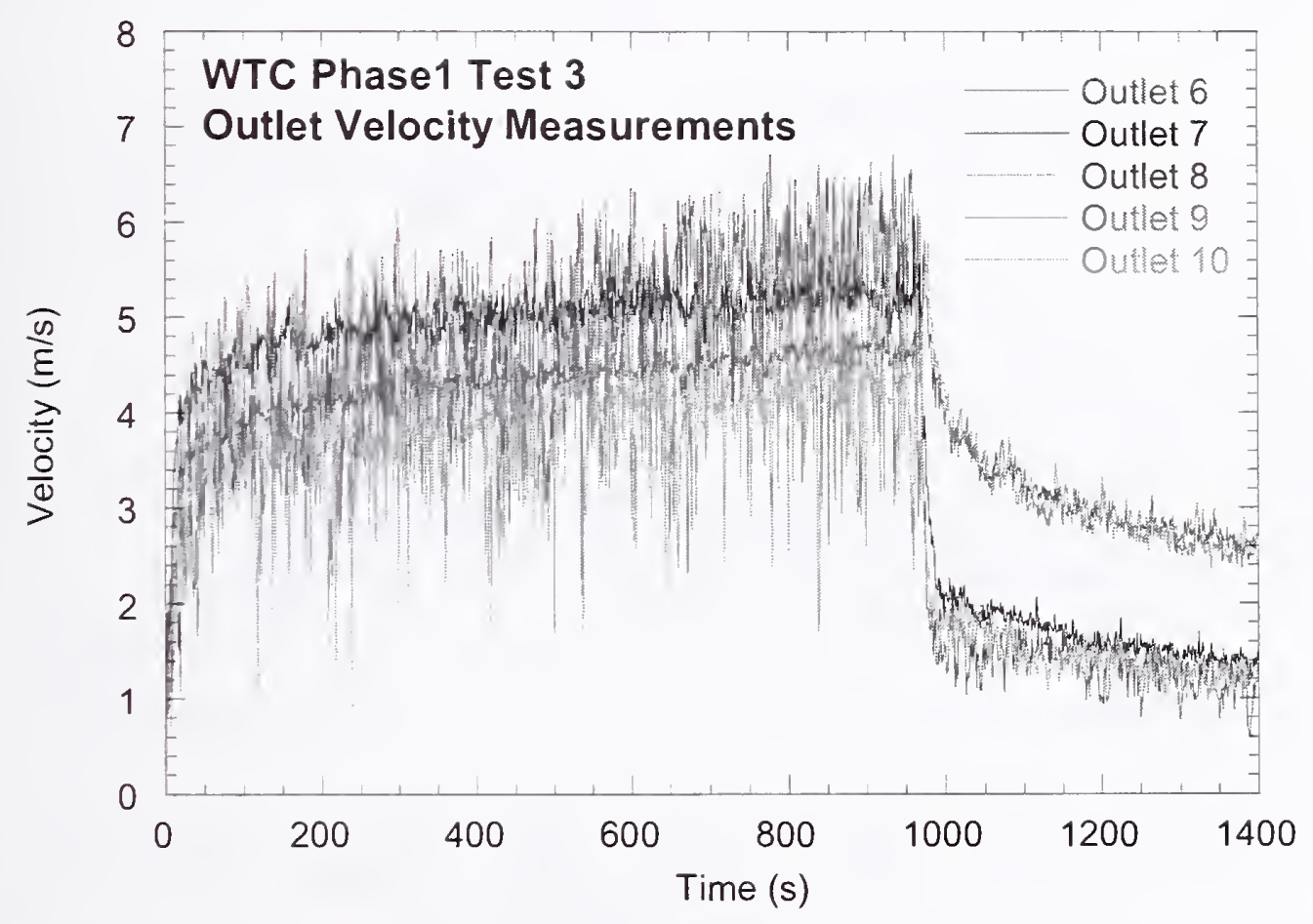

Figure D-22. Outlet velocities for Test 3, outlet locations $6,7,8,9$, and 10. 


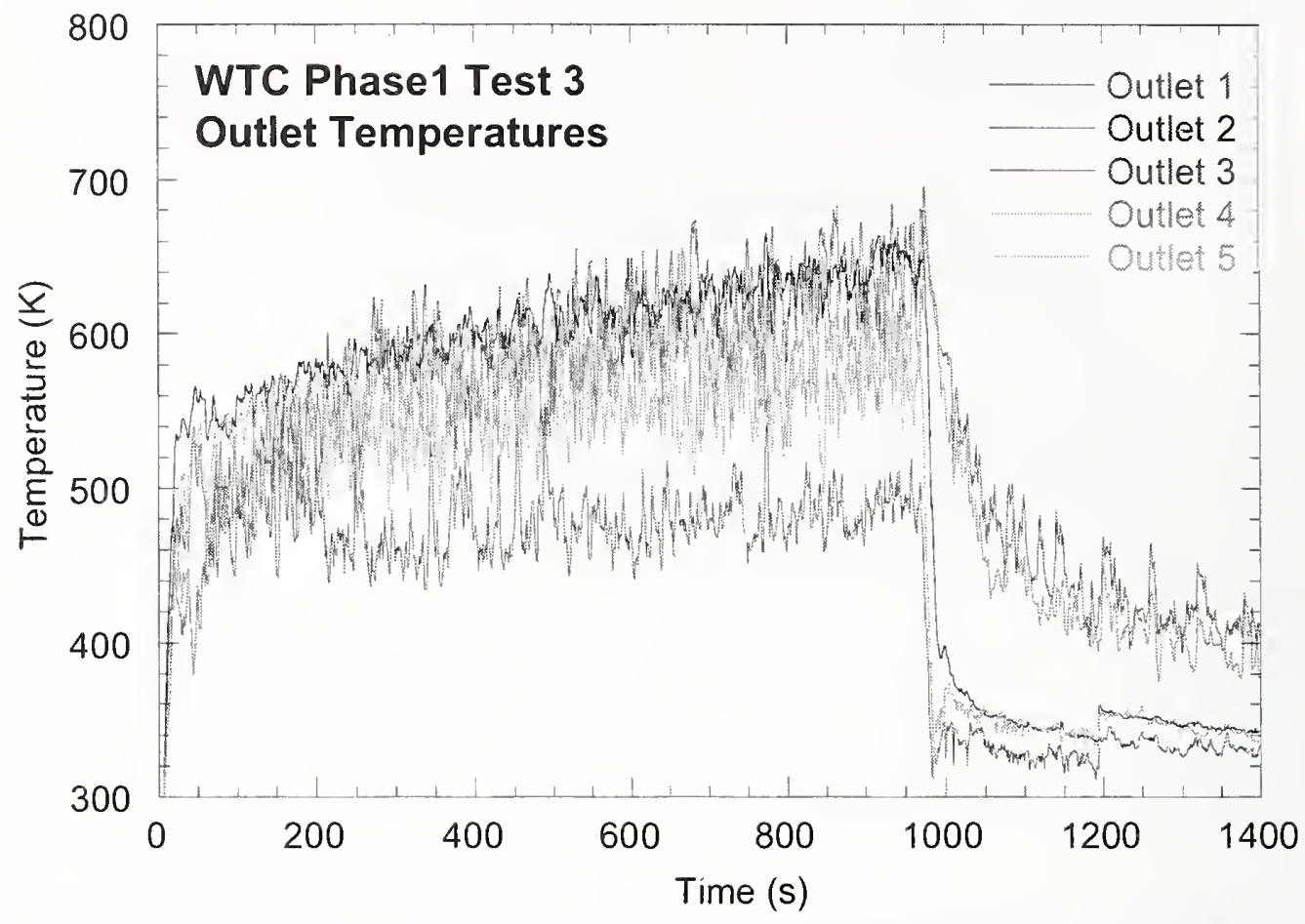

Figure D-23. Outlet temperatures for Test 3, outlet locations 1, 2, 3, 4, and 5.

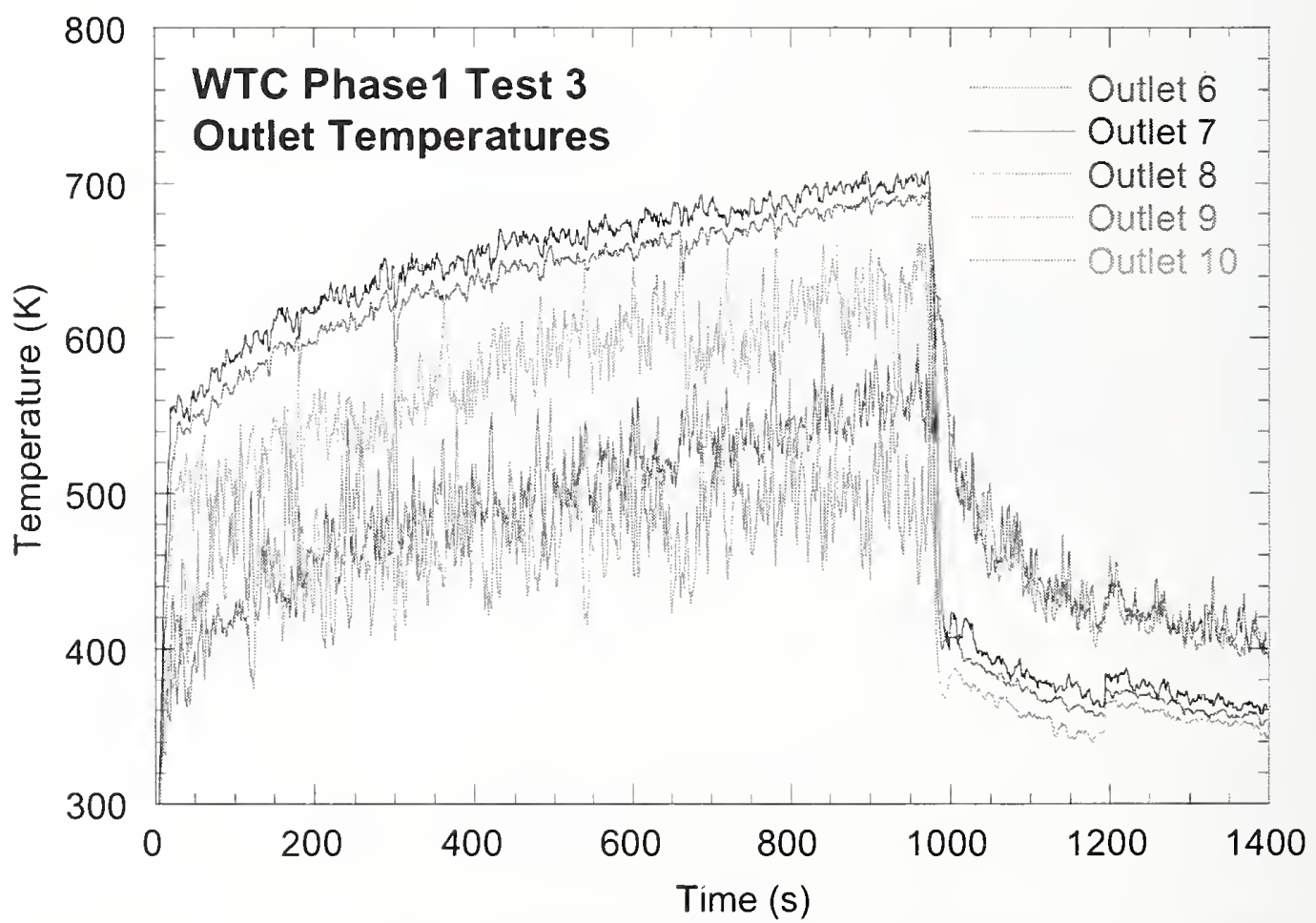

Figure D-24. Outlet temperatures for Test 3, outlet locations 6, 7, 8, 9, and 10. 


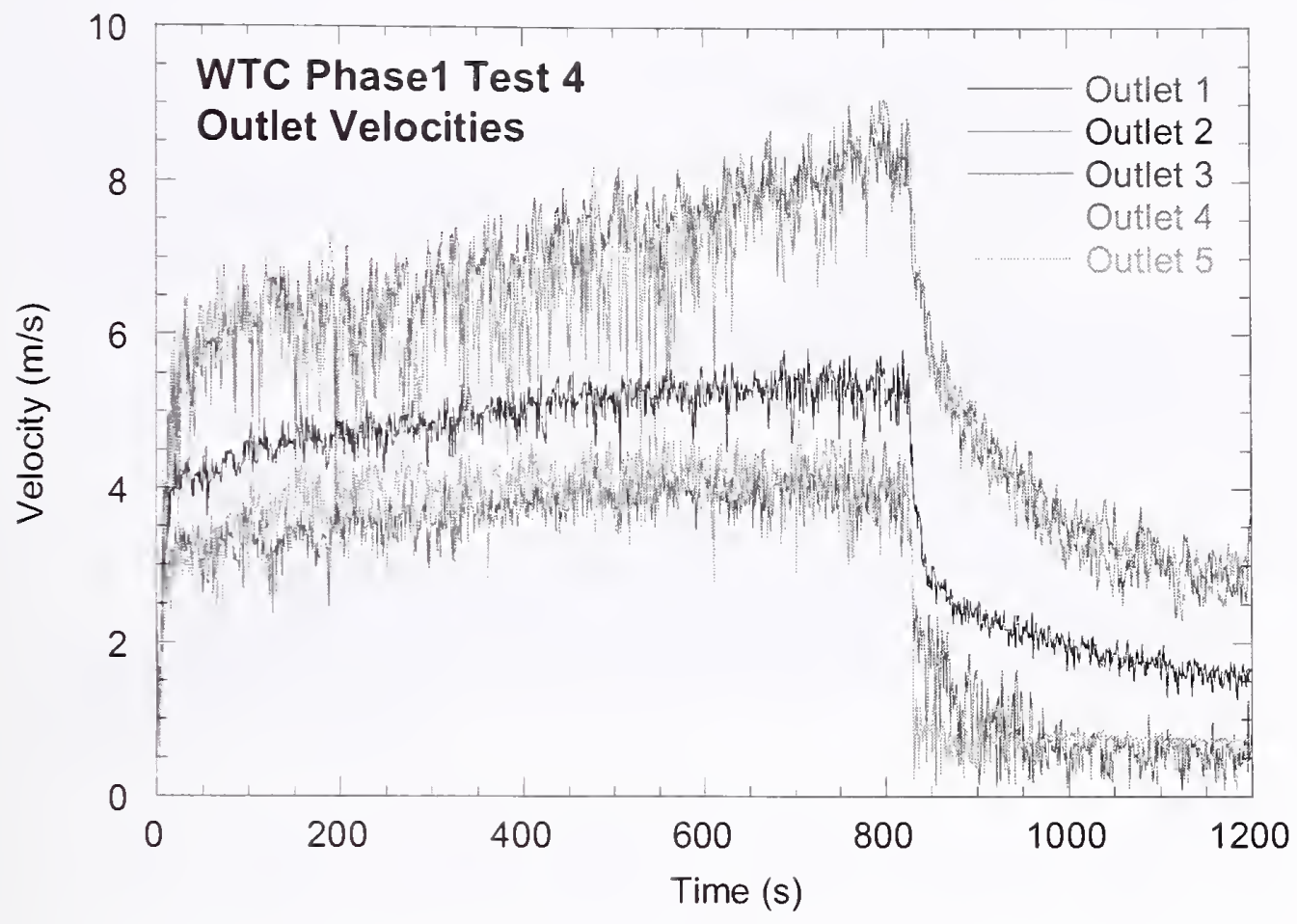

Figure D-25. Outlet velocities for Test 4, outlet locations 1, 2, 3, 4, and 5.

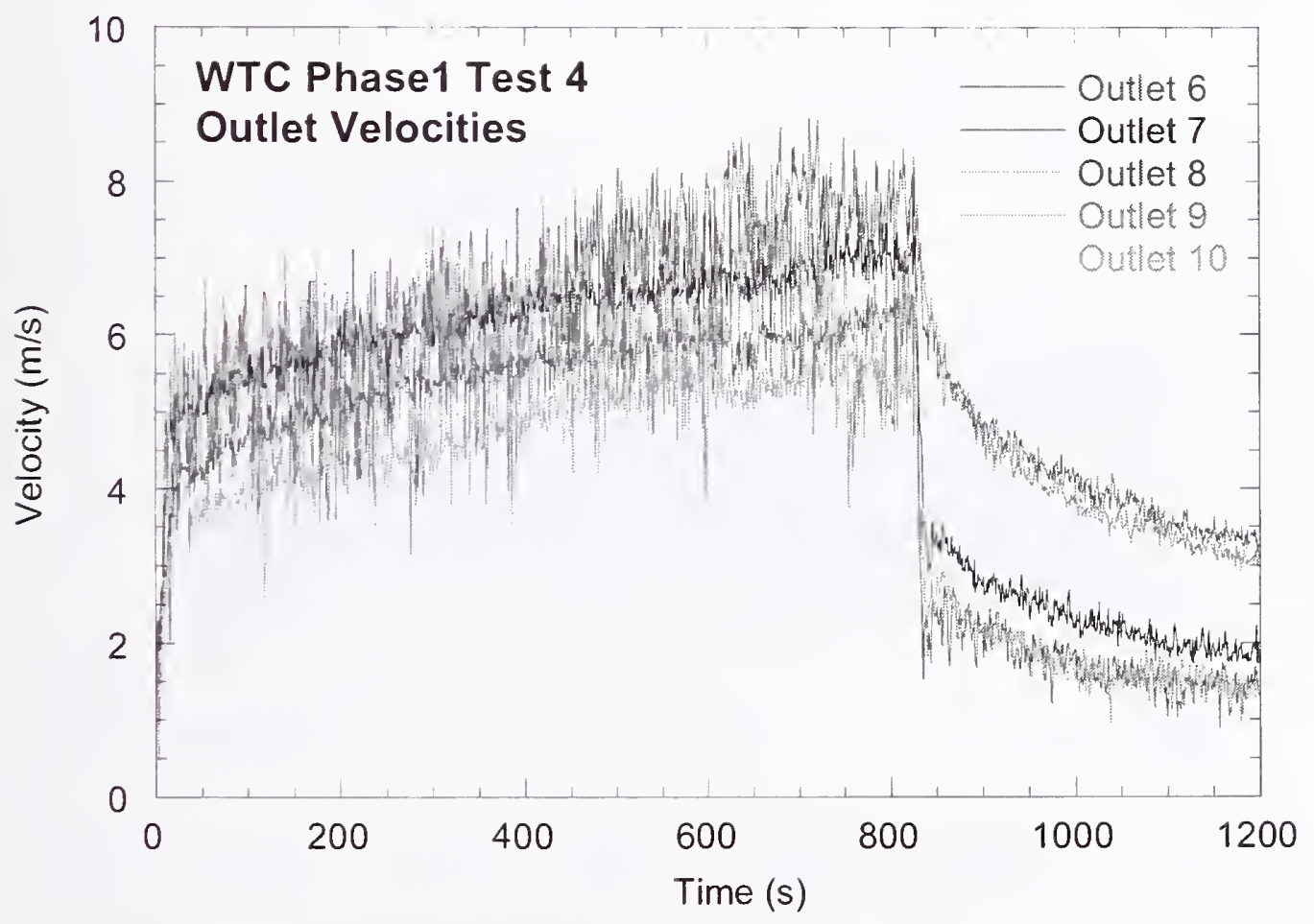

Figure D-26. Outlet velocities for Test 4, outlet locations 6, 7, 8, 9, and 10. 


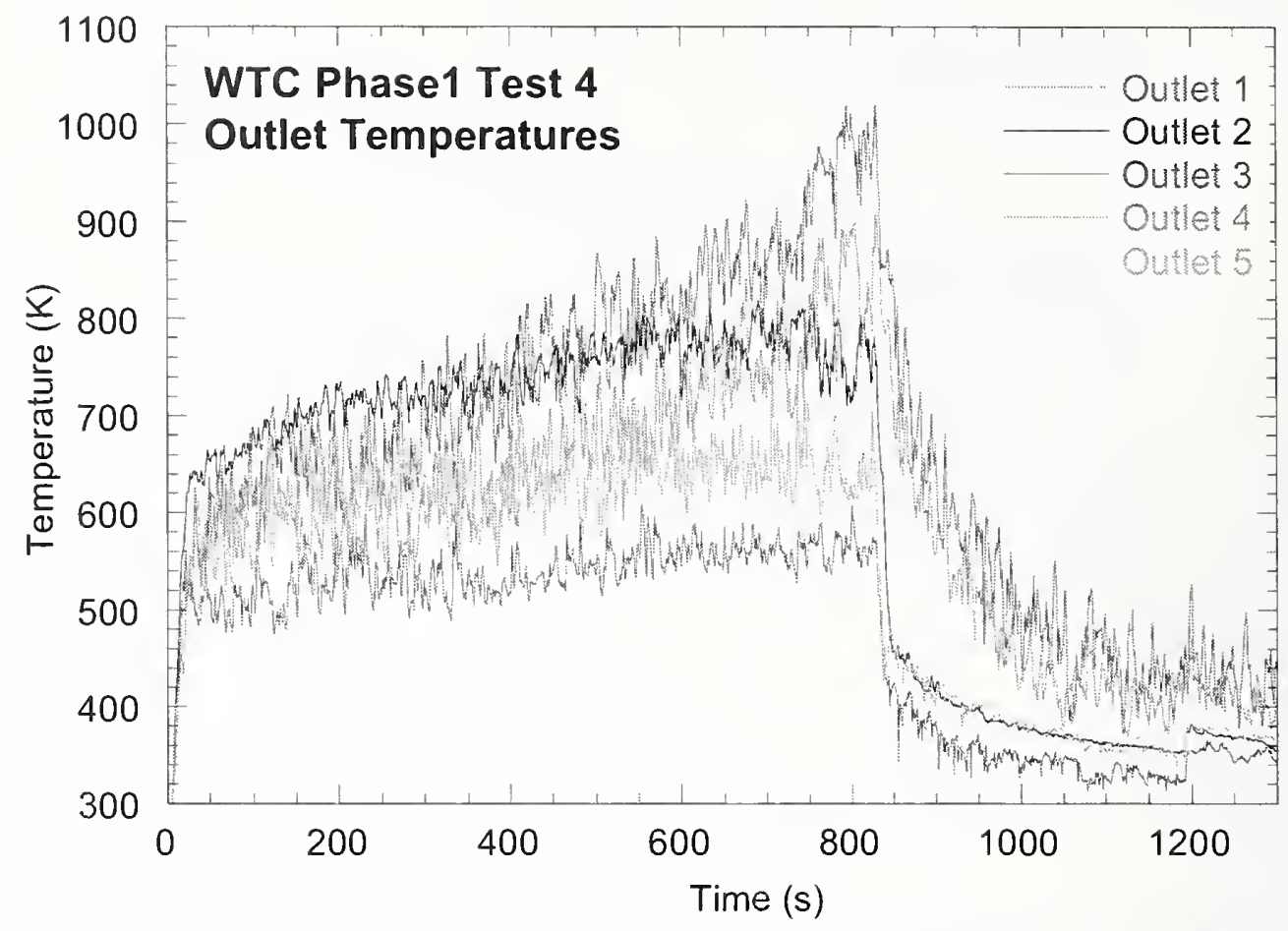

Figure D-27. Outlet temperatures for Test 4, outlet locations 1, 2, 3, 4, and 5.

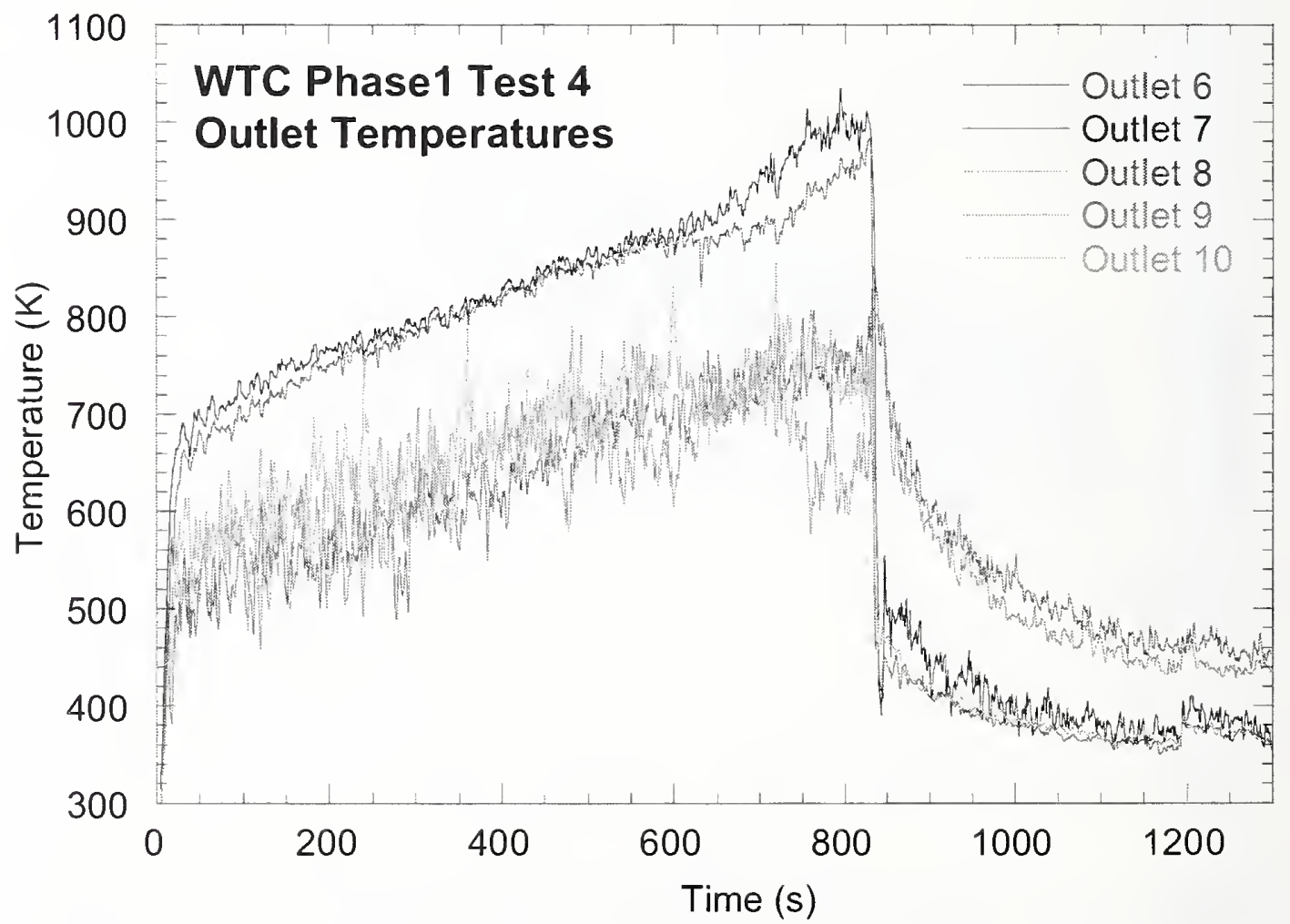

Figure D-28. Outlet temperatures for Test 4, outlet locations 6, 7, 8, 9, and 10. 


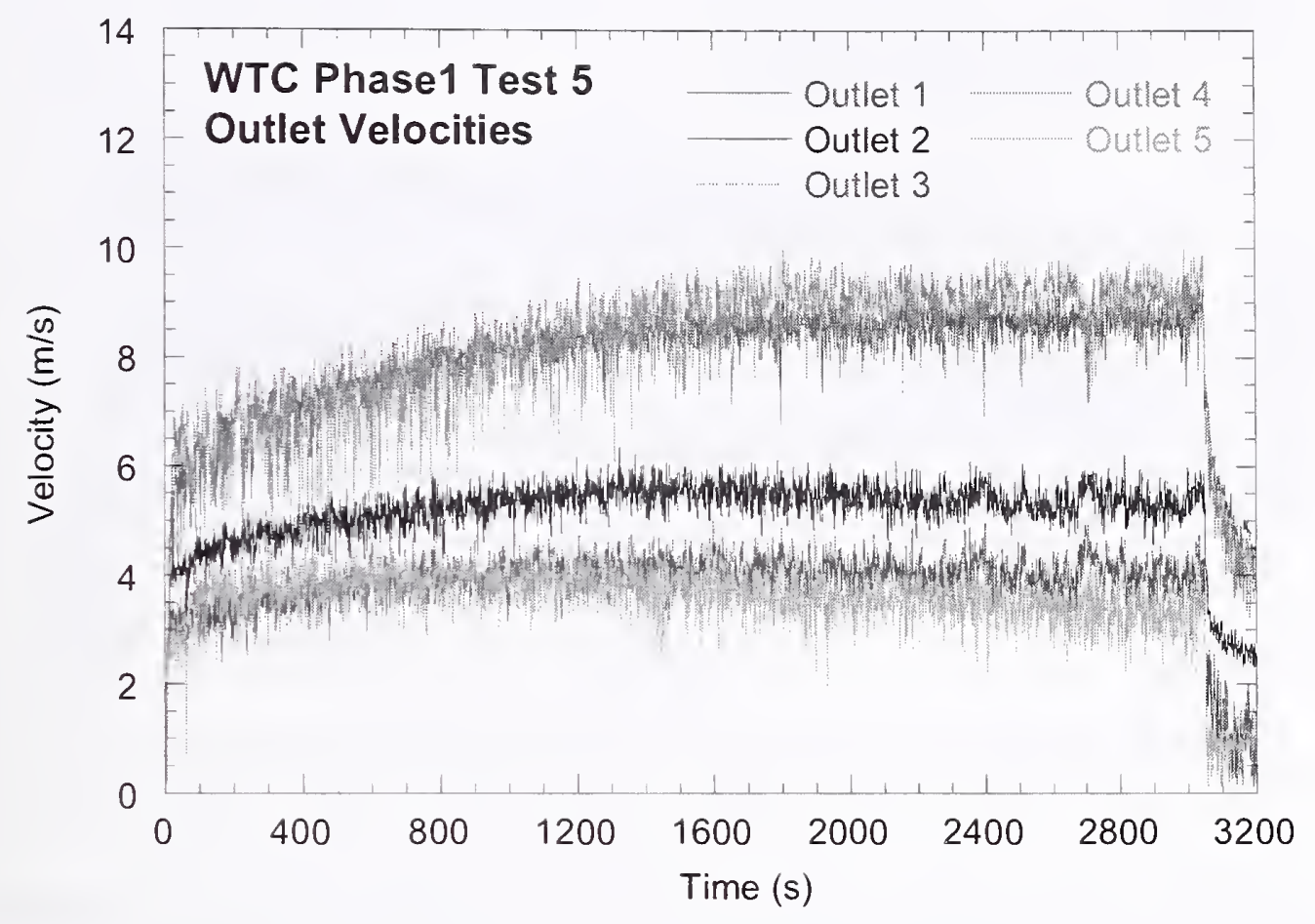

Figure D-29. Outlet velocities for Test 5, outlet locations 1, 2, 3, 4, and 5.

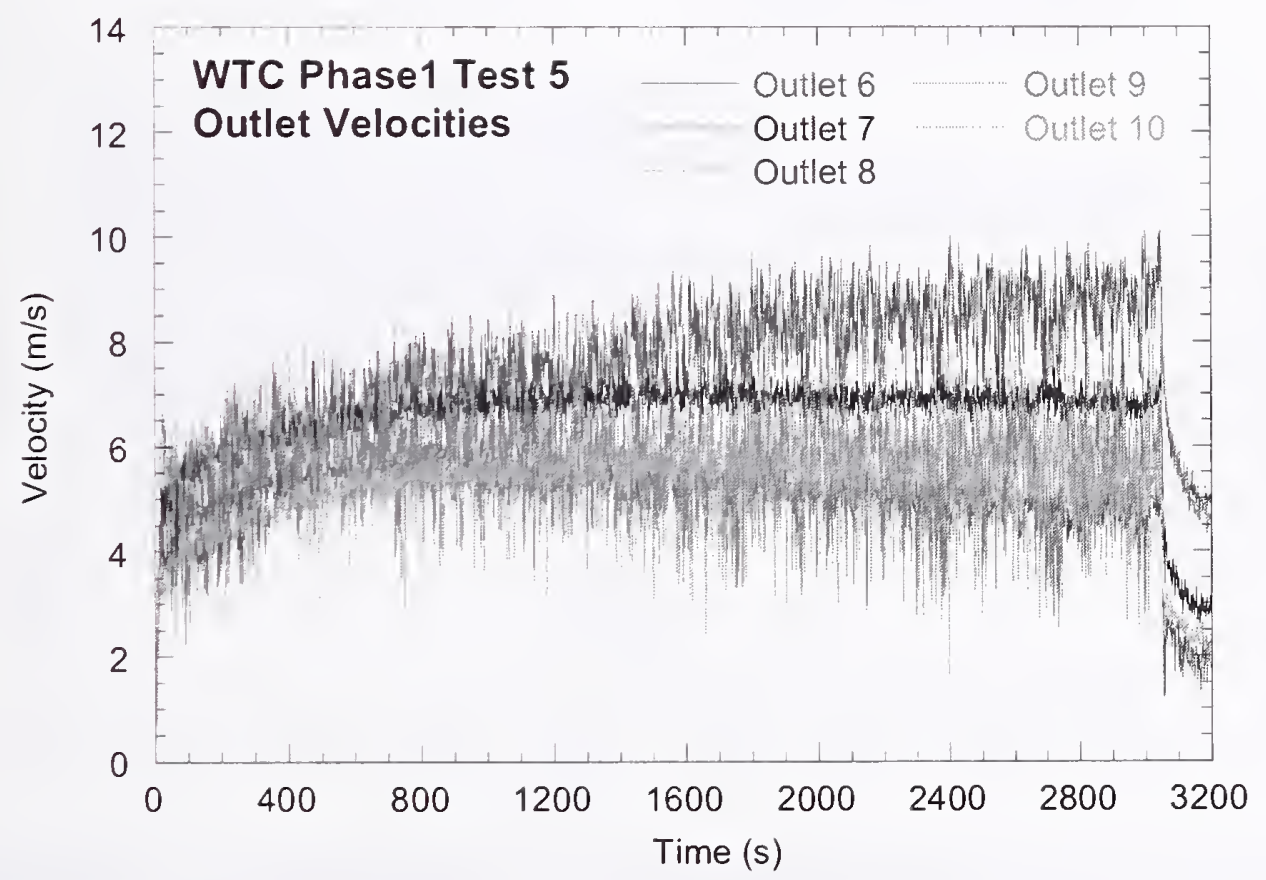

Figure D-30. Outlet velocities for Test 5, outlet locations 6, 7, 8, 9, and 10. 


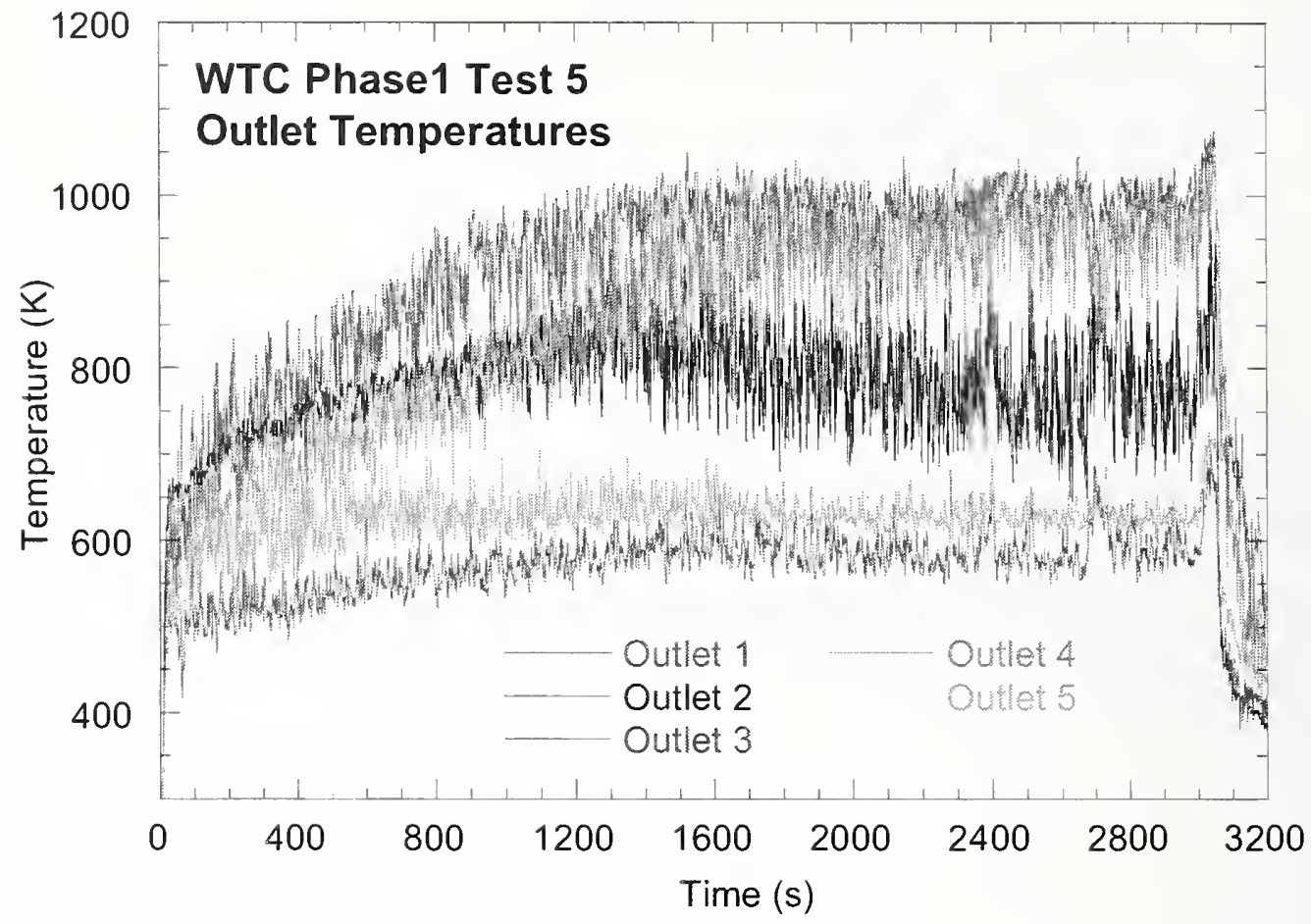

Figure D-31. Outlet temperatures for Test 5, outlet locations 1, 2, 3, 4, and 5.

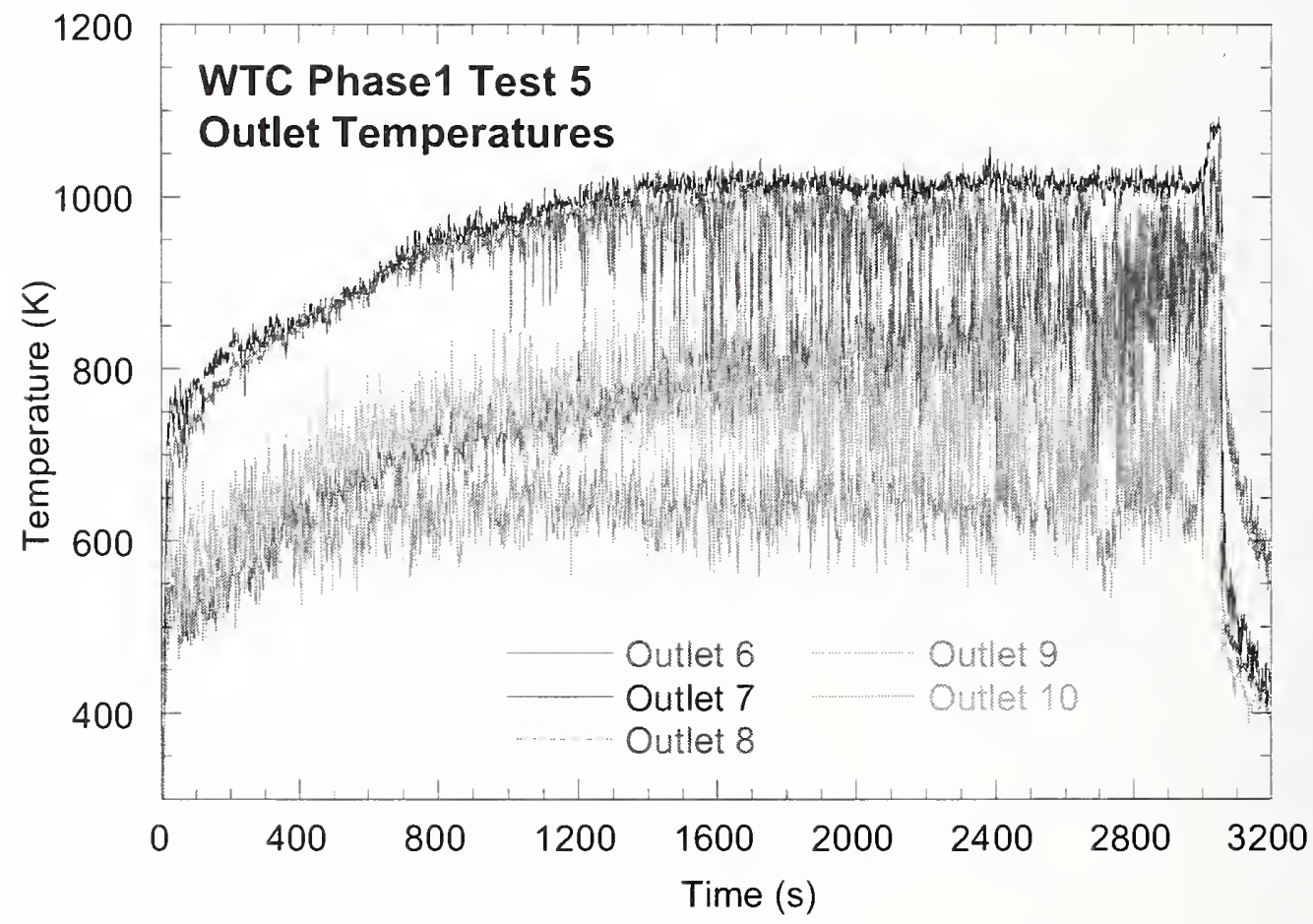

Figure D-32. Outlet temperatures for Test 5, outlet locations 6, 7, 8, 9, and 10. 


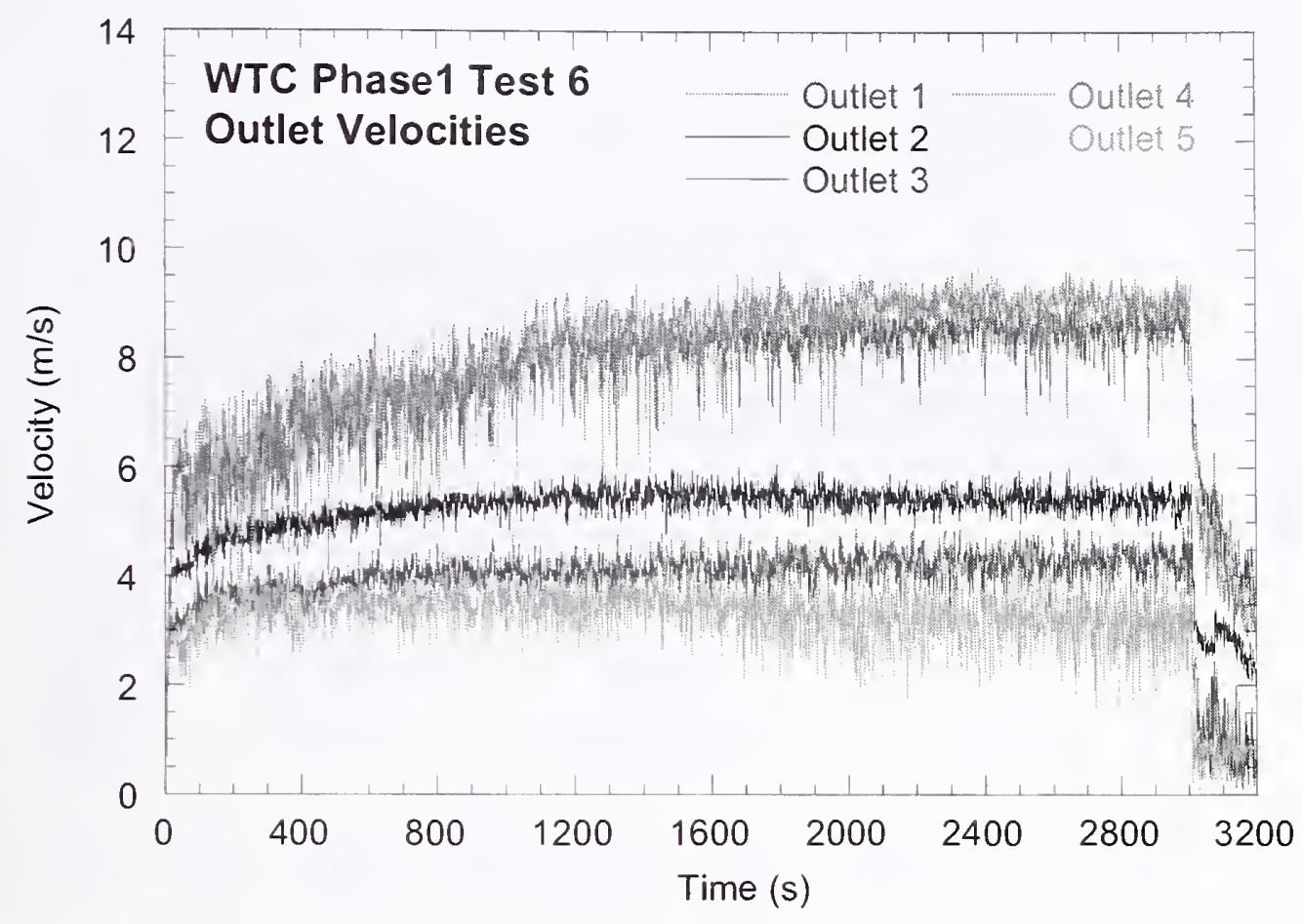

Figure D-33. Outlet velocities for Test 6 , outlet locations 1, 2, 3, 4, and 5.

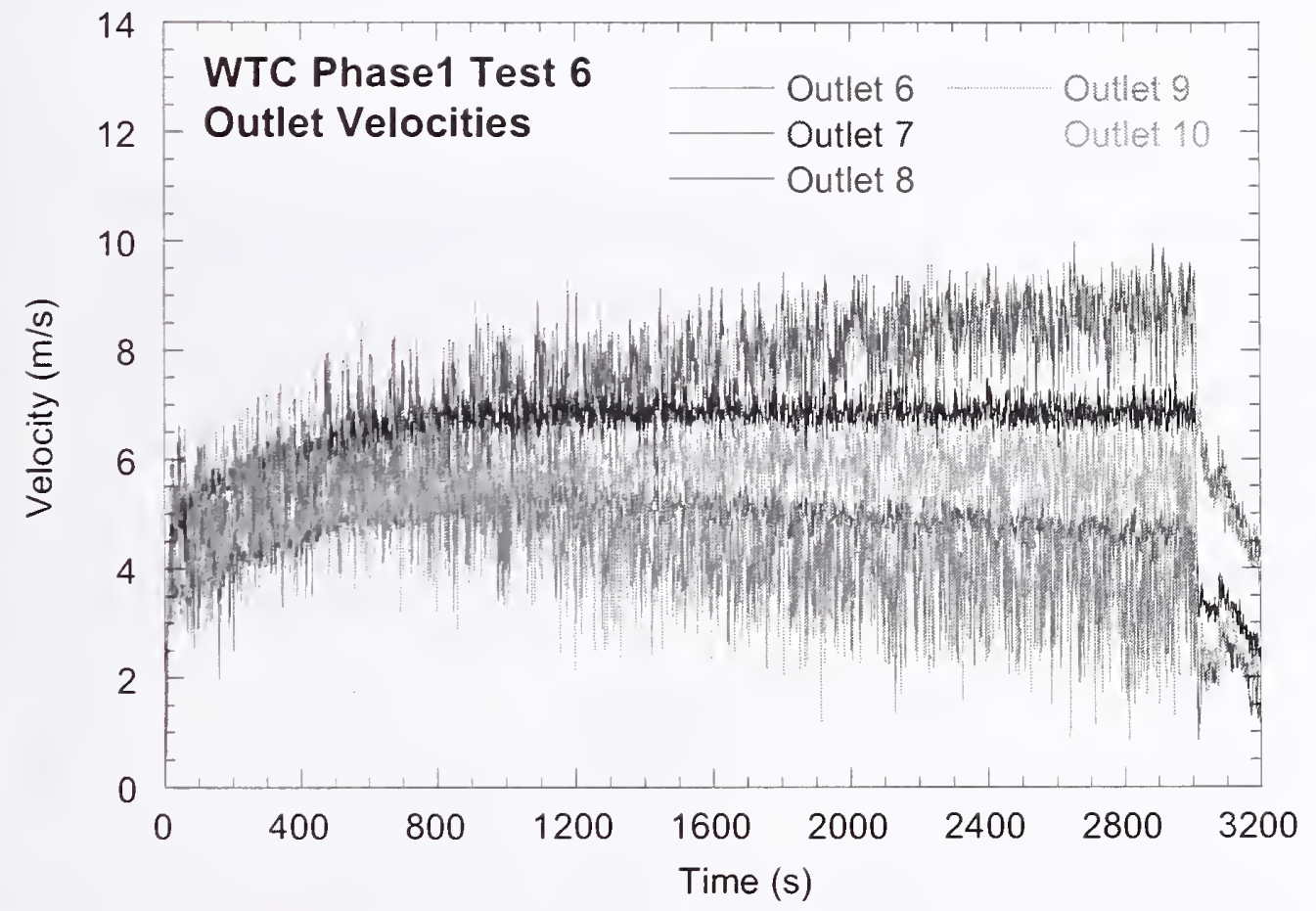

Figure D-34. Outlet velocities for Test 6, outlet locations 6, 7, 8, 9, and 10. 


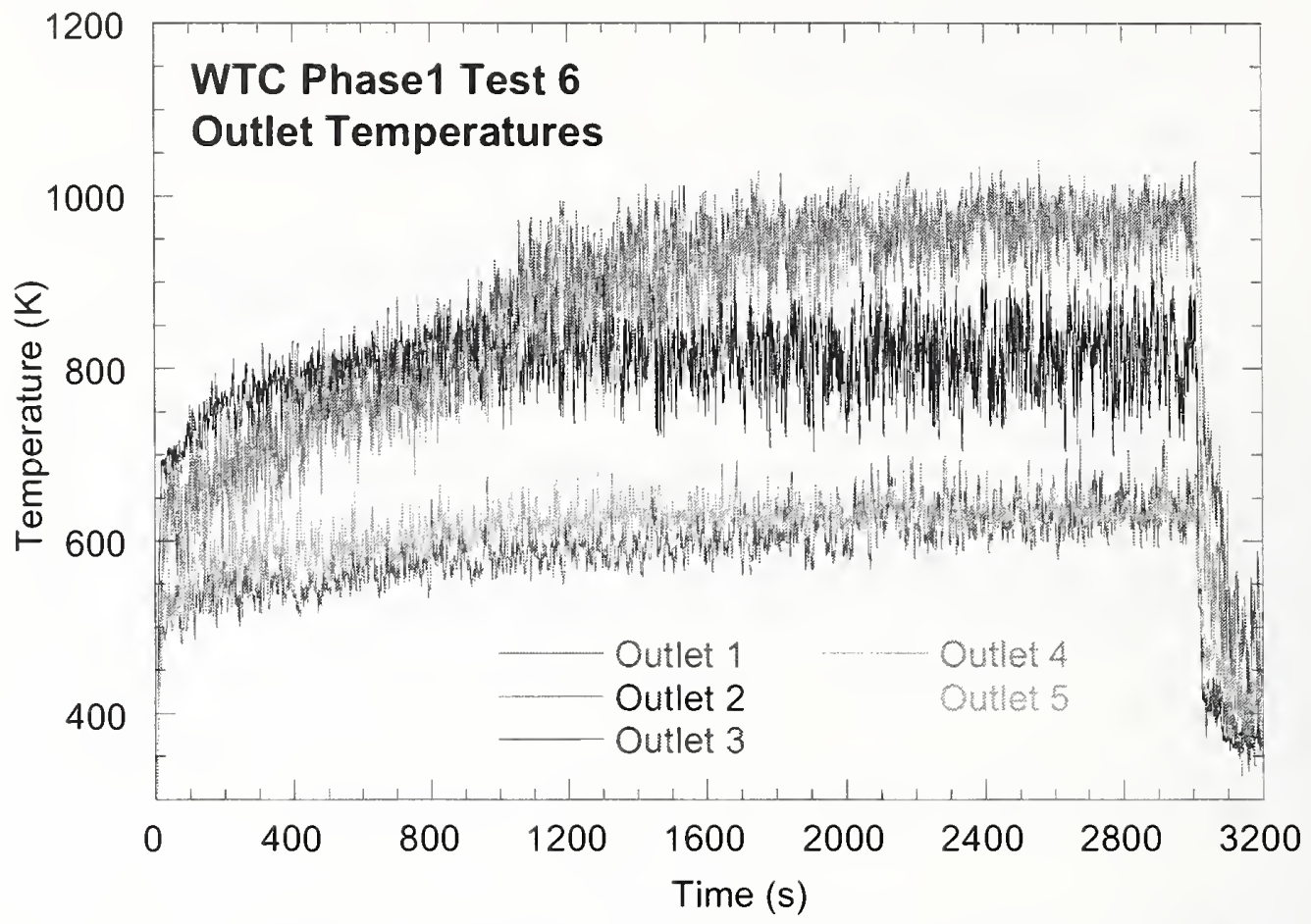

Figure D-35. Outlet temperatures for Test 6, outlet locations 1, 2, 3, 4, and 5.

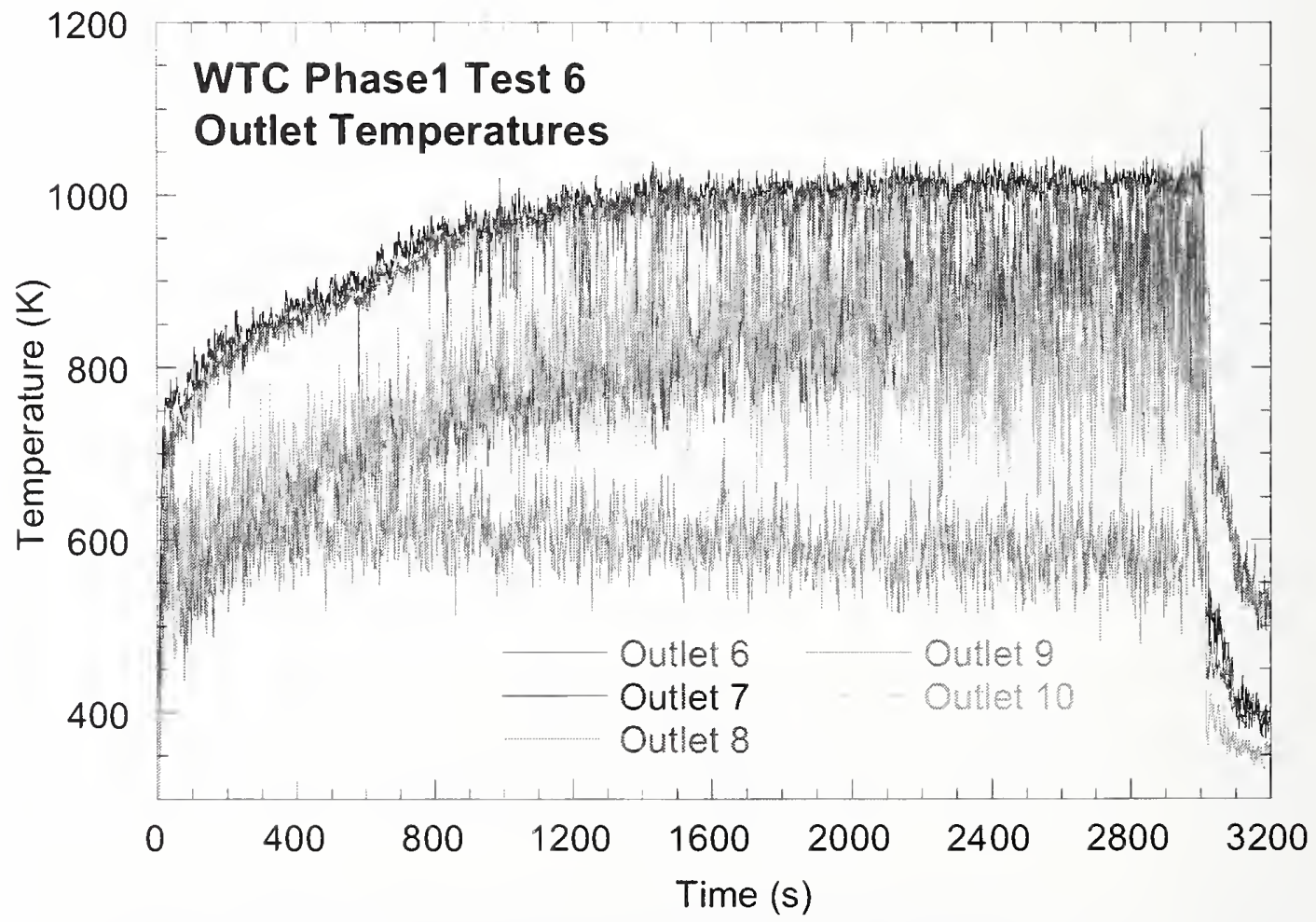

Figure D-36. Outlet temperatures for Test 6, outlet locations 6, 7, 8, 9, and 10. 


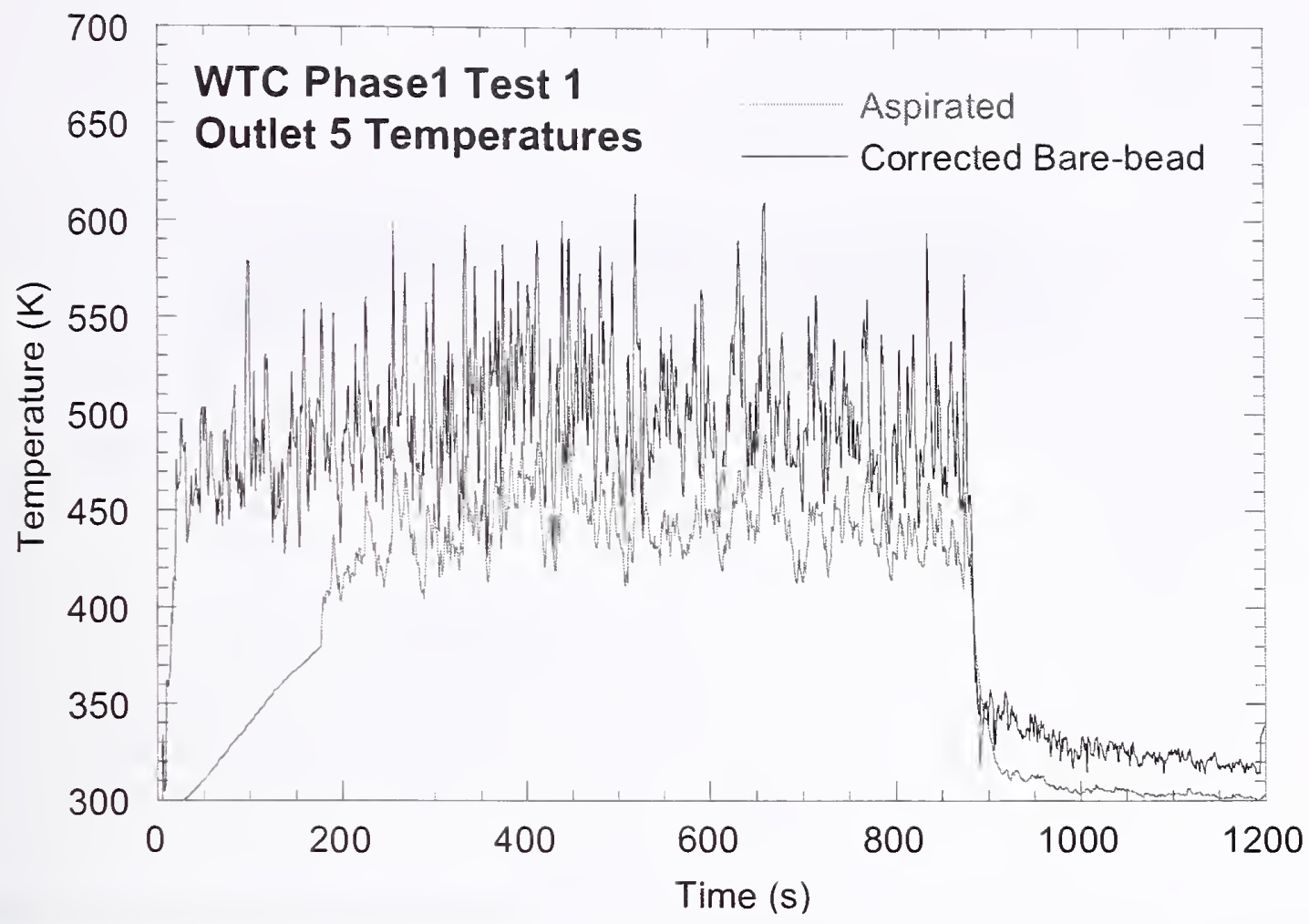

Figure D-37. Aspirated and bare-bead thermocouple temperatures at outlet 5 for Test 1.

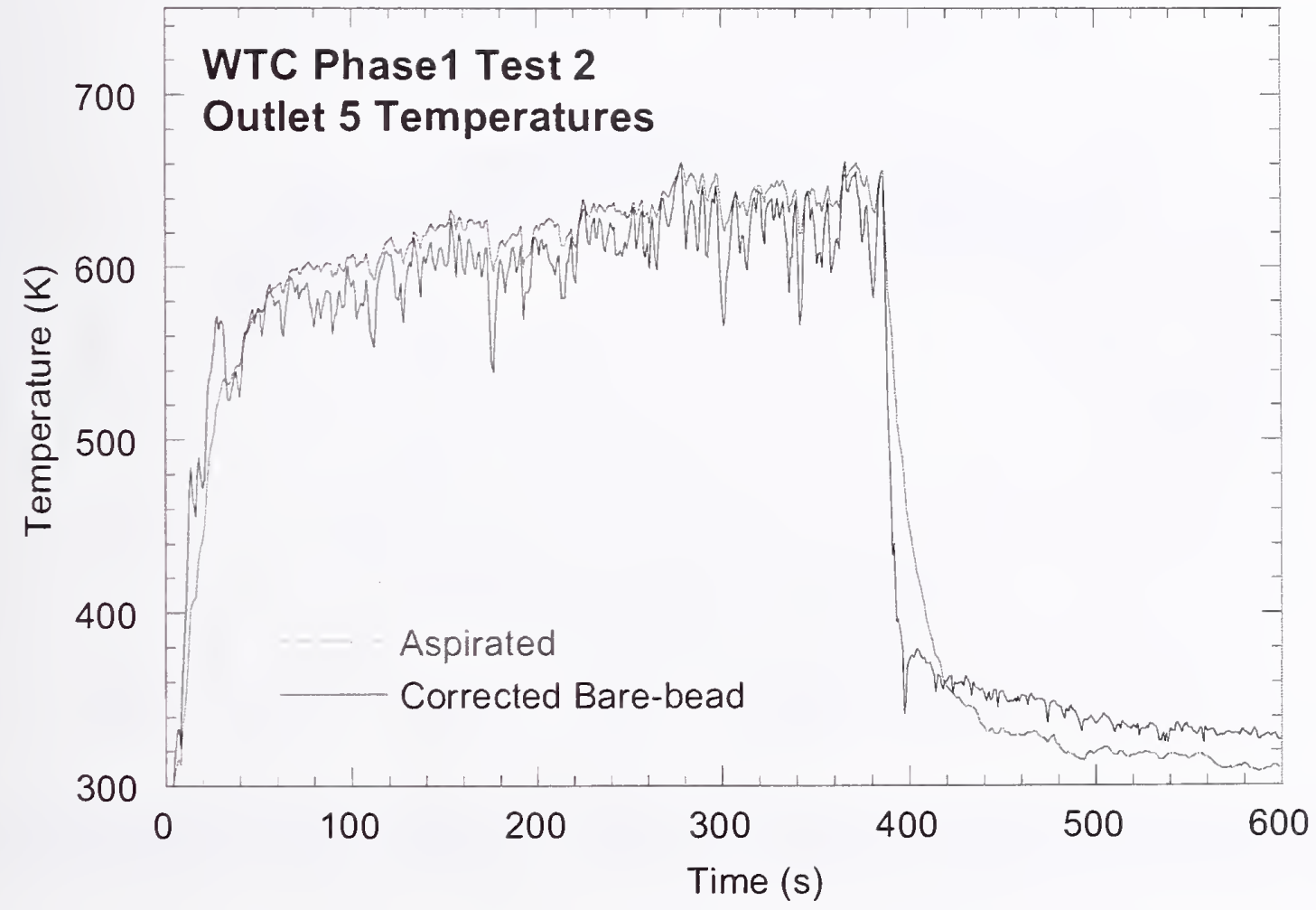

Figure D-38. Aspirated and bare-bead thermocouple temperatures at outlet 5 for Test 2. 


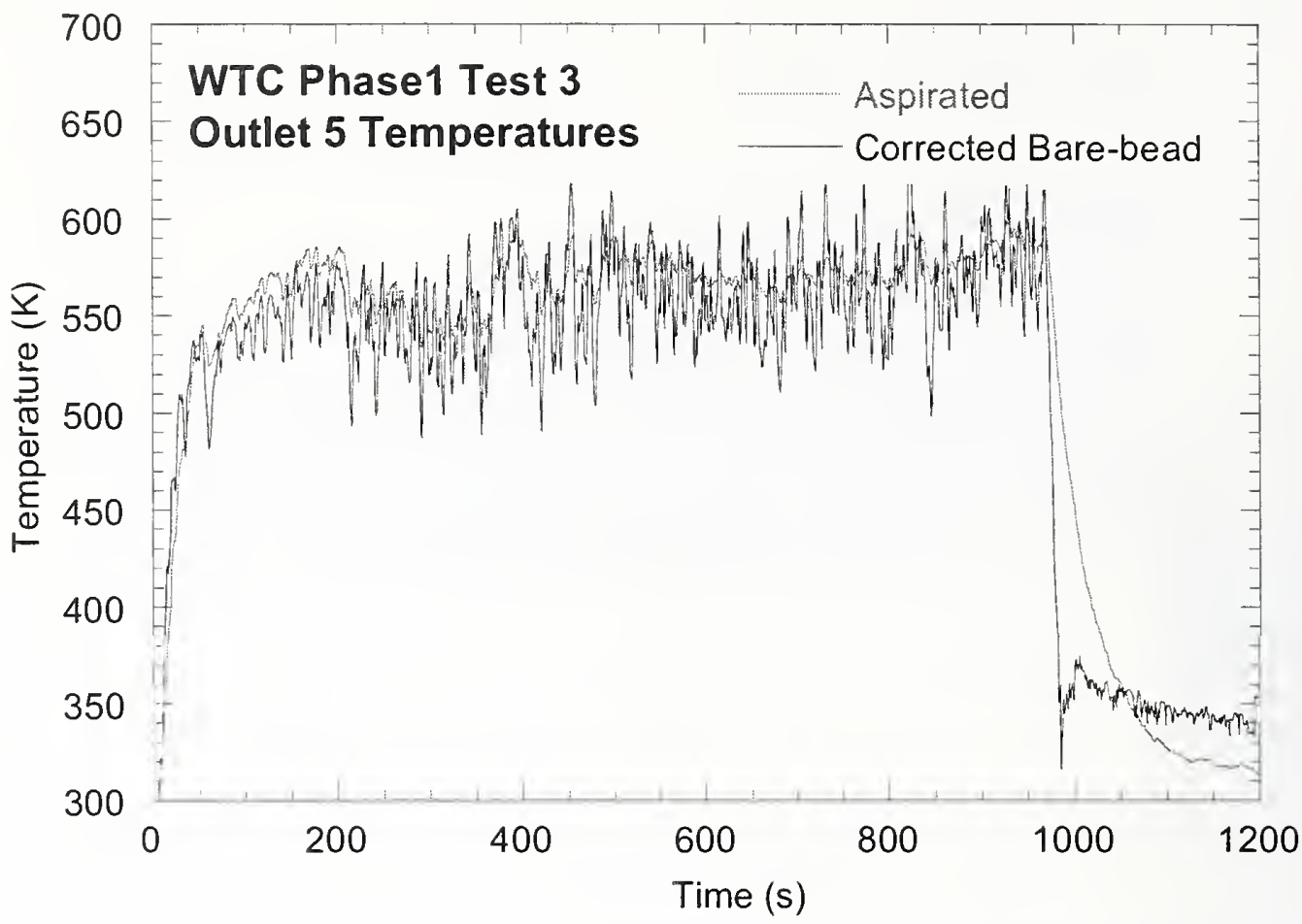

Figure D-39. Aspirated and bare-bead thermocouple temperatures at outlet 5 for Test 3.

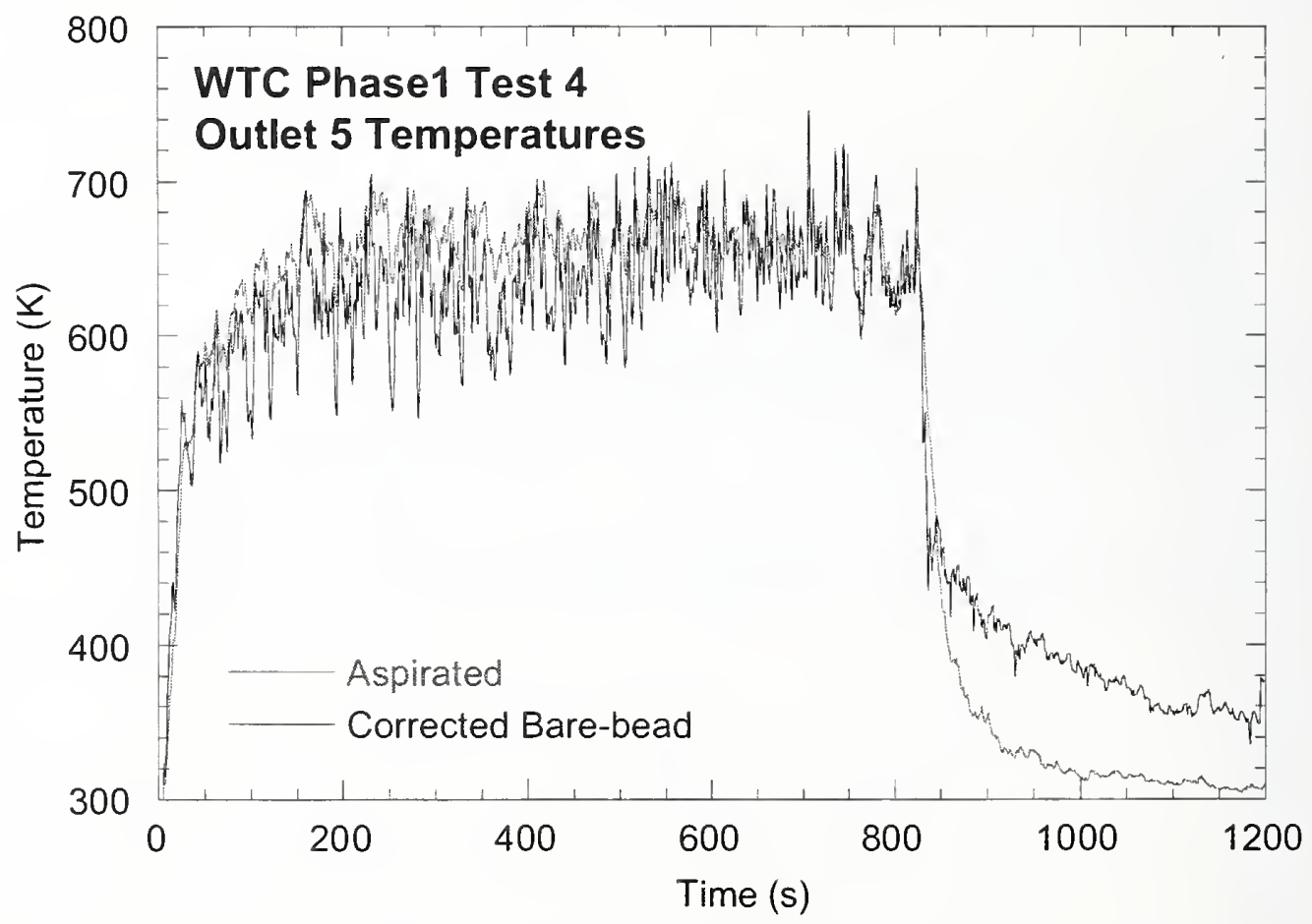

Figure D-40. Aspirated and bare-bead thermocouple temperatures at outlet 5 for Test 4. 


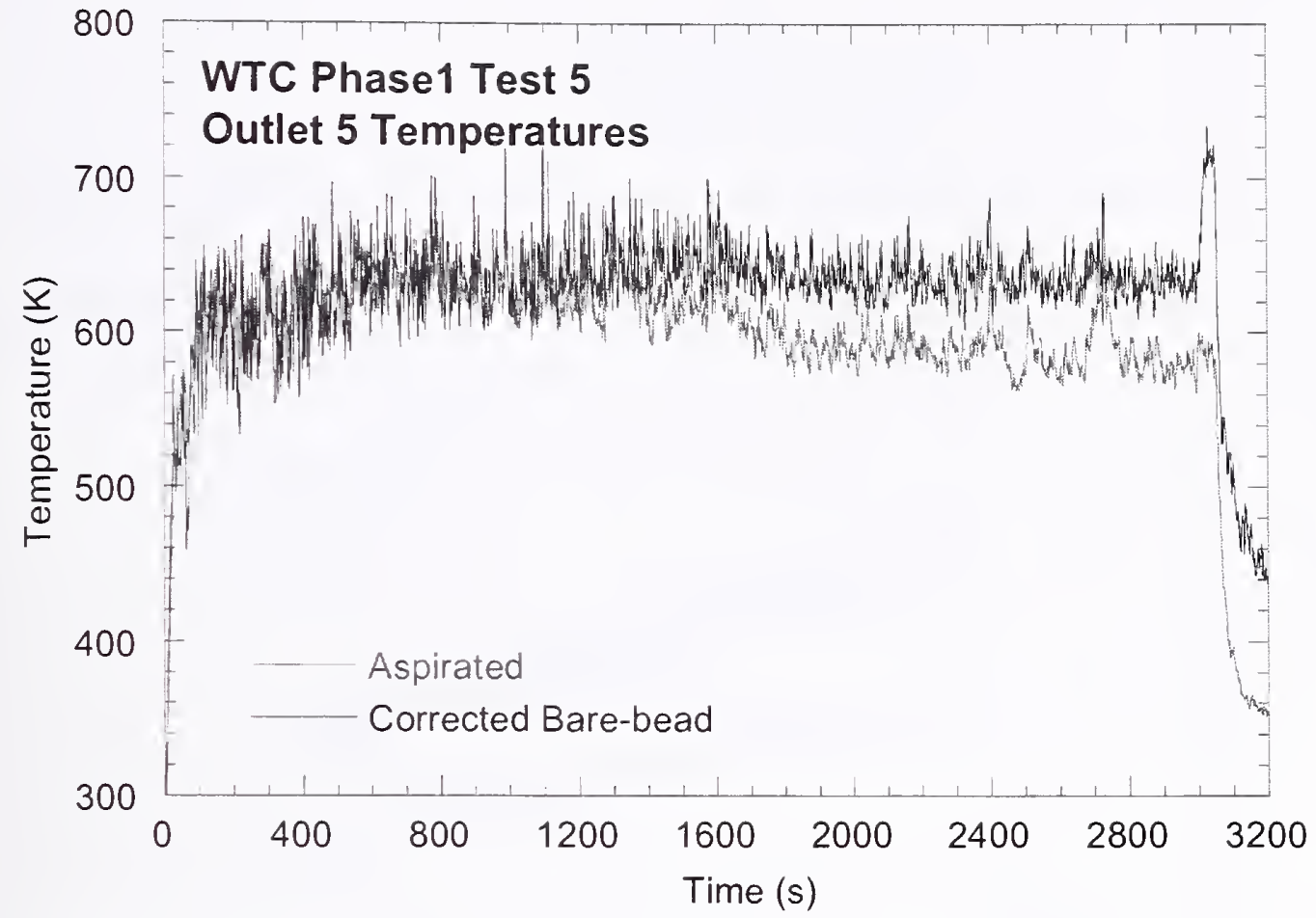

Figure D-41. Aspirated and bare-bead thermocouple temperatures at outlet 5 for Test 5.

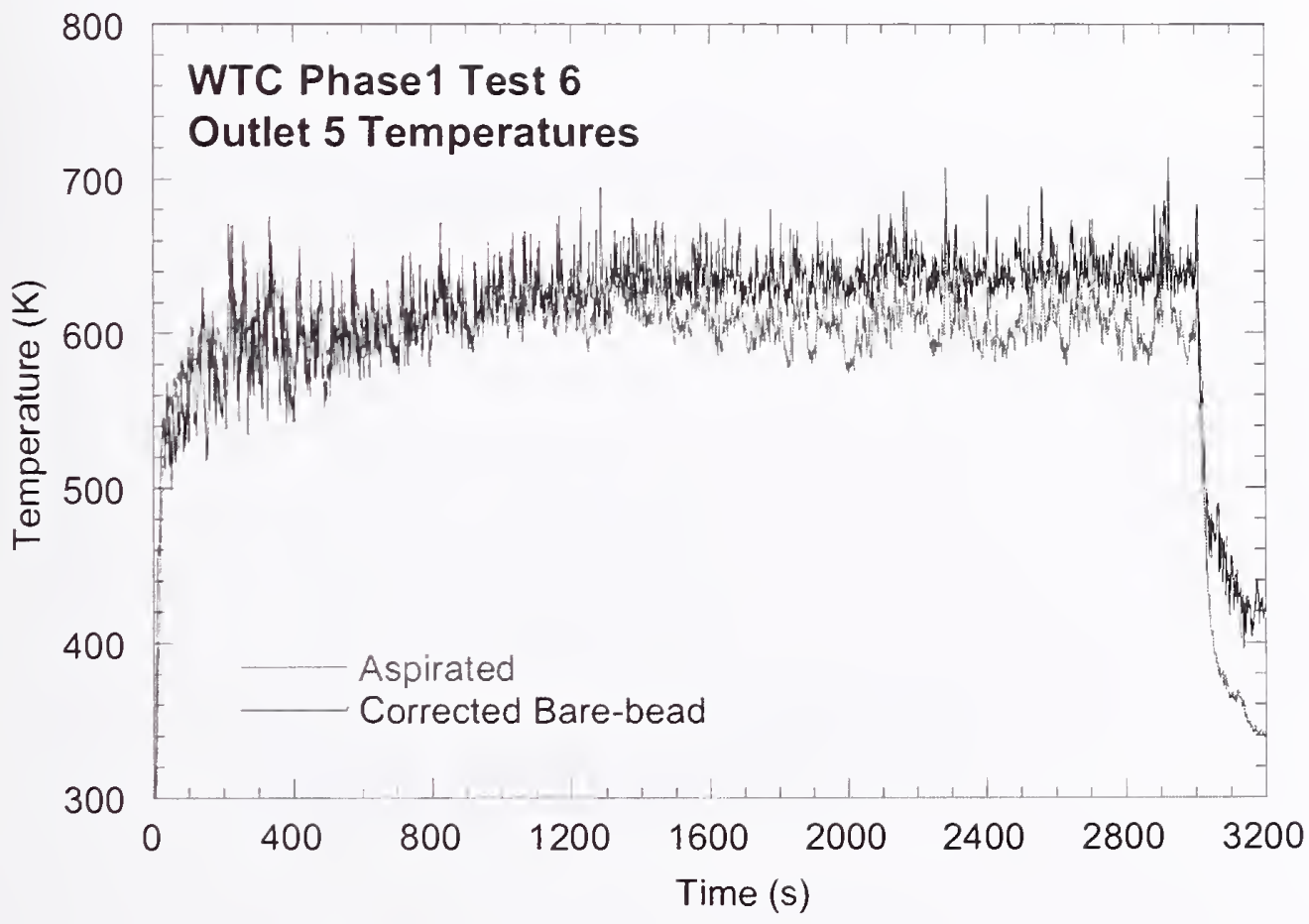

Figure D-42. Aspirated and bare-bead thermocouple temperatures at outlet 5 for Test 6. 
This page intentionally left blank. 


\section{Appendix E \\ HEAT FLUX MEASUREMENTS}

This appendix presents heat flux data that was not presented in Chapter 5 of this report (see Figs. E-1 through E-24). Further information on these measurements can be found in Chapter 5.

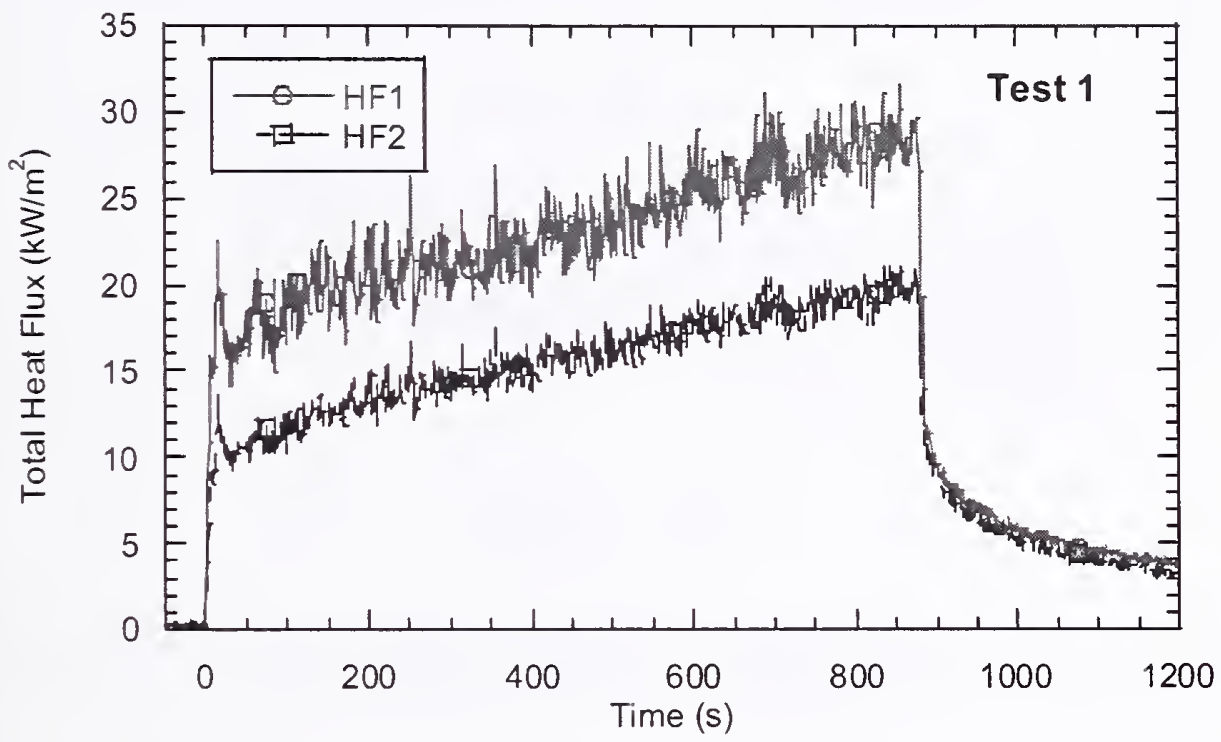

Figure E-1. Total heat flux recorded by the two flux gauges $15 \mathrm{~cm}$ above the floor, just downstream of the fire pan in Test 1.

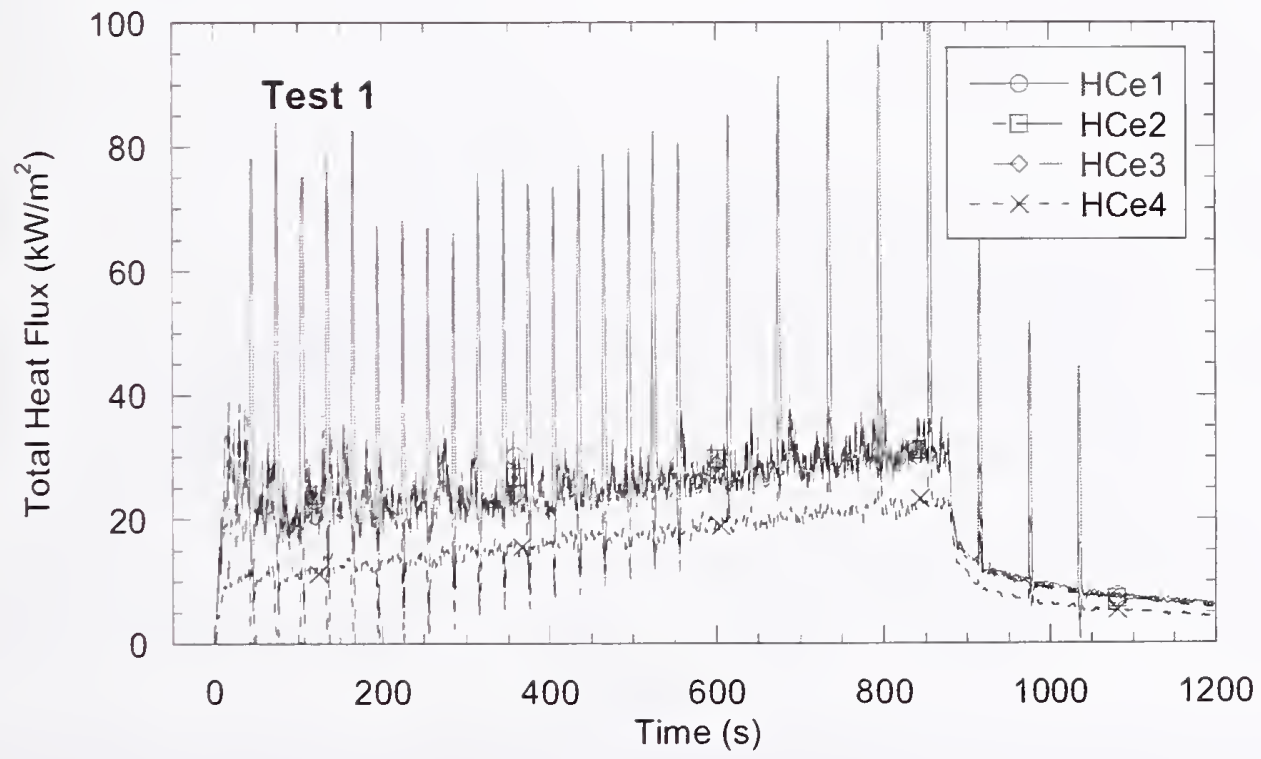

Figure E-2. Total heat flux recorded by the four flux gauges in the compartment ceiling in Test 1. The periodic spikes are due to the soot purge operation. 


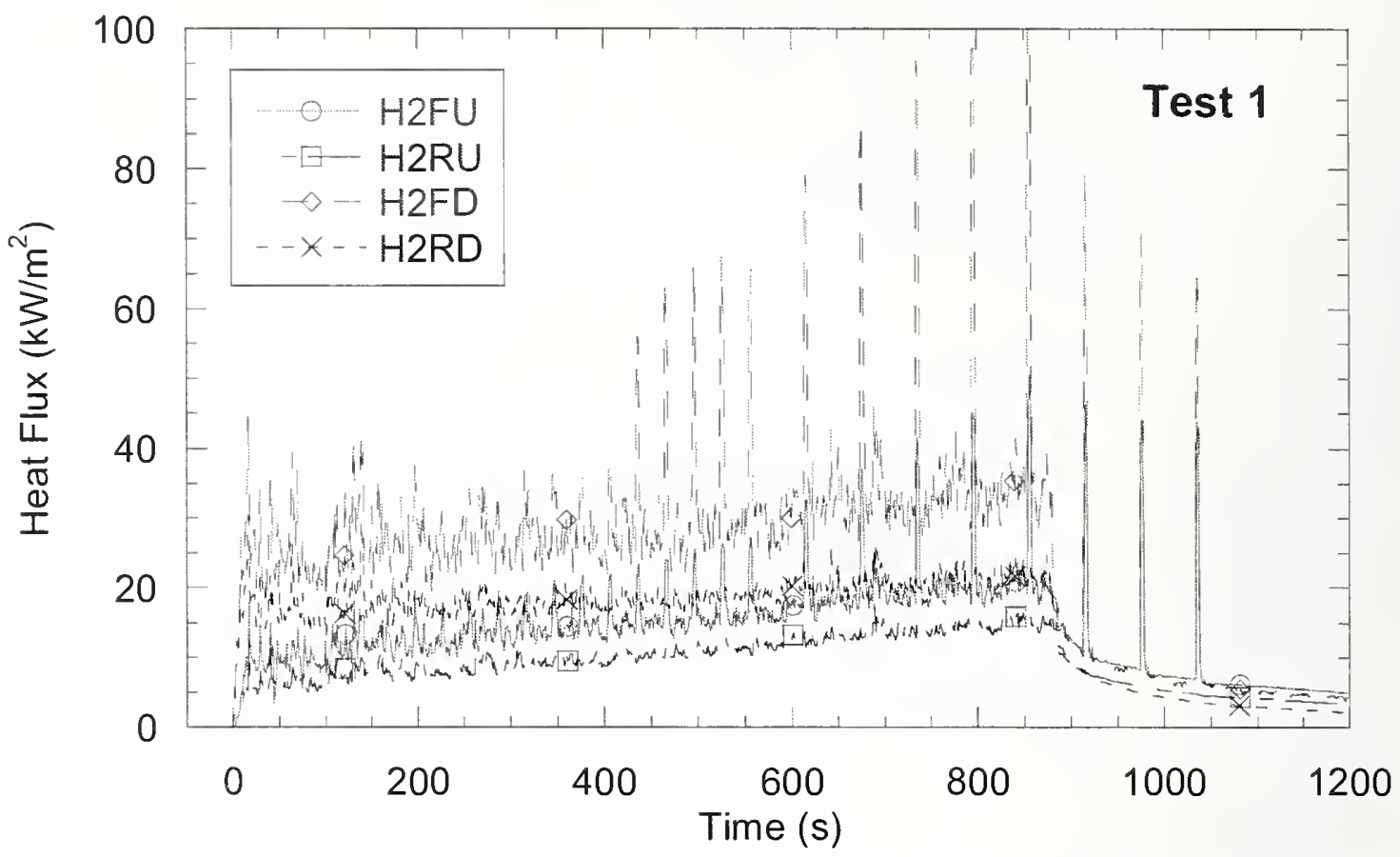

Figure E-3. Heat flux recorded by the two radiometers and two flux gauges in the measurement station in Test 1.

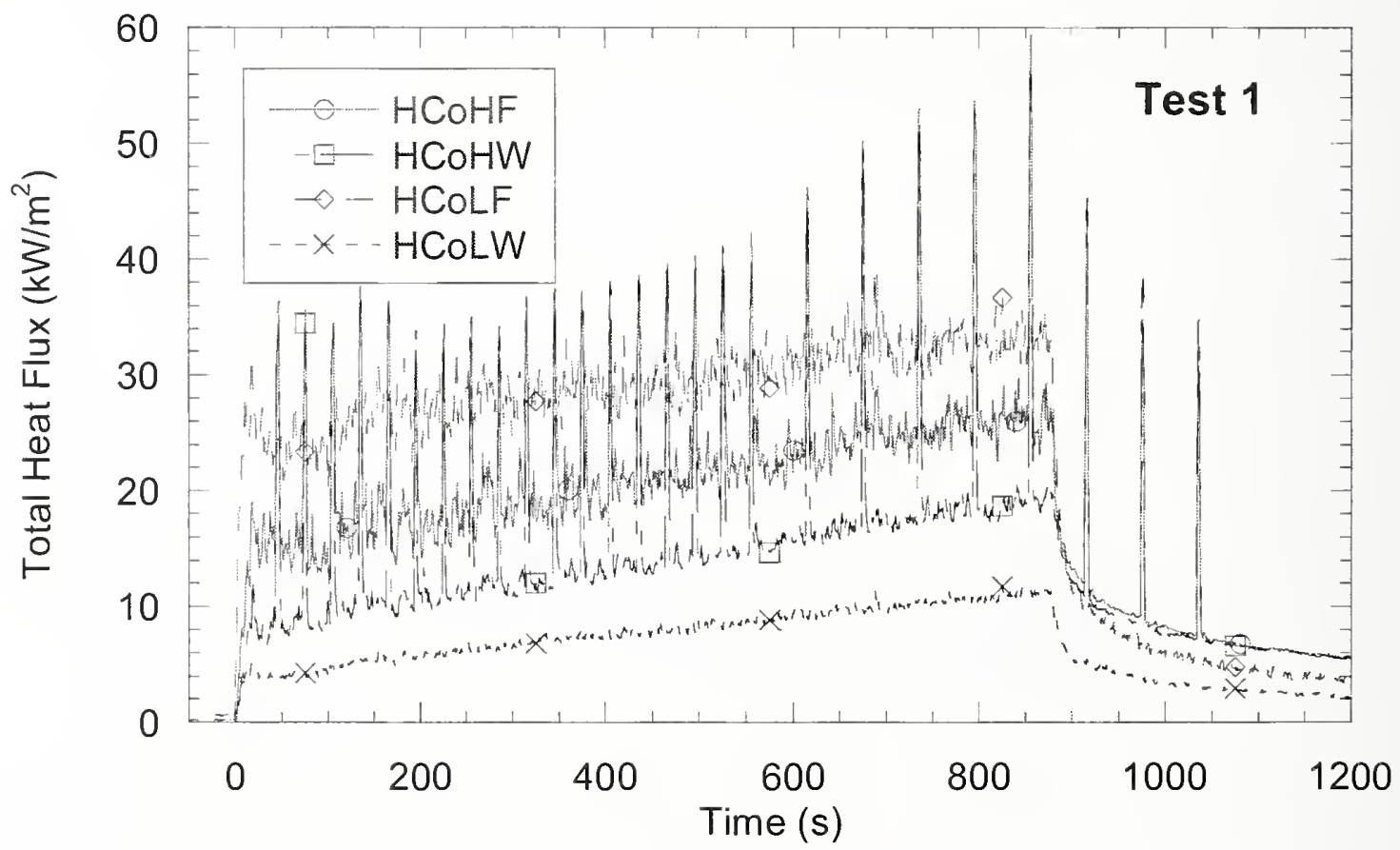

Figure E-4. Heat flux recorded by the two radiometers and two flux gauges on the column in Test 1. 


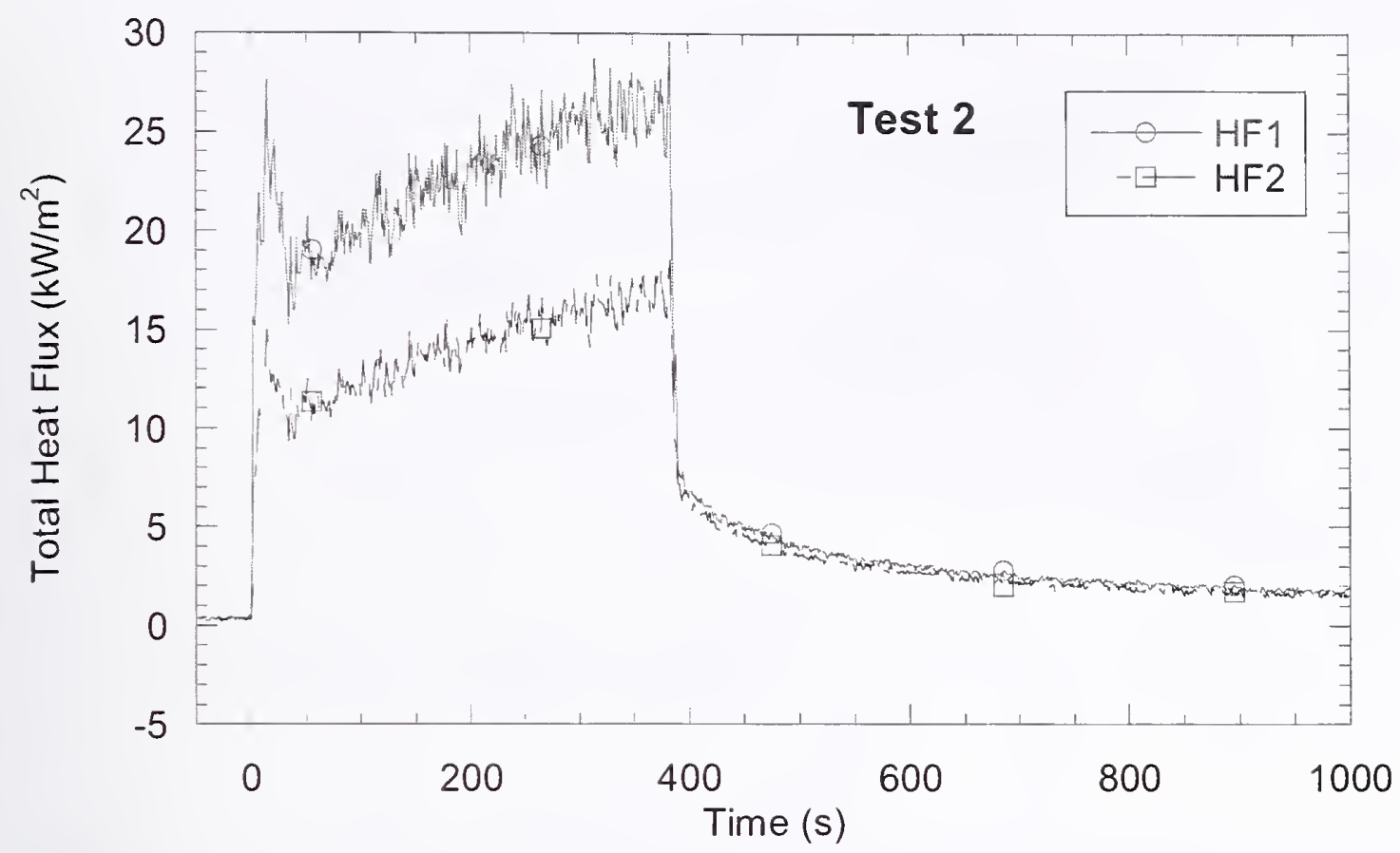

Figure E-5. Total heat flux recorded by the two flux gauges $15 \mathrm{~cm}$ above the floor, just downstream of the fire pan in Test 2.

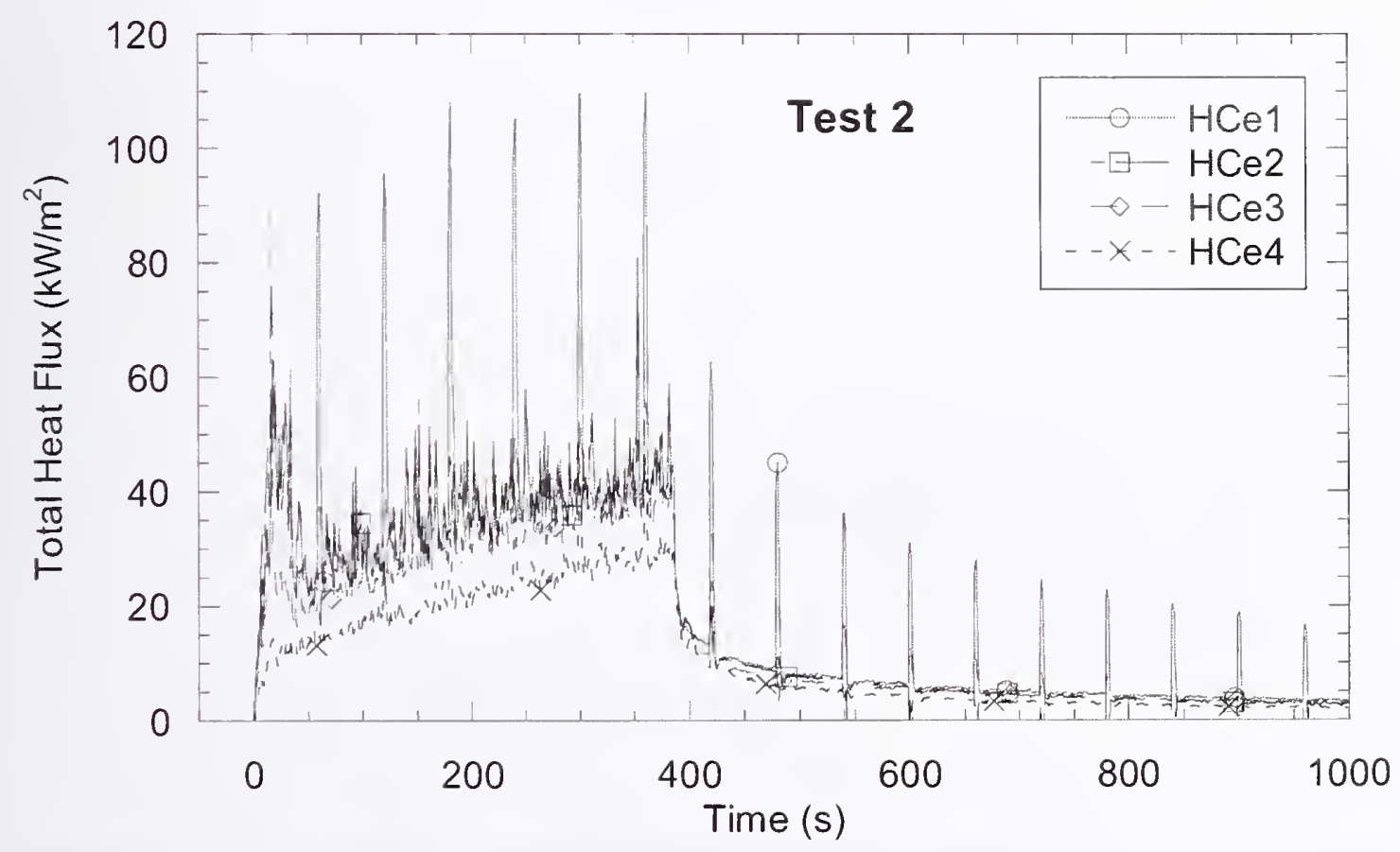

Figure E-6. Total heat flux recorded by the four flux gauges in the compartment ceiling in Test 2. The periodic spikes are due to the soot purge operation. 


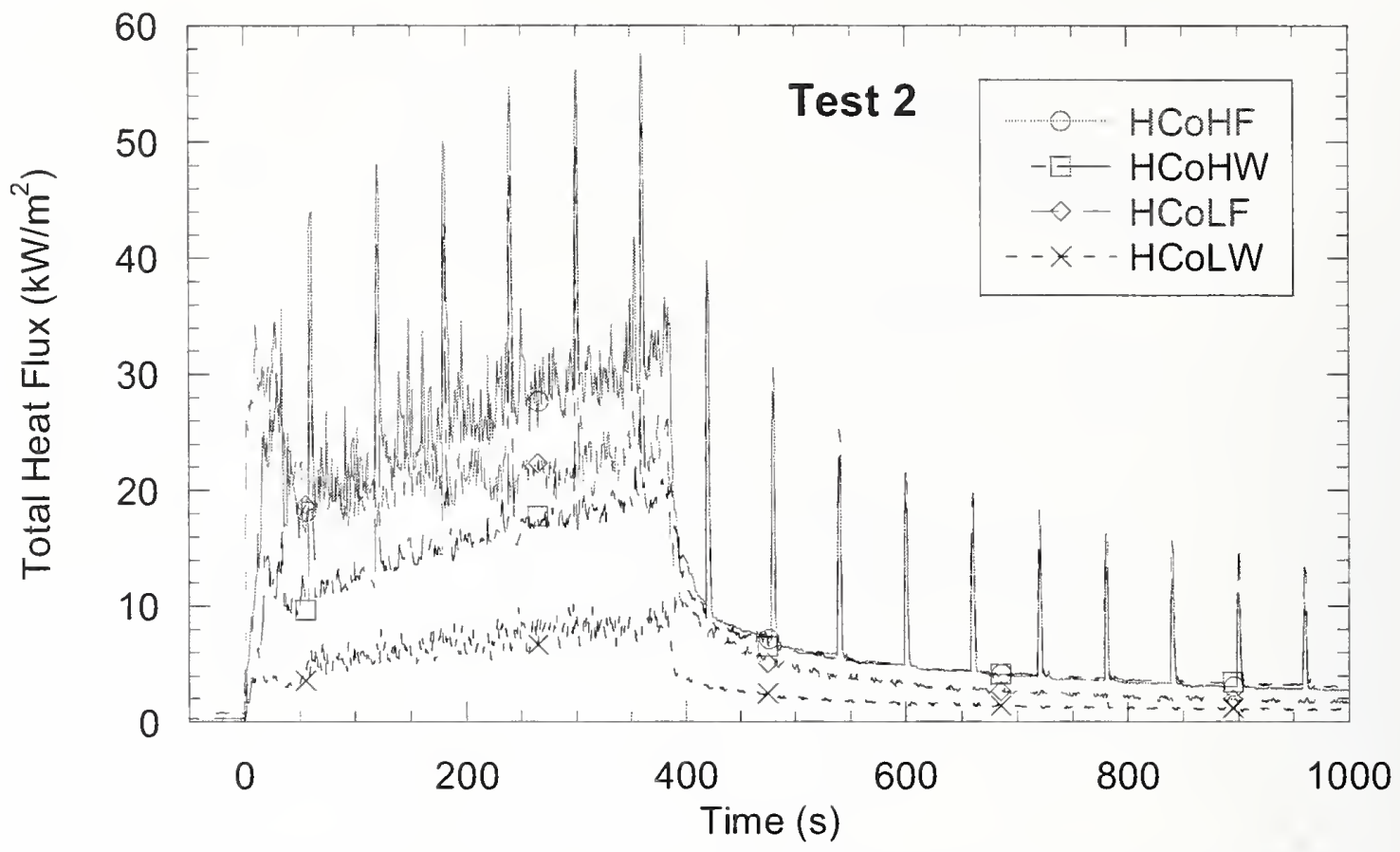

Figure E-7. Total heat flux recorded by the four flux gauges in structures adjacent to the vertical column in Test 2 . The periodic spikes are due to the soot purge operation on the two higher gauges.

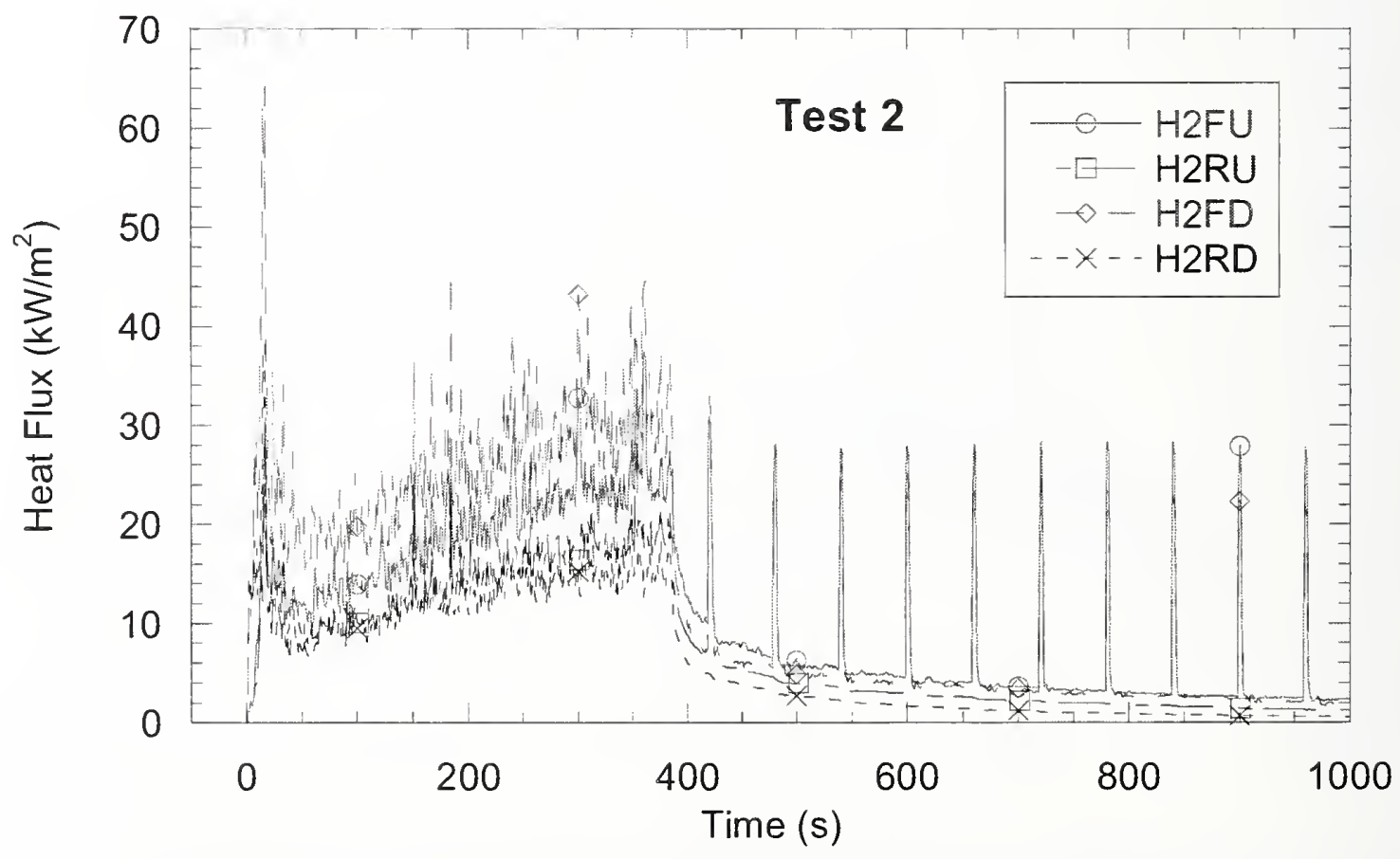

Figure E-8. Heat flux recorded by the two radiometers and two flux gauges in the measurement station in Test 2. 


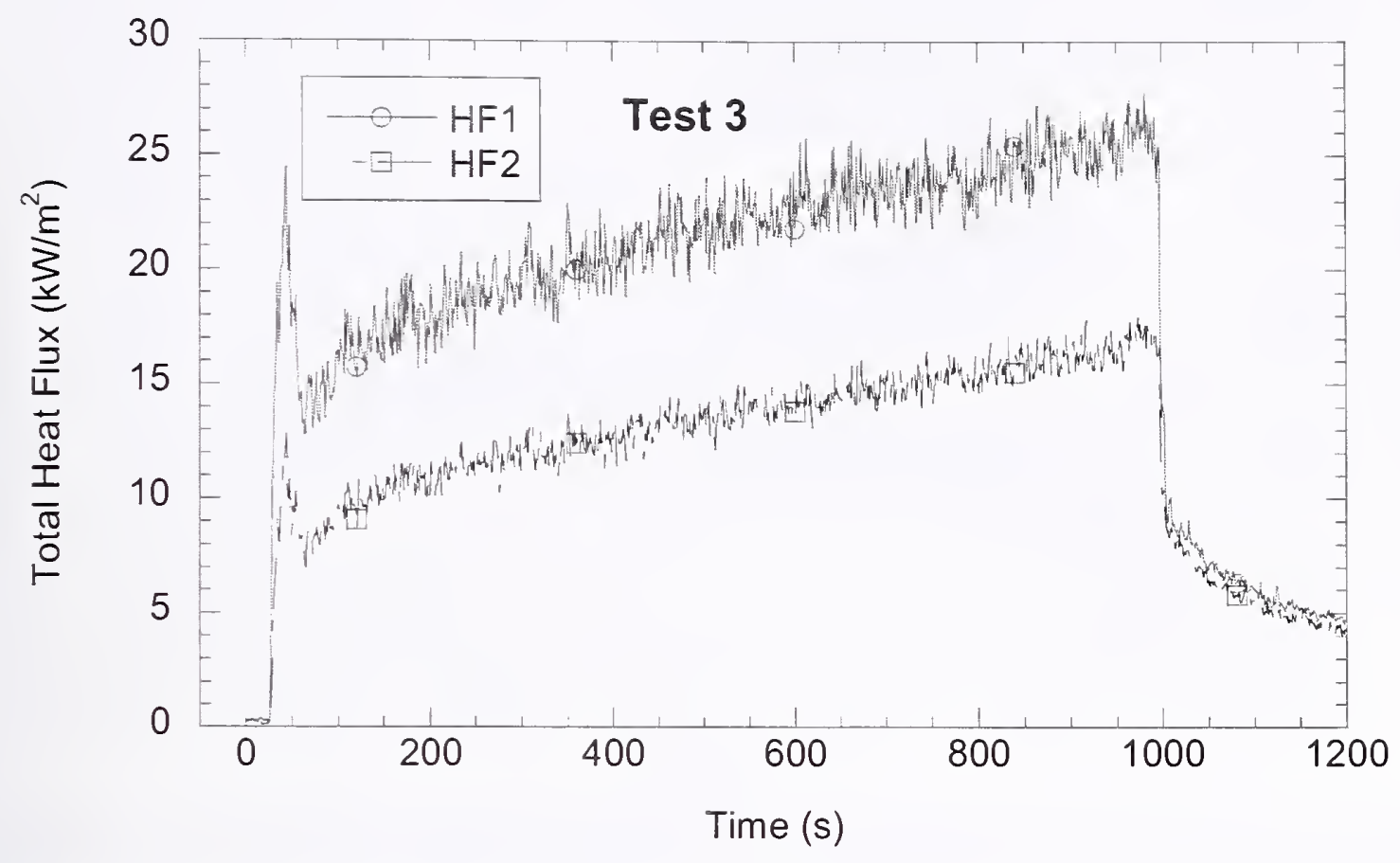

Figure E-9. Total heat flux recorded by the two flux gauges $15 \mathrm{~cm}$ above the floor, just downstream of the fire pan in Test 3.

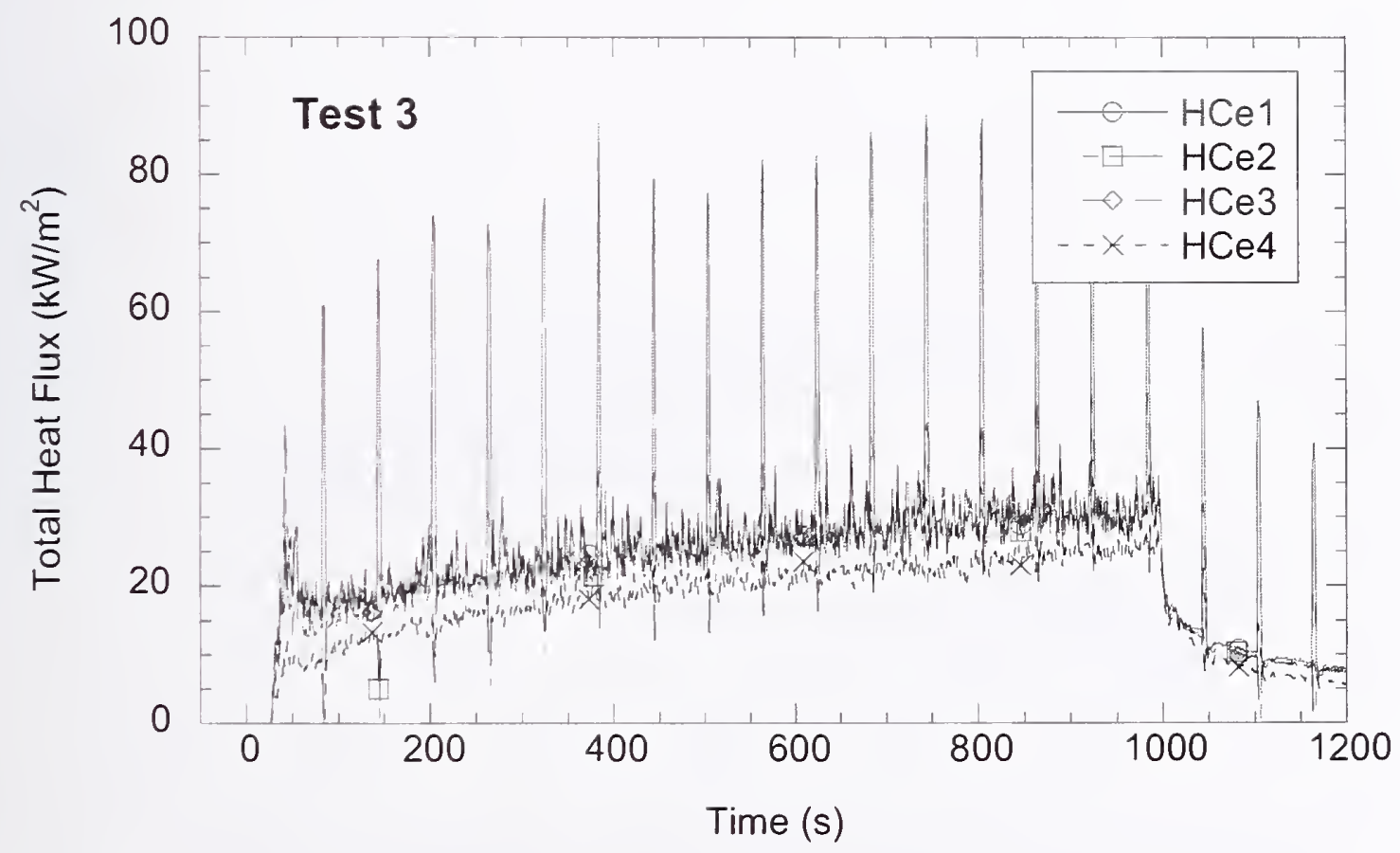

Figure E-10. Total heat flux recorded by the four flux gauges in the compartment ceiling in Test 3. The periodic spikes are due to the soot purge operation. 


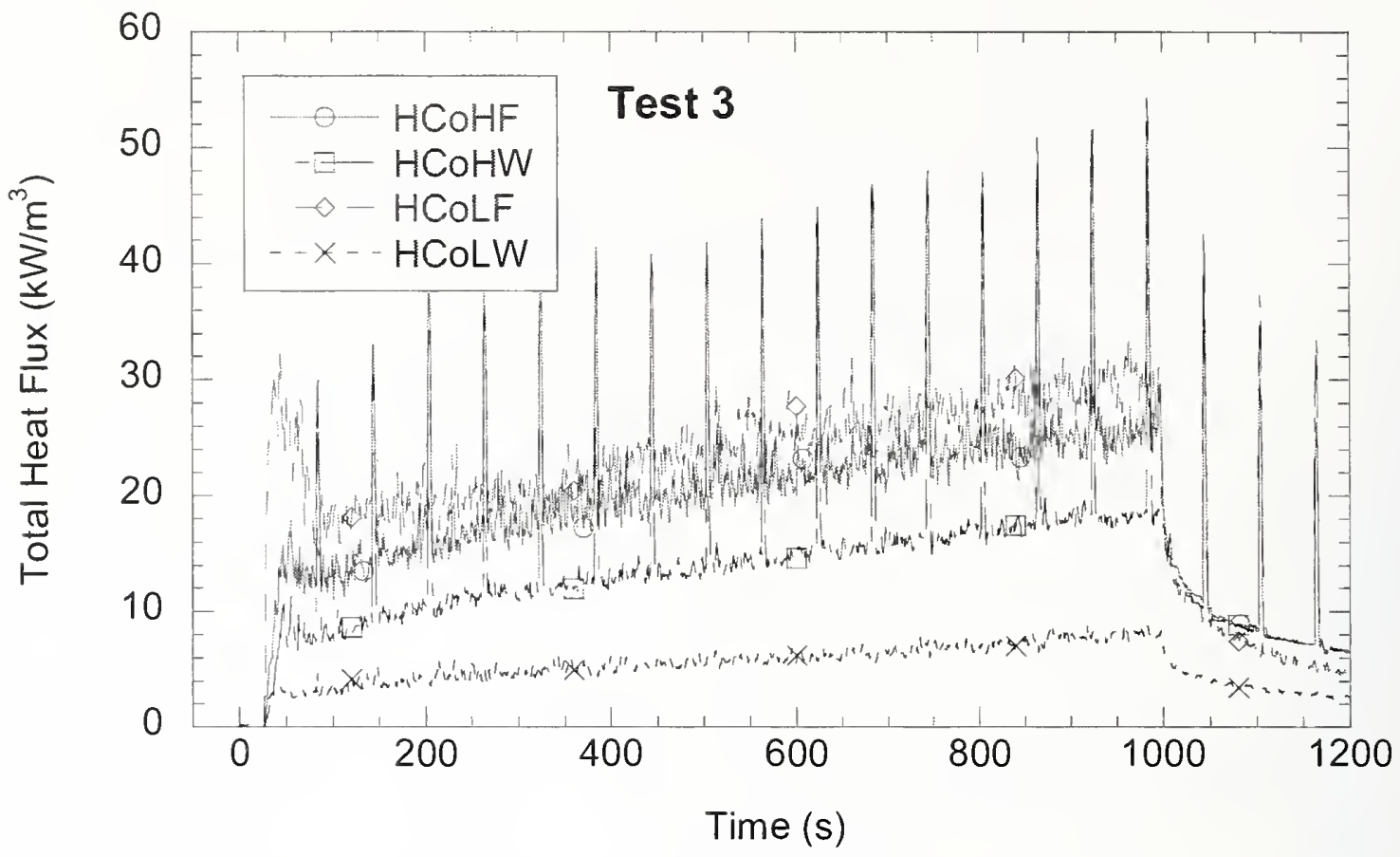

Figure E-11. Total heat flux recorded by the four flux gauges in structures adjacent to the vertical column in Test 3. The periodic spikes are due to the soot purge operation on the two higher gauges.

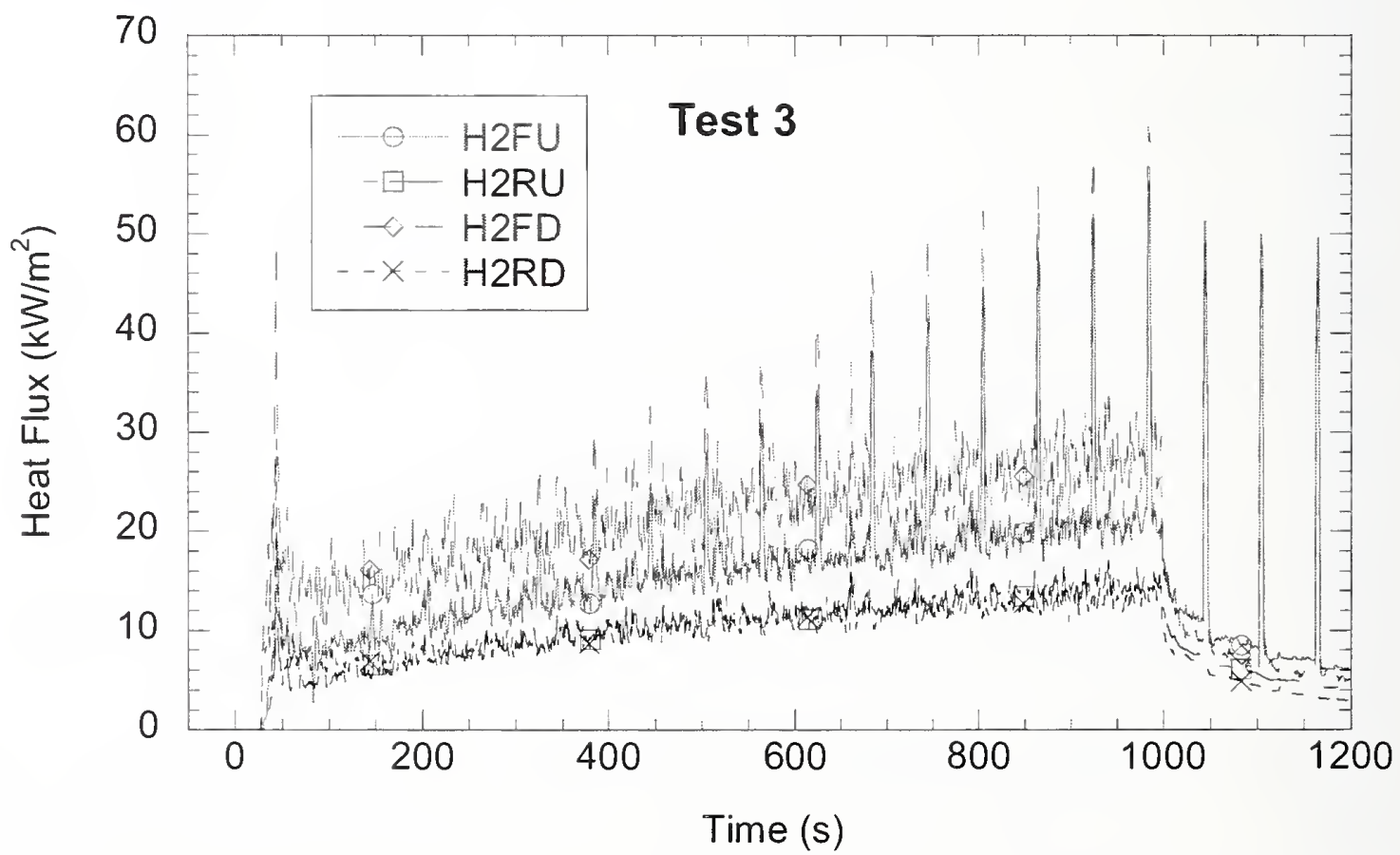

Figure E-12. Heat flux recorded by the two radiometers and two flux gauges in the measurement station in Test 3. 


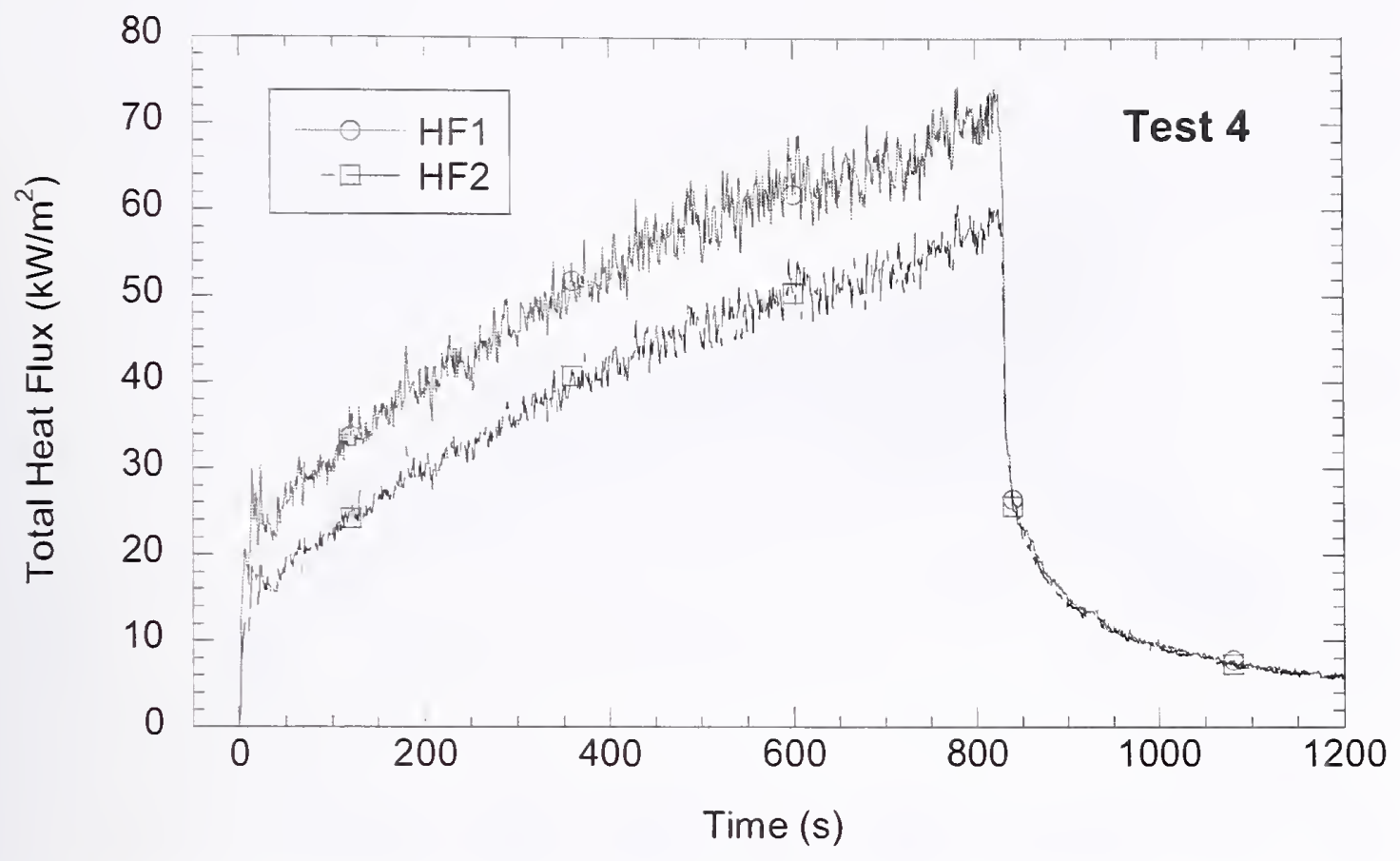

Figure E-13. Total heat flux recorded by the two flux gauges $15 \mathrm{~cm}$ above the floor, just downstream of the fire pan in Test 4.

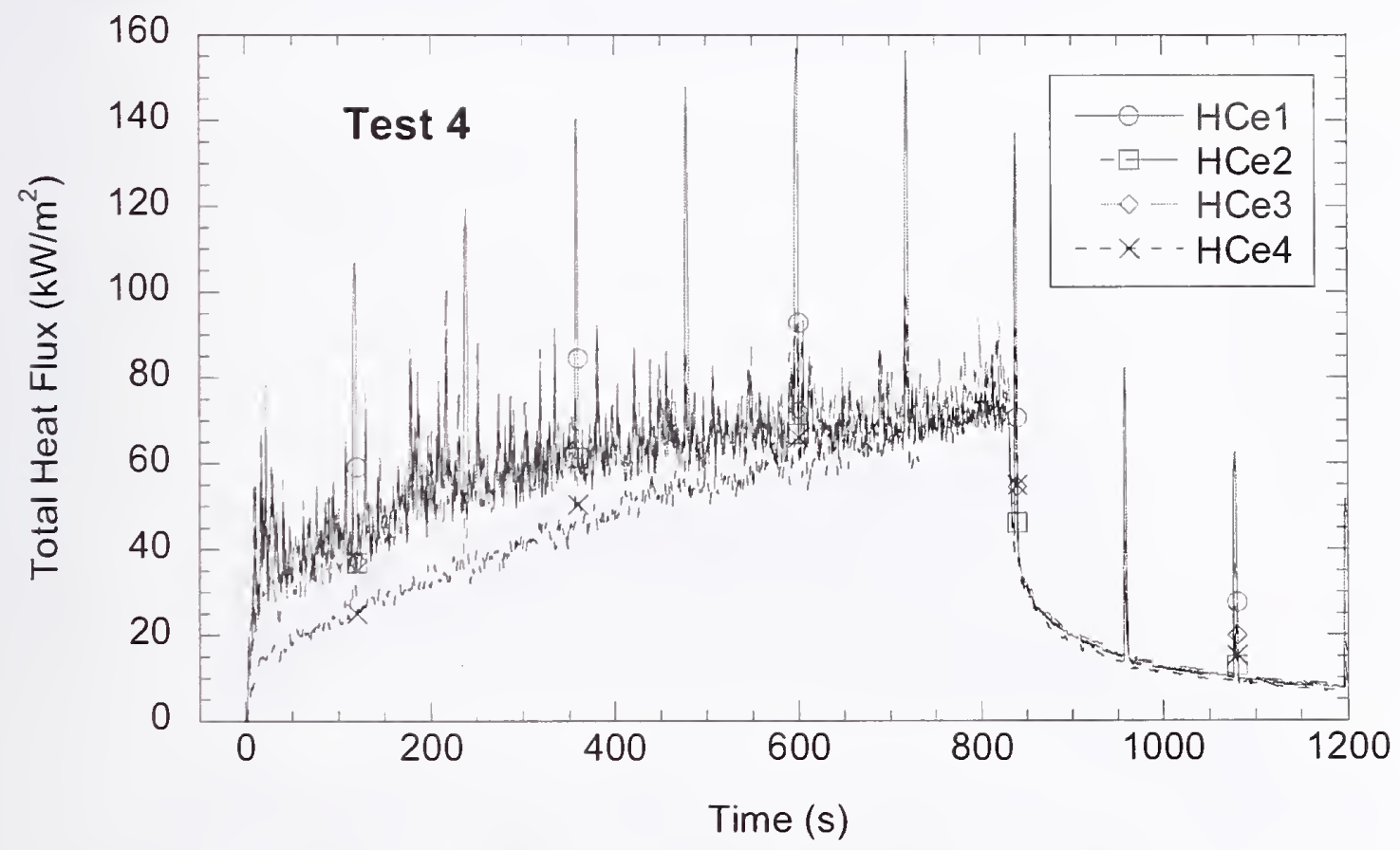

Figure E-14. Total heat flux recorded by the four flux gauges in the compartment ceiling in Test 4. The periodic spikes are due to the soot purge operation. 


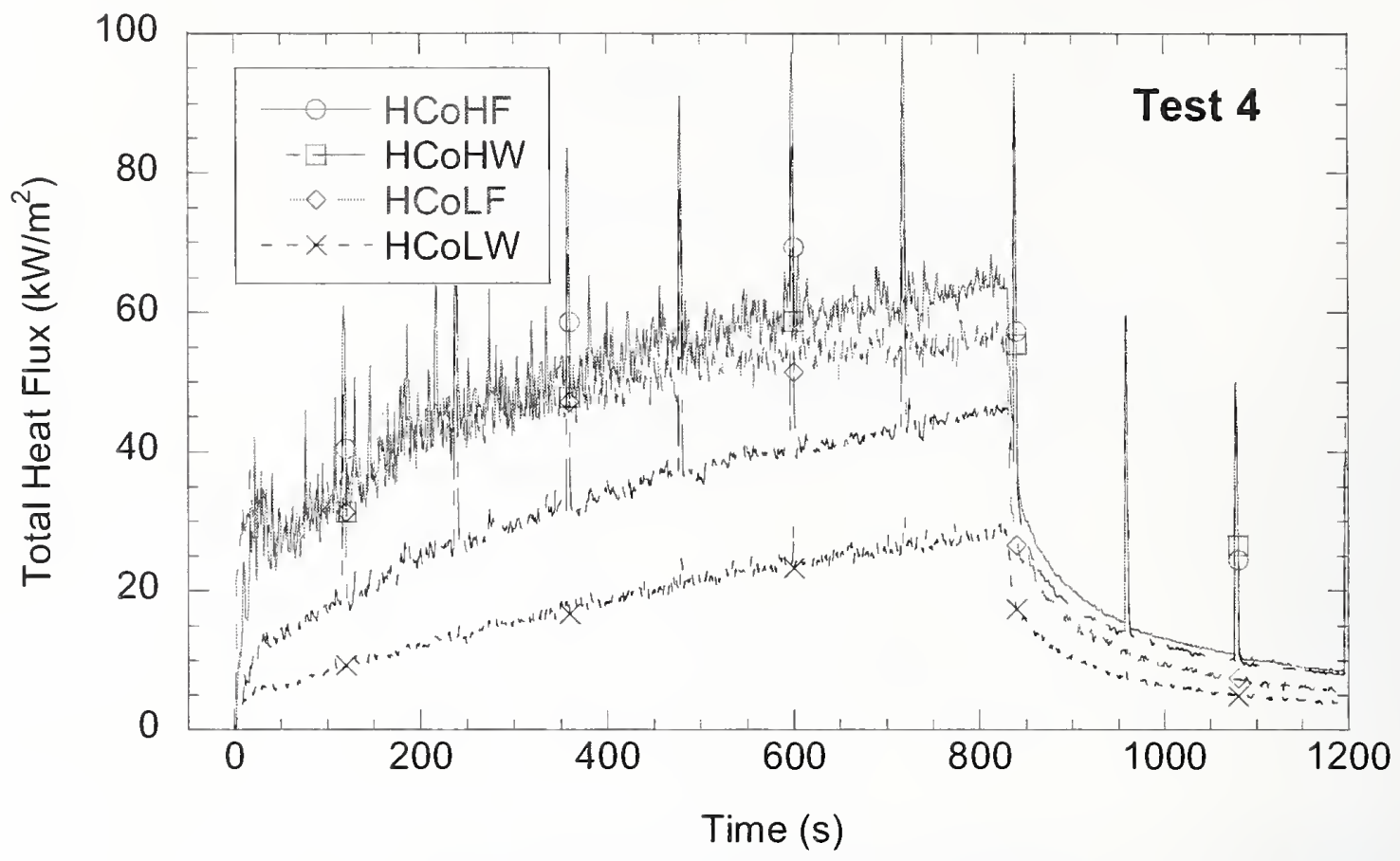

Figure E-15. Total heat flux recorded by the four flux gauges in structures adjacent to the vertical column in Test 4 . The periodic spikes are due to the soot purge operation on the two higher gauges.

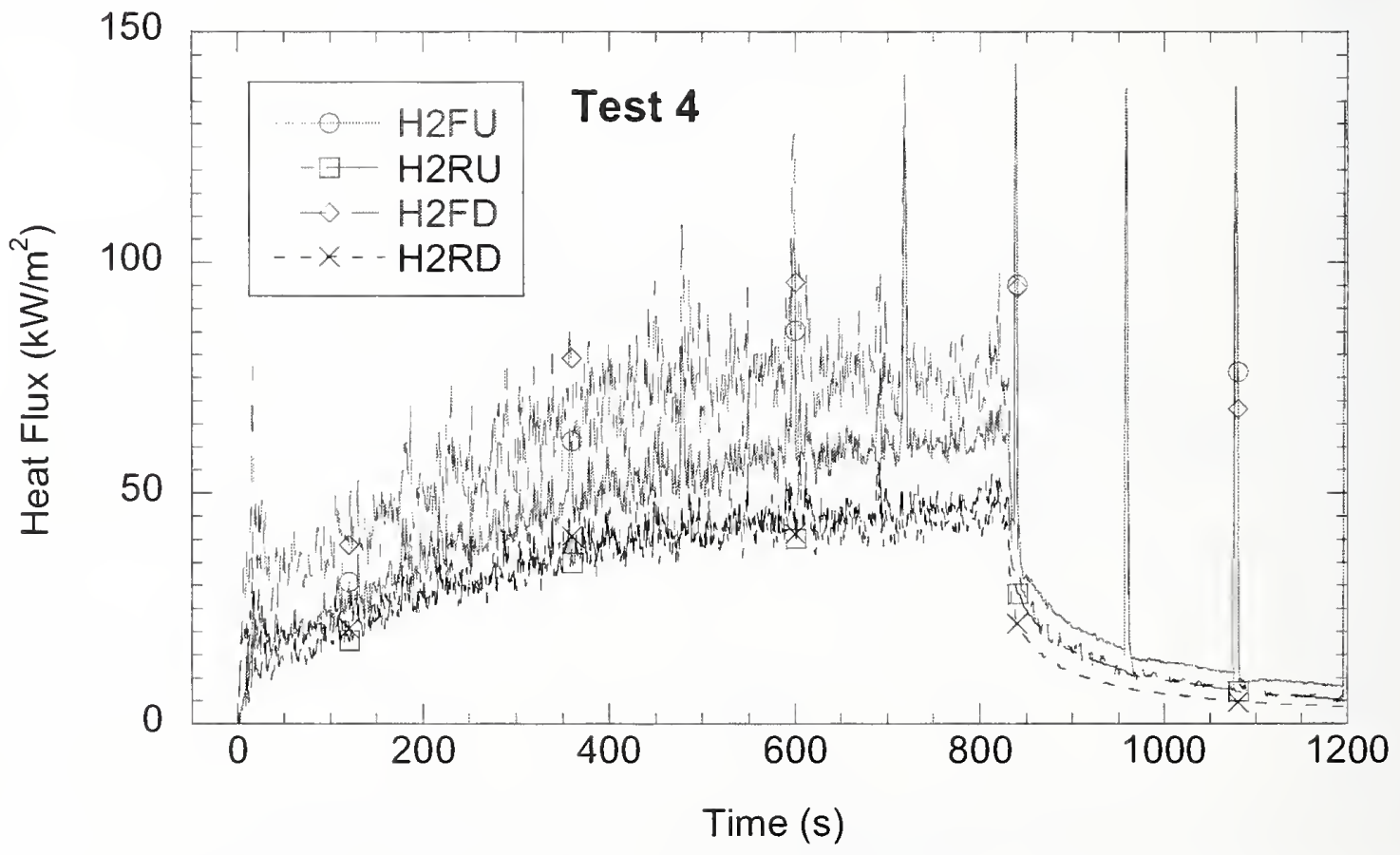

Figure E-16. Heat flux recorded by the two radiometers and two flux gauges in the measurement station in Test 4. 


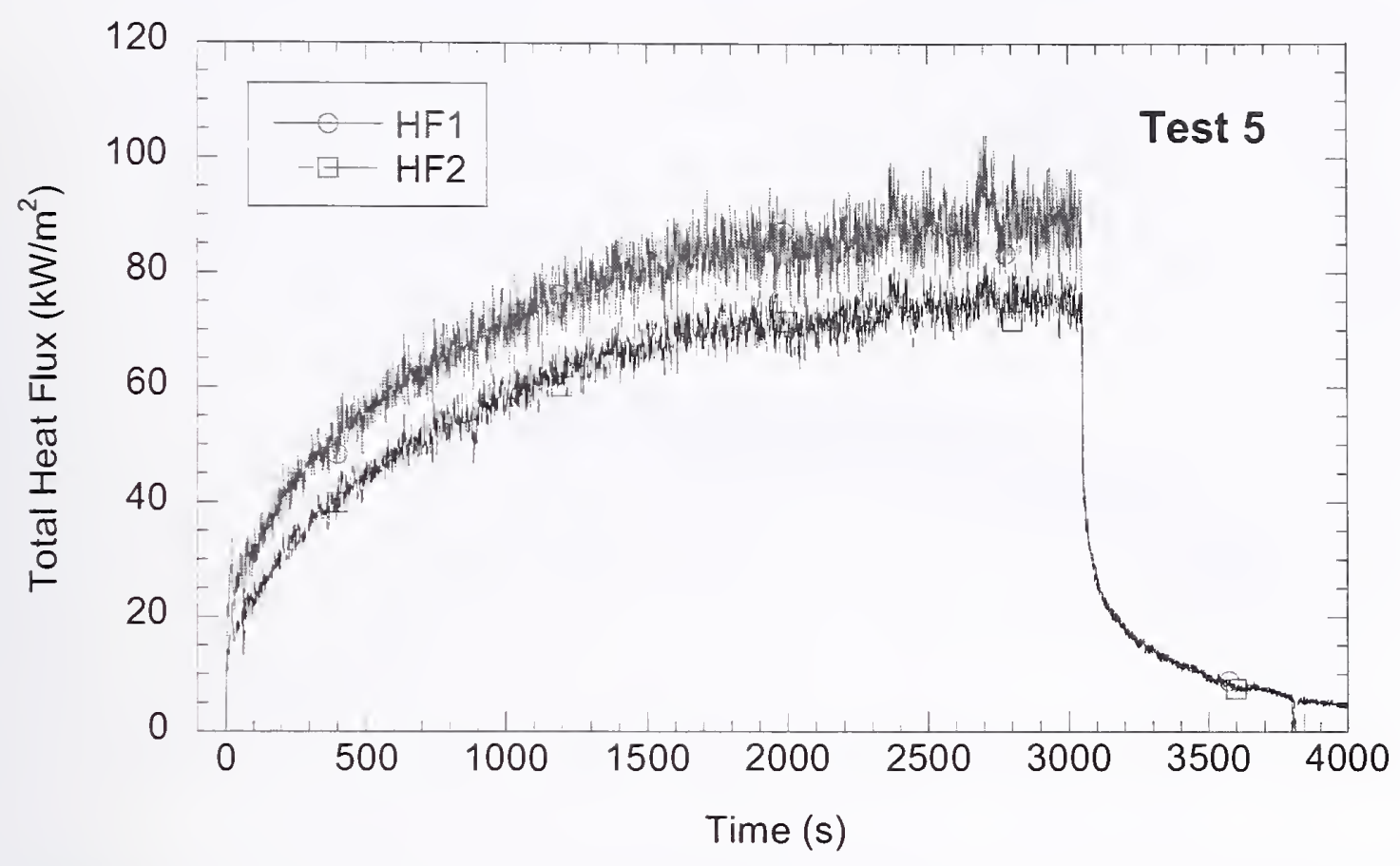

Figure E-17. Total heat flux recorded by the two flux gauges $15 \mathrm{~cm}$ above the floor, just downstream of the fire pan in Test 5.

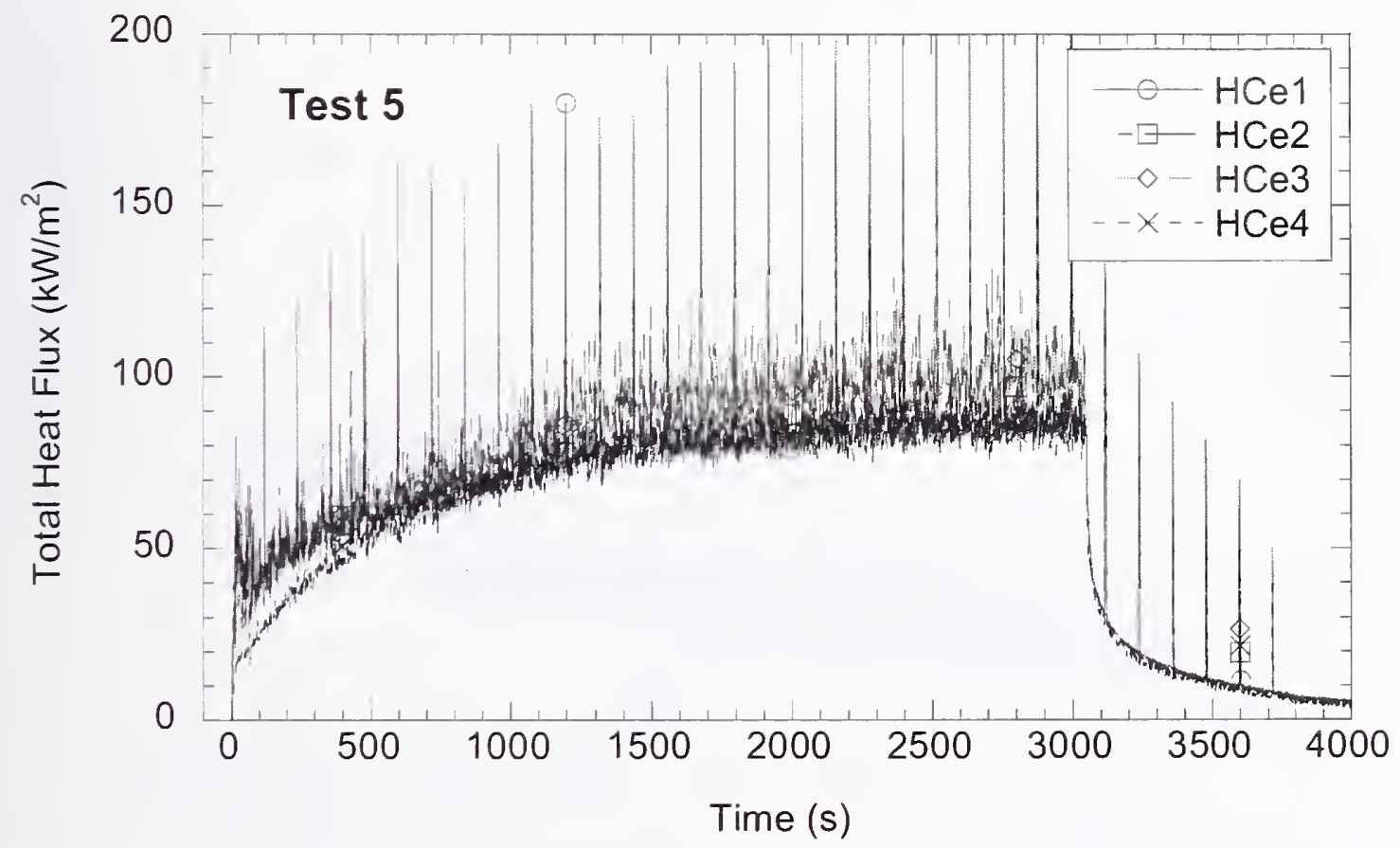

Figure E-18. Total heat flux recorded by the four flux gauges in the compartment ceiling in Test 5 . The periodic spikes are due to the soot purge operation. 


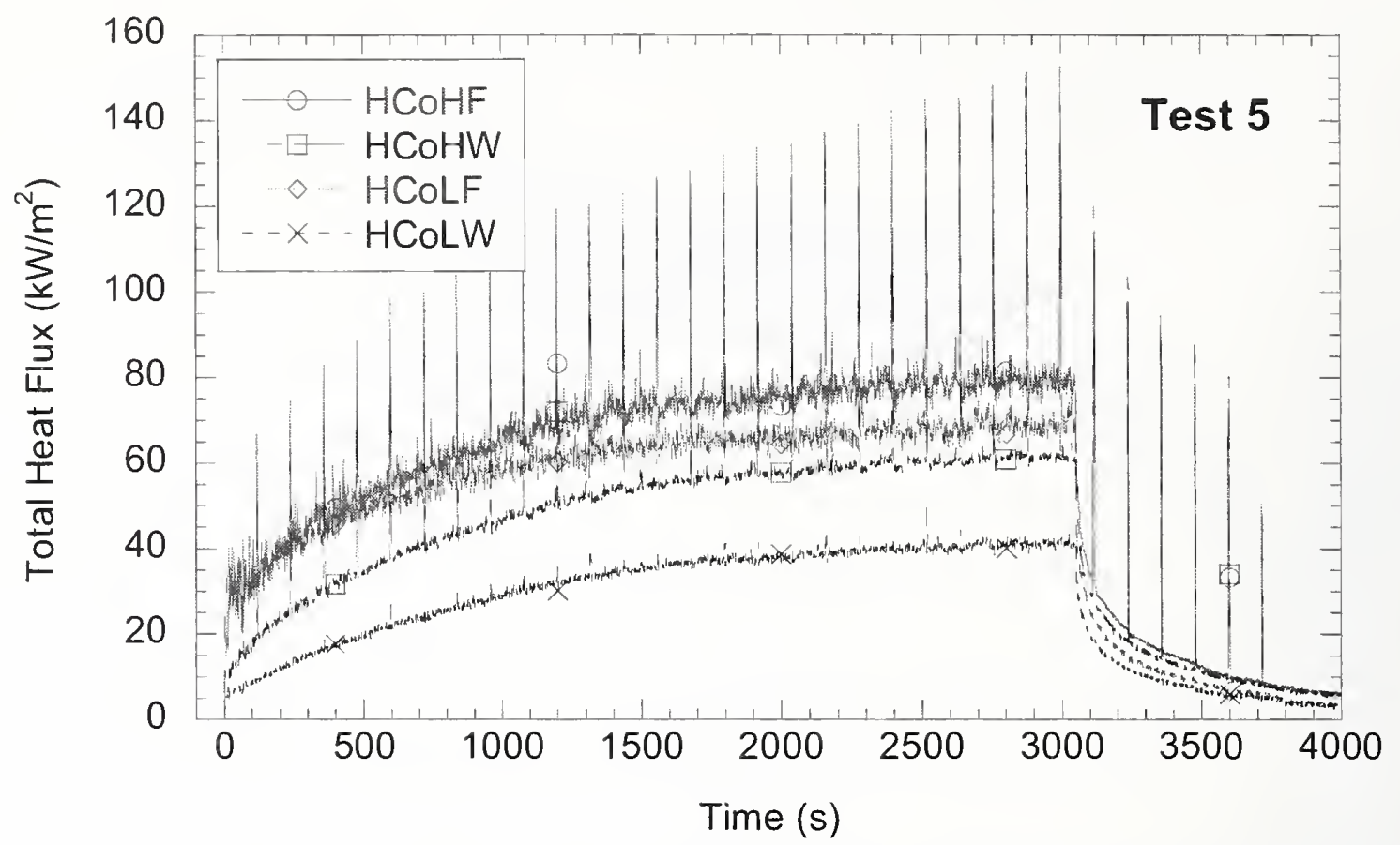

Figure E-19. Total heat flux recorded by the four flux gauges in structures adjacent to the vertical column in Test 5 . The periodic spikes are due to the soot purge operation on the two higher gauges.

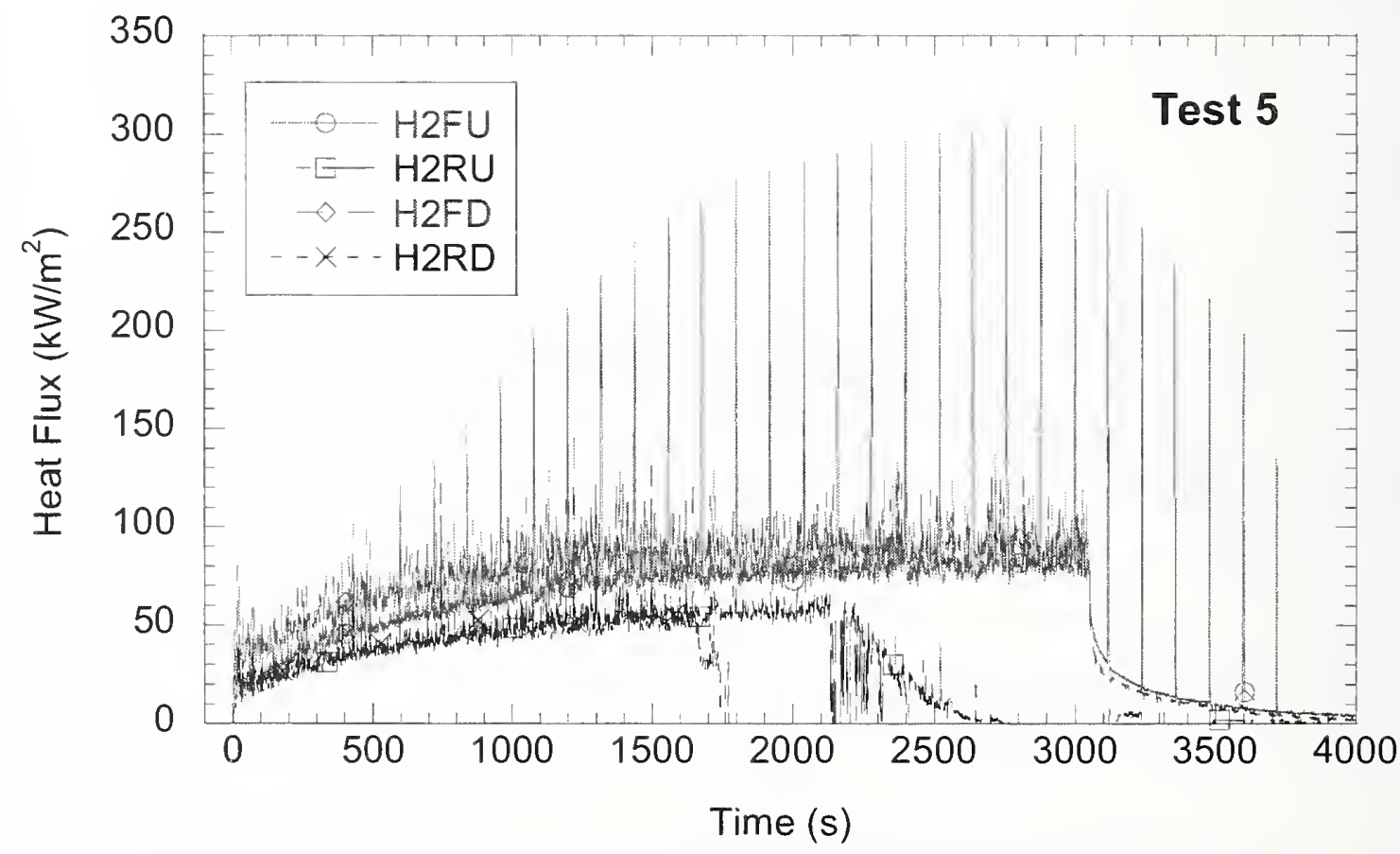

Figure E-20. Heat flux recorded by the two radiometers and two flux gauges in the measurement station in Test 5. Gauges H2RD and H2RU were damaged during the test. 


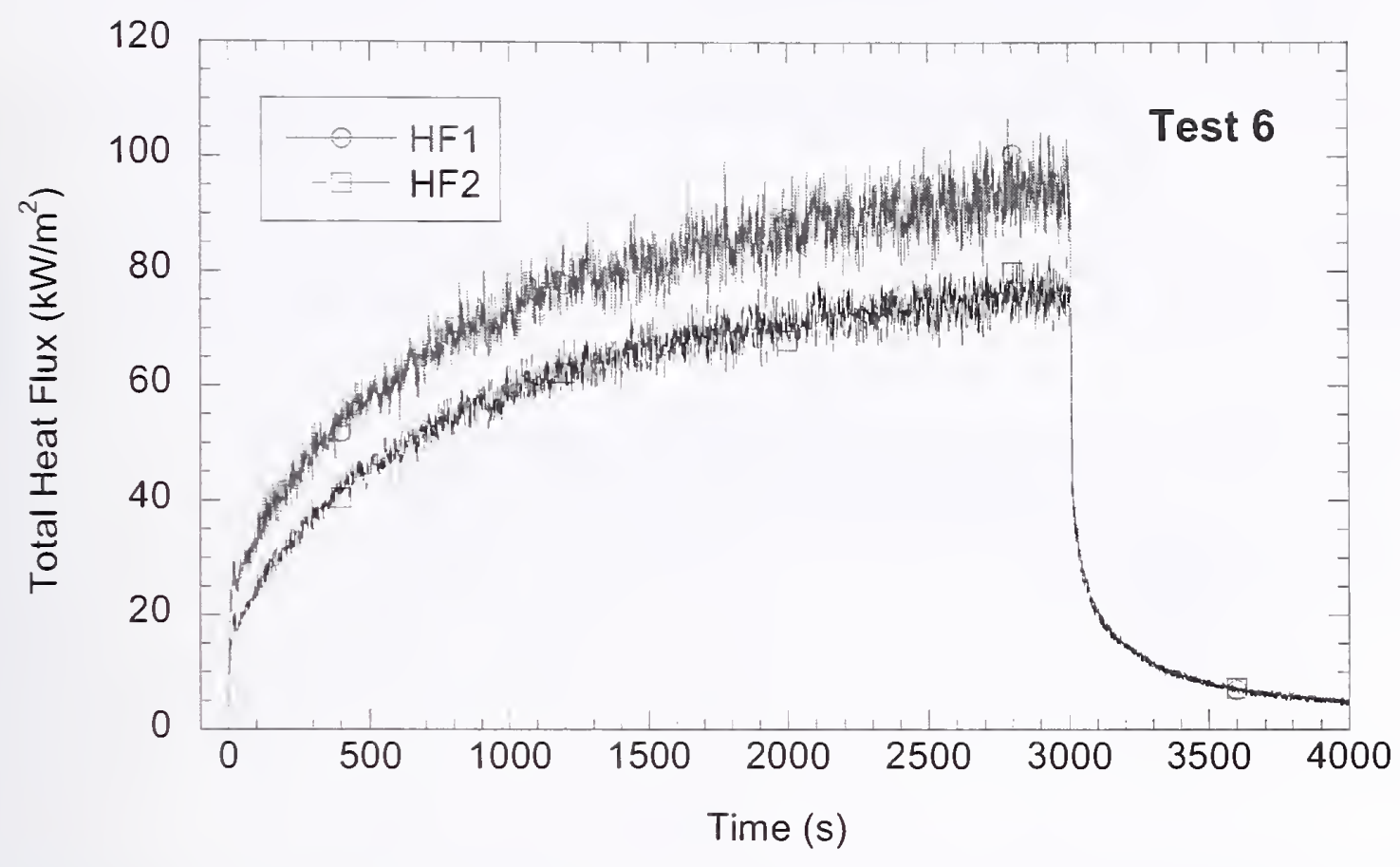

Figure E-21. Total heat flux recorded by the two flux gauges $15 \mathrm{~cm}$ above the floor, just downstream of the fire pan in Test 6.

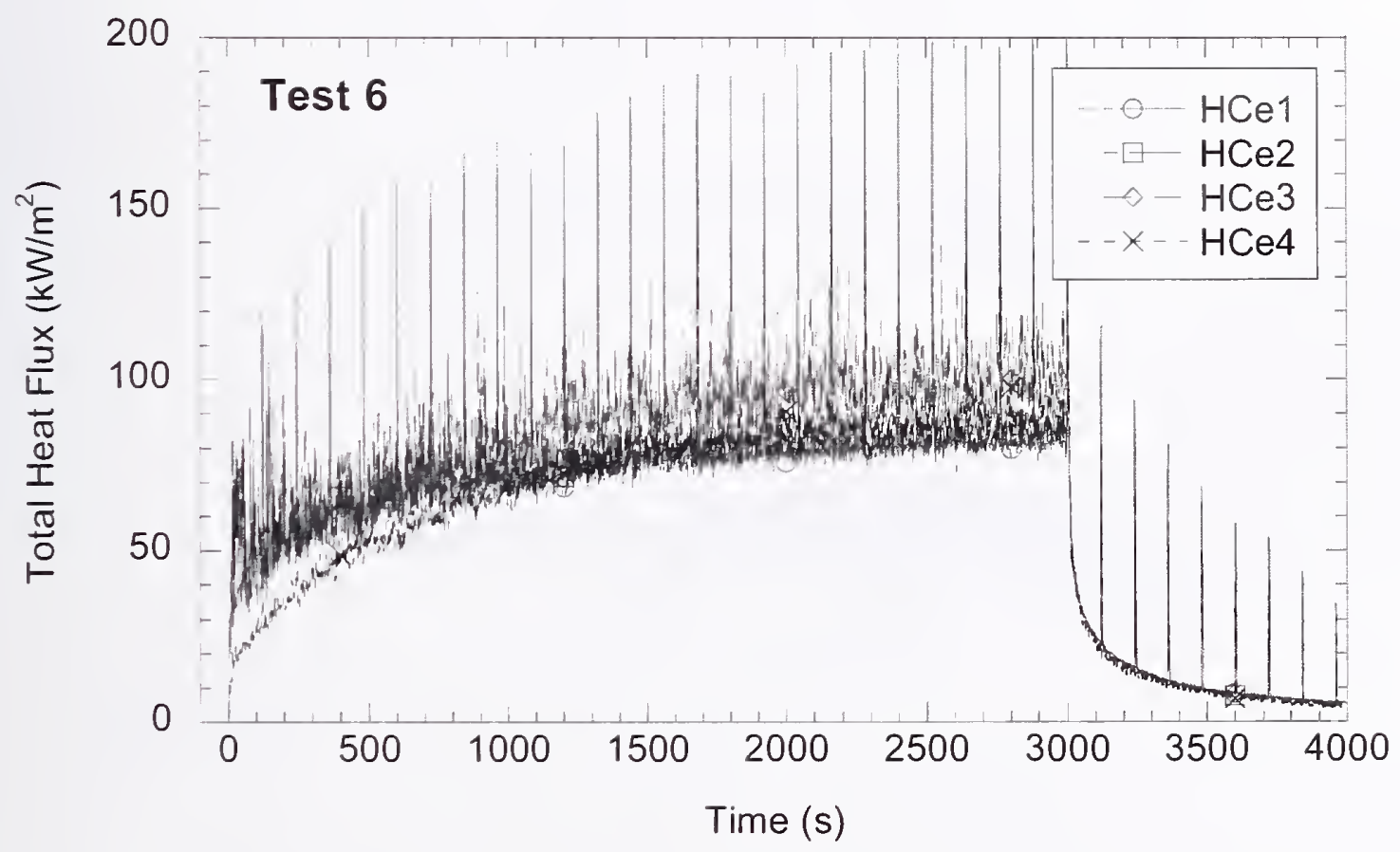

Figure E-22. Total heat flux recorded by the four flux gauges in the compartment ceiling in Test 6 . The periodic spikes are due to the soot purge operation. 


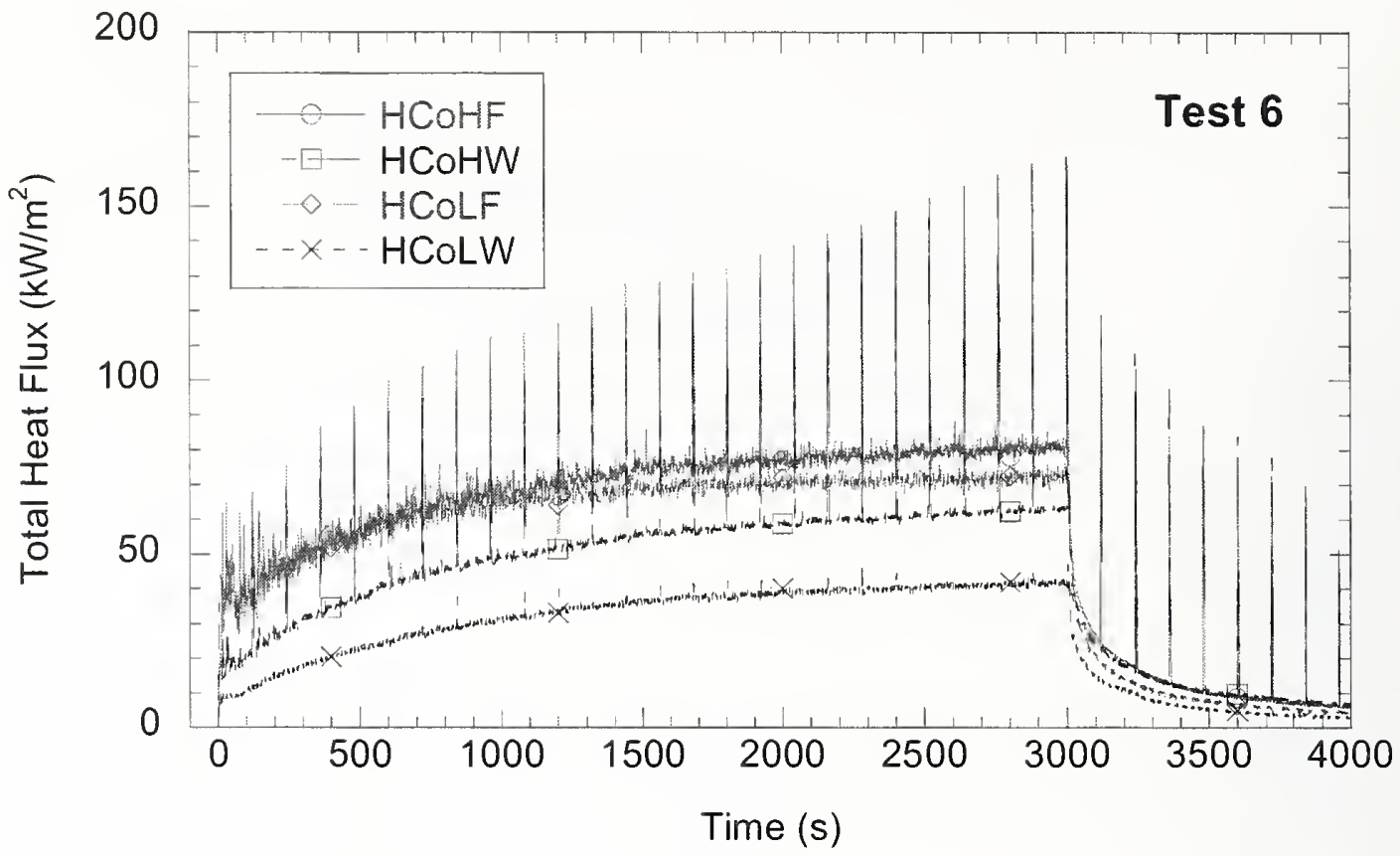

Figure E-23. Total heat flux recorded by the four flux gauges in structures adjacent to the vertical column in Test 6 . The periodic spikes are due to the soot purge operation on the two higher gauges.

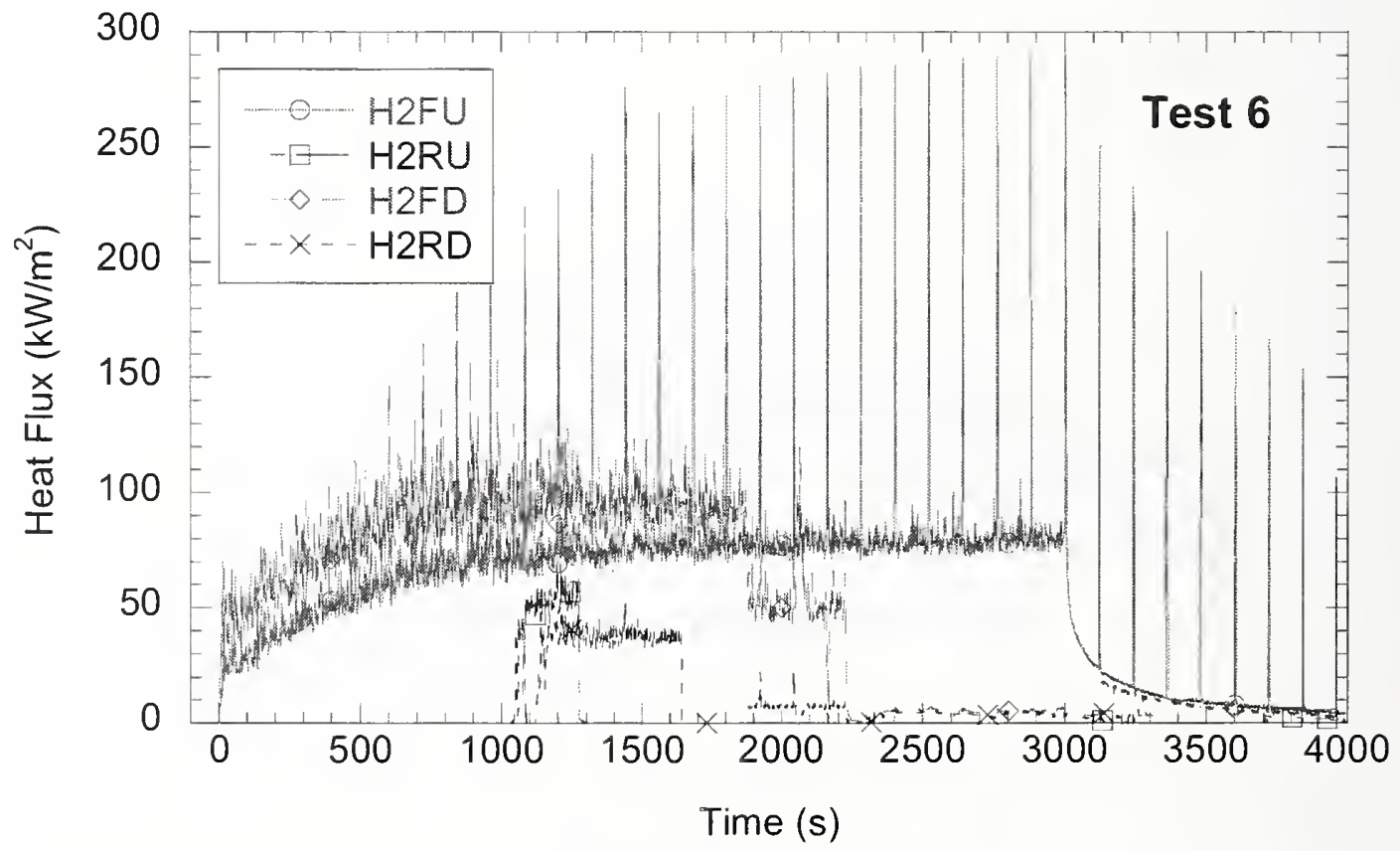

Figure E-24. Heat flux recorded by the two radiometers and two flux gauges in the measurement station in Test 6. Gauges H2FD, H2RU, and H2RD were damaged during the test. 


\section{Appendix F \\ Thermocouple Locations ON STEel Components}

Chapter 9 presents representative measurements of the temperature on the surface of the steel components and the sprayed fire-resistive material (SFRM) applied to those components. This appendix documents the location of the thermocouples on the surface of the SFRM and the steel components in terms of their position within the test compartment (Tables F-1 through F-5).

Table F-1. Thermocouple locations on bars in Tests 1, 2, and 3.

\begin{tabular}{|c|c|c|c|}
\hline Simple Bar & \multicolumn{3}{|c|}{ Test Chamber Coordinates $(\mathbf{c m})$} \\
\hline TC label & $\underline{\mathbf{X}}$ & $\underline{\mathbf{Y}}$ & $\underline{\mathbf{Z}}$ \\
\hline Location 1 & & & \\
\hline B-1 & 350 & 108 & 295 \\
\hline B-2 & 350 & 17 & 295 \\
\hline B-3 & 350 & -43 & 295 \\
\hline B-4 & 350 & -134 & 295 \\
\hline Location & & & \\
\hline B-1 & 500 & 102 & 295 \\
\hline B-2 & 500 & 12 & 295 \\
\hline B-3 & 500 & -49 & 295 \\
\hline B-4 & 500 & -139 & 295 \\
\hline
\end{tabular}

Table F-2. Thermocouple locations on bars in Tests 5 and 6.

\begin{tabular}{|c|c|c|c|}
\hline Simple Bar & \multicolumn{3}{|c|}{ Test Chamber Coordinates (cm) } \\
\hline TC Label & $\underline{\mathbf{X}}$ & $\underline{\mathbf{Y}}$ & $\underline{\mathbf{Z}}$ \\
\hline Location 1 & & & \\
\hline B-1 & 350 & 150 & 295 \\
\hline B-2 & 350 & 58 & 295 \\
\hline B-3 & 350 & -3 & 295 \\
\hline B-4 & 350 & -94 & 295 \\
\hline
\end{tabular}


Table F-3. Thermocouple locations on columns.

\begin{tabular}{|c|c|c|c|}
\hline $\begin{array}{c}\text { Column } \\
\text { Face Orientation } \\
1 \text { North } 2 \text { East } \\
3 \text { South } 4 \text { West }\end{array}$ & \multicolumn{3}{|c|}{ Test Chamber Coordinates $(\mathrm{cm})$} \\
\hline TC Label & $\underline{X}$ & $\underline{\mathbf{Y}}$ & $\underline{\mathbf{Z}}$ \\
\hline CU-1 & 281 & 69 & 369 \\
\hline $\mathrm{CU}-2$ & 299 & 55 & 369 \\
\hline CU-3 & 281 & 41 & 369 \\
\hline $\mathrm{CU}-4$ & 263 & 55 & 369 \\
\hline CM-1 & 281 & 69 & 213 \\
\hline $\mathrm{CM}-2$ & 299 & 55 & 213 \\
\hline CM-3 & 281 & 41 & 213 \\
\hline CM-4 & 263 & 55 & 213 \\
\hline CL-1 & 281 & 69 & 77 \\
\hline CL-2 & 299 & 55 & 77 \\
\hline CL-3 & 281 & 41 & 77 \\
\hline CL-4 & 263 & 55 & 77 \\
\hline
\end{tabular}

Key: $\mathrm{CU}$, column upper; $\mathrm{CM}$, column middle; $\mathrm{CL}$, column lower.

Table F-4. Thermocouple locations on truss A (location 1).

\begin{tabular}{|c|c|c|c|}
\hline Truss A & \multicolumn{3}{|c|}{ Test Chamber Coordinates (cm) } \\
\hline TC Label & $\underline{\mathbf{X}}$ & $\underline{\mathbf{Y}}$ & $\underline{\mathbf{Z}}$ \\
\hline TU-1 & 164 & -8 & 370 \\
\hline TU-2 & 313 & -8 & 370 \\
\hline TU-3 & 388 & -8 & 370 \\
\hline TU-4 & 537 & -8 & 370 \\
\hline TM-1 & 199 & -8 & 329 \\
\hline TM-2 & 335 & -8 & 329 \\
\hline TM-3 & 365 & -8 & 329 \\
\hline TM-4 & 502 & -8 & 329 \\
\hline TL-1 & 250 & -8 & 289 \\
\hline TL-2 & 300 & -8 & 289 \\
\hline TL-3 & 401 & -8 & 289 \\
\hline TL-4 & 451 & -8 & 289 \\
\hline
\end{tabular}

Key: TU, truss upper chord; TM, truss middle (web); TL, truss lower chord. 
Table F-5. Thermocouple locations on truss B (location 2).

\begin{tabular}{|c|c|c|c|}
\hline \multirow{2}{*}{ Truss B } & \multicolumn{3}{|c|}{ Test Chamber Coordinates $(\mathbf{c m})$} \\
\hline TC Label & $\underline{\mathbf{X}}$ & $\underline{\mathbf{Y}}$ & $\underline{\mathbf{Z}}$ \\
\hline TU-1 & 164 & -56 & 370 \\
\hline TU-2 & 313 & -56 & 370 \\
\hline TU-3 & 388 & -56 & 370 \\
\hline TU-4 & 537 & -56 & 370 \\
\hline TM-1 & 199 & -56 & 329 \\
\hline TM-2 & 335 & -56 & 329 \\
\hline TM-3 & 365 & -56 & 329 \\
\hline TM-4 & 502 & -56 & 329 \\
\hline TL-1 & 250 & -56 & 289 \\
\hline TL-2 & 300 & -56 & 289 \\
\hline TL-3 & 401 & -56 & 289 \\
\hline TL-4 & 451 & -56 & 289 \\
\hline
\end{tabular}

Key: TU, truss upper chord; TM, truss middle (web); TL, truss lower chord. 
This page intentionally left blank. 


\section{Appendix G \\ Temperature Histories of BARE AND CoATEd STEEL COMPONENTS}

Chapter 9 presents representative measurements of the temperature on the surface of the steel components and the sprayed fire-resistive material (SFRM) applied to those components. This appendix presents the measured temperature histories recorded for steel components and not shown in Chapter 9.

\section{G.1 BARE STEEL COMPONENTS}

Tests 1, 2, and 3 exposed the same set of two bars, one column, and two trusses to dircct exposure of heat flux and temperatures from a fuel pan fire. In all three tests, the thermal response of these componcnts to flame proximity or immersion was similar. The steel began to heat immediatcly upon initiation of the fire and to cool immediately after the fire was extinguished. The recorded response showed no lag time between the steel and gas for transferring radiant heat from the higher to lower temperature mediums. Test 1 steel surface temperatures are shown in Sec. G.1.1, Figs. G-1 through G-5; Test 2 temperatures are shown in Sec. G.1.2, Figs. G-6 through G-10; Test 3 temperatures are shown in Sec. G.1.3, Figs. G-11 through $\mathrm{G}-15$.

Bar A and both truss A and truss B were located over the fire pan, but the fire tended to lean with the airflow through the chamber and primarily immerse bar A and truss $\mathrm{B}$ in flames. The recorded thermocouple temperatures for these components (1) are $50{ }^{\circ} \mathrm{C}$ to $75^{\circ} \mathrm{C}$ higher than those recorded for bar B (Figs. G-2, G-7, and G-12) and truss A (Figs. G-4, G-9, and G-14) and (2) have a high frequency component imposed upon the average temperature. These behaviors can be secn for thermocouples TB3 and TB4 on the bars and thermocouples TL3, TU3, TL4, and TU2 on the trusses. See Figs. G-1, G-6, and G-11 for bar A and Figs. G-5, G-10, G-15 for truss B. Note that thermocouples TM2 and TM4 on truss B showed some irregularities in the cool down phase in Test 1, after the fire was extinguished, which was not evident in Test 2 but was more pronounced in Test 3. The cause of this irregularity is not known.

The columns were located next to the fire pan, but the airflow through the test chamber resulted in the fire leaning toward the exhaust outlet and away from the columns, so that they were heated primarily by radiation from the fire and the hot gas layer near the ceiling. The sides of the column facing the fire were heated more quickly, with TCU3 (at the ceiling level facing south), TCU2 (at the ceiling level facing east), and TCL2 (at the floor level facing east) recording maximum temperatures during the tests (Figs. G-3, G-8, and G-13). 
The thermocouple naming convention used in the figures is as follows:

For bars (i.e., TB4SB or TB3S):

TB Bars

$1,2,3,4 \quad$ Location of thermocouple along length

$\mathrm{S}$ Steel surface

A, B Bar number (for bare steel tests)

For columns (i.e., TCU3S or TCU2S):

TC

Columns

$\mathrm{U}, \mathrm{M}, \mathrm{L}$

Upper, middle, or lower location with respect to elevation

$1,2,3,4$

Location of thermocouple along length

$\mathrm{S}$

Steel surface

For trusses (i.e., TL2SA or TM3SB):

T Truss

$\mathrm{U}, \mathrm{M}, \mathrm{L} \quad$ Upper, middle, or lower location with respect to elevation

$1,2,3,4 \quad$ Location of thermocouple along length

$\mathrm{S} \quad$ Steel surface

A, B Bar or truss number

\section{G.1.1 Bare Steel Components Exposed to a $2 \mathrm{MW}$ Fire for 15 Min in Test 1}

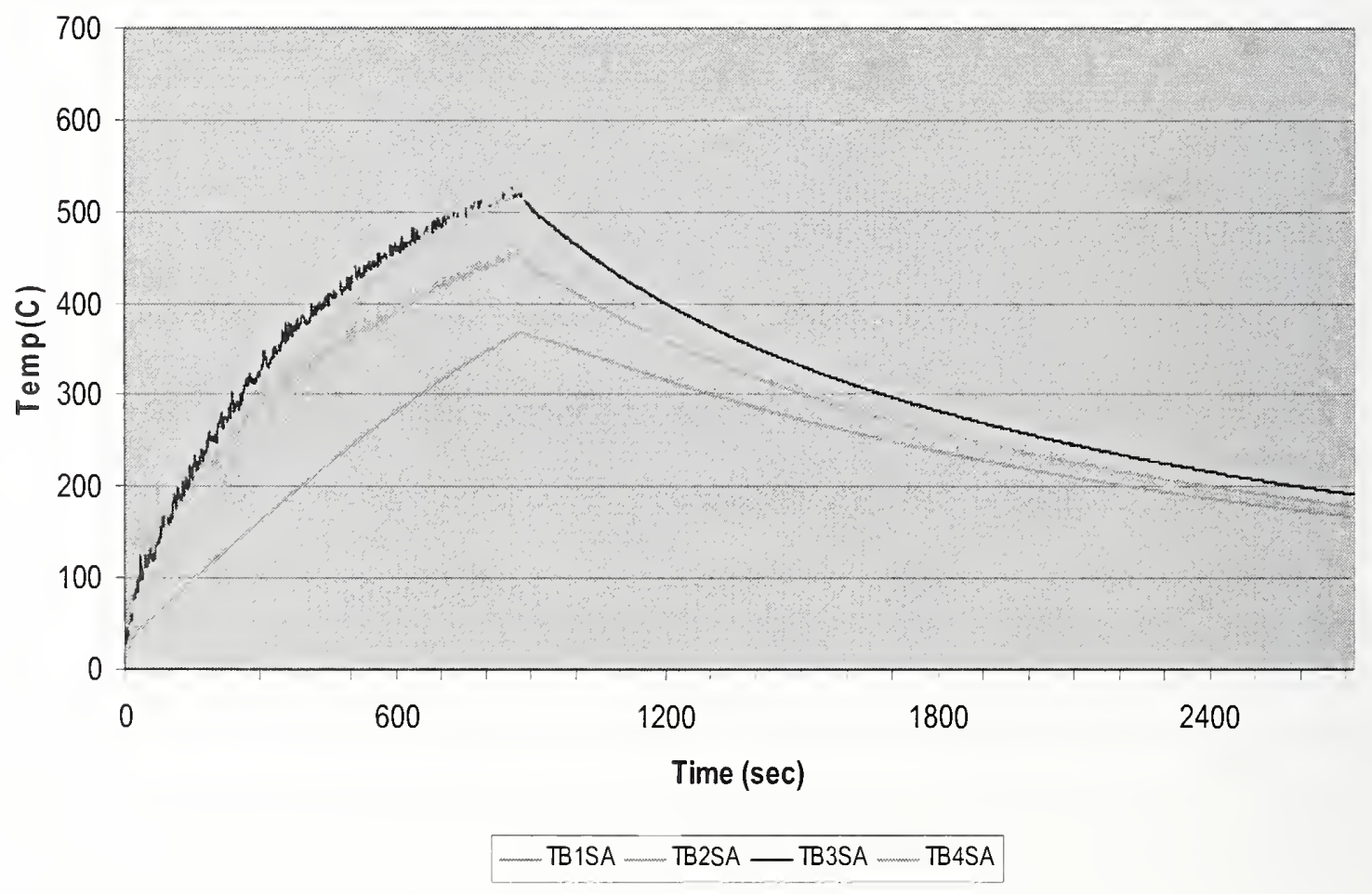

Figure G-1. Bare steel bar A in Test 1. 


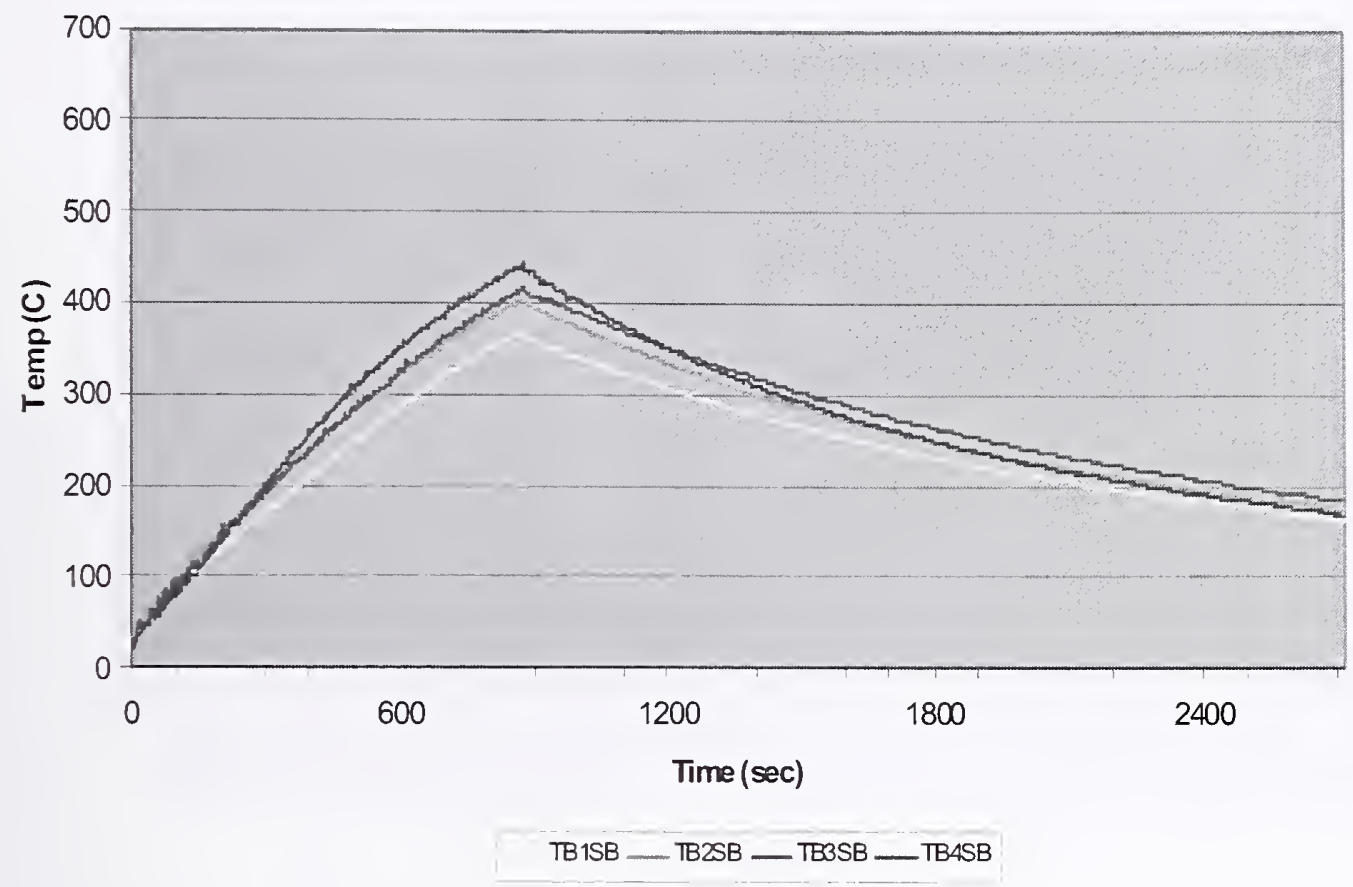

Figure G-2. Bare steel bar B in Test 1.

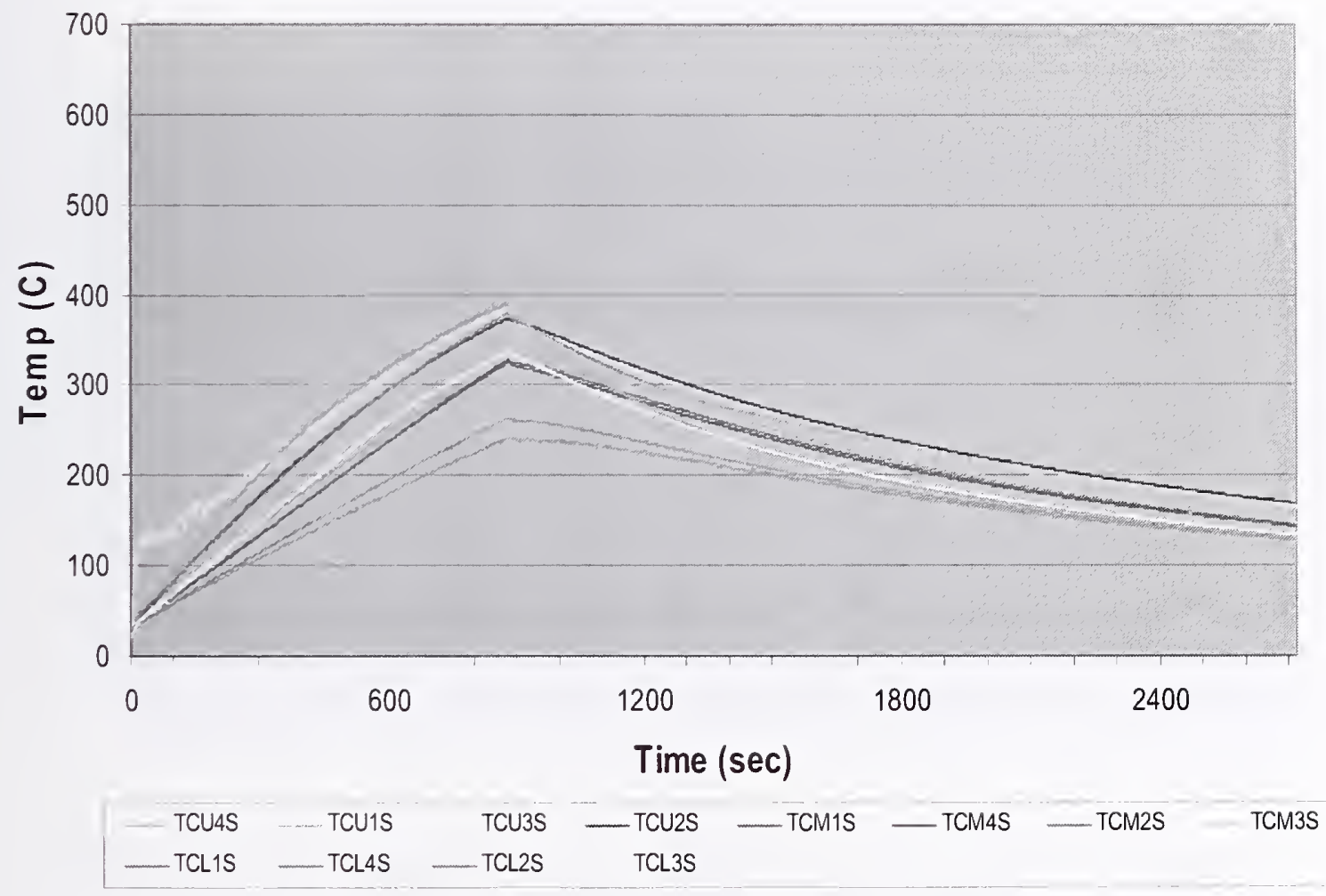

Figure G-3. Bare steel column in Test 1. 


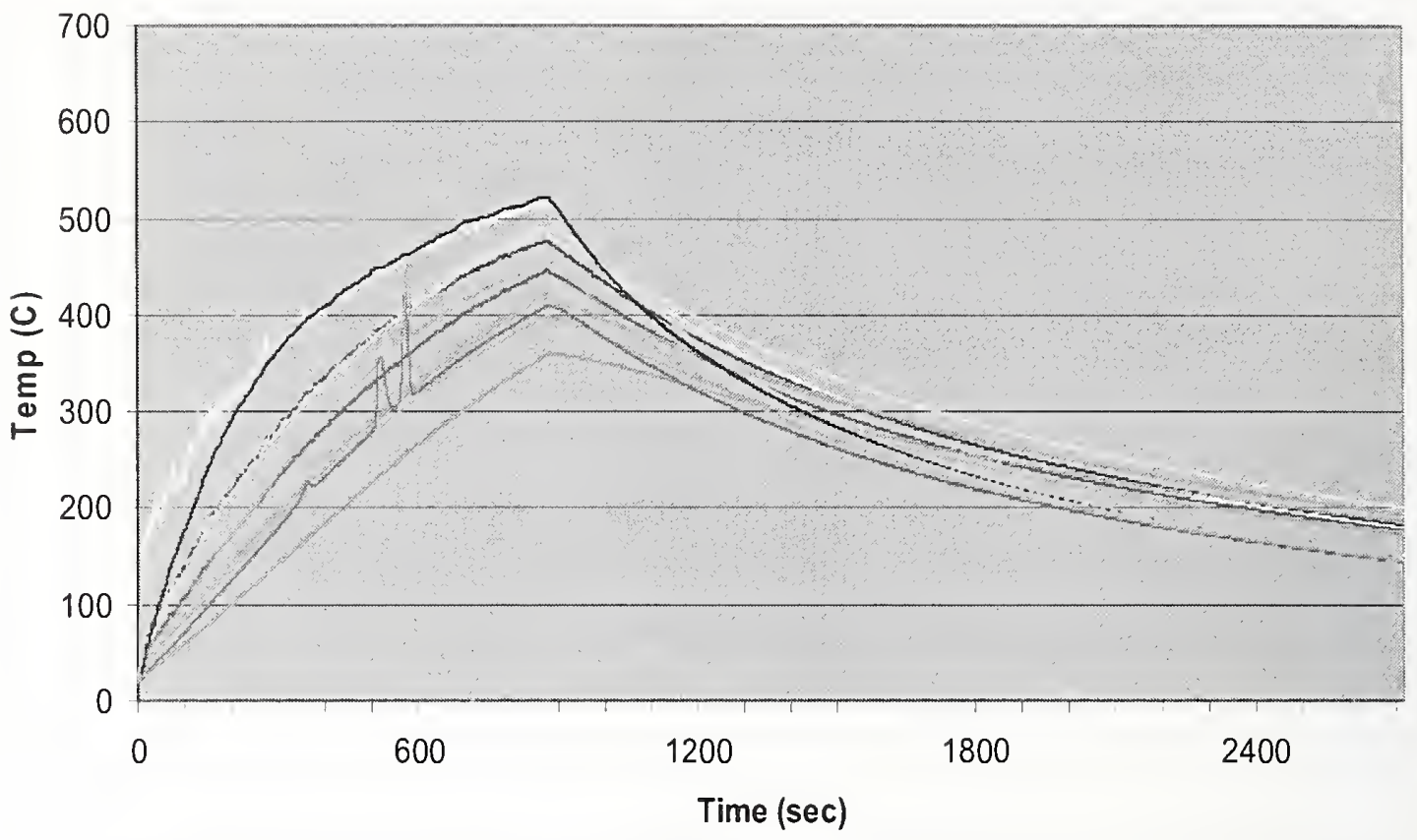

\begin{tabular}{rrrrrrrr} 
TU4SA & TU3SA & $-T U 2 S A$ & TU1SA & TM4SA & TM3SA & TM2SA & TM1SA \\
\hline TL1SA & $-\mathrm{TL} 4 S A$ & $\mathrm{TL3SA}$ & $-\mathrm{TL2SA}$ & & & &
\end{tabular}

Figure G-4. Bare steel truss A in Test 1.

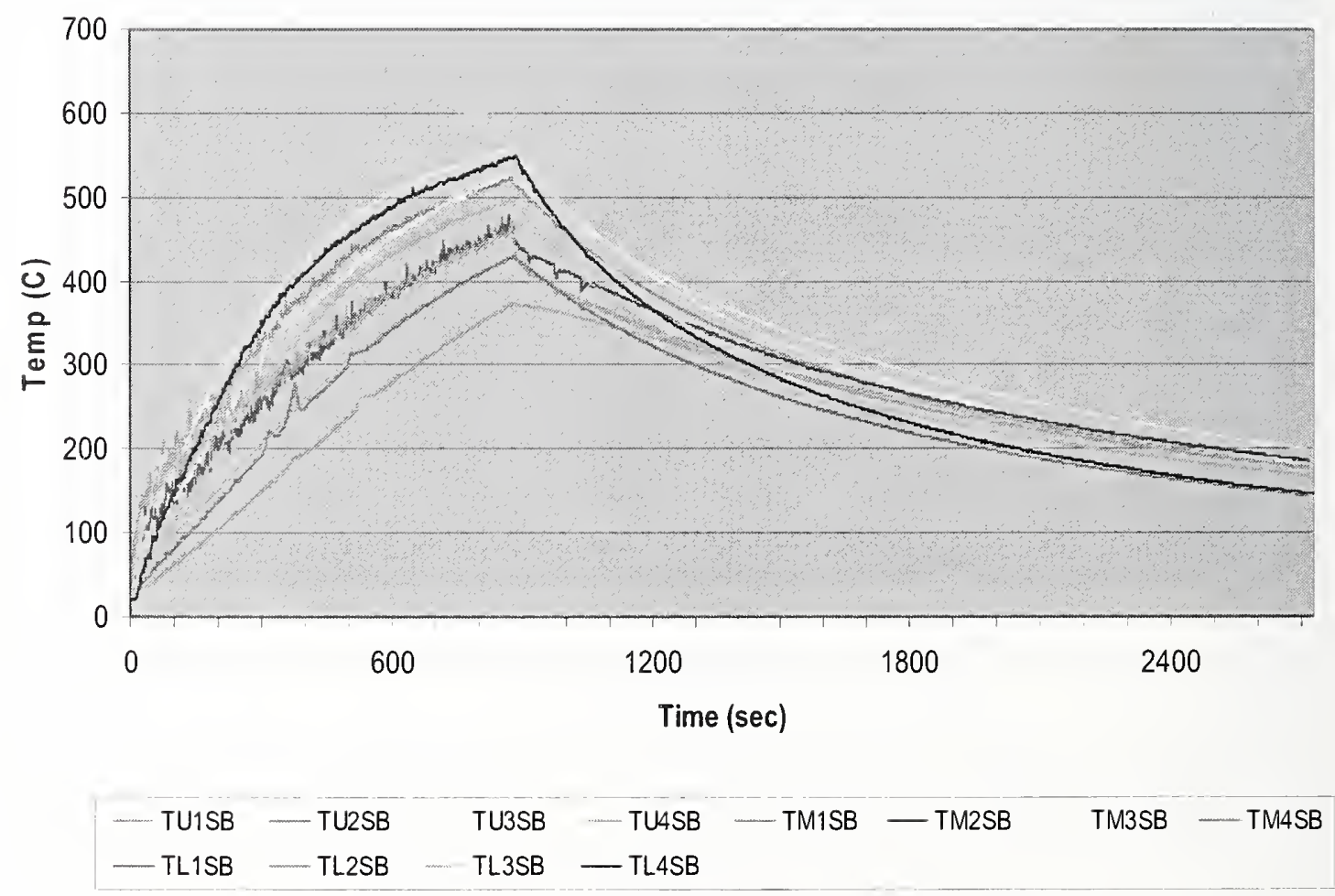

Figure G-5. Bare steel truss B in Test 1. 


\section{G.1.2 Bare Steel Components Exposed to a 3 MW Fire for 7 Min in Test 2}

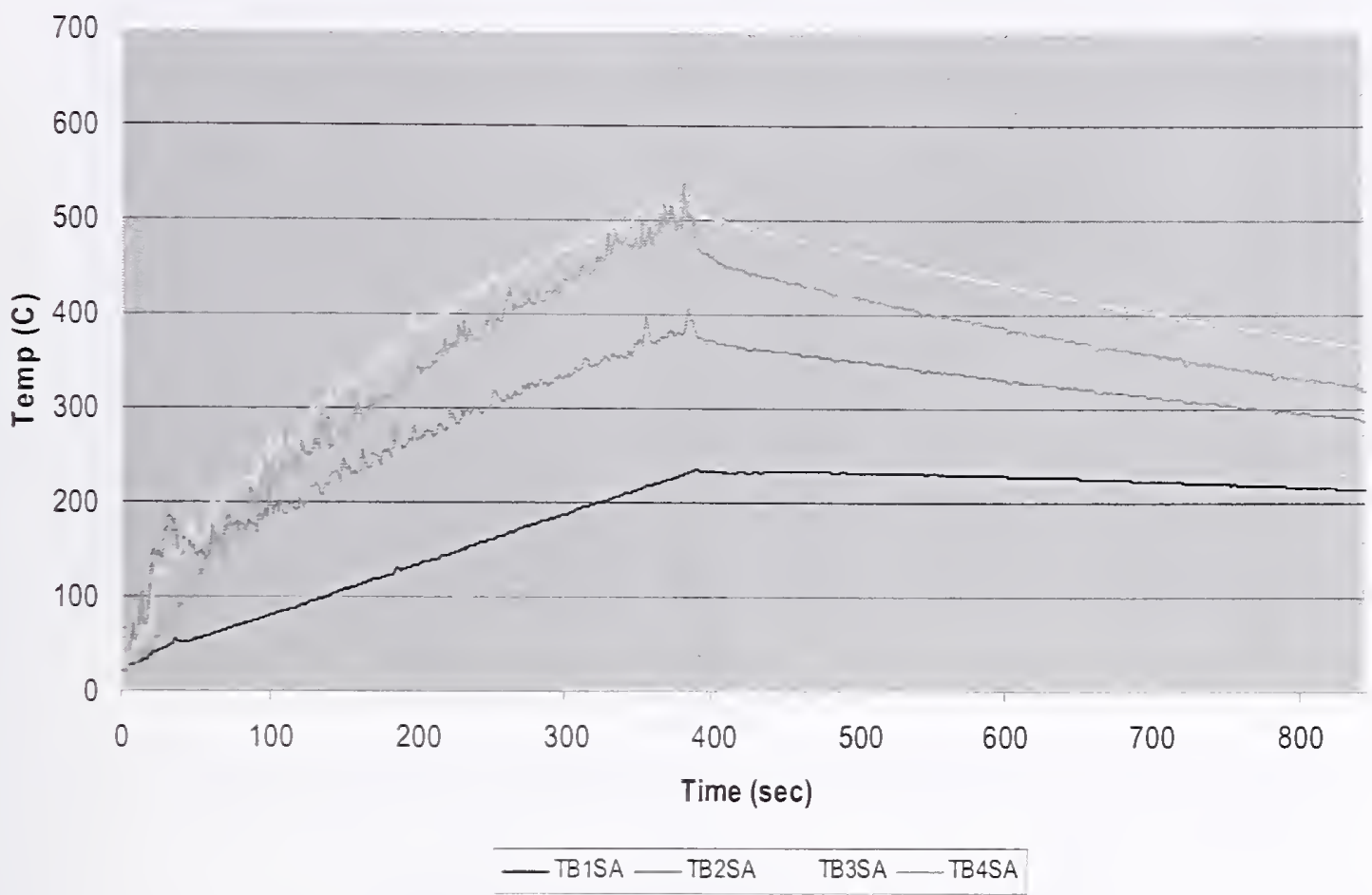

Figure G-6. Bare steel bar A in Test 2.

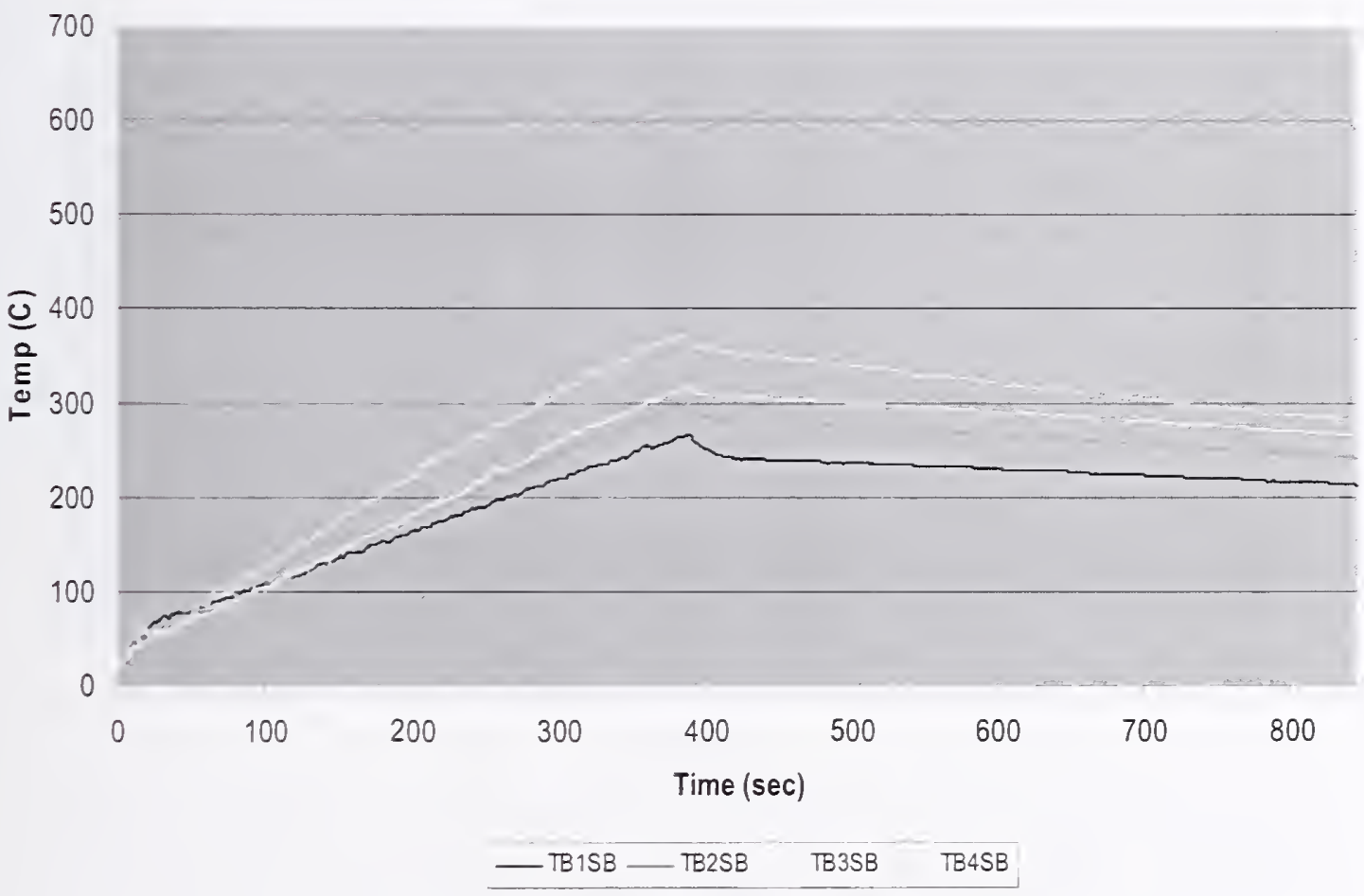

Figure G-7. Bare steel bar B in Test 2. 


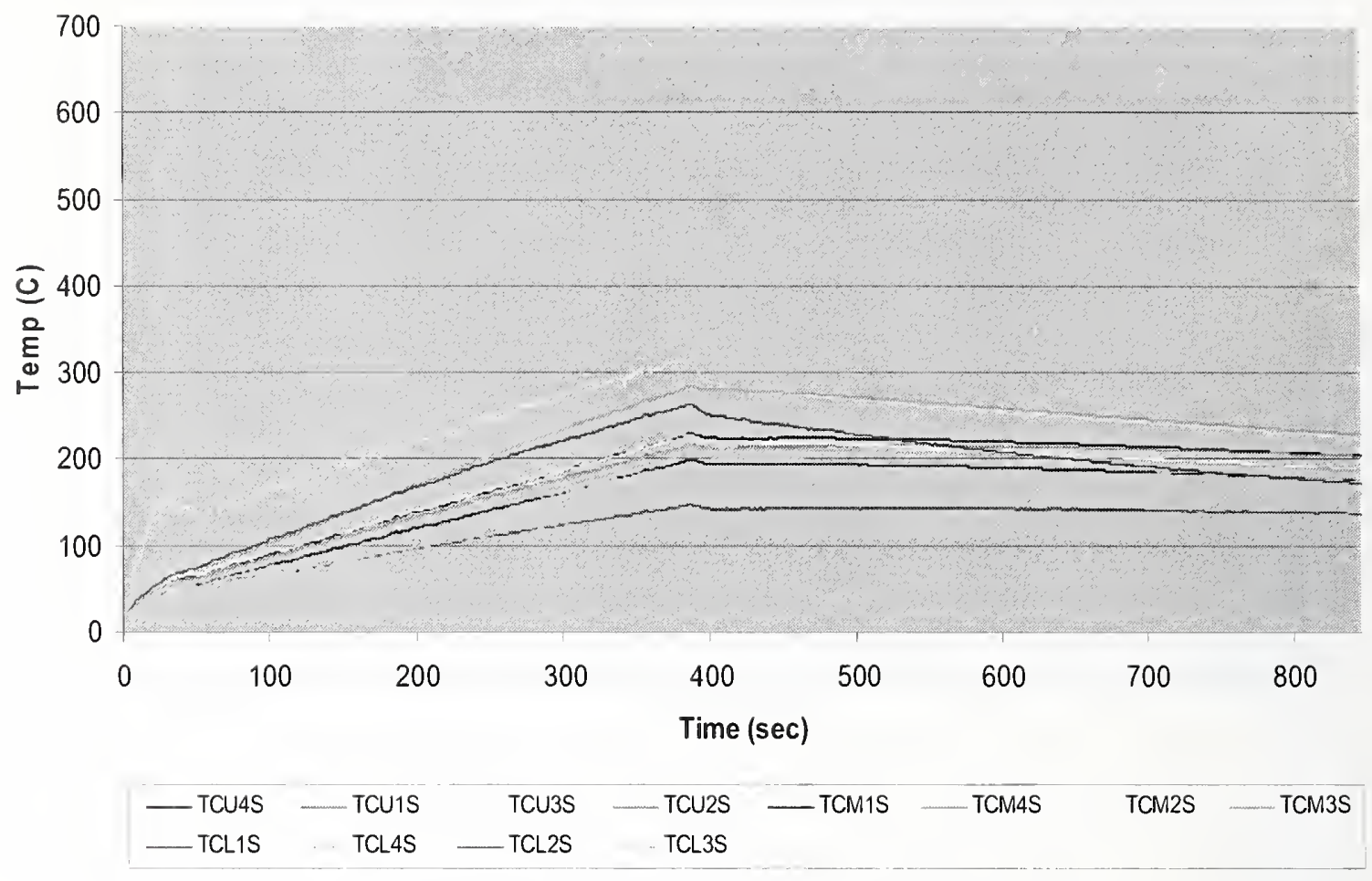

Figure G-8. Bare steel column in Test 2.

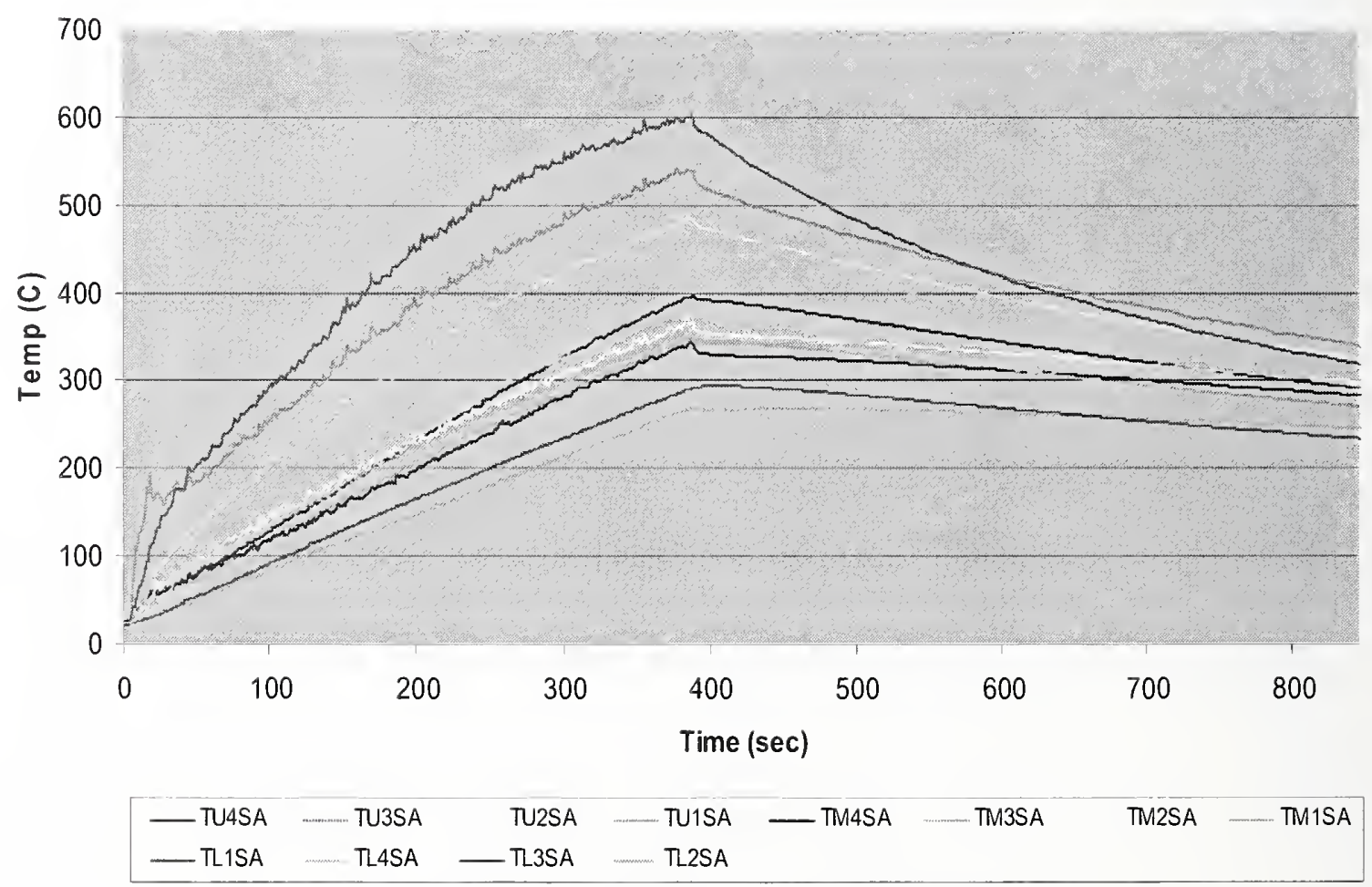

Figure G-9. Bare steel truss A in Test 2. 


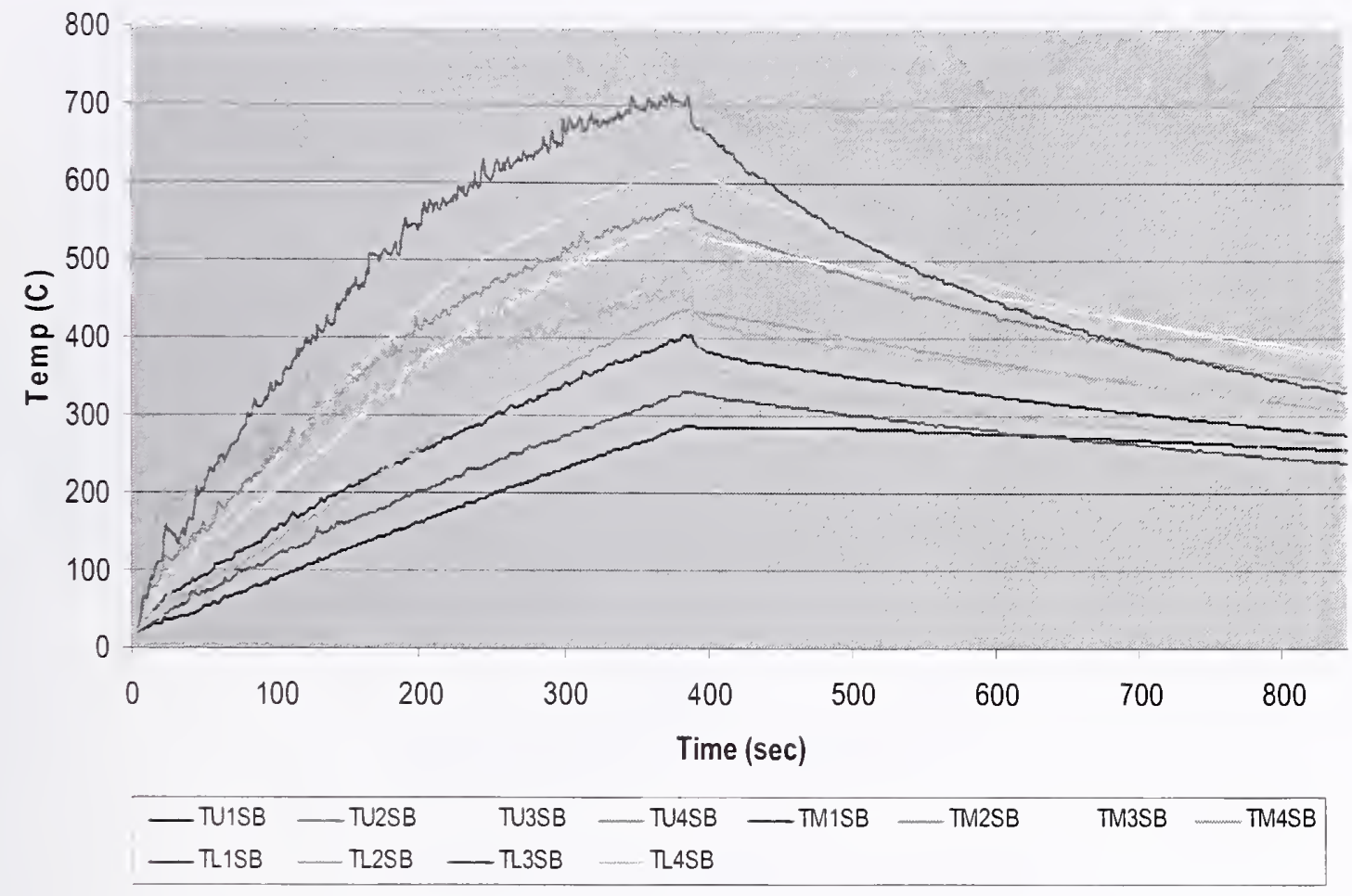

Figure G-10. Bare steel truss B in Test 2.

\section{G.1.3 Bare Steel Components Exposed to a 2 MW Fire for 15 Min in Test 3}

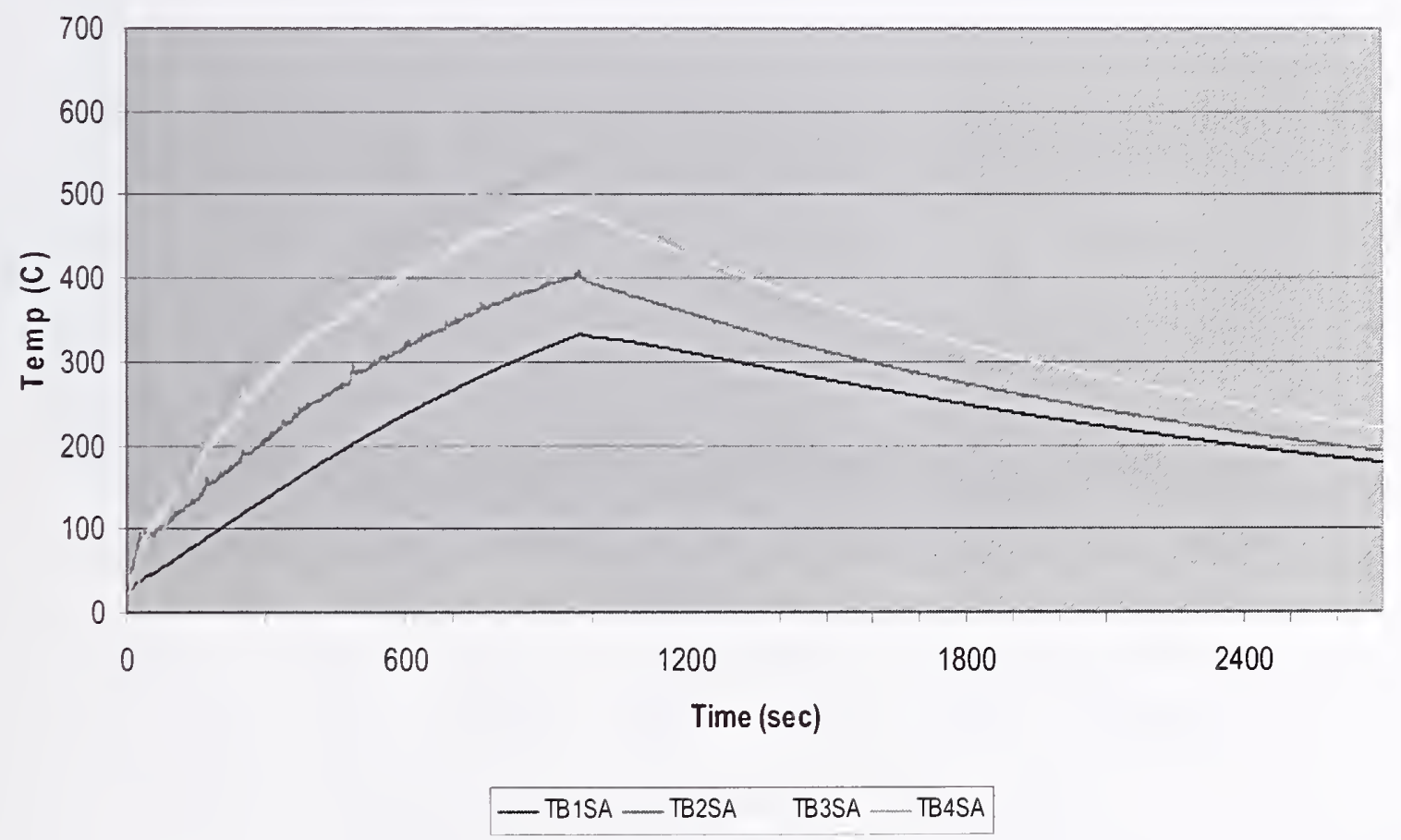

Figure G-11. Bare steel bar A in Test 3. 


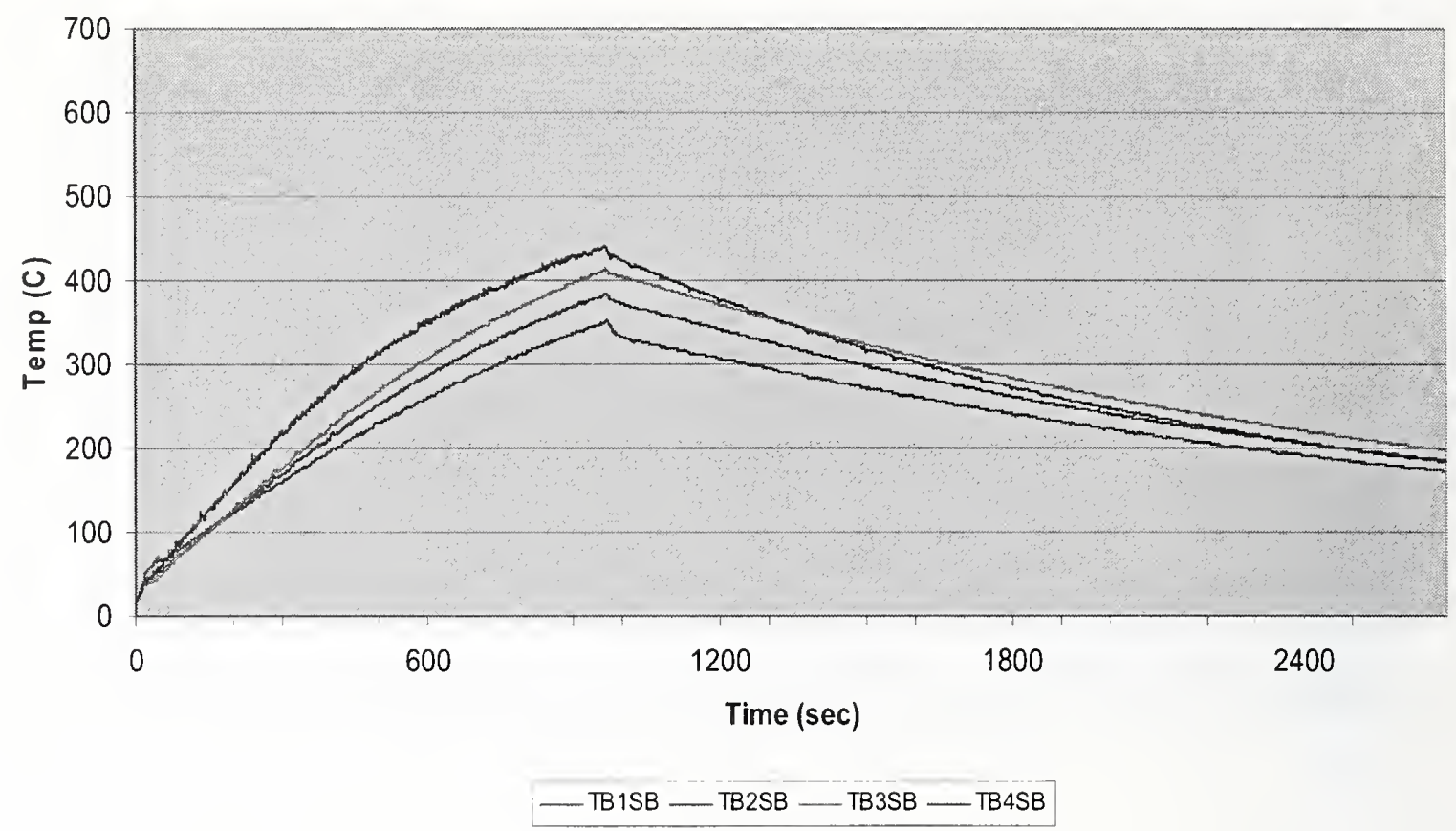

Figure G-12. Bare steel bar B in Test 3.

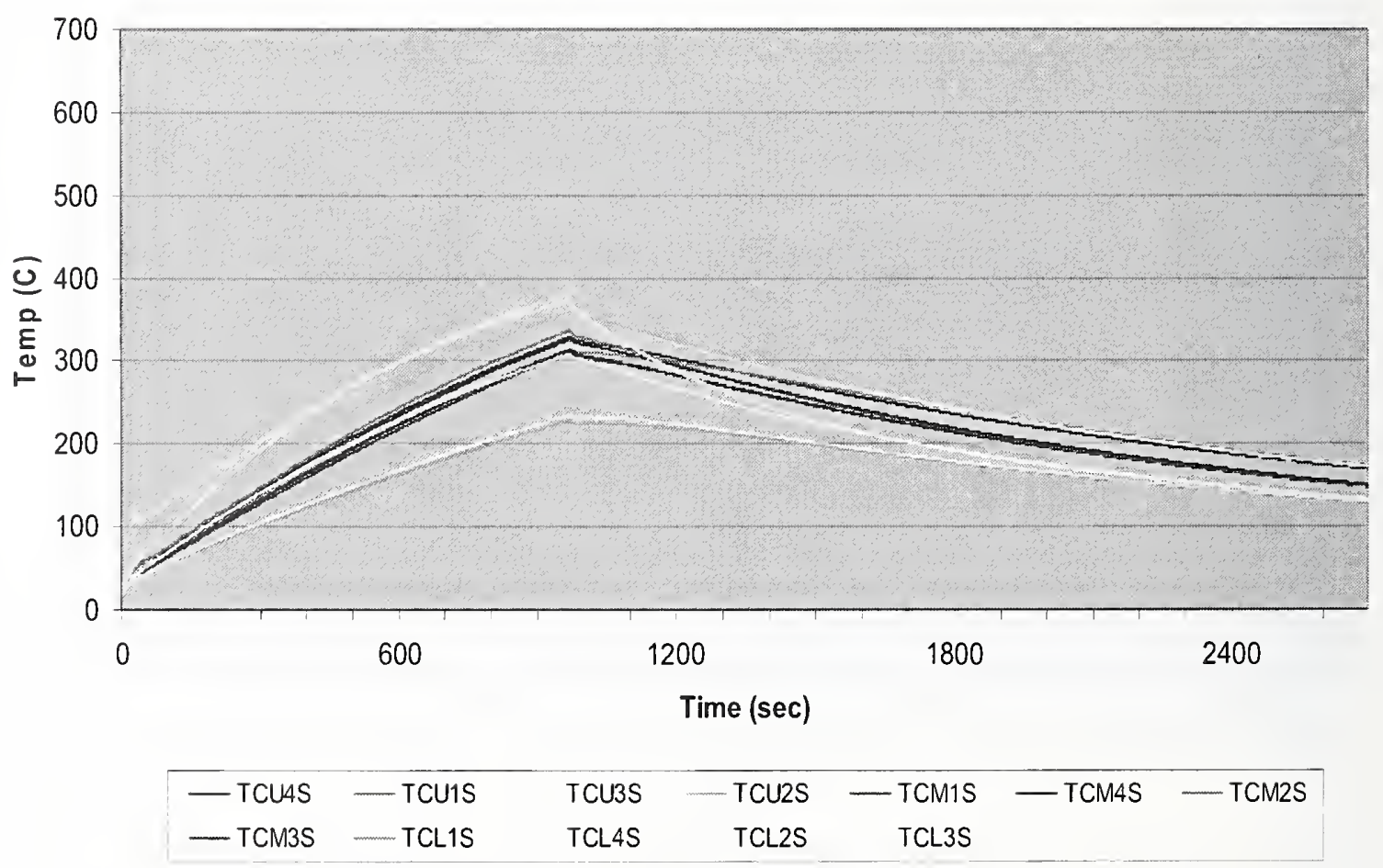

Figure G-13. Bare steel column in Test 3. 


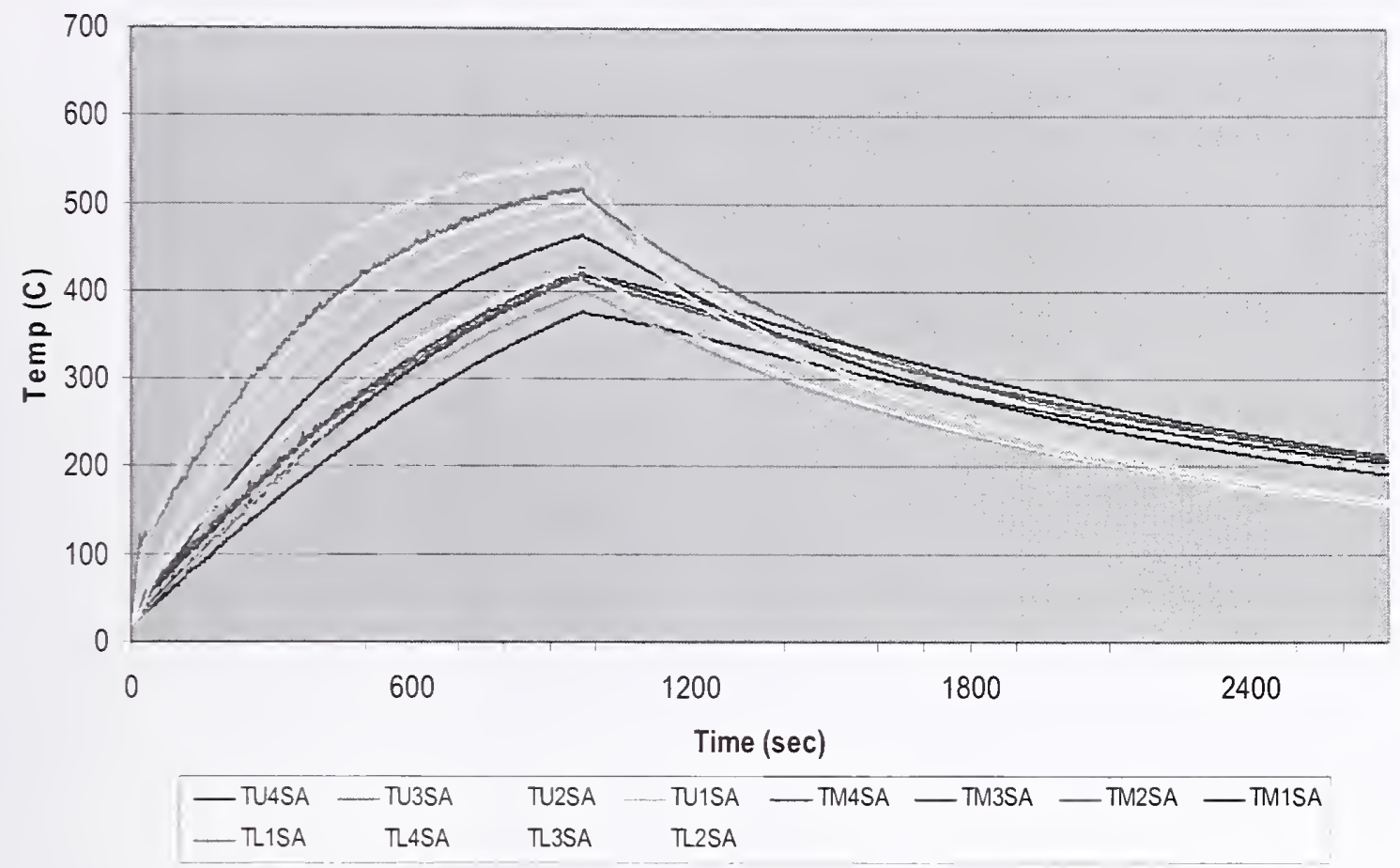

Figure G-14. Bare steel truss A in Test 3.

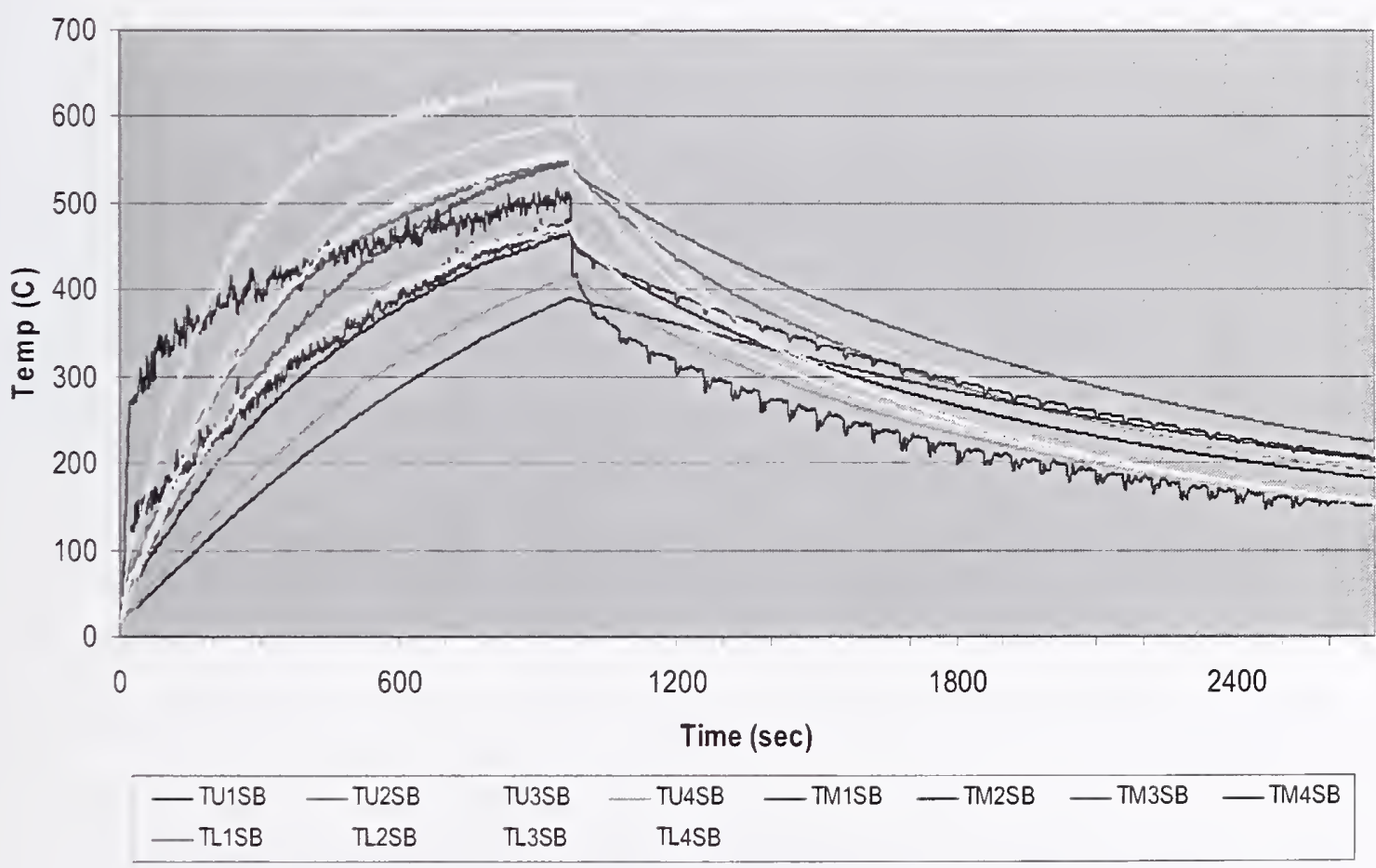

Figure G-15. Bare steel truss B in Test 3. 


\section{G.2 INSULATED STEEL COMPONENTS}

Tests 5 and 6 exposed separate sets of one bar, one column, and two trusses, insulated with sprayed fireresistive materials (SFRM), to direct exposure of heat flux and temperatures from a fuel pan fire. Test 4 was truncated after approximately $15 \mathrm{~min}$, due to a malfunction of the thermocouples that started a few minutes after the tests began. As no useful steel temperature data was obtained, Test 4 data are not included in this report. Test 5 SFRM and steel surface temperatures are shown in Sec. G.2.1, Figs. G-16 through G-19; Test 6 temperatures are shown in Sec. G.2.2, Figs. G-20 through G-23.

In both tests, the thermal response of these components to flame proximity or immersion was similar. The SFRM surface began to heat immediately upon initiation of the fire, reaching close to their peak temperatures in $5 \mathrm{~min}$ to $10 \mathrm{~min}$, and to cool immediately after the fire was extinguished. The protected steel responded more slowly, taking approximately $50 \mathrm{~min}$ with $1.91 \mathrm{~cm}(0.75 \mathrm{in}$.) of SFRM to reach $600^{\circ} \mathrm{C}$ temperatures as compared to $7 \mathrm{~min}$ when bare steel was subjected to a similar $3 \mathrm{MW}$ fire. The steel temperature rise was essentially uniform for all thermocouples until the steel temperatures reached $100{ }^{\circ} \mathrm{C}$, when the rate of temperature rise increased for all thermocouples, but at different rates. Steel temperatures continued to rise approximately $25{ }^{\circ} \mathrm{C}$ to $50{ }^{\circ} \mathrm{C}$ after the fire was extinguished over a 5 min to $10 \mathrm{~min}$ period, before cooling began to take place by transmitting heat through the insulation back into the relatively cooler gases.

The bar in each test was located over the fire and recorded similar temperatures for the SFRM and steel surface. Thermocouples TB1S and TB4S in Test 5 (Fig. G-16) were damaged during the SFRM application process. Thermocouples TB4 in Test 6 (Fig. G-20) showed some signal noise in the cool down phase in Test 1 after the fire was extinguished. The cause of this noise is not known.

The columns were located next to the fire pan, but the fire leaned toward the exhaust outlet and away from the columns, so that they were heated primarily by radiation from the hot gas layer near the ceiling. In Test 5 (Fig. G-17), the steel temperature rise was uniform for all thermocouples until the steel temperatures reached $100^{\circ} \mathrm{C}$, when the rate of temperature rise increased for all the thermocouples but at different rates. Note that thermocouple TCU1S in Test 5 was damaged during the SFRM application process. In Test 6 (Fig. G-21), however, the steel temperatures increased at different rates during the entire test. Reasons for the difference in the steel surface response between these two column tests are not apparent. (A short in the thermocouple signal appeared around 1,500 s to 1,600 s, but the recorded temperatures appear to be reasonable after this event and have been assumed to be correct records of the actual temperatures.) Test 5 steel temperatures at $50 \mathrm{~min}$ were approximately half of the steel temperatures in Test 6 , reflecting the increased nominal thickness of SFRM from $1.91 \mathrm{~cm}$ to $3.81 \mathrm{~cm}$ ( $0.75 \mathrm{in}$. to $1.5 \mathrm{in}$.). The upper portion of the columns near the ceiling heated more quickly than the rest of the column, due to the continual presence of a hot gas layer near the ceiling.

As in the bare steel tests, both truss A and truss B were located over the fire pan, but the fire primarily immersed truss $\mathrm{B}$ in flames. The trusses with $1.91 \mathrm{~cm}\left(0.75 \mathrm{in}\right.$.) of SFRM reached $100{ }^{\circ} \mathrm{C}$ in approximately $10 \mathrm{~min}$ (Figs. G-18, G-22, and G-23), and truss B in Test 5 with $3.81 \mathrm{~cm}$ (1.5 in.) of SFRM in Test 5 reached $100^{\circ} \mathrm{C}$ steel temperatures in $25 \mathrm{~min}$ (Fig. G-19), reflecting the effects of increased SFRM thickness. Thermocouples TM3IB and TL3IB became erratic approximately 35 min into Test 5 (these thermocouples are on the SFRM surface and subject to flame immersion during the test). Some of the other SFRM surface thermocouples also recorded abrupt jumps in their temperatures around 
this time, but the steel temperatures appear to be unaffected. Thermocouple TM3SA for truss A in Test 5 was damaged during the SFRM application process.

The thermocouple naming convention used in the figures is as follows:

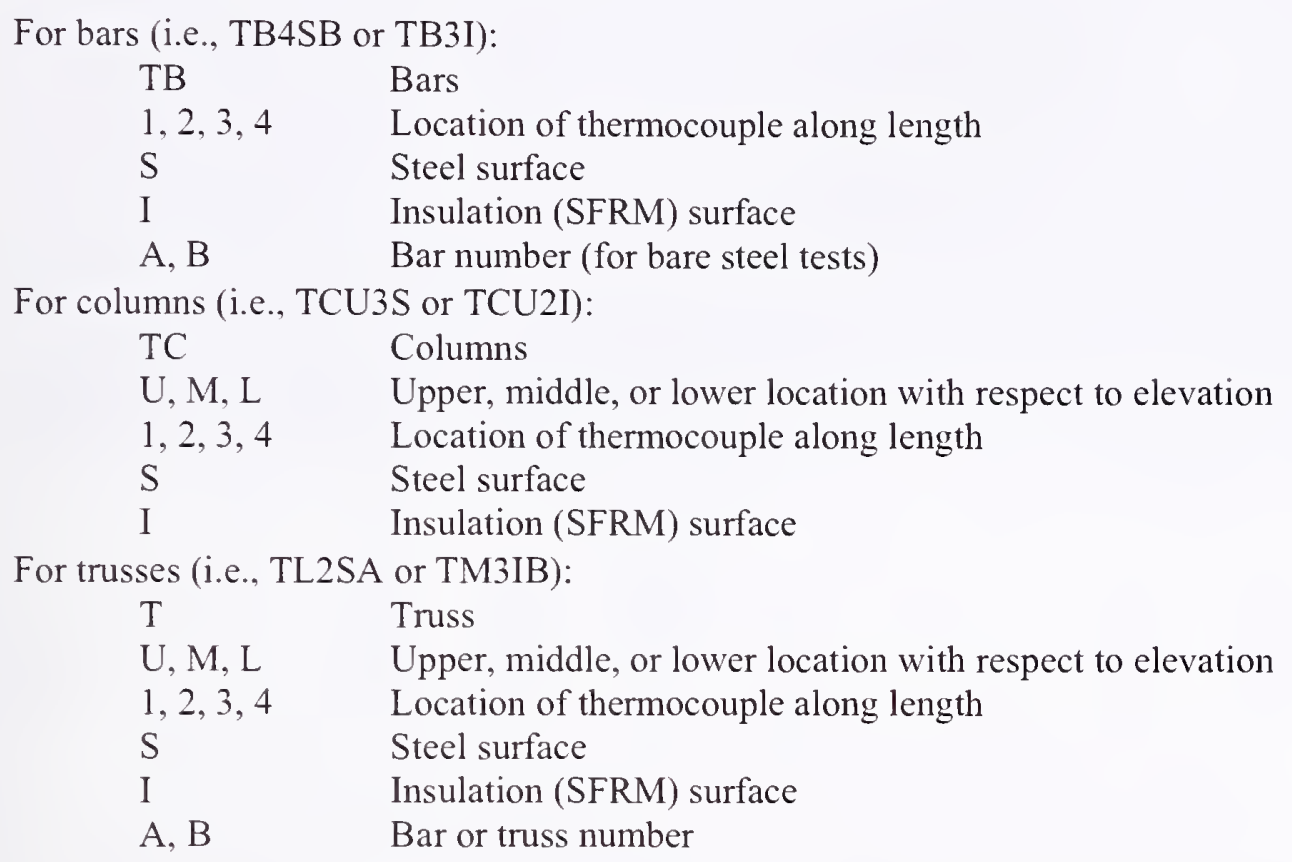

\section{G.2.1 Insulated Steel Components Exposed to a 3 MW Fire for 50 Min in Test 5}

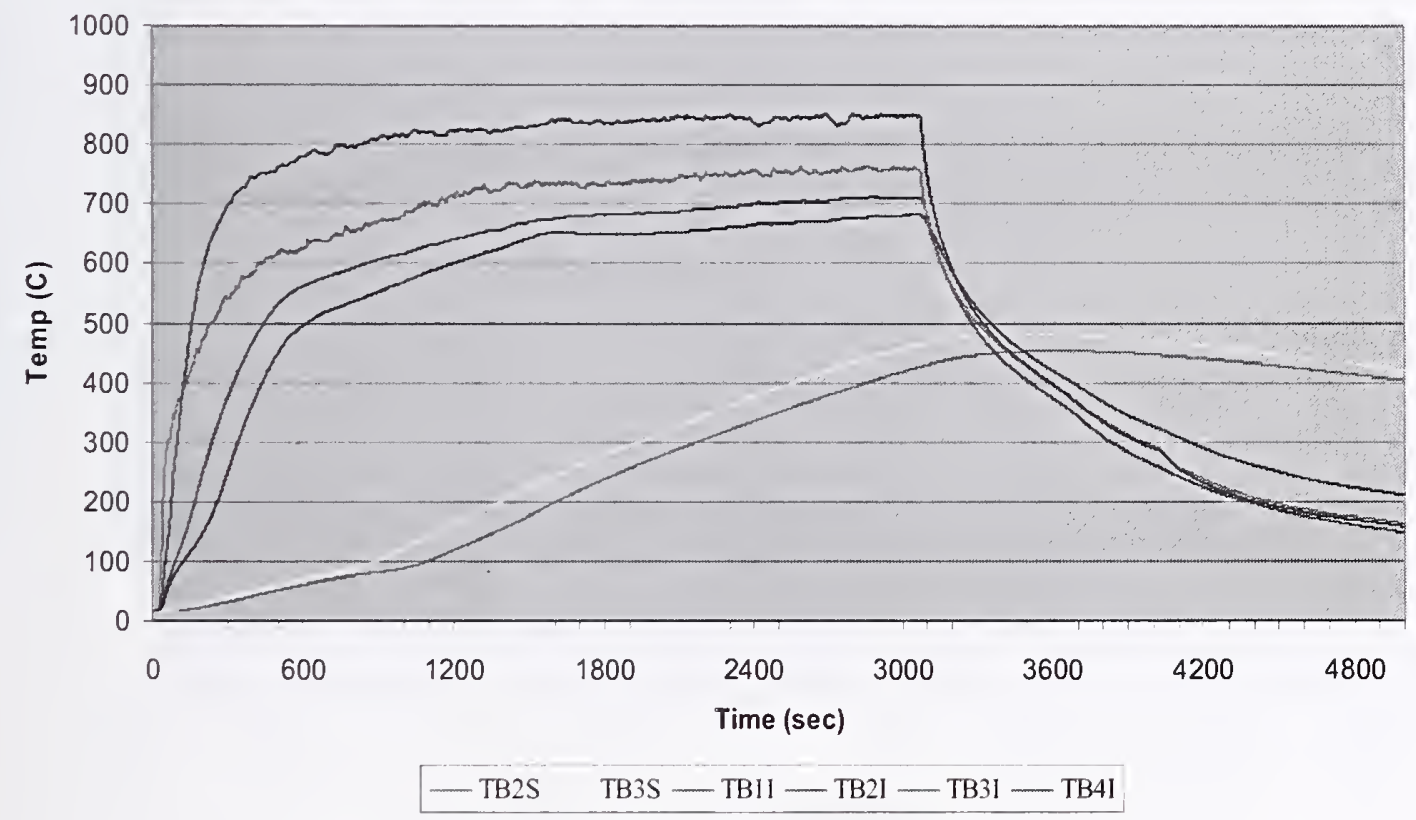

Figure G-16. Insulated (1.91 cm SFRM) steel bar in Test 5 . 


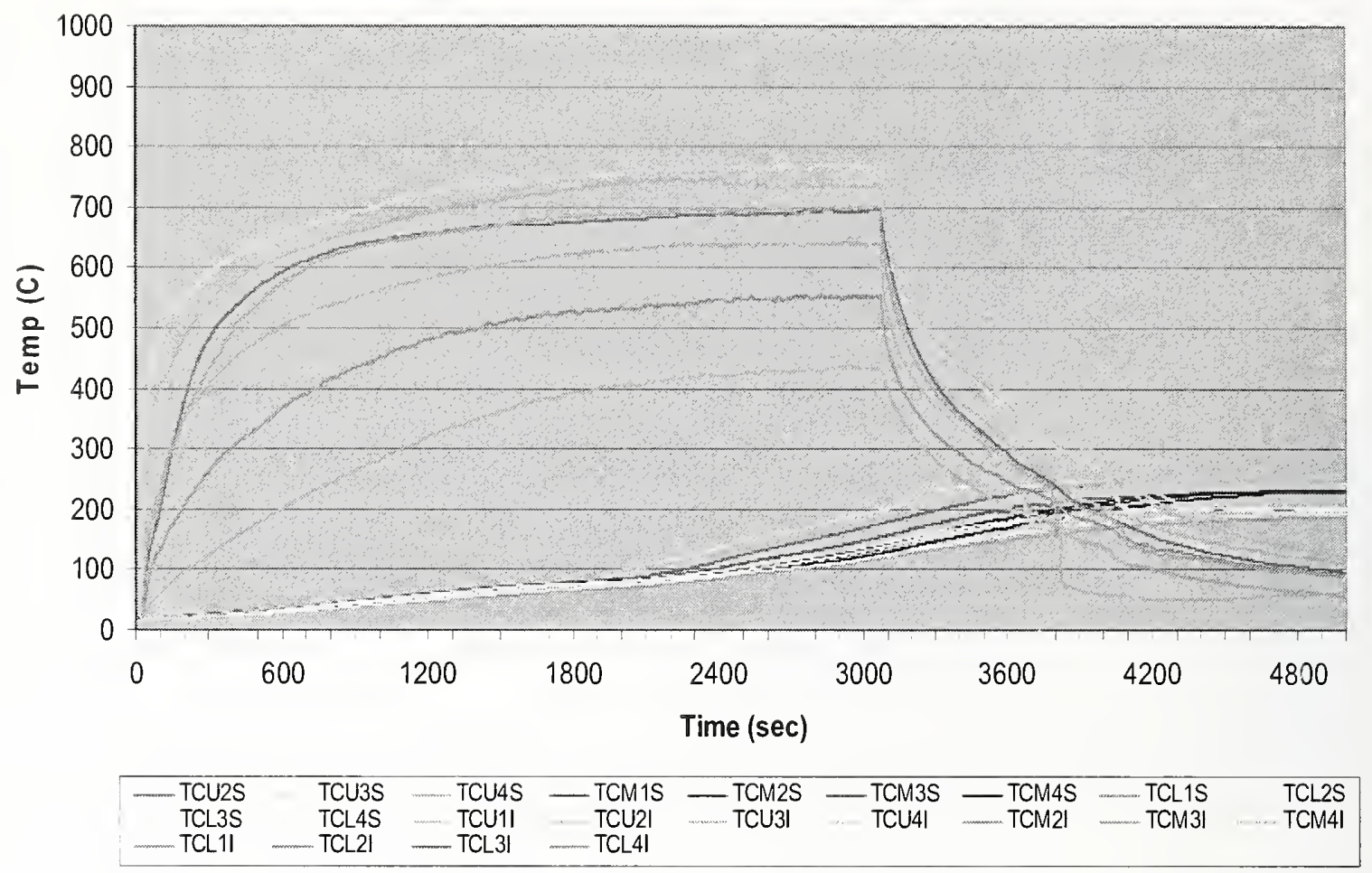

Figure G-17. Insulated (3.81 cm SFRM) steel column in Test 5.

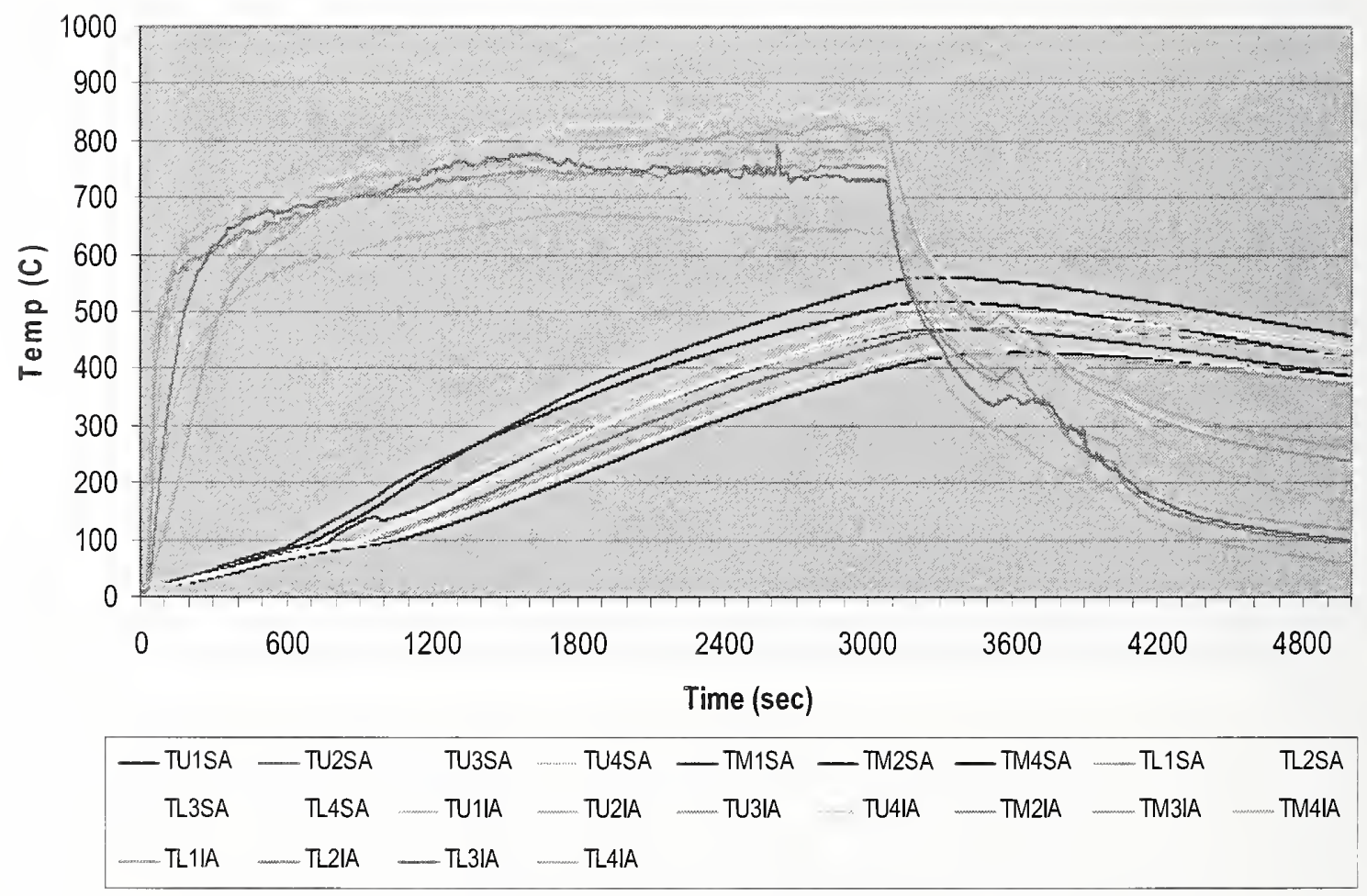

Figure G-18. Insulated (1.91 cm SFRM) steel truss A in Test 5. 


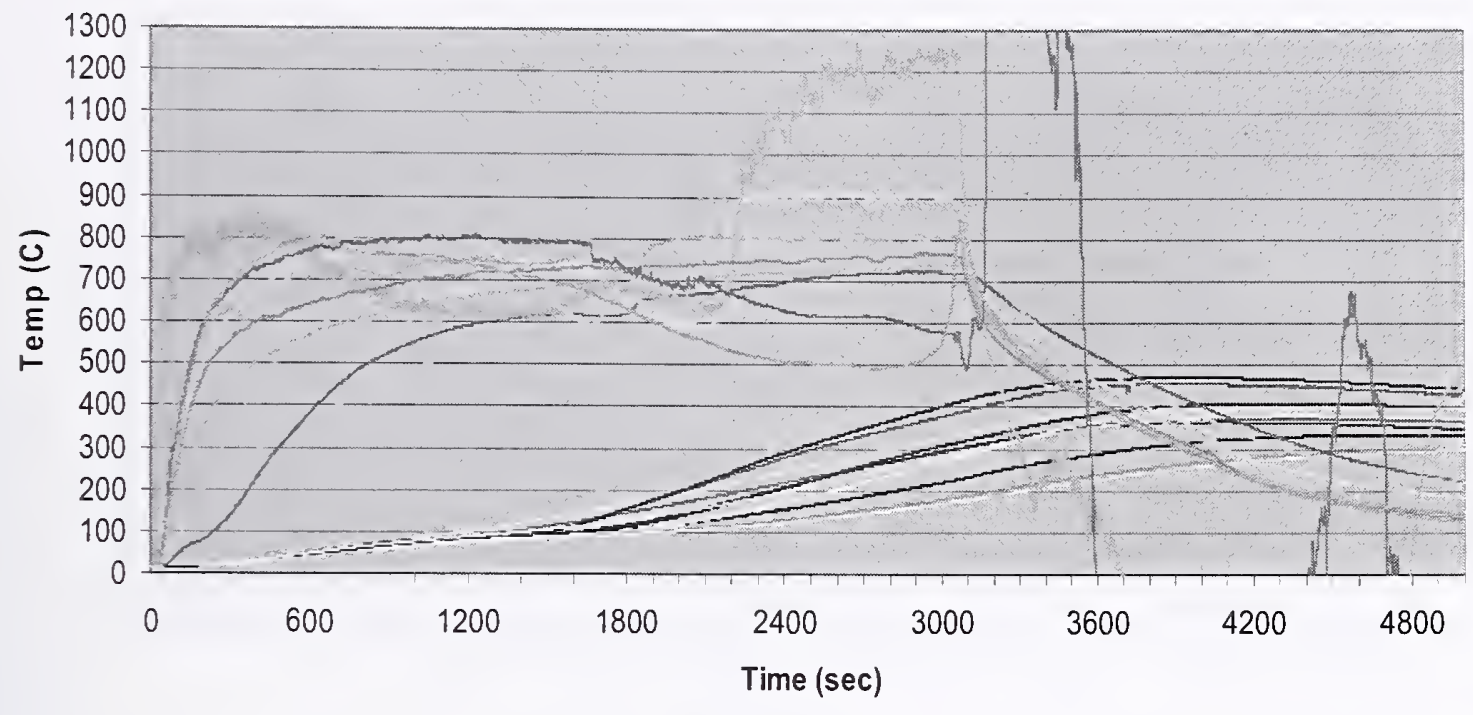

$\begin{array}{rrrrrrrr}-\mathrm{TU} 1 \mathrm{SB} & -\mathrm{TU} 2 \mathrm{SB} & \mathrm{TU} 3 \mathrm{SB} & \mathrm{TU} 4 \mathrm{SB} & -\mathrm{TM} 1 \mathrm{SB} & -\mathrm{TM} 2 \mathrm{SB} & -\mathrm{TM} 3 \mathrm{SB} & -\mathrm{TM} 4 \mathrm{SB} \\ -\mathrm{TL} 1 \mathrm{SB} & \mathrm{T} 2 \mathrm{SB} & \mathrm{T} 3 \mathrm{SB} & \mathrm{TL} 4 \mathrm{SB} & \mathrm{TU} 1 \mathrm{~B} & \mathrm{TU} 2 \mathrm{~B} & \mathrm{~T} 3 \mathrm{~B} & \mathrm{TU} 4 \mathrm{~B} \\ -\mathrm{TM} 1 \mathrm{~B} & -\mathrm{TM} 2 \mathrm{~B} & -\mathrm{TM} 3 \mathrm{~B} & -\mathrm{TM} 4 \mathrm{~B} & -\mathrm{TL} 1 \mathrm{~B} & -\mathrm{TL2B} & -\mathrm{T} 3 \mathrm{~B} & -\mathrm{TL} 4 \mathrm{~B}\end{array}$

Figure G-19. Insulated ( $3.81 \mathrm{~cm}$ SFRM) steel truss B in Test 5.

\section{G.2.2 Insulated Steel Components Exposed to a 3 MW Fire for 50 Min in Test 6}

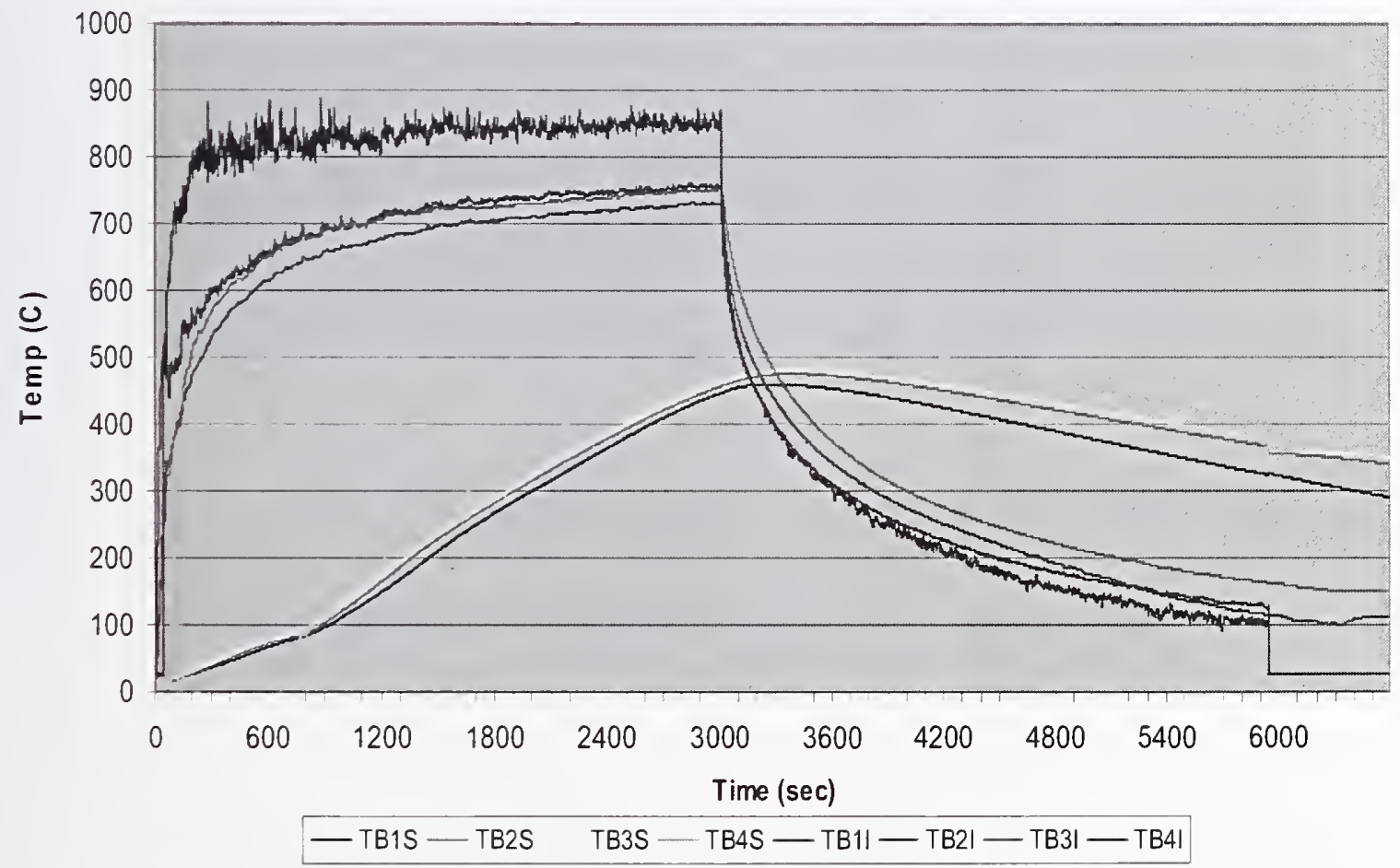

Figure G-20. Insulated (1.91 cm SFRM) steel bar in Test 6. 


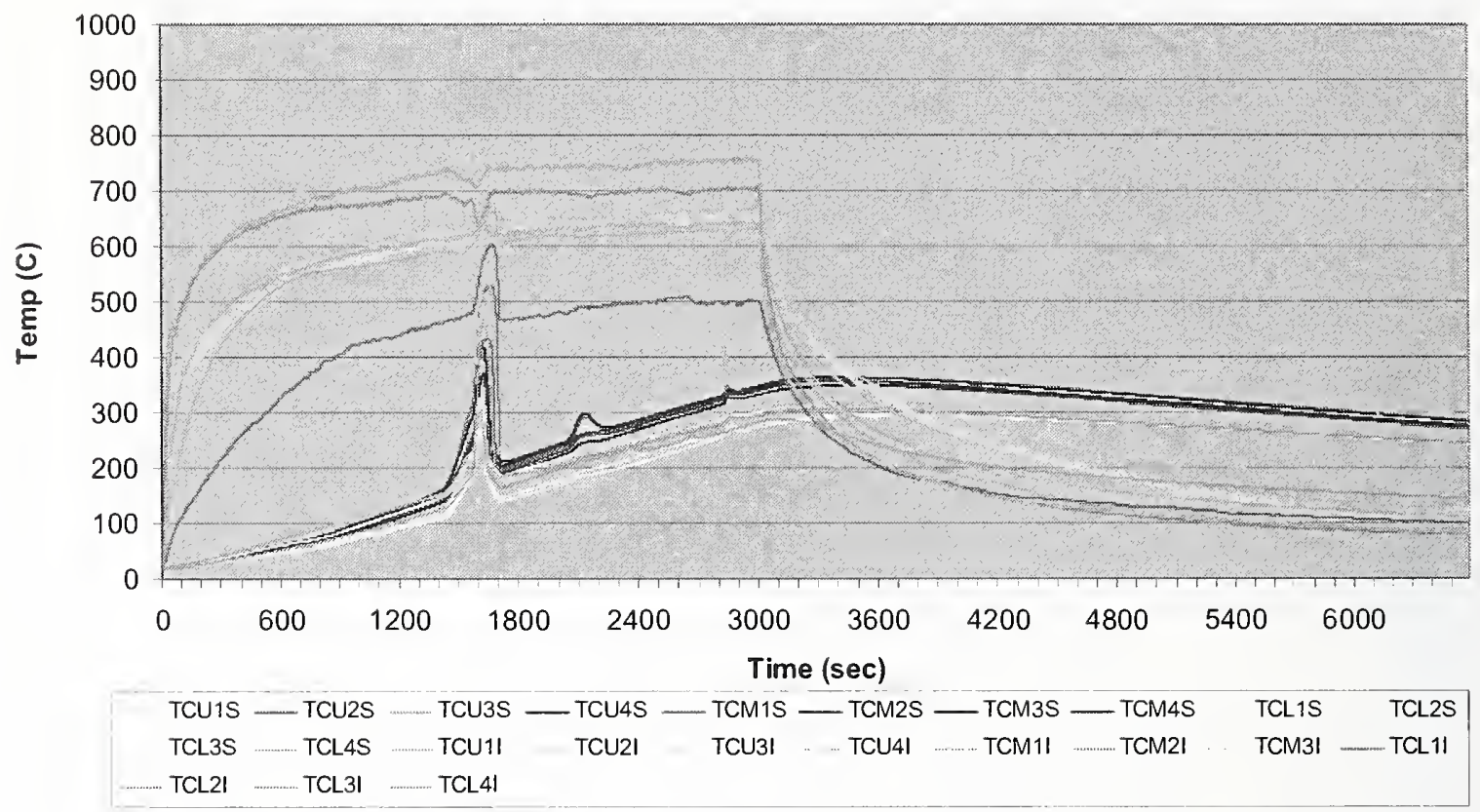

Figure G-21. Insulated (1.91 cm SFRM) steel column in Test 6.

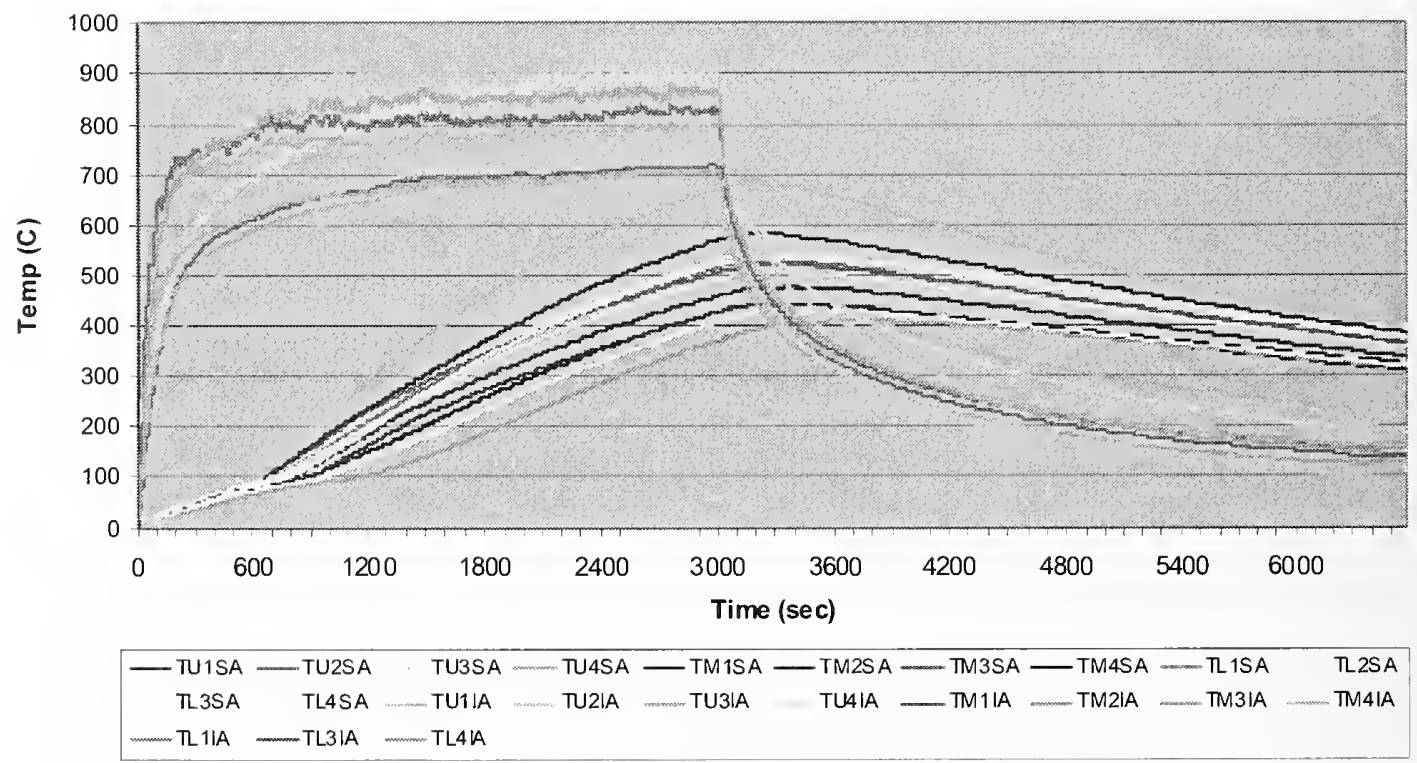

Figure G-22. Insulated (1.91 cm SFRM) steel truss A in Test 6. 


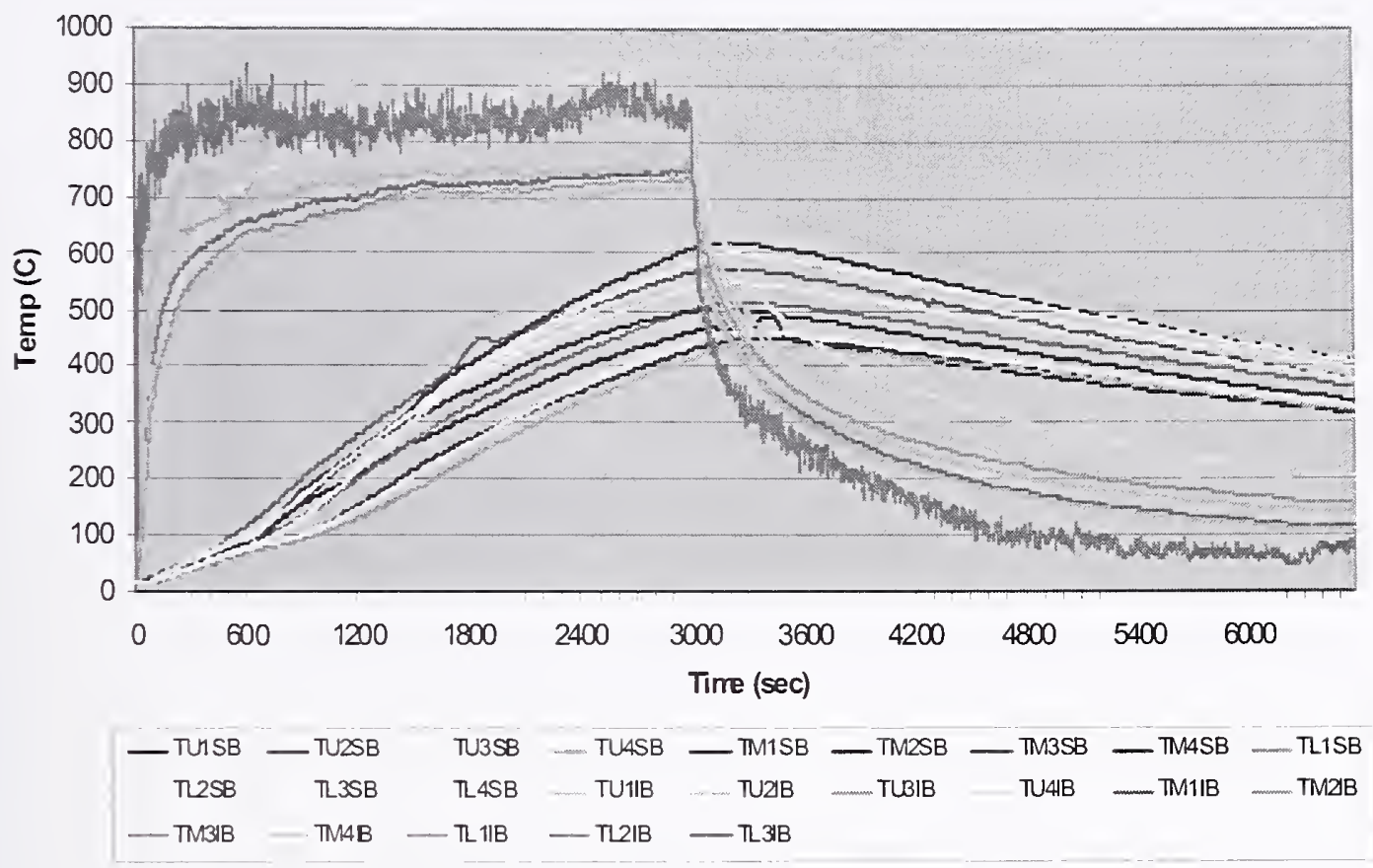

Figure G-23. Insulated (1.91 cm SFRM) steel truss B in Test 6. 
This page intentionally left blank. 

